UNIVERSIDADE DE BRASÍLIA

FACULDADE DE TECNOLOGIA

DEPARTAMENTO DE ENGENHARIA CIVIL E AMBIENTAL

\title{
MÉTODO PARA A DETERMINAÇÃO DA SUSTENTABILIDADE DE CICLOVIAS
}

RENATA ALMEIDA MOTTA

TESE DE DOUTORADO EM TRANSPORTES DEPARTAMENTO DE ENGENHARIA CIVIL E AMBIENTAL

FACULDADE DE TECNOLOGIA

\section{UNIVERSIDADE DE BRASÍLIA}

UNIVERSIDADE DE BRASÍLIA 
FACULDADE DE TECNOLOGIA

DEPARTAMENTO DE ENGENHARIA CIVIL E AMBIENTAL

\title{
MÉTODO PARA A DETERMINAÇÃO DA SUSTENTABILIDADE DE CICLOVIAS
}

RENATA ALMEIDA MOTTA

\author{
ORIENTADOR: PAULO CESAR MARQUES DA SILVA \\ CO-ORIENTADOR: AUGUSTO CÉSAR DE MENDONÇA BRASIL
}

TESE DE DOUTORADO EM TRANSPORTES

PUBLICAÇÃO: TD-004/2016

BRASÍLIA/DF: JUNHO - 2016 
UNIVERSIDADE DE BRASÍLIA

FACULDADE DE TECNOLOGIA

DEPARTAMENTO DE ENGENHARIA CIVIL E AMBIENTAL

MÉTODO PARA A DETERMINAÇÃO DA SUSTENTABILIDADE DE CICLOVIAS

RENATA ALMEIDA MOTTA

TESE DE DOUTORADO SUBMETIDA AO DEPARTAMENTO DE ENGENHARIA CIVIL E AMBIENTAL DA FACULDADE DE TECNOLOGIA DA UNIVERSIDADE DE BRASÍLIA COMO PARTE DOS REQUISITOS NECESSÁRIOS PARA A OBTENÇÃO DO GRAU DE DOUTORA.

APROVADA POR:

PAULO CESAR MARQUES DA SILVA, PhD (UnB)

(Orientador)

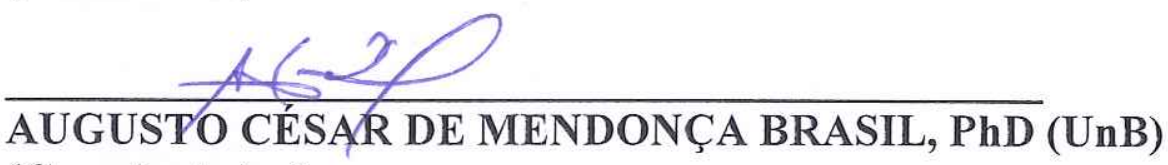

(Co-orientador)

$\frac{\text { IfNfocquer }}{\text { MARIAALICE PRUDENCIO JACQUES, PhD (UnB) }}$

(Examinador Interno)

Fabiana ferra de Arruda

FABIANA SERRA DE ARRUDA, Dr. (UnB)

(Examinador Interno)

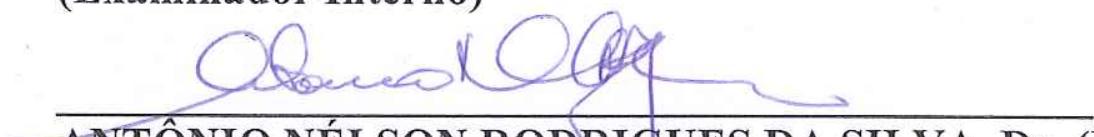

ANTÔNIO NÉLSON RODRIGUES DA SILVA, Dr. (EESC/USP)

(Examinador Externo)

'SUZANA KAHN/RIBEIRO, Dra. (COPPE/UFRJ)

(Examinador Externo)

BRASÍLIA/DF, 17 DE JUNHO DE 2016. 


\section{FICHA CATALOGRÁFICA}

MOTTA, RENATA ALMEIDA

Método para a Determinação da Sustentabilidade de Ciclovias [Distrito Federal] 2016.

xii, 276., 210x297mm (ENC/FT/UnB, Doutor, Transportes, 2016).

Tese de Doutorado - Universidade de Brasília. Faculdade de Tecnologia.

Departamento de Engenharia Civil e Ambiental.

1 - Mobilidade Sustentável

2 - Indicadores

3 - Ciclovias

4 - Método

$\mathrm{I}-\mathrm{ENC} / \mathrm{FT} / \mathrm{UnB}$

II - Título (série)

\section{REFERÊNCIA BIBLIOGRÁFICA}

MOTTA, R. A. (2016). Método para a Determinação da Sustentabilidade de Ciclovias. Tese de Doutorado, Publicação T.TD-004A/2016, Departamento de Engenharia Civil e Ambiental, Universidade de Brasília, Brasília, DF, 276p.

\section{CESSÃO DE DIREITOS}

AUTOR: Renata Almeida Motta

TÍTULO: Método para a Determinação da Sustentabilidade de Ciclovias.

GRAU: Doutora ANO: 2016

É concedida à Universidade de Brasília permissão para reproduzir cópias desta tese de doutorado e para emprestar ou vender tais cópias somente para propósitos acadêmicos e científicos. $\mathrm{O}$ autor reserva outros direitos de publicação e nenhuma parte desta tese de doutorado pode ser reproduzida sem a autorização por escrito do autor.

Renata Almeida Motta

CLN 411 bloco D ap 117

Asa Norte

Brasília - DF - Brasil - CEP: 70866-540 
Como o desenvolvimento sustentável pode ser definido e operacionalizado para que seja utilizado como ferramenta para ajustar os rumos que a sociedade vem tomando em relação à sua interação com o meio ambiente?

(Hans Michael Van Bellen, 2006) 


\section{DEDICATÓRIA}

Ao amor desinteressado ao próximo;

Aos criadores;

Aos meus queridos pais;

A todos os professores reais e virtuais que tive a oportunidade de ter;

A todos os meus queridos e futuros alunos;

Aos meus futuros filhos;

A todos meus colegas e amigos;

A todos que de alguma forma possibilitaram este trabalho. 


\section{AGRADECIMENTOS}

Aos criadores,

À minha querida família,

Ao meu pai, Marco, pelo apoio incondicional, paciência e carinho durante essa jornada,

À minha mãe, Elizabete Motta, meu irmão Rodrigo Motta, minha cunhada Priscilla Moura, pelo apoio incondicional em mais esta etapa da minha vida acadêmica,

Aos meus orientadores professor Paulo César e Augusto Brasil pela paciência, tolerância, sabedoria, amor e dedicação com que me orientaram, possibilitando mais esta conquista em minha vida,

A todos os professores, servidores e colegas do Programa de Pós-Graduação em Transportes da Universidade de Brasília (PPGT/UnB), pelos ensinamentos, companheirismo e cordialidade, em especial, à tão querida Lucinete Santos,

Aos queridos Ana Parisi e Paulo Cavalcanti que muito me auxiliaram com o desenvolvimento e planejamento das pesquisas de campo e sempre perguntavam sobre o andamento da pesquisa com muito carinho,

Aos especialistas que com suas diversas experiências e sabedoria auxiliaram a atribuir pesos aos indicadores discutidos neste trabalho. Sua dedicação, carinho, críticas e contribuição para a concretização deste trabalho foram fundamentais! Meu muito obrigada: Marco Motta, Luiz Pereira, José Góes, Michele Andrade, José Shimoishi, Fabiana Arruda, Jonas Bertucci, Ronaldo Alves e Janice Pereira,

À Universidade de Brasília e ao governo federal por possibilitarem o sonho de realizar um curso de doutorado e o custeio da pesquisa de campo,

À banca de qualificação e professores que muitos contribuíram para o estado atual deste trabalho: Fabiana Arruda, Michele Andrade, Antônio Nelson, Érika Cristine Kneib, José Fortes, Pastor Taco, Yaeko Yamashita,

Aos membros da banca examinadora, pelas contribuições,

À professora Maria Lúcia Galves da Universidade Estadual de Campinas - UNICAMP, que auxiliou na seleção do método multicritério para a construção do modelo,

Ao professor Alan da Silva da Universidade de Brasília - UNB, que auxiliou no planejamento da pesquisa de campo, principalmente no que diz respeito aos cálculos estatísticos,

Ao professor Hartmut Günther da Universidade de Brasília - UNB, que auxiliou com a instrução e formulação do questionário de opinião a ser aplicado com os ciclistas, 
Aos pesquisadores que pacientemente me auxiliaram com as entrevistas com os usuários das ciclovias: Daniel Vaz, Aléxia Palhano, Maria Dilma Santos e José Edval Filho,

Às pessoas especiais que contribuíram e me auxiliaram na produção deste trabalho: Juliana Leite, Mônica Veloso, Tainá Botelho, João Ricardo e Ronaldo Alves,

Aos membros do Comitê de Mobilidade Urbana por Bicicleta instituído pelo Decreto $\mathrm{n}^{\mathrm{o}}$ 33.158 de 2011, com representantes da sociedade civil e de 12 órgãos do Governo do Distrito Federal, com quem tive a oportunidade de conviver de perto e aprender,

Às colegas do IBRAM Renata Mongin, Patrícia Valls, Vandete Maldaner e Sandreani Nascente, pessoas nas quais me inspiro e busco me espelhar no dia a dia,

À minha melhor amiga, Beatriz Gomes, que sempre me apoiou com muito carinho nos momentos mais difíceis,

Aos queridos companheiros Evandro Lepletier, Arlindo Araújo e Karla Lopes, meus parceiros acadêmicos, que me permitem viver o sonho da docência diariamente de uma forma apaixonante e moderna, à distância. Vocês foram essenciais para me inspirar na finalização deste trabalho e a querer sempre mais,

A todos aqueles que me disseram "NÃO", que acabaram por me tornar mais forte e me instigaram a chegar até aqui,

Àqueles que cometeram absurdos presenciados por mim no setor de transportes, tanto na iniciativa privada quanto no serviço público, mas que também me tornaram mais forte na minha luta diária,

Àqueles que buscam mais alternativas de transportes de qualidade, menos poluentes, inclusivas, integradas, que atraiam o usuário, que ofereçam conforto, qualidade de vida e pontualidade;

Às minhas famílias de amigos (irmãos de coração) que estão sempre próximos: Nina Dubois, Valeska Torres, Fábio Bernardo, Rosita do Nascimento, Masao Tanaka, Maíra Cavalcanti, Marcelo Sousa, Roberta Monteiro, Clarissa Campos, João Renato, Álvaro Campos, Jurema Campo, Jussara Campos e Francisco Campos,

Este trabalho é para todos vocês! 


\title{
RESUMO
}

\section{MÉTODO PARA A DETERMINAÇÃO DA SUSTENTABILIDADE DE CICLOVIAS}

\author{
Autora: Renata Almeida Motta \\ Orientador: Paulo Cesar Marques da Silva \\ Programa de Pós-Graduação em Transportes \\ Brasília, junho de 2016.
}

Para amenizar os crescentes problemas de trânsito e de demanda por transporte, muitas cidades em vários países vêm adotando medidas para aumentar o uso do modo cicloviário e reduzir o uso de veículos particulares. No entanto, apesar de estar em voga a implantação de projetos cicloviários, principalmente mediante a justificativa de que é um modo sustentável de mobilidade, na realidade a mera construção de uma ciclovia pode não gerar consequências positivas ambientais, sociais e econômicas. Desta forma, é importante o desenvolvimento de instrumentos de análise da qualidade de sistemas cicloviários como forma de avaliar se a implantação de uma ciclovia em determinadas condições e local realmente proporciona impactos positivos. Nesta tese desenvolveu-se um método para mensurar o grau de sustentabilidade de uma ciclovia baseado em indicadores de mobilidade sustentável, que permite a comparação entre ciclovias, com consequente ranqueamento, bem como o monitoramento e identificação de pontos prioritários a serem considerados para futuras melhorias. O grau de mobilidade sustentável é composto por 28 indicadores, sendo sete ambientais, 15 sociais e seis econômicos. O desenvolvimento do método utilizou a análise multicritério e contou com a participação de um grupo multidisciplinar composto por especialistas do meio acadêmico, profissional e da sociedade civil para a atribuição de pesos dos indicadores. Este método foi testado em duas ciclovias no Distrito Federal. O grau de sustentabilidade da ciclovia do Varjão foi de 0,51 e o da ciclovia de Samambaia de 0,79, em uma escala de zero a um; diferença em termos de sustentabilidade explicada pelos indicadores relativos à quantidade de acidentes, à emissão de poluentes, ao volume de ciclistas e à integração, favoráveis à Samambaia. Verificou-se que os indicadores de mobilidade sustentável de ciclovias elencados nesta Tese, além de possibilitar uma classificação das ciclovias em termos de sustentabilidade e de ensejar o estabelecimento de prioridades para melhorias das ciclovias analisadas, são úteis também para auxiliar os tomadores de decisão no estabelecimento de diretrizes para cidades cada vez mais sustentáveis, com foco na qualidade de vida da população. Também são fundamentais no processo de monitoramento da sociedade em relação ao meio ambiente para avaliar a sustentabilidade das ciclovias existentes. 


\section{ABSTRACT \\ METHOD FOR DETERMINING SUSTAINABILITY OF BIKE PATHS}

In order to address the increasing traffic problems and demand for transportation, many cities in various countries have adopted measures to increase the use of bike paths and reduce the use of private motor vehicles. However, in spite of the trendy implementation of bike path projects, mostly under the justification that cycling is a sustainable mode of mobility, the mere building of bike paths may not generate positive environmental, social and economic consequences. Thus, instruments have been developed to analyze the quality of cycling infrastructure as a means to assess whether the implementation of a bike path under certain conditions and in a certain place actually provides positive impacts. In this thesis, a method is developed to measure the degree of sustainability of a bike path based on sustainable mobility indicators, which allows the comparison and ranking of bike paths, as well as monitoring and identification of priority issues to be considered for future improvements. The sustainable mobility index is comprised of 28 indicators, of which 7 are environmental, 15 are social and 6 are economic. The method was developed through the use of multicriteria analysis and included the participation of a multidisciplinary group composed of academic, business and civil society experts for the allocation of indicator weights. This method has been tested in two bike paths in the Federal District. The sustainability of the Varjão bike path was measured at 0.51, while the Samambaia bike path reached 0.79, on a scale from zero to one. The difference in terms of sustainability is explained by indicators related to number of accidents, emissions, number of cyclists and integration, which were better for Samambaia. It was found that the bike path sustainable mobility indicators listed in this Thesis, in addition to enabling the ranking of bike paths in terms of sustainability and allowing the establishment of priorities for improvement of the bike paths under analysis, are also useful to help decision makers establish guidelines for more sustainable cities, focusing on the population's quality of life. They are also key for the process of social and environmental monitoring to assess the sustainability of existing cycling infrastructure. 


\section{SUMÁRIO}

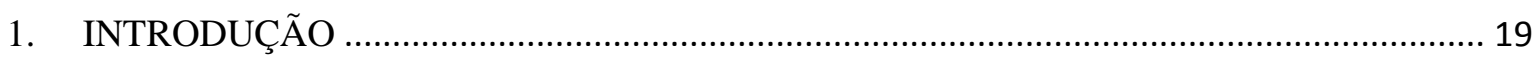

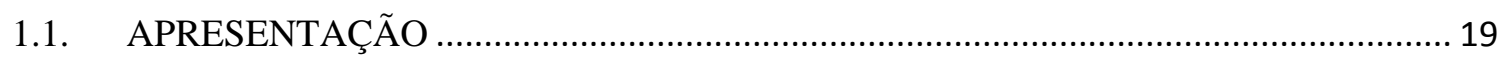

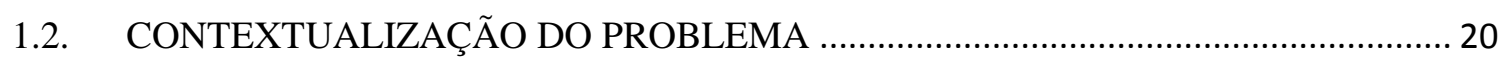

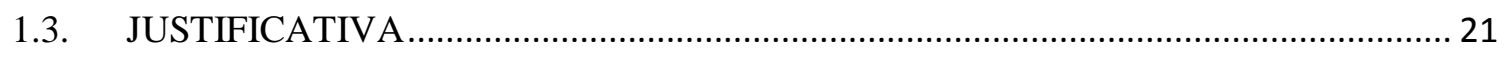

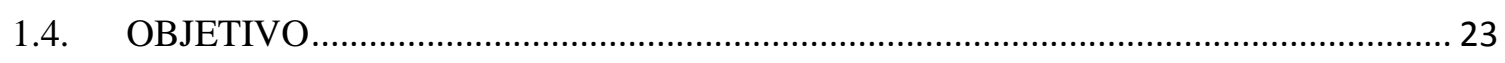

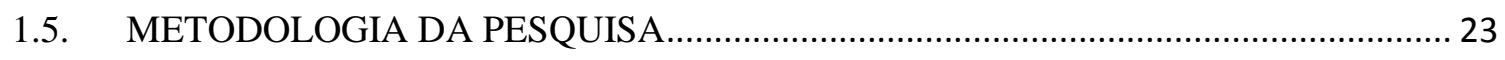

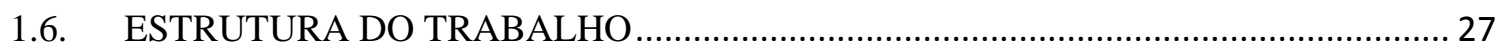

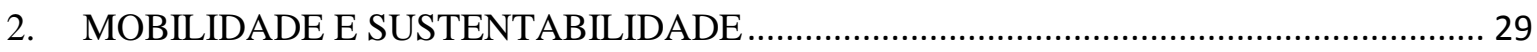

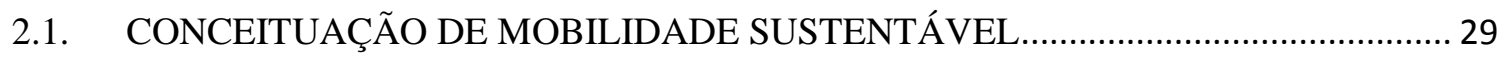

2.1.1. Sustentabilidade e Desenvolvimento Sustentável ............................................................. 29

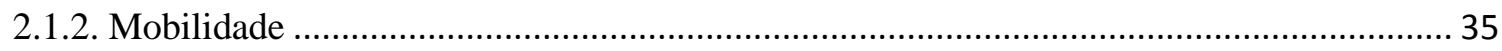

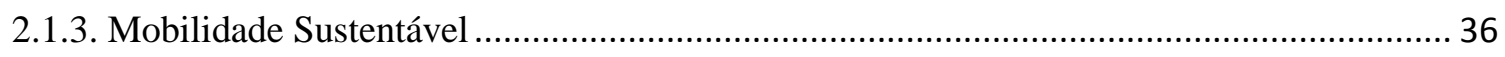

2.2. APLICAÇÃO DO CONCEITO E DE AÇÕES DE MOBILIDADE SUSTENTÁVEL ....... 39

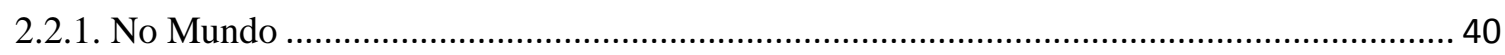

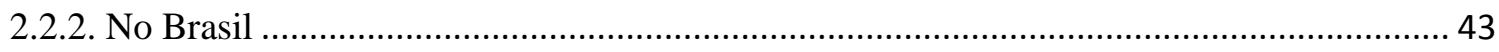

2.3. CONSIDERAÇÕES SOBRE OS PROBLEMAS BRASILEIROS DE MOBILIDADE...... 48

2.4. DESAFIOS DA MOBILIDADE SUSTENTÁVEL NO BRASIL ....................................... 50

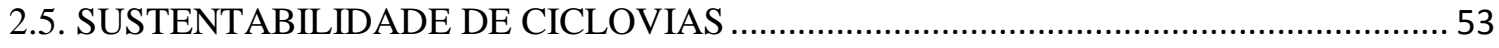

3. INDICADORES DE MOBILIDADE SUSTENTÁVEL APLICÁVEIS A CICLOVIAS ........ 60

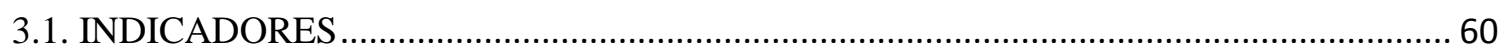

3.2. IDENTIFICAÇÃO E ANÁLISE DE INDICADORES DE MOBILIDADE SUSTENTÁVEL

3.3. CONSTRUÇÃO DE INDICADORES DE MOBILIDADE SUSTENTÁVEL APLICÁVEIS EM CICLOVIAS 
3.3.1. Considerações e Critérios para a Identificação de Indicadores de Mobilidade Sustentável

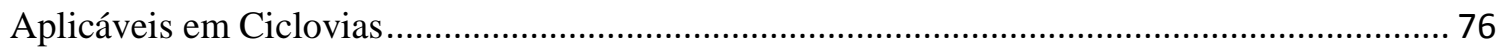

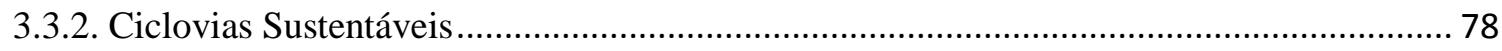

3.3.3. Proposição de Indicadores de Mobilidade Sustentável Aplicáveis em Ciclovias ............... 79

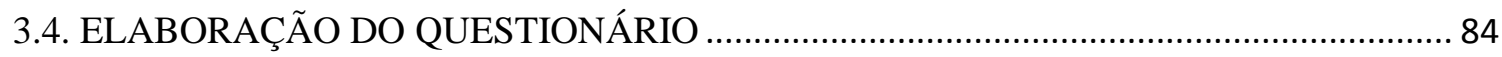

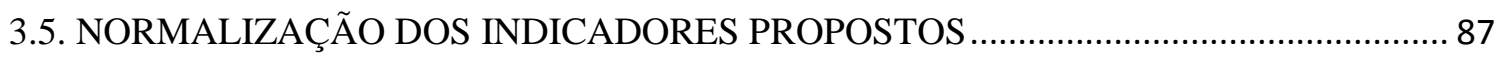

4. MÉTODO PARA A DETERMINAÇÃO DA SUSTENTABILIDADE DE CICLOVIAS ..... 90

4.1. MÉTODOS MULTICRITÉRIOS DE APOIO À DECISÃO............................................... 90

4.2. JUSTIFICATIVA DA ESCOLHA DE UM MÉTODO MULTICRITÉRIO PARA A

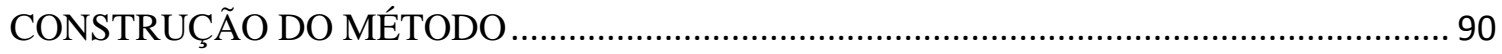

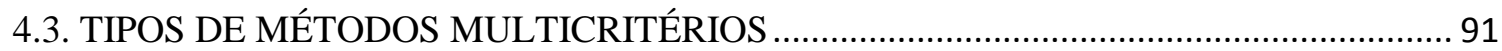

4.3.1. Métodos Multicritérios da Escola Americana ................................................................ 92

4.3.2. Métodos Multicritérios da Escola Europeia …….................................................................... 94

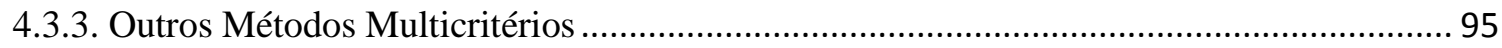

4.4. CONSIDERAÇÕES SOBRE A ESCOLHA DO MÉTODO MULTICRITÉRIO PARA A

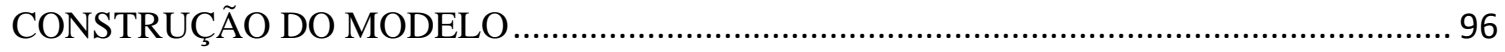

4.5. MÉTODO MULTICRITÉRIO ESCOLHIDO PARA A CONSTRUÇÃO DO MODELO.. 96

4.6. APLICAÇÃO DA FUNÇÃO MULTIATRIBUTO ADITIVA …........................................ 97

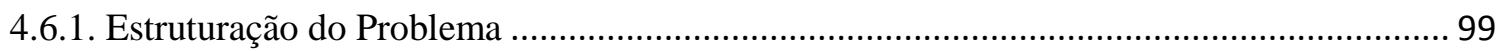

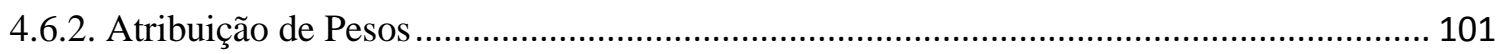

4.6.3. Função de Valor para a Mensuração da Mobilidade Sustentável em Ciclovias................ 114

5. ESTUDO DE CASO: APLICAÇÃO DO MÉTODO EM CICLOVIAS DO DISTRITO

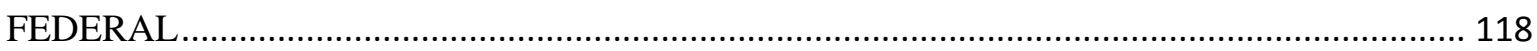

5.1. CICLOVIA DA RODOVIA DF-005 - ESTRADA PARQUE PARANOÁ - EPPR ............ 118

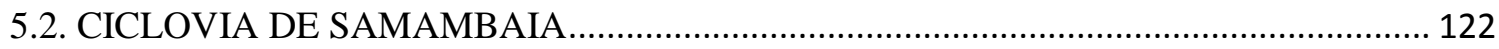

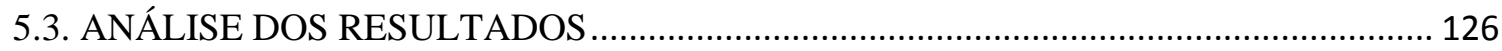

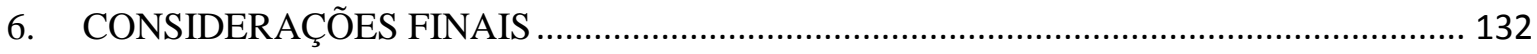

6.1. MOBILIDADE URBANA E SUSTENTABILIDADE AMBIENTAL .......................... 132

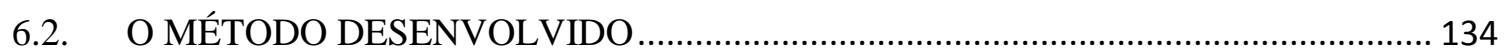


6.3. ALGUMAS CONSIDERAÇÕES SOBRE O DESENVOLVIMENTO DO MÉTODO 136

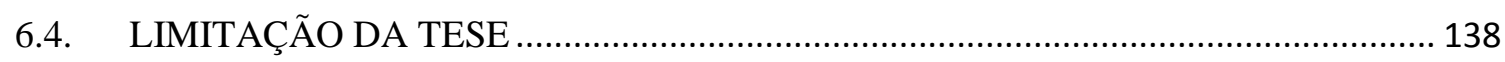

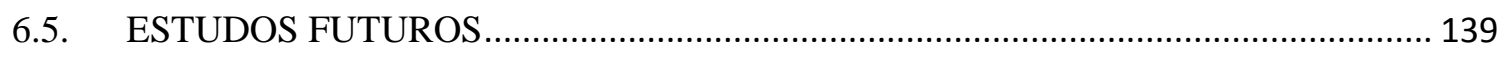

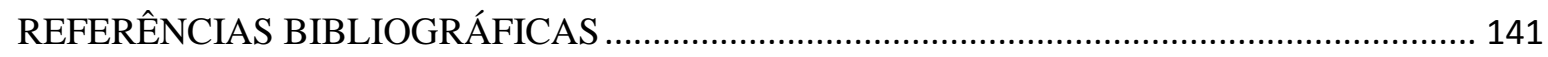

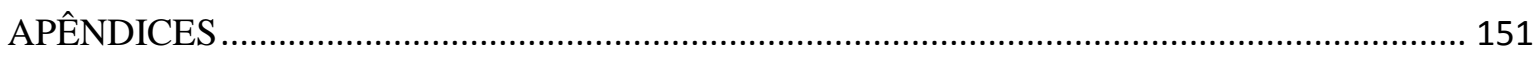

A FICHAS DOS INDICADORES DE MOBILIDADE SUSTENTÁVEL APLICÁVEIS EM

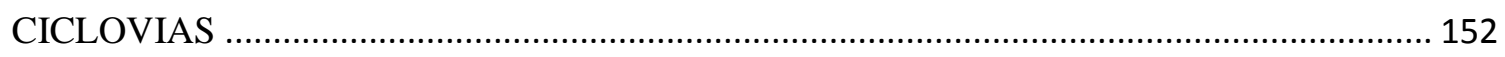

B QUESTIONÁRIO PARA OS USUÁRIOS DA CICLOVIA............................................ 181

C RESULTADOS DA APLICAÇÃO DO MÉTODO PARA A DETERMINAÇÃO DA SUSTENTABILIDADE DE CICLOVIAS NAS CICLOVIAS DO VARJÃO E DE

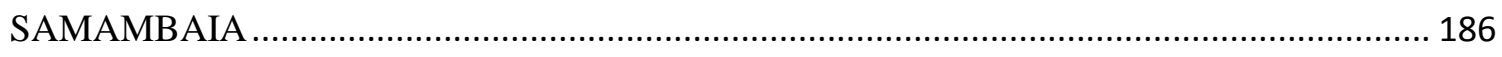

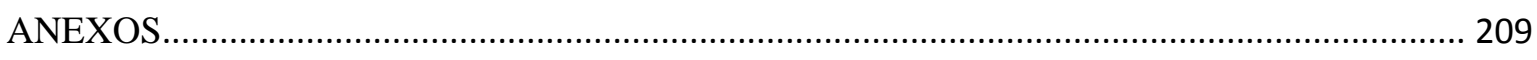

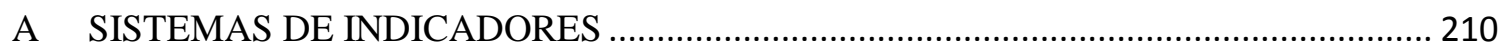




\section{LISTA DE TABELAS}

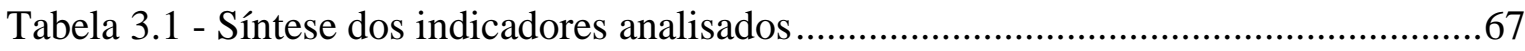

Tabela 3.2 - Características e impactos de ciclovias sustentáveis ........................................78

Tabela 3.3 - Indicadores econômicos, ambientais e sociais aplicáveis em ciclovias ..........79

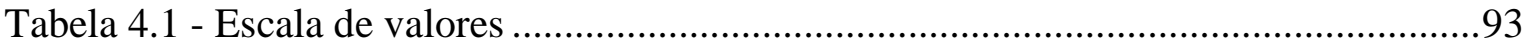

Tabela 4.2 - Atribuição dos pesos das dimensões de sustentabilidade pelos especialistas 107

Tabela 4.3 - Atribuição dos pesos das características desejáveis e impactos relevantes de ciclovias da dimensão social pelos especialistas ............................................................ 107

Tabela 4.4 - Atribuição dos pesos das características desejáveis e impactos relevantes de ciclovias da dimensão econômica pelos especialistas ..................................................... 108

Tabela 4.5 - Atribuição dos pesos das características desejáveis e impactos relevantes de ciclovias da dimensão ambiental pelos especialistas...................................................... 108

Tabela 4.6 - Atribuição dos pesos dos indicadores da promoção de acessibilidade e integração com sistemas de transporte público da dimensão social pelos especialistas .. 108 Tabela 4.7 - Atribuição dos pesos dos indicadores da promoção de segurança durante a mobilidade dos ciclistas da dimensão social pelos especialistas ...................................... 109

Tabela 4.8 - Atribuição dos pesos dos indicadores da promoção de saúde e lazer da dimensão social pelos especialistas 109

Tabela 4.9 - Atribuição dos pesos dos indicadores da promoção de equidade da dimensão econômica pelos especialistas

Tabela 4.10 - Atribuição dos pesos dos indicadores da redução de custos provenientes de acidentes com ciclistas na região da dimensão econômica pelos especialistas ................. 110

Tabela 4.11 - Atribuição dos pesos dos indicadores da redução de custos de poluição atmosférica da dimensão econômica pelos especialistas............................................... 110 Tabela 4.12 - Atribuição dos pesos dos indicadores da redução de emissão de poluentes de gases de efeito estufa da dimensão ambiental pelos especialistas 111

Tabela 4.13 - Atribuição dos pesos dos indicadores da redução do nível de pressão sonora proveniente da transferência de viagens motorizadas para o modo cicloviário da dimensão ambiental pelos especialistas

Tabela 4.14 - Atribuição dos pesos dos indicadores da requalificação urbana e minimização de danos ao meio ambiente da dimensão ambiental pelos especialistas

Tabela 5.1 - Resultados da aplicação do método para a determinação da sustentabilidade das

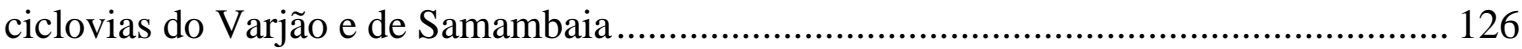

Tabela 1: Emissão e custos de poluentes emitidos por ônibus, automóveis e motos ....... 164 Tabela 2: Fatores de emissão de escapamento de $\mathrm{CH}_{4}$ para automóveis e veículos comerciais leves novos, movidos a gasolina $\mathrm{C}$ e a etanol hidratado, em g/km .............................. 166

Tabela 3: Fatores de emissão de $\mathrm{CH}_{4}$ para motocicletas em $\mathrm{g} / \mathrm{km}$................................ 168

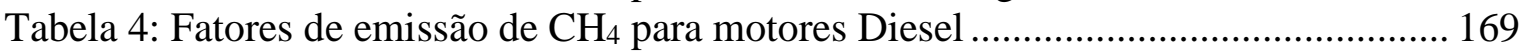

Tabela 5: Fatores de emissão de $\mathrm{CO}_{2}$ por ano-calendário e combustível.......................... 169

Tabela 6: Fatores de emissão de $\mathrm{N}_{2} \mathrm{O}$ por categoria e por combustível para veículos leves,

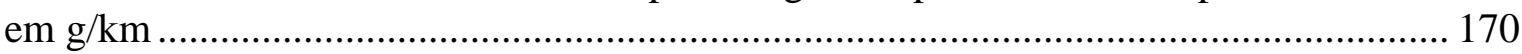

Tabela 7: Fatores de emissão de $\mathrm{N}_{2} \mathrm{O}$ por categoria para veículos do ciclo Diesel........... 171

Tabela 8: Fatores de emissão de escapamento de $\mathrm{CO}$ e $\mathrm{NO}_{x}$, para automóveis e veículos comerciais leves novos, movidos a gasolina $\mathrm{C}$ e a etanol hidratado, em $\mathrm{g} / \mathrm{km}$................ 172

Tabela 9: Fatores de emissão de $\mathrm{CO}$ e $\mathrm{NO}_{\mathrm{x}}$ para veículos movidos a GNV, em g/km .... 175

Tabela 10: Fatores de emissão de $\mathrm{CO}$ e $\mathrm{NO}_{\mathrm{x}}$ para motocicletas em $\mathrm{g} / \mathrm{km}$........................ 175

Tabela 11: Fatores de emissão de CO e NO $\mathrm{N}_{\mathrm{x}}$ para motores Diesel em gpoluente/km...... 175 
Tabela 12 - Ciclistas feridos e mortos nas proximidades das ciclovias do Varjão e de

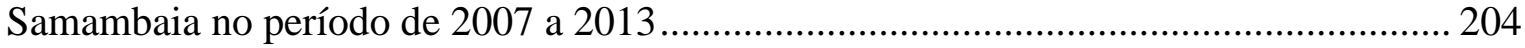

Tabela 13 - Indicadores selecionados para compor o IMUS .......................................... 210

Tabela 14 - Indicadores de mobilidade sustentável implantados no PLANUTS .............. 214

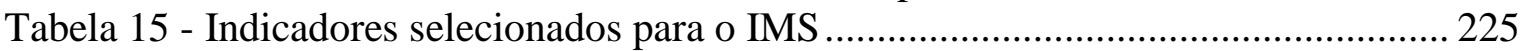

Tabela 16 - Indicadores de ocupação urbana relacionados com o sistema viário ............. 226

Tabela 17 - Proposta de indicadores de mobilidade sustentável ..................................... 227

Tabela 18 - Indicadores elaborados para os Programas Nacionais de Transporte ........... 232

Tabela 19 - Indicadores Sociais de Mobilidade Sustentável .......................................... 253

Tabela 20 - Indicadores Econômicos de Mobilidade Sustentável ......................................253

Tabela 21 - Indicadores Ambientais de Mobilidade Sustentável .................................... 254

Tabela 22 - Indicadores econômicos de mobilidade sustentável..................................... 255

Tabela 23 - Indicadores ambientais de mobilidade sustentável ..................................... 258

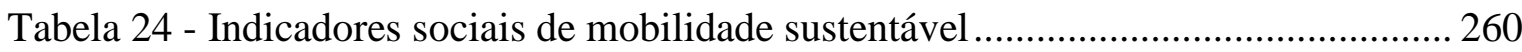

Tabela 25 - Indicadores de mobilidade sustentável........................................................... 263

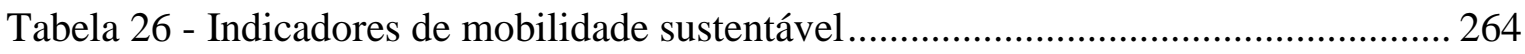

Tabela 27 - Indicadores de mobilidade sustentável.......................................................... 265

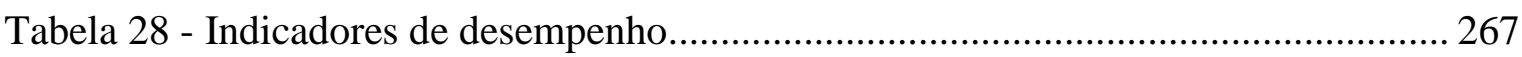

Tabela 29 - Indicadores de mobilidade sustentável........................................................ 269

Tabela 30 - Indicadores de desenvolvimento sustentável dos transportes ....................... 271

Tabela 31 - Indicadores recomendados para monitoramento de políticas de mobilidade

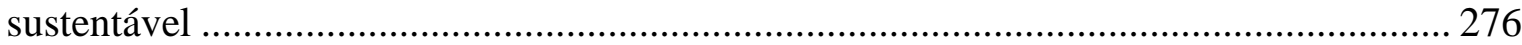




\section{LISTA DE FIGURAS}

Figura 1.1 - Estrutura da metodologia adotada para o desenvolvimento da pesquisa.........24

Figura 2.1 - Relação entre sustentabilidade, bem-estar e prosperidade material ..................32

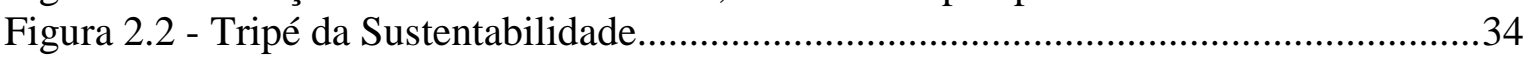

Figura 2.3 - Exemplo de espaço cicloviário compartilhado entre ciclistas e pedestres em

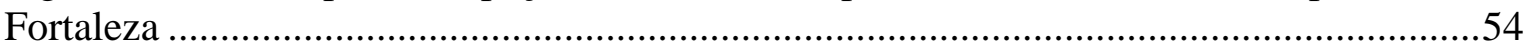

Figura 2.4 - Exemplo de espaço cicloviário parcialmente segregado em Fortaleza.............54

Figura 2.5 - Exemplo de espaço cicloviário totalmente segregado no Rio de Janeiro .........55

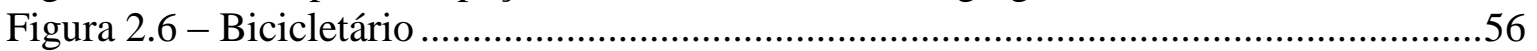

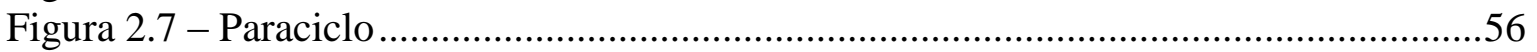

Figura 2.8 - Exemplo de ciclovia não sustentável (poste) em Manaus ...............................57

Figura 2.9 - Exemplo de ciclovia não sustentável (talude erodido) em Brasília ..................57

Figura 2.10 - Exemplo de ciclovia não sustentável no Rio de Janeiro.................................57

Figura 2.11 - Exemplo de ciclovia não sustentável no Pará ................................................57

Figura 2.12 - Exemplo de ciclovia não sustentável em São Paulo ......................................57

Figura 2.13 - Exemplo de ciclovia não sustentável em São Paulo .......................................57

Figura 2.14 - Exemplo de ciclovia não sustentável em São Paulo .......................................58

Figura 2.15 - Exemplo de ciclovia não sustentável em São Paulo ....................................58

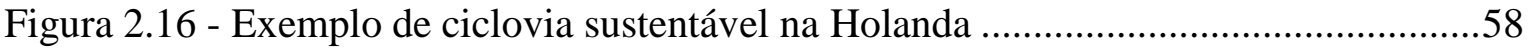

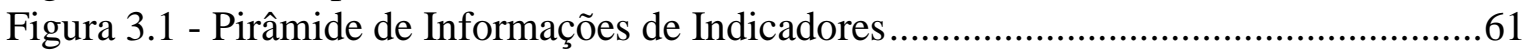

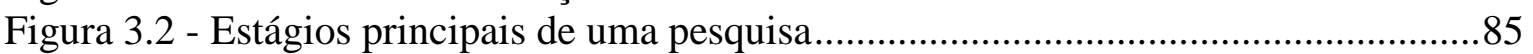

Figura 4.1 - Etapas do Processo Interativo de Decisão .......................................................98

Figura 4.2 - Estruturação do problema por meio da hierarquização em níveis ................ 100

Figura 4.3 - Atribuição dos pesos das dimensões de sustentabilidade .............................. 102

Figura 4.4 - Atribuição dos pesos das características desejáveis e impactos relevantes de

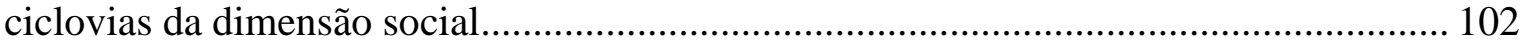

Figura 4.5 - Atribuição dos pesos das características desejáveis e impactos relevantes de ciclovias da dimensão econômica................................................................................... 103

Figura 4.6 - Atribuição dos pesos das características desejáveis e impactos relevantes de

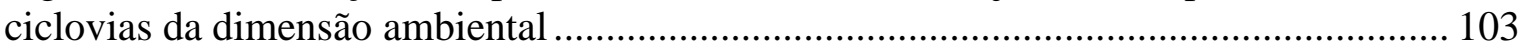

Figura 4.7 - Atribuição dos pesos dos indicadores da promoção de acessibilidade e integração com sistemas de transporte público da dimensão social ................................. 104

Figura 4.8 - Atribuição dos pesos dos indicadores da promoção de segurança durante a mobilidade dos ciclistas da dimensão social ................................................................. 104

Figura 4.9 - Atribuição dos pesos dos indicadores da promoção de saúde e lazer da dimensão

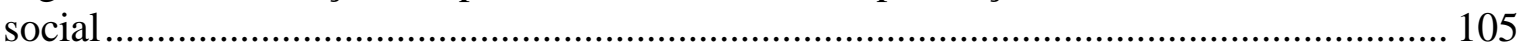

Figura 4.10 - Atribuição dos pesos dos indicadores da promoção de equidade da dimensão

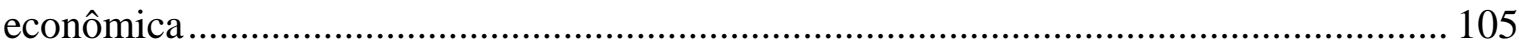

Figura 4.11 - Atribuição dos pesos dos indicadores da redução de custos provenientes de acidentes com ciclistas na região da dimensão econômica .............................................. 105

Figura 4.12 - Atribuição dos pesos dos indicadores redução de custo de poluição atmosférica

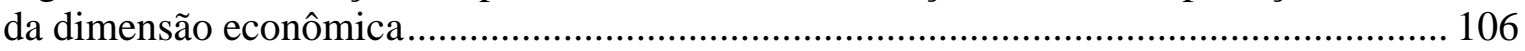

Figura 4.13 - Atribuição dos pesos dos indicadores da redução de emissão de poluentes de gases de efeito estufa da dimensão ambiental ................................................................... 106

Figura 4.14 - Atribuição dos pesos dos indicadores da redução do nível de pressão sonora proveniente da transferência de viagens motorizadas para o modo cicloviário da dimensão ambiental 106 
Figura 4.15 - Atribuição dos pesos dos indicadores da requalificação urbana e minimização de danos ao meio ambiente da dimensão ambiental ..................................................... 107 Figura 4.16 - Peso final de cada variável do método a partir da atribuição de pesos pelos

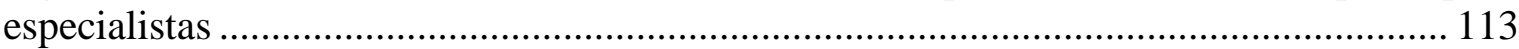
Figura 5.1 - Pontos de Contagem e de Pesquisa de Opinião 1 e 2 do Estudo de Caso do Varjão

Figura 5.2 - Entrevistadora na ciclovia do Varjão........................................................... 122

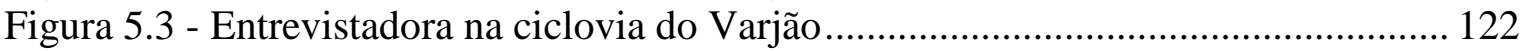

Figura 5.4 - Entrevistas com um usuário da ciclovia do Varjão...................................... 122

Figura 5.5 - Entrevistas com um usuário da ciclovia do Varjão....................................... 122

Figura 5.6 - Pontos de Contagem e de Pesquisa de Opinião 1 e 2 do Estudo de Caso de

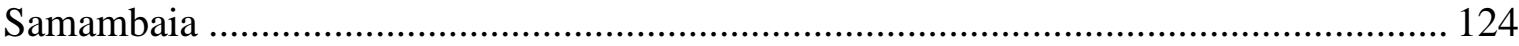

Figura 5.7 - Entrevistas com um usuário da ciclovia de Samambaia .............................. 125

Figura 5.8 - Entrevistas com um usuário da ciclovia de Samambaia................................ 125

Figura 5.9 - Entrevistas com usuários da ciclovia de Samambaia.................................... 125

Figura 5.10 - Entrevistas com usuários da ciclovia de Samambaia.................................. 125

Figura 5.11 - Entrevista com um usuário da ciclovia de Samambaia............................... 125

Figura 1 - Percentual de Viagens de Ciclistas por Motivo de Trabalho ou Estudo do Estudo

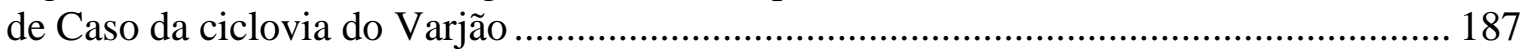

Figura 2 - Percentual de Viagens de Ciclistas por Motivo de Trabalho ou Estudo do Estudo

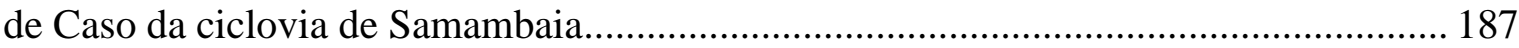

Figura 3 - Disponibilidade de Estacionamento de Bicicletas Junto às Ciclovia do Estudo de

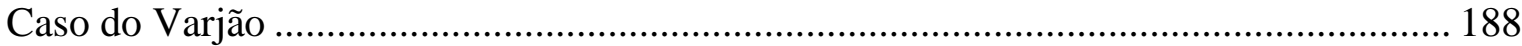

Figura 4 - Disponibilidade de Estacionamento de Bicicletas Junto às Ciclovia do Estudo de

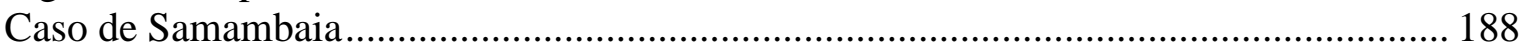

Figura 5 - Percepção do Ciclista com Relação a Furtos e Roubos nas Ciclovia do Estudo de Caso do Varjão 190

Figura 6 - Percepção do Ciclista com Relação a Furtos e Roubos nas Ciclovia do Estudo de Caso de Samambaia.

Figura 7 - Frequência de Policiamento na Ciclovia do Estudo de Caso do Varjão.......... 191

Figura 8 - Frequência de Policiamento na Ciclovia do Estudo de Caso do Varjão........... 191

Figura 9 - Localização Espacial e Conectividade com Outras Ciclovias do Estudo de Caso

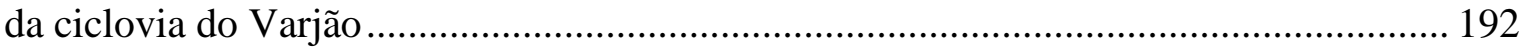

Figura 10 - Localização Espacial e Conectividade com Outras Ciclovias do Estudo de Caso da ciclovia de Samambaia .............................................................................................. 192

Figura 11 - Qualidade da Sinalização das Ciclovias, dos Cruzamentos Cicloviários e do Tratamento dos Locais Críticos do Estudo de Caso do Varjão ......................................... 193

Figura 12 - Qualidade da Sinalização das Ciclovias, dos Cruzamentos Cicloviários e do Tratamento dos Locais Críticos do Estudo de Caso do Samambaia ................................. 193

Figura 13 - Qualidade do Pavimento das Ciclovias do Estudo de Caso do Varjão........... 194

Figura 14 - Qualidade do Pavimento das Ciclovias do Estudo de Caso de Samambaia .. 194

Figura 15 - Qualidade da Drenagem das Ciclovia do Estudo de Caso do Varjão............. 195

Figura 16 - Qualidade da Drenagem das Ciclovia do Estudo de Caso de Samambaia .... 195 Figura 17 - Disponibilização de Iluminação Pública nos Arredores da Ciclovia do Estudo de

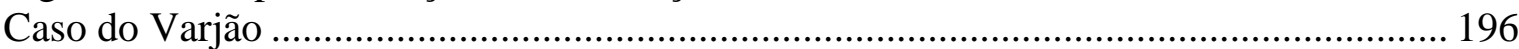

Figura 18 - Disponibilização de Iluminação Pública nos Arredores da Ciclovia do Estudo de

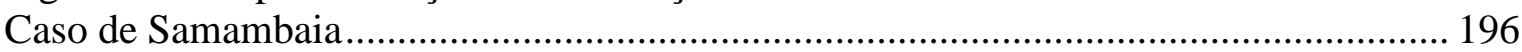

Figura 19 - Promoção de Saúde pela Ciclovia do Estudo de Caso do Varjão.................... 197

Figura 20 - Promoção de Saúde pela Ciclovia do Estudo de Caso de Samambaia ........... 197 
Figura 21 - Promoção de Lazer pelas Ciclovias do Estudo de Caso do Varjão

Figura 22 - Promoção de Lazer pelas Ciclovias do Estudo de Caso de Samambaia......... 198

Figura 23 - Promoção de Qualidade de Vida e Redução do Nível de Estresse dos Ciclistas do Estudo de Caso da ciclovia do Varjão 199

Figura 24 - Promoção de Qualidade de Vida e Redução do Nível de Estresse dos Ciclistas do Estudo de Caso da ciclovia de Samambaia 199

Figura 25 - Percentual de Ciclistas que não Possuem Veículo Particular do Estudo de Caso das Ciclovia do Varjão 200

Figura 26 - Percentual de Ciclistas que não Possuem Veículo Particular do Estudo de Caso das Ciclovia de Samambaia. 200

Figura 27 - Percentual de Transferência do Modo a Pé para o Cicloviário do Estudo de Caso da Ciclovia do Varjão 201

Figura 28 - Percentual de Transferência do Modo a Pé para o Cicloviário do Estudo de Caso da Ciclovia de Samambaia 201

Figura 29 - Percentual de Ciclistas que se Beneficiaram dos Efeitos Positivos Indiretos Gerados pelas Ciclovias, como Aquisição de Emprego, Educação e outras Oportunidades dos Estudo de Caso do Varjão 202

Figura 30 - Percentual de Ciclistas que se Beneficiaram dos Efeitos Positivos Indiretos Gerados pelas Ciclovias, como Aquisição de Emprego, Educação e outras Oportunidades dos Estudo de Caso de Samambaia 202

Figura 31 - Percentual de Ciclistas que Obtiveram Redução de Gastos Devido à Utilização da Ciclovia do Estudo de Caso do Varjão 203

Figura 32 - Percentual de Ciclistas que Obtiveram Redução de Gastos Devido à Utilização da Ciclovia do Estudo de Caso de Samambaia. 203

Figura 33 - Redução do Nível de Pressão Sonora Proveniente da Transferência de Viagens Motorizadas para o Modo Cicloviário do Estudo de Caso da ciclovia do Varjão 206 Figura 34 - Redução do Nível de Pressão Sonora Proveniente da Transferência de Viagens Motorizadas para o Modo Cicloviário do Estudo de Caso da ciclovia de Samambaia .... 206 Figura 35 - Promoção de Áreas Verdes nos arredores das ciclovias do Estudo de Caso da ciclovia do Varjão. 207

Figura 36 - Promoção de Áreas Verdes nos arredores das ciclovias do Estudo de Caso da ciclovia de Samambaia 207 


\section{INTRODUÇÃO}

Este Capítulo tem como objetivo apresentar o problema, os objetivos, as justificativas, a metodologia e a estrutura do trabalho.

\subsection{APRESENTAÇÃO}

As cidades do mundo, particularmente as de maior porte, têm enfrentado problemas de congestionamento, acidentes e ambientais devido à crescente urbanização e motorização. É de fundamental importância a adoção de instrumentos que auxiliem no controle dos efeitos negativos causados pelo setor de transportes ao meio ambiente, à saúde e ao bem-estar social de suas populações.

Na última década intensificou-se a publicação de artigos, documentos e livros sobre temas como sustentabilidade e desenvolvimento sustentável. No entanto, a explicitação de problemas do setor de transportes, de seu planejamento e de políticas relacionadas à sustentabilidade é ainda recente. O setor de transportes possui grande potencial de aplicação do conceito de sustentabilidade, uma vez que é um dos que mais contribuem nos dias de hoje para o consumo de recursos energéticos e para a emissão de poluentes locais e gases de efeito estufa (GEE).

A mensuração da sustentabilidade pode ser utilizada como uma ferramenta no processo de tomada de decisões da sociedade em relação ao meio ambiente. A Comissão de Desenvolvimento Sustentável (Comissionon Sustanaible Development - CSD), criada pela Organização das Nações Unidas (ONU), considera ser de fundamental importância a criação de padrões que sirvam de referência para medir o progresso da sociedade em direção a um futuro sustentável por meio de uma base mundial, uma vez que a maioria dos indicadores existentes não é adequada para se alcançar esse objetivo. Preocupações como estas estão registradas em documentos importantes como a Agenda 21, a qual ressalta a necessidade de construção de indicadores de desenvolvimento sustentável. 
Em várias cidades do mundo, ações em prol da sustentabilidade têm sido direcionadas ao uso do transporte não motorizado, principalmente por meio do estímulo do uso do modo cicloviário como meio de transporte. Incentivos têm sido oferecidos para viabilizar a mudança dos modos motorizados para modos de transporte não motorizados, como a construção de ciclovias, ciclofaixas, sistemas de compartilhamento de bicicletas públicas e composição de ambientes mais agradáveis para o ciclista.

Muitas cidades ainda não apresentam infraestrutura apropriada ao transporte não motorizado, principalmente em países em desenvolvimento como o Brasil. Há problemas de planejamento da rede cicloviária com trechos descontínuos e falta de conexões com terminais de transporte público de qualidade; segurança das ciclovias e ciclofaixas implantadas, além da carência de ciclovias e ciclofaixas.

Por outro lado, é necessário que a construção de novas ciclovias busque promover mobilidade para a demanda reprimida, inclusão social, transferência dos modos motorizados para o modo cicloviário, redução do consumo de energia, de emissão de poluentes, de ruídos, de acidentes, do nível de estresse dos ciclistas em relação à disputa de espaço com o tráfego misto, aumento da segurança dos ciclistas e benefícios gerados pelo esforço físico saudável de pedalar, fatores os quais estão intrinsecamente relacionados com a geometria e com a qualidade da infraestrutura cicloviária.

Assim sendo, este trabalho visa discutir o tema mobilidade sustentável relacionado com as características físicas e operacionais das ciclovias e propor um método para avaliálas. Com isto, será possível verificar o grau de sustentabilidade de uma ciclovia, o que facilitará o planejamento, a elaboração de novos projetos e melhorias em ciclovias existentes, o estabelecimento de prioridades diante das condições atuais das ciclovias, tendências e locais que necessitam intervenção, bem como o monitoramento da eficiência das ações tomadas.

\subsection{CONTEXTUALIZAÇÃO DO PROBLEMA}

Os impactos ambientais gerados pelo setor de transportes são complexos e necessitam de um sistema integrado para a coleta, armazenamento e análise de dados. No Brasil, o setor de transportes não possui uma sistemática de avaliação de programas e projetos de infraestrutura desde a etapa de planejamento, além de apresentar deficiências para o monitoramento e supervisão das infraestruturas existentes. 
O Ministério das Cidades (2016) tem desenvolvido ações na área de mobilidade urbana, entre eles o Sistema Nacional de Informações da Mobilidade Urbana - SIMU, que, quando em operação, disponibilizará dados e possibilitará o cálculo de indicadores de mobilidade. Segundo o Ministério, o sistema já se encontra concebido e projetos pilotos foram realizados em nove cidades para validação da metodologia de coleta de dados para o sistema. O SIMU será disponibilizado para participação e acesso de todos os municípios brasileiros.

Assim, é possível que, futuramente, o país venha a dispor de informações de mobilidade urbana capazes de permitir o planejamento e avaliação dos seus programas e projetos de mobilidade sustentável. Porém, no momento isto não acontece, constituindo uma dificuldade na área de mobilidade urbana.

Por sua vez, o Ministério dos Transportes (MT) não tem atualmente foco no transporte urbano. Segundo o Centro Interdisciplinar de Estudos em Transportes - CEFTRU (BRASIL, 2007a), o MT possui dificuldades para acompanhar e avaliar os Programas Nacionais de Transporte, pois muitos dos indicadores utilizados são inadequados e não possibilitam a obtenção de resultados consistentes e válidos para a avaliação dos programas.

Se já existem dificuldades para a avaliação e acompanhamento de projetos tradicionais de transporte no Brasil, problema maior é a ausência de métodos de avaliação e monitoramento para o caso de projetos de transporte não motorizado, como os cicloviários, principalmente sob o ponto de vista da mobilidade sustentável.

Atualmente, não existe um método disponível para comparar dois projetos de infraestrutura cicloviária e determinar qual seria o mais sustentável. Também não existe uma forma de verificar se uma ciclovia existente é sustentável nem de monitorá-la ao longo do tempo a fim de averiguar sua condição de sustentabilidade.

\subsection{JUSTIFICATIVA}

O crescimento populacional das cidades, muitas vezes desordenado, o aumento excessivo do uso de veículos particulares, a queda no uso do transporte público e o aumento das emissões de poluentes atmosféricos são alguns dos problemas que afligem os centros urbanos brasileiros e têm contribuído para a perda da qualidade de vida nas cidades. Segundo Motta et al. (2007), este modelo vem se mostrando ineficaz e insustentável. 
Em várias cidades foram investidos vultosos recursos em infraestrutura viária, sem os resultados esperados de diminuição dos congestionamentos. A melhoria do fluxo de veículos proporcionada por obras de infraestrutura viária verifica-se apenas no curto prazo, pois logo se reverte em maior uso do transporte individual e em novos congestionamentos. Constata-se que os problemas de congestionamento não podem ser resolvidos apenas pela construção de novas vias (MOTTA et al., 2007).

Estes problemas têm incentivado a revisão dos conceitos e formas de planejamento e gestão urbana, principalmente no que diz respeito às questões relacionadas à gestão do setor de transportes e à mobilidade. Muitos pesquisadores e tomadores de decisão têm buscado novas formas de analisar, discutir e encontrar soluções para estas questões.

Há a necessidade de adoção de estratégias que reduzam a demanda de viagens por transporte individual e que incentivem o uso de sistemas mais sustentáveis adequados ao contexto socioeconômico de cada região.

A inclusão da bicicleta nos deslocamentos urbanos deve ser considerada medida importante para alcançar a mobilidade sustentável. O transporte por bicicleta tem sido implantado em vários países como uma solução mais barata e eficaz em áreas congestionadas.

No entanto, a simples implantação de uma ciclovia pode não trazer ganhos ambientais, sociais ou econômicos. É preciso verificar se uma determinada ciclovia realmente proporciona impactos positivos e, quantitativamente e qualitativamente, aferir resultados neste sentido. Assim, a realização deste trabalho justifica-se na medida em que existe a necessidade do estabelecimento de indicadores para determinar o grau de sustentabilidade de ciclovias, uma vez que esses indicadores permitirão avaliá-las do ponto de vista da mobilidade sustentável.

Os indicadores de mobilidade sustentável de ciclovias também poderão auxiliar o estabelecimento e monitoramento de diretrizes para cidades cada vez mais sustentáveis, com foco na qualidade de vida da população. 


\subsection{OBJETIVO}

O objetivo desta tese é desenvolver um método baseado em indicadores de mobilidade sustentável para ser aplicado em ciclovias existentes, a fim de possibilitar a determinação do grau de sustentabilidade de cada ciclovia, a comparação entre elas, o monitoramento ao longo do tempo, com consequente ranqueamento, bem como a identificação de pontos prioritários a serem considerados para futuras melhorias.

\subsection{METODOLOGIA DA PESQUISA}

Como método de procedimento, inicialmente foi realizada uma pesquisa secundária e indireta, baseada na pesquisa documental e bibliográfica.

Em um segundo momento, especialistas do setor de transportes foram consultados para auxiliar o desenvolvimento das etapas 3 e 4, apresentadas na Figura 1.1, a qual sintetiza a metodologia utilizada para o desenvolvimento desta tese.

Foi também realizada uma pesquisa descritiva, com observação direta, por meio de dois estudos de caso, os quais permitiram a verificação da aplicabilidade do método desenvolvido. 
A metodologia utilizada para o desenvolvimento desta tese consiste nas etapas apresentadas na Figura 1.1.

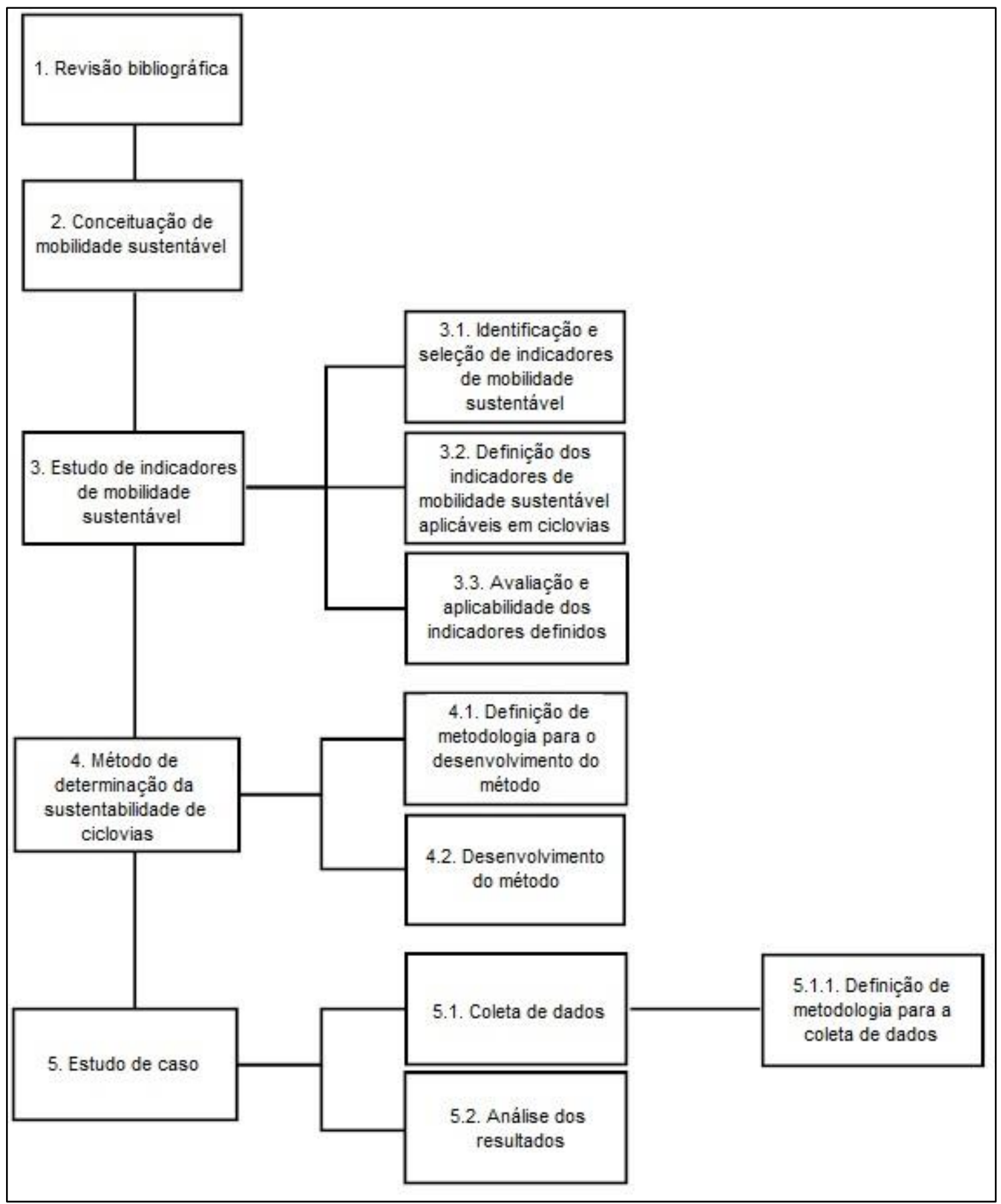

Figura 1.1: Estrutura da metodologia adotada para o desenvolvimento da pesquisa 
Apresenta-se a seguir a descrição da metodologia adotada para o desenvolvimento da pesquisa:

1. Revisão bibliográfica: primeiramente, foram adquiridos, por meio de revisão bibliográfica junto à literatura nacional e internacional, conhecimentos detalhados e consistentes sobre o objeto e a finalidade dos conceitos de sustentabilidade, desenvolvimento sustentável, mobilidade, mobilidade sustentável e indicadores, com o intuito de delimitar a área de estudo e adquirir base teórica para o desenvolvimento e execução deste trabalho.

2. Conceituação de mobilidade sustentável: foi abordada a relação entre sustentabilidade e mobilidade urbana, a fim de definir os elementos que caracterizam a mobilidade como sustentável.

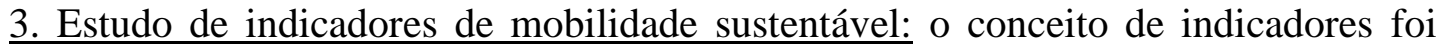
pesquisado amplamente com a finalidade de permitir uma visão crítica necessária ao desenvolvimento de um método para a determinação da sustentabilidade de ciclovias. Os indicadores mais confiáveis e consistentes relacionados com o tema foram levantados e analisados.

3.1. Identificação e seleção de indicadores de mobilidade sustentável: foi realizada uma pesquisa documental e bibliográfica, considerando as três dimensões da sustentabilidade - ambiental, econômica e social, a fim de identificar os indicadores de mobilidade sustentável aplicáveis em ciclovias.

3.2. Definição dos indicadores de mobilidade sustentável aplicáveis em ciclovias: uma vez concluído o levantamento dos indicadores, estes foram estudados, analisados, adaptados e desenvolvidos, a fim de definir os que possuíam potencial de aplicação no método. 
3.3. Avaliação e aplicabilidade dos indicadores definidos: foram analisadas a importância, a consistência e a viabilidade do levantamento dos dados e do cálculo dos indicadores, definidos na etapa anterior, para selecionar os mais adequados para a construção do método.

4. Método de determinação da sustentabilidade de ciclovias: os indicadores selecionados foram agregados para gerar um método capaz de fornecer a síntese do estado de mobilidade sustentável de uma ciclovia, através do cálculo de um grau de sustentabilidade, variável entre 0 a 1 , o qual pode ser utilizado por tomadores de decisão como uma ferramenta de diagnóstico, planejamento e monitoramento da mobilidade urbana.

4.1. Definição de metodologia para o desenvolvimento do método: nesta etapa foram identificadas e analisadas aplicações de indicadores relacionados com o conceito de mobilidade urbana sustentável na área de transporte terrestre, a fim de verificar quais metodologias foram utilizados em seu desenvolvimento. Ao analisar as vantagens e limitações das metodologias mais utilizadas foi identificada a mais adequada para a construção do método, considerando os indicadores selecionados na etapa 3.3.

4.2. Desenvolvimento do método: O método foi construído a partir um procedimento multicritério baseado na Teoria da Utilidade Multiatributo (Multiattribute Utility Theory) ou Função Multiatributo Aditiva, após análise das metodologias possíveis.

5. Estudo de caso: o método foi aplicado por meio de dois estudos de caso na ciclovia do Varjão, localizada paralelamente à DF-005 (Estrada Parque Paranoá - EPPR), e na ciclovia de Samambaia, paralela à $1^{\mathrm{a}}$ Avenida Norte e à $1^{\mathrm{a}}$ Avenida Sul.

5.1. Coleta de dados: as informações coletadas foram sistematizadas e o grau de mobilidade sustentável das ciclovias calculado de acordo com o método desenvolvido. 
5.1.1. Definição de metodologia para a coleta dos dados: a partir dos indicadores selecionados na etapa 3.3 e da elaboração do questionário disponibilizado no apêndice para a obtenção da opinião dos usuários das ciclovias, foi finalizada a metodologia para realizar a coleta dos dados dos estudos de caso.

5.2. Análise dos Resultados: os resultados obtidos nos estudos de caso foram analisados para verificar se os graus de mobilidade sustentável obtidos refletiam os aspectos positivos e negativos da ciclovia quanto à mobilidade sustentável, bem como para fins de comparação entre ambos os casos, além da avaliação da importância do método.

\subsection{ESTRUTURA DO TRABALHO}

O presente estudo foi estruturado em seis Capítulos descritos a seguir.

O primeiro Capítulo apresenta a introdução, contendo o contexto, o problema, os objetivos, as justificativas e a metodologia do estudo.

O segundo Capítulo discute o objeto e a finalidade dos conceitos de sustentabilidade, de mobilidade sustentável e de desenvolvimento sustentável, com o intuito de subsidiar a aplicação dos conceitos de sustentabilidade em ciclovias e adquirir base teórica para o desenvolvimento e execução deste trabalho. Aborda também a relação entre sustentabilidade, mobilidade urbana e ciclovias, a fim de definir os elementos que caracterizam este tipo de mobilidade como sustentável. Este Capítulo também discute como este tema vem sendo abordado pelas políticas públicas de planejamento urbano no Brasil e exemplifica conceitos de infraestrutura cicloviária, ciclovias sustentáveis e não sustentáveis.

No terceiro Capítulo, o conceito de indicadores é discutido amplamente com a finalidade de permitir uma visão crítica necessária ao desenvolvimento de um método para determinar a sustentabilidade de ciclovias, bem como o levantamento dos indicadores existentes relacionados com a mobilidade sustentável no espaço urbano.

No quarto Capítulo, os indicadores selecionados foram agregados para gerar um método capaz de fornecer a síntese do estado de mobilidade sustentável de uma ciclovia. Este método poderá ser utilizado por tomadores de decisão como uma ferramenta de diagnóstico, planejamento e monitoramento da mobilidade urbana. 
No quinto Capítulo, o método desenvolvido foi aplicado por meio de estudos de caso em duas ciclovias urbanas do Distrito Federal, uma de responsabilidade do DETRAN/DF e outra do DER/DF. Quanto à sustentabilidade das ciclovias, os resultados obtidos nos estudos de caso foram tabulados, comparados e analisados, a fim de testar a aplicabilidade do método criado.

O sexto Capítulo apresenta as considerações finais e as recomendações para futuros estudos. 


\section{MOBILIDADE E SUSTENTABILIDADE}

Este Capítulo tem como objetivo a discussão do objeto e da finalidade dos conceitos de sustentabilidade, de mobilidade sustentável e de desenvolvimento sustentável, com o intuito de reunir os conceitos para avaliar a sustentabilidade de ciclovias e adquirir base teórica para o desenvolvimento e execução desta tese, bem como abordar a relação entre sustentabilidade e mobilidade urbana, com o propósito de definir os elementos que caracterizam a mobilidade como sustentável. Este Capítulo também debate como este tema vem sendo abordado pelas políticas públicas de planejamento urbano no Brasil e no mundo.

\subsection{CONCEITUAÇÃO DE MOBILIDADE SUSTENTÁVEL}

De acordo com Lakatos e Marconi (2007) conceituar significa: "refletir através de conceitos precisos aquilo que ocorre no mundo dos fenômenos existenciais, ou seja, ajustar o termo mais adequado capaz de exprimir através do seu significado ao que realmente se oferece na realidade e não que a realidade existencial tenha que se ajustar ao conceito".

Uma vez que até hoje não existe uma definição universalmente aceita de sustentabilidade, de desenvolvimento sustentável e de mobilidade sustentável, a fim de delimitar os significados e abrangências adotados neste trabalho, tais expressões foram conceituadas pela autora deste trabalho nos subitens a seguir.

\subsubsection{Sustentabilidade e Desenvolvimento Sustentável}

Existem mais de 160 definições que abordam os conceitos de sustentabilidade e desenvolvimento sustentável (VAN BELLEN, 2006). A diferença nas definiçõos decorre das distintas abordagens que o conceito apresenta.

Inicialmente, a expressão sustentabilidade surgiu focada em preocupações ambientais de longo prazo causadas por impactos indiretos, porém foi expandida para incluir problemas de outras áreas. Desta maneira, a concepção de uma definição comum para o conceito de sustentabilidade gera diversas discussões. Observa-se que existe hoje um enorme número de abordagens que procuram explicar este conceito, no entanto devido à grande variedade de definições do conceito, não se sabe exatamente o que o termo significa. 
O Relatório Brundtland, elaborado pela Comissão Mundial sobre Meio Ambiente e Desenvolvimento, possui a definição mais conhecida internacionalmente, que afirma que o desenvolvimento sustentável é o que atende às necessidades das gerações presentes sem comprometer a possibilidade de as gerações futuras atenderem suas próprias necessidades (WCED, 1987).

Outro documento de fundamental importância é a Agenda 21. Estabelecida pelos princípios apresentados na Declaração do Rio sobre Meio Ambiente e Desenvolvimento, especifica os objetivos e ações necessárias para alcançar o desenvolvimento sustentável (UNITED NATIONS, 1992).

Segundo Van Bellen (2006), o conceito do desenvolvimento sustentável foi primeiramente discutido pela International Union for Conservation of Nature, no documento intitulado World's Conservation Strategy (IUCN; UNEP; WWF, 1980). O documento afirma que para o desenvolvimento ser sustentável devem ser considerados aspectos referentes às dimensões social e ecológica, bem como fatores econômicos, dos recursos vivos e não vivos.

De acordo com Brüseke (1995), outros pontos importantes na discussão desse conceito no século XX foram: o Relatório sobre os Limites do Crescimento em 1972, o surgimento do conceito de ecodesenvolvimento em 1973, a Declaração de Cocoyok em 1974 e o relatório da Fundação Dag-Hammarskjöd em 1975.

Um dos mais conhecidos estudos decorrentes da ação do Clube de Roma, o relatório mundialmente conhecido como "Os Limites do Crescimento", afirma que a humanidade corre sérios riscos de sobrevivência devido ao ritmo do crescimento da população e da poluição, ao intenso consumismo e degradação de recursos naturais (MEADOWS et al., 1972).

A Declaração de Cocoyok, estabelecida em uma reunião da Conferência das Nações Unidas, concluiu que a explosão populacional é decorrente da absoluta falta de recursos em alguns países, haja vista que quanto maior a pobreza, maior é o crescimento demográfico. $\mathrm{O}$ documento ressalta que a destruição ambiental também decorre da pobreza e que os países desenvolvidos têm grande responsabilidade nos problemas globais, pois possuem um nível elevado de consumo (BRÜSEKE, 1995; VAN BELLEN, 2006). 
O Relatório da Fundação Dag-Hammarskjöd discute a problemática do abuso de poder e sua relação com a degradação ecológica. Cita também diversos exemplos de devastação de paisagens na África do Sul e Marrocos e destaca a importância da mobilização de forças capazes de mudar as estruturas dos sistemas vigentes (BRÜSEKE, 1995).

Autores como Sachs (1986) e Dahl (1997) alertam para a componente social do desenvolvimento sustentável, prioritariamente questões como educação, participação e preservação dos recursos naturais, conjuntamente com a satisfação das necessidades básicas.

Por sua vez, Van Bellen (2006) ressalta que o conceito de bem-estar não é fácil de construir nem medir. Os indicadores sociais são considerados especialmente controversos, pois refletem contextos políticos e julgamentos de valor.

O trabalho de Pronk e Ul Haq (1992) destaca o papel do crescimento socioeconômico na sustentabilidade. Para eles, o desenvolvimento é sustentável quando o crescimento econômico traz justiça e oportunidades para todos os seres humanos do planeta, sem privilégio para algumas espécies, sem destruir os recursos naturais finitos e sem ultrapassar a capacidade de carga do sistema.

Segundo Krama (2008), sustentabilidade não é um estado fixo, trata-se de um processo contínuo de evolução sem o comprometimento da continuidade da vida. Bossel (1999) afirma que a sustentabilidade é um conceito dinâmico através de um processo evolutivo e adaptativo, sujeito a mudanças contínuas.

Para Pires (2003) sustentabilidade é um termo tomado da ecologia e diz respeito à tendência dos ecossistemas à estabilidade, ao equilíbrio dinâmico, à homeostase (capacidade de autorregulação dos sistemas), com base na interdependência e complementaridade de formas vivas. Assim, sustentabilidade implica noções de estabilidade e equilíbrio dinâmico.

A sustentabilidade do desenvolvimento é um problema complexo, pois envolve várias questões inseparáveis e exige uma reflexão sobre a própria noção de desenvolvimento, confundida muitas vezes com crescimento. O desenvolvimento sustentável requer a maximização de eficiência enquanto provê bem-estar. 
A Figura 2.1 mostra que à medida que a prosperidade material aumenta, se não houver o estabelecimento de limites sustentáveis, a ineficiência tende a aumentar. Conforme a sustentabilidade dos recursos torne-se prioridade, a eficiência tende a aumentar dentro de um nível ótimo de conforto. Desta maneira, percebe-se que para haver sustentabilidade é preciso haver limitação de consumo de recursos, ou seja, o estabelecimento de limites é necessário para o desenvolvimento sustentável de uma sociedade.

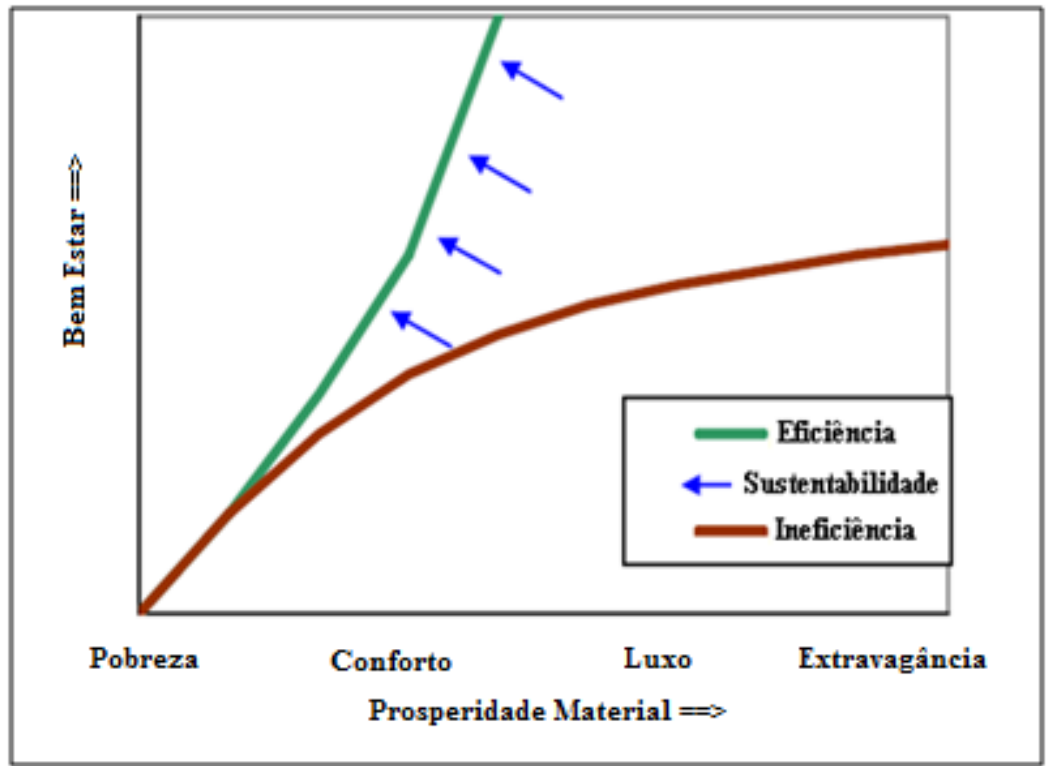

Figura 2.1: Relação entre sustentabilidade, bem-estar e prosperidade material (Adaptação de LITMAN, 2008a)

Faber et al. (2005) buscaram estudar diferentes definições de sustentabilidade, classificá-las e mostrar a evolução do seu significado em diferentes décadas. Além disso, estes autores formularam um conjunto de aspectos para analisar o desenvolvimento do termo sustentabilidade: artefato ("o que"), orientação do objetivo ("relativo ou absoluto") e interação comportamental ("estático ou dinâmico"). As primeiras definições de sustentabilidade apresentavam uma visão construtiva, absoluta e estática de seu significado. Entretanto, a discussão sobre sustentabilidade avançou de forma tal que se transformou em uma orientação também construtiva, porém, relativa e dinâmica. Assim, a sustentabilidade não foca mais um estado último de sustentabilidade, ao contrário, objetiva um processo de mudanças e melhoria contínua dos artefatos de sustentabilidade. 
Pearce e Atkinson (1993) vão além da definição de sustentabilidade da Comissão de Bruntland, afirmando que não somente a quantidade de recursos naturais, mas principalmente o estoque de capital deve ser mantido para haver sustentabilidade. Assim sendo, estabelecem que para a existência de desenvolvimento sustentável são necessárias condições de manutenção do estoque de capital sempre constante. Isto significa que mesmo que haja a redução da quantidade de um recurso natural, a sustentabilidade pode ainda existir desde que o capital não diminua. Portanto, para Pearce e Atkinson (1993) e outros autores que seguiram a mesma linha (REPETTO e MAGRATH, 1988), a sustentabilidade é uma função do estoque de Capital Humano e de Capital Natural.

A definição de sustentabilidade do Relatório Brundtland é criticada por Dahl (1997), que a acusa de ser muito geral, uma vez que não implica responsabilidades específicas a respeito das dimensões do desenvolvimento sustentável e nem em relação às gerações futuras. No entanto, Dahl reconhece que não é tarefa fácil conceitualizar o termo.

Segundo Rutherford (1997), é necessária uma abordagem holística para a seleção de indicadores, de forma a representar as propriedades do sistema e não apenas os elementos dos subsistemas. É preciso observar o problema sob diferentes perspectivas que, em sua opinião, devem ser a econômica, a ambiental e a social.

Assim sendo, verifica-se que existem múltiplos níveis de sustentabilidade, o que leva à questão da inter-relação dos subsistemas que devem ser sustentáveis, o que, entretanto, por si só, não garante a sustentabilidade do sistema como um todo. 
O conceito Triple Bottom Line foi proposto por Elkington (1994) com o intuito de auxiliar a compreensão e disseminação da sustentabilidade por meio do tripé “economicamente viável”, "socialmente justo" e "ecologicamente correto" (Figura 2.2), denominado de tripé da sustentabilidade. Por meio deste tripé, o desenvolvimento passou a ter um enfoque de crescimento sistêmico, a partir do reconhecimento de que a sociedade depende da economia, a economia depende do ecossistema global e o ecossistema depende da sociedade.

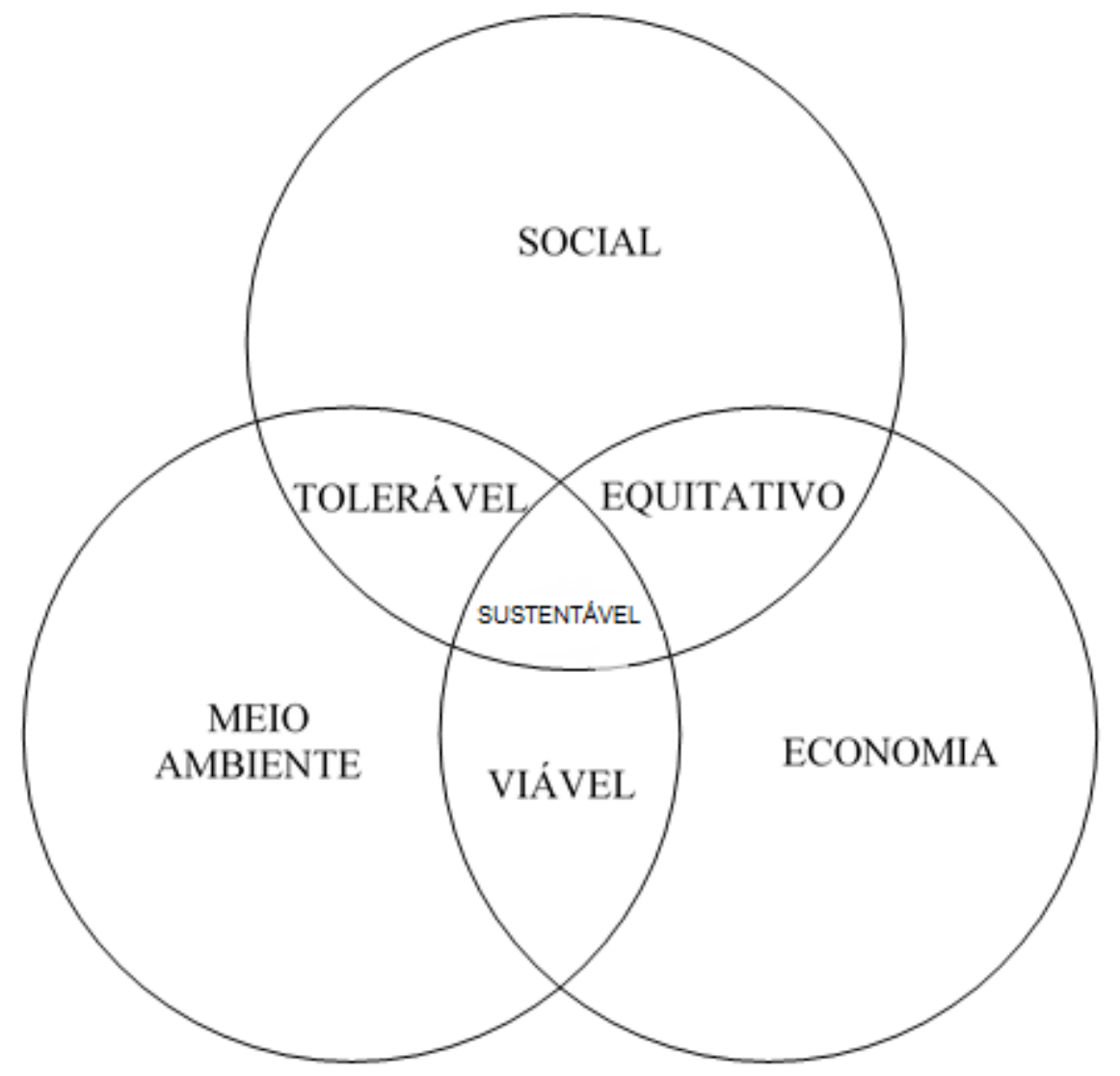

Figura 2.2: Tripé da Sustentabilidade

Muitos dos sistemas de indicadores existentes foram desenvolvidos por razões específicas: ambientais, econômicas, de saúde, sociais, entre outras. Entretanto, as dimensões do tripé da sustentabilidade possuem um potencial representativo dentro do contexto do desenvolvimento sustentável. A formulação de indicadores com base neste tripé pode ajudar a identificar os problemas ambientais e a designar objetivos para o setor de transportes. 
Diante do exposto, conclui-se que todos os aspectos do conceito de sustentabilidade apresentados neste trabalho mostram a diversidade e complexidade deste termo. No entanto, Van Bellen (2006) defende que apesar das dificuldades que essas características conferem ao estudo do desenvolvimento sustentável, que a diversidade deste conceito deve servir não como obstáculo na procura de seu entendimento, mas, sim, como fator de motivação criador de novas visões sobre ferramentas para descrever e medir a sustentabilidade de diferentes sistemas.

Com fins de delimitar o conceito adotado nos próximos itens desta tese, conceituase desenvolvimento sustentável como sendo uma ideologia realista baseada na necessidade de mudança dos padrões de desenvolvimento que apresentam risco aos ecossistemas e à vida, visando o progresso da humanidade através de esforços contínuos baseados em valores como eficiência, equilíbrio, ética e equidade.

\subsubsection{Mobilidade}

O dicionário The American Heritage Dictionary define mobilidade como "qualidade ou estado de ser móvel" e móvel como a "capacidade de se mover ou ser movido de um lugar para outro". Segundo a Comissão Mundial sobre Meio Ambiente e Desenvolvimento, entende-se por mobilidade o trânsito de pessoas, bens e serviços (CMMAD, 1991).

De acordo com Pontes (2010), a mobilidade está relacionada à liberdade de se movimentar e às possibilidades de acesso aos meios necessários para tal, ou seja, a mobilidade relaciona-se com o desejo do indivíduo de alcançar determinado destino e com a capacidade do indivíduo de se deslocar. Vasconcellos (2001) define mobilidade como sendo a "habilidade de movimentar-se" em decorrência das condições físicas e econômicas.

A utilização do conceito de mobilidade ainda é muito recente no Brasil, tendo sido inicialmente definido pelo Ministério das Cidades (2004) como um atributo relacionado aos deslocamentos realizados por indivíduos em suas atividades. Já a Lei Federal no 12.587, sancionada em 3 de janeiro de 2012, responsável por instituir as diretrizes da Política Nacional de Mobilidade Urbana, define mobilidade urbana como a "condição em que se realizam os deslocamentos de pessoas e cargas no espaço urbano". 
A mobilidade é usualmente medida nas pesquisas de origem e destino pelo número médio de viagens que as pessoas realizam em um dia típico, por qualquer modo e para qualquer finalidade. Já o índice de imobilidade quantifica o número de pessoas que não realizam nenhum deslocamento (MINISTÉRIO DAS CIDADES, 2007).

Cabe salientar que a mobilidade é condicionada por fatores socioeconômicos da população. Assim, a limitação da mobilidade de um cidadão pode interferir em sua condição de acesso aos bens e serviços urbanos, de forma a diminuir sua qualidade de vida. Neste contexto, é preciso haver condições adequadas de mobilidade e, portanto, o planejamento de transportes deve ser norteado pela mobilidade de seus cidadãos, uma vez que a mobilidade se tornou um requisito essencial para o funcionamento de uma sociedade moderna.

Com fins de delimitar o conceito adotado nos próximos itens desta tese, conceituase mobilidade como a capacidade de um indivíduo se locomover no espaço diante de meios físicos que permitam seu deslocamento e das condições econômicas inerentes a esta locomoção.

\subsubsection{Mobilidade Sustentável}

A mobilidade não deve mais ser pensada apenas como um atributo de maior velocidade, agilidade, aceleração dos movimentos e sim como um exercício democrático e saudável dentro das cidades, que possibilite o acesso aos benefícios da urbanidade (PONTES, 2010).

O conceito de mobilidade sustentável preza pela melhoria da eficiência energética dos veículos, por combustíveis e tecnologias mais limpas, por formas de planejamento urbano que minimizem as distâncias percorridas, pela diminuição do transporte individual, pela integração de diferentes modos de transporte e pelo incentivo de meios de transporte de alta capacidade e não motorizados. 
A mobilidade sustentável tem sido objeto de estudos que procuram soluções e incentivam políticas para a melhoria das qualidades social e ambiental urbanas por meio de intervenções no sistema de transportes e no planejamento urbano. São importantes diretrizes da mobilidade sustentável (WILLIAMS e BANISTER, 1997; BANCO MUNDIAL, 2002; MMA et al., 2002, SEDU/PR, 2002; MOORE e JOHNSON, 1994; UNDSD, 2003; CARVALHO, 2005; VAN BELLEN, 2006; LITMAN e BURWELL, 2006):

- Planejamento integrado entre desenvolvimento urbano e transportes;

- Gestão integrada do uso do solo, transportes e trânsito;

- Participação efetiva do público no planejamento dos transportes;

- Incentivos econômicos e prioridade ao transporte público e massivo;

- Restrições a veículos particulares;

- Incentivo ao transporte não motorizado;

- Integração de diferentes modos de transportes;

- Veículos e combustíveis mais eficientes;

- Redução das emissões veiculares.

A Organização de Cooperação e Desenvolvimento Econômico (OECD, 2002) define como um sistema de transporte ambientalmente sustentável aquele que não prejudica a saúde dos habitantes ou ecossistemas e que preenche as necessidades de deslocamento dos habitantes com o uso de recursos renováveis abaixo dos níveis de regeneração ou com o uso de fontes não renováveis abaixo das taxas de desenvolvimento de recursos substitutos renováveis. Segundo a OECD, a mobilidade sustentável requer que o planejamento de transportes seja consistente com a integridade dos ecossistemas e não agrave fenômenos globais adversos como a mudança climática e a destruição da camada de ozônio.

Para a União Europeia, o conceito de mobilidade sustentável deve compreender os seguintes princípios (BICKEL et al., 2003):

- Permitir o acesso básico e que necessidades de desenvolvimento dos indivíduos, companhias e sociedades sejam atingidas de forma segura e de maneira consistente com a saúde humana e dos ecossistemas, promovendo equidade para a geração atual e futura; 
- Possuir custo acessível para todos, operar de forma justa e eficiente, oferecer variedade de modos de transportes, suportar uma economia competitiva, bem como o equilíbrio do desenvolvimento regional;

- Limitar as emissões e resíduos considerando a habilidade do planeta de absorvê-los, usar recursos renováveis abaixo ou até o limite de sua taxa de geração e recursos não renováveis abaixo ou até o limite de sua taxa de desenvolvimento de substitutos renováveis, minimizando o impacto do uso do solo e geração de ruído.

De acordo com o Projeto PROSPECTS (Procedures for Recommending Sustainable Planning of European City Transport Systems) elaborado pelo Instituto de Planejamento de Transporte e Engenharia de Tráfego (TUW-IVV, 2004, The Institute for Transport Planning and Traffic Engineering), o conceito de mobilidade sustentável deve compreender os seguintes aspectos:

- Proporcionar acesso aos bens e serviços de forma eficiente para todos habitantes de áreas urbanas;

- Proteger o meio ambiente, patrimônio cultural e ecossistemas para a geração presente;

- Não colocar em perigo as oportunidades de futuras gerações em alcançar, no mínimo, a mesma qualidade de vida da geração presente, incluindo o bemestar derivado do meio ambiente e patrimônio cultural.

Segundo o maior encontro de Chefes de Estado e delegações já organizado pela ONU para divulgar temas ligados à sustentabilidade, conhecido como Rio+20 (UNITED NATIONS, 2012) e também como Conferência das Nações Unidas sobre Desenvolvimento Sustentável, a mobilidade é essencial para o desenvolvimento sustentável e pode reforçar o crescimento econômico, bem como melhorar a acessibilidade. Cabe salientar que durante a Rio+20, houve o reconhecimento da importância do incentivo à mobilidade não motorizada, nomeadamente por meio da promoção de infraestruturas para bicicletas. 
Com fins de delimitar o conceito adotado nos próximos itens desta tese, conceituase mobilidade sustentável como forma de mobilidade que promova mudança de paradigma no planejamento dos transportes, capaz de se manter ao longo do tempo sem que suas atividades prejudiquem a saúde humana, o meio ambiente e o bem-estar social, promovendo o desenvolvimento econômico, a eficiência da aplicação dos recursos no setor de transporte e os meios de transporte não motorizados.

\subsection{APLICAÇÃO DO CONCEITO E DE AÇÕES DE MOBILIDADE SUSTENTÁVEL}

De forma geral, constatam-se as seguintes dificuldades no que concerne à aplicação do conceito e de ações de mobilidade sustentável em nível nacional e internacional:

- Identificar limites críticos para o uso sustentável do meio ambiente relacionados com o conceito de mobilidade urbana;

- Lidar com a interdependência da mobilidade sustentável, devido à conexão das atividades de transportes com outras atividades, escolhas de localidades e estilos de vida;

- Solucionar conflitos entre os interesses coletivos e individuais, pois nem sempre o que é considerado como uma melhoria coletiva na qualidade de vida é compatível com os interesses individuais;

- Definir uma contribuição ótima dos setores econômicos para solucionar problemas de sustentabilidade.

Desta forma, é possível concluir que o termo mobilidade sustentável é considerado vago e complexo de ser aplicado. Assim sendo, para fins de aprofundamento de estudo e análise foram levantadas as principais ações de aplicação do conceito e de ações de mobilidade em nível internacional e nacional. 


\subsubsection{No Mundo}

Paralelamente aos esforços em identificar o conceito de mobilidade sustentável e as críticas à sua aplicabilidade, algumas iniciativas no sentido de colocar em prática estes conceitos têm sido desenvolvidos e implantados. O Prêmio de Mobilidade Sustentável desenvolvido pelo Instituto de Políticas de Transporte e Desenvolvimento (Institute for Transportation and Development Policy - ITDP, 2013) é oferecido anualmente desde 2005 à cidade que obteve mais progresso ao longo do ano em relação ao aumento da mobilidade de seus residentes ao mesmo tempo em que buscou reduzir a emissão de poluição e aumentar a segurança e acessibilidade de ciclistas e pedestres.

Os vencedores do Prêmio de Mobilidade Sustentável até o momento são:

- 2005: Bogotá (Colômbia) - implantou um sistema rápido e de alta capacidade de ônibus, reconhecido internacionalmente pela sigla BRT (Bus Rapid Transit), denominado Transmilênio. Ao longo do BRT Transmilênio foram também implantadas ciclovias, as quais elevaram o número de viagens por bicicleta de $0,4 \%$ para 4,5\% das viagens totais. Estima-se a redução de 2.791.689 toneladas de CO2 ${ }^{1}{ }^{1}$ para o período de 2006 a 2012 (MOTTA, 2009);

- 2006: Seul (Coréia do Sul) - uma rodovia de seis quilômetros e meio que cobria o Rio Cheonggyecheon foi substituída por um parque, com calçadas de alta qualidade e praças públicas. Além disto, um BRT com a extensão de 58 quilômetros foi construído na região. Tais medidas contribuíram para a redução da temperatura na região e promoveram o aumento de verde no centro de Seul (CERVERO, 2010);

\footnotetext{
1 Equivalência em dióxido de carbono, $\mathrm{CO}_{2 \mathrm{eq}}$ ou $\mathrm{CO}_{2 \mathrm{e}}$, é uma medida internacionalmente aceita que expressa a quantidade de GEEs em termos equivalentes da quantidade de $\mathrm{CO}_{2}$. A equivalência leva em conta o potencial de aquecimento global dos gases envolvidos e calcula quanto de $\mathrm{CO}_{2}$ seria emitido se todos os GEEs fossem emitidos como esse gás. A medida $\mathrm{CO}_{2 \text { eq }}$ é usada para comparar as emissões de diversos gases de efeito estufa baseada na quantidade de dióxido de carbono que teria o mesmo potencial de aquecimento global (GWP), medido em um período de tempo especificado.
} 
- 2007: Guayaquil (Equador) - implantou um BRT, denominado Metrovia, de 15 quilômetros, o qual transporta 96 mil passageiros por dia. Além disso, realizou-se a revitalização de espaços públicos deteriorados para estimular o transporte não motorizado;

- 2008: Paris (França) e Londres (Inglaterra) - Paris revolucionou o conceito de compartilhamento de bicicletas com um sistema de alta capacidade denominado Vélib ("Bicicletas da liberdade"). As pessoas podem pagar, até mesmo com cartões de crédito, uma pequena taxa para usar as bicicletas e retorná-las em qualquer uma das 1.800 estações do Vélib, localizadas a cada 300 metros. O sistema possui atualmente 20 mil bicicletas. Até novembro de 2007 mais de 11 milhões de viagens já haviam sido feitas. Em 2008 Paris já havia construído mais de 314 quilômetros de ciclovias, de forma que houve um aumento de $48 \%$ nas viagens realizadas por bicicletas em comparação com os últimos cinco anos. Além disso, três novos corredores de BRT foram inaugurados em 2007. Paris também priorizou os pedestres através da renovação de espaços, praças públicas, calçadas largas e novas paisagens. Todas estas melhorias resultaram na redução de $20 \%$ de veículos no tráfego e em $9 \%$ nas emissões de $\mathrm{CO}_{2}$. Por sua vez, Londres adotou o pedágio urbano para reduzir problemas de congestionamento. Em 2007 o congestionamento foi reduzido em 21\%, evitando a emissão de 16\% de GEE. O número de passageiros de ônibus aumentou $45 \%$ e o uso de bicicleta aumentou em $43 \%$ até 2007 . A cada ano, aproximadamente 120 milhões de libras são arrecadadas pelo pedágio urbano e investidas no transporte público;

- 2009: Nova York (Estados Unidos) - Nova York transformou aproximadamente 200 mil metros quadrados de espaço viário e vagas de estacionamento em ciclovias, áreas para pedestres, praças públicas e calçadas;

- 2010: Ahmedabad (Índia) - o BRT Janmarg foi o primeiro do país com estações atrativas, proteção para chuva, pagamento antecipado e embarque rápido. Os ônibus oferecem embarque em nível para facilitar a acessibilidade de idosos, cadeirantes e crianças. Em junho de 2011, o sistema já realizava 115 mil viagens por dia. Estimase que a implantação de Janmarg evite a emissão anual de 288 mil toneladas de $\mathrm{CO}_{2}$; 
- 2011: Guangzhou (China) - implantou um sistema de BRT integrado com ciclovias, sistema de empréstimos de bicicleta (113 estações, 5.000 bicicletas e 5.500 vagas para bicicletas nas estações) e estações de metrô, transportando mais de 800 mil passageiros por dia, ou seja, mais passageiros do que o metrô da cidade. Guangzhou também implantou o Donghaochong Greenway, um projeto paisagístico ao longo de um canal poluído combinado com parques, praças e transporte não motorizado;

- 2012 ( $1^{\circ}$ semestre): São Francisco (Estados Unidos) - São Francisco promoveu o Programa SFPark, uma medida inteligente de gerenciamento de estacionamentos em distritos comerciais nos arredores da cidade, com a colaboração de grupos empresariais locais e da comunidade. Também implantou o programa de espaços públicos que criou novas praças e parques com a substituição de estacionamentos por calçadas. A rede cicloviária foi expandida para atrair ciclistas de todas as idades. Estima-se um aumento de $20 \%$ de viagens por bicicletas até 2020 . A cidade também implantou zonas de velocidade reduzida nas proximidades de escolas e expandiu o Programa de ciclovia recreativa aos domingos;

- 2012 ( $2^{\circ}$ semestre): Medellin (Colômbia) - A quantidade e qualidade dos espaços públicos foram melhoradas, com a implantação de calçadões para pedestres e parques ambientais. Foi também implantado um programa de bicicletas públicas com integração com sistemas de transporte de alta capacidade, considerando pontos estratégicos da cidade. Foi inaugurado o BRT Metroplús, com integração física e tarifária com os sistemas locais do metrô e do bonde. Foi realizada a melhoria de áreas onde os cruzamentos não eram adequados e onde o acesso universal não se fazia presente, além da instalação de iluminação nos locais de travessia. Também foi implantado o Sistema de Mobilidade Inteligente (SIMM), baseado nos Sistemas Inteligentes de Transporte (Intelligent Transportation Systems- ITS), visando à melhoria da fluidez da mobilidade dos usuários, segurança viária, inclusive utilizando-se de equipamentos eletrônicos de controle de velocidade. Foi criado também um programa de compartilhamento de carro denominado "Compartilhe o seu carro". Até 2012, 171 instituições aderiram ao programa. As instituições relacionadas com mobilidade passaram a oferecer informações e serviços de ouvidoria para os usuários por meio das redes sociais e de sites na internet. Também foi realizado o controle de emissão do escapamento dos veículos e a melhoria local da qualidade do enxofre; 
- 2013: Cidade do México (México) - implantou vários projetos que melhoraram a mobilidade e a qualidade de vida dos seus cidadãos, tais como o sistema de BRT. Este foi expandido devido à construção da linha 4, um corredor que liga o centro histórico da cidade ao aeroporto. Também foi colocado em prática um programa de estacionamentos para veículos denominado "Ecoparq" que expandiu o antigo sistema de bicicletas públicas denominado "Ecobici". Foram construídas e revitalizadas ciclovias, calçadas para pedestres e espaços e parques públicos como a Alameda Central e a Praça Tlaxcoaque;

- 2014: Buenos Aires (Argentina) - Buenos Aires implantou dois sistemas de BRT: o Metrobus, com 23 quilômetros, e o MetrobusSur, com 3,5 quilômetros, conjuntamente com ambientes amigáveis para pedestres, além da promoção de caminhadas, viagens de ciclistas, de emissões e o aumento de segurança.

\subsubsection{No Brasil}

Em 3 de janeiro de 2012 foi sancionada a Lei Federal $n^{\circ}$ 12.587, que instituiu as diretrizes da Política Nacional de Mobilidade Urbana. Esta Lei estabelece princípios, diretrizes e instrumentos para que os municípios possam executar uma política de mobilidade urbana que promova a acessibilidade universal, a inclusão social e o desenvolvimento sustentável das cidades nas dimensões socioeconômicas e ambientais. Como principais diretrizes a serem observadas, destacam-se:

- Integração com a política de desenvolvimento urbano e respectivas políticas setoriais de habitação, saneamento básico, planejamento e gestão do uso do solo;

- Prioridade dos modos de transportes não motorizados sobre os motorizados e dos serviços de transporte público coletivo sobre o transporte individual motorizado;

- Integração entre os modos e serviços de transporte urbano;

- Mitigação dos custos ambientais, sociais e econômicos dos deslocamentos de pessoas e cargas na cidade;

- Incentivo ao desenvolvimento científico tecnológico e ao uso de energias renováveis e menos poluentes. 
A Política Nacional de Mobilidade Urbana inova ao estabelecer que todos os municípios brasileiros com mais de 20.000 habitantes deverão elaborar um Plano de Mobilidade Urbana, compatível com os respectivos planos diretores ou neles inserido. Estabelece também que nos Municípios sem sistema de transporte público coletivo ou individual, o Plano de Mobilidade Urbana deverá ter o foco no transporte não motorizado e no planejamento da infraestrutura urbana destinada aos deslocamentos a pé e por bicicleta.

Até então, a Lei Federal $n^{\circ} 10.257$, denominada de Estatuto da Cidade, estabelecia que a elaboração de um plano de transporte urbano era obrigatória apenas para aqueles municípios com mais de 500 mil habitantes. A fim de orientar os municípios no processo de elaboração dos Planos Diretores de Transporte e de Mobilidade, o Ministério das Cidades elaborou um guia de referência para a elaboração do Plano de Mobilidade Urbana (MINISTÉRIO DAS CIDADES, 2015).

O Estatuto da Cidade possui grande importância devido a ter estabelecido as diretrizes gerais da política urbana, mediante a garantia do direito a cidades sustentáveis, entendido como o direito à terra urbana, à moradia, ao saneamento ambiental, à infraestrutura urbana, ao transporte e aos serviços públicos, ao trabalho e ao lazer, para as gerações presentes e futuras. Esta lei também estabeleceu que as cidades brasileiras com mais de 20 mil habitantes e aquelas inseridas na área de influência de empreendimentos ou atividades com significativo impacto, integrantes de regiões metropolitanas, aglomerações urbanas ou de áreas de especial interesse turístico devem instituir um plano diretor, aprovado por lei municipal, como o instrumento básico da política de desenvolvimento e expansão urbana, o qual deverá ser revisto, pelo menos, a cada dez anos.

Importante também é considerar o Programa Brasileiro de Mobilidade por Bicicleta, conhecido como Bicicleta Brasil, lançado pelo Ministério das Cidades no ano de 2004. O Programa visa estimular os municípios e estados a desenvolver e aprimorar ações que favoreçam o uso mais seguro da bicicleta como modo de transporte. Entre os instrumentos de implementação do Programa estão a publicação de material de capacitação, a realização de cursos e seminários, a implantação de banco de dados, a criação de novas fontes de financiamento e a divulgação de boas práticas (BRASIL, 2007b). 
No Programa Brasileiro de Mobilidade por Bicicleta (BRASIL, 2007b), destaca-se a publicação de um Caderno de Referência para Elaboração do Plano de Mobilidade por Bicicleta nas Cidades. O caderno contém conceitos fundamentais, informações técnicas, elementos básicos de projetos, metodologia para a elaboração de planos de mobilidade por bicicleta e constitui importante fonte de informação técnica para os municípios e estados brasileiros.

Merece também destaque a Lei Federal no 8.723, de 1993, a qual estabelece limites para os veículos novos comercializados no País, quanto à redução dos níveis de emissão de monóxido de carbono, óxido de nitrogênio, hidrocarbonetos, álcoois, aldeídos, fuligem, material particulado e outros compostos poluentes. O Conselho Nacional de Meio Ambiente (CONAMA) tem também aprovado diversas resoluções disciplinadoras que estabelecem especificações de calibração, regulagem e manutenção do motor, dos sistemas de alimentação de combustível, de ignição, de carga elétrica, de partida, de arrefecimento, de escapamento, procedimentos e limites para as emissões ambientais de gases, partículas, opacidade e ruído.

Ênfase deve ser dada também ao Plano Nacional sobre Mudança do Clima. Publicado em 2008 e elaborado pelo Comitê Interministerial sobre Mudança do Clima, representou um marco importante para a formulação de políticas públicas ao ressaltar as práticas mais relevantes de mitigação pelo setor de transportes: utilização de veículos eficientes, modernização de frota, expansão do uso de sistemas ferroviários e aquaviários e incentivos aos transportes coletivos em substituição aos particulares.

Como forma de confirmar legalmente estas novas diretrizes e de reforçar o compromisso do país, em 2009 foi sancionada a Lei Federal no 12.187, a qual instituiu a Política Nacional sobre Mudança do Clima (PNMC) e, em 2010, o Decreto Federal nº 7.390, que a regulamenta. A PNMC contém princípios, objetivos, diretrizes e instrumentos que visam compatibilizar o desenvolvimento socioeconômico nacional com a proteção do sistema climático. Para tanto, a PNMC estabelece que as políticas públicas e programas governamentais deverão compatibilizar-se com seus princípios e instrumentos. 
A PNMC prevê o estabelecimento de planos setoriais de mitigação e de adaptação às mudanças climáticas com vistas à consolidação de uma economia de baixa emissão de carbono em setores fundamentais para a economia brasileira, dentre eles o transporte público urbano e os sistemas modais de transporte interestadual de cargas e passageiros. Os planos setoriais visam contribuir para o atendimento de metas gradativas de redução de emissões antrópicas quantificáveis e verificáveis, considerando as especificidades de cada setor, inclusive por meio de Mecanismos de Desenvolvimento Limpo (MDL) e de Ações de Mitigação Nacionalmente Apropriadas (Nationally Appropriate Mitigation ActionsNAMAs).

A PNMC estabelece que os planos setoriais deveriam ser elaborados até o ano de 2012, com o seguinte conteúdo mínimo: meta de redução de emissões em 2020, incluindo metas gradativas com intervalo máximo de três anos, ações a serem implementadas, definição de indicadores para o monitoramento e avaliação de sua efetividade, proposta de instrumentos de regulação e incentivo para implementação do respectivo Plano, e estudos setoriais de competitividade com estimativa de custos e impactos.

Também importante para a mobilidade sustentável é o compromisso voluntário de redução de gases de efeito estufa firmado pelo Governo Brasileiro. Em 2015, no período de 30 de novembro a 16 de dezembro, durante a $21^{\text {a }}$ Conferência entre as Partes (COP) da Convenção Quadro das Nações Unidas sobre Mudanças Climáticas (CQNUMC, ou em inglês, United Nations Framework Convention on Climate Change, UNFCCC), o Brasil firmou uma postura proativa diante das mudanças climáticas e voluntariou-se a estabelecer metas mensuráveis de redução de emissões de $\mathrm{CO}_{2 \text { eq. }}$.

As seguintes metas foram estabelecidas pelo Brasil na COP 21: redução das emissões no ano de 2025 de $37 \%$ e em 2030 de $43 \%$ em relação ao ano base de 2005 , ou seja, redução aproximada de $0,75 \mathrm{GtCO}_{2 \text { eq }}$ em 2025 e de $0,88 \mathrm{GtCO}_{2 \text { eq }}$ em 2030 em relação ao ano base de 2005 (UNFCCC, 2015). 
O Ministério dos Transportes e o Ministério das Cidades (BRASIL, 2013) elaboraram o Plano Setorial de Transporte e da Mobilidade Urbana para Mitigação das Mudanças Climáticas - PSTM. Foram previstas a construção de cenários de emissões e a proposição de estudos e pesquisas para a definição de ações de abatimento. O PSTM foi elaborado em consonância com planos e programas nacionais infraestruturantes, tais como o Plano Nacional de Transportes e Logística - PNLT, Plano Nacional de Eficiência Energética - PNEF, $1^{\circ}$ Inventário Nacional de Emissões Atmosféricas por Veículos Automotores Rodoviários e o $1^{\mathrm{o}}$ Inventário Nacional de Emissões Atmosféricas do Transporte Ferroviário de Cargas.

De acordo com o PSTM (BRASIL, 2013), uma das medidas consideradas necessárias para a promoção da mitigação de poluentes locais e gases de efeito estufa é o aumento do uso da bicicleta nos sistemas de mobilidade urbana. Porém, para calcular o abatimento é necessário promover um levantamento sobre a extensão de infraestrutura cicloviária que está sendo implantada no país, bem como a realização de pesquisas pós-implantação de infraestrutura para conhecer a real transferência modal do transporte motorizado para a bicicleta.

Destaque também deve ser dado ao Plano Nacional de Logística de Transportes (PNLT) que vem sendo desenvolvido pelo Ministério dos Transportes e pelo Ministério da Defesa desde 2007 para tratar do planejamento nacional de médio e longo prazos do setor de transportes de cargas, visando propiciar a promoção da sustentabilidade ambiental e a redução dos custos dos transportes. Em 2011, o último PNLT (BRASIL, 2011), até então publicado, descreve um plano para a obtenção do equilíbrio da matriz brasileira de transportes, contempla os aspectos logísticos, a integração com o planejamento territorial, a redução de desigualdades regionais, a integração continental e serve de base à elaboração dos Planos Plurianuais de Investimentos no horizonte de 2011 a 2031. 


\subsection{CONSIDERAÇÕES SOBRE OS PROBLEMAS BRASILEIROS DE MOBILIDADE}

Do ponto de vista da mobilidade sustentável, a infraestrutura de transportes do Brasil não atende às atuais demandas econômicas e sociais do país. O país carece de investimentos para atender a elevada demanda de infraestrutura no setor de transportes, problema que é agravado pelo crescimento populacional. No Brasil, em julho de 2014, a população brasileira ultrapassou 202 milhões de habitantes (IBGE, 2013a) e estima-se que em 2060 excederá 218 milhões (IBGE, 2013b). Caso a frota de veículos no Brasil continue aumentando, os problemas de mobilidade poderão ainda piorar.

Não é à toa que a IEA (2009) alertou que 90\% do aumento das emissões nos próximos anos devem vir de países em desenvolvimento, os quais buscam se desenvolver rapidamente.

Verifica-se no país um desequilíbrio na distribuição modal, uma vez que o sistema rodoviário concentra 52\% dos fluxos de carga, enquanto os modos ferroviário, aquaviário e aéreo juntos respondem por apenas 48\% (BRASIL, 2011). Considerando que os modos ferroviário e aquaviário são mais eficientes energeticamente e menos poluidores, o desequilíbrio da matriz de transporte brasileira não contribui para a consolidação de uma economia de baixo consumo de carbono no país.

Considerando-se apenas o consumo final energético, o setor de transportes brasileiro é o maior contribuinte pela produção de $\mathrm{CO}_{2}$, em consequência do consumo de combustíveis fósseis. Isto com o agravante de ter a demanda por tais combustíveis aumentada a cada ano. Em 2012, o setor de transportes foi responsável por $48 \%$ das emissões de $\mathrm{CO}_{2}$ do setor de energia e por $30 \%$ do total das emissões totais de $\mathrm{CO}_{2}$ no Brasil (MCTI, 2014).

O grande responsável pelas emissões de $\mathrm{CO}_{2}$ do setor de transportes brasileiro é o modo rodoviário. Segundo o Balanço Energético Nacional (MME, 2014), em 2013 este modo foi responsável por $93 \%$ do total do consumo final energético do setor de transportes.

Além disso, o país não possui forma eficaz e regular de fiscalização e controle das emissões de GEE por veículos automotores. O Conselho Nacional do Meio Ambiente CONAMA é responsável pela imposição dos limites de emissão e a fiscalização fica a cargo dos estados e municípios. 
A Resolução no 418 do CONAMA (BRASIL, 2009) tornou obrigatória a inspeção veicular nos municípios do país com mais de três milhões de veículos, entretanto, muitos destes municípios não têm seguido esta resolução. Assim, ainda circulam no país veículos muito antigos e fora dos padrões de regulamentação nacionais. Segundo estudo realizado pela CETESB (2011), no Brasil apenas 10\% da frota (veículos antigos) responde por cerca de $50 \%$ das emissões totais de poluentes lançados na atmosfera, devido à precária condição de manutenção.

Observa-se nas grandes e médias cidades brasileiras a utilização intensiva do transporte individual em detrimento do coletivo e a falta de consideração para com os meios não motorizados. De 1992 a 2014, a indústria automobilística brasileira vivenciou uma fase de crescimento diante de fortes incentivos governamentais, com ênfase à produção de veículos econômicos, que podem ser financiados em até três anos. A frota brasileira de veículos foi estimada em 1994 em 27 milhões e, em abril de 2015, em 88 milhões. Isto representa um crescimento de 326\% num período de 21 anos (DENATRAN, 2015).

Além do excesso de veículos particulares criar problemas de mobilidade nos grandes centros diante da formação de congestionamentos, as tarifas de transporte público coletivo têm crescido em ritmo superior ao da inflação. Segundo Gomide et al. (2012), na última década, a tarifa de transporte público por ônibus subiu mais de $50 \%$ acima da inflação medida pelo Índice Nacional de Preços ao Consumidor (INPC). Tal fato tem contribuído para o desestímulo do uso do transporte coletivo.

Além disso, Carvalho et al. (2013) apontam para a exclusão de famílias brasileiras em função da falta de capacidade de pagamento pelos serviços de transporte, uma vez que entre os $10 \%$ brasileiros mais pobres, cerca de $30 \%$ das famílias não efetuam gastos com transporte. A política de vale-transporte não atinge os trabalhadores mais pobres, pois a maioria trabalha informalmente e não possui carteira assinada.

Por outro lado, constata-se que a política de preços de combustíveis adotada atualmente no país também gera resultados perversos sob a ótica ambiental. De forma análoga, o comportamento do preço do óleo diesel no Brasil aponta para uma política insustentável de mobilidade, uma vez que cresceu 129\% acima da inflação nos últimos 12 anos e subiu 50\% a mais do que o preço da gasolina na última década (MORAIS e COSTA, 2010, CARVALHO et al., 2013). 
Com relação ao transporte não motorizado, apesar de a bicicleta ter sido eleita pela ONU como o meio de transporte ecologicamente mais sustentável do planeta, a maioria das cidades brasileiras não apresenta infraestrutura apropriada ao deslocamento de ciclistas. De acordo com o Observatório Nacional de Segurança Viária (2014), em 2012, no Brasil, foram registradas 1.828 vítimas fatais e 10.649 vítimas não fatais em acidentes de trânsito envolvendo ciclistas. Estes acidentes decorrem principalmente da precariedade da infraestrutura disponível e inibem maior participação da bicicleta como meio de transporte no Brasil.

De forma idêntica, a maioria das cidades brasileiras não apresenta infraestrutura apropriada para a locomoção a pé, o que aumenta conflitos entre o pedestre com ciclistas e outros veículos. As calçadas, quando existentes, oferecem constantemente riscos devido a problemas como desníveis abruptos, guias e rampas irregulares; medidas mínimas exigidas inadequadas; mobiliário urbano mal colocado; piso inadequado e péssimas condições de manutenção. De acordo com o Observatório Nacional de Segurança Viária (2014), em 2012, 11.605 pedestres morreram e 47.921 ficaram feridos devido aos acidentes de trânsito.

Diante destas constatações, verifica-se que as ações de mobilidade no país não têm conseguido evitar a exclusão social. Também não têm trazido resultados concretos em termos de prioridade ao transporte coletivo urbano e ao não motorizado de forma a garantir a sustentabilidade nos grandes centros.

\subsection{DESAFIOS DA MOBILIDADE SUSTENTÁVEL NO BRASIL}

Segundo o Relatório Especial sobre a Gestão dos Riscos de Eventos Extremos e Desastres para o Avanço da Adaptação às Alterações Climáticas - Special Report on Managing the Risks of Extreme Events and Disasters to Advance Climate Change Adaptation (IPCC, 2011), em decorrência do aquecimento do clima na Terra neste século é possível que ocorram consequências como aumento nas temperaturas extremas, ondas de calor, chuvas intensas, secas severas, ciclones mais fortes, dentre outras.

Assim, sendo, o IPCC recomendou urgência na elaboração de planos nos níveis global, regional e local de reação às possíveis catástrofes, visando à adaptação ao crescente risco de eventos climáticos extremos ligados às mudanças climáticas. 
No entanto, percebe-se que até o momento o governo brasileiro não se preocupou suficientemente com os grandes desafios ambientais enfrentados na atualidade e sobre suas possíveis consequências, uma vez que muitas das políticas atuais do setor de transportes brasileiro ainda não possuem como foco a mobilidade sustentável.

Verifica-se a existência de alguns esforços brasileiros em prol da mobilidade sustentável como a obrigação de aditivação da gasolina com álcool anidro, a exigência de motores e combustíveis mais limpos, a substituição gradativa do diesel com menor teor de enxofre, a criação do Painel Brasileiro de Mudanças Climáticas (PBMC), espelhado no Painel Intergovernamental de Mudanças Climáticas (IPCC), e a criação do Fundo Nacional sobre Mudança do Clima (FNMC) com a finalidade de assegurar recursos para projetos, estudos e financiamento de empreendimentos que visem à adaptação e mitigação da mudança do clima.

Apesar dos esforços desenvolvidos em prol da mobilidade, estes não são suficientes para vencer os problemas apresentados no item anterior. Para que o Brasil atinja um nível de mobilidade sustentável comparável ao de países desenvolvidos, é necessário que o país supere os seguintes desafios:

- Melhoria contínua do marco regulatório do setor de transportes na área ambiental;

- Maior capacitação financeira e técnica do setor de transportes;

- Implantação de programas educacionais de conscientização da importância da mobilidade sustentável, a fim de promover a mudança de comportamento, hábitos e padrões de mobilidade dos usuários;

- Disseminação de informações e indicadores consistentes sobre mobilidade sustentável;

- Viabilização do equilíbrio da matriz de transporte, com maior participação de modos menos poluentes e da integração e combinação eficiente dos diversos modos;

- Aumento dos investimentos públicos em infraestrutura nas modalidades ferroviária, aquaviária e na expansão da capacidade dos aeroportos;

- Utilização de modos alternativos ao rodoviário no transporte regional e interregional;

- Promoção do planejamento adequado do ordenamento do território;

- Promoção do planejamento integrado do uso do solo e transporte;

- Promoção do adensamento das áreas centrais e controle da dispersão urbana; 
- Incentivo ao uso de sistemas de mobilidade sustentável adequados ao contexto socioeconômico de cada região;

- Promoção da utilização de veículos de baixo impacto poluidor: elétricos, híbridos, a gás natural e de tecnologias mais limpas (Euro V, Euro VI e Euro VII);

- Incentivo ao uso de combustíveis e tecnologias que utilizem recursos renováveis;

- Priorização da produção de combustíveis de qualidade, com baixo teor de enxofre e poluentes em geral;

- Desenvolvimento de novas fontes energéticas e aumento da eficiência energética dos veículos flexfuel;

- Priorização do transporte coletivo sobre o individual;

- Desincentivo da utilização do transporte individual através da promoção de políticas de deslocamento de usuários do transporte individual para o público;

- Transferência de eventuais recursos oriundos dos mecanismos de gestão da demanda pelo transporte individual motorizado para o aperfeiçoamento dos sistemas de transporte público;

- Implantação e incentivo ao uso de transporte público de alta qualidade, moderno e eficiente através de projetos de Mecanismo de Desenvolvimento Limpo (MDL);

- Aumento da atratividade do transporte público através de políticas e propagandas;

- Aumento do percentual de biodiesel adicionado ao diesel nos veículos do transporte coletivo;

- Incentivo de sistemas de transporte coletivo de alta capacidade segregados do tráfego em geral, na modalidade adequada à realidade da área urbana: ônibus, BRT, trólebus, bondes, veículos leves sobre trilhos, trens e metrôs;

- Promoção de subsídio governamental para possibilitar o barateamento das tarifas do transporte público coletivo;

- Incentivo da criação de uma tarifa diferenciada de energia elétrica para o transporte público que privilegie alternativas de baixo impacto poluidor;

- Promoção de zonas livres de veículos particulares;

- Proibição do tráfego de veículos mais poluentes em áreas centrais congestionadas ou poluídas através de programa de etiquetagem que informe a categoria de emissão dos veículos; 
- Obrigação nacional de etiquetagem veicular do consumo de combustível para apoiar a escolha do consumidor;

- Adoção de medidas de restrição aos veículos particulares (rodízio de veículos, pedágio urbano, dentre outras);

- Redução do número de vagas de estacionamento em áreas centrais e constante fiscalização;

- Incentivo à utilização do transporte não motorizado mediante a expansão da malha cicloviária, com implantação de equipamentos urbanos necessários à sua operação e integração com o transporte coletivo;

- Promoção de sistemas de compartilhamento de bicicletas públicas;

- Priorização da circulação de pedestres, através da infraestrutura necessária e condições adequadas de segurança e conforto nas calçadas e nas travessias viárias;

- Implantação de sistemas de controle de tráfego e de velocidade eficazes, visando o aumento da segurança e redução de acidentes;

- Implantação de programas nacionais de inspeção veicular de poluentes e ruído;

- Incentivo da renovação da frota com mais de 15 anos;

- Promoção de kits nacionais de retrofit para veículos antigos;

- Utilização de pneus "verdes" que reduzam o consumo de combustível;

- Promoção de ações de requalificação dos espaços públicos na construção e manutenção de infraestrutura viária, visando o aumento dos espaços verdes e de conforto ambiental;

- Promoção da arborização de vias para contribuir para a redução da temperatura local e auxiliar na proteção da infraestrutura viária diante de chuvas intensas.

\subsection{SUSTENTABILIDADE DE CICLOVIAS}

Espaço cicloviário é a estruturação favorável para a utilização da bicicleta em uma determinada área do território, seja ela um estado, município ou uma cidade (BRASIL, 2007a). Desta maneira, estes espaços designam toda a infraestrutura projetada para a circulação de bicicletas. 
Segundo Miranda (2007), existem três tipologias de espaços cicloviários:

- Espaços Compartilhados - admite a circulação de dois ou mais modos de transporte, como bicicleta e pedestre ou bicicleta e veículos motorizados (GONDIM, 2010), como mostra a Figura 2.3;

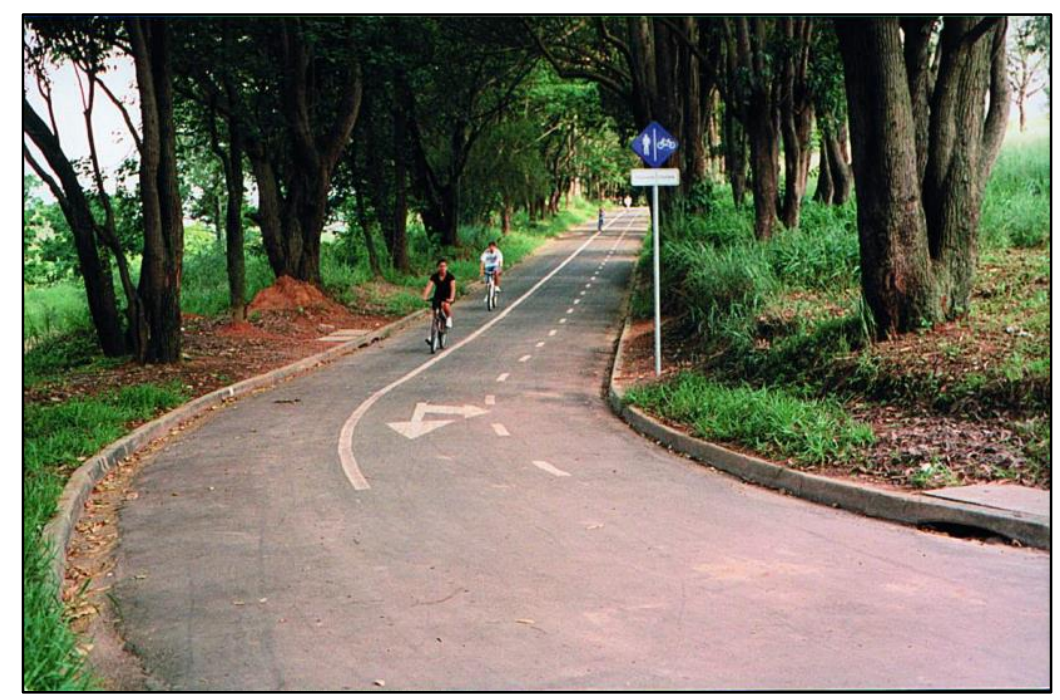

Figura 2.3: Exemplo de espaço cicloviário compartilhado entre ciclistas e pedestres em Fortaleza (GEIPOT, 2001)

- Espaços Parcialmente Segregados - são as faixas, denominadas de ciclofaixas, nas pistas de rolamento ou nas calçadas, delimitadas por sinalização horizontal ou diferenciação de piso, sem a utilização de obstáculos físicos (GONDIM, 2010), como mostra a Figura 2.4;

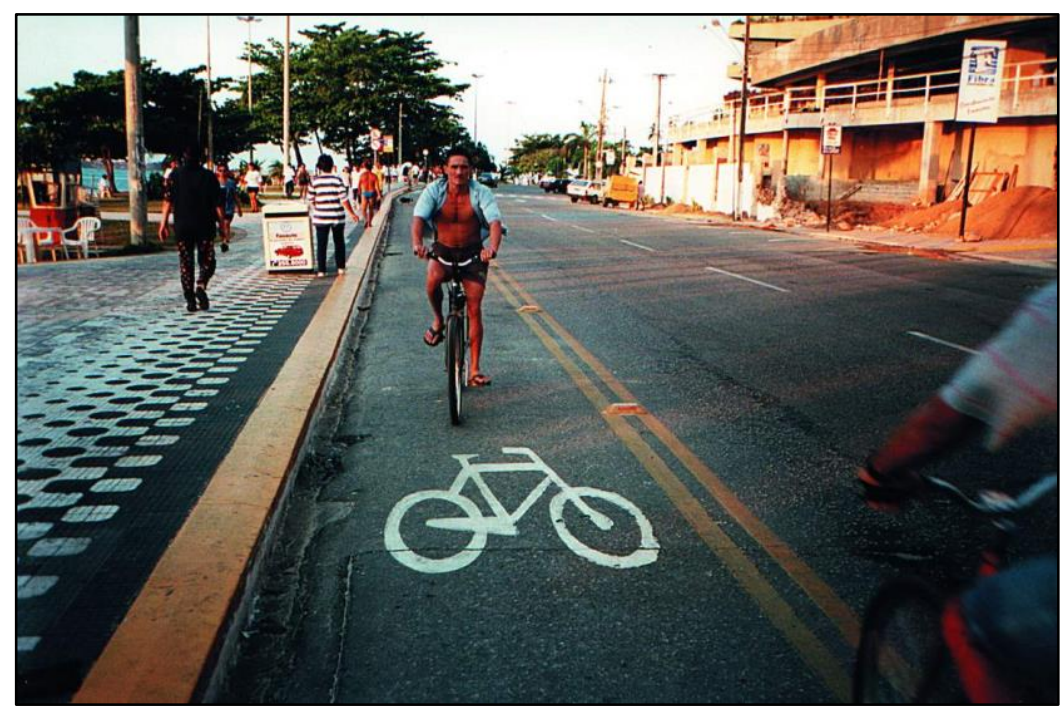

Figura 2.4: Exemplo de espaço cicloviário parcialmente segregado em Fortaleza (GEIPOT, 2001) 
- Espaços Totalmente Segregados - são os espaços unidirecionais ou bidirecionais denominados de ciclovias para a circulação exclusiva de bicicletas, segregados de automóveis e pedestres, mediante a utilização de obstáculos físicos como calçadas, muretas ou meio-fios (GONDIM, 2010). Estes espaços podem ser localizados no canteiro central, nas laterais das vias, ou podem possuir um traçado independente da malha viária, como mostra a Figura 2.5.

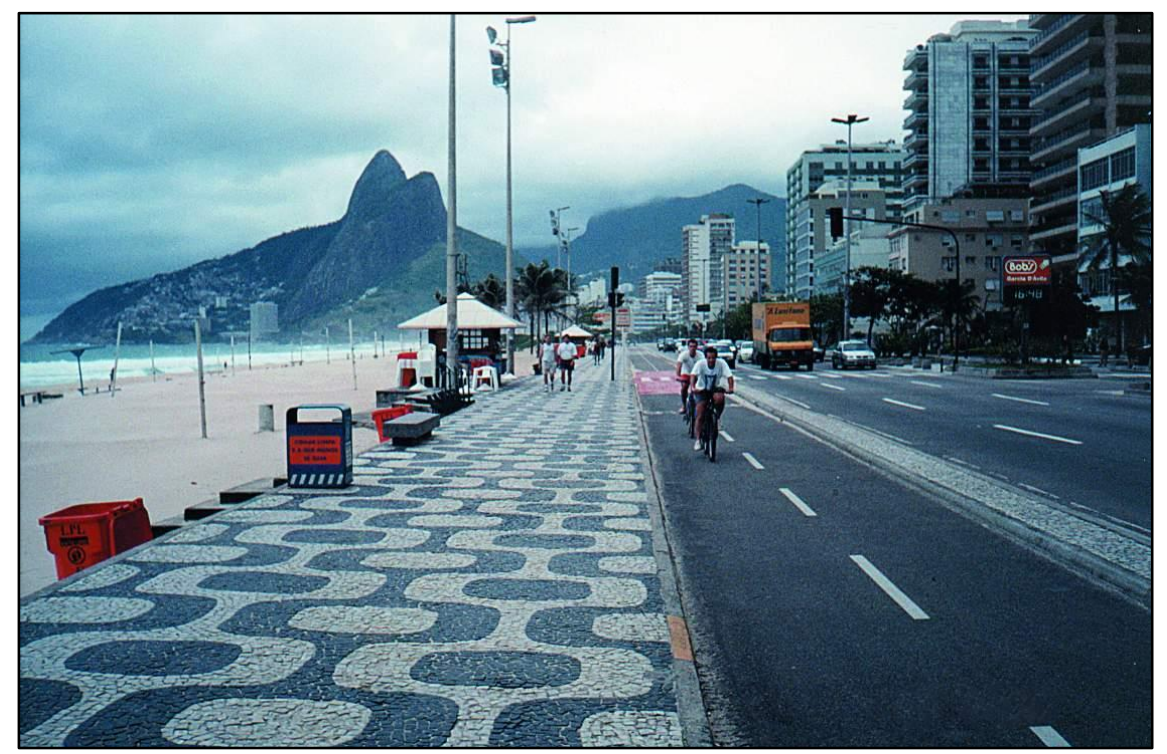

Figura 2.5: Exemplo de espaço cicloviário totalmente segregado no Rio de Janeiro (GEIPOT, 2001)

Outro conceito derivado de espaços cicloviários são as ciclorrotas. Segundo GONDIM (2001), ciclorrotas são as vias selecionadas para fazer uma determinada rota a ser percorrida por bicicletas junto ao tráfego compartilhado ou com restrições para o acesso por veículos motorizados, instituídas para períodos curtos de tempo, como fins de semana e feriados.

Ainda quanto à infraestrutura cicloviária, outro conceito importante refere-se aos tipos de estacionamento de bicicletas. Bicicletários são estacionamentos fechados e com controle de acesso, cobertos ou não, pagos ou gratuitos, como mostra a Figura 2.6. Já paraciclos são estacionamentos abertos e geralmente ao ar livre, como mostra a Figura 2.7. O que diferencia os bicicletários dos paraciclos é, basicamente, o controle de acesso (DISTRITO FEDERAL, 2013). 

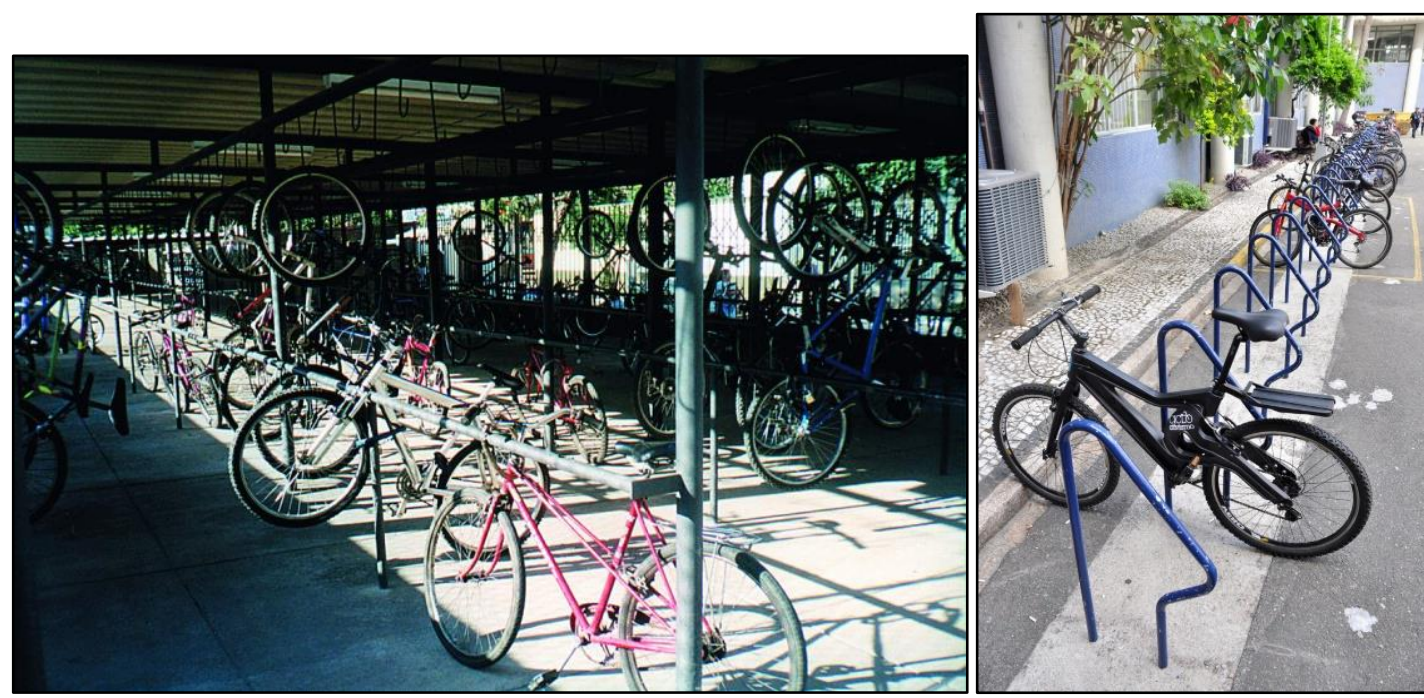

Figuras 2.6 e 2.7: Diferença entre bicicletário (GEIPOT, 2001) e paraciclo (CICLOATIVISMO, 2015)

Devido à separação do tráfego misto, observa-se que as ciclovias oferecem maior proteção e segurança ao ciclista, diminuem o número de acidentes, proporcionam maior fluidez e evitam conflitos em congestionamentos.

Segundo Pires (2008), muitos pesquisadores defendem o uso de espaços exclusivos e separados para bicicletas, como as ciclovias, pois aumentam a sensação de segurança e elevam o número de usuários.

O método proposto nesta tese é aplicável às ciclovias, que constituem espaços seguros para os ciclistas. Assim sendo, o método não se aplica aos espaços compartilhados ou parcialmente e segregados, devido à diferença de características físicas e operacionais.

Optou-se neste estudo por avaliar estruturas cicloviárias que já estejam em operação e não em fase de projeto, pois muitas ciclovias têm sido implantadas no Brasil e anunciadas como projetos sustentáveis, ainda que muitas vezes esta sustentabilidade seja questionável.

Uma ciclovia pode não ser sustentável devido a diversos aspectos que serão explorados a fundo no próximo Capítulo. E, ao invés de promover mais segurança, pode acabar por promover ainda mais acidentes e desestimular os ciclistas a utilizá-la, como mostram as Figuras 2.8 a 2.15 .

A Figura 2.16 apresenta um exemplo de uma ciclovia sustentável.

Ressalta-se que as Figuras 2.8 a 2.16 não representam todas as condições de sustentabilidade das ciclovias, pois nem todas são possíveis de serem vistas por meio de fotografias, como por exemplo, a redução do nível de pressão sonora proveniente da transferência de viagens motorizadas para o modo cicloviário. 

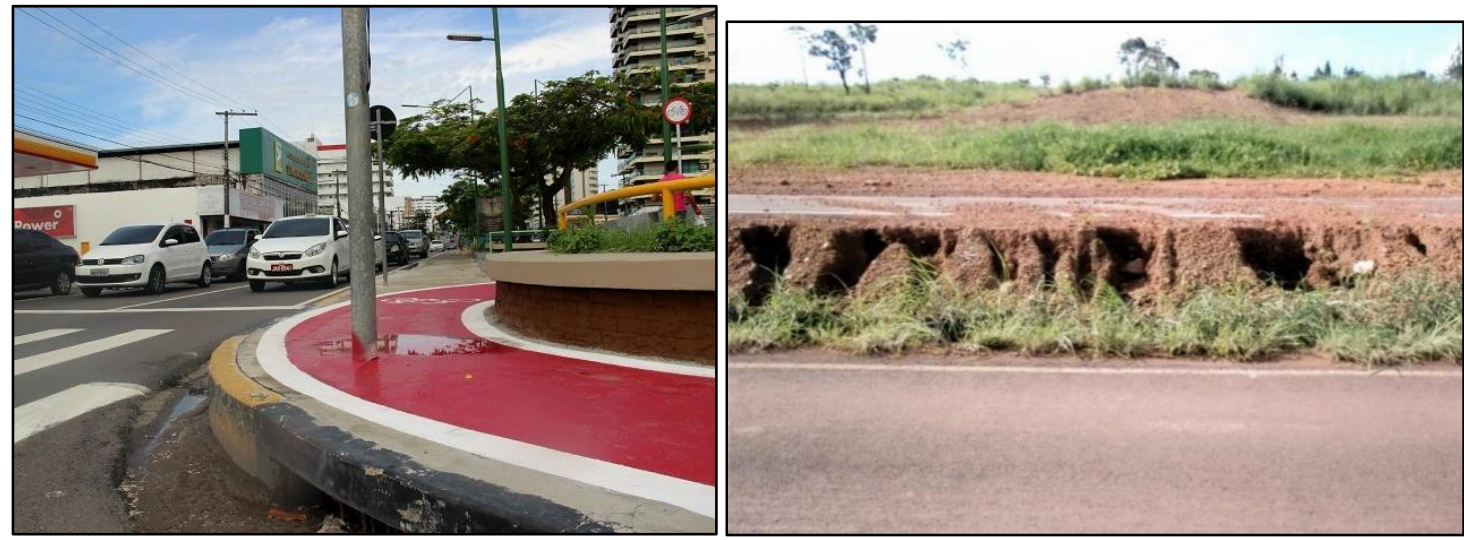

Figuras 2.8 e 2.9: Exemplos de ciclovias não sustentáveis respectivamente em Manaus (poste) e em Brasília (talude erodido) (GLOBO, 2015 e ASSOCIAÇÃO PARK WAY RESIDENCIAL, 2015)

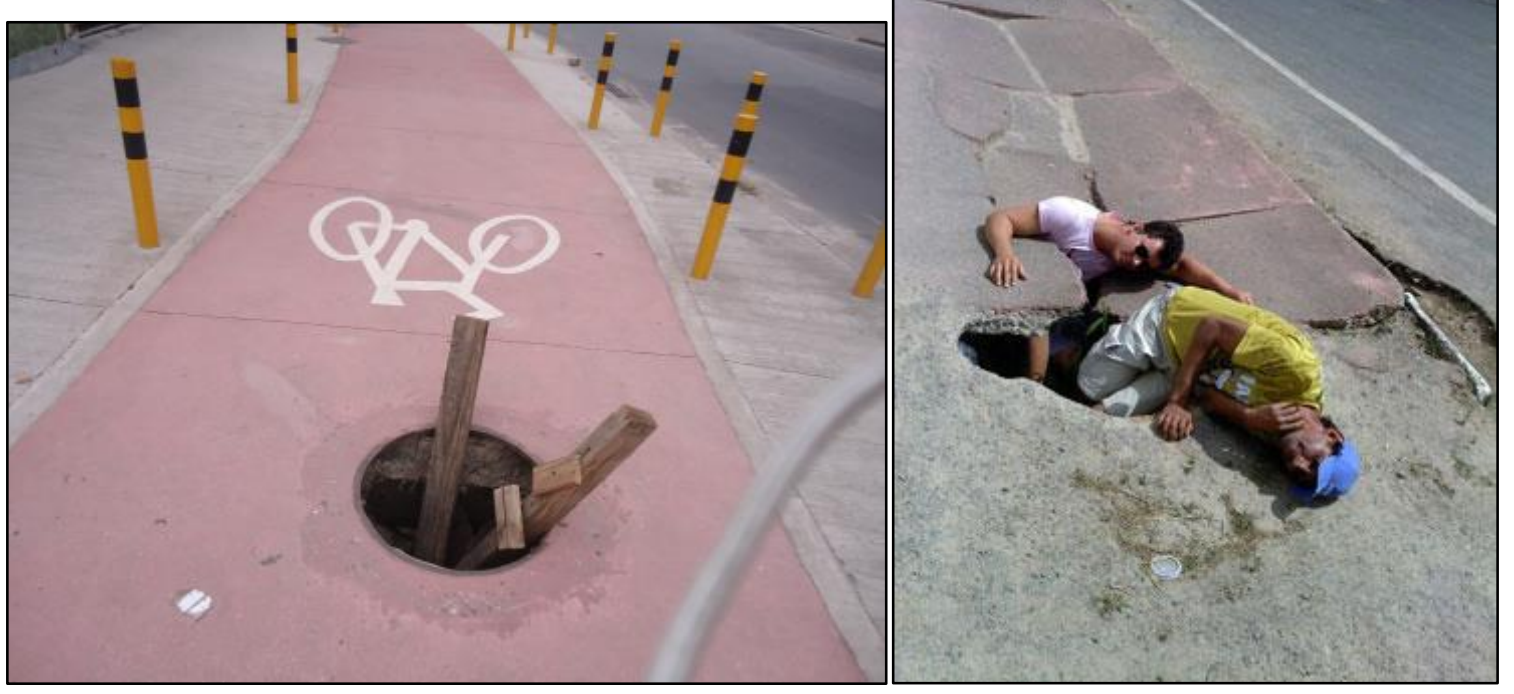

Figuras 2.10 e 2.11: Exemplo de ciclovia não sustentável respectivamente no Rio de Janeiro (GUIMARÃES, 2012) e no Pará (PORTAL LAGARTENSE, 2011)
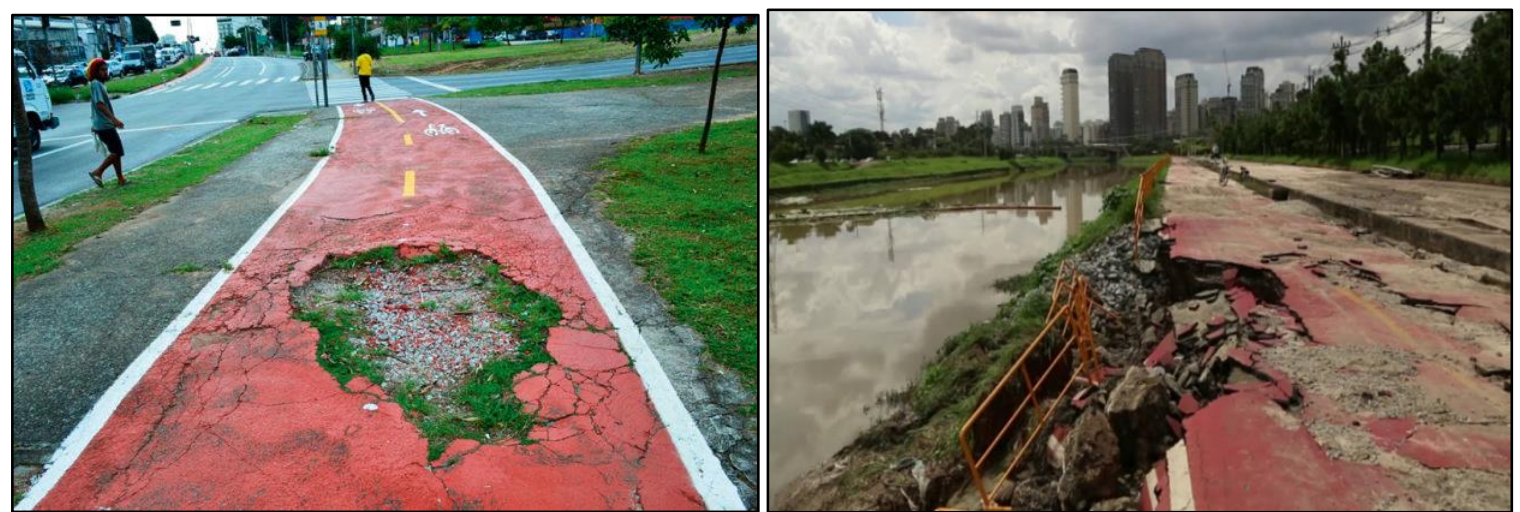

Figuras 2.12 e 2.13: Exemplo de ciclovias não sustentáveis em São Paulo (YARAK, 2015 e GRELLET, 2015) 


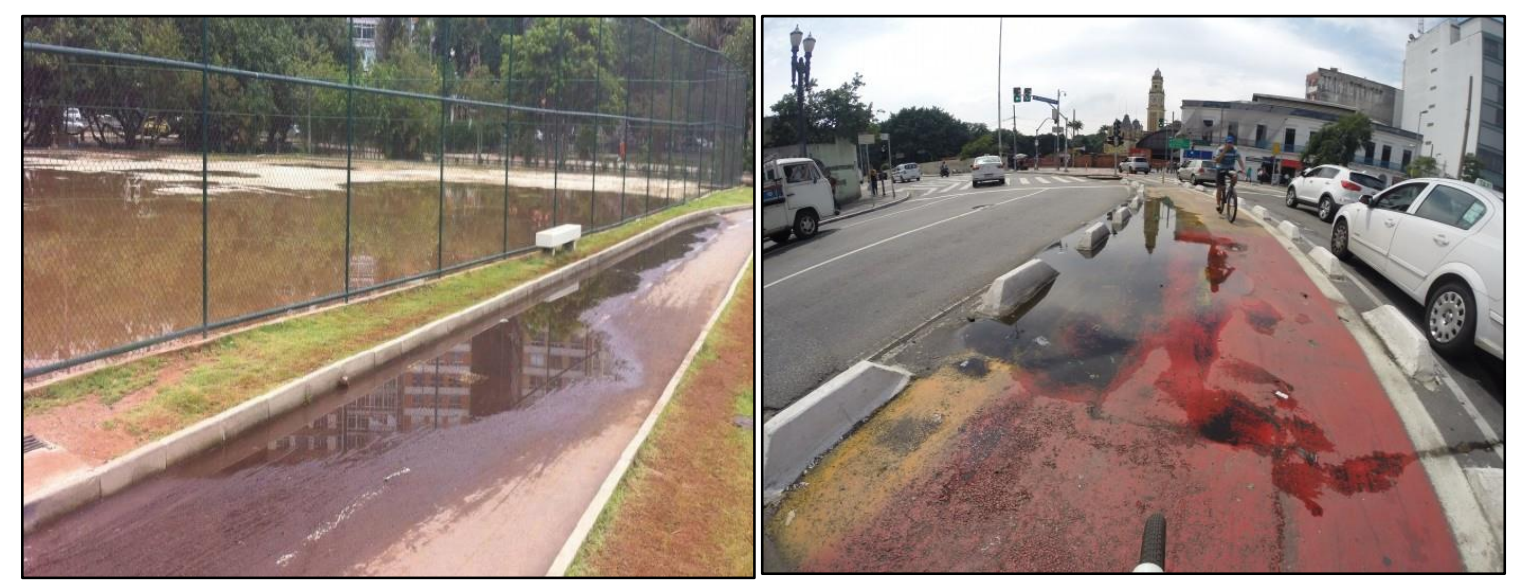

Figuras 2.14 e 2.15: Exemplo de ciclovias não sustentáveis em São Paulo (VALINHO, 2013 e CARVALHO, 2015)

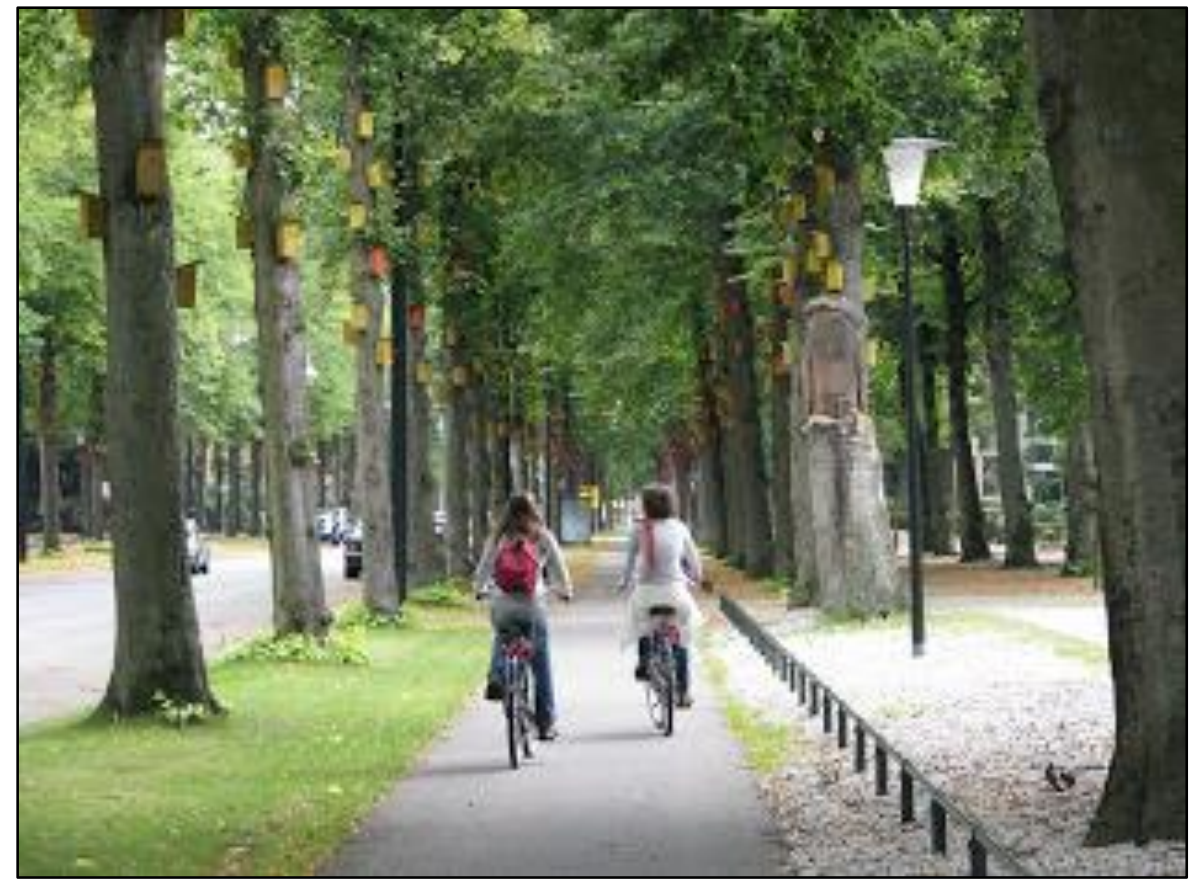

Figura 2.16: Exemplo de ciclovia sustentável na Holanda (CABRAL, 2008)

Ainda que não seja possível estabelecer uma sustentabilidade absoluta, visto que algo sempre será sustentável ou não diante de algum parâmetro pré-definido, o presente estudo da sustentabilidade de ciclovias é importante para possibilitar o cálculo do grau de sustentabilidade de cada ciclovia e a comparação entre elas. 
Neste Capítulo foram discutidos conceitos como sustentabilidade, desenvolvimento sustentável, mobilidade sustentável, mobilidade e sustentabilidade, sustentabilidade de ciclovias, bem como a aplicação do conceito e de ações de mobilidade sustentável no mundo e no brasil, os desafios da mobilidade sustentável no Brasil e considerações sobre os problemas brasileiros de mobilidade. No próximo Capítulo foram discutidos os conceitos de indicadores, a identificação e análise de indicadores de mobilidade sustentável, ciclovias sustentáveis e possíveis indicadores de mobilidade sustentável aplicáveis a ciclovias. Também são estabelecidos critérios para a identificação de indicadores de mobilidade sustentável aplicáveis em ciclovias, propostos indicadores de mobilidade sustentável aplicáveis em ciclovias, normalizados os indicadores propostos e, por fim, apresenta-se a metodologia utilizada para desenvolver o questionário de opinião a ser aplicado aos usuários da ciclovia. 


\section{INDICADORES DE MOBILIDADE SUSTENTÁVEL APLICÁVEIS A CICLOVIAS}

Neste Capítulo, o conceito de indicadores é amplamente discutido com a finalidade de permitir uma visão crítica necessária ao desenvolvimento de indicadores para o método de determinação da sustentabilidade de ciclovias. A importância do desenvolvimento e monitoramento de indicadores de mobilidade relacionados com o conceito de sustentabilidade também é abordada, bem como os procedimentos metodológicos para a construção de indicadores de mobilidade sustentável aplicáveis em ciclovias.

\subsection{INDICADORES}

O termo indicador é originário do latim indicare, que significa descobrir, apontar, estimar, indicar a direção e tornar público (Instituto de Recursos Mundiais - World Resources Institute - WRI, 1995). Assim sendo, os indicadores têm a função de possibilitar a percepção de uma tendência ou fenômeno que não seja imediatamente detectável e auxiliar na identificação de problemas e suas causas e na orientação e estabelecimento de prioridades.

Segundo Gallopín (1997), a definição de um indicador de sustentabilidade baseia-se nas seguintes representações: “uma variável, um parâmetro, uma medida, um substituto, um valor, um medidor, um instrumento de medida, uma fração, um índice, um pedaço de informação, uma quantidade simples, um método empírico, um sinal ou uma estatística".

Os indicadores podem ser comparados aos sentidos humanos (visão, audição, tato, olfato, paladar), uma vez que podem auxiliar na identificação de como as coisas são percebidas e como devem receber atenção (LITMAN, 2008b).

Um indicador pode ser definido como um atributo quantitativo, qualitativo e até mesmo descritivo, que cumpra com as seguintes funções: simplificar, mensurar, analisar e comunicar (TAPAJÓS, 2002). Ou seja, a finalidade é permitir a compreensão de fenômenos mais complexos, tornando-os quantificáveis e compreensíveis, de maneira que possam ser analisados em diferentes contextos. 
A Figura 3.1 demonstra que os indicadores são instrumentos que auxiliam na redução da quantidade de informação até um número adequado de parâmetros para análise. Assim sendo, os indicadores têm o potencial de traduzir conceitos abstratos e difíceis de serem mensurados em entidades operacionais e mensuráveis, fornecendo uma informação resumida sobre determinado fato (WRI, 1995). Agregados através de métodos aritméticos ou regras de decisão, permitem a construção de índices, os quais podem simplificar ainda mais alguns parâmetros complexos.

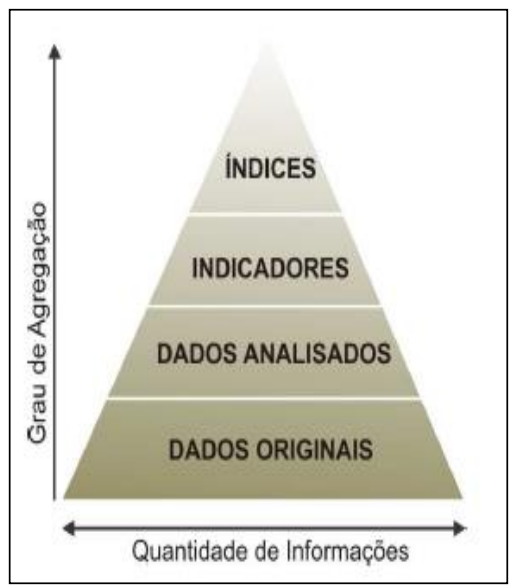

Figura 3.1: Pirâmide de Informações de Indicadores (WRI, 1995)

Os indicadores, se bem utilizados, podem ser fundamentais para análises técnicas e servir como importantes subsídios para políticas públicas. Podem também quantificar objetivos, a fim de refletir a eficácia de uma estratégia (KÖLBL et al., 2008).

Para a OECD (1993), os indicadores têm como objetivo gerar um significado sintético e devem ser desenvolvidos para uma finalidade específica, como por exemplo, ser utilizados para analisar o progresso diante de alguma meta, objetivo ou projeto.

As características que definem um indicador partem da quantificação e simplificação da informação diante do entendimento dos problemas. Portanto, uma atividade ou opção pode parecer ótima e desejável quando avaliada por meio de um conjunto de indicadores, mas prejudicial quando avaliada por outro. Assim sendo, é preciso cuidado ao estabelecer indicadores.

Segundo Galopin (1996), os indicadores devem seguir alguns requisitos universais:

- Os valores dos indicadores devem ser mensuráveis ou observáveis;

- Os dados precisam estar disponíveis; 
- A metodologia para a coleta e o processamento dos dados, bem como para a construção dos indicadores, deve ser clara, transparente e padronizada;

- Os indicadores ou grupo de indicadores devem ser financeiramente viáveis;

- Os meios para construir e monitorar os indicadores devem estar disponíveis, incluindo capacidade financeira, humana e técnica;

- Deve existir aceitação política dos indicadores, uma vez que indicadores não legitimados pelos tomadores de decisão são incapazes de influenciar as decisões.

Segundo o Banco Mundial (1999), a definição de um indicador deve ser precedida pela compreensão cuidadosa da situação a que se destina, por meio de uma relação de causa e efeito. Assim sendo, é preciso verificar se há:

- Relevância direta com os objetivos da pesquisa, projeto ou método: relacionado ao entendimento dos objetivos e dos problemas ambientais e sociais causados;

- Limite no número de indicadores: é fundamental a seletividade de pequenos grupos de indicadores para diminuir a complexidade da construção do índice;

- Custos realistas no desenvolvimento: ainda que um indicador seja realista e prático, os custos para determiná-lo devem ser considerados, além de critérios de rapidez e facilidade.

- Confiabilidade: idealmente, um indicador representa uma medida confiável, construído a partir de uma base científica sólida. Contudo, se o indicador "ideal" não está disponível (por problemas de dados ou questões de confiabilidade), uma aproximação deve ser utilizada, até a solução do problema. 
Segundo o Instituto de Recursos Mundiais - World Resources Institute - WRI (1995) e Machado (2010), os indicadores têm duas funções básicas:

- Descritiva: aportam informações sobre uma determinada realidade empírica, situação social ou ação política; e

- Valorativa: agregam informação de juízo de valor a uma situação. Deste modo, os indicadores podem ser utilizados na gestão de políticas públicas, a partir da comparação temporal:

$\checkmark$ Ex-ante: a partir do diagnóstico de uma situação, para subsidiar a definição do problema;

$\checkmark$ In curso: a partir do monitoramento e avaliação da execução, revisão do planejamento e correção de desvios; e

$\checkmark$ Ex-post: a partir da avaliação por meio dos resultados e alcance de metas.

Os impactos da mobilidade na sustentabilidade podem ser abordados por indicadores dos tipos qualitativos e quantitativos. Os primeiros usam descrições para caracterizar os sistemas e comportamentos. Os segundos baseiam-se em métodos matemáticos e indicadores mensuráveis, considerados mais úteis ao planejamento (MACHADO, 2010).

De acordo com Kayano e Caldas (2002), os indicadores podem ser classificados em simples e compostos, dependendo da quantidade de informação utilizada para a sua definição. Os simples descrevem imediatamente um determinado aspecto da realidade (exemplo: número de bicicletas), já os compostos apresentam a relação entre situações ou ações, de forma a permitir conclusões objetivas.

No entanto, muitas vezes os indicadores resultam em uma leitura simplista da realidade, ignorando casos mais complexos. Diante disso, índices têm sido desenvolvidos por meio de sistemas que combinam muitas vezes indicadores simples e compostos. Para tanto, os indicadores devem ser selecionados com cuidado para gerarem informações úteis.

Segundo Litman (2008b), na maioria das situações estudadas por ele, a utilização de apenas um indicador mostrou-se não suficiente, sendo necessária a utilização de um conjunto, a fim de medir um objetivo maior. No entanto, Litman ressalta que, na prática, muitas vezes é inviável aplicar todos os indicadores existentes devido aos dados disponíveis e custos de coleta e análise. Para tanto, é fundamental priorizar os indicadores mais importantes e que deverão ser aplicados diante do objetivo que se deseja medir. 
Segundo Gudmundsson (2001), uma das questões mais difíceis na seleção e utilização dos diferentes indicadores de sustentabilidade são suas inter-relações. Deve-se evitar que os mesmos custos ou benefícios sejam levados em conta duas ou mais vezes e que apresentem contradições ou ambivalência em relação à sustentabilidade.

Também nem sempre é possível relacioná-los claramente aos três pilares da sustentabilidade: social, ambiental e econômico, pois alguns indicadores relacionam-se com mais de uma dimensão. Dependendo das razões para sua inclusão, podem descrever um problema diferente (MACHADO, 2010).

Ressalta-se que as unidades de medida dos indicadores devem ser normalizadas para facilitar comparações (per capita, por ano, quilômetro, veículo/ano, moeda, etc), uma vez que elas dependem da forma como os problemas são definidos e as soluções priorizadas (LITMAN, 2008b).

Por fim, cabe salientar que a Agenda 21 (UNITED NATIONS, 1992) apontou que indicadores de desenvolvimento sustentável precisam ser desenvolvidos para fornecer bases sólidas para a tomada de decisões em todos os níveis e contribuir para a sustentabilidade da autorregulação do meio ambiente e de sistemas integrados de desenvolvimento.

Assim sendo, verifica-se a necessidade do desenvolvimento e monitoramento de indicadores de mobilidade relacionados com o conceito de sustentabilidade, inclusive em ciclovias, uma vez que ainda não existe um sistema de indicadores para este relevante modo de transporte.

\subsection{IDENTIFICAÇÃO E ANÁLISE DE INDICADORES DE MOBILIDADE SUSTENTÁVEL}

A fim de possibilitar a identificação e seleção de indicadores de mobilidade sustentável aplicáveis a ciclovias, foram realizadas pesquisas documentais e bibliográficas com abrangência nacional e internacional, considerando as três dimensões da sustentabilidade - ambiental, econômica e social. 
Ao todo foram analisados 17 sistemas de indicadores de mobilidade sustentável, um total de 650 indicadores, os quais foram utilizados como base para a construção de indicadores aplicáveis em ciclovias no tópico 3.3:

- Indicadores da Associação Nacional de Transportes Públicos - ANTP (2012);

- Indicadores da Agência Europeia do Meio Ambiente (EUROPEAN ENVIRONMENTAL AGENCY, 2011);

- Indicadores do Índice de Mobilidade Sustentável - IMS (MACHADO, 2010);

- Indicadores recomendados para monitoramento de políticas de mobilidade sustentável (MAMELI e MARLETTO, 2009);

- Indicadores de mobilidade sustentável do Planejamento Urbano e de Transportes Integrado e Sustentável - PLANUTS (MAGAGNIN, 2008);

- Indicadores do Índice de Mobilidade Urbana Sustentável - IMUS (COSTA, 2008);

- Indicadores Sociais de Mobilidade Sustentável (LITMAN, 2008b);

- Indicadores elaborados para os Programas Nacionais de Transporte (BRASIL, 2007a);

- Indicadores de mobilidade sustentável da Comissão Europeia (EUROPEAN COMMISSION, 2005);

- Indicadores de ocupação urbana relacionados com o sistema viário (CAMPOS e MELO, 2005);

- Indicadores de mobilidade sustentável (CAMPOS e RAMOS, 2005);

- Indicadores de mobilidade sustentável do Conselho Empresarial Mundial de Mobilidade Sustentável (WBCSD, 2004);

- Indicadores de mobilidade sustentável do Conselho Empresarial Mundial de Mobilidade Sustentável (WBCSD, 2003);

- Indicadores de mobilidade sustentável (NICOLAS et al., 2003);

- Indicadores de transportes que causam impactos ambientais BORKEN (2003);

- Indicadores para o desenvolvimento sustentável dos transportes do Centro Científico Federal de Políticas da Bélgica (BELGIAN FEDERAL SCIENCE POLICY, 2002);

- Indicadores de mobilidade sustentável da Organização para a Cooperação Econômica e Desenvolvimento (OECD, 1999). 
A Tabela 3.1 apresenta uma síntese dos indicadores destes sistemas que podem ser relacionados com ciclovias sustentáveis. Na Tabela, ao lado de cada tema, são apresentados diversos indicadores. Tais indicadores, além de outros, são descritos com maior profundidade no Anexo A. 


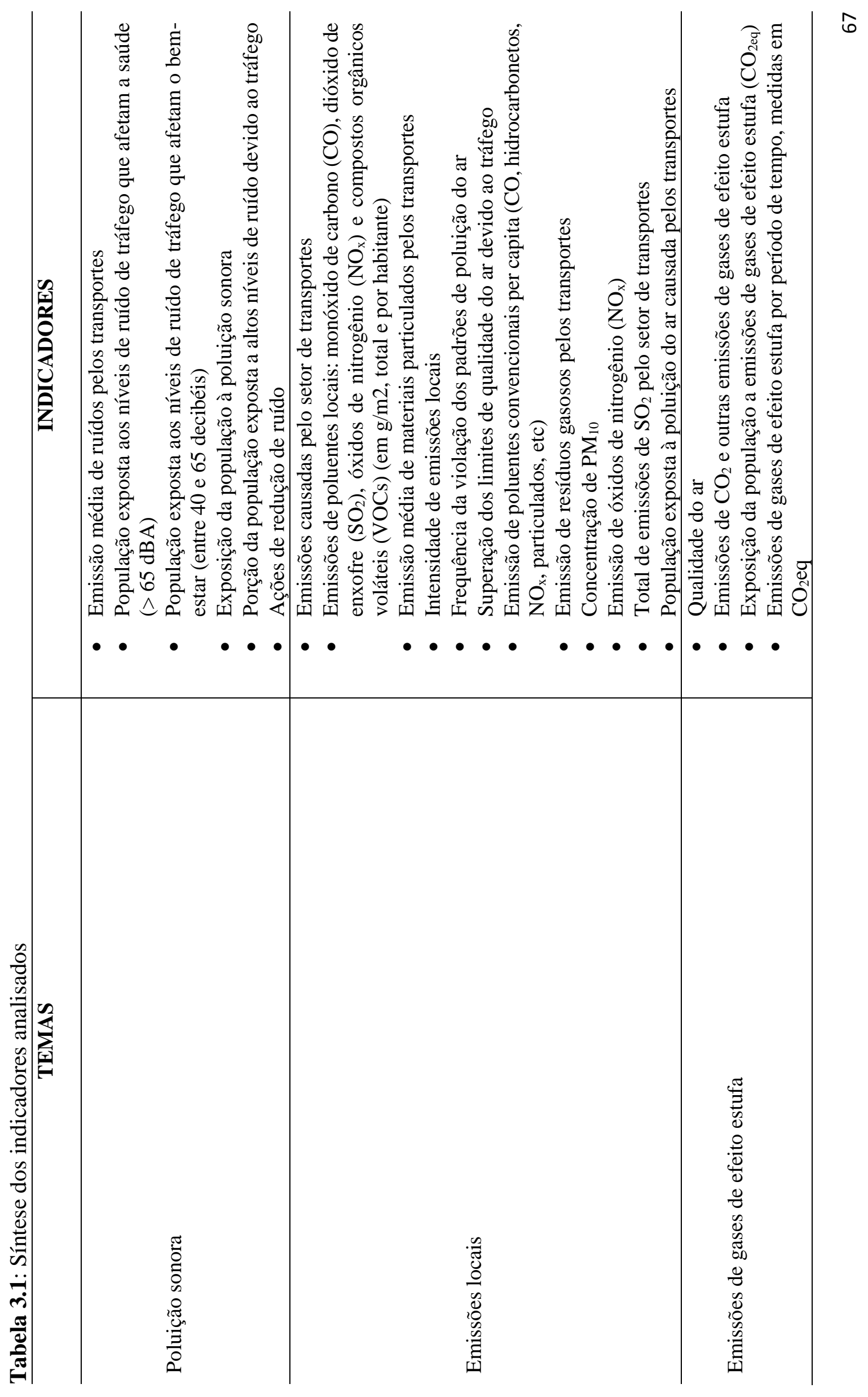




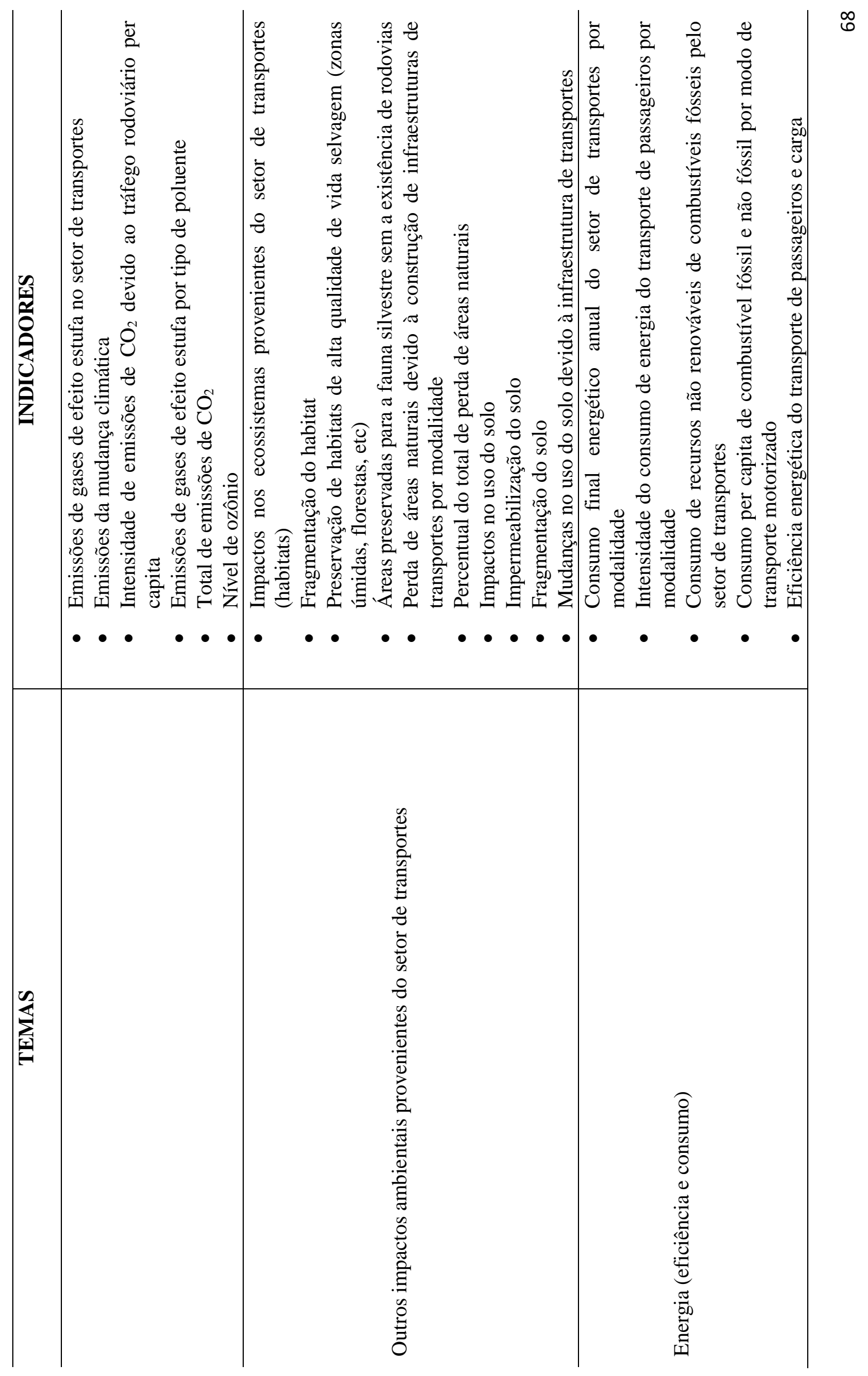




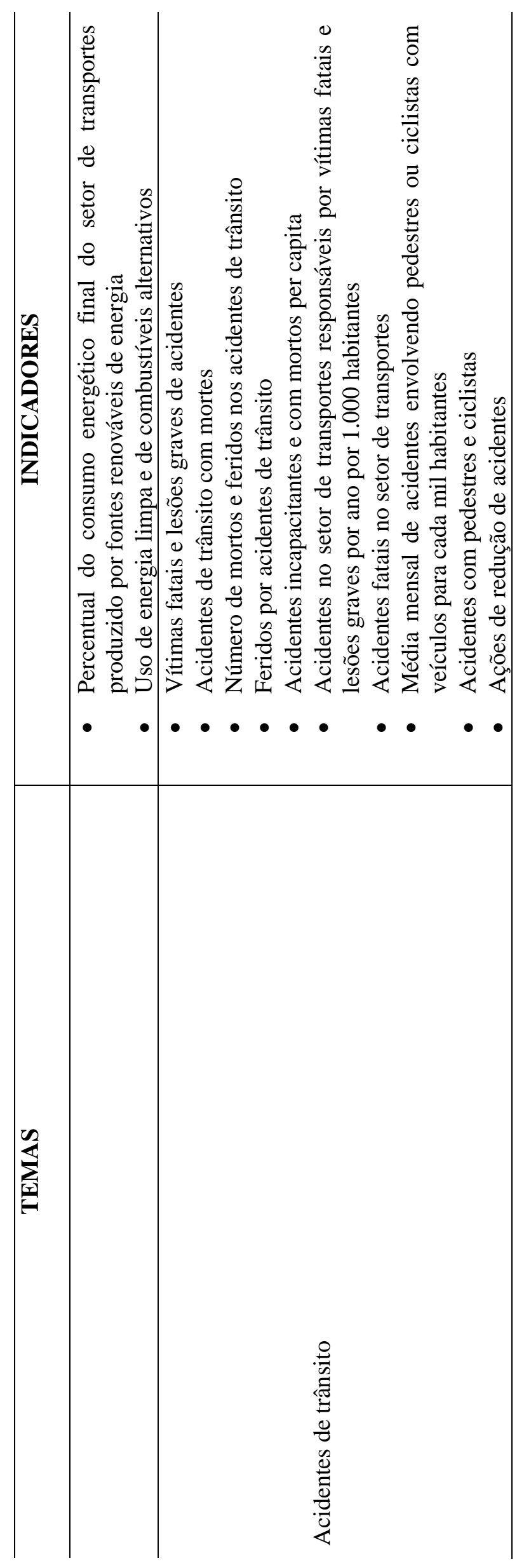




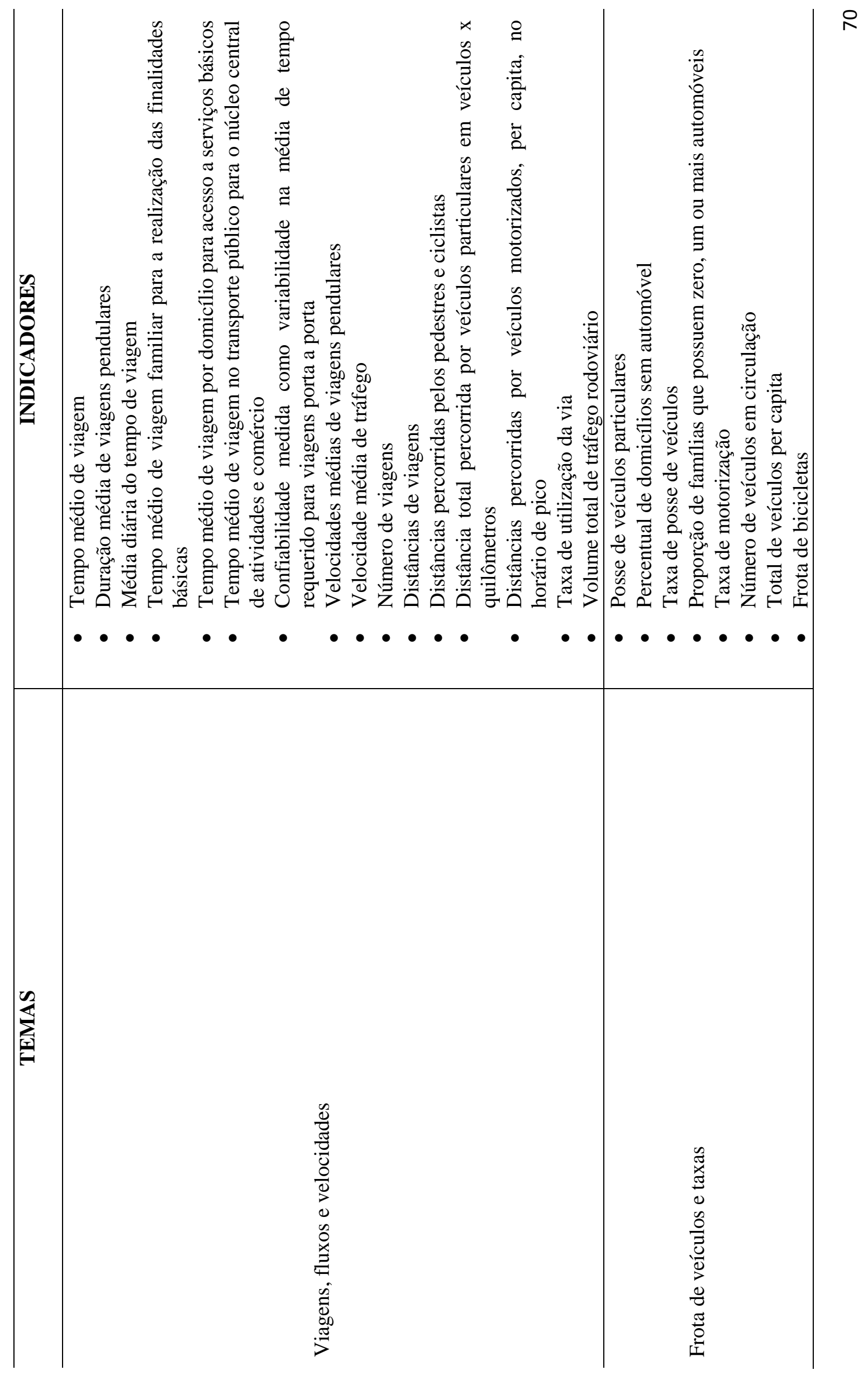




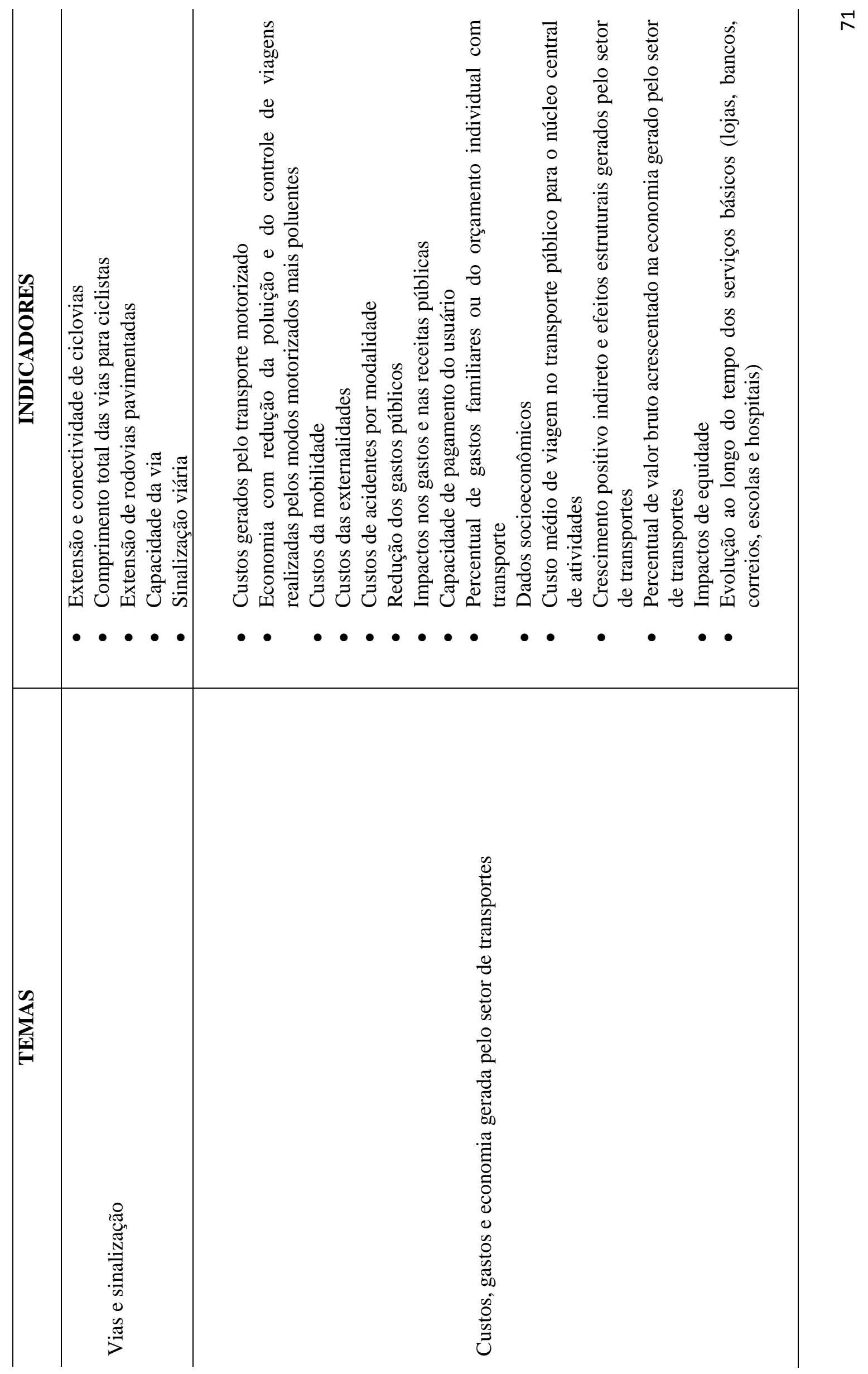




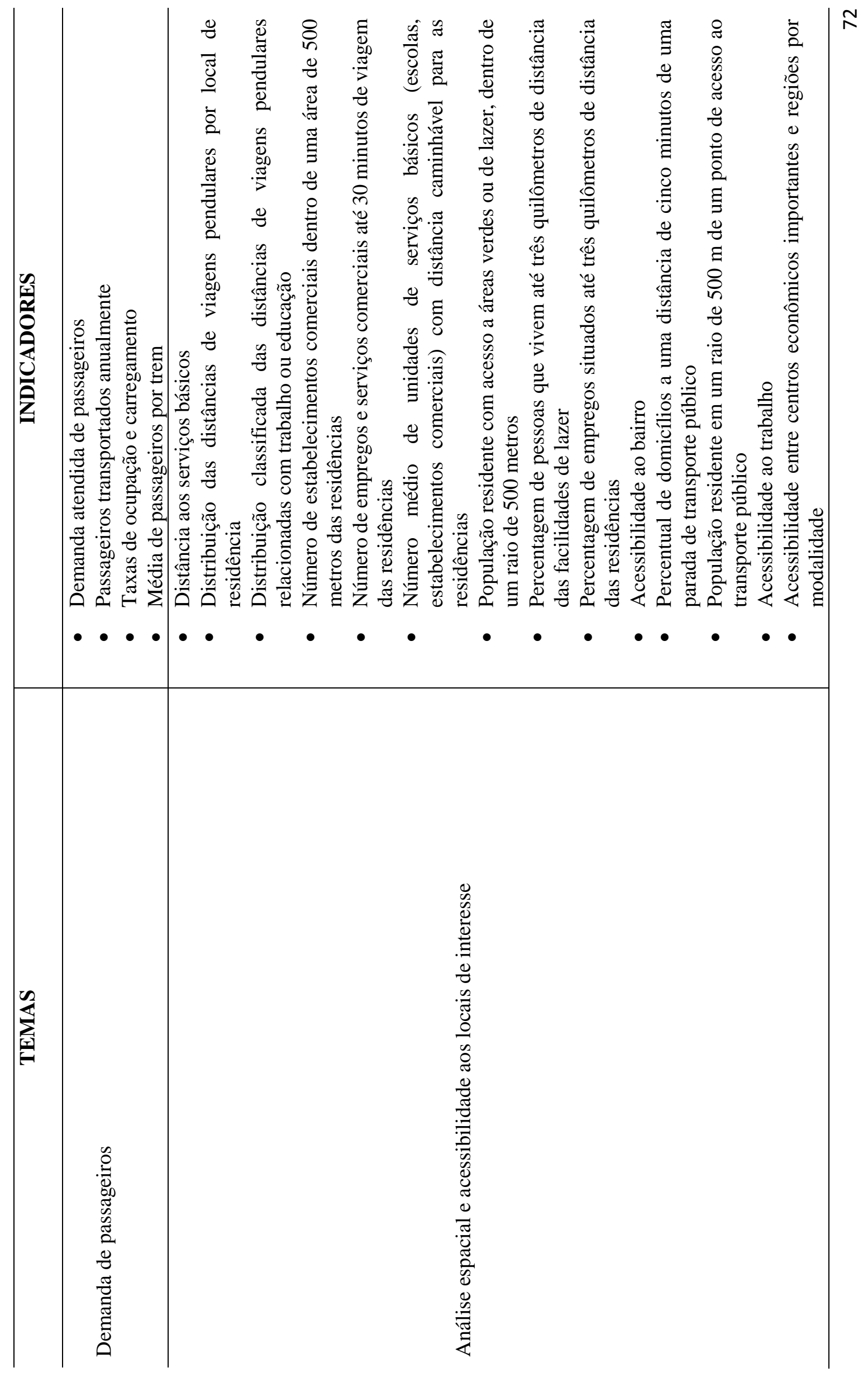




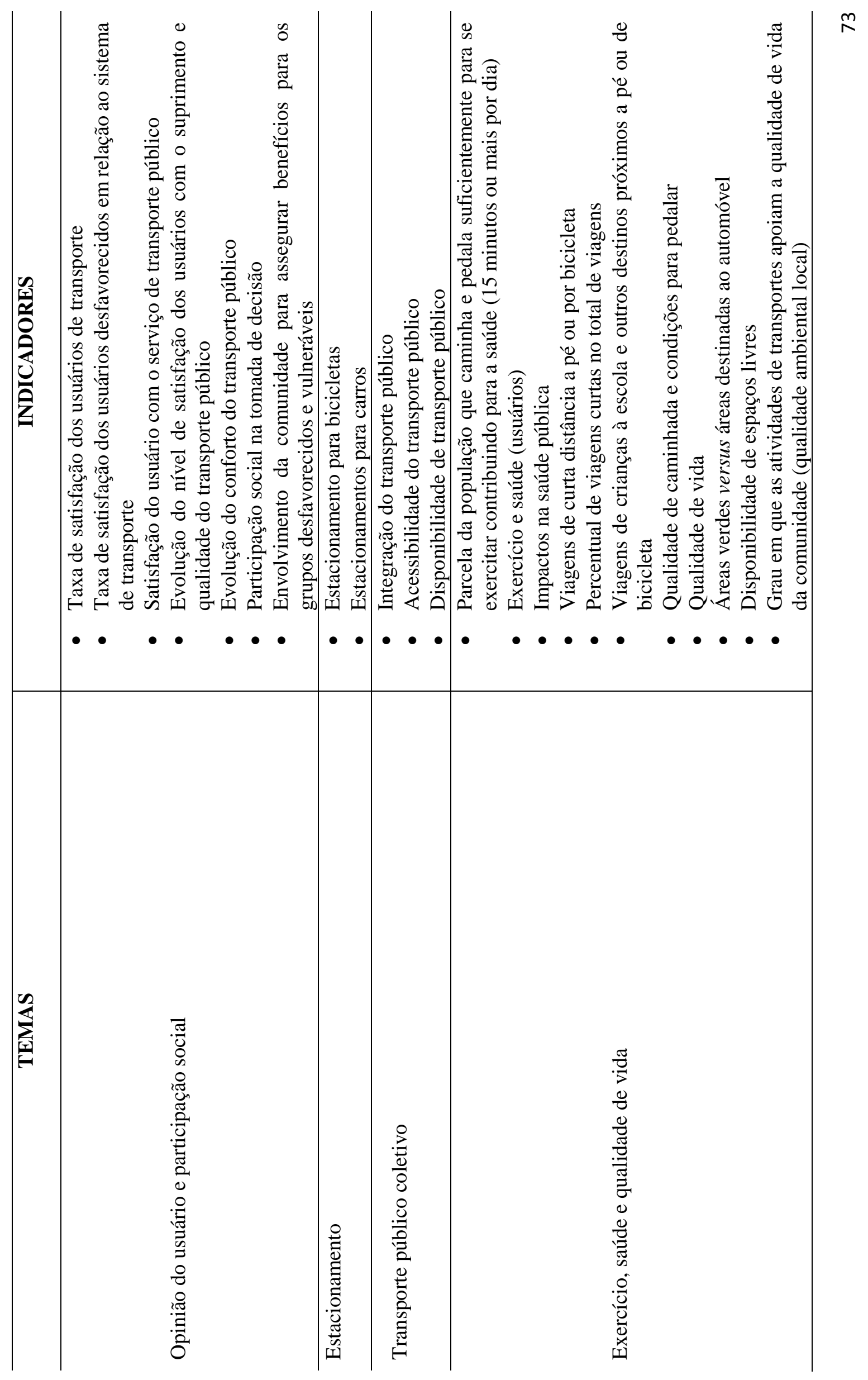




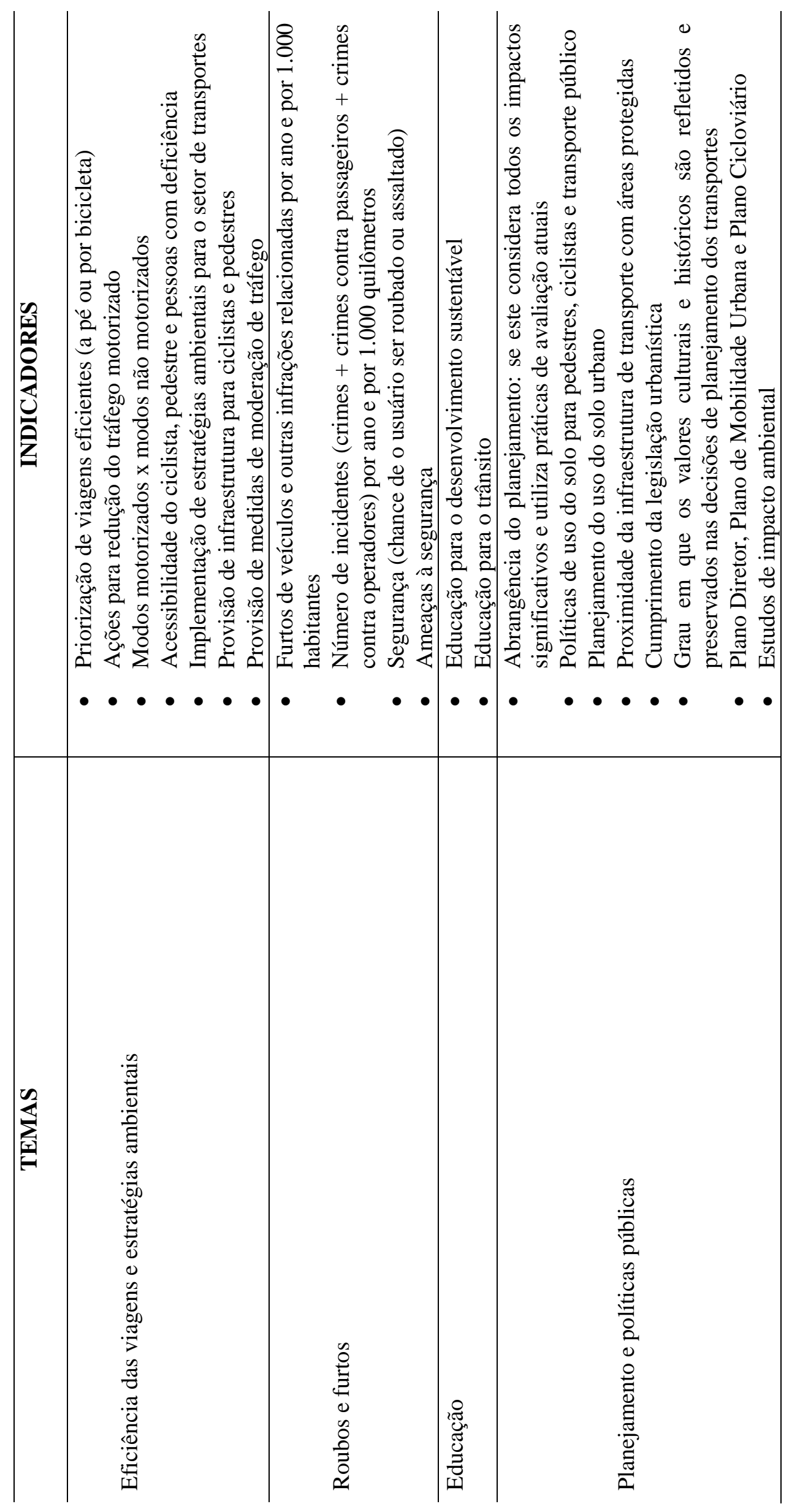

N 
A análise dos 650 indicadores considerados nesta Teste, cujo resumo consta da Tabela 3.1, em conjunto com diversas considerações e critérios apresentados nos próximos itens deste capítulo, possibilitaram selecionar e criar indicadores voltados à sustentabilidade de ciclovias, capazes de gerar um método para determinar a sustentabilidade de ciclovias.

\subsection{CONSTRUÇÃO DE INDICADORES DE MOBILIDADE SUSTENTÁVEL APLICÁVEIS EM CICLOVIAS}

Da mesma forma que não há uma definição única de sustentabilidade da mobilidade, constata-se, a partir da análise dos indicadores de mobilidade sustentável descritos no tópico 3.2, que não existem indicadores padronizados para o planejamento sustentável da mobilidade.

Ressalta-se que Machado (2010) concluiu em seu trabalho que não há um entendimento único acerca do que deve ser medido quanto à mobilidade sustentável. Em adição, a Comissão Europeia (EUROPEAN COMMISSION, 2005) afirma que não há consenso sobre indicadores para a avaliação de um sistema de transporte sustentável. Assim sendo, cada jurisdição ou organização deve desenvolver seu próprio conjunto com base nas suas necessidades, habilidades e interesses (LITMAN, 2008b).

Embora muitos indicadores tenham sido analisados no tópico 3.2, não foi identificado nenhum conjunto de indicadores de mobilidade sustentável para aplicação em ciclovias, o que reforça a importância da criação destes indicadores. 


\subsubsection{Considerações e Critérios para a Identificação de Indicadores de Mobilidade Sustentável Aplicáveis em Ciclovias}

As seguintes considerações e critérios foram elaborados para orientar e nortear a identificação de indicadores de mobilidade sustentável aplicáveis em ciclovias:

- O conceito Triple Bottom Line, proposto por Elkington (1994), com o intuito de auxiliar a compreensão e disseminação da sustentabilidade por meio do tripé economicamente viável, socialmente justo e ecologicamente correto, denominado de tripé da sustentabilidade, apresentado no Capítulo 2, foi utilizado para a definição das dimensões de sustentabilidade, empregadas para a identificação dos indicadores (social, econômica e ambiental);

- As recomendações do guia de auxílio à seleção de indicadores de mobilidade sustentável de Litman (2008b) foram seguidas para permitir a seleção, adaptação e construção de indicadores baseados em informações confiáveis, acessíveis, rápidas e precisas para esta situação particular. Litman (2008b) defende que há uma tensão entre a conveniência prática e a abrangência (alcance) ao selecionar indicadores e ressalta que indicadores mais simples devem ser selecionados pela facilidade de coleta e por sua capacidade de propiciar a tomada de decisão. Um pequeno conjunto de indicadores, utilizando-se de dados disponíveis, é conveniente e prático para coletar, analisar e utilizar, desde que cuidados sejam tomados para não negligenciar os impactos importantes; ao contrário, um conjunto maior, embora mais abrangente, pode gerar problemas para a coleta de dados, elevados custos de análise e prazos longos;

- A seleção dos indicadores voltados às ciclovias foi definida de modo que sua aplicação possa ser realizada basicamente por meio de consultas diretas a órgãos ligados à mobilidade urbana e de informações coletáveis com pesquisas de opinião com ciclistas;

- Os indicadores identificados foram submetidos a uma pesquisa de opinião com ciclistas e especialistas em transportes com a intenção de refiná-los e torná-los mais consistentes e aplicáveis; 
- Os indicadores de mobilidade de transporte de carga dos sistemas de indicadores citados no tópico 3.2 não foram utilizados, uma vez que a bicicleta é utilizada basicamente para a mobilidade de pessoas e não de bens;

- Por não serem aplicáveis à mobilidade sustentável referente a ciclovias, os indicadores dos seguintes temas não foram utilizados:

$\checkmark$ No sistema de transporte público: fiscalização, política tarifária, idade da frota, parâmetros operacionais (velocidade, frequência, pontualidade, índice de passageiros/km e outros) e rendimento dos operadores de transporte;

$\checkmark$ No sistema de tráfego: taxa de ocupação de veículos automotores, velocidade de tráfego, custos de congestionamento, carga e descarga, gerenciamento de tráfego e receitas públicas provenientes de impostos e taxas do sistema de tráfego;

$\checkmark$ Evolução de preços de combustíveis e de eletricidade relacionados com custos por passageiro transportado;

$\checkmark$ Despesas públicas e privadas em sistemas de transporte e de tráfego. 


\subsubsection{Ciclovias Sustentáveis}

A fim de identificar indicadores potenciais para esta situação, primeiramente buscouse enumerar as características desejáveis e impactos relevantes de uma ciclovia sustentável (Tabela 3.2), sob o ponto de vista da mobilidade nas dimensões social, econômica e ambiental.

Tabela 3.2: Características e impactos de ciclovias sustentáveis

\begin{tabular}{c|c}
\hline $\begin{array}{c}\text { Dimensão de } \\
\text { Sustentabilidade }\end{array}$ & Características/Impactos \\
\hline \multirow{4}{*}{ Social } & $\begin{array}{c}\text { Promoção de acessibilidade e integração } \\
\text { com sistemas de transporte público }\end{array}$ \\
\cline { 2 - 2 } & $\begin{array}{c}\text { Promoção de segurança durante a } \\
\text { mobilidade dos ciclistas }\end{array}$ \\
\cline { 2 - 2 } Econômica & Promoção de saúde e lazer \\
\cline { 2 - 2 } & $\begin{array}{c}\text { Redução de custos provenientes de } \\
\text { acidentes com ciclistas na região }\end{array}$ \\
\cline { 2 - 2 } & Redução de custo de poluição atmosférica \\
\hline \multirow{5}{*}{ Ambiental } & $\begin{array}{c}\text { Redução de emissão de poluentes } \\
\text { atmosféricos }\end{array}$ \\
\cline { 2 - 2 } & Redução do nível de pressão sonora \\
\cline { 2 - 2 } & $\begin{array}{c}\text { Requalificação urbana e minimização de } \\
\text { danos ao meio ambiente }\end{array}$ \\
\hline
\end{tabular}

2 Equidade é um termo original do latim “equitas" e refere-se à igualdade. Atualmente, este conceito tem sido amplamente utilizado como orientador de políticas de diversas áreas, com o propósito de torná-las mais razoáveis e justas. A equidade visa à semelhança de oportunidades, baseando-se em valores como a ética e a justiça na distribuição de oportunidades. 


\subsubsection{Proposição de Indicadores de Mobilidade Sustentável Aplicáveis em Ciclovias}

Com base nos indicadores analisados no tópico 3.2, nas considerações e critérios estabelecidos no tópico 3.3.1 e nas características desejáveis e impactos relevantes de ciclovias sustentáveis definidas no tópico 3.3.2, a Tabela 3.3 foi elaborada com o intuito de definir indicadores econômicos, ambientais e sociais aplicáveis em ciclovias. Para cada característica/impacto da Tabela 3.2 foram desenvolvidos indicadores específicos com suas respectivas unidades de medida.

Tabela 3.3: Indicadores econômicos, ambientais e sociais aplicáveis em ciclovias

\begin{tabular}{|c|c|c|c|}
\hline $\begin{array}{c}\text { Dimensão de } \\
\text { Sustentabilidade }\end{array}$ & Características/Impactos & Indicador & $\begin{array}{l}\text { Unidade } \\
\text { medida }\end{array}$ \\
\hline \multirow{6}{*}{ Social } & \multirow{5}{*}{$\begin{array}{l}\text { Promoção de acessibilidade } \\
\text { e integração com sistemas } \\
\text { de transporte público }\end{array}$} & $\begin{array}{ll}\text { Volume } & \text { de } \\
\text { bicicletas } & \text { na } \\
\text { ciclovia } & \\
\end{array}$ & $\begin{array}{l}\text { Volume de } \\
\text { bicicletas por hora }\end{array}$ \\
\hline & & $\begin{array}{l}\text { Existência de áreas } \\
\text { comerciais } \\
\text { unidades de ensino } \\
\text { dentro de uma } \\
\text { distância de } 500 \\
\text { metros da ciclovia }\end{array}$ & $\begin{array}{l}\text { Quantidade de áreas } \\
\text { comerciais } \\
\text { unidades de ensino } \\
\text { dentro de uma } \\
\text { distância de } 500 \\
\text { metros da ciclovia }\end{array}$ \\
\hline & & $\begin{array}{l}\text { Percentual de } \\
\text { viagens de ciclistas } \\
\text { por motivo de } \\
\text { trabalho ou estudo }\end{array}$ & $\%$ \\
\hline & & $\begin{array}{l}\text { Disponibilidade de } \\
\text { estacionamentos de } \\
\text { bicicletas junto à } \\
\text { ciclovia }\end{array}$ & $\begin{array}{ll}\text { - } & \text { Muito boa } \\
- & \text { Boa } \\
\text { - } & \text { Nem } \\
\text { boa/nem ruim } \\
\text { - } & \text { Ruim } \\
- & \text { Muito Ruim } \\
\end{array}$ \\
\hline & & $\begin{array}{l}\text { Integração } \\
\text { intermodal }\end{array}$ & $\begin{array}{ll}- & \text { Muito boa } \\
\text { - } & \text { Boa } \\
\text { - } & \text { Nem } \\
\text { boa/nem ruim } \\
\text { - } & \text { Ruim } \\
\text { - } & \text { Muito Ruim }\end{array}$ \\
\hline & $\begin{array}{l}\text { Promoção de segurança } \\
\text { durante a mobilidade dos } \\
\text { ciclistas }\end{array}$ & $\begin{array}{l}\text { Percepção do } \\
\text { ciclista com relação } \\
\text { a furtos e roubos na } \\
\text { ciclovia }\end{array}$ & $\begin{array}{l}\text { - Ocorrência } \\
\text { muito elevada } \\
\text { - Ocorrência } \\
\text { elevada } \\
\text { - Ocorrência } \\
\text { média }\end{array}$ \\
\hline
\end{tabular}




\begin{tabular}{|c|c|c|c|}
\hline $\begin{array}{c}\text { Dimensão de } \\
\text { Sustentabilidade }\end{array}$ & Características/Impactos & Indicador & $\begin{array}{ll}\text { Unidade } \\
\text { medida }\end{array}$ \\
\hline \multirow{8}{*}{ Social } & & & $\begin{array}{l}\text { - Ocorrência } \\
\text { muito baixa } \\
\text { - Ocorrência } \\
\text { baixa }\end{array}$ \\
\hline & & $\begin{array}{lr}\text { Frequência } & \text { de } \\
\text { policiamento } & \text { nas } \\
\text { imediações } & \text { da } \\
\text { ciclovia } & \end{array}$ & $\begin{array}{ll}- & \text { Muito boa } \\
- & \text { Boa } \\
\text { - } & \text { Nem } \\
\text { boa/nem ruim } \\
\text { - } & \text { Ruim } \\
- & \text { Muito Ruim } \\
\end{array}$ \\
\hline & & $\begin{array}{l}\text { Localização } \\
\text { espacial e } \\
\text { conectividade com } \\
\text { outras ciclovias }\end{array}$ & $\begin{array}{ll}- & \text { Muito boa } \\
- & \text { Boa } \\
\text { - } & \text { Nem } \\
\text { boa/nem ruim } \\
\text { - } & \text { Ruim } \\
- & \text { Muito Ruim } \\
\end{array}$ \\
\hline & & $\begin{array}{lr}\text { Qualidade } & \text { da } \\
\text { sinalização } & \text { da } \\
\text { ciclovia, } & \text { dos } \\
\text { cruzamentos } & \\
\text { cicloviários e } & \text { do } \\
\text { tratamento } & \text { dos } \\
\text { locais críticos } & \\
\end{array}$ & $\begin{array}{ll}- & \text { Muito boa } \\
\bullet & \text { Boa } \\
- & \text { Nem } \\
\text { boa/nem ruim } \\
-\quad & \text { Ruim } \\
- & \text { Muito Ruim } \\
\end{array}$ \\
\hline & & $\begin{array}{ll}\text { Qualidade } & \text { do } \\
\text { pavimento } & \text { da } \\
\text { ciclovia } & \end{array}$ & $\begin{array}{ll}- & \text { Muito boa } \\
- & \text { Boa } \\
\text { - } & \text { Nem } \\
\text { boa/nem ruim } \\
\text { - } & \text { Ruim } \\
- & \text { Muito Ruim } \\
\end{array}$ \\
\hline & & $\begin{array}{ll}\text { Qualidade } & \text { da } \\
\text { drenagem } & \text { da } \\
\text { ciclovia } & \end{array}$ & $\begin{array}{ll}\bullet & \text { Muito boa } \\
- & \text { Boa } \\
\text { - } & \text { Nem } \\
\text { boa/nem ruim } \\
\text { - } & \text { Ruim } \\
- & \text { Muito Ruim } \\
\end{array}$ \\
\hline & & $\begin{array}{l}\text { Disponibilização } \\
\text { de iluminação } \\
\text { pública } \\
\text { arredores } \\
\text { ciclovia }\end{array}$ & $\begin{array}{ll}- & \text { Muito boa } \\
\text { - } & \text { Boa } \\
\text { - } & \text { Nem } \\
\text { boa/nem ruim } \\
\text { - } & \text { Ruim } \\
- & \text { Muito Ruim } \\
\end{array}$ \\
\hline & Promoção de saúde e lazer & Promoção de saúde & $\%$ \\
\hline
\end{tabular}




\begin{tabular}{|c|c|c|c|}
\hline $\begin{array}{c}\text { Dimensão de } \\
\text { Sustentabilidade }\end{array}$ & Características/Impactos & Indicador & $\begin{array}{ll}\text { Unidade } & \text { de } \\
\text { medida }\end{array}$ \\
\hline & & $\begin{array}{l}\text { Promoção de } \\
\text { atividade de lazer }\end{array}$ & $\%$ \\
\hline & & $\begin{array}{l}\text { Promoção de } \\
\text { qualidade de vida e } \\
\text { redução do nível de } \\
\text { estresse dos } \\
\text { ciclistas }\end{array}$ & $\begin{array}{ll}\text { - } & \text { Muito boa } \\
\text { - } & \text { Boa } \\
\text { - } & \text { Nem } \\
\text { boa/nem ruim } \\
\text { - } & \text { Ruim } \\
\text { - } & \text { Muito Ruim } \\
\end{array}$ \\
\hline \multirow{6}{*}{ Econômica } & \multirow{4}{*}{ Promoção de equidade } & $\begin{array}{lr}\text { Percentual } & \text { de } \\
\text { ciclistas que não } \\
\text { possuem veículo } \\
\text { particular }\end{array}$ & $\%$ \\
\hline & & $\begin{array}{l}\text { Percentual } \quad \text { de } \\
\text { transferência do } \\
\text { modo a pé para o } \\
\text { cicloviário }\end{array}$ & $\%$ \\
\hline & & $\begin{array}{lr}\text { Percentual } & \text { de } \\
\text { ciclistas que se } \\
\text { beneficiaram dos } \\
\text { efeitos positivos } \\
\text { indiretos gerados } \\
\text { pela ciclovia como } \\
\text { aquisição de d d } \\
\text { emprego, educação } \\
\text { eratras } \\
\text { oportunidades }\end{array}$ & $\%$ \\
\hline & & $\begin{array}{lr}\text { Percentual } & \text { de } \\
\text { ciclistas } & \text { que } \\
\text { obtiveram redução } \\
\text { de gastos devido à } \\
\text { utilização } \\
\text { ciclovia }\end{array}$ & $\%$ \\
\hline & $\begin{array}{l}\text { Redução de custos } \\
\text { provenientes de acidentes } \\
\text { com ciclistas na região }\end{array}$ & $\begin{array}{l}\text { Variação anual da } \\
\text { quantidade de } \\
\text { ciclistas mortos em } \\
\text { acidentes na região } \\
\text { da ciclovia por } \\
\text { habitante por ano }\end{array}$ & $\%$ \\
\hline & $\begin{array}{l}\text { Redução de custo de } \\
\text { poluição atmosférica }\end{array}$ & $\begin{array}{l}\text { Redução do custo } \\
\text { anual de poluentes } \\
\text { devido à } \\
\text { transferência de } \\
\text { viagens } \\
\text { motorizadas para o } \\
\text { modo cicloviário }\end{array}$ & $\mathrm{R} \$$ por ano \\
\hline
\end{tabular}




\begin{tabular}{|c|c|c|c|}
\hline $\begin{array}{c}\text { Dimensão de } \\
\text { Sustentabilidade }\end{array}$ & Características/Impactos & Indicador & $\begin{array}{ll}\text { Unidade } & \text { de } \\
\text { medida } & \end{array}$ \\
\hline \multirow{7}{*}{ Ambiental } & \multirow[b]{2}{*}{$\begin{array}{l}\text { Redução de emissões de } \\
\text { poluentes atmosféricos }\end{array}$} & $\begin{array}{lr}\text { Redução } & \text { de } \\
\text { emissão } & \text { de } \\
\text { poluentes de gases } \\
\text { de efeito estufa }\end{array}$ & $\begin{array}{l}\text { Toneladas de } \mathrm{CO}_{2 \mathrm{eq}} \\
\text { por ano. }\end{array}$ \\
\hline & & $\begin{array}{ll}\text { Redução } & \text { de } \\
\text { emissão } & \text { de } \\
\text { poluentes locais } & \end{array}$ & $\begin{array}{c}\text { Toneladas de } \\
\text { poluentes locais } \\
\text { (monóxido de } \\
\text { carbono }(\mathrm{CO}) \mathrm{e} \\
\text { óxidos de } \\
\text { nitrogênio, }\left(\mathrm{NO}_{\mathrm{x}}\right) \text { ) } \\
\text { por ano }\end{array}$ \\
\hline & $\begin{array}{l}\text { Redução do nível de } \\
\text { pressão sonora }\end{array}$ & $\begin{array}{lr}\text { Redução do nível } \\
\text { de pressão sonora } \\
\text { proveniente da } \\
\text { transferência } \\
\text { viagens } \\
\text { motorizadas para o } \\
\text { modo cicloviário }\end{array}$ & $\begin{array}{ll}- & \text { Muito boa } \\
\text { - } & \text { Boa } \\
\text { - } & \text { Nem } \\
\text { boa/nem ruim } \\
\text { - } & \text { Ruim } \\
\text { - } & \text { Muito Ruim } \\
\end{array}$ \\
\hline & \multirow{4}{*}{$\begin{array}{l}\text { Requalificação urbana e } \\
\text { minimização de danos ao } \\
\text { meio ambiente }\end{array}$} & $\begin{array}{l}\text { Promoção de áreas } \\
\text { verdes }\end{array}$ & $\begin{array}{ll}- & \text { Muito boa } \\
\text { - } & \text { Boa } \\
\text { - } & \text { Nem } \\
\text { boa/nem ruim } \\
\text { - } & \text { Ruim } \\
\text { - } & \text { Muito Ruim } \\
\end{array}$ \\
\hline & & $\begin{array}{l}\text { Qualidade das } \\
\text { áreas nas } \\
\text { imediações da } \\
\text { ciclovia em termos } \\
\text { de não abandono e } \\
\text { degradação }\end{array}$ & $\begin{array}{ll}\text { - } & \text { Muito boa } \\
\text { - } & \text { Boa } \\
\text { - } & \text { Nem } \\
\text { boa/nem ruim } \\
\text { - } & \text { Ruim } \\
\text { - } & \text { Muito Ruim }\end{array}$ \\
\hline & & $\begin{array}{l}\text { Compatibilidade_da } \\
\text { ciclovia com o uso } \\
\text { e ocupação do solo } \\
\text { e com a legislação } \\
\text { em vigor }\end{array}$ & $\begin{array}{ll}- & \text { Muito boa } \\
\text { - } & \text { Boa } \\
\text { - } & \text { Nem } \\
\text { boa/nem ruim } \\
\text { - } & \text { Ruim } \\
\text { - } & \text { Muito Ruim } \\
\end{array}$ \\
\hline & & $\begin{array}{lr}\text { Intensidade } & \text { de } \\
\text { danos causados } & \text { ao } \\
\text { meio ambiente } \\
\text { devido } & \text { à } \\
\text { construção } & \text { ou } \\
\text { restauração } & \text { da } \\
\text { ciclovia } & \\
\end{array}$ & $\begin{array}{l}\text { - Sem } \\
\text { impactos } \\
\text { - Impactos de } \\
\text { pequeno porte } \\
\text { - Impactos } \\
\text { significativos. }\end{array}$ \\
\hline
\end{tabular}


É importante ressaltar que oito especialistas em mobilidade urbana, de nível sênior, com larga experiência em mobilidade urbana, auxiliaram na construção das Tabelas 3.2 e 3.3, por meio de recomendações e críticas, de forma a possibilitar o alcance dos seguintes resultados:

- Sugestão de agrupamento das características desejáveis e impactos relevantes de ciclovias sustentáveis, de forma a resultar em um número menor de características. Antes da análise dos especialistas haviam sido selecionados 21 características/impactos (dez sociais, quatro econômicos e sete ambientais). Após a contribuição dos especialistas houve uma redução considerável de características/impactos, que ao todo somam nove (três sociais, três econômicos e três ambientais);

- Inclusão e redução de indicadores, com o número de reduções maior que o de inclusões. De 39 indicadores previamente selecionados, estes foram revistos e refinados, de forma que o número total de indicadores passou a ser de 28;

- Modificação do posicionamento das características desejáveis e impactos relevantes de ciclovias sustentáveis, segundo as dimensões de sustentabilidade, e, também, dos indicadores, de acordo com as características/impactos;

- Ajustes diversos de conteúdo e de redação da descrição dos indicadores;

- Ajustes para melhorias nas unidades de medida dos indicadores.

Ressalta-se que alguns indicadores foram definidos na dimensão ou característica considerada mais adequada pelo conjunto de especialistas, já que alguns temas se aplicam a mais de uma dimensão.

As fichas dos indicadores propostos neste Capítulo encontram-se detalhadas no Apêndice A desta tese, de forma a especificar:

- Nome do indicador;

- Dimensão de sustentabilidade;

- Descrição;

- Unidade de medida;

- Como medir;

- Normalização (explicada com detalhes no item 3.5 desta tese). 
Apresenta-se a seguir a metodologia utilizada para construir o questionário.

\subsection{ELABORAÇÃO DO QUESTIONÁRIO}

Segundo Günther (2003), são três os caminhos principais para compreender o comportamento humano no contexto das ciências sociais empíricas:

(1) observar o comportamento que ocorre naturalmente no âmbito real;

(2) criar situações artificiais e observar o comportamento diante de tarefas definidas para essas situações;

(3) perguntar às pessoas sobre o que fazer (fazem) e pensar (pensam).

Neste trabalho, foi utilizado o terceiro caminho, a fim de permitir que valores sejam atribuídos a alguns indicadores por meio de pesquisa de opinião com o usuário.

O levantamento de dados por pesquisa assegura melhor representatividade e permite generalização para uma população mais ampla (GÜNTHER, 2003).

Com o objetivo de adquirir conhecimento para a elaboração de um questionário adequado, realizou-se uma revisão de literatura sobre como elaborar um questionário, de modo a levantar as principais orientações das principais referências no assunto.

De acordo com Yaremko et al. (1986), um questionário pode ser definido como "um conjunto de perguntas sobre um determinado tópico que não testa a habilidade do respondente, mas mede sua opinião, seus interesses, aspectos de personalidade e informação biográfica".

Para a elaboração do questionário em tela, partiu-se da seguinte reflexão: qual é o objetivo da pesquisa em termos dos conceitos a serem pesquisados e da população alvo? Desta forma, o objetivo do estudo possibilitou a determinação da forma do instrumento, das perguntas a serem respondidas, da maneira da sua aplicação, da população alvo e da amostra necessária.

O tamanho da amostra para a aplicação da pesquisa em cada ciclovia foi definido posteriormente no Capítulo 5, segundo critérios técnicos. 
A Figura 3.2 apresenta os estágios principais de uma pesquisa (SCHUMAN e KALTON, 1985). A partir dos objetivos de uma pesquisa é possível realizar o levantamento das relações conceito/item e população alvo/amostra. Estas relações determinam a maneira de administrar o questionário, de como editá-lo e codificá-lo e de como os dados devem ser processados e analisados.

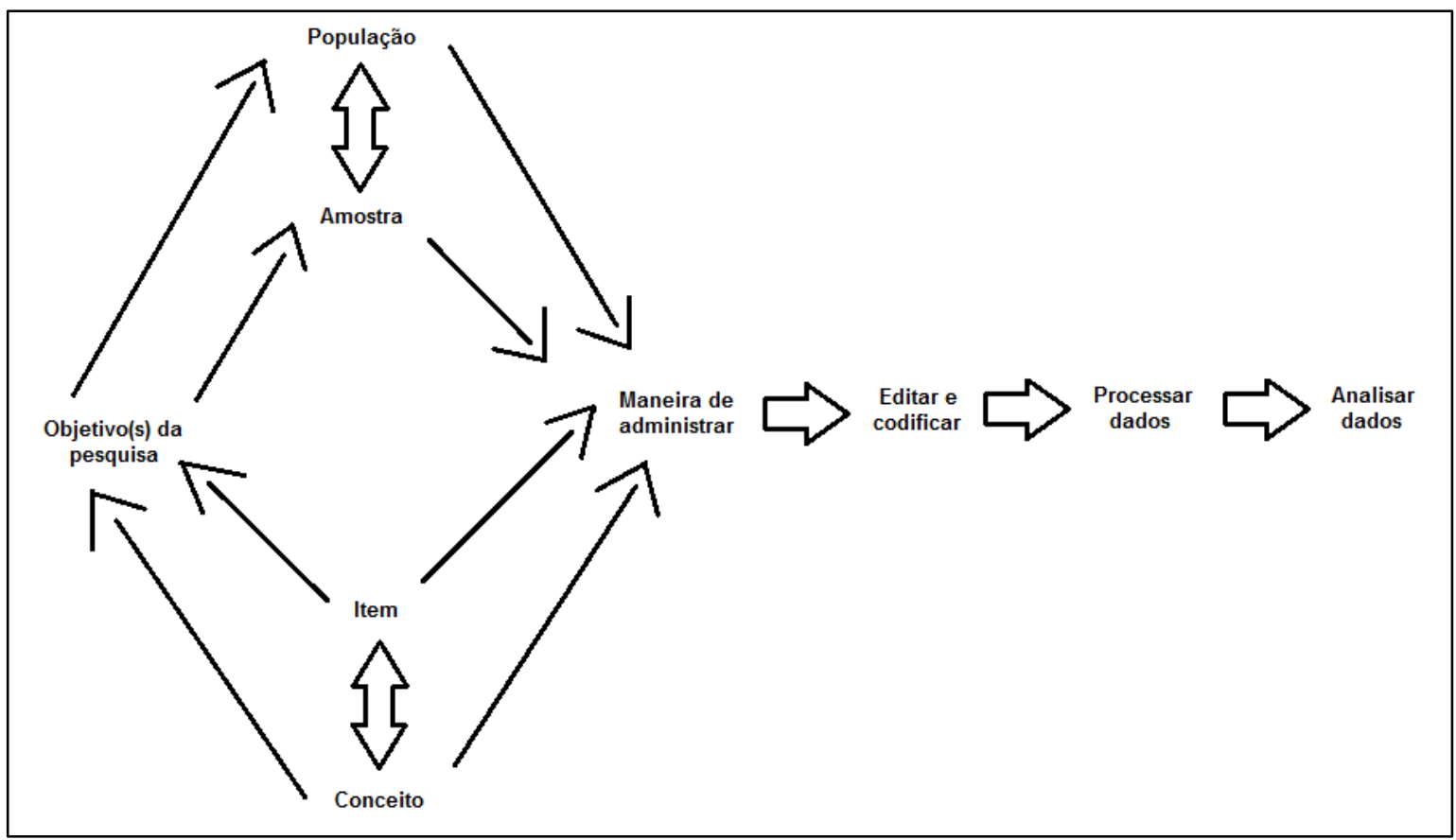

Figura 3.2: Estágios principais de uma pesquisa (Adaptação de SCHUMAN e KALTON, 1985)

Quais são as razões que levam uma pessoa a responder um instrumento de pesquisa? Dillman (1978), Rodeghier (1996) e Günther (2003) definem questões importantes para maximizar a disposição do respondente de participar da pesquisa:

- Estabelecer confiança:

$\checkmark$ Identificando-se com uma instituição conhecida e legitimada;

$\checkmark$ Aproveitando relacionamentos de troca (brindes e elogios);

$\checkmark$ Oferecendo um sinal de apreciação antecipada;

$\checkmark$ Mostrando que a opinião do respondente é valorizada;

$\checkmark$ Deixando o respondente falar o que pensa e o ouvindo com atenção;

$\checkmark$ Mantendo o nível de interesse do respondente o mais alto possível;

$\checkmark$ Mantendo o nível de atenção do respondente o mais alto possível; 
- Reduzir o custo de responder:

$\checkmark$ Fazendo com que a tarefa pareça breve;

$\checkmark$ Mantendo a tarefa do respondente o mais fácil possível;

$\checkmark$ Reduzindo esforços físico e mental requeridos;

$\checkmark \quad$ Direcionando do item mais geral para o mais específico; do menos delicado e menos pessoal, para o mais delicado e mais pessoal;

$\checkmark \quad$ Levando em consideração na formulação do questionário o nível educacional dos respondentes;

$\checkmark$ Eliminando a possibilidade de embaraços;

$\checkmark$ Eliminando qualquer implicação de subordinação;

$\checkmark$ Eliminando qualquer custo financeiro;

- Recompensar o respondente:

$\checkmark$ Demonstrando consideração;

$\checkmark$ Tornando o instrumento interessante;

$\checkmark$ Oferecendo apreciação verbal usando uma abordagem consultiva;

$\checkmark$ Apoiando seus valores.

Diante destas orientações, buscou-se a elaboração de um formulário de pesquisa que contribuísse significativamente para reduzir o esforço físico e mental do respondente, além de assegurar que todos os temas de interesse fossem tratados em uma ordem que mantivesse o interesse do respondente em responder o questionário até o fim sem se sentir mal.

Fowler (1998) define uma boa pergunta como aquela que gera respostas fidedignas e válidas. Assim sendo, uma pergunta bem elaborada deve conter as seguintes características básicas:

$\checkmark$ Cada pergunta deve ser específica, breve e clara.

$\checkmark$ A pergunta precisa ser comunicada consistentemente;

$\checkmark$ A pergunta precisa ser compreendida consistentemente;

$\checkmark$ As expectativas quanto à resposta precisam ser claras para o respondente;

$\checkmark$ A menos que se esteja verificando conhecimento, os respondentes devem ter toda informação necessária para responder o questionário. 
Além disso, uma das principais preocupações em pesquisas empíricas é a definição da escala de medida apropriada para a coleta de informações. Diante desta apreensão, verificou-se que para quantificar e qualificar a sustentabilidade de uma ciclovia, a escala Likert seria adequada, uma vez que permite ao respondente responder uma pergunta de acordo com uma escala de alternativas.

A escala Likert é um tipo de escala de resposta psicométrica (LIKERT, 1932), largamente utilizada em pesquisas, utilizada em levantamento de atitudes, opiniões e avaliações (ALEXANDRE et al., 2003, GÜNTHER, 2003, MOLITERNO, 2010).

A discussão sobre o número de categorias a ser definido na escala baseia-se, particularmente, na necessidade ou não de inclusão da categoria central. Um questionamento importante referente a essa escala é a definição do número apropriado de categorias a ser incluído no questionário, de forma simétrica ou com um número ímpar de categorias, com a categoria do meio (central) representando uma indecisão.

Em seu trabalho, Alexandre et al. (2003) afirmam que "a retirada da categoria central pode conduzir o entrevistado a ter uma tendência de marcar na escala uma posição positiva ou negativa. Independentemente do número de alternativas é importante que estejam balanceadas e exista para o respondente a opção de não se comprometer, que é diferente de não saber opinar".

Uma das grandes preocupações em qualquer pesquisa, em particular naquelas onde o elemento humano é o decisor das informações com base em sua percepção, é o registro da real opinião do entrevistado. Assim sendo, este trabalho se preocupou bastante com esta questão. Na definição das alternativas das respostas, cada indicador foi individualmente considerado.

O questionário elaborado para possibilitar a mensuração dos 28 indicadores encontrase disponibilizado no Apêndice B desta tese.

\subsection{NORMALIZAÇÃO DOS INDICADORES PROPOSTOS}

Uma questão importante a ser discutida é a dos critérios para a tomada de decisão em relação à associação do valor que representa a condição de um indicador, uma vez que normalmente os valores de diferentes indicadores não são comparáveis entre si, de forma a inviabilizar a sua agregação imediata. 
Assim sendo, buscou-se normalizar para uma mesma escala de valores os diferentes indicadores utilizados nesta tese para viabilizar a sua agregação.

Segundo Costa (2008), a normalização dos critérios ou indicadores visa permitir sua agregação e comparação. O processo de normalização é necessário, uma vez que os valores que caracterizam diferentes indicadores não são comparáveis entre si e são representados frequentemente através de diferentes escalas, o que inviabiliza a sua agregação imediata.

Para o cálculo do Índice de Mobilidade Urbana Sustentável - IMUS (COSTA, 2008) foi realizado um processo para a obtenção de uma pontuação normalizada para os valores dos indicadores, definida entre os limites mínimo e máximo de 0,00 a 1,00, respectivamente. O método para a obtenção desta pontuação variou de um indicador para outro, dependendo da natureza da informação associada ao mesmo (informação quantitativa e/ou qualitativa).

A maior parte dos processos de normalização utiliza um valor máximo e outro mínimo para a definição de uma escala, em que a forma mais simples para a obtenção dos valores intermediários é uma variação linear (EASTMAN, 1997 e COSTA, 2008). A normalização é feita com base nos valores apresentados na escala de avaliação por meio de associação direta ou interpolada.

Para facilitar o processo de normalização dos indicadores aplicáveis em ciclovias e atender às diferentes características dos mesmos, foram construídas Tabelas com uma escala de avaliação para cada indicador, com limites mínimo e máximo fixados $(0,00$ e 1,00, respectivamente) e valores de referência para a pontuação do indicador. Estas Tabelas estão disponíveis nas fichas dos indicadores nos apêndices.

Cabe ressaltar que as escalas de avaliação propostas nesta tese permitem tornar os indicadores comparáveis e possíveis de serem agregados por meio de um método matemático.

Os valores das escalas de avaliação dos indicadores da mobilidade sustentável em ciclovias foram estabelecidos com base na revisão da literatura, em padrões nacionais e internacionais, em experiências já difundidas no desenvolvimento de índices, em indicadores urbanos e em análise inédita da autora desta tese. 
A metodologia utilizada para a normalização dos indicadores baseou-se nas instruções de Costa (2008):

"Após a definição do questionário, priorizando a síntese do número de quesitos, deve ser procedida a apuração que levará à determinação dos indicadores. Alguns critérios para essa apuração devem ser estabelecidos como:

(1) Pontuação dos quesitos: determinação de uma escala de valores para pontuação dos quesitos que compõem os questionários;

(2) Apuração dos questionários: visa determinar a forma como se dará a apuração dos questionários;

(3) Critérios para apuração dos indicadores: estabelecimento do procedimento de cálculo e o estabelecimento de limites inferiores e superiores para a composição de faixas de indicadores;

(4) Interpretação dos indicadores: trata dos procedimentos que devem ser aplicados para o uso dos indicadores e seus graus de sustentabilidade".

Neste Capítulo foram discutidos os conceitos de indicadores, a identificação e análise de indicadores de mobilidade sustentável, ciclovias sustentáveis e possíveis indicadores de mobilidade sustentável aplicáveis a ciclovias. Também foram estabelecidos critérios para a identificação de indicadores de mobilidade sustentável aplicáveis em ciclovias, propostos indicadores de mobilidade sustentável aplicáveis em ciclovias, normalizados os indicadores propostos e, por fim, apresentou-se a metodologia utilizada para desenvolver o questionário de opinião aplicado nos usuários da ciclovia.

O próximo Capítulo apresenta o desenvolvimento de um método para a determinação da sustentabilidade de ciclovias. Para tanto, são estudados diversos métodos multicritérios de apoio à decisão de diferentes escolas e feitas considerações sobre a escolha do método multicritério para a construção do modelo. Opta-se pelo método da Escola Americana denominado Teoria da Utilidade Multiatributo. Assim, o problema é estruturado e apresenta-se como deve ser aplicada a função de valor multiatributo aditiva para a mensuração da mobilidade sustentável em ciclovias. 


\section{MÉTODO PARA A DETERMINAÇÃO DA SUSTENTABILIDADE DE CICLOVIAS}

Os indicadores selecionados no Capítulo 3 foram agregados para gerar um método capaz de fornecer a síntese do estado de mobilidade sustentável de uma ciclovia, por meio do cálculo de um índice global.

Este índice pode ser utilizado por tomadores de decisão como uma ferramenta de diagnóstico, planejamento e monitoramento da mobilidade urbana, a partir da comparação de ciclovias e trechos cicloviários implantados.

\subsection{MÉTODOS MULTICRITÉRIOS DE APOIO À DECISÃO}

Segundo Miller (1956), o ser humano tem dificuldades para considerar um número elevado de fatores e elencá-los simultaneamente conforme sua importância. Diante desta limitação, diversos métodos e ferramentas de apoio à decisão foram elaborados para auxiliar na sistematização de informações e definição de preferências, permitindo a análise de problemas complexos não tratáveis pelos procedimentos intuitivos empíricos usuais.

A fim de evitar que decisões sejam tomadas com base em único critério, surgiram os métodos multicritérios, que permitem análises baseadas em vários itens, proporcionando um processo de decisão mais robusto.

Ao discutir a complexidade de problemas de mobilidade sustentável, Marshall (2001) e Banister (2008) recomendaram o uso da análise multicritério para analisar problemas ambientais e sociais.

\subsection{JUSTIFICATIVA DA ESCOLHA DE UM MÉTODO MULTICRITÉRIO PARA A CONSTRUÇÃO DO MÉTODO}

Optou-se neste trabalho pela utilização de um método multicritério devido a esta abordagem permitir a avaliação dos indicadores para o caso específico em questão, diante das seguintes decisões:

- Envolvimento de especialistas no assunto, com poder de decisão e influência na construção do método;

- Multidisciplinaridade de especialistas com diferentes experiências e conhecimentos; 
- Variações das possíveis diferenças de percepção dos especialistas dos conceitos de sustentabilidade, desenvolvimento sustentável, mobilidade e mobilidade sustentável;

- Oportunidade para os especialistas refletirem sobre os conflitos, levando em consideração outros pontos de vista e argumentos;

- Construção de uma base para o diálogo entre a autora e os especialistas;

- Consideração de indicadores independentemente do tipo de dados (quantitativos ou qualitativos) e da escala de medida;

- Atribuição de pesos aos indicadores com o propósito de quantificar a importância relativa de cada um em relação ao objetivo da análise;

- Interpretação de cada alternativa como um acordo entre objetivos em conflito;

- Consenso de uma solução potencial satisfatória como compromisso entre diferentes pontos de vista, mesmo que em conflito;

- Construção de critérios de avaliação e definição dos parâmetros que serão utilizados para agregação dos indicadores para guiar a decisão.

Foram desenvolvidos, nas três últimas décadas, diversos métodos multicritérios. A fim de possibilitar a seleção do método multicritério ideal para ser utilizado neste trabalho, o tópico 4.4 apresenta os tipos de métodos multicritérios mais utilizados na atualidade.

\subsection{TIPOS DE MÉTODOS MULTICRITÉRIOS}

É vasta a possibilidade de utilização de métodos multicritérios. Existem vários métodos desenvolvidos para a abordagem e tratamento de problemas com múltiplos critérios, os quais são explicados a seguir com base nos trabalhos de Schmidt (1995), almeida e Costa (2003), Vilas Boas (2006) e Neumann (2008).

Segundo estes autores, duas escolas de métodos multicritérios se destacam na literatura:

- Escola Americana: destacam-se a Teoria da Utilidade Multiatributo, AHP e MACHBETH;

- Escola Europeia ou Francesa: destacam-se os métodos de sobre classificação ELECTRE e PROMETHEE. 
Uma diferença importante entre a Escola Americana e a Europeia é que a Americana assume que todos os estados são comparáveis e que existe a transitividade nas relações de preferência, não permitindo alternativas incomparáveis. Ou seja, se A é preferível a B e B é preferível a C, então A é preferível a C. Ao contrário da Escola Americana, a Escola Europeia permite uma modelagem mais flexível, uma vez que aceita a incomparabilidade entre alternativas, permitindo aos especialistas uma das seguintes alternativas:

- Uma alternativa é indiferente a outra;

- Uma alternativa é incomparável a outra;

- Uma alternativa é preferível a outra com preferência forte;

- Uma alternativa é preferível a outra com preferência fraca.

\subsubsection{Métodos Multicritérios da Escola Americana}

A Teoria da Utilidade Multiatributo (Multiattribute Utility Theory), também conhecida como Função Multiatributo Aditiva, introduzida por Keeney e Raiffa (1976), é uma abordagem muito utilizada, cuja intenção é a associação de um valor a cada alternativa, produzindo uma ordem de preferência entre as alternativas de modo consistente com os julgamentos de valor dos especialistas. Estes julgamentos são representados em uma função de utilidade. Em síntese, este método consiste em calcular uma utilidade, expressa por uma nota ou pontuação, para cada objetivo ou critério e depois essas utilidades são somadas, ponderando os critérios, de acordo com sua respectiva importância aos demais. O objetivo dos especialistas neste método é maximizar o valor de utilidade, sendo que a pontuação baixa em um critério pode ser compensada por um valor maior em outro critério.

O método denominado Processo de Análise Hierárquica (Analytic Hierarchy Process - AHP), desenvolvido por Saaty (1980), foi um dos primeiros métodos voltados para o ambiente de decisão multicritério e é apontado como o mais utilizado hoje em todo o mundo. 
O método AHP decompõe um problema multicritério complexo em um sistema de hierarquia de objetivos para gerar uma matriz com a importância relativa das alternativas em cada critério (objetivo). Em síntese, este método utiliza as comparações par a par de cada elemento do mesmo nível hierárquico por meio do julgamento de especialistas para mensuração de critérios quantitativos, qualitativos, tangíveis e intangíveis. A comparação par a par é um procedimento dividido em três etapas: definição de uma hierarquia, definição dos pesos dos atributos e cálculo dos valores finais por alternativas.

Todos os indicadores são comparados par a par por especialistas que utilizam as escalas de valores apresentadas na Tabela 4.1.

Tabela 4.1: Escala de valores (SAATY, 1980)

\begin{tabular}{|c|c|c|}
\hline $\begin{array}{c}\text { Intensidade Relativa } \\
\text { de Importância }\end{array}$ & Definição & Explicação \\
\hline 1 & Igual importância & $\begin{array}{l}\text { Os dois critérios contribuem } \\
\text { igualmente para o objetivo }\end{array}$ \\
\hline 3 & $\begin{array}{c}\text { Menor importância de um sobre o } \\
\text { outro }\end{array}$ & $\begin{array}{c}\text { Um dos critérios é } \\
\text { levemente mais favorável do } \\
\text { que o outro }\end{array}$ \\
\hline 5 & Essencial ou forte & $\begin{array}{l}\text { Um dos critérios é } \\
\text { consideravelmente mais } \\
\text { favorável do que o outro }\end{array}$ \\
\hline 7 & Importância muito grande & $\begin{array}{c}\text { Um dos critérios é } \\
\text { fortemente superior ao outro } \\
\text { e isto é observado na prática }\end{array}$ \\
\hline 9 & Importância absoluta & $\begin{array}{l}\text { A importância de um critério } \\
\text { sobre o outro é } \\
\text { evidentemente muito maior }\end{array}$ \\
\hline $2,4,6,8$ & $\begin{array}{l}\text { Valores intermediários entre dois } \\
\text { tipos de julgamento }\end{array}$ & $\begin{array}{l}\text { Quando um meio termo é } \\
\text { necessário }\end{array}$ \\
\hline Valores recíprocos & $\begin{array}{l}\text { Se um critério i tem um dos valores } \\
\text { anteriores quando comparada com } \\
\text { um critério j, então j tem um valor } \\
\text { recíproco quando comparado com i }\end{array}$ & - \\
\hline
\end{tabular}


Outro método bastante conhecido da escola Americana é o MACBETH (Measuring Attrativeness by a Categorical Based Evaluation Technique), criado por Costa e Vansnick (1994). Este método é baseado no método de utilidade aditiva que necessita somente de julgamentos qualitativos sobre as diferenças de valor e ajuda os especialistas a quantificar a atratividade relativa entre as opções. Em síntese, o método MACBETH visa construir uma escala de intervalos de preferência sobre um conjunto de ações, sem a necessidade de representação numérica destas preferências, ou seja, por meio do julgamento qualitativo mede-se a diferença de atratividade entre as alternativas. A expressão dos julgamentos dos especialistas é feita por uma escala semântica formada por seis categorias: muito fraca, fraca, moderada, forte, muito forte e extrema.

\subsubsection{Métodos Multicritérios da Escola Europeia}

Os métodos da família ELECTRE (Elimination et Choix Traduisant la Réalité) são denominados Métodos de Superação. Eles diferenciam-se entre si pelos problemas tratados, pelas informações inter e intracritérios utilizadas e pela quantidade de relações de superação construídas (VILAS BOAS, 2006). Estes métodos consideram os pesos como uma medida da importância que cada critério tem para os especialistas e não como uma taxa marginal de substituição, já que as avaliações de cada alternativa nos diferentes critérios não se agrupam em uma avaliação global e sim empregam a informação dos pesos com a finalidade de construir coeficientes de concordância e de discordância dos especialistas.

Os métodos PROMÉTHÉE (Preference Ranking Organization Method for Enrichment Evaluations) se baseiam na comparação paritária e levam em consideração os desvios nas avaliações entre as alternativas. Assim os especialistas podem especificar uma preferência pequena ou grande de acordo com os desvios. Uma análise de concordância ou discordância, baseada no parâmetro de veto, é realizada para avaliar a relação de superação entre as alternativas (ALMEIDA e COSTA, 2003). 


\subsubsection{Outros Métodos Multicritérios}

O método denominado Tomada de Decisão Interativa Multicritério (TODIM) tem como base as Escola Europeia e Americana, pois combina aspectos provenientes da teoria da utilidade multiatributo, do método AHP e dos métodos Electre. O método está fundamentado na avaliação de alternativas em relação a um conjunto de critérios de decisão, sendo estes avaliados em uma escala ordinal. O TODIM é fundamentado na Teoria dos Prospectos, segundo a qual a maneira como as pessoas decidem em uma determinada situação de risco decorre do contexto em que esta está inserida, ou seja, nas situações que envolvem ganhos, a tendência do ser humano é ser mais conservador, enquanto que em situações envolvendo perdas as pessoas se mostram mais propensas ao risco (RANGEL e GOMES, 2007).

O método de Análise Verbal de Decisões (VDA) visa apoiar o processo de tomada de decisão por meio da representação verbal, sendo ideal para a resolução de problemas desestruturados. Em síntese, o método VDA se orienta pela utilização de formas verbais para elucidar preferências e avaliar alternativas decisórias. Sua principal qualidade é não desprezar a influência que a pouca habilidade das pessoas no trabalho com números tem sobre o julgamento e o processamento de informações em situações decisórias.

O método ZAPROS-LM, baseado nos princípios do VDA, foi criado para solucionar problemas de ordenação e visa à construção de uma escala ordinal para todos os critérios, de forma que todas as alternativas sejam ordenadas a partir das preferências declaradas pelos especialistas, sendo recomendado para problemas decisórios com muitas alternativas a serem avaliadas, uma vez que o seu objetivo é estabelecer um ranking das alternativas selecionadas (LARICHEV e MOSHKOVICH, 1997).

A Metodologia Multicritério de Apoio à Decisão Construtivista (Multicriteria Decision Aid Constructivist) considera que o entendimento do problema deva ocorrer de forma gradativa, quando não se tem conhecimento de todos os detalhes sobre o problema em análise e dos elementos nele envolvidos (COSTA, 2008). Assim, o entendimento do problema evolui ao longo do processo, enquanto novas informações vão sendo geradas e adquiridas, possibilitando o amadurecimento da opinião dos atores envolvidos. Assim a solução do problema não se limita a alternativas disponíveis, mas sim aos valores e objetivos disponíveis. 


\subsection{CONSIDERAÇÕES SOBRE A ESCOLHA DO MÉTODO MULTICRITÉRIO PARA A CONSTRUÇÃO DO MODELO}

Estudos comparativos entre os diferentes métodos de apoio à decisão multicritério mostram que não existem metodologias que possam ser apontadas como melhores em relação às outras em qualquer situação (LARICHEV e OLSON, 2001 e ROY, 2005).

Para uma determinada situação, os métodos de apoio à decisão podem apresentar diferentes respostas para o mesmo problema de decisão (OZERNOY, 1992 e TRIANTAPHYLLOU, 2000). Portanto, é importante identificar qual é o método mais adequado ao processo de tomada de decisão, considerando o contexto e o tipo de problema a ser resolvido.

Escolher um método multicritério envolve vários fatores, dentre os quais se destacam as características do problema analisado, do contexto considerado e da estrutura de preferências da problemática (GOMES et al., 2006). Para Bouyssou et al. (2000), esta escolha é resultado de uma avaliação dos parâmetros escolhidos, do tipo e da precisão dos dados e do conhecimento sobre o problema.

Os métodos multicritérios também vêm sendo aplicados na avaliação da sustentabilidade no setor de transportes. Campos e Ramos (2005) elaboraram uma proposta de indicadores de mobilidade sustentável com base na conjugação das características do uso e ocupação do solo e do sistema de transportes a partir do Método Multicritério do Processo Analítico Hierárquico da Escola Americana.

Já Costa (2008) utilizou em seu trabalho a Metodologia Multicritério de Apoio à Decisão Construtivista para desenvolver o Índice de Mobilidade Urbana Sustentável (IMUS).

\subsection{MÉTODO MULTICRITÉRIO ESCOLHIDO PARA A CONSTRUÇÃo DO MODELO}

Optou-se pela escolha de um método da Escola Americana, uma vez que o método desenvolvido necessitou que todos os indicadores fossem analisados, comparados e recebessem pesos de acordo com sua importância diante da mobilidade sustentável, não permitindo alternativas incomparáveis. Desta forma, foram excluídos os métodos multicritérios da Escola Europeia. 
Inicialmente, pensou-se em usar o método AHP, um dos mais utilizados atualmente, para permitir a realização par a par dos indicadores. No entanto, segundo Frasson (2011), diversos autores levantaram dúvidas sobre as complicações que podem surgir com o uso do AHP, como a ausência de fundamento de teoria estatística e o fato do número de comparações requeridas ser muitas vezes considerado alto.

Para o estudo em questão, a especialista em métodos multicritérios da UNICAMP sugeriu como opção o método da Função Multiatributo Aditiva, por ser uma abordagem muito utilizada, cuja intenção é a associação de um valor a cada indicador, produzindo uma ordem de preferência entre os indicadores de modo consistente com os julgamentos de valor dos especialistas, ponderando-os, de acordo com sua respectiva importância aos demais.

Diante desta indicação e das considerações apresentadas no tópico 4.3, optou-se por utilizar este método da Escola Americana denominado Teoria da Utilidade Multiatributo (Multiattribute Utility Theory) ou Função Multiatributo Aditiva.

\subsection{APLICAÇÃO DA FUNÇÃO MULTIATRIBUTO ADITIVA}

A Função Multiatributo Aditiva é caracterizada pela capacidade de analisar um problema de tomada de decisão por meio da construção de níveis hierárquicos. A fim de permitir uma visão global da relação complexa inerente à situação, o problema é decomposto, permitindo que os especialistas sejam capazes de ordenar e comparar itens dentro de seus diferentes contextos (VIOLATO et al., 2012).

Esta função se aplica às necessidades do problema estudado por esta tese, uma vez que permite a sistematização por meio de níveis hierárquicos de uma ampla gama de problemas de decisão nos contextos ambiental, econômico e social, devido a sua simplicidade, base matemática, e capacidade de avaliar fatores qualitativos e quantitativos, sejam eles tangíveis ou intangíveis. 
Segundo Vilas Boas (2005), as hierarquias geralmente são utilizadas em situações que envolvem incerteza, a exemplo dos problemas ambientais, e devem ser construídas de tal forma que:

- Incluam todos os elementos importantes para a avaliação, permitindo que, se necessário, eles possam ser modificados ao longo do processo;

- Considerem o ambiente que cerca o problema;

- Identifiquem as questões ou atributos que contribuam para a solução;

- Identifiquem os participantes envolvidos com o problema.

Outro ponto forte desta metodologia é a forma de agregação dos indicadores, que exige que o tomador de decisão participe ativamente no processo de estruturação e na avaliação do problema, o que contribui para tornar os resultados propostos pelo método mais consistentes.

A metodologia Função Multiatributo Aditiva, adotada neste trabalho, divide-se nas seguintes etapas para possibilitar a composição de um processo interativo de decisão, como mostra a Figura 4.1.

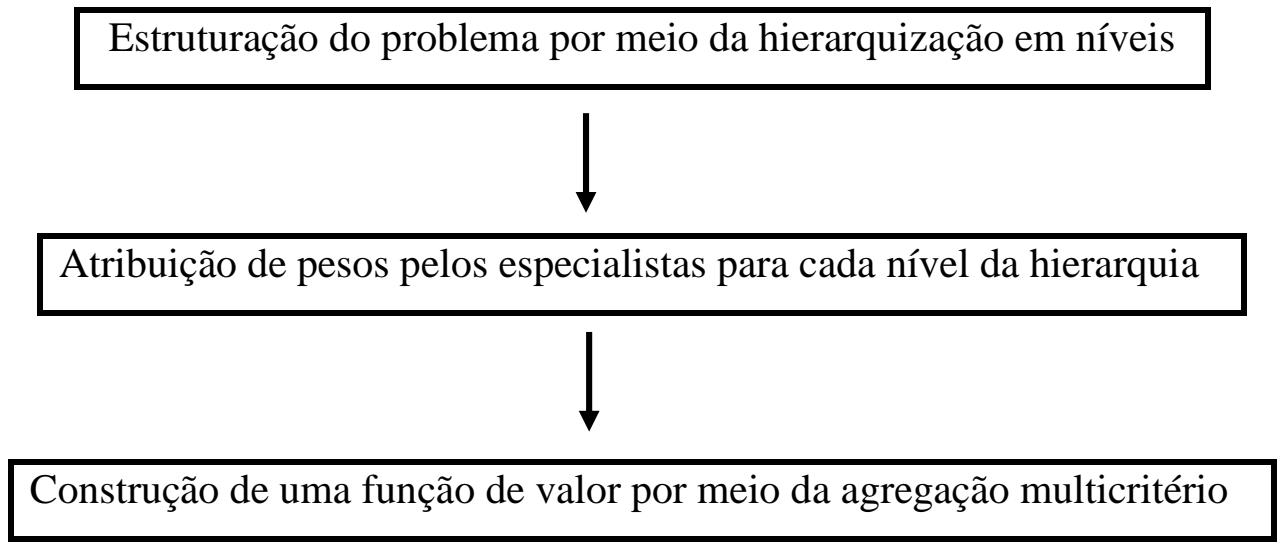

Figura 4.1: Etapas do Processo Interativo de Decisão 


\subsubsection{Estruturação do Problema}

A estruturação é fundamental no processo de auxílio multicritério à decisão, pois visa viabilizar o entendimento da situação decisória por parte dos que estão envolvidos no processo de decisão. Nela são definidos, caracterizados e organizados os critérios e aspectos relevantes para a tomada de decisão e que, posteriormente, serão avaliados (VIOLATO et al., 2011).

A estruturação apresentada a seguir compreende as seguintes atividades: definição do rótulo do problema, caracterização do contexto decisório, identificação e hierarquização dos objetivos fundamentais e definição dos indicadores, seguindo as orientações de Galves (2005).

Durante a construção da hierarquia, foi possível identificar com maior precisão o rótulo do problema, que passou a ser: "Determinação da sustentabilidade de ciclovias". O problema foi estruturado por meio da hierarquização dos seguintes níveis:

\footnotetext{
$\checkmark$ Dimensões de sustentabilidade; $1 \mathrm{r}$

$\checkmark$ Características desejáveis e impactos relevantes de ciclovias;

$\checkmark$ Indicadores.
}

A partir destes três níveis, os atributos foram detalhados e organizados em uma hierarquia de itens fundamentais, apresentados na Figura 4.2.

No primeiro nível têm-se as dimensões de sustentabilidade para definir o primeiro nível de análise mais global, de forma a permitir a representação dos conjuntos de indicadores representativos de cada dimensão: ambiental, econômica e social. Desta forma, torna-se possível mensurar o quanto uma ciclovia ou trecho cicloviário possui de sustentabilidade a partir de cada dimensão.

No segundo nível têm-se as características desejáveis e impactos relevantes de ciclovias, com o propósito de representar os objetivos que devem ser medidos para avaliar a sustentabilidade de cada dimensão.

No terceiro nível têm-se os indicadores. A cada item do segundo nível da hierarquia foi associado um ou mais indicadores, para medir o seu desempenho. Desta forma, será possível mensurar se cada impacto ou característica desejável de uma ciclovia está sendo atendida ou não, com o propósito de verificar se uma ciclovia é mais ou menos sustentável a partir de cada dimensão estabelecida. 


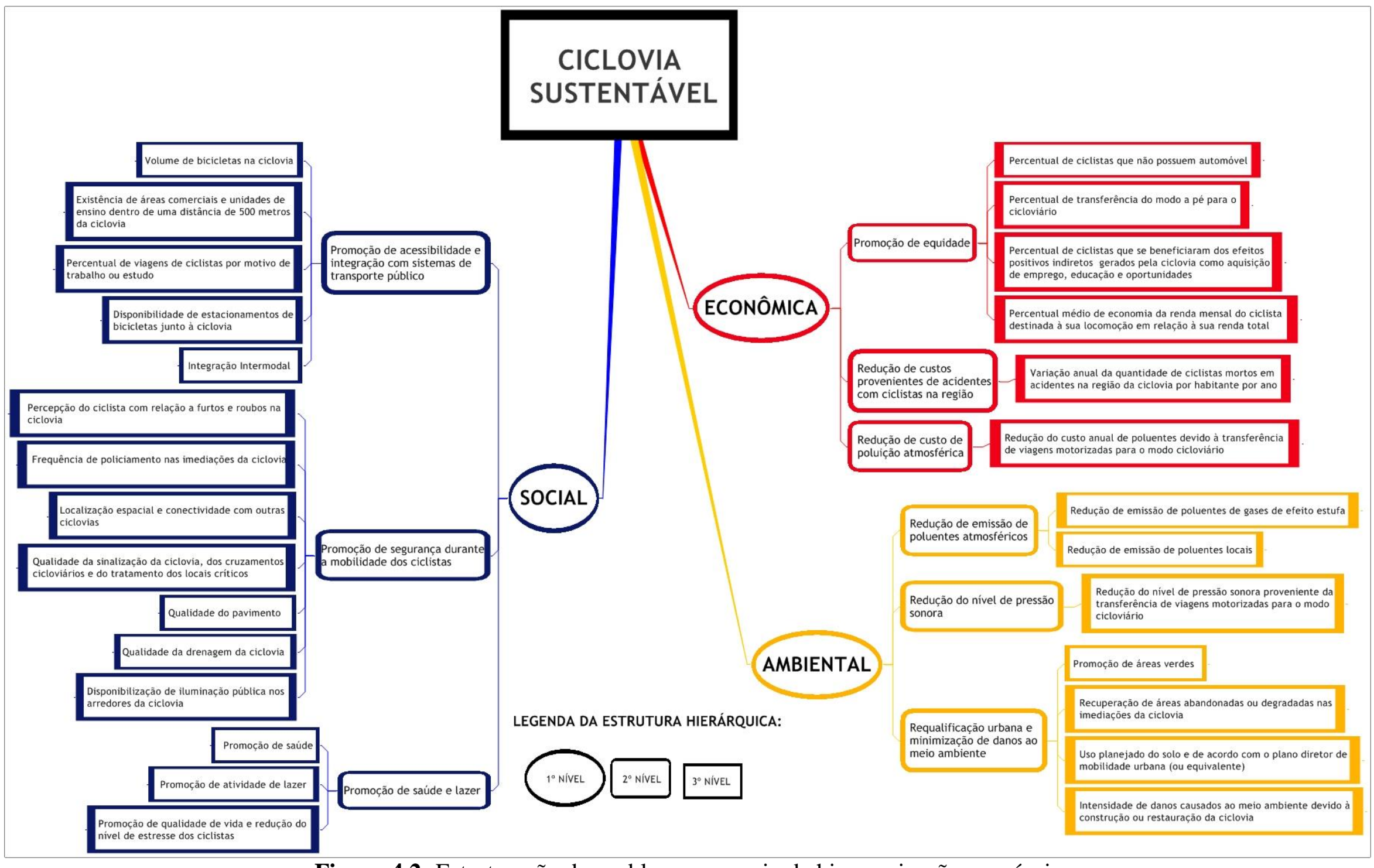

Figura 4.2: Estruturação do problema por meio da hierarquização em níveis 


\subsubsection{Atribuição de Pesos}

Qualquer análise ambiental apresenta caráter complexo, tendo em vista a contemplação da ampla gama de variáveis inter-relacionadas (MOURA et al., 2009). Portanto, há a necessidade de consideração de diferentes visões, resultantes de análises multidisciplinares de especialistas.

Para a segunda etapa da metodologia Função Multiatributo Aditiva, foram selecionados nove especialistas, conhecedores da realidade do objeto em análise, com o propósito de obter um grupo multidisciplinar para viabilizar a integração das opiniões e de diferentes experiências sobre a complexidade das variáveis envolvidas por meio da atribuição de pesos. Foram selecionados três representantes do meio acadêmico, três representantes atuantes na área profissional e três representantes da sociedade civil.

Cabe lembrar que no Capítulo anterior, oito especialistas em mobilidade urbana de nível sênior participaram da análise dos indicadores inicialmente definidos e propuseram refinamentos, com agrupamentos, inclusões e ajustes de redação e descrição.

Como representantes do meio acadêmico foram selecionados três professores da PósGraduação de Transportes da Universidade de Brasília, com doutorado na área, sendo um deles Diretor do Centro Interdisciplinar de Estudos em Transportes da Universidade de Brasília (CEFTRU).

Como representantes atuantes na área profissional foram selecionados três mestres em Engenharia de Transportes: um Diretor da Secretaria Nacional de Transportes e da Mobilidade Urbana do Ministério das Cidades, um representante da Secretaria de Política Nacional de Transportes do Ministério dos Transportes; e um servidor da Companhia de Planejamento do Distrito Federal - CODEPLAN.

Como representantes da sociedade civil, foram selecionados três representantes da sociedade civil: o Presidente da Organização Não Governamental - ONG - Rodas da Paz; o Presidente do Instituto Pedala Brasília de Mobilidade Sustentável; e a Fundadora e Coordenadora da ONG Rebas do Cerrado.

Ao todo, cada especialista atribuiu 40 pesos somando-se todas as variáveis do método. A função do peso é dar a devida relevância à variável em questão de acordo com as preferências e experiência dos especialistas. 
Para cada nível hierárquico foi realizado o cálculo das médias dos especialistas, com o propósito de buscar homogeneizar suas respostas. As médias finais foram ponderadas de acordo com seus pesos, para que ao todo, o método totalizasse $100 \%$.

As Figuras 4.3 a 4.15 foram elaboradas para facilitar o entendimento e a atribuição pelos especialistas dos pesos para cada nível hierárquico.

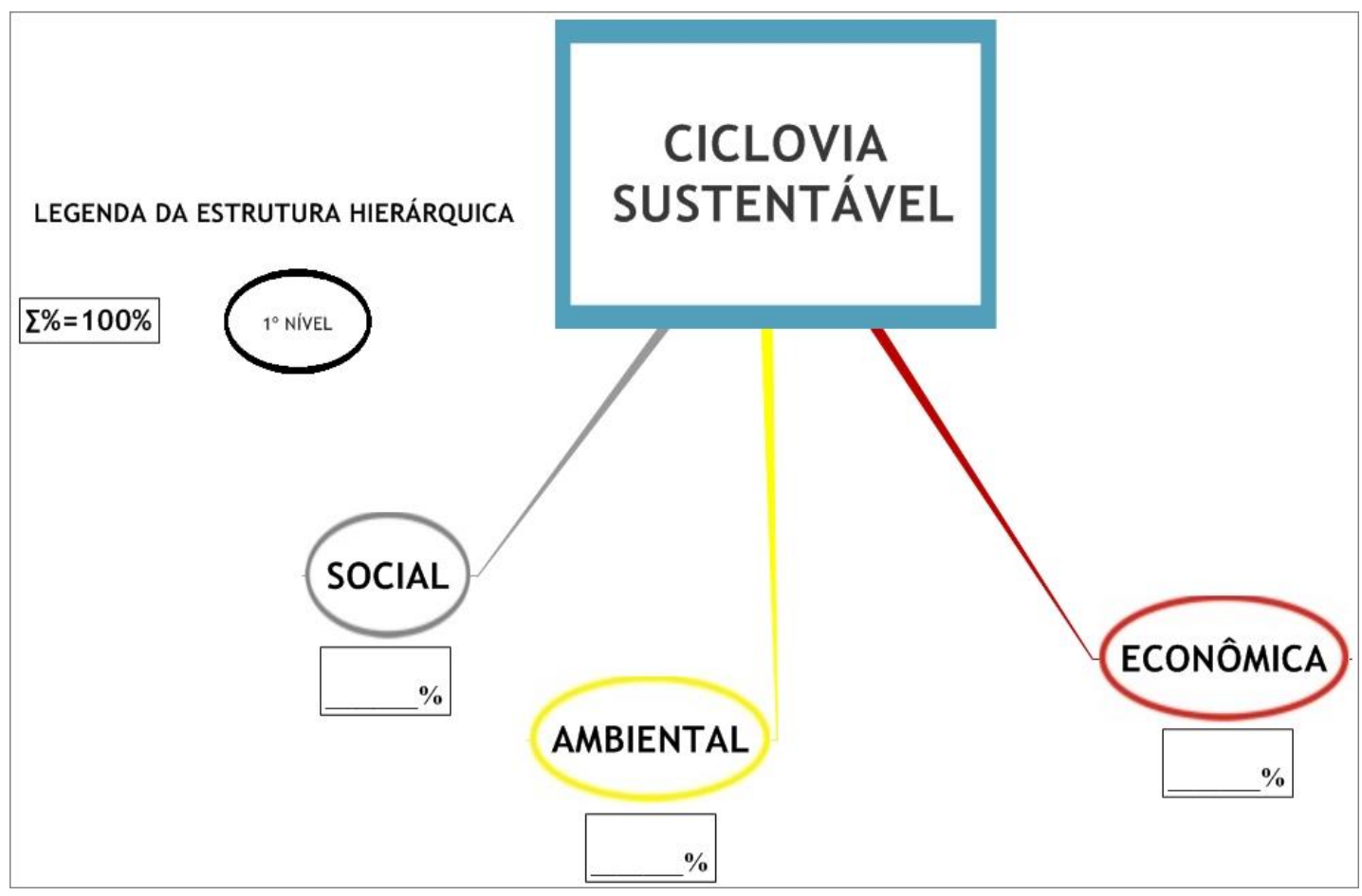

Figura 4.3: Atribuição dos pesos das dimensões de sustentabilidade

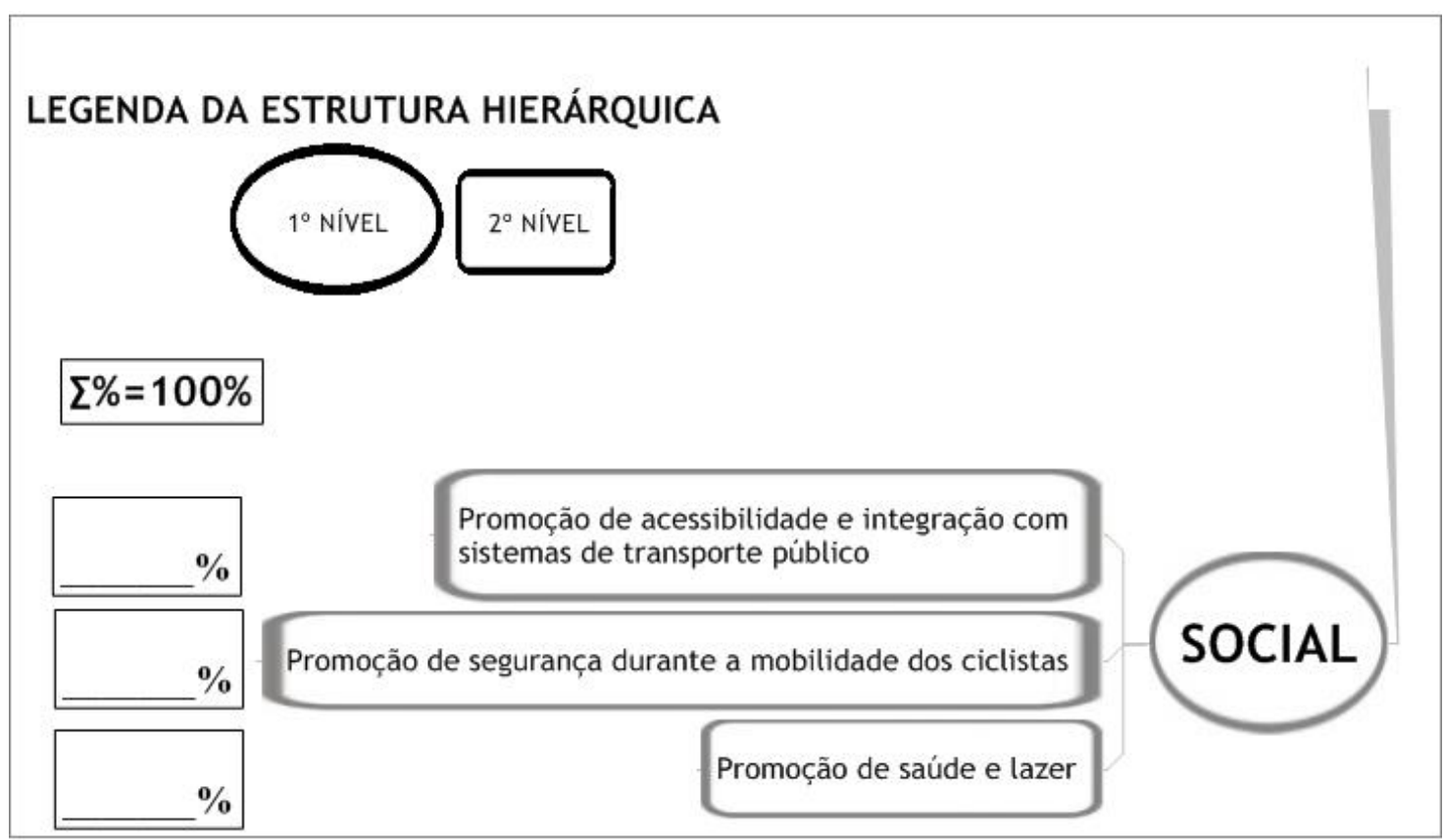

Figura 4.4: Atribuição dos pesos das características desejáveis e impactos relevantes de ciclovias da dimensão social 


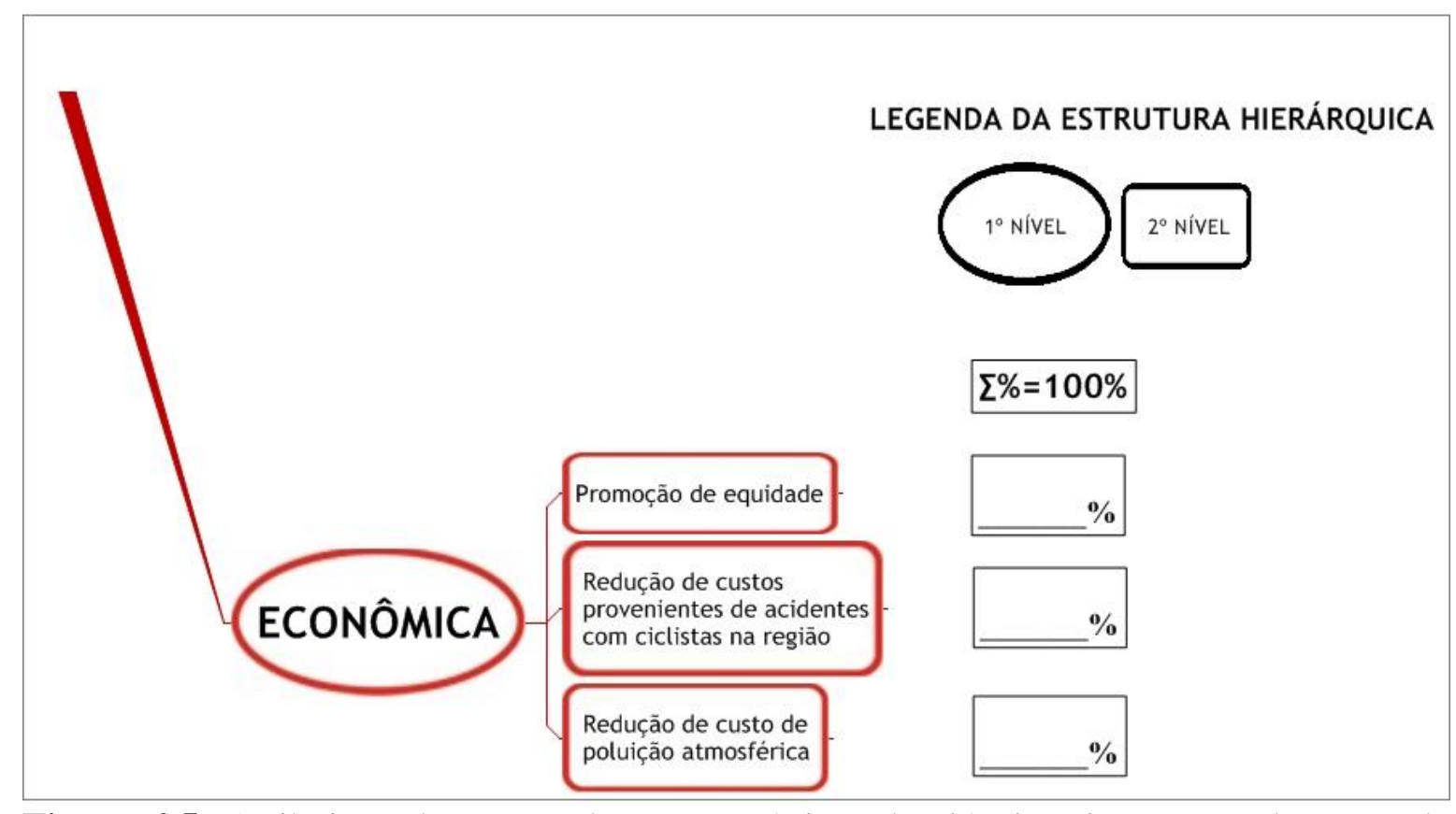

Figura 4.5: Atribuição dos pesos das características desejáveis e impactos relevantes de ciclovias da dimensão econômica

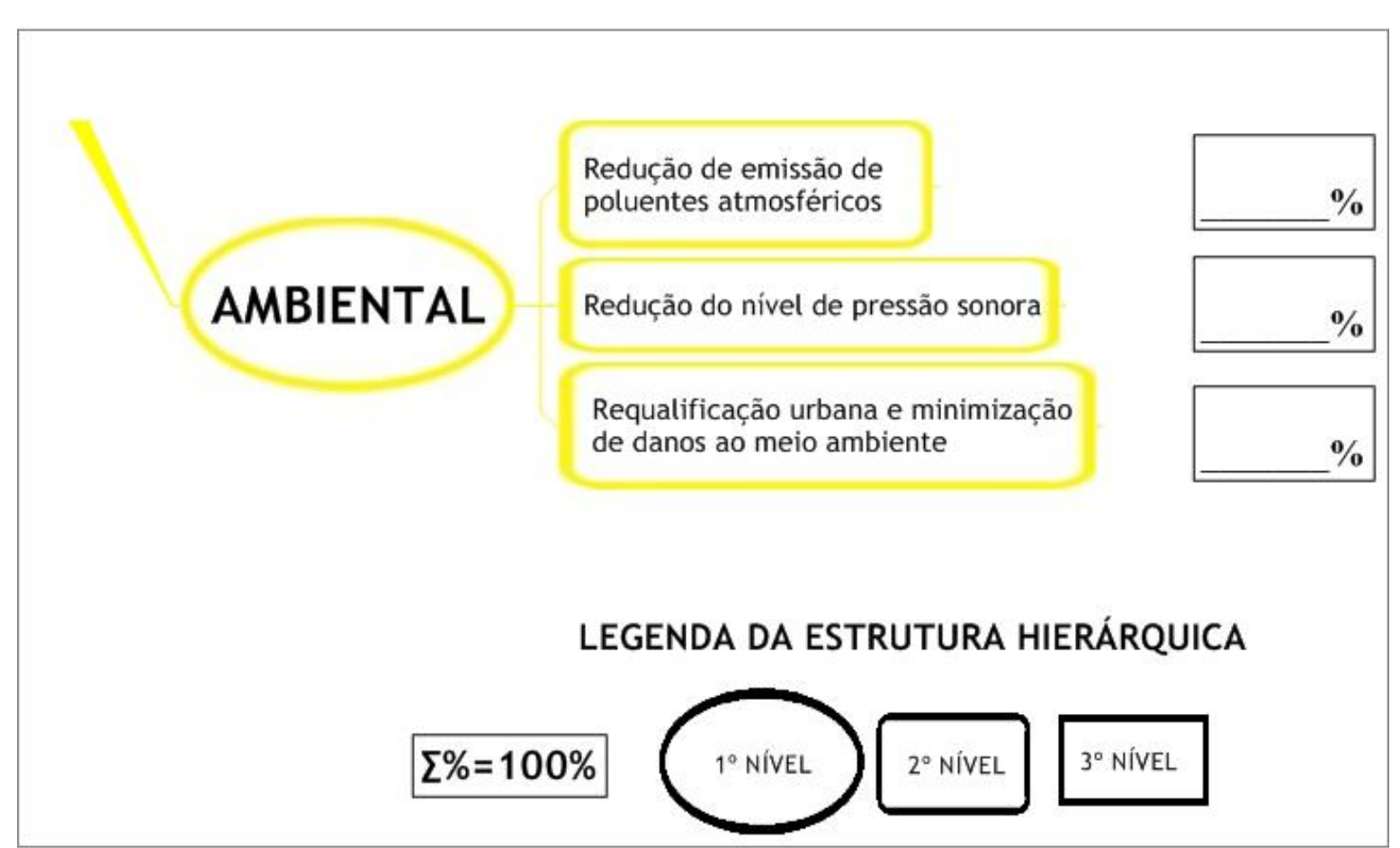

Figura 4.6: Atribuição dos pesos das características desejáveis e impactos relevantes de ciclovias da dimensão ambiental 


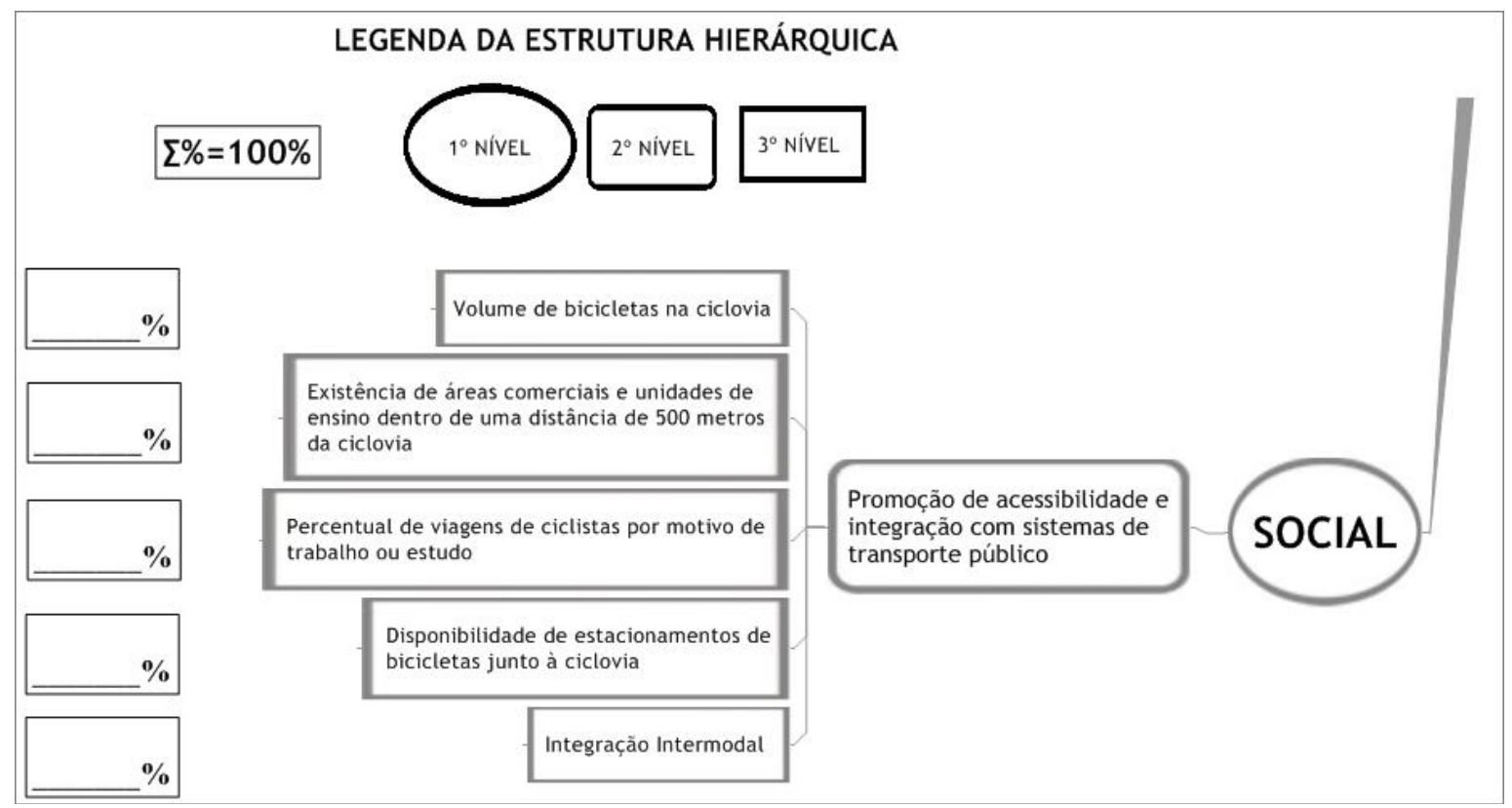

Figura 4.7: Atribuição dos pesos dos indicadores da promoção de acessibilidade e integração com sistemas de transporte público da dimensão social

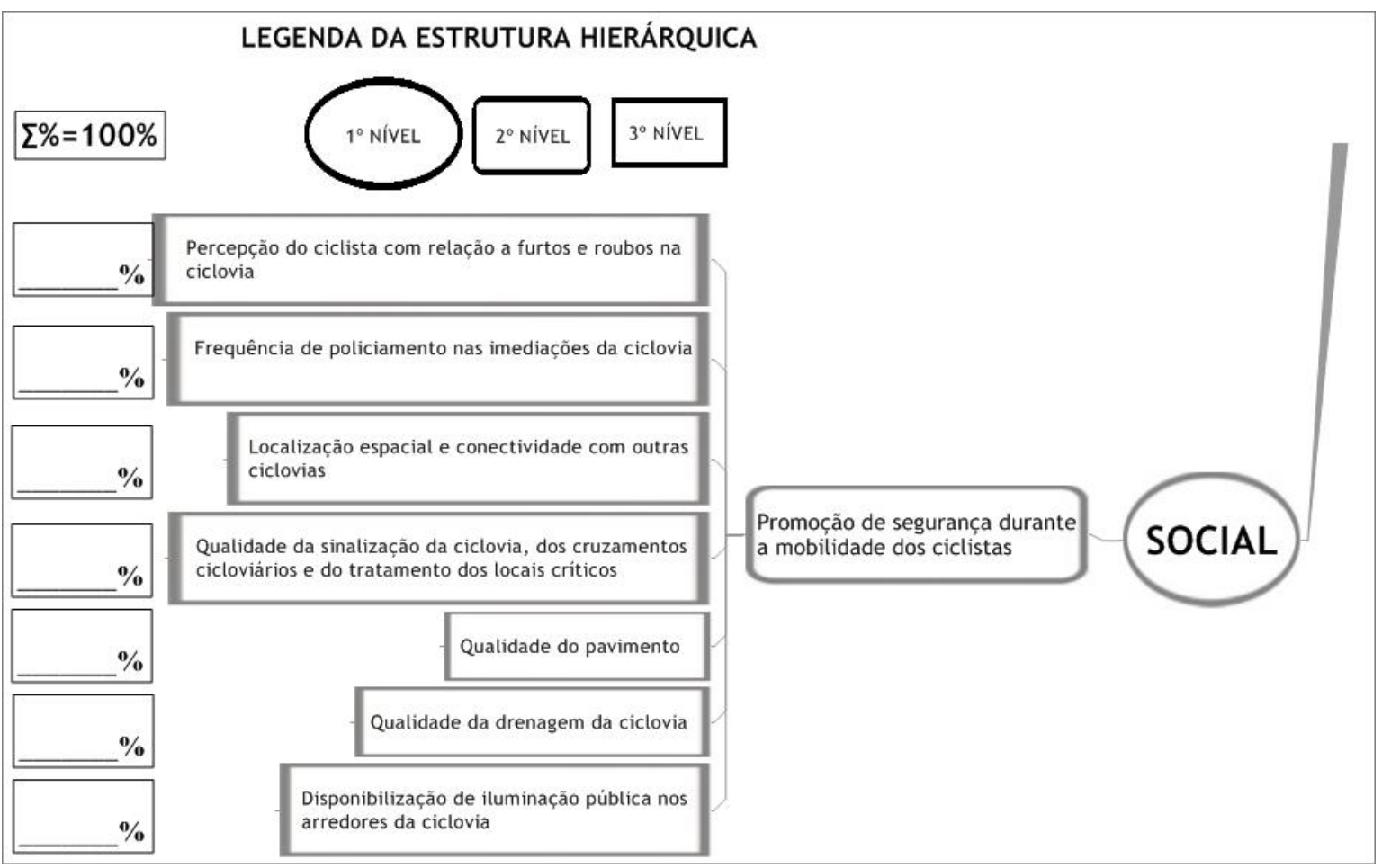

Figura 4.8: Atribuição dos pesos dos indicadores da promoção de segurança durante a mobilidade dos ciclistas da dimensão social 


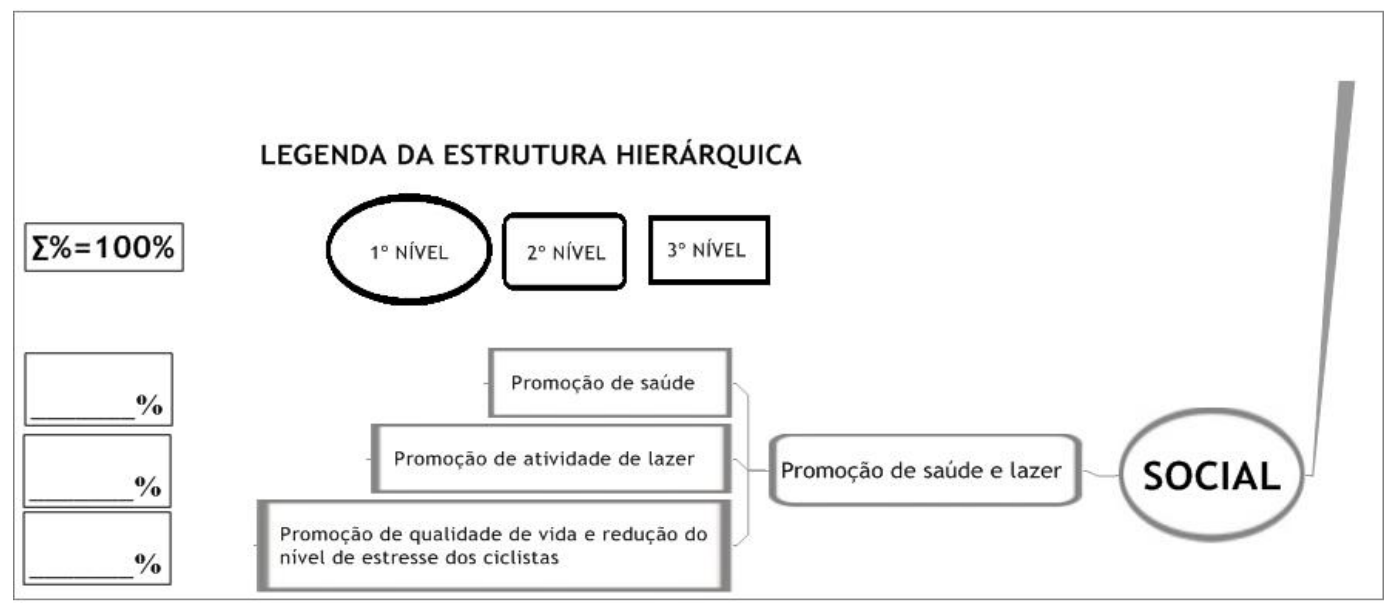

Figura 4.9: Atribuição dos pesos dos indicadores da promoção de saúde e lazer da dimensão social

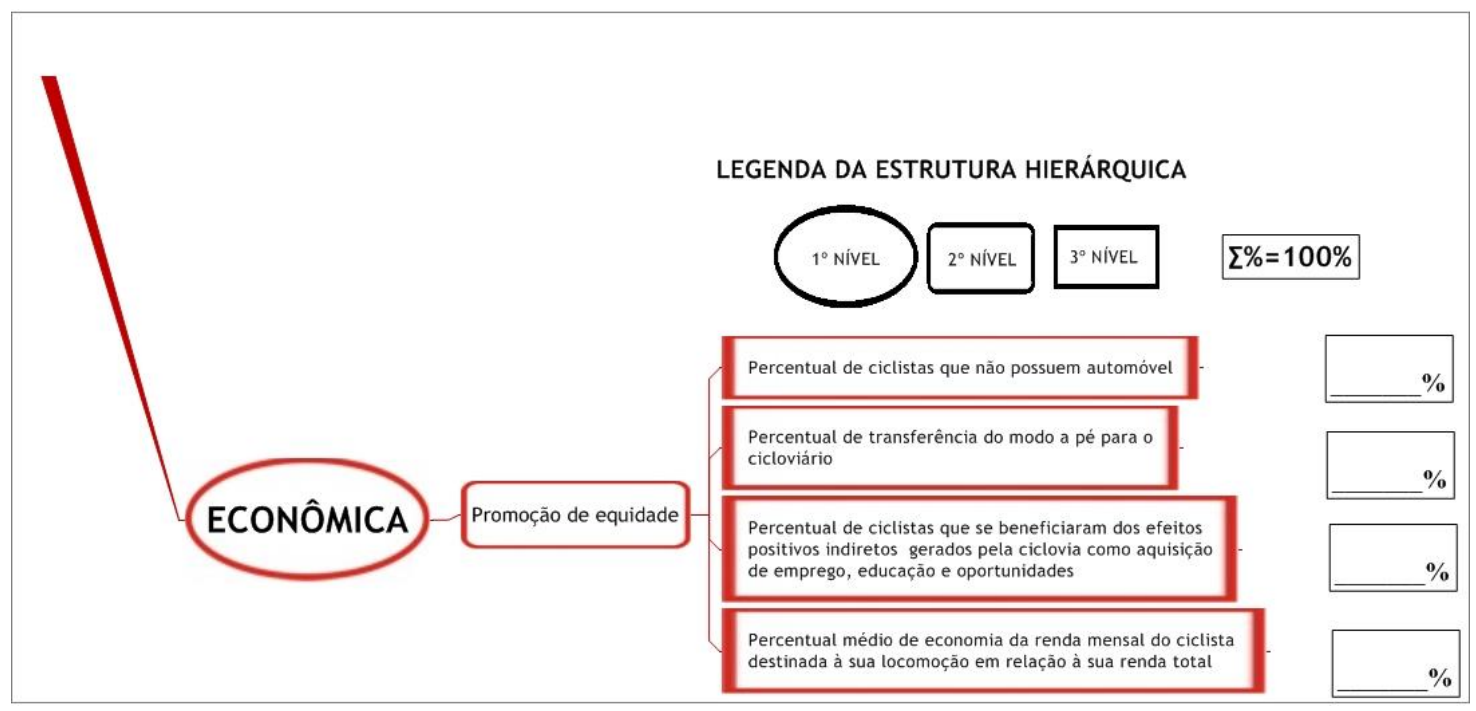

Figura 4.10: Atribuição dos pesos dos indicadores da promoção de equidade da dimensão econômica

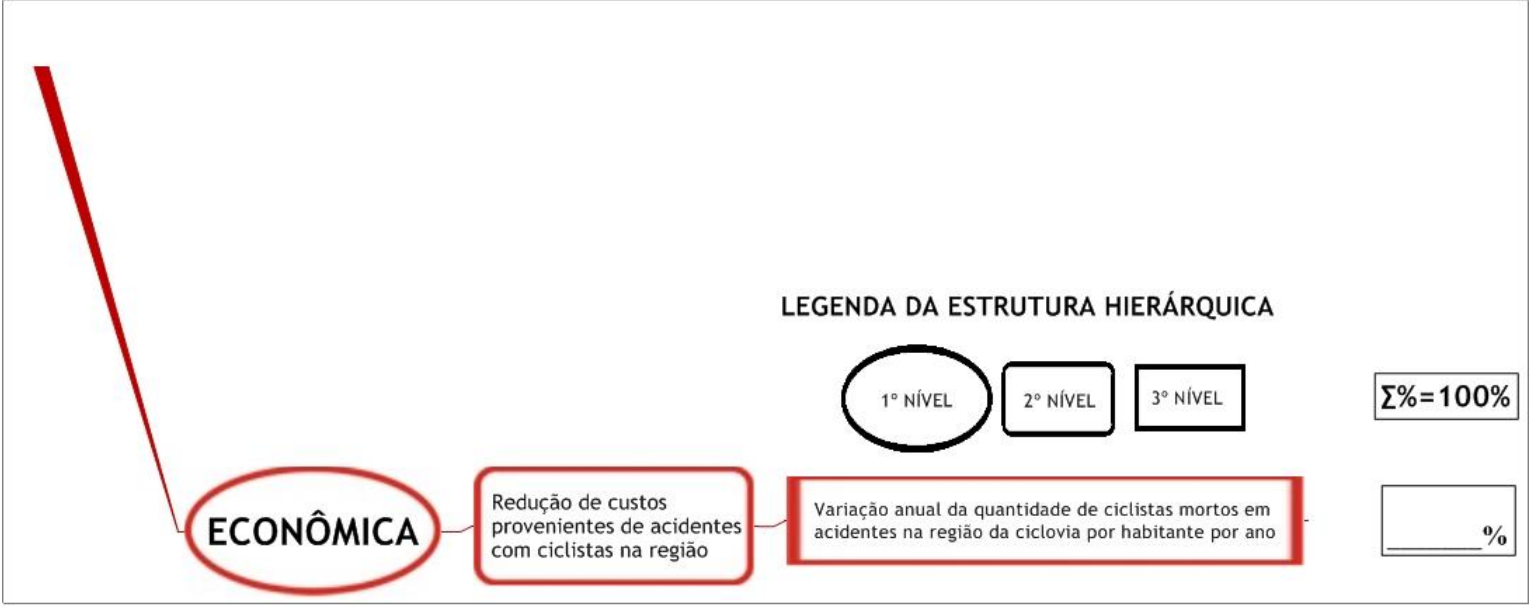

Figura 4.11: Atribuição dos pesos dos indicadores da redução de custos provenientes de acidentes com ciclistas na região da dimensão econômica 


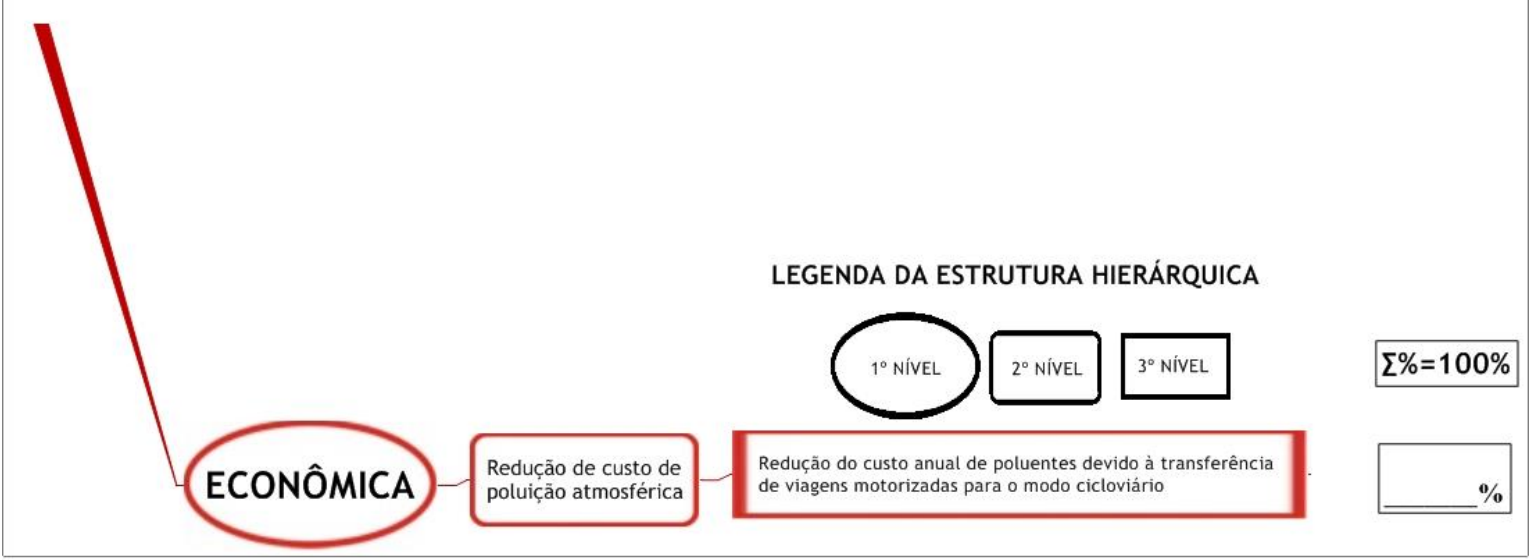

Figura 4.12: Atribuição dos pesos dos indicadores redução de custo de poluição atmosférica da dimensão econômica

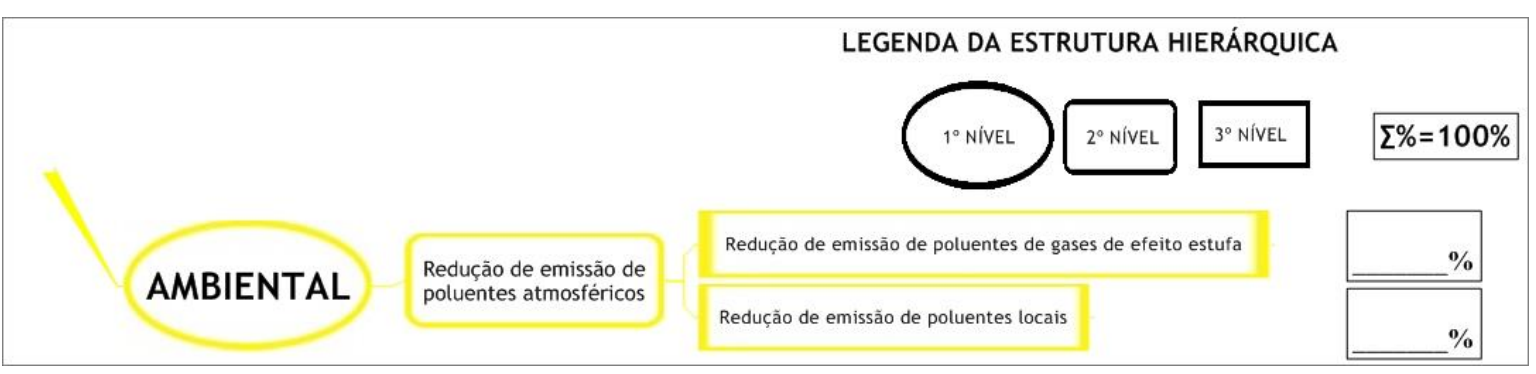

Figura 4.13: Atribuição dos pesos dos indicadores da redução de emissão de poluentes de gases de efeito estufa da dimensão ambiental

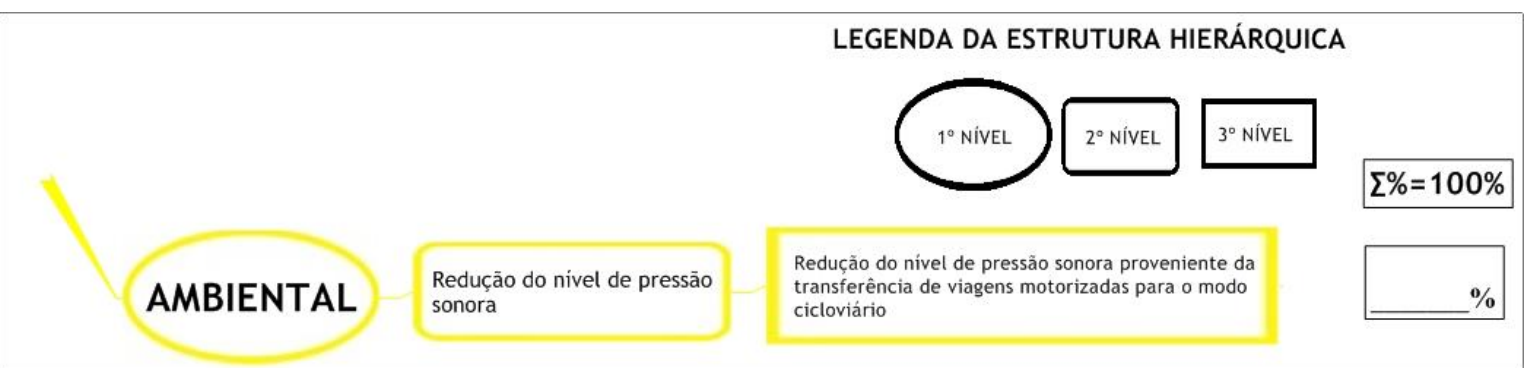

Figura 4.14: Atribuição dos pesos dos indicadores da redução do nível de pressão sonora proveniente da transferência de viagens motorizadas para o modo cicloviário da dimensão ambiental 


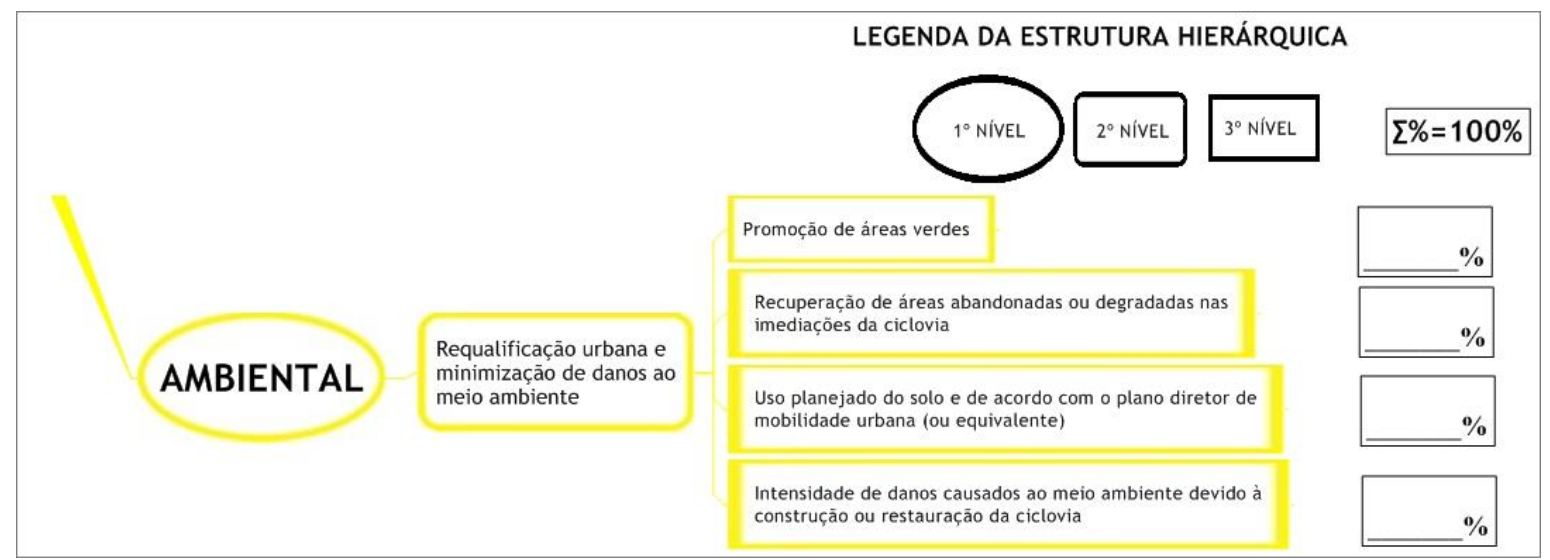

Figura 4.15: Atribuição dos pesos dos indicadores da requalificação urbana e minimização de danos ao meio ambiente da dimensão ambiental

Os graus de importância das variáveis nos três níveis da estrutura hierárquica foram estabelecidos por meio de pesos, atribuídos pelos especialistas. Os valores foram tratados por meio do procedimento de média aritmética, conforme mostram as Tabelas 4.2 a 4.14.

Tabela 4.2: Atribuição dos pesos das dimensões de sustentabilidade pelos especialistas

\begin{tabular}{l|c|c|c|c|c|c|c|c|c|c}
\hline Pesos/Especialistas & $\mathbf{1}$ & $\mathbf{2}$ & $\mathbf{3}$ & $\mathbf{4}$ & $\mathbf{5}$ & $\mathbf{6}$ & $\mathbf{7}$ & $\mathbf{8}$ & $\mathbf{9}$ & Média \\
\hline Social & $40 \%$ & $60 \%$ & $40 \%$ & $40 \%$ & $50 \%$ & $30 \%$ & $33,3 \%$ & $40 \%$ & $20 \%$ & $39,3 \%$ \\
\hline Ambiental & $40 \%$ & $25 \%$ & $35 \%$ & $40 \%$ & $30 \%$ & $30 \%$ & $33,3 \%$ & $35 \%$ & $30 \%$ & $33,1 \%$ \\
\hline Econômica & $20 \%$ & $15 \%$ & $25 \%$ & $20 \%$ & $20 \%$ & $40 \%$ & $33,3 \%$ & $25 \%$ & $50 \%$ & $27,6 \%$ \\
\hline
\end{tabular}

Tabela 4.3: Atribuição dos pesos das características desejáveis e impactos relevantes de ciclovias da dimensão social pelos especialistas

\begin{tabular}{|c|c|c|c|c|c|c|c|c|c|c|}
\hline Pesos/Especialistas & 1 & 2 & 3 & 4 & 5 & 6 & 7 & 8 & 9 & Média \\
\hline $\begin{array}{lr}\text { Promoção } & \text { de } \\
\text { acessibilidade } & \mathrm{e} \\
\text { integração } & \text { com } \\
\text { sistemas de transporte } \\
\text { público }\end{array}$ & $40 \%$ & $40 \%$ & $30 \%$ & $30 \%$ & $30 \%$ & $60 \%$ & $30 \%$ & $30 \%$ & $70 \%$ & $40,0 \%$ \\
\hline $\begin{array}{lr}\text { Promoção } & \text { de } \\
\text { segurança durante a } \\
\text { mobilidade dos } \\
\text { ciclistas }\end{array}$ & $40 \%$ & $50 \%$ & $40 \%$ & $40 \%$ & $50 \%$ & $25 \%$ & $60 \%$ & $50 \%$ & $20 \%$ & $41,7 \%$ \\
\hline $\begin{array}{l}\text { Promoção de saúde e } \\
\text { lazer }\end{array}$ & $20 \%$ & $10 \%$ & $30 \%$ & $30 \%$ & $20 \%$ & $15 \%$ & $10 \%$ & $20 \%$ & $10 \%$ & $18,3 \%$ \\
\hline
\end{tabular}


Tabela 4.4: Atribuição dos pesos das características desejáveis e impactos relevantes de ciclovias da dimensão econômica pelos especialistas

\begin{tabular}{l|c|c|c|c|c|c|c|c|c|c}
\hline Pesos/Especialistas & $\mathbf{1}$ & $\mathbf{2}$ & $\mathbf{3}$ & $\mathbf{4}$ & $\mathbf{5}$ & $\mathbf{6}$ & $\mathbf{7}$ & $\mathbf{8}$ & $\mathbf{9}$ & Média \\
\hline $\begin{array}{l}\text { Promoção de } \\
\text { equidade }\end{array}$ & $40 \%$ & $65 \%$ & $25 \%$ & $40 \%$ & $35 \%$ & $20 \%$ & $60 \%$ & $10 \%$ & $30 \%$ & $36,1 \%$ \\
\hline $\begin{array}{l}\text { Redução de custos } \\
\text { provenientes de } \\
\text { acidentes com } \\
\text { ciclistas na região }\end{array}$ & $30 \%$ & $25 \%$ & $50 \%$ & $30 \%$ & $50 \%$ & $40 \%$ & $20 \%$ & $50 \%$ & $30 \%$ & $36,1 \%$ \\
\hline $\begin{array}{l}\text { Redução de custo } \\
\text { de poluição } \\
\text { atmosférica }\end{array}$ & $30 \%$ & $10 \%$ & $25 \%$ & $30 \%$ & $15 \%$ & $40 \%$ & $20 \%$ & $40 \%$ & $40 \%$ & $27,8 \%$ \\
\hline
\end{tabular}

Tabela 4.5: Atribuição dos pesos das características desejáveis e impactos relevantes de ciclovias da dimensão ambiental pelos especialistas

\begin{tabular}{l|c|c|c|c|c|c|c|c|c|c}
\hline Pesos/Especialistas & $\mathbf{1}$ & $\mathbf{2}$ & $\mathbf{3}$ & $\mathbf{4}$ & $\mathbf{5}$ & $\mathbf{6}$ & $\mathbf{7}$ & $\mathbf{8}$ & $\mathbf{9}$ & Média \\
\hline $\begin{array}{l}\text { Redução de emissão } \\
\text { pe poluentes } \\
\text { atmosféricos }\end{array}$ & $70 \%$ & $40 \%$ & $33,33 \%$ & $30 \%$ & $25 \%$ & $30 \%$ & $35 \%$ & $50 \%$ & $40 \%$ & $39,3 \%$ \\
\hline $\begin{array}{l}\text { Redução do nível de } \\
\text { pressão sonora }\end{array}$ & $10 \%$ & $10 \%$ & $33,33 \%$ & $20 \%$ & $25 \%$ & $10 \%$ & $25 \%$ & $20 \%$ & $20 \%$ & $19,3 \%$ \\
\hline $\begin{array}{l}\text { Requalificação } \\
\text { urbana } \\
\text { minimização de } \\
\text { danos ao meio } \\
\text { ambiente }\end{array}$ & $20 \%$ & $50 \%$ & $33,33 \%$ & $50 \%$ & $50 \%$ & $60 \%$ & $40 \%$ & $30 \%$ & $40 \%$ & $41,4 \%$ \\
\hline
\end{tabular}

Tabela 4.6: Atribuição dos pesos dos indicadores da promoção de acessibilidade e integração com sistemas de transporte público da dimensão social pelos especialistas

\begin{tabular}{l|c|c|c|c|c|c|c|c|c|c}
\hline \multicolumn{1}{c}{ Pesos/Especialistas } & $\mathbf{1}$ & $\mathbf{2}$ & $\mathbf{3}$ & $\mathbf{4}$ & $\mathbf{5}$ & $\mathbf{6}$ & $\mathbf{7}$ & $\mathbf{8}$ & $\mathbf{9}$ & Média \\
\hline $\begin{array}{l}\text { Volume de bicicletas na } \\
\text { ciclovia }\end{array}$ & $40 \%$ & $10 \%$ & $30 \%$ & $10 \%$ & $10 \%$ & $10 \%$ & $15 \%$ & $40 \%$ & $20 \%$ & $20,6 \%$ \\
\hline $\begin{array}{l}\text { Existência de áreas } \\
\text { comerciais e unidades de } \\
\text { ensino dentro de uma } \\
\text { distância de 500 metros } \\
\text { da ciclovia }\end{array}$ & $10 \%$ & $10 \%$ & $20 \%$ & $10 \%$ & $40 \%$ & $25 \%$ & $20 \%$ & $15 \%$ & $15 \%$ & $18,3 \%$ \\
\hline $\begin{array}{l}\text { Percentual de viagens de } \\
\text { ciclistas por motivo de } \\
\text { trabalho ou estudo }\end{array}$ & $10 \%$ & $30 \%$ & $20 \%$ & $24 \%$ & $30 \%$ & $25 \%$ & $30 \%$ & $15 \%$ & $25 \%$ & $23,2 \%$ \\
\hline $\begin{array}{l}\text { Disponibilidade de } \\
\text { estacionamentos de } \\
\text { bicicletas junto à } \\
\text { ciclovia }\end{array}$ & $20 \%$ & $20 \%$ & $10 \%$ & $26 \%$ & $10 \%$ & $10 \%$ & $15 \%$ & $15 \%$ & $15 \%$ & $15,7 \%$ \\
\hline Integração intermodal & $20 \%$ & $30 \%$ & $20 \%$ & $30 \%$ & $10 \%$ & $30 \%$ & $20 \%$ & $15 \%$ & $25 \%$ & $22,2 \%$ \\
\hline
\end{tabular}


Tabela 4.7: Atribuição dos pesos dos indicadores da promoção de segurança durante a mobilidade dos ciclistas da dimensão social pelos especialistas

\begin{tabular}{l|c|c|c|c|c|c|c|c|c|c}
\hline \multicolumn{1}{c|}{ Pesos/Especialistas } & $\mathbf{1}$ & $\mathbf{2}$ & $\mathbf{3}$ & $\mathbf{4}$ & $\mathbf{5}$ & $\mathbf{6}$ & $\mathbf{7}$ & $\mathbf{8}$ & $\mathbf{9}$ & Média \\
\hline $\begin{array}{l}\text { Percepção do ciclista } \\
\text { com relação a furtos e } \\
\text { roubos na ciclovia }\end{array}$ & $10 \%$ & $10 \%$ & $25 \%$ & $12 \%$ & $5 \%$ & $20 \%$ & $10 \%$ & $10 \%$ & $10 \%$ & $12,4 \%$ \\
\hline $\begin{array}{l}\text { Frequência de } \\
\text { policiamento nas } \\
\text { imediações da ciclovia }\end{array}$ & $10 \%$ & $20 \%$ & $15 \%$ & $12 \%$ & $5 \%$ & $20 \%$ & $10 \%$ & $10 \%$ & $10 \%$ & $12,4 \%$ \\
\hline $\begin{array}{l}\text { Localização espacial e } \\
\text { conectividade com } \\
\text { outras ciclovias }\end{array}$ & $10 \%$ & $15 \%$ & $10 \%$ & $16 \%$ & $30 \%$ & $10 \%$ & $20 \%$ & $30 \%$ & $10 \%$ & $16,8 \%$ \\
\hline $\begin{array}{l}\text { Qualidade da sinalização } \\
\text { ciclovia, dos } \\
\text { cruzamentos } \\
\text { cicloviários e do } \\
\text { tratamento dos locais } \\
\text { críticos }\end{array}$ & $30 \%$ & $20 \%$ & $5 \%$ & $20 \%$ & $5 \%$ & $20 \%$ & $25 \%$ & $30 \%$ & $30 \%$ & $20,6 \%$ \\
\hline $\begin{array}{l}\text { Qualidade do pavimento } \\
\text { da ciclovia }\end{array}$ & $20 \%$ & $10 \%$ & $15 \%$ & $18 \%$ & $5 \%$ & $5 \%$ & $10 \%$ & $5 \%$ & $20 \%$ & $12,0 \%$ \\
\hline $\begin{array}{l}\text { Qualidade da drenagem } \\
\text { da ciclovia }\end{array}$ & $10 \%$ & $10 \%$ & $5 \%$ & $6 \%$ & $30 \%$ & $5 \%$ & $10 \%$ & $5 \%$ & $5 \%$ & $9,6 \%$ \\
\hline $\begin{array}{l}\text { Disponibilidade de } \\
\text { iluminação pública nos } \\
\text { arredores da ciclovia }\end{array}$ & $10 \%$ & $15 \%$ & $25 \%$ & $16 \%$ & $20 \%$ & $20 \%$ & $15 \%$ & $10 \%$ & $15 \%$ & $16,2 \%$ \\
\hline
\end{tabular}

Tabela 4.8: Atribuição dos pesos dos indicadores da promoção de saúde e lazer da dimensão social pelos especialistas

\begin{tabular}{l|c|c|c|c|c|c|c|c|c|c}
\hline \multicolumn{1}{c}{ Pesos/Especialistas } & $\mathbf{1}$ & $\mathbf{2}$ & $\mathbf{3}$ & $\mathbf{4}$ & $\mathbf{5}$ & $\mathbf{6}$ & $\mathbf{7}$ & $\mathbf{8}$ & $\mathbf{9}$ & Média \\
\hline Promoção de saúde & $30 \%$ & $15 \%$ & $30 \%$ & $25 \%$ & $30 \%$ & $20 \%$ & $40 \%$ & $25 \%$ & $40 \%$ & $28,3 \%$ \\
\hline $\begin{array}{l}\text { Promoção de atividade } \\
\text { de lazer }\end{array}$ & $30 \%$ & $25 \%$ & $30 \%$ & $25 \%$ & $30 \%$ & $20 \%$ & $10 \%$ & $25 \%$ & $40 \%$ & $26,1 \%$ \\
\hline $\begin{array}{l}\text { Promoção de qualidade } \\
\text { de vida e redução do } \\
\text { nível de estresse dos } \\
\text { ciclistas }\end{array}$ & $40 \%$ & $60 \%$ & $40 \%$ & $50 \%$ & $40 \%$ & $60 \%$ & $50 \%$ & $50 \%$ & $20 \%$ & $45,6 \%$ \\
\hline
\end{tabular}


Tabela 4.9: Atribuição dos pesos dos indicadores da promoção de equidade da dimensão econômica pelos especialistas

\begin{tabular}{l|c|c|c|c|c|c|c|c|c|c}
\hline \multicolumn{1}{c|}{ Pesos/Especialistas } & $\mathbf{1}$ & $\mathbf{2}$ & $\mathbf{3}$ & $\mathbf{4}$ & $\mathbf{5}$ & $\mathbf{6}$ & $\mathbf{7}$ & $\mathbf{8}$ & $\mathbf{9}$ & Média \\
\hline $\begin{array}{l}\text { Percentual de ciclistas } \\
\text { que não possuem } \\
\text { veículo particular }\end{array}$ & $25 \%$ & $10 \%$ & $20 \%$ & $15 \%$ & $30 \%$ & $5 \%$ & $20 \%$ & $10 \%$ & $30 \%$ & $18,3 \%$ \\
\hline $\begin{array}{l}\text { Percentual de } \\
\text { transferências do modo a } \\
\text { pé para o cicloviário }\end{array}$ & $25 \%$ & $20 \%$ & $20 \%$ & $15 \%$ & $40 \%$ & $20 \%$ & $20 \%$ & $10 \%$ & $20 \%$ & $21,1 \%$ \\
\hline $\begin{array}{l}\text { Percentual de ciclistas } \\
\text { que se beneficiaram dos } \\
\text { efeitos positivos } \\
\text { indiretos gerados pela } \\
\text { ciclovia como aquisição } \\
\text { de emprego, educação e } \\
\text { outras oportunidades }\end{array}$ & $25 \%$ & $30 \%$ & $30 \%$ & $10 \%$ & $10 \%$ & $35 \%$ & $20 \%$ & $40 \%$ & $20 \%$ & $24,5 \%$ \\
\hline $\begin{array}{l}\text { Percentual de ciclistas } \\
\text { que obtiveram redução } \\
\text { de gastos devido à } \\
\text { utilização da ciclovia }\end{array}$ & $25 \%$ & $40 \%$ & $30 \%$ & $60 \%$ & $20 \%$ & $40 \%$ & $40 \%$ & $40 \%$ & $30 \%$ & $36,1 \%$ \\
\hline
\end{tabular}

Tabela 4.10: Atribuição dos pesos dos indicadores da redução de custos provenientes de acidentes com ciclistas na região da dimensão econômica pelos especialistas

\begin{tabular}{l|c|c|c|c|c|c|c|c|c|c}
\hline Pesos/Especialistas & $\mathbf{1}$ & $\mathbf{2}$ & $\mathbf{3}$ & $\mathbf{4}$ & $\mathbf{5}$ & $\mathbf{6}$ & $\mathbf{7}$ & $\mathbf{8}$ & $\mathbf{9}$ & Média \\
\hline $\begin{array}{l}\text { Variação anual da } \\
\text { quantidade de } \\
\text { ciclistas mortos em } \\
\text { acidentes na região } \\
\text { da ciclovia por } \\
\text { habitante por ano }\end{array}$ & $100 \%$ & $100 \%$ & $100 \%$ & $100 \%$ & $100 \%$ & $100 \%$ & $100 \%$ & $100 \%$ & $100 \%$ & $100 \%$ \\
\hline
\end{tabular}

Tabela 4.11: Atribuição dos pesos dos indicadores da redução de custos de poluição atmosférica da dimensão econômica pelos especialistas

\begin{tabular}{l|c|c|c|c|c|c|c|c|c|c}
\hline Pesos/Especialistas & $\mathbf{1}$ & $\mathbf{2}$ & $\mathbf{3}$ & $\mathbf{4}$ & $\mathbf{5}$ & $\mathbf{6}$ & $\mathbf{7}$ & $\mathbf{8}$ & $\mathbf{9}$ & Média \\
\hline $\begin{array}{l}\text { Redução de custo } \\
\text { anual de poluentes } \\
\text { devido à } \\
\text { transferência de }\end{array}$ & $100 \%$ & $100 \%$ & $100 \%$ & $100 \%$ & $100 \%$ & $100 \%$ & $100 \%$ & $100 \%$ & $100 \%$ & $100 \%$ \\
viagens motorizadas \\
para o modo \\
cicloviário
\end{tabular}


Tabela 4.12: Atribuição dos pesos dos indicadores da redução de emissão de poluentes de gases de efeito estufa da dimensão ambiental pelos especialistas

\begin{tabular}{l|c|c|c|c|c|c|c|c|c|c}
\hline \multicolumn{1}{c|}{ Pesos/Especialistas } & $\mathbf{1}$ & $\mathbf{2}$ & $\mathbf{3}$ & $\mathbf{4}$ & $\mathbf{5}$ & $\mathbf{6}$ & $\mathbf{7}$ & $\mathbf{8}$ & $\mathbf{9}$ & Média \\
\hline $\begin{array}{l}\text { Redução de emissão de } \\
\text { poluentes de gases de } \\
\text { efeito estufa }\end{array}$ & $50 \%$ & $30 \%$ & $50 \%$ & $50 \%$ & $50 \%$ & $40 \%$ & $50 \%$ & $40 \%$ & $30 \%$ & $43,3 \%$ \\
\hline $\begin{array}{l}\text { Redução de emissão de } \\
\text { poluentes locais }\end{array}$ & $50 \%$ & $70 \%$ & $50 \%$ & $50 \%$ & $50 \%$ & $60 \%$ & $50 \%$ & $60 \%$ & $70 \%$ & $56,7 \%$ \\
\hline
\end{tabular}

Tabela 4.13: Atribuição dos pesos dos indicadores da redução do nível de pressão sonora proveniente da transferência de viagens motorizadas para o modo cicloviário da dimensão ambiental pelos especialistas

\begin{tabular}{l|c|c|c|c|c|c|c|c|c|c}
\hline Pesos/Especialistas & $\mathbf{1}$ & $\mathbf{2}$ & $\mathbf{3}$ & $\mathbf{4}$ & $\mathbf{5}$ & $\mathbf{6}$ & $\mathbf{7}$ & $\mathbf{8}$ & $\mathbf{9}$ & Média \\
\hline $\begin{array}{l}\text { Redução do nível de } \\
\text { pressão sonora } \\
\text { proveniente da } \\
\text { transferência de } \\
\text { viagens motorizadas } \\
\text { para o modo } \\
\text { cicloviário }\end{array}$ & & & & & & & & & & \\
\hline
\end{tabular}

Tabela 4.14: Atribuição dos pesos dos indicadores da requalificação urbana e minimização de danos ao meio ambiente da dimensão ambiental pelos especialistas

\begin{tabular}{l|c|c|c|c|c|c|c|c|c|c}
\hline \multicolumn{1}{c|}{ Pesos/Especialistas } & $\mathbf{1}$ & $\mathbf{2}$ & $\mathbf{3}$ & $\mathbf{4}$ & $\mathbf{5}$ & $\mathbf{6}$ & $\mathbf{7}$ & $\mathbf{8}$ & $\mathbf{9}$ & Média \\
\hline $\begin{array}{l}\text { Promoção de áreas } \\
\text { verdes }\end{array}$ & $40 \%$ & $25 \%$ & $25 \%$ & $20 \%$ & $10 \%$ & $5 \%$ & $20 \%$ & $20 \%$ & $10 \%$ & $19,4 \%$ \\
\hline $\begin{array}{l}\text { Qualidade das áreas nas } \\
\text { imediações da ciclovia } \\
\text { em termos de não } \\
\text { abandono degradação }\end{array}$ & $15 \%$ & $25 \%$ & $25 \%$ & $30 \%$ & $30 \%$ & $20 \%$ & $20 \%$ & $20 \%$ & $20 \%$ & $22,8 \%$ \\
\hline $\begin{array}{l}\text { Compatibilidade da } \\
\text { ciclovia com o uso e } \\
\text { ocupação do solo e com } \\
\text { a legislação em vigor }\end{array}$ & $40 \%$ & $40 \%$ & $25 \%$ & $30 \%$ & $50 \%$ & $60 \%$ & $50 \%$ & $50 \%$ & $40 \%$ & $42,8 \%$ \\
\hline $\begin{array}{l}\text { Intensidade de danos } \\
\text { causados ao meio } \\
\text { ambiente devido à } \\
\text { construção } \\
\text { restauração da ciclovia }\end{array}$ & $5 \%$ & $10 \%$ & $25 \%$ & $20 \%$ & $10 \%$ & $15 \%$ & $10 \%$ & $10 \%$ & $30 \%$ & $15 \%$ \\
\hline
\end{tabular}

As médias dos pesos atribuídos pelos especialistas são definidas como constantes de escala, conforme define Bocca (2012): "no método de agregação aditiva, as constantes de escala são "fatores de ponderação" que permitem sintetizar os desempenhos obtidos em cada atributo, por uma dada alternativa (ação potencial), em um único valor global. Dessa forma, as alternativas tornam-se comparáveis por meio de seus valores globais”.

Ensslin et al. (2000) definem constantes de escala como parâmetros que os decisores julgam adequados para agregar, de forma compensatória, desempenhos locais nos critérios em um desempenho global. 
Diante do exposto e dos pesos atribuídos pelos especialistas, a Figura 4.16 apresenta o peso final de cada variável, ou seja, as constantes de escala utilizadas na construção da função de valor, que agrega todos os indicadores do método considerando-se a percentagem de $100 \%$ para o método como um todo. 


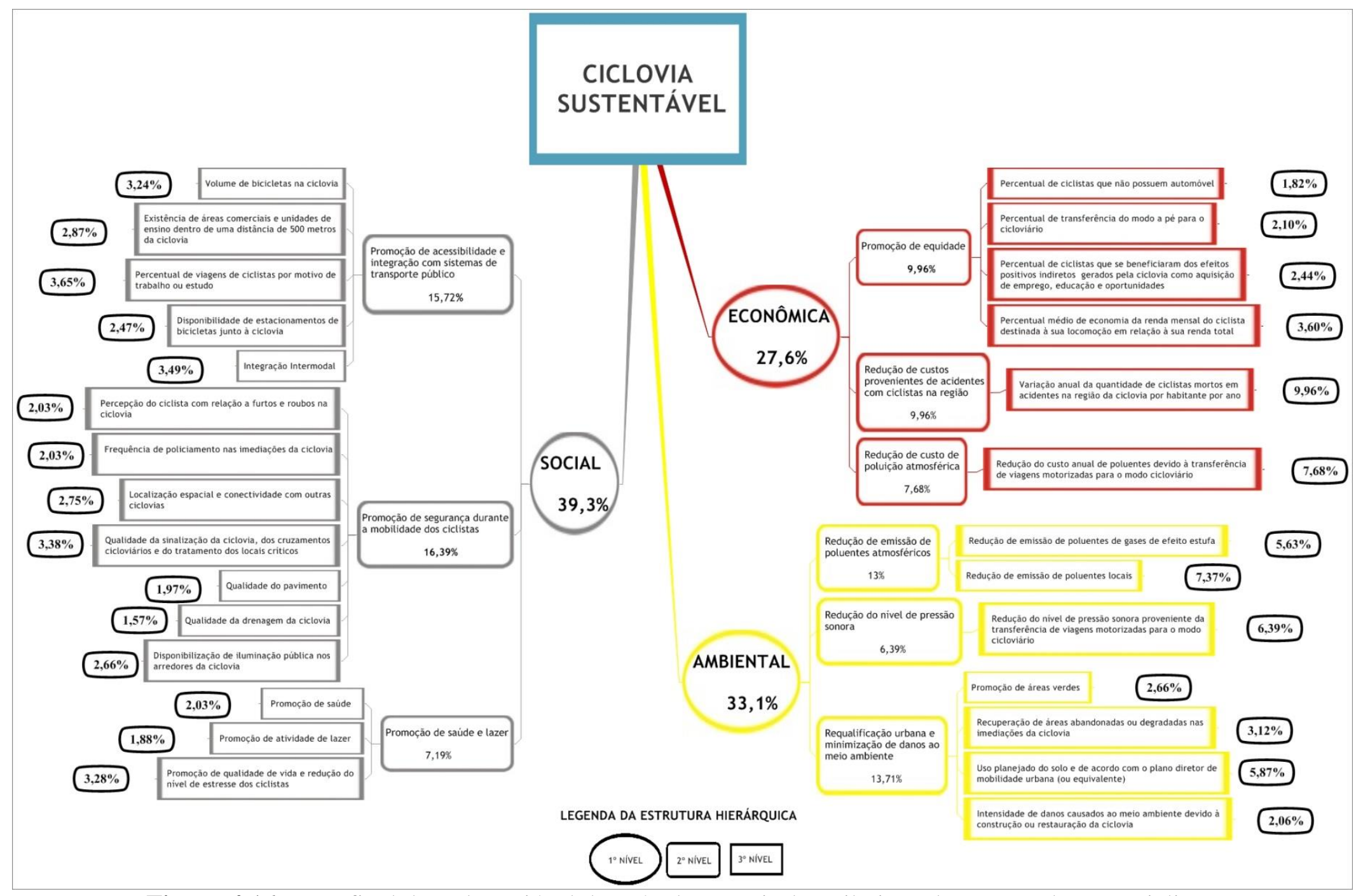

Figura 4.16: Peso final de cada variável do método a partir da atribuição de pesos pelos especialistas 


\subsubsection{Função de Valor para a Mensuração da Mobilidade Sustentável em Ciclovias}

De acordo com Violato et al. (2011), uma função de valor é considerada um instrumento matemático para auxiliar a articulação das preferências dos especialistas.

De forma simplificada, o método de agregação utilizado para elaborar o método da Função de Valor Multiatributo na Forma Aditiva pode ser expresso pela Equação 4.1 (VIOLATO et al., 2012):

$$
V=w_{1} \times v_{1}+w_{2} \times v_{2}+w_{3} \times v_{3}+\ldots+w_{n \times v_{n}} \text { em que: }
$$

$V=$ valor global da função;

$\mathrm{w}_{1}, \mathrm{w}_{2}, \mathrm{w}_{3}, \ldots, \mathrm{w}_{\mathrm{n}}$ são as constantes de escala dos atributos $1,2, \ldots, \mathrm{n}, \mathrm{em}$ função do julgamento dos tomadores de decisão;

$\mathrm{v}_{1}, \mathrm{v}_{2}, \mathrm{v}_{3}, \ldots, \mathrm{v}_{\mathrm{n}}$ são os valores a serem atribuídos aos atributos $1,2, \ldots, \mathrm{n}$.

$n$ é o número de atributos.

As constantes de escala representam as relações de perdas e ganhos entre os atributos, admitidas pelo decisor. Ou seja, elas devem refletir o quanto o decisor estaria disposto a "abrir mão" em um, ou mais de um atributo, para ganhar nos demais (BOCCA, 2012).

As constantes de escala (ou taxas de substituição) transformam valores locais de preferência (de cada atributo) em valores globais, na função de agregação aditiva, de forma que a somatória das constantes de escala é igual a um. 
A partir da Equação 4.1, apresenta-se a seguir a função de valor, por meio da Equação 4.2, e procedimentos para possibilitar a agregação dos indicadores utilizados na elaboração do método para mensuração da mobilidade sustentável em ciclovias:

$$
\mathbf{G S}=\mathbf{w}_{1} \times \mathbf{v}_{\mathbf{1}}+\mathbf{w}_{\mathbf{2}} \times \mathbf{v}_{\mathbf{2}}+\mathbf{w}_{\mathbf{3}} \times \mathbf{v}_{\mathbf{3}}+\ldots+\mathbf{w}_{\mathbf{n} \times \mathbf{v}_{\mathbf{n}}} \text { em que: }
$$

$G S=$ grau de sustentabilidade da ciclovia;

$w_{1}, w_{2}, \ldots, w_{n}$ são constantes de escala dos indicadores $1,2, \ldots, n$ a serem adotadas conforme os pesos finais estabelecidos pelos especialistas, apresentadas na Figura 4.16;

$v_{1}, v_{2}, \ldots, v_{n}$ são os valores atribuídos aos indicadores $1,2, \ldots, n$ por meio da aplicação do modelo em alguma ciclovia, diante da aplicação do questionário nos ciclistas (verficar os apêndices) e dos valores verificados tecnicamente em campo ou em cadastros públicos. Os valores $v_{1}, v_{2}, \ldots, v_{n}$ devem ser atribuídos levando - se em conta as normas e pontuações estabelecidas na ficha individual de cada indicador disponibilizada no Apêndice A desta tese;

$n$ é o número de indicadores. No caso, são 28 indicadores, ou seja, $n=28$. 
Considerando os valores das constantes de escala dados pelos especialistas, chega-se à função de valor do grau de sustentabilidade da ciclovia, objetivo principal desta tese, por meio da Equação (4.3):

$$
\begin{aligned}
& \text { GS }=0,0324 \times v_{1}+0,0287 \times v_{2}+0,0365 \times v_{3}+0,0247 \times v_{4}+0,0349 \times v_{5}+ \\
& 0,0203 \times v_{6}+0,0203 \times v_{7}+0,0275_{\times v_{8}+0,0338 \times v_{9}+0,0197 \times v_{10}+} \\
& 0,0157 \times v_{11}+0,0266_{\times v_{12}}+0,0203 \times v_{13}+0,0188 \times v_{14}+0,0328 \times v_{15}+ \\
& 0,0182 \times v_{16}+0,0210 \times v_{17}+0,0244 \times v_{18}+0,0360 \times v_{19}+0,0996 \times v_{20}+ \\
& 0,0768 \times v_{21}+0,0563 \times v_{22}+0,0737 \times v_{23}+0,0639 \times v_{24}+0,0266 \times v_{25}+ \\
& 0,0312 \times v_{26}+0,0587 \times v_{27}+0,0206 \times v_{28}, \text { em que: }
\end{aligned}
$$

$v_{1}, v_{2}, \ldots, v_{n}$ - valores a serem atribuídos, por meio da aplicação do modelo na ciclovia, aos seguintes indicadores:

$1=$ Volume de bicicletas na ciclovia;

2 = Existência de áreas comerciais e unidades de ensino dentro de uma distância de 500 metros da ciclovia;

3 = Percentual de viagens de ciclistas por motivo de trabalho ou estudo;

4 = Disponibilidade de estacionamentos de bicicletas junto à ciclovia;

5 = Integração intermodal;

6 = Percepção do ciclista com relação a furtos e roubos na ciclovia;

7 = Frequência de policiamento nas imediações da ciclovia;

8 = Localização espacial e conectividade com outras ciclovias;

9 = Qualidade da sinalização da ciclovia,dos cruzamentos cicloviários

e do tratamento dos locais críticos;

10 = Qualidade do pavimento da ciclovia;

11 = Qualidade da drenagem da ciclovia;

12 = Disponibilidade de iluminação pública nos arredores da ciclovia;

13 = Promoção de saúde;

14 = Promoção de atividade de lazer;

15 = Promoção de qualidade de vida e redução do nível de estresse dos ciclistas; 
16 = Percentual de ciclistas que não possuem veículo particular;

17 = Percentual de transferências do modo a pé para o cicloviário;

18 = Percentual de ciclistas que se beneficiaram dos efeitos positivos

indiretos gerados pela ciclovia como aquisição de emprego, educação e oportunidades;

$19=$ Percentual de ciclistas que obtiveram redução de gastos devido à utilização da ciclovia;

20 = Variação anual da quantidade de ciclistas mortos em acidentes

na região da ciclovia por habitante por ano;

21 = Redução de custo anual de poluentes devido à transferência de

viagens motorizadas para o modo cicloviário;

22 = Redução de emissão de poluentes de gases de efeito estufa;

23 = Redução de emissão de poluentes locais;

$24=$ Redução do nível de pressão sonora proveniente de viagens

motorizadas para o modo cicloviário;

25 = Promoção de áreas verdes;

26 = Qualidade das áreas nas imediações da ciclovia em termos de não abandono e degradação;

27 = Compatibilidade da ciclovia com o uso e ocupação do solo e com a legislação em vigor;

28 = Intensidade de danos ao meio ambiente devido à construção ou restauração da ciclovia.

Por fim, este Capítulo objetivou desenvolver um método para a determinação da sustentabilidade de ciclovias. Para tanto, foram estudados diversos métodos multicritérios de apoio à decisão de diferentes escolas e feitas considerações sobre a escolha do método multicritério para a construção do modelo. Optou-se pelo método da Escola Americana denominado Teoria da Utilidade Multiatributo. Assim, o problema foi estruturado e apresentou-se como deve ser aplicada a função de valor multiatributo aditiva para a mensuração da mobilidade sustentável em ciclovias. No próximo Capítulo são descritos a aplicação e os resultados do Método nas ciclovias do Varjão e de Samambaia do Distrito Federal, com o intuito de testar o método desenvolvido nesta Tese. 


\section{ESTUdO DE CASO: APLICAÇÃO DO MÉTODO EM CICLOVIAS DO DISTRITO FEDERAL}

A fim de testar o método e verificar a sua aplicabilidade, foram realizados dois estudos de caso, descritos a seguir, em duas ciclovias do Distrito Federal.

\subsection{CICLOVIA DA RODOVIA DF-005 - ESTRADA PARQUE PARANOÁ - EPPR}

A ciclovia da Rodovia DF-005 (Estrada Parque Paranoá - EPPR), representada pela linha vermelha na Figura 5.1, inicia-se na interseção da DF-005 com a DF-006, no lado direito da rodovia DF-005, no sentido da DF-009. Na entrada para o Varjão, a ciclovia prossegue no canteiro central da rodovia e termina na interseção da DF-005 com a DF-015, totalizando 9,8 quilômetros.

A rodovia junto da qual se encontra a ciclovia em estudo possui um volume de tráfego de veículos moderado, com duas pistas e duas faixas por sentido. Junto à rodovia encontrase o Varjão e o Setor de Mansões do Lago Norte, caracterizando a ocupação do solo lindeiro como predominantemente habitacional.

Foram estabelecidos dois pontos de contagem para a ciclovia de Varjão. O ponto 1, localizado próximo à entrada do Varjão, perto de uma travessia elevada de pedestres, de um ponto de ônibus e lanchonete e, o ponto 2, localizado mais próximo ao Setor de Mansões do Lago Norte e de uma lanchonete, são mostrados na Figura 5.1.

O volume de bicicletas na ciclovia (não considera ciclistas que circulam fora dela) foi a média das contagens dos dois pontos. A identificação precisa das duas ciclovias foi feita em campo. Os pontos de pesquisa foram também estabelecidos após trabalhos de campo. 
Barbetta (2002) disponibiliza equações estatísticas para determinação de tamanhos de amostras e para cálculo de erros. A equação 5.1 foi utilizada para os cálculos amostrais na ciclovia do Varjão.

$$
n_{o}=\frac{z^{2} p(1-p)}{E^{2}} \text { em que: }
$$

$n_{o}=$ tamanho da amostra para população infinita;

$p=p$ é a proporção considerando uma amostra de tamanho $n_{0}$;

$z=$ nível de confiança;

$E=$ margem de erro ou erro máximo de estimativa.

A partir de alguns cálculos iniciais e também devido a questões operacionais de campo, um total de 148 questionários foram aplicados em 4 dias de entrevistas, realizadas em agosto de 2014, por pesquisadores contratados que verificaram a opinião dos usuários quanto à sustentabilidade das referidas ciclovias, conforme ilustrado nas Figuras 5.2 a 5.5.

Aplicando-se a Equação 5.1 encontrou-se um erro de 8,1\%, considerando-se os seguintes parâmetros:

$$
\begin{aligned}
& n_{o}=148 \\
& \mathrm{z}=1,96 \\
& \mathrm{p}=0,5
\end{aligned}
$$

Devido ao número pouco expressivo de ciclistas que passaram pelo ponto 2 na ciclovia (a maioria passava pela pista), decidiu-se aplicar todos os questionários nas imediações do ponto 1 . 
Os pesquisadores das contagens de tráfego foram treinados para realizar as contagens. Após o treinamento, estes foram divididos em dois grupos, considerando cada posto:

- Ciclovia do Varjão - Posto 1 - Dia 05/8/14 (terça-feira):

$\checkmark \quad$ Grupo 1 - aplicou a pesquisa de 6 às 13 horas

$\checkmark \quad$ Grupo 2 - aplicou a pesquisa de 13 às 20 horas

- Ciclovia do Varjão - Posto 2 - Dia 05/8/14 (terça-feira):

$\checkmark \quad$ Grupo 1 - aplicou a pesquisa de 6 às 13 horas

$\checkmark \quad$ Grupo 2 - aplicou a pesquisa de 13 às 20 horas 


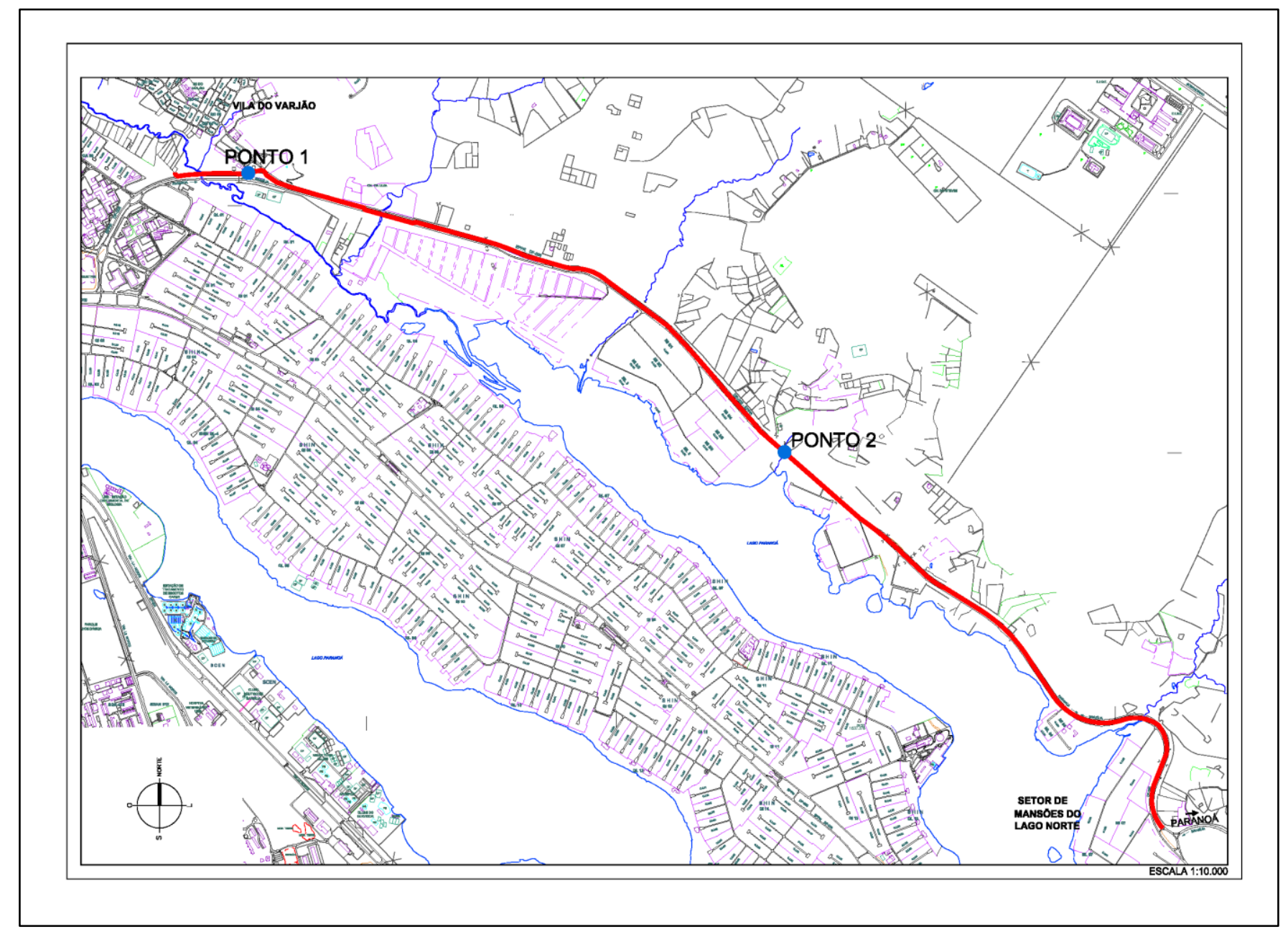

Figura 5.1: Pontos de Contagem e de Pesquisa de Opinião 1 e 2 do Estudo de Caso do Varjão 

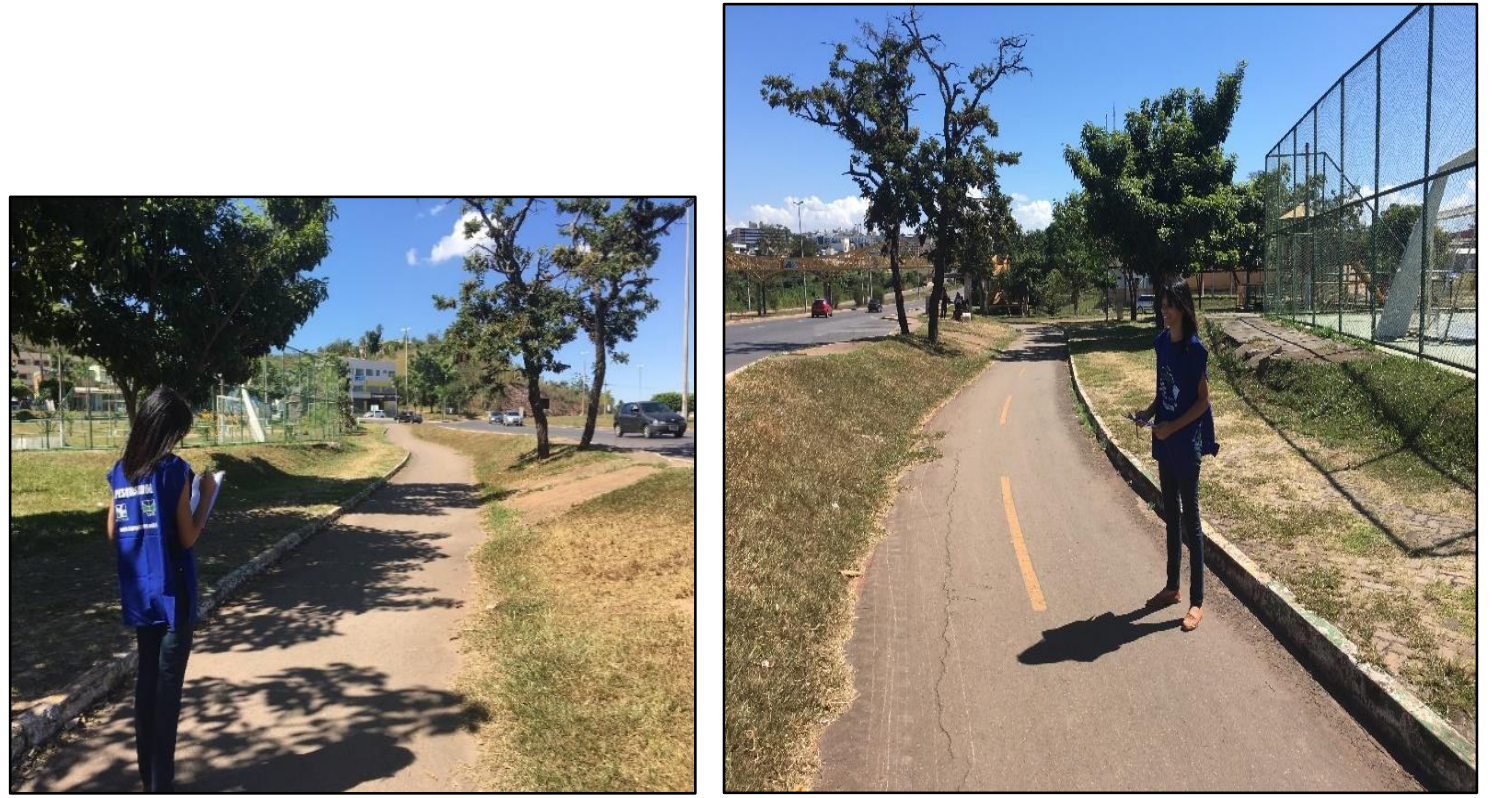

Figuras 5.2 e 5.3: Entrevistadora na ciclovia do Varjão
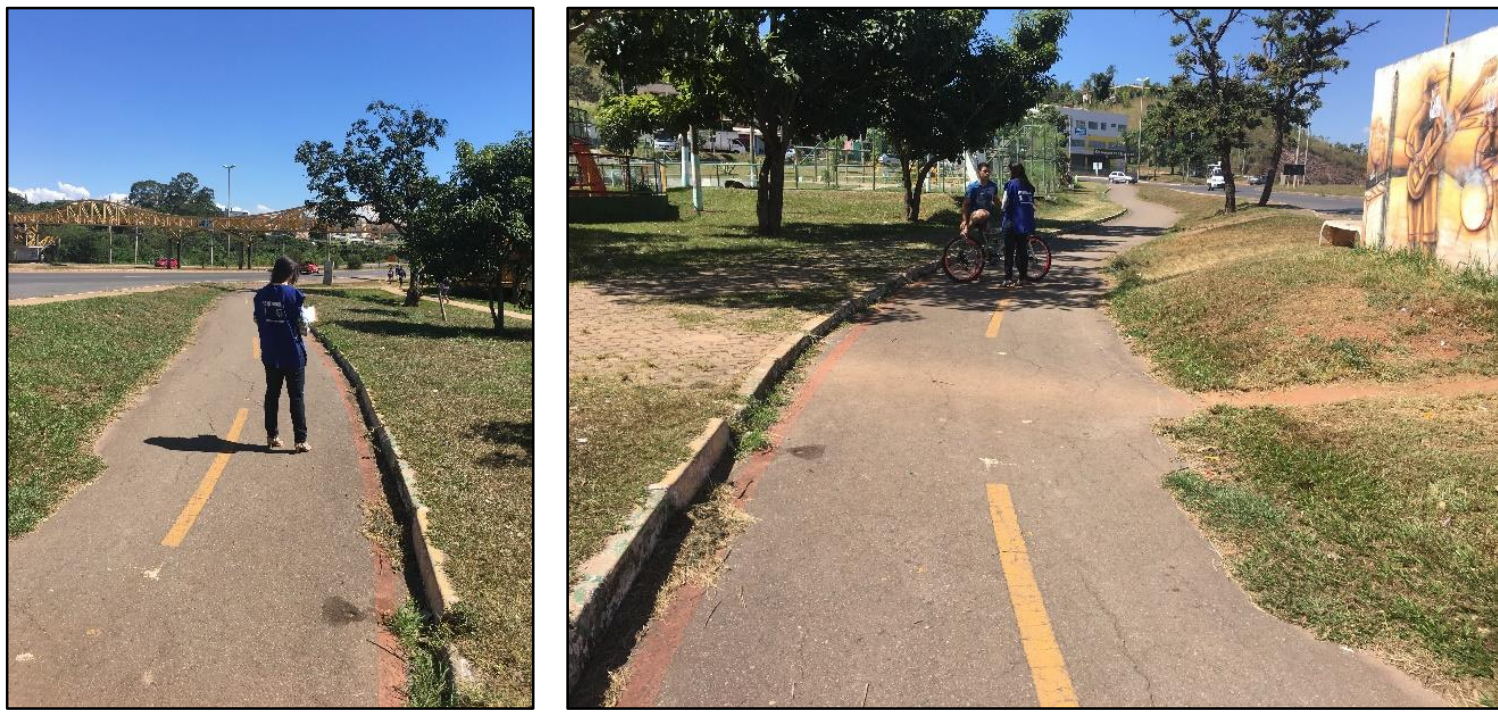

Figuras 5.4 e 5.5: Entrevistas com um usuário da ciclovia do Varjão

\subsection{CICLOVIA DE SAMAMBAIA}

A ciclovia de Samambaia, representada pela linha vermelha na Figura 5.6, inicia-se na $1^{\text {a }}$ Avenida Norte, entre as quadras 200 e 400, continua pela Feira Permanente, na 202 Norte, segue até a estação do metrô de Samambaia Sul e termina na $1^{\text {a }}$ Avenida Sul, entre as quadras 100 e 300, totalizando 13 quilômetros. 
Foram estabelecidos dois pontos de contagem para a ciclovia de Samambaia. O ponto 1, localizado próximo à QN 310, conjunto 1, perto de um ponto de ônibus e lanchonete e, o ponto 2, localizado próximo à QS 406, conjunto $\mathrm{B}$, em frente ao BRB e de uma lanchonete, são mostrados na Figura 5.6.

O volume de bicicletas na ciclovia (não considera ciclistas que circulam fora dela) foi a média das contagens dos dois pontos. A identificação precisa na ciclovia foi feita em campo. Os pontos de pesquisa foram também estabelecidos após trabalhos de campo.

Por meio da aplicação de questionários com usuários da ciclovia (total de 293 questionários aplicados em 4 dias de entrevistas realizadas em agosto de 2014), pesquisadores verificaram a opinião dos usuários quanto à sustentabilidade das referidas ciclovias, conforme ilustram as Figuras 5.7 a 5.11. Metade dos questionários da amostra foi aplicada nas imediações do posto 1 e a outra metade nas imediações do ponto 2 .

Aplicando-se a Equação 5.1, do item 5.1, encontrou-se um erro referente à amostra adotada de 5,7\%, considerando-se os seguintes parâmetros:

$n_{o}=293$

$\mathrm{Z}=1,96$

$\mathrm{p}=0,5$

Os pesquisadores das contagens de tráfego foram treinados para realizar as contagens. Após o treinamento, estes foram divididos em dois grupos, considerando cada posto:

- Ciclovia de Samambaia - Posto 1 - Dia 06/8/14 (quarta-feira):

$\checkmark \quad$ Grupo 1 - aplicou a pesquisa de 6 às 13 horas

$\checkmark \quad$ Grupo 2 - aplicou a pesquisa de 13 às 20 horas

- Ciclovia de Samambaia - Posto 2 - Dia 06/8/14 (quarta-feira):

$\checkmark \quad$ Grupo 1 - aplicou a pesquisa de 6 às 13 horas

$\checkmark \quad$ Grupo 2 - aplicou a pesquisa de 13 às 20 horas 


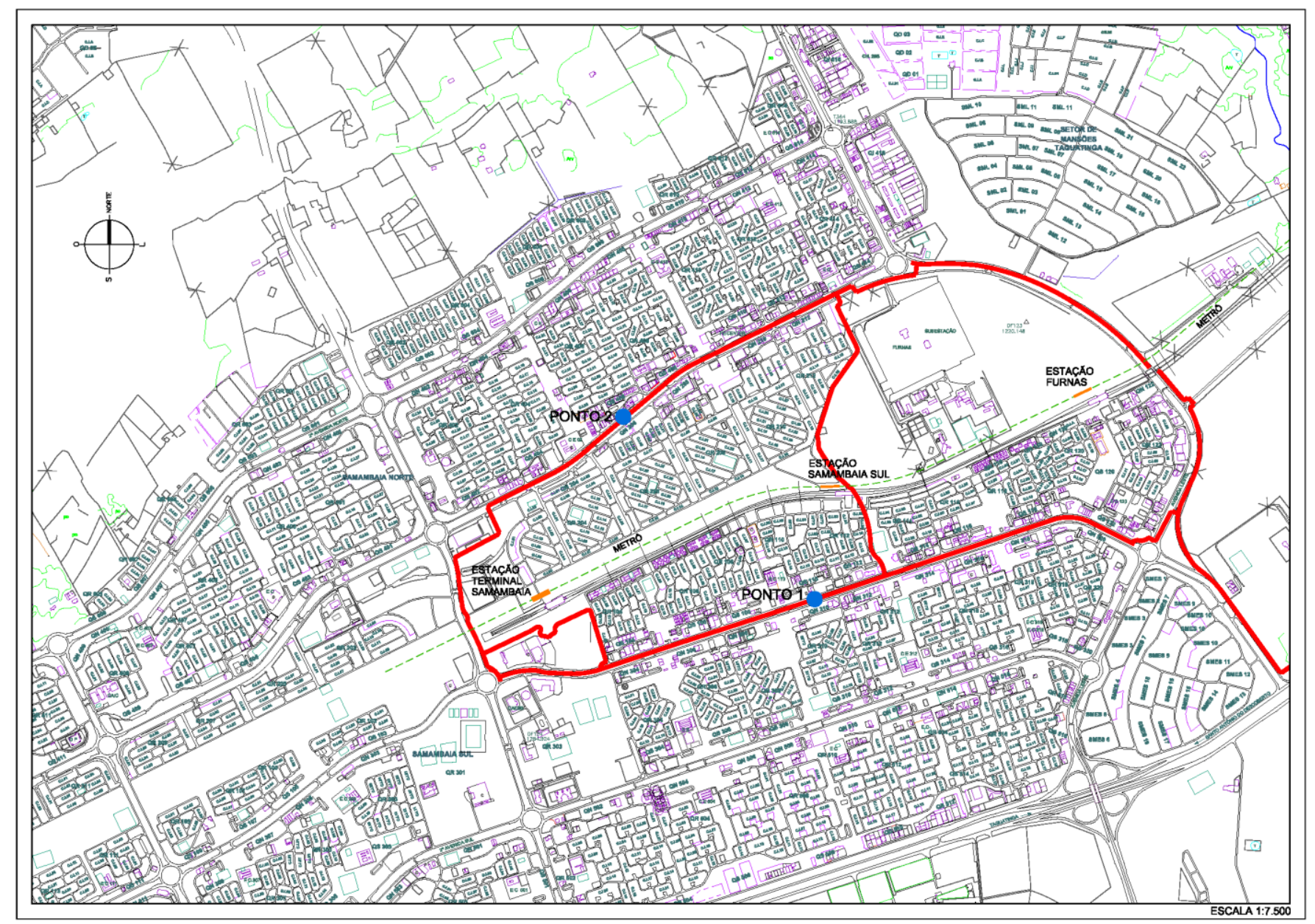

Figura 5.6: Pontos de Contagem e de Pesquisa de Opinião 1 e 2 do Estudo de Caso de Samambaia 

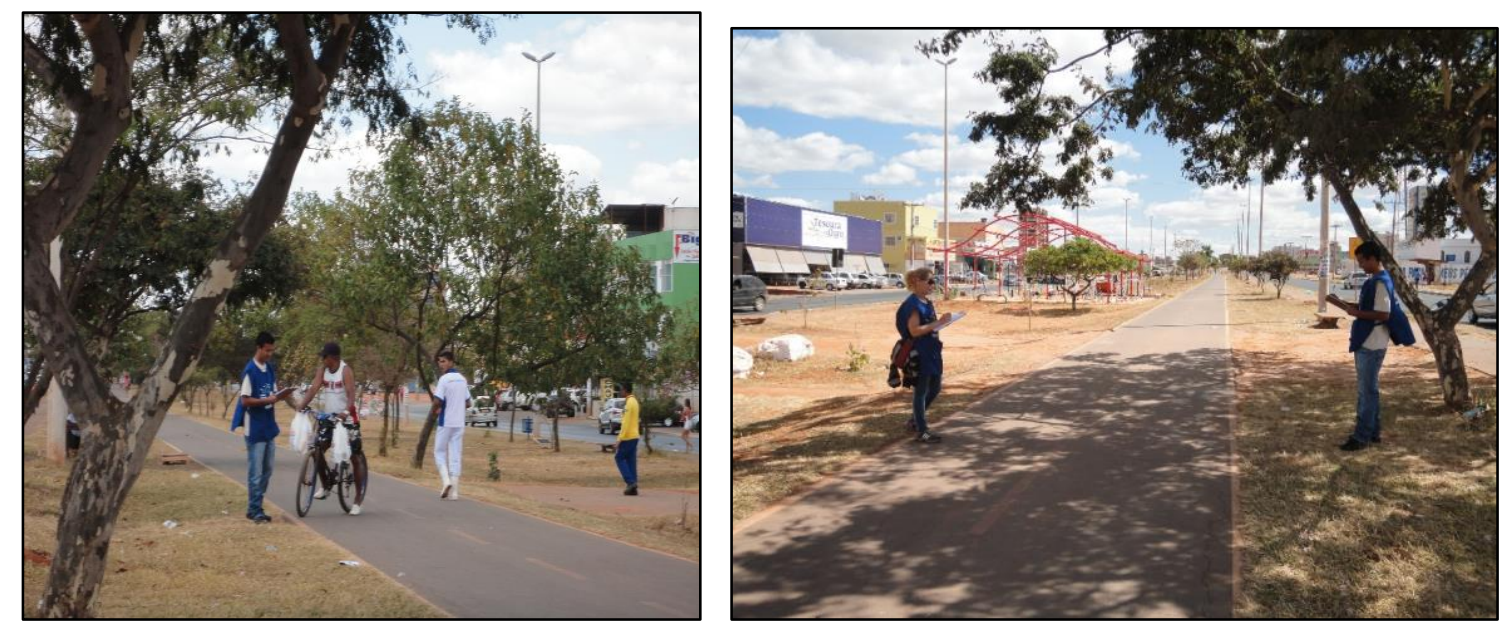

Figuras 5.7 e 5.8: Entrevistas com um usuário da ciclovia de Samambaia
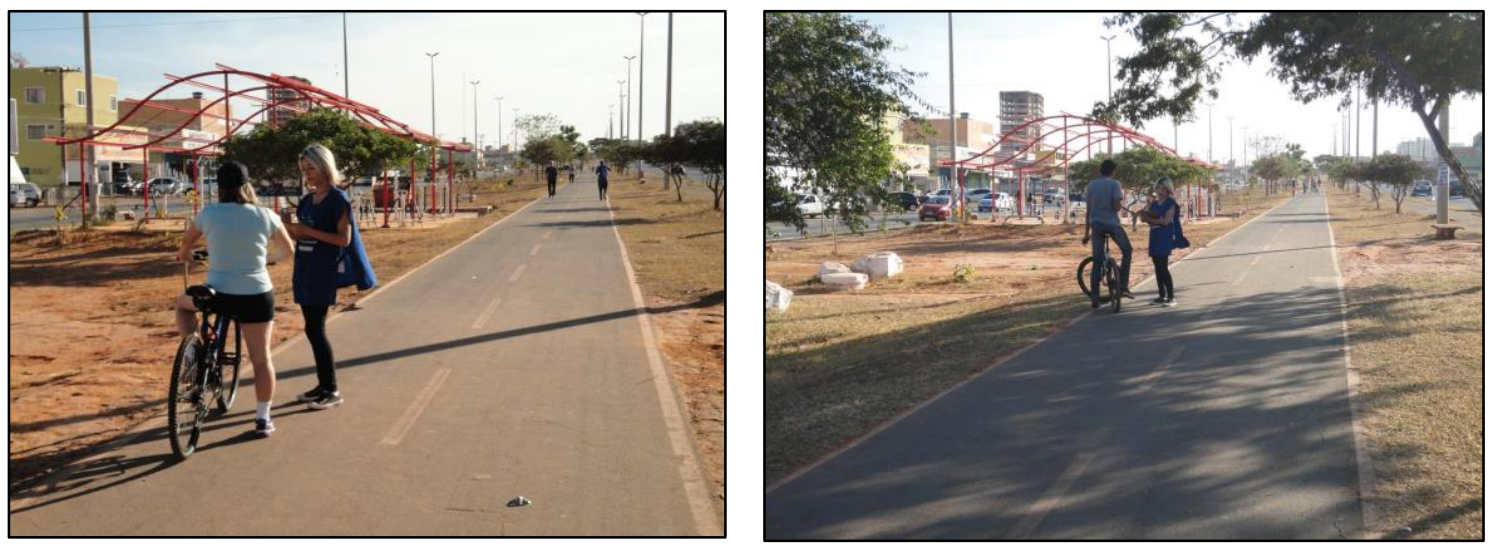

Figuras 5.9 e 5.10: Entrevistas com usuários da ciclovia de Samambaia

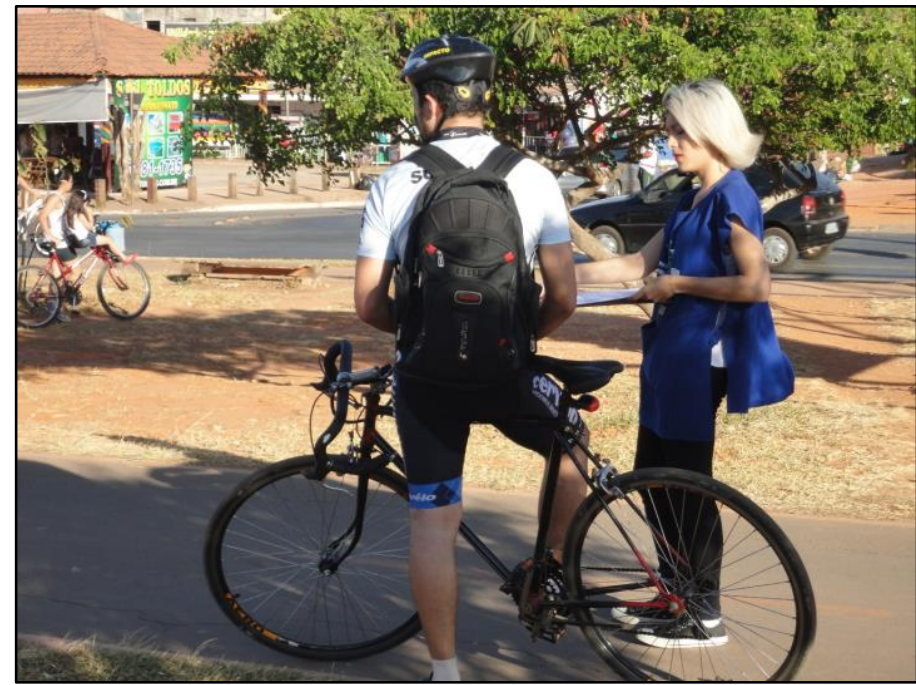

Figuras 5.11: Entrevista com um usuário da ciclovia de Samambaia 


\subsection{ANÁLISE DOS RESULTADOS}

A aplicação do método nas duas ciclovias objeto do estudo de caso é apresentada na Tabela 5.1. O grau de sustentabilidade da ciclovia, conforme mostrado no Capítulo anterior, é calculado de acordo com a função apresentada por meio da Equação 4.3.

$$
\begin{aligned}
& \text { GS }=0,0324 \times v_{1}+0,0287 \times v_{2}+0,0365 \times v_{3}+0,0247 \times v_{4}+0,0349 \times v_{5}+ \\
& 0,0203 \times v_{6}+0,0203 \times v_{7}+0,0275_{\times v_{8}+0,0338 \times v_{9}+0,0197 \times v_{10}+} \\
& 0,0157 \times v_{11}+0,0266_{\times v_{12}+0,0203 \times v_{13}+0,0188 \times v_{14}+0,0328 \times v_{15}+} \\
& 0,0182 \times v_{16}+0,0210 \times v_{17}+0,0244 \times v_{18}+0,0360 \times v_{19}+0,0996 \times v_{20}+ \\
& 0,0768 \times v_{21}+0,0563 \times v_{22}+0,0737 \times v_{23}+0,0639 \times v_{24}+0,0266 \times v_{25}+ \\
& 0,0312 \times v_{26}+0,0587 \times v_{27}+0,0206 \times v_{28}
\end{aligned}
$$

\begin{tabular}{|c|c|c|c|c|c|}
\hline \multirow[t]{2}{*}{ INDICADORES } & \multicolumn{2}{|c|}{$\begin{array}{c}\text { VALORES ATRIBUÍDOS } \\
\text { NAS RESPOSTAS AOS } \\
\text { QUESTIONÁRIOS E NA } \\
\text { ANÁLISE TÉCNICA DAS } \\
\text { CONDIÇÕES DA } \\
\text { CICLOVIA }\left(\mathbf{v}_{1}, \mathbf{v}_{2}, \ldots, \mathbf{v}_{28}\right) \\
\end{array}$} & \multirow[t]{2}{*}{$\begin{array}{l}\text { CONSTANTES } \\
\text { DE ESCALA } \\
\left(\mathrm{w}_{1}, \mathrm{w}_{2}, \ldots, \mathrm{w}_{28}\right)\end{array}$} & \multicolumn{2}{|c|}{$\begin{array}{c}\text { GRAU DE } \\
\text { SUSTENTABILIDADE }\end{array}$} \\
\hline & VARJÃOO & SAMAMBAIA & & VARJÃO & SAMAMBAIA \\
\hline $\begin{array}{ll}1-\text { Volume } & \text { de } \\
\text { bicicletas } & \text { na } \\
\text { ciclovia } & \end{array}$ & 0,25 & 0,50 & 0,0324 & 0,0081 & 0,0162 \\
\hline $\begin{array}{l}2 \text { - Existência de } \\
\text { áreas comerciais e } \\
\text { unidades de ensino } \\
\text { dentro de uma } \\
\text { distância de } 500 \\
\text { metros da ciclovia }\end{array}$ & 0,50 & 1,00 & 0,0287 & 0,0143 & 0,0287 \\
\hline $\begin{array}{l}3 \text { - Percentual de } \\
\text { viagens de ciclistas } \\
\text { por motivo de } \\
\text { trabalho ou estudo }\end{array}$ & 0,75 & 0,50 & 0,0365 & 0,0274 & 0,0182 \\
\hline $\begin{array}{l}4 \text { - Disponibilidade } \\
\text { de estacionamento } \\
\text { de bicicletas junto } \\
\text { à ciclovia }\end{array}$ & 0,25 & 0,25 & 0,0247 & 0,0061 & 0,0061 \\
\hline $\begin{array}{l}5-\quad \text { Integração } \\
\text { intermodal }\end{array}$ & 0,00 & 0,75 & 0,0349 & 0,00 & 0,0262 \\
\hline $\begin{array}{l}6 \text { - Percepção do } \\
\text { ciclistaram }\end{array}$ & 0,25 & 0,50 & 0,0203 & 0,0051 & 0,0101 \\
\hline
\end{tabular}

Tabela 5.1: Resultados da aplicação do método para a determinação da sustentabilidade das ciclovias do Varjão e de Samambaia 


\begin{tabular}{|c|c|c|c|c|c|}
\hline \multirow[t]{2}{*}{ INDICADORES } & \multicolumn{2}{|c|}{$\begin{array}{l}\text { VALORES ATRIBUÍDOS } \\
\text { NAS RESPOSTAS AOS } \\
\text { QUESTIONÁRIOS E NA } \\
\text { ANÁLISE TÉCNICA DAS } \\
\text { CONDIÇÕES DA } \\
\text { CICLOVIA }\left(v_{1}, v_{2}, \ldots, v_{28}\right) \\
\end{array}$} & \multirow[t]{2}{*}{$\begin{array}{l}\text { CONSTANTES } \\
\text { DE ESCALA } \\
\left(\mathbf{w}_{1}, \mathbf{w}_{2}, \ldots, \mathbf{w}_{28}\right)\end{array}$} & \multicolumn{2}{|c|}{$\begin{array}{c}\text { GRAU DE } \\
\text { SUSTENTABILIDADE }\end{array}$} \\
\hline & VARJÃO & SAMAMBAIA & & VARJÃO & SAMAMBAIA \\
\hline $\begin{array}{l}\text { relação a furtos e } \\
\text { roubos na ciclovia }\end{array}$ & & & & & \\
\hline $\begin{array}{lr}7 \text { - Frequência de } \\
\text { policiamento nas } \\
\text { imediações } \\
\text { ciclovia }\end{array}$ & 0,50 & 0,25 & 0,0203 & 0,0101 & 0,0051 \\
\hline $\begin{array}{l}8 \text { - Localização } \\
\text { espacial e } \\
\text { conectividade com } \\
\text { outras ciclovias }\end{array}$ & 0,25 & 0,75 & 0,0275 & 0,0069 & 0,0206 \\
\hline $\begin{array}{ll}9 \text { - Qualidade } & \text { da } \\
\text { sinalização } & \text { da } \\
\text { ciclovia, } & \text { dos } \\
\text { cruzamentos } & \\
\text { cicloviários e do } \\
\text { tratamento dos } \\
\text { locais críticos }\end{array}$ & 0,50 & 0,75 & 0,0338 & 0,0169 & 0,0253 \\
\hline $\begin{array}{l}10 \text { - Qualidade do } \\
\text { pavimento }\end{array}$ & 0,75 & 0,75 & 0,0197 & 0,0148 & 0,0148 \\
\hline $\begin{array}{lr}11 \text { - Qualidade da } \\
\text { drenagem } & \text { da } \\
\text { ciclovia } & \\
\end{array}$ & 0,75 & 0,75 & 0,0157 & 0,0118 & 0,0118 \\
\hline $\begin{array}{lr}12 & - \\
\text { Disponibilização } \\
\text { de iluminação } \\
\text { pública } \quad \text { nos } \\
\text { arredores r da } \\
\text { ciclovia }\end{array}$ & 0,75 & 0,75 & 0,0266 & 0,0199 & 0,0199 \\
\hline $\begin{array}{l}13 \text { - Promoção de } \\
\text { saúde }\end{array}$ & 1,00 & 1,00 & 0,0203 & 0,0203 & 0,0203 \\
\hline $\begin{array}{l}14 \text { - Promoção de } \\
\text { atividade de lazer }\end{array}$ & 0,75 & 1,00 & 0,0188 & 0,0141 & 0,0188 \\
\hline $\begin{array}{l}15 \text { - Promoção de } \\
\text { qualidade de vida e } \\
\text { redução do nível } \\
\text { de estresse dos } \\
\text { ciclistas } \\
\end{array}$ & 0,75 & 1,00 & 0,0328 & 0,0246 & 0,0328 \\
\hline $\begin{array}{l}16 \text { - Percentual de } \\
\text { ciclistas que não } \\
\text { possuem veículo } \\
\text { particular }\end{array}$ & 0,75 & 0,75 & 0,0182 & 0,0136 & 0,0136 \\
\hline $\begin{array}{l}17 \text { - Percentual de } \\
\text { transferência do } \\
\text { modo a pé para o } \\
\text { cicloviário }\end{array}$ & 1,0 & 1,0 & 0,0210 & 0,0210 & 0,0210 \\
\hline
\end{tabular}




\begin{tabular}{|c|c|c|c|c|c|}
\hline \multirow[t]{2}{*}{ INDICADORES } & \multicolumn{2}{|c|}{$\begin{array}{c}\text { VALORES ATRIBUÍDOS } \\
\text { NAS RESPOSTAS AOS } \\
\text { QUESTIONÁRIOS E NA } \\
\text { ANÁLISE TÉCNICA DAS } \\
\text { CONDIÇÕES DA } \\
\text { CICLOVIA }\left(\mathrm{v}_{1}, \mathrm{v}_{2}, \ldots, \mathrm{v}_{28}\right)\end{array}$} & \multirow[t]{2}{*}{$\begin{array}{l}\text { CONSTANTES } \\
\text { DE ESCALA } \\
\left(\left(\mathbf{w}_{1}, \mathbf{w}_{2}, \ldots, \mathbf{w}_{28}\right)\right.\end{array}$} & \multicolumn{2}{|c|}{$\begin{array}{c}\text { GRAU DE } \\
\text { SUSTENTABILIDADE }\end{array}$} \\
\hline & VARJÃO & SAMAMBAIA & & VARJÃO & SAMAMBAIA \\
\hline $\begin{array}{l}18 \text { - Percentual de } \\
\text { ciclistas que se } \\
\text { beneficiaram dos } \\
\text { efeitos positivos } \\
\text { indiretos gerados } \\
\text { pela ciclovia, } \\
\text { como aquisição de } \\
\text { emprego, } \\
\text { educação e outras } \\
\text { oportunidades }\end{array}$ & 1,0 & 1,0 & 0,0244 & 0,0244 & 0,0244 \\
\hline $\begin{array}{l}19 \text { - Percentual de } \\
\text { ciclistas que } \\
\text { obtiveram redução } \\
\text { de gastos devido à } \\
\text { utilização da } \\
\text { ciclovia }\end{array}$ & 1,0 & 1,0 & 0,0360 & 0,0360 & 0,0360 \\
\hline $\begin{array}{lr}20 \quad- & \text { Variação } \\
\text { anual } & \text { da } \\
\text { quantidade de } & \text { diclistas mortos em } \\
\text { acidentes de } & \text { trânsito na região } \\
\text { da ciclovia por } \\
\text { habitante por ano }\end{array}$ & 0 & 1,00 & 0,0996 & 0,00 & 0,0996 \\
\hline $\begin{array}{l}21 \text { - Redução do } \\
\text { custo anual de } \\
\text { poluentes devido à } \\
\text { transferência de } \\
\text { viagens } \\
\text { motorizadas para o } \\
\text { modo cicloviário }\end{array}$ & 0,25 & 0,75 & 0,0768 & 0,0192 & 0,0576 \\
\hline $\begin{array}{l}22 \text { - Redução de } \\
\text { emissão de } \\
\text { poluentes de gases } \\
\text { de efeito estufa }\end{array}$ & 0,25 & 0,75 & 0,0563 & 0,0141 & 0,0422 \\
\hline $\begin{array}{l}23 \text { - Redução de } \\
\text { emissão de } \\
\text { poluentes locais }\end{array}$ & 0,25 & 0,75 & 0,0737 & 0,0184 & 0,0553 \\
\hline $\begin{array}{l}24 \text { - Redução do } \\
\text { nível de pressão } \\
\text { sonora proveniente } \\
\text { da transferência de } \\
\text { viagens } \\
\text { motorizadas para o } \\
\text { modo cicloviário }\end{array}$ & 0,50 & 0,50 & 0,0639 & 0,0319 & 0,0319 \\
\hline
\end{tabular}




\begin{tabular}{|c|c|c|c|c|c|}
\hline \multirow[t]{2}{*}{ INDICADORES } & \multicolumn{2}{|c|}{$\begin{array}{c}\text { VALORES ATRIBUÍDOS } \\
\text { NAS RESPOSTAS AOS } \\
\text { QUESTIONÁRIOS E NA } \\
\text { ANÁLISE TÉCNICA DAS } \\
\text { CONDIÇÕES DA } \\
\text { CICLOVIA }\left(\mathrm{v}_{1}, \mathrm{v}_{2}, \ldots ., \mathrm{v}_{28}\right) \\
\end{array}$} & \multirow[t]{2}{*}{$\begin{array}{l}\text { CONSTANTES } \\
\text { DE ESCALA } \\
\left(\mathbf{w}_{1}, \mathbf{w}_{2}, \ldots, \mathbf{w}_{28}\right)\end{array}$} & \multicolumn{2}{|c|}{$\begin{array}{c}\text { GRAU DE } \\
\text { SUSTENTABILIDADE }\end{array}$} \\
\hline & VARJÃO & SAMAMBAIA & & VARJÃO & SAMAMBAIA \\
\hline $\begin{array}{l}25 \text { - Promoção de } \\
\text { áreas verdes }\end{array}$ & 0,75 & 0,75 & 0,0266 & 0,0199 & 0,0199 \\
\hline $\begin{array}{l}26-\text { Qualidade das } \\
\text { áreas nas } \\
\text { imediações da } \\
\text { ciclovia em termos } \\
\text { de não abandono e } \\
\text { degradação }\end{array}$ & 1,0 & 1,0 & 0,0312 & 0,0312 & 0,0312 \\
\hline $\begin{array}{l}27 \\
\text { Compatibilidade } \\
\text { da ciclovia com o } \\
\text { uso e ocupação do } \\
\text { solo com a } \\
\text { legislação } \\
\text { vigor }\end{array}$ & 1,0 & 1,0 & 0,0587 & 0,0587 & 0,0587 \\
\hline $\begin{array}{lr}28 \text { - Intensidade de } \\
\text { danos causados ao } \\
\text { meio ambiente } \\
\text { devido } \\
\text { construção a } \\
\text { restauração } \\
\text { ciclovia } \\
\end{array}$ & 1,0 & 1,0 & 0,0206 & 0,0206 & 0,0206 \\
\hline GRAU & & - & - & 0,51 & 0,79 \\
\hline
\end{tabular}

O grau de sustentabilidade da ciclovia do Varjão, segundo os cálculos acima, é de 0,51, e o da ciclovia de Samambaia é de 0,79. 
A ciclovia de Samambaia possui maior volume de ciclistas, muitas residências e áreas comerciais nas imediações, o que não acontece junto à ciclovia do Varjão. Portanto, aparenta ter mais sustentabilidade para quem circula pelas mesmas. Ainda assim, a diferença em termos de sustentabilidade na aplicação do método foi bastante elevada, sendo o grau de sustentabilidade em Samambaia 0,28 superior ao da ciclovia do Varjão, em uma escala de zero a um.

O Apêndice C desta Tese estabelece uma comparação mais detalhada das notas atribuídas pelos ciclistas nas respostas aos questionários, bem como nas avaliações técnicas, para alguns quesitos, feitos pela autora após contatos e reuniões com servidores do governo do Distrito Federal. Dessa forma, a comparação das notas das duas ciclovias, com comentários e gráficos, é feita para os 28 indicadores que compõem o Método, o que possibilita melhor compreensão da diferença verificada entre os graus de sustentabilidade.

Outro ponto importante a considerar, que em grande parte explica esta diferença, é que alguns indicadores que receberam pontuação alta pelos especialistas, especificamente as constantes de escala $\mathrm{w}_{20}, \mathrm{w}_{21}, \mathrm{w}_{22}$ e $\mathrm{w}_{23}$, tiveram também diferenças altas em favor da ciclovia de Samambaia nas notas atribuídas ( $\left.\mathrm{v}_{20}, \mathrm{v}_{21}, \mathrm{v}_{22} \mathrm{e} \mathrm{v}_{23}\right)$.

São os seguintes esses quatro indicadores e suas pontuações:

- 20 - Variação anual da quantidade de ciclistas mortos em acidentes de trânsito na região da ciclovia por habitante por ano
○ $\mathrm{w}_{20}: 0,0996$
- $\quad \mathrm{V}_{20}$ Samambaia: 1,00
○ $\quad \mathrm{v}_{20}$ : Varjão: 0,00
$\bigcirc \quad \mathrm{w}_{20} \mathrm{x} \mathrm{v}_{20}$ Samambaia $=0,0996 \times 1,00=\mathbf{0 , 0 9 9 6}$
$\circ \quad \mathrm{w}_{20} \times \mathrm{v}_{20}$ Varjão $=0,0996 \times 0,00=\mathbf{0 , 0 0}$

- 21 - Redução do custo anual de poluentes devido à transferência de viagens motorizadas para o modo cicloviário
○ $\quad \mathrm{w}_{21}: 0,0768$
○ $\quad v_{21}$ Samambaia: 0,75
○ $\quad \mathrm{v}_{21}$ : Varjão: 0,25
$\circ \quad \mathrm{w}_{21} \times \mathrm{v}_{21}$ Samambaia $=0,0768 \times 0,75=\mathbf{0 , 0 5 7 6}$
$\bigcirc \quad \mathrm{w}_{21} \times \mathrm{v}_{21} \operatorname{Varjão}=0,0768 \times 0,25=\mathbf{0 , 0 1 9 2}$

- 22 - Redução de emissão de poluentes de gases de efeito estufa
○ w $_{22}: 0,0563$
○ $\quad v_{22}$ Samambaia: 0,75 
○ $\quad \mathrm{v}_{22}$ : Varjão: 0,25

$\bigcirc \quad \mathrm{w}_{22} \times \mathrm{v}_{22}$ Samambaia $=0,0563 \times 0,75=\mathbf{0 , 0 4 2 2}$

$\bigcirc \quad \mathrm{w}_{22} \times \mathrm{v}_{22} \operatorname{Varjão}=0,0563 \times 0,25=\mathbf{0 , 0 1 4 1}$

- 23 - Redução de emissão de poluentes locais

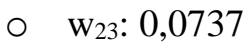
○ $\quad \mathrm{V}_{23}$ Samambaia: 0,75
○ $\quad$ V23: $_{23}$ Varjão: 0,25
$\bigcirc \quad \mathrm{w}_{23} \times \mathrm{v}_{23}$ Samambaia $=0,0737 \times 0,75=\mathbf{0 , 0 5 5 3}$
$\bigcirc \quad \mathrm{w}_{23} \times \mathrm{v}_{23} \operatorname{Varjão}=0,0737 \times 0,25=\mathbf{0 , 0 1 8 4}$

Complementarmente, cabe ressaltar que o percentual de viagens de ciclistas por motivo de trabalho ou estudo é maior no Varjão do que em Samambaia. No Varjão, não há integração entre os ciclistas com outros modos de transporte. Em Samambaia, há uma integração boa entre os ciclistas e três estações de metrô, ainda que não haja com ônibus. A percepção do ciclista com relação à localização espacial e conectividade com outras ciclovias, qualidade da sinalização da ciclovia, dos cruzamentos cicloviários e do tratamento dos locais críticos, promoção de atividade de lazer e promoção de qualidade de vida e redução do nível de estresse dos ciclistas foi também considerada maior em Samambaia.

Com relação à variação anual da quantidade de ciclistas mortos em acidentes de trânsito na região da ciclovia por ano, no Varjão, houve aumento de uma morte de ciclista, comparando os anos de 2007 e 2013, enquanto que em Samambaia houve redução.

Neste Capítulo foram descritos a aplicação e os resultados do Método nas ciclovias do Varjão e de Samambaia do Distrito Federal, com o intuito de testar o método desenvolvido nesta Tese. No próximo Capítulo são apresentadas as considerações finais deste trabalho. 


\section{CONSIDERAÇÕES FINAIS}

Este Capítulo tem como objetivo principal apresentar considerações sobre três aspectos: o método desenvolvido, a limitação identificada no desenvolvimento do estudo e sugestões de futuros trabalhos científicos. Antes, porém, aborda os principais aspectos da mobilidade urbana e sustentabilidade ambiental discutidos neste trabalho.

\subsection{MOBILIDADE URBANA E SUSTENTABILIDADE AMBIENTAL}

No desenvolvimento desta Tese, realizou-se uma descrição ampla dos temas mobilidade urbana e sustentabilidade. Assim sendo, ressaltam-se alguns dos pontos discorridos no estudo.

Apesar de a bicicleta ter sido eleita pela ONU como o meio de transporte ecologicamente mais sustentável do planeta, a maioria das cidades brasileiras não apresenta infraestrutura apropriada ao deslocamento de ciclistas, ocorrendo problemas de planejamento da rede cicloviária com trechos descontínuos, falta de conexões com terminais de transporte público, problemas de segurança nas ciclovias e ciclofaixas implantadas e carência de ciclovias, ciclofaixas e estacionamentos para bicicletas.

Incentivos ao uso da bicicleta devem ser realizados em conjunto com políticas urbanas que desfavoreçam o uso do veículo motorizado individual e com medidas de controle e restrições do uso dos automóveis, uma vez que os veículos automotores de transporte individual ferem os interesses coletivos da sociedade e geram externalidades, como congestionamentos, poluição sonora e atmosférica e acidentes.

O transporte por bicicleta é uma alternativa econômica e ecologicamente adequada, que confere ainda ao ciclista liberdade e praticidade.

No entanto, a simples implantação de uma ciclovia pode não trazer ganhos ambientais, sociais ou econômicos. A busca pela sustentabilidade deve estar presente no planejamento e construção de ciclovias. O fato de uma ciclovia ser pouco sustentável não impede que as pessoas a utilizem, mas desmotiva bastante o seu uso, de forma que muitos ciclistas acabam por não a utilizar, resultando em um gasto ineficiente de recursos públicos, uma vez que não atrai usuários e não promove a bicicleta como meio de transporte. 
Ainda que as ciclovias apresentem seus inconvenientes como dificuldades de utilização em dias chuvosos, dificuldades para determinados tipos de usuário - mulheres com sapato alto, por exemplo - elas fazem sentido para outros grupos de usuários, principalmente em áreas mais carentes que acabam sendo excluídas da mobilidade urbana por meio motorizado. É importante que o usuário disponha de várias opções modais para o seu deslocamento e cabe considerar que o modo cicloviário está cada vez mais presente em diversos países, principalmente nos desenvolvidos.

Em várias cidades do mundo, ações em prol da sustentabilidade têm sido direcionadas ao uso do transporte não motorizado, que exerce um papel crucial no "espaço social", principalmente por meio do estímulo do uso do modo cicloviário como meio de transporte.

Por fim, uma política de incentivo à construção de paraciclos e de bicicletários também é fundamental para a ampliação do uso da bicicleta no território brasileiro.

Com relação a convenções, políticas e planos que contemplam a sustentabilidade e, assim, respaldam o uso mais intensivo da bicicleta, algumas considerações são feitas a seguir.

Em 2009 foi sancionada a Lei Federal n ${ }^{\circ}$ 12.187, a qual instituiu a Política Nacional sobre Mudança do Clima (PNMC) e, em 2010, o Decreto Federal n ${ }^{\mathbf{o}}$ 7.390, que a regulamenta. A PNMC contém princípios, objetivos, diretrizes e instrumentos que visam compatibilizar o desenvolvimento socioeconômico nacional com a proteção do sistema climático e as políticas públicas e programas governamentais deverão compatibilizar-se com seus princípios e instrumentos.

No período de 30 de novembro de 2015 a 16 de dezembro do mesmo ano foi realizada a $21^{\mathrm{a}}$ Conferência entre as Partes da Convenção Quadro das Nações Unidas sobre Mudanças Climáticas em Paris. Esta Conferência estabeleceu compromissos traduzidos pelas seguintes metas: redução das emissões no ano de 2025 de $37 \%$ e em 2030 de $43 \%$ em relação ao ano base de 2005, ou seja, redução aproximada de $0,75 \mathrm{GtCO}_{2 \text { eq }}$ em 2025 e de $0,88 \mathrm{GtCO}_{2 \text { eq }}$ em 2030 em relação ao ano base de 2005.

O Ministério dos Transportes e o Ministério das Cidades (BRASIL, 2013) elaboraram o Plano Setorial de Transporte e da Mobilidade Urbana para Mitigação das Mudanças Climáticas - PSTM. Foram definidos cenários de emissões e feita proposição de estudos e pesquisas para a definição de ações de abatimento. 
De acordo com o PSTM (BRASIL, 2013), uma das medidas consideradas necessárias para a promoção da mitigação de poluentes locais e gases de efeito estufa é o aumento do uso da bicicleta nos sistemas de mobilidade urbana. Para calcular o abatimento é necessário promover um levantamento sobre a extensão de infraestrutura cicloviária que está sendo implantada no país, bem como a realização de pesquisas pós-implantação de infraestrutura para conhecer a real transferência do modo do transporte motorizado para a bicicleta.

Em 3 de janeiro de 2012 foi sancionada a Lei Federal $n^{\circ} 12.587$, que instituiu as diretrizes da Política Nacional de Mobilidade Urbana. Esta Lei inovou ao estabelecer que todos os municípios brasileiros com mais de 20.000 habitantes deverão elaborar um Plano de Mobilidade Urbana, compatível com os respectivos planos diretores ou neles inserido. Estabelece também que, nos Municípios sem sistema de transporte público coletivo, o Plano de Mobilidade Urbana deverá ter o foco no transporte não motorizado e no planejamento da infraestrutura urbana destinada aos deslocamentos a pé e por bicicleta.

\subsection{O MÉTODO DESENVOLVIDO}

Esta Tese desenvolveu um método para mensurar o grau de sustentabilidade de ciclovias, denominado Método para a Determinação da Sustentabilidade de Ciclovias.

A função de valor do grau de sustentabilidade da ciclovia, objetivo principal desta tese, é a Equação 4.3:

$$
\begin{aligned}
& \text { GS }=0,0324 \times v_{1}+0,0287 \times v_{2}+0,0365 \times v_{3}+0,0247 \times v_{4}+0,0349 \times v_{5}+ \\
& 0,0203 \times v_{6}+0,0203 \times v_{7}+0,0275_{\times v_{8}+0,0338 \times v_{9}+0,0197 \times v_{10}+} \\
& 0,0157 \times v_{11}+0,0266 \times v_{12}+0,0203 \times v_{13}+0,0188 \times v_{14}+0,0328 \times v_{15}+ \\
& 0,0182 \times v_{16}+0,0210 \times v_{17}+0,0244 \times v_{18}+0,0360 \times v_{19}+0,0996 \times v_{20}+ \\
& 0,0768 \times v_{21}+0,0563 \times v_{22}+0,0737 \times v_{23}+0,0639 \times v_{24}+0,0266 \times v_{25}+ \\
& 0,0312 \times v_{26}+0,0587 \times v_{27}+0,0206 \times v_{28}
\end{aligned}
$$

Cabe salientar que as variáveis da Equação 4.3 podem ser consultadas no subitem 4.6.3 desta Tese. 
O objetivo desta Tese foi alcançado, visto que foi desenvolvido um método baseado em indicadores de mobilidade sustentável, aplicável em ciclovias existentes. Assim sendo, a partir da utilização deste método, é possível atribuir um grau de sustentabilidade de uma forma generalizada para o estado atual de uma ciclovia, e permitir, desta forma, a comparação entre o grau de sustentabilidade entre diferentes ciclovias ou, até mesmo, com a mesma ciclovia em diferentes épocas.

Ainda que não seja possível afirmar, a partir do método criado nesta Tese, se uma determinada ciclovia é sustentável ou não, visto que algo sempre será sustentável ou não diante de algum parâmetro pré-definido, o presente estudo da sustentabilidade de ciclovias é importante para possibilitar o cálculo do grau de sustentabilidade de cada ciclovia e a comparação entre elas.

A determinação do grau de sustentabilidade de ciclovias e a análise individual dos indicadores podem ser úteis ao planejamento cicloviário, à elaboração de novos projetos, à definição de melhorias em ciclovias existentes e ao estabelecimento de prioridades diante das condições atuais das ciclovias, bem como ao monitoramento da eficiência das ações tomadas.

Com relação à referida análise individual dos indicadores, cita-se como exemplo o indicador 20 - variação anual da quantidade de ciclistas mortos em acidentes de trânsito na região da ciclovia por habitante por ano, para o qual os especialistas atribuíram o maior peso entre os 28 indicadores. Significa, para os gestores e projetistas, que a segurança é fator da mais alta relevância ao se considerar a sustentabilidade de ciclovias.

Os indicadores de mobilidade sustentável de ciclovias elencados nesta Tese poderão auxiliar no estabelecimento de diretrizes para cidades cada vez mais sustentáveis, com foco na qualidade de vida da população. Também podem contribuir no processo de tomada de decisões da sociedade em relação ao meio ambiente.

Cabe salientar que o método foi desenvolvido com o foco em aspectos técnicos, mas sem deixar de lado a opinião do ciclista, que é essencial neste processo de avaliação, uma vez que se este não se sentir atraído a utilizar a ciclovia, esta não tem razão de existir.

O método desenvolvido neste trabalho é apropriado para identificar pontos prioritários a serem considerados para futuras melhorias em ciclovias existentes e comparar ciclovias em termos de sustentabilidade. Desta forma, pretende-se inibir a implantação e manutenção de ciclovias que não gerem consequências positivas ambientais, sociais e econômicas. 
A partir do uso deste método é possível que os tomadores de decisão estabeleçam prioridades para melhorias das ciclovias analisadas, bem como diretrizes para cidades cada vez mais sustentáveis, a fim de aumentar a qualidade de vida da população.

Uma análise de sensibilidade foi realizada com o intuito de verificar a variação do grau de sustentabilidade (GS) das ciclovias do Varjão e de Samambaia ao comparar dois conjuntos de constantes de escalas $\left(\mathrm{w}_{1}, \mathrm{w}_{2} \ldots, \mathrm{w}_{28}\right)$. O primeiro conjunto é o que consta do método proposto nesta tese, com os pesos atribuídos pelos especialistas, enquanto o segundo considera constantes de escalas idênticas $\left(\mathrm{w}_{1}=\mathrm{W}_{2}=\ldots=\mathrm{W}_{28}\right)$.

O grau de sustentabilidade da ciclovia do Varjão, calculado com base em constantes de escala de mesmo valor (1 / 28), é de 0,60 , cerca de $17,6 \%$ superior ao GS calculado segundo o método desta tese $=0,51$.

O GS da ciclovia de samambaia, calculado com base em constantes de escala de mesmo valor, é de 0,77 , cerca de $2,5 \%$ inferior ao GS calculado segundo o método desta tese $=0,79$.

\subsection{ALGUMAS CONSIDERAÇÕES SOBRE O DESENVOLVIMENTO DO MÉTODO}

Foram selecionados nove especialistas, conhecedores da realidade do objeto em análise, com o propósito de obter um grupo multidisciplinar para viabilizar a integração das opiniões e de diferentes experiências sobre a complexidade das variáveis envolvidas por meio da atribuição de pesos.

Assim sendo, foram selecionados três representantes do meio acadêmico, três representantes atuantes na área profissional e três representantes da sociedade civil. Ao todo, cada especialista estabeleceu 40 pesos somando-se todas as variáveis do método. A função do peso é dar a devida relevância à variável em questão de acordo com as preferências e experiência dos especialistas. Para cada nível hierárquico foi realizado o cálculo das médias dos especialistas, com o propósito de buscar homogeneizar suas respostas. As médias finais foram ponderadas de acordo com seus pesos, para que ao todo, o método totalizasse $100 \%$. 
O fato de os especialistas terem dado aproximadamente $40 \%$ à dimensão social no primeiro nível da dimensão hierárquica (Figura 4.16) pode representar um reflexo da preocupação com a exclusão social. Nota-se também como a dimensão ambiental vem ganhando cada vez mais importância nas discussões. Antes vista como inimiga e empecilho para o desenvolvimento, hoje é uma aliada para a qualidade de vida, tendo ficado em segunda posição, com $33 \%$, e a dimensão econômica por último, com $27 \%$.

A fim de testar o método e verificar a sua aplicabilidade, foram realizados estudos de caso em duas ciclovias do Distrito Federal para verificar seus graus de mobilidade sustentável, a importância do método e a viabilidade operacional dos indicadores. O grau de sustentabilidade da ciclovia do Varjão foi de 0,51 e o da ciclovia de Samambaia de 0,79.

Verificou-se que a ciclovia de Samambaia possui maior volume de ciclistas, muitas residências e áreas comerciais nas imediações, o que não acontece junto à ciclovia do Varjão. Portanto, aparenta ter mais sustentabilidade para quem circula pelas mesmas. Ainda assim, a diferença em termos de sustentabilidade na aplicação do método foi bastante elevada, sendo o grau de sustentabilidade em Samambaia 0,28 superior ao da ciclovia do Varjão, em uma escala de zero a um.

O percentual de viagens de ciclistas por motivo de trabalho ou estudo é maior no Varjão do que em Samambaia. No Varjão não há integração entre os ciclistas com outros modos de transporte. Em Samambaia, há uma integração boa entre os ciclistas e três estações de metrô, ainda que não haja com ônibus. A percepção do ciclista com relação à localização espacial e conectividade com outras ciclovias, com a qualidade da sinalização da ciclovia, dos cruzamentos cicloviários e do tratamento dos locais críticos, promoção de atividade de lazer e promoção de qualidade de vida e redução do nível de estresse dos ciclistas foi também considerada maior em Samambaia.

Com relação à variação anual da quantidade de ciclistas mortos em acidentes de trânsito na região da ciclovia por ano, no Varjão houve aumento de uma morte de ciclista, comparando os anos de 2007 e 2013, enquanto que em Samambaia houve redução. 
Outro ponto importante que em grande parte explica esta diferença é que alguns indicadores que receberam pontuação alta pelos especialistas, especificamente as constantes de escala "variação anual da quantidade de ciclistas mortos em acidentes de trânsito na região da ciclovia por habitante por ano", "redução do custo anual de poluentes devido à transferência de viagens motorizadas para o modo cicloviário", "redução de emissão de poluentes de gases de efeito estufa" e "redução de emissão de poluentes locais" tiveram também diferenças altas em favor da ciclovia de Samambaia nas notas atribuídas pelos ciclistas e pela autora $\left(\mathrm{v}_{20}, \mathrm{v}_{21}, \mathrm{v}_{22} \mathrm{e} \mathrm{v}_{23}\right)$.

Verificou-se que, no Varjão, mais da metade dos ciclistas usa a bicicleta como meio de transporte.

Um dos conflitos verificados durantes as entrevistas de opinião foi a utilização das ciclovias pelos pedestres. No entanto, não se observou maiores conflitos entre eles, ou seja, há um convívio relativamente harmonioso entre eles, o que não acontece quando se considera o transporte individual motorizado. Isso ocorre, pois, a maioria das cidades brasileiras não apresenta infraestrutura apropriada para a locomoção a pé, o que aumenta conflitos entre o pedestre com ciclistas e outros veículos.

As calçadas, quando existentes, oferecem constantemente riscos devido a problemas como desníveis abruptos, guias e rampas irregulares; medidas mínimas exigidas inadequadas; mobiliário urbano mal colocado; piso inadequado e péssimas condições de manutenção.

\subsection{LIMITAÇÃO DA TESE}

Uma limitação deste trabalho é que, originalmente, na concepção dos indicadores 21 = Redução de custo anual de poluentes devido à transferência de viagens motorizadas para o modo cicloviário, 22 = Redução de emissão de poluentes de gases de efeito estufa, e 23 = Redução de emissão de poluentes locais, Os valores de referência para a pontuação foram percentuais de redução de custo ou da quantidade de poluentes devido à transferência de viagens para o modo cicloviário em relação ao custo ou quantidade total de poluentes na situação "sem ciclovia". 
Os cálculos na situação "sem ciclovia" mostraram-se inviáveis por dois motivos:

- Carência de dados dos volumes classificados de tráfego;

- Dificuldade de estabelecer o comprimento do trecho na situação "sem ciclovia" para efeitos de cálculos dos custos totais ou quantidades totais de poluentes globais ou locais. Isto porque para o cálculo da redução dos custos ou das quantidades de poluentes devido à transferência de viagens para a ciclovia cada ciclista que realizou a transferência modal teve um comprimento de viagem definido a partir das informações de cada um. Mas, cientificamente, fica difícil definir o comprimento do trecho (trecho médio) para os cálculos na situação "sem ciclovia" (comprimento do trecho a ser beneficiado).

Os valores de referência foram então estabelecidos a partir da aplicação do método nas ciclovias do Varjão e da Samambaia, a partir da média dos custos e das quantidades de poluentes calculados para estas ciclovias.

\subsection{ESTUDOS FUTUROS}

A seguir são sugeridos alguns temas para novos estudos de cunho científicoacadêmico em cursos de pós-graduação nas universidades. Alguns visam ao aperfeiçoamento do Método para a Determinação da Sustentabilidade de Ciclovias, enquanto outros se relacionam direta ou indiretamente com os trabalhos desenvolvidos. São os seguintes os temas sugeridos:

- Estudo com o objetivo de garantir maior consistência aos valores de referência dos seguintes indicadores:

21 = Redução de custo anual de poluentes devido à transferência de viagens motorizadas para o modo cicloviário, $22=$ Redução de emissão de poluentes de gases de efeito estufa, e 23 = Redução de emissão de poluentes locais,

Para isso, propõe-se que o Método para a Determinação da Sustentabilidade de Ciclovias seja aplicado em número representativo de ciclovias brasileiras, de modo a estabelecer o custo e as quantidades de poluentes que representem valores médios da realidade brasileira; 
- Estudo para que o Método para a Determinação da Sustentabilidade de Ciclovias seja aplicado em várias ciclovias para determinar o grau de sustentabilidade a partir do qual a ciclovia pode ser considerada sustentável;

- Estudo para a adaptação do Método para a Determinação da Sustentabilidade de Ciclovias para possibilitar a comparação de projetos ainda não implantados de infraestrutura cicloviária;

- Estudo com o objetivo de calcular os ganhos ambientais e de acidentes de trânsito, de forma científica, porém, com maior facilidade de aplicação;

- Estudos com a utilização dos 28 indicadores estabelecidos nesta Tese ou de parte deles para possibilitar o desenvolvimento de outros métodos;

- Vulnerabilidade às questões climáticas;

- Considerando que as mudanças climáticas constituem uma questão atual e que no ano atual de 2016 duas mortes ocorreram devido ao desabamento de parte da estrutura da Ciclovia Tim Maia no Rio de Janeiro, provocada pelo problema da força dos ventos e das ondas, eventos extremos associados ao clima, recomenda-se que em estudos futuros seja considerada a utilização de um indicador relacionado com a vulnerabilidade da infraestrutura da ciclovia frente às mudanças climáticas. 


\section{REFERÊNCIAS BIBLIOGRÁFICAS}

ABIPEÇAS e SINDIPEÇAS. Relatório da Frota Circulante de 2015. Disponível em: <http://www.sindipecas.org.br/sindinews/Economia/R_Frota_Circulante_Marco_2015.pdf> em maio de 2016.

ALEXANDRE, João Welliandre Carneiro, ANDRADE, Dalton Francisco, VASCONCELOS, Alan Pereira, ARAUJO, Ana Maria Souza, BATISTA, Ana Maria Souza. Análise do Número de Categorias da Escala de Likert Aplicada à Gestão pela Qualidade Total através da Teoria da Resposta ao Item. XXIII Encontro Nacional de Engenharia de Produção. Ouro Preto, Minas Gerais, 2003. Disponível em: <http://www.abepro.org.br/biblioteca/ENEGEP2003_TR0201_0741.pdf> em maio de 2016.

AlmeIDA, A. T. e COSTA, A. P. C. S. Aplicações com Métodos Multicritérios de Apoio à Decisão. Universidade Federal de Pernambuco, 2003.

ANTP. Relatório Geral de 2010 do Sistema de Informações da Mobilidade Urbana. Associação Nacional de Transportes Públicos, 2010a.

ANTP. Sistema de Informações da Mobilidade Urbana. Custos dos Deslocamentos. Custos para usar ônibus, Moto e Automóvel. Dados de março de 2010. Associação Nacional de Transportes Públicos, $2010 \mathrm{~b}$.

ANTP. Sistema de Informações da Mobilidade Urbana. Associação Nacional de Transportes Públicos, 2012. Disponível em: <http://portal1.antp.net/site/simob/default.aspx> em maio de 2016.

ASSOCIAÇÃO PARK WAY RESIDENCIAL. Na defesa do bem-estar dos moradores e do cinturão verde para Brasília! A Ciclovia da 25 vai desabar! Disponível em: <http://associacaoparkwayresidencial.blogspot.com.br/p/eventos.html> em maio de 2016.

COSTA, C. A. B. e VANSNICK, J. C. "MACHBETH: An Interactive Path Towards the Construction of Cardinal Value Functions". "International Transactions”. Operational Research, n. 1, p. 489-500, 1994.

BANCO MUNDIAL. Brasil: Justo, Competitivo, Sustentável. Contribuições para Debate. Banco Internacional para Reconstrução e Desenvolvimento, 2002.

BANCO MUNDIAL. Environmental Performance Indicators. Washington, D.C. Banco Mundial, 1999.

BANISTER, D. “The Sustainable Mobility Paradigm.” Transport Policy, 15(2): 73-80, 2008.

BARBETTA, P. A. Estatística Aplicada às Ciências Sociais. 5 ${ }^{\text {a }}$ Edição Revisada. Florianópolis: Edição da UFSC, 2002.

BELGIAN FEDERAL SCIENCE POLICY. Levers for a Sustainable Development Policy - Final Reports. “Scientific Support Plan for a Sustainable Development Policy SPSD 1", 2002.

BICKEL, Peter, AHVENHARJU, Sanna, KÖNNÖLÄ, Totti, HJELT, Mari, DE TOMMASI, Roberto, AREND, Michal, RÖHLING, Wolfgang e BURG, Robert. Setting the Context for Defining Sustainable Transport and Mobility. "SUMMA. Version 2.0”. "European Comission”, 2003.

BOCCA, Lucas Scatulin. Auxílio Multicritério à Decisão Aplicado à Implantação de Sistema de Armazenamento de Grãos na Propriedade Rural. Dissertação de Mestrado em Engenharia Civil, Arquitetura e Urbanismo. Universidade Estadual de Campinas, 2012.

BORKEN, Jens. Indicator for Sustainable Mobility - A Policy Oriented Approach. "Proceeding Transport and Environment". "1º Symposium”, Avignon, France, 2003. 
BOSSEL, H. Indicators for Sustainable Development: Theory, Method and Application. "International Institute for Sustainable Development”, Canadá, 1999.

BOUYSSOU, D.; MARCHANT, T.; PIRLOT, M.; PERNY, P.; TSOUKIÁS e A.; VINCKE, P. Evaluation and Decision Models: A Critical Perspective. Boston: Kluwer Academic, 2000.

BRASIL. Constituição da República Federativa do Brasil de 1988.

BRASIL. Metodologia Integrada de Suporte ao Planejamento, Acompanhamento e Avaliação dos Programas Nacionais de Transporte: Relatório Síntese. Ministério dos Transportes, Secretaria de Gestão de Programas de Transportes, Universidade de Brasília - Centro de Formação de Recursos Humanos em Transportes - CEFTRU, 2007a.

BRASIL. Caderno de Referência para Elaboração de Plano de Mobilidade por Bicicleta nas Cidades. Caderno 1. Coleção Bicicleta Brasil. Programa Brasileiro de Mobilidade por Bicicleta. Secretaria Nacional de Transporte e da Mobilidade Urbana - Ministério das Cidades. Brasília, Distrito Federal. 232 p. $2007 \mathrm{~b}$.

BRASIL. Resolução $n^{o}$ 418. Dispõe sobre critérios para a elaboração de Planos de Controle de Poluição Veicular - PCPV e para a implantação de Programas de Inspeção e Manutenção de Veículos em Uso I/M pelos órgãos estaduais e municipais de meio ambiente e determina novos limites de emissão e procedimentos para a avaliação do estado de manutenção de veículos em uso. Conselho Nacional do Meio Ambiente. CONAMA. 2009.

BRASIL. Indicadores de Programas: Guia Metodológico. Ministério do Planejamento, Orçamento e gestão, Secretaria de Planejamento e Investimentos Estratégicos. Brasília, 2010.

BRASIL. Plano Nacional de Logística e Transportes - PNLT - Sumário Executivo, 2011.

BRASIL. Plano Setorial de Transporte e de Mobilidade Urbana para Mitigação e Adaptação à Mudança do Clima - PSTM. Ministério dos Transportes. Ministério das Cidades. 2013. Disponível em: <http://www.transportes.gov.br/images/ACOES_PROGRAMAS/Politica_MeioAmbiente.pdf> em maio de 2016.

BRÜSEKE F. J. O Problema do Desenvolvimento Sustentável. Núcleo de Altos Estudos Amazônicos - NAEA, 1995.

CABRAL, Francisco Caldeira: Arte Do Equilíbrio Dinâmico Da Vida. Conversa Sobre Arquitetura Paisagista, p. 58. 2008. Disponível em: <http://nucleoap.blogspot.com.br/2008/10/fotos-da-viagem-holanda.html> em maio de 2016.

CAMPOS, V. B. G. e MELO, B. P. Relacionando a Ocupação Urbana com o Sistema Viário para o Desenvolvimento Sustentável. 2005. Disponível em: <http://www.ime.eb.br/ webde2/prof/vania/pubs/(8)Ocupacaourbana-sistemaviario.pdf> em maio de 2016.

CAMPOS, V. B. G.; RAMOS, R. A. R. Proposta de Indicadores de Mobilidade Urbana Sustentável Relacionando Transporte e Uso do Solo. PLURIS. São Carlos. São Paulo, 2005.

CARVALHO, Fernanda. Teste em ciclovias revela armadilhas em São Paulo, 2015. Disponível em: <http://www.mancheteonline.com.br/teste-em-ciclovias-revela-armadilhas-em-sao-paulo> em maio de 2016. 
CARVALHO, N. R. V. Indicadores Ambientais para o Transporte com Foco na Qualidade do Ar. Dissertação de Mestrado em Transportes. Universidade Federal do Rio de Janeiro, COPPE, 2005.

CARVAlHO, Carlos H. R.de, GOMIDE, A. de A., PEREIRA, Rafael. H. M., MATION, L. F., BALBIM, R. N., NETO, V. C. de L., GALINDO, E. P., Krause e GUEDES, E. P. Tarifação e financiamento do transporte público urbano. Instituto de Pesquisa Econômica Aplicada, Brasília, 2013.

CMMAD. Nosso Futuro Comum. Comissão Mundial sobre Meio Ambiente e Desenvolvimento. Ed. Fundação Getúlio Vargas, Rio de Janeiro, 1991.

CERVERO, R. Gestão do Transporte e Mobilidade Urbana: Estratégias e Soluções que Funcionam. $7^{o}$ Encontro da Aliança das Capitais. Brasília, Distrito Federal, 2010.

CETESB. Emissão Veicular - Transporte Sustentável. Companhia Ambiental do Estado de São Paulo, 2011.

CICLOATIVISMO. Paraciclos. 2015. Disponível em <http://www.cicloativismo.com/entenda-asdiferencas/paraciclo> em maio de 2016.

COMGAS. Rendimento. 2015.2 Disponível em: <http://www.comgas.com.br/pt/comgasParaVoce/Veicular/Paginas/form_gasolina.html> em maio de 2016.

COSTA, Marcela da Silva. Um Índice de Mobilidade Urbana Sustentável. Tese de Doutorado em Planejamento e Operação de Sistemas de Transportes. Escola de Engenharia de São Carlos. Universidade de São Paulo, 2008.

COSTA, Marcela da Silva. Mobilidade urbana sustentável: um estudo comparativo e as bases de um sistema de gestão para Brasil e Portugal. Dissertação de Mestrado em Transportes. Escola de Engenharia de São Carlos. Universidade de São Paulo, 2003.

DAHL, Arthur L.” The Big Picture: Comprehensive Approach.” In: Moldan, B.;Bilharz S. (Eds). Sustainability Indicators: Report of the Project on Indicator of Sustainable Development. Chichester: John Wiley\& Sons Ltda, 1997.

DA SILVA, Alan Ricardo. Reunião pessoal com o professor adjunto do Departamento de Estatística da Universidade de Brasília, UNB. 2014.

DENATRAN. Anuário Estatístico do DENATRAN. Departamento Nacional de Trânsito. Registro Nacional de Acidentes e Estatísticas de Trânsito. RENAEST, 2015.

DER/UNB. Contagens de Tráfego nas Rodovias do Distrito Federal - Pesquisas com Duração de 24 horas. Departamento de Estradas de Rodagem do Distrito Federal. Universidade de Brasília, 2005.

DILLMAN, D. A. Mail and Telephone Surveys: The Total Design Method. Nova York. Wiley, 1978.

DISTRITO FEDERAL. Plano de Mobilidade por Bicicleta no Distrito Federal. Casa Civil do Distrito Federal, 19 p., 2013.

EASTMAN, J. R. IDRISI for Windows: User's Guide. "Version 2.0.” Clark University". "Graduate School of Geography.” Worcester, MA, Estados Unidos, 1997.

ELKINGTON. "Towards the Sustainable Corporation: Win-win-win Business Strategies for Sustainable Development", California Management Review, v. 36 n. 2, p. 90-100, 1994. 
ENSSLIN, L.; DUTRA, A.; ENSSLIN, S. R. MCDA. "A Constructivist Approach to the Management of Human Resources at a Governmental Agency." International Transactions in Operational Research vol. 7, 2000 .

EUROPEAN COMMISSION. Sustainable Mobility, Policy Measures and Assessment - SUMMA - Final Publishable Report 2.0, 2005.2 Disponível em: <http://www.tmleuven.be/project/summa/summa-d8.pdf> em maio de 2016.

EUROPEAN ENVIRONMENTAL AGENCY. TERM 2011: Transport Indicators Tracking Progress Towards Environmental Targets in Europe. "Laying the Foundations for Greener Transport". EEA Report $\mathrm{n}^{\mathrm{o}}$ 7, 2011.

FABER, N.; JORNA R.; VAN ENGELEN, J. "The Sustainability of "Sustainability" - A Study into the Conceptual Foundations of the Notion of "Sustainability". Journal of Environmental Assessment Policy and Management, Vol. 7, No. 1 (March 2005) p. 1-33, "Imperial College Press", 2005.

FOWLER, F. J. Design and Evaluation of Survey Questions. In BICKMAN, L. e ROG, D. J. Handbook of Applied Social Research Methods (pp. 343-374). Thousand Oaks, Califórnia, Sage, 1998.

FRASSON, Alexandre Cesar. Escolha de Alternativa Tecnológica para Tratamento e Destino Final de Lodo Gerado no Tratamento de Efluentes Líquidos de Agroindústrias com Base no Método AHP. Dissertação de Mestrado. Universidade Estadual de Londrina, 2011.

GALLOPÍN, G. Indicators and their Use: Information for Decision Making. In: Moldan, B.; Billharz, S. Sustainability Indicators. New York. John Wiley and Sons, 1997.

GALLOPÍN, G. "Environmental and Sustainability Indicators and the Concept of Situational Indicators. A Systems Approach.” Environmental Modeling and Assessment, v. 1, n. 3, p. 101-117, 1996.

GALVES, Maria Lúcia. E-mails trocados com a professora do Departamento de Geotecnia e Transportes da Universidade Estadual de Campinas - UNICAMP. São Paulo, 2012.

GALVES, M. L. "Structuring Decision Situations: a Brief Overview”. In Barthélemy, J. P. e Lenca, P. (eds.), Advances in Multicriteria Decision Aid. Brest, p. 32-40, 2005.

GEIPOT. Planejamento Cicloviário: Diagnóstico Nacional. Empresa Brasileira de Planejamento de Transportes. Brasília, 196 p., 2001.

GLOBO. Cadeirante e especialista apontam falhas em obra de ciclovia em Manaus. 2015. Disponível em: <http://g1.globo.com/am/amazonas/noticia/2015/02/cadeirante-e-especialista-apontam-falhas-emobra-de-ciclovia-em-manaus.html> em maio de 2016.

GOMES, L. F. A. M., GOMES, C. F. S. e ALMEIDA, A. T. Tomada de Decisão Gerencial: Enfoque Multicritério. Editora Atlas, 264p, 2002.

GOMES, L. F. A. M.; GONZALEZ-ARAYA, M. C. \& CARIGNANO, C. Tomada de Decisões em Cenários Complexos. Pioneira Thompson Learning, 168p., 2004.

GOMES, L. F. A. M; GOMES, C. F. S e ALMEIDA, A. T. Tomada de Decisão Gerencial: Enfoque Multicritério. $2^{\text {a }}$ edição. São Paulo: Atlas, 2006.

GOMES, E. G., MELlO, J. C. C. B. S. MANGABEIRA, J.A. C. Índice Multicritério de Bem-Estar Social Rural em um Município da Região Amazônica. Pesquisa Operacional vol. 28, n.1.Rio de Janeiro, 2008. 
GOMIDE, A. de A., CARVAlHO, Carlos H. R. de, PEREIRA, Rafael. H. M., GALINDO, E. P., NETO, V.

C. de L. A. Nova Lei de Diretrizes da Política Nacional de Mobilidade Urbana. Instituto de Pesquisa Econômica Aplicada, Brasília, 2012.

GONDIM, Mônica Fiuza. Transporte Não Motorizado na Legislação Urbana no Brasil. Dissertação de Mestrado em Engenharia de Transportes. Universidade Federal do Rio de Janeiro, 2001.

GONDIM, Mônica Fiuza. Cadernos de desenho: ciclovias. Rio de janeiro. Editora COPPE/UFRJ, 2010.

GRELLET, Fábio. Trecho de Ciclovia no Rio Afunda por Causa de Vazamento. Disponível em <http://topicos.estadao.com.br/ciclovia> em jul. de 2015.

GUIMARÃES, V. Manual de sobrevivência na calçada: um guia prático para pedestres e ciclistas nas novas ciclovias da zona oeste do Rio de Janeiro. 2012. Disponível em: <https://historiadoesporte.wordpress.com/2012/01> em maio de 2016.

GUDMUNDSSON, H. "Indicators and performance measures for Transportation, Environment and Sustainability in North America". Research Notes n. 148. "Ministry of Environment and Energy". "National Environmental Research Institute", 2001. Disponível em: <http://www2.dmu.dk/1_viden/2_Publikationer/3_arbrapporter/rapporter/AR148.pdf> em maio de 2016.

GÜNTHER, H. Como Elaborar um Questionário (Série: Planejamento de Pesquisa nas Ciências Sociais, $n^{\circ}$ 01). Brasília, DF: UnB, Laboratório de Psicologia Ambiental, 2003.

IBGE. Estimativas populacionais para os municípios brasileiros em 01.07.2013. Instituto Brasileiro de Geografia e Estatística, 2013a. Disponível em: <http://www.ibge.gov.br/home/estatistica/populacao/estimativa2013/default.shtm> em maio de 2016.

IBGE. Projeção da População do Brasil por sexo e idade: 2000-2060. Instituto Brasileiro de Geografia e Estatística, 2013b. Disponível em: <http://www.ibge.gov.br/home/estatistica/populacao/projecao_da_populacao/2013/default_tab.shtm> em maio de 2016.

IEA. Transport, Energy and $\mathrm{CO}_{2}$.International Energy Agency, Paris, 2009.

IPCC. Intergovernmental Panel on Climate Change Special Report on Managing the Risks of Extreme Events and Disasters to Advance Climate Change Adaptation. "Intergovernmental Panel on Climate Change", 2011.

IPCC. Intergovernmental Panel on Climate Change. "Directrices del IPCC para los inventários nacionales de gases de efecto invernadero". Reino Unido: IPCC WGI Technical Support Unit, 1997.

ITDP. Sustainable Transport Award. Instituto de Políticas de Transporte e Desenvolvimento, 2013. Disponível em: <http://www.itdp.org/get-involved/sustainable-transport-award> em maio de 2016.

IUCN, UNEP e WWF. World Conservation Strategy: Living Resource Conservation for Sustainable Development. "Union of Conservation Scientists" - IUCN. "United Nations Environment Programme" UNEP. "World Wide Fund for Nature" - WWF. 1980. Disponível em: <http://data.iucn.org/dbtwwpd/edocs/WCS-004.pdf> em maio de 2016. 
KAYANO, J. e CALDAS, E. Indicadores para o Diálogo. In: SPINK, Peter, CACCIA-BAVA, Silvio e PAULICS, Veronika. Novos Contornos da Gestão Local: Conceitos em Construção. São Paulo. FGVEAESP, 2002.

KEENEY, R. L. e RAIFFA, H. Decision with Multiple Objectives: Preferences and Value Trade-Offs. New York: John Wiley, 1976.

KÖLBL, R., M. NIEGL e H. KNOFLACHER. “A Strategic Planning Methodology”. Transport Policy, n. 15, p. 273-282, 2008.

KRAMA, Márcia Regina. Análise dos Indicadores de Desenvolvimento Sustentável no Brasil Usando a Ferramenta Painel de Sustentabilidade. Dissertação de Mestrado em Engenharia de Produção e Sistemas. Pontifícia Universidade Católica do Paraná, 2008.

LAKATOS, Eva Maria e MARCONI, Marina de Andrade. Metodologia do Trabalho Científico. $7^{\text {a }}$ edição. Editora Atlas, 2007.

LARICHEV e MOSHKOVICH. Verbal Decision Analysis for Unstructured Problems. Boston: Kluwer. Academic Publishers. 1997.

LARICHEV, O. I. e OLSON, D. L. Multiple Criteria Analysis in Strategic Siting Problem. Dordrecht: "Kluwer Academic Publishers", 2001.

LIKERT, Rensis. "A Technique for the Measurement of Attitudes", Archives of Psychology v. 140: pp. 1-55, 1932.

LITMAN, T. e BURWELL, D. "Issues in Sustainable Transportation”. Global Environmental Issues, Vol. 6, No. 4, 2006.

LITMAN, Todd. Well Measured: Developing Indicators for Comprehensive and Sustainable Transport Planning. "Victoria Transport Policy Institute", 2008a. Disponível em: <http://www.vtpi.org/wellmeas.pdf> em mai. de 2015.

LITMAN, T. "Sustainable Transportation Indicators". A Recommended Research Program for Developing Sustainable Transportation Indicators and Data. "Transportation Research Board Annual Meeting", 2008b.

MACHADO, Laura. Índice de Mobilidade Sustentável para Avaliar a Qualidade de Vida Urbana. Dissertação de Mestrado em Planejamento Urbano. Universidade Federal do Rio Grande do Sul, 2010.

MAGAGNIN, Renata Cardoso. Um Sistema de Suporte à Decisão na Internet para o Planejamento da Mobilidade Urbana. Tese de Doutorado em Transportes. Escola de Engenharia de São Carlos. Universidade de São Paulo, 2008.

MAMELI, Francesca e Gerardo MARLETTO. “A Selection of Indicators for Monitoring Sustainable Urban Mobility Policies". In Trasporti, Ambiente e Territorio. Franco Angeli, Milano, pp.167-174, 2009.

MARSHALL, S. "The Challenge of Sustainable Transport.” In: Layard, A., Davoudi, S., Batty, S. (Eds.), Planning for a Sustainable Future. Spon, London, pp. 131-147, 2001.

MCTI. Estimativas Anuais de Emissões de Gases de Efeito Estufa no Brasil. $2^{a}$ edição. Ministério da Ciência, Tecnologia e Inovação, 2014. 
MEADOWS, D. L., MEADOWS, D. H., RANDERS, J.; BEHRENS, W.W. Limites do Crescimento - Um Relatório para o Projeto do Clube de Roma sobre o Dilema da Humanidade. São Paulo: Ed. Perspectiva, 1972.

MENDES, J. F. G. Avaliação da Qualidade de Vida em Cidades: Fundamentos e Aplicações. Plano Integrado: em Busca de desenvolvimento Sustentável para Cidades de Pequeno e Médio Portes”. Braga, Portugal, 2004.

MILleR, G. A. “The Magical Number Seven, Plus or Minus Two”. The Psychological Reviewv. 63, 1956.

MINISTÉRIO DAS CIDADES. Sistema de Informações em Mobilidade Urbana - SIMU. Disponível: <http://www.cidades.gov.br/mobilidade-urbana/informacoes-e-indicadores/232-secretaria-nacionalde-transporte-e-da-mobilidade/informacoes-e-indicadores-semob/4095-sistema-de-informacoes-emmobilidade-urbana-simu> em mai. de 2015.

MINISTÉRIO DAS CIDADES. Caderno de referência para elaboração de Plano de Mobilidade Urbana. Brasília, 2007.

MINISTÉRIO DAS CIDADES. Política Nacional de Mobilidade Urbana Sustentável. Cadernos MCidades $\mathrm{n}^{\circ}$ $6,2004$.

MINISTÉRIO DAS CIDADES. Caderno de Referência para o Plano de Mobilidade Urbana. Brasília, 2015.

MIRANDA, A. C. M. Se Tivesse que Ensinar a Projetar Ciclovias. In: ANTP. Transporte Cicloviário. Associação Nacional de Transportes Públicos. São Paulo, p. 68-111, 2007.

MMA, IBAMA e IPEA. Meio Ambiente e Transporte Urbano: Análise Bibliográfica e Propostas sob o Enfoque das Políticas Públicas. Ministério do Meio Ambiente. Instituto Brasileiro de Meio Ambiente. Instituto de Pesquisa Econômica Aplicada, 2002.

MMA. Inventário Nacional de Emissões Atmosféricas por Veículos Automotores Rodoviários 2013. Ano Base 2012. Relatório Final. Ministério do Meio Ambiente, 2013.

MOLITERNO, Paulo Henrique Cotrim. Utilização da Lógica Paraconsistente na Elaboração de Síntese de Questionário de Avaliação: Caso do Ensino Superior. Dissertação de Mestrado. UNIP. São Paulo, 2010.

MOORE, J. A. e JOHNSON, J. M. Transportation, Land Use and Sustainability. "Florida Center for Community Design + Research", Florida, 1994. Disponível em: <http://www.fccdr.usf.edu/upload/projects/tlushtml/default.htm> em mai. de 2015.

MORAIS, Maria da Piedade e COSTA, Marco Aurélio (Org.). Infraestrutura Social e Urbana no Brasil: Subsídios para uma Agenda de Pesquisa e Formulação de Políticas Públicas. Livro 6, Volume 2. Projeto Perspectivas do Desenvolvimento Brasileiro. Instituto de Pesquisa Econômica Aplicada, 2010.

MOTTA, R. A; RIBEIRO, S. K. e PORTUGAL, L. S. Análise Crítica de Corredores de Ônibus sob o Ponto de Vista Ambiental. Revista dos Transportes Públicos, n.116, ano 30, 4. Trimestre. Associação Nacional de Transportes Públicos, 2007.

MOTTA, Renata Almeida. Benefícios Ambientais em Decorrência da Implantação de Sistemas de Transporte Rápido e de Alta Capacidade de Ônibus - o Caso do Transmilênio. Dissertação de Mestrado em Transportes. Programa de Engenharia de Transportes, COPPE, Universidade Federal do Rio de Janeiro, 2009. 
MOURA, Ana Clara Mourão, FREIRE, Gerson J. Mattos, OLIVEIRA, Renata Hungari de, SANTANA, Sheyla Aguilar de, PEREIRA, Marcílio Felício, SOARES, América Maria Eleutério, VOLL, Vera Lúcia. Geoprocessamento no Apoio a Políticas do Programa Vila Viva em Belo Horizonte - MG: Intervenções em Assentamentos Urbanos Precários. Revista Brasileira de Cartografia nº 61/02, 2009.

NEUMANN, Alexandre Guimarães. Modelo Multicritério no Processo de Seleção de Subempreiteiros na Construção Civil. Dissertação de Mestrado em Estruturas e Construção Civil. Universidade de Brasília, 2008.

NICOLAS, J. P; POCHET, J.; POIMBOEUF, H. “Towards Sustainable Mobility Indicators - Application to the Lyons Conurbation”. Transport Policy, Vol. 10, n³, “Urban Transport Policy Instruments", p. $197-$ 208, 2003.

OBSERVATÓRIO NACIONAL DE SEGURANÇA VIÁRIA. Retrato da Segurança Viária no Brasil. Ambev S.A. FALCONI Consultores de Resultados. 107p, 2014.

OECD. Indicators for the Integration of Environmental Concerns into Transport Policies. "Organisation for Economic Co-operation and Development”, 1999.

OECD, Report on the OECD Conference Environmentally Sustainable Transport (EST): Futures, Strategies and Best Practice, 2002.

OECD. “OECD Core Set of Indicators for Environmental Performance Reviews”. Environmental Monograph $\mathrm{n}^{\circ}$ 80. Paris. "Organization for Economic Cooperation and Development”, 1993.

OZERNOY, V. M. “Choosing the Best Multiple Criteria Decision-Making Method”. INFOR, v. 30, n. 2, p. 159-171, 1992.

PEARCE, D. W. e ATKINSON, G. "Capital Theory and the Measurement of Sustainable Development: an Indicator of Weak Sustainability”. Ecological Economics, v. 8: p.103-108, 1993.

PIRES, C. C. Potencialidades Cicloviárias no Plano Piloto. Dissertação de Mestrado em Arquitetura e Urbanismo, Universidade de Brasília. Distrito Federal, 2008.

PIRES, Mauro Oliveira. A Perspectiva do Desenvolvimento Sustentável. In: Little, Paul E. Políticas Ambientais no Brasil: Análises, Instrumentos e Experiências. Instituto Internacional de Educação no Brasil- IIEB, 2003.

PONTES, Taís Furtado. Avaliação da Mobilidade Urbana na Área Metropolitana de Brasília. Dissertação de Mestrado em Arquitetura e Urbanismo. Universidade de Brasília, 2010.

PORTAL LAGARTENSE. Buracos continuam a "engolir" a Ciclovia da Cidade. 2011. Disponível em: <http://www.lagartense.com.br/5207/buracos-continuam-a-engolir-a-ciclovia-da-cidade-nova> em maio de 2016.

PREFEITURA DE PORTO ALEGRE. Plano Diretor Cicloviário Integrado de Porto Alegre. Relatório Final, 2008.

Disponível

em:

<http://lproweb.procempa.com.br/pmpa/prefpoa/eptc/usu_doc/pdci_relatorio_final.pdf > em maio de 2016.

PRONK, J.; UL HAQ, M. Sustainable Development: from Concept to Action. "United Nations Development Programme", Nova York, 1992. 
RANGEL, L. A.D. e GOMES, L. Z. A. M. Determinação do Valor de Referência do Aluguel de Imóveis Residenciais Empregando o Método TODIM. Revista PO, 2007.

REPETTO, Robert e MAGRATH, William B. Market Mechanisms. "Natural Resources Accounting”. World Resources Institute, Washington, D.C, 1988.

RODEGHIER, M. Surveys with Confidence: A Practical Guide to Survey Research Using SPSS. In LINDZEY

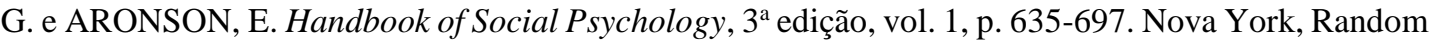
House, 1996.

ROY, B. Paradigms and Challenges. In: FIGUEIRA, J.; GRECO, S.; EHRGOTT, M. Multiple Criteria Decision Analysis: State of the Art Surveys. Boston: Springer, 2005.

SCHUMAN, H. e KALTON, G. Survey Methods - Chapter 12. In: LINDZEY, G e ARONSON, E. (eds) Handbook of Social Psychology (vol 1). New York: Random Press. 1985.

RUTHERFORD, I. Use of Models to link Indicators of Sustainable Development. In: MOLDAN, B.; BILHARZ, S. "Sustainability Indicators: Report of the Project on Indicators of Sustainable Development”. Chichester: John Wiley \& Sons Ltda., 1997.

SAATY, T. L. The Analytic Hierarchy Process. New York: McGraw Hill Company, 1980.

SACHS, I. Ecodesenvolvimento, Crescer sem Destruir. Vértice, São Paulo, 1986.

SCHMIDT, A. M. A. Processo de Apoio à Tomada se Decisão Abordagens: AHP e MACBETH. Dissertação de Mestrado em Engenharia de Produção. Universidade Federal de Santa Catarina, 1995.

SEDU/PR. Indicadores de Transportes Urbanos. Sistema Nacional de Indicadores Urbanos - SNIU, Vol. II, 62 p., 2002.

TAPAJÓS, Dilaelson Rego. Modelo de Indicadores de Sustentabilidade Aplicável a Hidrovias na Amazônia MISAHA. Tese de Doutorado. Universidade Federal do Rio Grande do Sul, 2002.

THE CENTRE FOR SUSTAINABLE TRANSPORTATION. Sustainable Transportation Performance Indicators. "Underlying Data and Calculations", 2003.

TRIANTAPHYlloU, E. Multi-Criteria Decision Making Methods: A Comparative Study. Dordrecht: "Kluwer Academic Publishers", 2000.

TRB. Highway Capacity Manual. "Transportation Research Board. National Research Council”, Washington, D.C, 2010.

TUW-IVV.PROSPECTS: Cities Decision Making Requirements. Summary of Responses from Core Cities. "The Institute for Transport Planning and Traffic Engineering. Vienna University of Technology". Áustria, 2004.

UNDSD. Sustainable Development Issues: Energy, Transport and Atmosphere. "United Nations Division for Sustainable Development”, 2003. Disponível em: http://www.un.org/esa/sustdev/sdissues/ transport/transp.htm em mai. de 2015.

UNITED NATIONS. The Future We Want. Rio+20. 2012. Disponível em: <http://www.un.org/disabilities/documents/rio20_outcome_document_complete.pdf> em mai. de 2016. 
UNITED NATIONS. Conference on Environment and Development (Unced). Agenda 21 - "Program of Action for Sustainable Development": "Rio Declaration on Environmental and Development", "United Nation Conference on Environment and Development”, Rio de Janeiro, Brasil, 1992.

UNFCCC. Adoption of the Paris Agreement. Twenty-First Session. Paris. "United Nations Framework Convention on Climate Change." 2015.2 Disponível em: <https://unfccc.int/resource/docs/2015/cop21/eng/109r01.pdf> em julho de 2016.

VAlinho, A. L. Parque do Cantagalo Continua Sofrendo com Alagamentos, 2013. Disponível em: $<$ http://oglobo.globo.com/eu-reporter/parque-do-cantagalo-continua-sofrendo-com-alagamentos$7444958>$ em maio de 2016.

VAN BELLEN, H. M. Indicadores de Sustentabilidade: uma Análise Comparativa. 2a edição, Rio de Janeiro, Fundação Getúlio Vargas, 256 p, 2006.

VASCONCELlos, E. A. Transporte Urbano, Espaço e Equidade: Análise das Políticas Públicas. $3^{\mathrm{a}}$ edição. Editora Anablume, São Paulo, 2001.

VILAS BOAS. C. de L. Métodos Multicritérios de Análise de Decisão (MMAD) para as Decisões Relacionadas ao Uso Múltiplo de Reservatórios: Analytic Hierarchy Process (AHP). XVI Simpósio Brasileiro de Recursos Hídricos. João Pessoa, 2005.

VILAS BOAS, C. de L. Modelos Multicritérios de Apoio à Decisão Aplicado ao Uso Múltiplo de Reservatórios: Estudo da Barragem do Ribeirão João Leite. Dissertação de Mestrado em Gestão Econômica do Meio Ambiente. Universidade de Brasília, 2006.

VIOLATO, R.R., GALVES, M.L., OLIVEIRA, D.D.G.. "Non-motorized Mobility in Central Urban Areas: Application of Multi-Criteria Decision Aid in the City of Campinas, Brazil”. International Journal of Sustainable Transportation, $2012 . \quad$ Disponível em: <http://www.tandfonline.com/doi/full/10.1080/15568318.2012.713445> em maio de 2016.

VIOLATO, R. R., MONTEIRO, V. L. e GALVES, M. L. Incentivo às Viagens pelo Modo a Pé: Aplicação da Metodologia de Auxílio Multicritério à Decisão. Revista dos Transportes Públicos - ANTP - Ano 33 2011 - $2^{\circ}$ quadrimestre, 2011.

WBCSD. Indicators of Sustainable Mobility. "World Business Council for Sustainable Development”, 2003.

WBCSD. Mobility 2030: Meeting the Challenges to Sustainable. "World Business Council for Sustainable Development", 2004.

WCED. Our common Future. Oxford University Press, 1987.

WILLIAMS, J. e BANISTER, D. Land use Options to Reduce the Need to Travel, RTPI Conference, West Midlands, Junho, 1997.

WRI. Environmental Indicators: A Systematic Approach to Measuring and Reporting on Environmental Policy Performance in the Context of Sustainable Development, "World Resources Institute", Washington, 1995.

YARAK, A. A parada das ciclovias. 2015. Disponível em: <http://vejasp.abril.com.br/materia/ciclovias-obrasparalisadas-justica-prefeitura> em maio de 2016.

YAREMKO, R. K., HARARI, H., HARRISON, R. C. e LYNN, E. Handbook of Research and Quantitative Methods in Psychology. Hillsdale, NJ: Lawrence Erlbaum, 1986. 
APÊNDICES 


\section{A FICHAS DOS INDICADORES DE MOBILIDADE SUSTENTÁVEL APLICÁVEIS EM CICLOVIAS}

Nome do Indicador: Volume de bicicletas na ciclovia.

Dimensão de sustentabilidade: social.

Descrição: indicador da demanda de viagens na ciclovia com o propósito de verificar a promoção de acessibilidade para os ciclistas e o nível de carregamento da ciclovia.

Unidade de medida: volume de bicicletas por hora (ou por dia).

Como medir: contagem volumétrica de bicicletas em uma ou mais seções da ciclovia, em uma hora de pico (ou em período maior).

Normalização: para definir o critério de pontuação deste indicador levou-se em consideração as seguintes faixas de demanda adotadas pelo Plano Diretor Cicloviário Integrado de Porto Alegre (PREFEITURA DE PORTO ALEGRE, 2008) (soma dos fluxos nos dois sentidos):

- Baixa: Fluxos diários menores que 500 ciclistas.

- Média: Fluxos diários entre 500 e 3.000 ciclistas.

- Média alta: Fluxos diários entre 3.000 e 7.000 ciclistas.

- Alta: Fluxos diários superiores a 7.000 ciclistas.

Ressalta-se que o Manual de Capacidade Viária (Highway Capacity Manual - HCM), referência mundial para a avaliação da qualidade de serviço de rodovias (TRB, 2010), também estabelece níveis de serviço caracterizados para as condições operacionais de uma ciclovia. No entanto, a metodologia sugerida pelo HCM é demais complexa para normalizar este indicador, uma vez que se baseia na habilidade do ciclista de manter uma velocidade ótima, no número de vezes que encontra ou ultrapassa outro e na liberdade de manobra.

O conceito de capacidade também não foi utilizado neste trabalho, pois segundo o HCM (TRB, 2010), este apresenta pouca utilidade no projeto e análise de ciclovia, podendo apresentar dados dispersos, uma vez que a qualidade do serviço se deteriora em níveis de fluxo bem abaixo da capacidade.

A partir das Contagens de Tráfego nas Rodovias do Distrito Federal realizadas pelo Departamento de Estradas de Rodagem do Distrito Federal e pela Universidade de Brasília DER/UNB (2005), calculou-se o percentual do volume de tráfego na hora de pico em relação ao volume total diário das rodovias, bem como o percentual de volume de bicicletas na hora de pico em relação ao volume total diário de bicicletas, considerando, em ambos os casos, o valor médio para os postos de contagem. 
Dessa forma, foi possível estimar que o percentual do volume de tráfego na hora de pico é de $11,7 \%$ em relação ao volume total diário de veículos automotores e de $21,9 \%$ o volume de bicicletas na hora de pico em relação ao volume total diário de bicicletas. Conclui-se que as viagens por bicicletas são mais concentradas em determinado período do dia do que as viagens do tráfego geral ou de veículos automotores, e, portanto, para fins de cálculos, o percentual do volume de bicicletas na hora de pico é de $21,9 \%$ em relação ao volume total diário de bicicletas.

\begin{tabular}{c|l}
\hline Pontuação & \multicolumn{1}{c}{ Valores de Referência } \\
\hline 1,00 & O volume total diário de bicicletas na ciclovia é $\geq 7.000$. \\
\hline 0,75 & O volume total diário de bicicletas na ciclovia é $\geq 3.000$ e $<7.000$. \\
\hline 0,50 & O volume total diário de bicicletas na ciclovia é $\geq 500 \mathrm{e}<3.000$. \\
\hline 0,25 & O volume total diário de bicicletas na ciclovia é $\geq 100 \mathrm{e}<500$. \\
\hline 0,00 & O volume total diário de bicicletas na ciclovia é $<100$. \\
\hline
\end{tabular}

Observações: No caso da presente tese, para garantir um maior rigor acadêmico, as contagens de bicicletas nas ciclovias foram feitas observando um período de 14 horas (06 às 20 horas). A partir das contagens, os volumes foram expandidos para 24 horas, com base no estudo citado nos parágrafos anteriores (DER/UNB, 2005). Calculou-se o percentual do volume de bicicletas no período de 20 às 06 horas em relação ao volume total diário de bicicletas, considerando o valor médio para os postos de contagem. $\mathrm{O}$ percentual encontrado foi de $8,7 \%$.

Apesar de no item "como medir", ter sido indicado contagem volumétrica de bicicletas em uma hora de pico em uma ou mais seções da ciclovia, se possível, recomenda-se, contagens considerando períodos mais longos, como o caso desta tese, que considerou o período de 14 horas.

Nome do Indicador: Existência de áreas comerciais e unidades de ensino dentro de uma distância de 500 metros da ciclovia.

Dimensão de sustentabilidade: social.

Descrição: Indicador que verifica a existência de áreas comerciais e unidades de ensino dentro de uma distância de 500 metros da ciclovia, com o propósito de averiguar se a infraestrutura cicloviária promove acessibilidade aos habitantes da região.

Unidade de medida: quantidade de áreas comerciais e unidades de ensino dentro de uma distância de 500 metros da ciclovia.

Como medir: verificação da existência ou ausência de áreas comerciais e unidades de ensino dentro de uma distância de 500 metros da ciclovia pelo técnico responsável pela aplicação do método. 
Normalização: atribuir a pontuação correspondente à avaliação do técnico de acordo com os seguintes valores de referência:

\begin{tabular}{c|l}
\hline Pontuação & \multicolumn{1}{c}{ Valores de Referência } \\
\hline 1,00 & $\begin{array}{l}\text { A região é densa quanto a áreas comerciais e unidades de ensino } \\
\text { dentro de uma distância de 500 metros da ciclovia. }\end{array}$ \\
\hline 0,75 & $\begin{array}{l}\text { Há uma quantidade grande de áreas comerciais e unidades de } \\
\text { ensino dentro de uma distância de 500 metros da ciclovia. }\end{array}$ \\
\hline 0,50 & $\begin{array}{l}\text { Há uma quantidade razoável de áreas comerciais e unidades de } \\
\text { ensino dentro de uma distância de 500 metros da ciclovia. }\end{array}$ \\
\hline 0,25 & $\begin{array}{l}\text { Há uma quantidade pequena de áreas comerciais e unidades de } \\
\text { ensino dentro de uma distância de 500 metros da ciclovia. }\end{array}$ \\
\hline 0,00 & $\begin{array}{l}\text { Não há áreas comerciais e unidades de ensino dentro de uma } \\
\text { distância de 500 metros da ciclovia. }\end{array}$ \\
\hline
\end{tabular}

Nome do Indicador: Percentual de viagens de ciclistas por motivo de trabalho ou estudo.

Dimensão de sustentabilidade: social.

Descrição: indicador do motivo de viagens na ciclovia com o propósito de identificar o percentual de viagens por motivo de trabalho ou estudo em relação à quantidade total de viagens.

Unidade de medida: $\%$.

Como medir: entrevistas diretas com os usuários.

Normalização: atribuir a pontuação correspondente à média das entrevistas com os usuários, de acordo com os seguintes valores de referência:

\begin{tabular}{c|l}
\hline Pontuação & \multicolumn{1}{c}{ Valores de Referência } \\
\hline 1,00 & $\begin{array}{l}\text { As viagens de ciclistas por motivo de trabalho ou estudo são } \geq 80 \% \\
\text { das viagens totais. }\end{array}$ \\
\hline 0,75 & $\begin{array}{l}\text { As viagens de ciclistas por motivo de trabalho ou estudo são } \geq \text { a } 60 \% \\
\mathrm{e}<\text { do que } 80 \% \text { das viagens totais. }\end{array}$ \\
\hline 0,50 & $\begin{array}{l}\text { As viagens de ciclistas por motivo de trabalho ou estudo são } \geq \text { a } 40 \% \\
\mathrm{e}<\text { do que } 60 \% \text { das viagens totais. }\end{array}$ \\
\hline 0,25 & $\begin{array}{l}\text { As viagens de ciclistas por motivo de trabalho ou estudo são } \geq \text { a } 20 \% \\
\text { e do que }<40 \% \text { das viagens totais. }\end{array}$ \\
\hline 0,00 & $\begin{array}{l}\text { As viagens de ciclistas por motivo de trabalho ou estudo são }<20 \% \\
\text { das viagens totais. }\end{array}$ \\
\hline
\end{tabular}


Nome do Indicador: Disponibilidade de estacionamentos de bicicletas junto à ciclovia.

Dimensão de sustentabilidade: social.

Descrição: indicador que verifica a percepção do ciclista com relação à suficiência de paraciclos ao longo da ciclovia, com o propósito de verificar a disponibilização de paraciclos na ciclovia e nas imediações da ciclovia (polos geradores de viagens: shoppings, escolas, etc).

Unidade de medida: Muito boa; boa; nem boa/nem ruim; ruim; e muito ruim.

Como medir: entrevistas diretas com os usuários da ciclovia.

Normalização: atribuir a pontuação correspondente à média das entrevistas com os usuários de acordo com os seguintes valores de referência:

\begin{tabular}{c|l}
\hline Pontuação & \multicolumn{1}{c}{ Valores de Referência } \\
\hline 1,00 & Muito boa. \\
\hline 0,75 & Boa. \\
\hline 0,50 & Nem boa/nem ruim. \\
\hline 0,25 & Ruim. \\
\hline 0,00 & Muito ruim. \\
\hline
\end{tabular}

Nome do Indicador: Integração Intermodal

Dimensão de sustentabilidade: social.

Descrição: indicador que avalia a integração das bicicletas com sistemas de transporte público coletivo na região, com o propósito de medir o nível de integração da ciclovia com o transporte público coletivo.

Unidade de medida: Muito boa; boa; nem boa/nem ruim; ruim; e muito ruim.

Como medir: avaliação direta pelo técnico responsável pela aplicação do método.

Normalização: atribuir a pontuação correspondente à avaliação do técnico de acordo com os seguintes valores de referência:

\begin{tabular}{c|l}
\hline Pontuação & \multicolumn{1}{c}{ Valores de Referência } \\
\hline 1,00 & Muito boa. \\
\hline 0,75 & Boa. \\
\hline 0,50 & Nem boa/nem ruim. \\
\hline 0,25 & Ruim. \\
\hline 0,00 & Muito ruim. \\
\hline
\end{tabular}


Nome do Indicador: Percepção do ciclista com relação a furtos e roubos na ciclovia.

Dimensão de sustentabilidade: social.

Descrição: indicador que verifica a percepção dos ciclistas com relação à ocorrência de furtos e roubos na ciclovia.

Unidade de medida: ocorrência muito elevada, ocorrência elevada, ocorrência média e ocorrência baixa, ocorrência muito baixa.

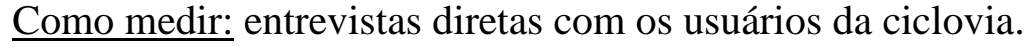

Normalização: atribuir a pontuação correspondente à média das entrevistas com os usuários de acordo com os seguintes valores de referência:

\begin{tabular}{c|l}
\hline Pontuação & \multicolumn{1}{c}{ Valores de Referência } \\
\hline 1,00 & Ocorrência muito baixa. \\
\hline 0,75 & Ocorrência baixa. \\
\hline 0,50 & Ocorrência média. \\
\hline 0,25 & Ocorrência elevada. \\
\hline 0,00 & Ocorrência muito elevada. \\
\hline
\end{tabular}

Nome do Indicador: Frequência de policiamento nas imediações da ciclovia.

Dimensão de sustentabilidade: social.

Descrição: indicador que verifica a satisfação dos ciclistas com o policiamento nas imediações da ciclovia, com o propósito de verificar a segurança durante a mobilidade dos ciclistas.

Unidade de medida: Muito boa; boa; nem boa/nem ruim; ruim; e muito ruim.

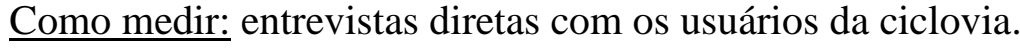

Normalização: atribuir a pontuação correspondente à média das entrevistas com os usuários de acordo com os seguintes valores de referência:

\begin{tabular}{c|l}
\hline Pontuação & \multicolumn{1}{c}{ Valores de Referência } \\
\hline 1,00 & Muito boa. \\
\hline 0,75 & Boa. \\
\hline 0,50 & Nem boa/nem ruim. \\
\hline 0,25 & Ruim. \\
\hline 0,00 & Muito ruim. \\
\hline
\end{tabular}


Nome do Indicador: Localização espacial e conectividade com outras ciclovias.

Dimensão de sustentabilidade: social.

Descrição: indicador que verifica a satisfação do ciclista com a localização espacial da ciclovia, bem como com sua conectividade com outras (rede cicloviária), com o propósito de verificar se esta possibilita que o modo cicloviário possa operar de forma eficiente e competir com outros modos.

Unidade de medida: Muito boa; boa; nem boa/nem ruim; ruim; e muito ruim.

Como medir: entrevistas diretas com os usuários da ciclovia.

Normalização: atribuir a pontuação correspondente à média das entrevistas com os usuários de acordo com os seguintes valores de referência:

\begin{tabular}{c|l}
\hline Pontuação & \multicolumn{1}{c}{ Valores de Referência } \\
\hline 1,00 & Muito boa. \\
\hline 0,75 & Boa. \\
\hline 0,50 & Nem boa/nem ruim. \\
\hline 0,25 & Ruim. \\
\hline 0,00 & Muito ruim. \\
\hline
\end{tabular}

Nome do Indicador: Qualidade da sinalização da ciclovia, dos cruzamentos cicloviários e do tratamento dos locais críticos

Dimensão de sustentabilidade: social.

Descrição: indicador que verifica a satisfação do ciclista com a qualidade da sinalização da ciclovia, com os cruzamentos desta com as vias de tráfego e com o tratamento de locais perigosos para os ciclistas, com o propósito de verificar se o tratamento dado contribui para atrair ciclistas e possibilitar que o modo cicloviário possa operar de forma eficiente e competir com outros modos.

Unidade de medida: Muito boa; boa; nem boa/nem ruim; ruim; e muito ruim.

Como medir: entrevistas diretas com os usuários da ciclovia.

Normalização: atribuir a pontuação correspondente à média das entrevistas com os usuários de acordo com os seguintes valores de referência:

\begin{tabular}{c|l}
\hline Pontuação & \multicolumn{1}{c}{ Valores de Referência } \\
\hline 1,00 & Muito boa. \\
\hline 0,75 & Boa. \\
\hline 0,50 & Nem boa/nem ruim. \\
\hline 0,25 & Ruim. \\
\hline 0,00 & Muito ruim. \\
\hline
\end{tabular}


Nome do Indicador: Qualidade do pavimento da ciclovia.

Dimensão de sustentabilidade: social.

Descrição: indicador que verifica a satisfação do ciclista com a qualidade do pavimento da ciclovia, com o propósito de verificar se ela contribui para atrair ciclistas e possibilitar que o modo cicloviário possa operar de forma eficiente e competir com outros modos.

Unidade de medida: Muito boa; boa; nem boa/nem ruim; ruim; e muito ruim.

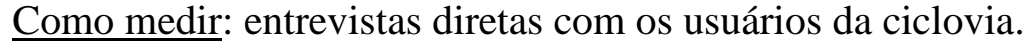

Normalização: atribuir a pontuação correspondente à média das entrevistas com os usuários de acordo com os seguintes valores de referência:

\begin{tabular}{c|l}
\hline Pontuação & \multicolumn{1}{c}{ Valores de Referência } \\
\hline 1,00 & Muito boa. \\
\hline 0,75 & Boa. \\
\hline 0,50 & Nem boa/nem ruim. \\
\hline 0,25 & Ruim. \\
\hline 0,00 & Muito ruim. \\
\hline
\end{tabular}

Nome do Indicador: Qualidade da drenagem da ciclovia.

Dimensão de sustentabilidade: social.

Descrição: indicador que verifica a satisfação do ciclista com a qualidade do escoamento de água da ciclovia, com o propósito de verificar se ela contribui para atrair ciclistas e possibilitar que o modo cicloviário possa operar de forma eficiente e competir com outros modos.

Unidade de medida: Muito boa; boa; nem boa/nem ruim; ruim; e muito ruim.

Como medir: entrevistas diretas com os usuários da ciclovia.

Normalização: atribuir a pontuação correspondente à média das entrevistas com os usuários de acordo com os seguintes valores de referência:

\begin{tabular}{c|l}
\hline Pontuação & \multicolumn{1}{c}{ Valores de Referência } \\
\hline 1,00 & Muito boa. \\
\hline 0,75 & Boa. \\
\hline 0,50 & Nem boa/nem ruim. \\
\hline 0,25 & Ruim. \\
\hline 0,00 & Muito ruim. \\
\hline
\end{tabular}


Nome do Indicador: Disponibilização de iluminação pública nos arredores da ciclovia.

Dimensão de sustentabilidade: social.

Descrição: indicador que verifica a satisfação do ciclista com a existência de iluminação pública nos arredores da ciclovia, com o propósito de verificar se esta possui qualidade para atrair ciclistas e possibilitar que o modo cicloviário possa operar de forma eficiente e competir com outros modos.

Unidade de medida: Muito boa; boa; nem boa/nem ruim; ruim; e muito ruim.

Como medir: entrevistas diretas com os usuários da ciclovia.

Normalização: atribuir a pontuação correspondente à média das entrevistas com os usuários de acordo com os seguintes valores de referência:

\begin{tabular}{c|l}
\hline Pontuação & \multicolumn{1}{c}{ Valores de Referência } \\
\hline 1,00 & Muito boa. \\
\hline 0,75 & Boa. \\
\hline 0,50 & Nem boa/nem ruim. \\
\hline 0,25 & Ruim. \\
\hline 0,00 & Muito ruim. \\
\hline
\end{tabular}

Nome do Indicador: Promoção de saúde

Dimensão de sustentabilidade: social.

Descrição: Indicador que mede o percentual de usuários que pedalam suficientemente para se exercitar (mínimo de 15 minutos de pedalada contínua), contribuindo para sua saúde e para a redução dos problemas de saúde pública.

Unidade de medida: \%.

Como medir: entrevistas diretas com os usuários da ciclovia.

Normalização: atribuir a pontuação correspondente à média das entrevistas com os usuários de acordo com os seguintes valores de referência:

\begin{tabular}{c|l}
\hline Pontuação & \multicolumn{1}{c}{ Valores de Referência } \\
\hline 1,00 & $\begin{array}{l}\text { A quantidade de usuários da ciclovia que pedalam sem parar por } \\
\text { pelo menos 15 minutos é } \geq 80 \%\end{array}$ \\
\hline 0,75 & $\begin{array}{l}\text { A quantidade de usuários da ciclovia que pedalam sem parar por } \\
\text { pelo menos 15 minutos é } \geq 60 \% \text { e }<80 \% .\end{array}$ \\
\hline 0,50 & $\begin{array}{l}\text { A quantidade de usuários da ciclovia que pedalam sem parar por } \\
\text { pelo menos 15 minutos é } \geq 40 \%<60 \% .\end{array}$ \\
\hline 0,25 & $\begin{array}{l}\text { A quantidade de usuários da ciclovia que pedalam sem parar por } \\
\text { pelo menos 15 minutos é } \geq 20 \%<40 \% .\end{array}$ \\
\hline
\end{tabular}




\begin{tabular}{c|l}
\hline 0,00 & $\begin{array}{l}\text { A quantidade de usuários da ciclovia que pedalam sem parar por } \\
\text { pelo menos } 15 \text { minutos é }<20 \% .\end{array}$ \\
\hline
\end{tabular}

Nome do Indicador: Promoção de atividade de lazer.

Dimensão de sustentabilidade: social.

Descrição: indicador que reflete o lazer como motivo de viagens na ciclovia com o propósito de identificar o percentual de viagens por este motivo em relação à quantidade total de viagens.

Unidade de medida: $\%$.

Como medir: entrevistas diretas com os usuários.

Normalização: atribuir a pontuação correspondente à média das entrevistas com os usuários, de acordo com os seguintes valores de referência:

\begin{tabular}{c|l}
\hline Pontuação & \multicolumn{1}{c}{ Valores de Referência } \\
\hline 1,00 & As viagens de ciclistas por motivo de lazer são $\geq 80 \%$ das viagens. \\
\hline 0,75 & $\begin{array}{l}\text { As viagens de ciclistas por motivo de lazer são } \geq 60 \% \text { e }<80 \% \text { das } \\
\text { viagens. }\end{array}$ \\
\hline 0,50 & $\begin{array}{l}\text { As viagens de ciclistas por motivo de lazer são } \geq 40 \% \text { e }<60 \% \text { das } \\
\text { viagens. }\end{array}$ \\
\hline 0,25 & $\begin{array}{l}\text { As viagens de ciclistas por motivo de lazer são } \geq 20 \% \text { e }<40 \% \text { das } \\
\text { viagens. }\end{array}$ \\
\hline 0,00 & As viagens de ciclistas por motivo de lazer são $<20 \%$ das viagens. \\
\hline
\end{tabular}

Nome do Indicador: Promoção de qualidade de vida e redução do nível de estresse dos ciclistas.

Dimensão de sustentabilidade: social.

Descrição: Indicador que avalia o grau de satisfação dos usuários com a ciclovia, do ponto de vista da promoção da qualidade de vida e redução do estresse do ciclista.

Unidade de medida: Muito boa; boa; nem boa/nem ruim; ruim; e muito ruim.

Como medir: entrevistas diretas com os usuários da ciclovia.

Normalização: atribuir a pontuação correspondente à média das entrevistas com os usuários de acordo com os seguintes valores de referência:

\begin{tabular}{c|l}
\hline Pontuação & \multicolumn{1}{c}{ Valores de Referência } \\
\hline 1,00 & Muito boa. \\
\hline 0,75 & Boa. \\
\hline 0,50 & Nem boa/nem ruim. \\
\hline 0,25 & Ruim. \\
\hline
\end{tabular}




\begin{tabular}{|c|c|}
\hline 0,00 & Muito ruim. \\
\hline \multirow{2}{*}{\multicolumn{2}{|c|}{$\begin{array}{l}\text { Nome do Indicador: Percentual de ciclistas que não possuem veículo particular. } \\
\text { Dimensão de sustentabilidade: econômica. }\end{array}$}} \\
\hline & \\
\hline \multicolumn{2}{|c|}{$\begin{array}{l}\text { Descrição: indicador que mede o percentual de ciclistas que não possui automóvel, com o } \\
\text { propósito de verificar o quanto a ciclovia promove de equidade }{ }^{3} \text { econômica. }\end{array}$} \\
\hline \multicolumn{2}{|c|}{ Unidade de medida: $\%}$. \\
\hline \multicolumn{2}{|c|}{ Como medir: entrevistas diretas com os usuários da ciclovia. } \\
\hline \multicolumn{2}{|c|}{$\begin{array}{l}\text { Normalização: atribuir a pontuação correspondente à média das entrevistas com os } \\
\text { usuários de acordo com os seguintes valores de referência: }\end{array}$} \\
\hline Pontuação & Valores de Referência \\
\hline 1,00 & $\begin{array}{l}\text { O percentual de ciclistas que possui um veículo particular é }<20 \% \\
\text { do total. }\end{array}$ \\
\hline 0,75 & $\begin{array}{l}\text { O percentual de ciclistas que possui um veículo particular é } \leq 40 \% \\
\text { e }>20 \% \text { do total. }\end{array}$ \\
\hline 0,50 & $\begin{array}{l}\text { O percentual de ciclistas que possui um veículo particular é } \leq 60 \% \\
\text { e }>40 \% \text { do total. }\end{array}$ \\
\hline 0,25 & $\begin{array}{l}\text { O percentual de ciclistas que possui um veículo particular é } \leq 80 \% \\
\text { e }>60 \% \text { do total. }\end{array}$ \\
\hline 0,00 & $\begin{array}{l}\text { O percentual de ciclistas que possui um veículo particular é > } 80 \% \\
\text { do total. }\end{array}$ \\
\hline
\end{tabular}

Nome do Indicador: Percentual de transferência do modo a pé para o cicloviário.

Dimensão de sustentabilidade: econômica.

Descrição: indicador que mede o percentual de pessoas que se locomoviam anteriormente a pé, por falta de condições financeiras, e que passaram a utilizar a ciclovia após sua implantação, com o propósito de verificar se a ciclovia promove equidade econômica.

Unidade de medida: $\%$.

Como medir: entrevistas diretas com os usuários da ciclovia.

Normalização: atribuir a pontuação correspondente à média das entrevistas com os usuários de acordo com os seguintes valores de referência:

3 Equidade é um termo original do latim "equitas" e refere-se à igualdade. Atualmente, este conceito tem sido amplamente utilizado como orientador de políticas de diversas áreas, com o propósito de torná-las mais razoáveis e justas. A equidade visa à semelhança de oportunidades, baseando-se em valores como a ética e a justiça na distribuição de oportunidades. 


\begin{tabular}{|c|l|}
\hline Pontuação & \multicolumn{1}{c}{ Valores de Referência } \\
\hline 1,00 & $\begin{array}{l}\text { As viagens transferidas do modo a pé para o cicloviário são } \geq 10 \% \\
\text { das viagens totais. }\end{array}$ \\
\hline 0,50 & $\begin{array}{l}\text { As viagens transferidas do modo a pé para o cicloviário são } \geq 1 \% \text { e } \\
<\text { do que } 10 \% \text { das viagens totais. }\end{array}$ \\
\hline 0,00 & $\begin{array}{l}\text { As viagens transferidas do modo a pé para o cicloviário são }<1 \% \\
\text { das viagens totais. }\end{array}$ \\
\hline
\end{tabular}

Nome do Indicador: Percentual de ciclistas que se beneficiaram dos efeitos positivos indiretos gerados pela ciclovia como aquisição de emprego, educação e outras oportunidades.

Dimensão de sustentabilidade: econômica.

Descrição: indicador que mede o percentual de ciclistas beneficiados pela implantação da ciclovia por meio da obtenção de emprego, educação e oportunidades análogas, com o propósito de verificar a equidade promovida pela ciclovia.

Unidade de medida: $\%$.

Como medir: entrevistas diretas com os usuários da ciclovia.

Normalização: atribuir a pontuação correspondente à média das entrevistas com os usuários de acordo com os seguintes valores de referência:

\begin{tabular}{c|l}
\hline Pontuação & \multicolumn{1}{c}{ Valores de Referência } \\
\hline 1,00 & $\begin{array}{l}\text { O percentual de ciclistas que se beneficiaram dos efeitos positivos } \\
\text { indiretos gerados pela ciclovia é } \geq 10 \% \text { do total de ciclistas. }\end{array}$ \\
\hline 0,50 & $\begin{array}{l}\text { O percentual de ciclistas que se beneficiaram dos efeitos positivos } \\
\text { indiretos gerados pela ciclovia é } \geq 1 \% \text { e }<10 \% \text { do total de ciclistas. }\end{array}$ \\
\hline 0,00 & $\begin{array}{l}\text { O percentual de ciclistas que se beneficiaram dos efeitos positivos } \\
\text { indiretos gerados pela ciclovia é }<1 \% \text { do total de ciclistas. }\end{array}$ \\
\hline
\end{tabular}

Nome do Indicador: Percentual de ciclistas que obtiveram redução de gastos devido à utilização da ciclovia.

Dimensão de sustentabilidade: econômica.

Descrição: indicador que mede o quanto o ciclista deixou de gastar com sua mobilidade após a implantação da ciclovia, em relação à sua renda mensal, com o propósito de verificar a equidade promovida pela ciclovia.

Unidade de medida: $\%$.

Como medir: entrevistas diretas com os usuários da ciclovia.

Normalização: atribuir a pontuação correspondente à média das entrevistas com os usuários de acordo com os seguintes valores de referência: 


\begin{tabular}{|c|l|}
\hline Pontuação & \multicolumn{1}{c|}{ Valores de Referência } \\
\hline 1,00 & $\begin{array}{l}\text { O percentual médio de economia da renda mensal do ciclista } \\
\text { destinada à sua locomoção em relação à sua renda total é } \geq 10 \% .\end{array}$ \\
\hline 0,75 & $\begin{array}{l}\text { O percentual de ciclistas que se beneficiaram dos efeitos positivos } \\
\text { indiretos gerados pela ciclovia é } \geq 6 \text { e }<10 \% .\end{array}$ \\
\hline 0,50 & $\begin{array}{l}\text { O percentual de ciclistas que se beneficiaram dos efeitos positivos } \\
\text { indiretos gerados pela ciclovia é } \geq 3 \% \text { e }<6 \% .\end{array}$ \\
\hline 0,25 & $\begin{array}{l}\text { O percentual de ciclistas que se beneficiaram dos efeitos positivos } \\
\text { indiretos gerados pela ciclovia é }>0 \% \text { e }<3 \% .\end{array}$ \\
\hline 0,00 & $\begin{array}{l}\text { O percentual médio de economia da renda mensal do ciclista } \\
\text { destinada à sua locomoção em relação à sua renda total é }=0 \% .\end{array}$ \\
\hline
\end{tabular}

Nome do Indicador: Variação anual da quantidade de ciclistas mortos em acidentes de trânsito na região da ciclovia por habitante por ano.

Dimensão de sustentabilidade: econômica.

Descrição: indicador que verifica se houve aumento ou redução anual na quantidade de ciclistas mortos em acidentes na região da ciclovia, com o propósito de averiguar se a implantação desta ciclovia promove a redução de custos provenientes de acidentes com ciclistas na região.

Unidade de medida: $\%$.

Como medir: por meio da verificação, no órgão de trânsito, da quantidade de ciclistas mortos em acidentes de trânsito na região analisada e comparação com anos anteriores (se possível à implantação da ciclovia).

Normalização: atribuir a pontuação correspondente à avaliação do técnico, de acordo com os seguintes valores de referência:

\begin{tabular}{c|l}
\hline Pontuação & \multicolumn{1}{c}{ Valores de Referência } \\
\hline 1,00 & $\begin{array}{l}\text { A redução da quantidade de ciclistas mortos em acidentes de trânsito } \\
\text { na região da ciclovia por habitante por ano é } \geq 60 \% .\end{array}$ \\
\hline 0,75 & $\begin{array}{l}\text { A redução da quantidade de ciclistas mortos em acidentes de trânsito } \\
\text { na região da ciclovia por habitante por ano é }>40 \text { e } \leq 60 \% .\end{array}$ \\
\hline 0,50 & $\begin{array}{l}\text { A redução da quantidade de ciclistas mortos em acidentes de trânsito } \\
\text { na região da ciclovia por habitante por ano é }>20 \text { e } \leq 40 \% .\end{array}$ \\
\hline 0,25 & $\begin{array}{l}\text { A redução da quantidade de ciclistas mortos em acidentes de trânsito } \\
\text { na região da ciclovia por habitante por ano é }>0 \text { e } \leq 20 \% .\end{array}$ \\
\hline 0,00 & $\begin{array}{l}\text { A redução da quantidade de ciclistas mortos em acidentes de trânsito } \\
\text { na região da ciclovia por habitante por ano é }=0 \% .\end{array}$ \\
\hline
\end{tabular}


Nome do Indicador: Redução do custo anual de poluentes devido à transferência de viagens motorizadas para o modo cicloviário.

Dimensão de sustentabilidade: econômica.

Descrição: indicador que mede a redução do custo anual de poluentes para a sociedade decorrente de viagens anteriormente realizadas por veículos motorizados, diante da quantidade de poluentes evitados devido à transferência para o modo cicloviário.

Unidade de medida: $\mathrm{R} \$$ por ano.

Como medir: por meio de entrevistas diretas com os usuários da ciclovia devem ser obtidas as quantidades e distâncias das viagens anteriormente realizadas por meio de veículos automotores. Estes dados devem ser expandidos para o período de um ano. A partir dos dados anuais, o cálculo do custo de poluentes devido à transferência de viagens motorizadas para o modo cicloviário deve ser realizado a partir dos dados do custo da poluição por quilômetro, estimado pela Associação Nacional de Transportes Públicos (ANTP, 2010a).

O Sistema de Informações da Mobilidade Urbana da Associação Nacional de Transportes Públicos (ANTP) desde 2003 estima anualmente os custos associados à poluição atmosférica gerados pelo transporte urbano, baseando-se nos dados de emissão de poluentes (gramas $/ \mathrm{km}$ ) disponibilizados anualmente pela Companhia de Tecnologia de Saneamento Ambiental de São Paulo - CETESB/SP. A ANTP estima os custos por tonelada de cada poluente $\left(\mathrm{CO}, \mathrm{HC}, \mathrm{NO}_{\mathrm{x}}, \mathrm{MP}, \mathrm{SO}_{\mathrm{x}}\right.$ e $\left.\mathrm{CO}_{2}\right)$ através da média de valores internacionais adaptados à economia brasileira por meio da PPC - Paridade do Poder de Compra (Banco Mundial).

Os parâmetros apresentados na Tabela 1 foram adotados pela ANTP para a geração dos dados de poluição (emissão e custos) na elaboração dos estudos do Sistema de Informações da Mobilidade Urbana referentes ao perfil da mobilidade urbana no Brasil em 2010.

Tabela 1: Emissão e custos de poluentes emitidos por ônibus, automóveis e motos (ANTP, 2010a)

\begin{tabular}{l|c|c|c|c|c|c}
\hline \multicolumn{1}{c|}{$\begin{array}{c}\text { POLUIÇÃO } \\
\text { Indicador }\end{array}$} & \multicolumn{7}{c}{ POLUENTES } \\
\cline { 2 - 7 } & CO & HC & MP & $\mathbf{N O}_{\mathbf{x}}$ & $\mathbf{S O}_{\mathbf{x}}$ & $\mathbf{C O}_{\mathbf{2}}$ \\
\hline Emissão ônibus $(\mathrm{R} \$ / \mathrm{km})$ & 1,84 & 0,51 & 0,35 & 10,23 & 0,13 & $1.197,00$ \\
\hline Emissão Auto $(\mathrm{R} \$ / \mathrm{km})$ & 3,00 & 0,17 & 0,08 & 0,17 & 0,07 & 196,00 \\
\hline Emissão Moto $(\mathrm{R} \$ / \mathrm{km})$ & 4,20 & 0,82 & 0,05 & 0,15 & 0,02 & 81,70 \\
\hline $\begin{array}{l}\text { Custo Emissão Onibus } \\
(\mathrm{R} \$ / \mathrm{km})\end{array}$ & 0,0017 & 0,0021 & 0,0085 & 0,0485 & 0,0023 & 0,1768 \\
\hline Custo Emissão Auto $(\mathrm{R} \$ / \mathrm{km})$ & 0,0028 & 0,0007 & 0,0019 & 0,0008 & 0,0013 & 0,0289 \\
\hline Custo Emissão Moto $(\mathrm{R} \$ / \mathrm{km})$ & 0,0039 & 0,0034 & 0,0012 & 0,0007 & 0,0004 & 0,0121 \\
\hline
\end{tabular}

Cabe ressaltar que no caso de ônibus admitiu-se que sua ocupação média no meio urbano é de 30 passageiros, dado utilizado pelo Sistema de Informações da Mobilidade Urbana da ANTP (2010b) para calcular os custos para usar ônibus, moto e automóvel no Brasil. 


\begin{tabular}{|c|c|}
\hline \multicolumn{2}{|c|}{$\begin{array}{l}\text { Normalização: A pontuação deve ser atribuída de acordo com os valores de referência a } \\
\text { seguir, definidos a partir da média de redução de custos anuais de poluentes calculados } \\
\text { para duas ciclovias brasilienses. A fim de garantir maior consistência a estes valores de } \\
\text { referência, propõe-se nas Considerações Finais, a realização de novos estudos científicos, } \\
\text { com a aplicação deste método, em número representativo de ciclovias brasileiras, de modo } \\
\text { a estabelecer valores médios que representem a realidade brasileira. }\end{array}$} \\
\hline & Val \\
\hline 1,00 & $\begin{array}{l}\text { to anual de poluentes devido à transferência de } \\
\text { as para o modo cicloviário é } \geq \mathrm{R} \$ 22.282,00 \text {. }\end{array}$ \\
\hline 0,75 & $\begin{array}{l}\text { A redução do custo anual de poluentes devido à transferência de } \\
\text { viagens motorizadas para o modo cicloviário é } \geq \mathrm{R} \$ 14.487,00 \mathrm{e}< \\
\mathrm{R} \$ 22.282,00 \text {. }\end{array}$ \\
\hline 0,50 & $\begin{array}{l}\text { A redução do custo anual de poluentes devido à transferência de } \\
\text { viagens motorizadas para o modo cicloviário é } \geq \mathrm{R} \$ 9.658,00 \text { e }< \\
\mathrm{R} \$ 14.487,00 \text {. }\end{array}$ \\
\hline 0,25 & $\begin{array}{l}\text { A redução do custo anual de poluentes devido à transferência de } \\
\text { viagens motorizadas para o modo cicloviário é } \geq \mathrm{R} \$ 5.795,00 \text { e }< \\
\mathrm{R} \$ 9.658,00 \text {. }\end{array}$ \\
\hline 0,00 & $\begin{array}{l}\text { A redução do custo anual de poluentes devido à transferência de } \\
\text { viagens motorizadas para o modo cicloviário é }<\mathrm{R} \$ 5.795,00 \text {. }\end{array}$ \\
\hline
\end{tabular}

Nome do Indicador: Redução de emissão de poluentes de gases de efeito estufa.

Dimensão de sustentabilidade: ambiental.

Descrição: indicador que mede a quantidade de gases de efeito estufa deixada de ser emitida (mitigada) por ano proveniente da transferência de viagens motorizadas para o modo cicloviário, com o propósito de verificar o quanto a implantação da ciclovia promove de redução de emissões de gases de efeito estufa.

Unidade de medida: toneladas de $\mathrm{CO}_{2 \mathrm{eq}}{ }^{4}$ por ano.

Como medir: por meio de entrevistas diretas com os usuários da ciclovia devem ser obtidas as quantidades e distâncias das viagens anteriormente realizadas por meio de veículos automotores, o tipo de combustível e ano do veículo que costumava ser utilizado para realizá-las. Com estes dados, o cálculo das emissões de $\mathrm{CO}_{2 \text { eq }}$ evitadas (mitigadas) por quilômetro por ano proveniente da transferência de viagens motorizadas para o modo cicloviário será possível a partir da Tabela 2 denominada "Fatores de emissão de escapamento de $\mathrm{CH}_{4}$ para automóveis e veículos comerciais leves novos, movidos a gasolina $\mathrm{C}$ e a etanol hidratado em $\mathrm{g} / \mathrm{km}$ ", da Tabela 3 "Fatores de emissão de $\mathrm{CH}_{4}$ para motocicletas em g/km", da Tabela 4 "Fatores de emissão de $\mathrm{CH}_{4}$ para motores Diesel", da Tabela 5 "Fatores de emissão de $\mathrm{CO}_{2}$ por ano-calendário e combustível", da Tabela 6

\footnotetext{
${ }^{4}$ Equivalência em dióxido de carbono, $\mathrm{CO}_{2}$ eq ou $\mathrm{CO}_{2 \mathrm{e}}$, é uma medida internacionalmente aceita que expressa a quantidade de GEEs em termos equivalentes da quantidade de $\mathrm{CO}_{2}$. A equivalência leva em conta o potencial de aquecimento global dos gases envolvidos e calcula quanto de $\mathrm{CO}_{2}$ seria emitido se todos os GEEs fossem emitidos como esse gás. A medida $\mathrm{CO}_{2 \text { eq }}$ é usada para comparar as emissões de diversos gases de efeito estufa baseada na quantidade de dióxido de carbono que teria o mesmo potencial de aquecimento global (GWP), medido em um período de tempo especificado.
} 
"Fatores de emissão de $\mathrm{N}_{2} \mathrm{O}$ por categoria e por combustível para veículos leves em $\mathrm{g} / \mathrm{km}$ " e da Tabela 7 "Fatores de emissão de $\mathrm{N}_{2} \mathrm{O}$ por categoria para veículos do ciclo Diesel, constantes no $2^{\circ}$ Inventário Nacional de Emissões Atmosféricas por Veículos Automotores Rodoviários" (MMA, 2013).

No caso de ônibus, admitiu-se que sua ocupação média no meio urbano é de 30 passageiros, dado utilizado pelo Sistema de Informações da Mobilidade Urbana da ANTP (2010b) para calcular os custos para usar ônibus, moto e automóvel no Brasil.

Cabe ressaltar que para efeitos de cálculo dos gases de efeito estufa (GEEs), foram acatados os poluentes $\mathrm{CO}_{2}, \mathrm{CH}_{4}$ e $\mathrm{N}_{2} \mathrm{O}$ considerados como GEEs no $2^{\circ}$ Inventário Nacional de Emissões Atmosféricas por Veículos Automotores Rodoviários (MMA, 2013).

Admitiu-se, para fins de cálculos, a idade média da frota circulante de ônibus urbano no ano de 2014 de 9 anos e de moto de 6 anos (ABIPEÇAS e SINDIPEÇAS, 2015), bem como os seguintes consumos médios por tipos de combustível: automóvel $(8,0 \mathrm{~km} / \mathrm{l})$ (MMA, 2013), ônibus $(0,4 \mathrm{l} / \mathrm{km})$, moto $(0,04 \mathrm{l} / \mathrm{km})$ (ANTP, 2010b) e gás $\left(12,5 \mathrm{~km} / \mathrm{m}^{3}\right)$ (COMGAS, 2015). Também foi admitido para fins de cálculo que o Potencial de Aquecimento Global do metano é 21 vezes maior que o valor de referência do $\mathrm{CO}_{2}$ e do óxido nitroso é 310 vezes maior (IPCC, 1997).

Tabela 2: Fatores de emissão de escapamento de $\mathrm{CH}_{4}$ para automóveis e veículos comerciais leves novos, movidos a gasolina $\mathrm{C}$ e a etanol hidratado, em g/km (MMA, 2013)

\begin{tabular}{c|c|c}
\hline Ano/modelo & Combustível & $\mathbf{C H}_{4}$ \\
\hline \multirow{2}{*}{ Até 1983 } & Gasolina C & 0,45 \\
\cline { 2 - 3 } & $\begin{array}{c}\text { Etanol } \\
\text { hidratado }\end{array}$ & 0,24 \\
\hline \multirow{2}{*}{$1984-1985$} & Gasolina C & 0,36 \\
\cline { 2 - 3 } & $\begin{array}{c}\text { Etanol } \\
\text { hidratado }\end{array}$ & 0,24 \\
\hline \multirow{2}{*}{$1986-1987$} & Gasolina C & 0,3 \\
\cline { 2 - 3 } & $\begin{array}{c}\text { Etanol } \\
\text { hidratado }\end{array}$ & 0,24 \\
\hline \multirow{2}{*}{1989} & Gasolina C & 0,26 \\
\cline { 2 - 3 } & $\begin{array}{c}\text { Etanol } \\
\text { hidratado }\end{array}$ & 0,26 \\
\cline { 2 - 3 } & Gasolina C & 0,24 \\
\hline \multirow{2}{*}{1990} & $\begin{array}{c}\text { Etanol } \\
\text { hidratado }\end{array}$ & 0,24 \\
\cline { 2 - 3 } & Gasolina C & 0,21 \\
\hline \multirow{2}{*}{1991} & $\begin{array}{c}\text { Etanol } \\
\text { hidratado }\end{array}$ & 0,2 \\
\cline { 2 - 3 } & Gasolina C & 0,2 \\
\hline \multirow{2}{*}{1992} & $\begin{array}{c}\text { Etanol } \\
\text { hidratado }\end{array}$ & 0,17 \\
\cline { 2 - 3 } & Gasolina C & 0,09 \\
\cline { 2 - 3 } Etanol & 0,09 \\
\hline \multirow{2}{*}{1993} & Gasolina C & 0,09 \\
\cline { 2 - 3 } & $\begin{array}{c}\text { Etanol } \\
\text { hidratado }\end{array}$ & 0,11 \\
\hline
\end{tabular}




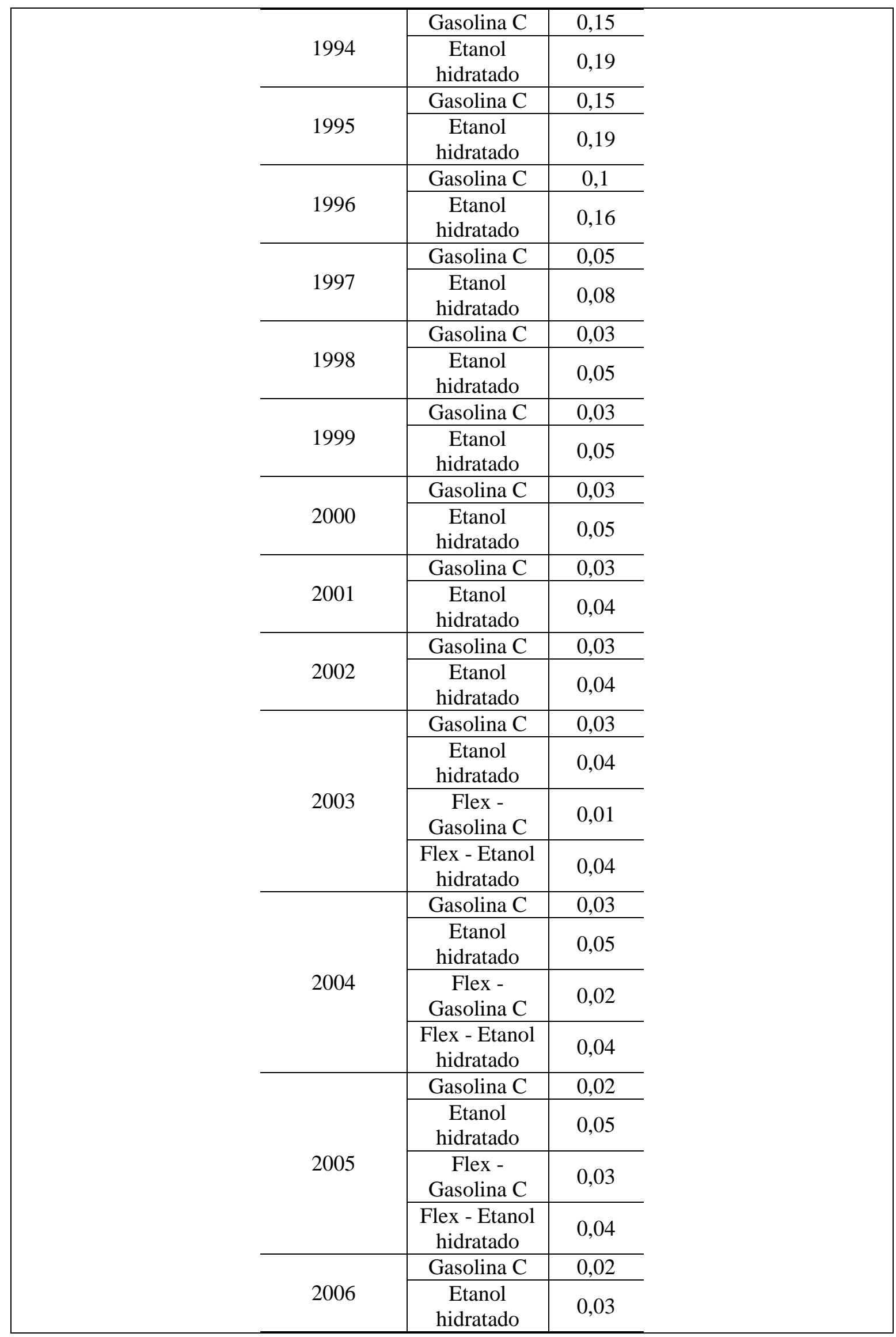




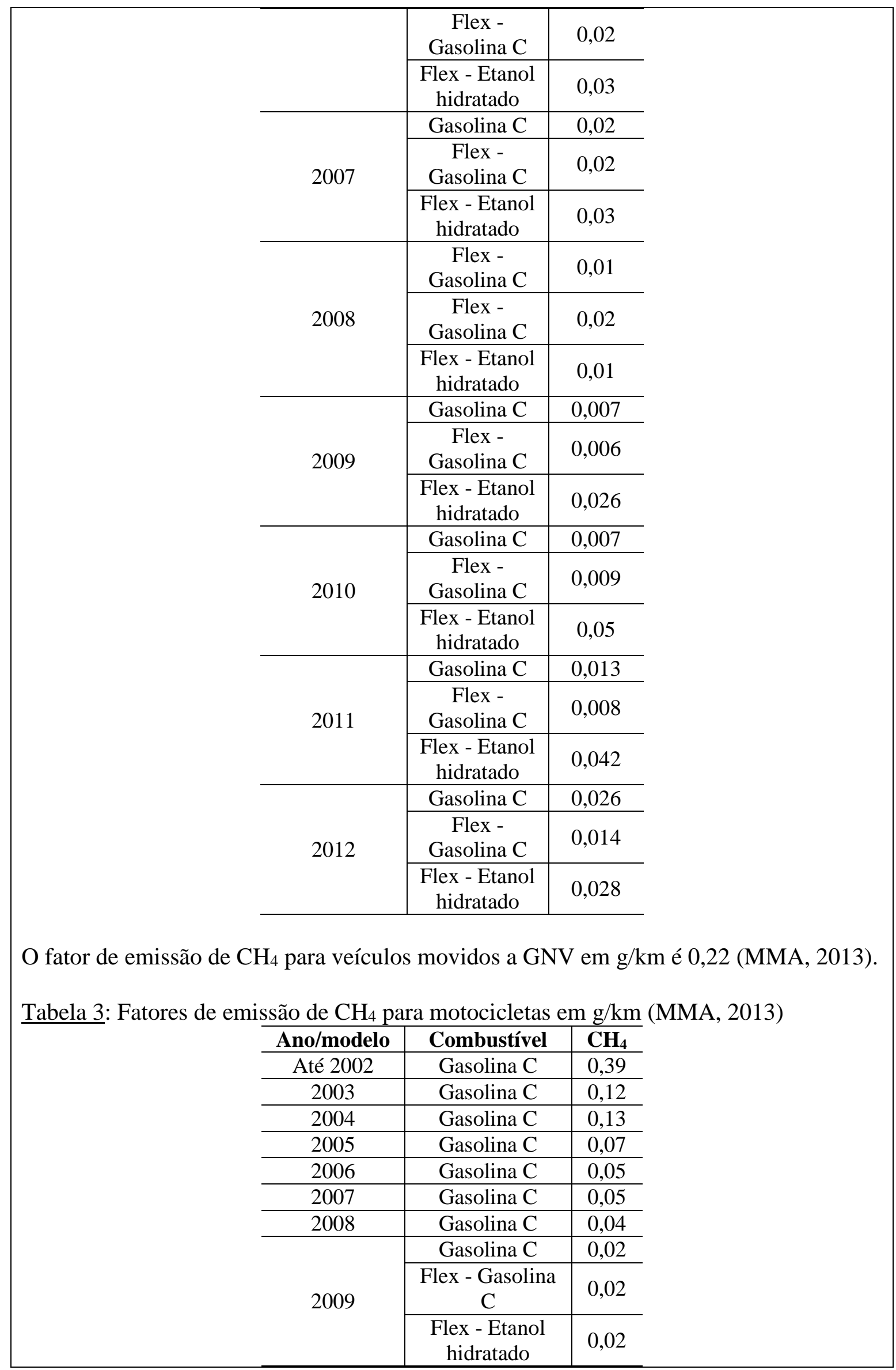




\begin{tabular}{|c|c|c}
\hline \multirow{2}{*}{2010} & Gasolina C & 0,02 \\
\cline { 2 - 3 } & $\begin{array}{c}\text { Flex - Gasolina } \\
\text { C }\end{array}$ & 0,02 \\
\cline { 2 - 3 } & $\begin{array}{c}\text { Flex - Etanol } \\
\text { hidratado }\end{array}$ & 0,02 \\
\hline \multirow{2}{*}{2011} & Gasolina C & 0,03 \\
\cline { 2 - 3 } & $\begin{array}{c}\text { Flex - Gasolina } \\
\text { C }\end{array}$ & 0,02 \\
\cline { 2 - 3 } & $\begin{array}{c}\text { Flex - Etanol } \\
\text { hidratado }\end{array}$ & 0,02 \\
\hline \multirow{2}{*}{2012} & Gasolina C & 0,03 \\
\cline { 2 - 3 } & $\begin{array}{c}\text { Flex - Gasolina } \\
\text { C }\end{array}$ & 0,02 \\
\cline { 2 - 3 } & $\begin{array}{c}\text { Flex - Etanol } \\
\text { hidratado }\end{array}$ & 0,02 \\
\hline
\end{tabular}

Tabela 4: Fatores de emissão de $\mathrm{CH}_{4}$ para motores Diesel (MMA, 2013)

\begin{tabular}{l|l}
\hline \multicolumn{1}{c|}{ Categoria } & $\mathbf{C H}_{\mathbf{4}}(\mathbf{g} / \mathbf{k m})$ \\
\hline Comerciais Leves Diesel & 0,005 \\
\hline Ônibus & 0,060 \\
\hline Caminhões & 0,060 \\
\hline
\end{tabular}

Tabela 5: Fatores de emissão de $\mathrm{CO}_{2}$ por ano-calendário e combustível (MMA, 2013)

\begin{tabular}{|c|c|c|c|c|c|}
\hline $\begin{array}{c}\text { Ano } \\
\text { calendário }\end{array}$ & $\begin{array}{c}\text { Gasolina } \\
\text { Automotiva } \\
(\mathrm{kg} / \mathrm{L})\end{array}$ & $\begin{array}{c}\text { Etanol } \\
\text { Hidratado } \\
(\mathrm{kg} / \mathrm{L})\end{array}$ & $\begin{array}{c}\text { Etanol } \\
\text { Anidro } \\
(\mathrm{kg} / \mathrm{L})\end{array}$ & $\begin{array}{c}\text { Diesel } \\
\text { Mineral } \\
(\mathrm{kg} / \mathrm{L})\end{array}$ & $\begin{array}{c}\text { GNV } \\
\left(\mathrm{kg} / \mathrm{m}^{3}\right)\end{array}$ \\
\hline 1980 & 2,209 & \multirow{17}{*}{1,457} & \multirow{17}{*}{1,526} & 2,631 & \multirow{8}{*}{ - } \\
\hline 1981 & 2,209 & & & 2,646 & \\
\hline 1982 & 2,212 & & & 2,656 & \\
\hline 1983 & 2,261 & & & 2,649 & \\
\hline 1984 & 2,258 & & & 2,674 & \\
\hline 1985 & 2,278 & & & 2,665 & \\
\hline 1986 & 2,275 & & & 2,686 & \\
\hline 1987 & 2,261 & & & 2,680 & \\
\hline 1988 & 2,281 & & & 2,671 & \multirow{9}{*}{1,999} \\
\hline 1989 & 2,266 & & & 2,686 & \\
\hline 1990 & 2,261 & & & 2,686 & \\
\hline 1991-1997 & 2,261 & & & 2,674 & \\
\hline 1998 & 2,243 & & & 2,646 & \\
\hline 1999 & 2,232 & & & 2,631 & \\
\hline 2000 & 2,220 & & & 2,613 & \\
\hline 2001-2004 & 2,212 & & & 2,603 & \\
\hline $2005-2012$ & 2,212 & & & 2,603 & \\
\hline
\end{tabular}




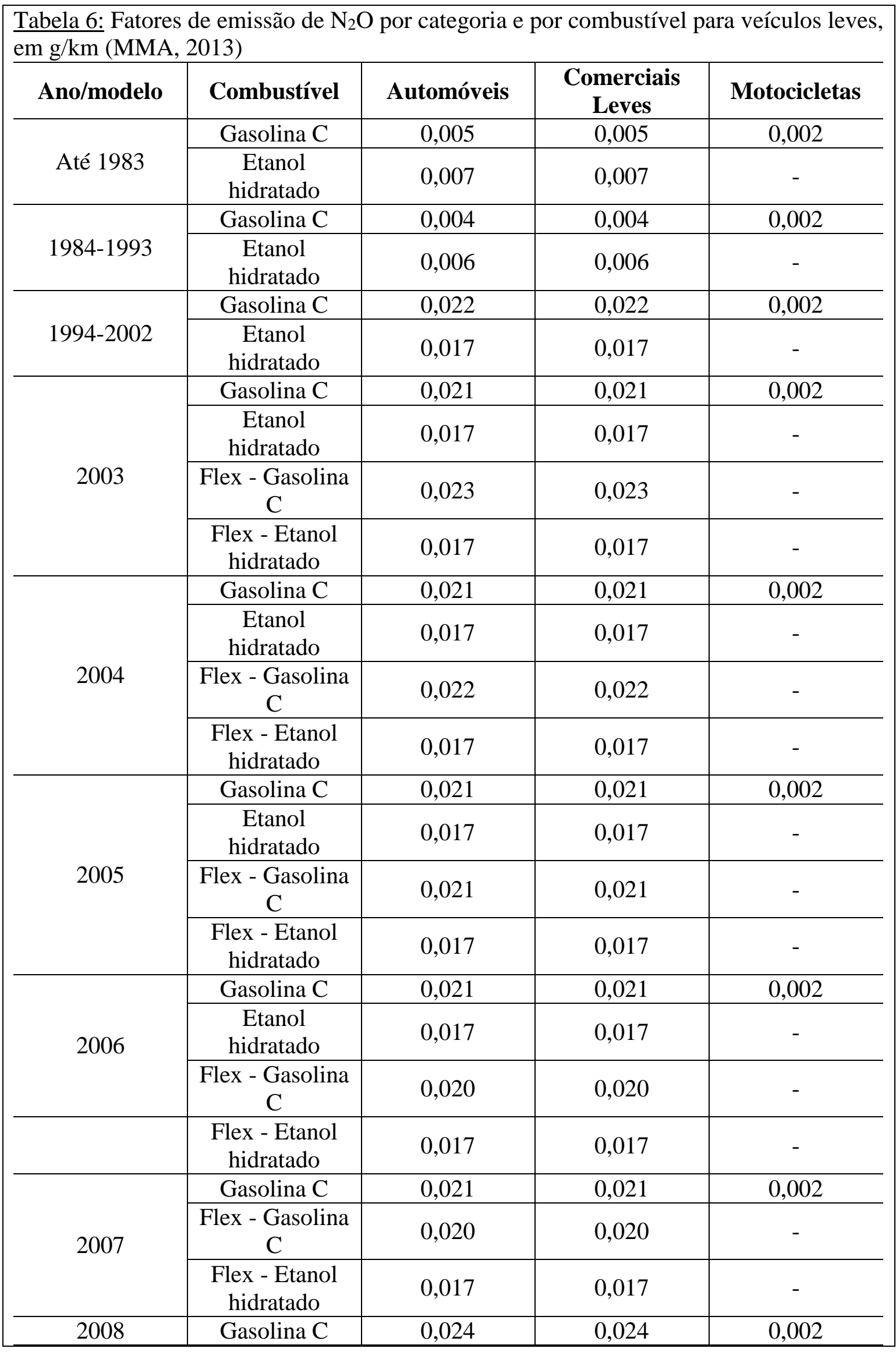




\begin{tabular}{|c|c|c|c|c|}
\hline & $\begin{array}{c}\text { Flex - Gasolina } \\
\text { C }\end{array}$ & 0,020 & 0,020 & - \\
\hline & $\begin{array}{c}\text { Flex - Etanol } \\
\text { hidratado }\end{array}$ & 0,017 & 0,017 & - \\
\hline \multirow{3}{*}{2009} & Gasolina C & 0,025 & 0,025 & 0,002 \\
\hline & $\begin{array}{c}\text { Flex - Gasolina } \\
\text { C }\end{array}$ & 0,020 & 0,020 & 0,002 \\
\hline & $\begin{array}{c}\text { Flex - Etanol } \\
\text { hidratado }\end{array}$ & 0,017 & 0,017 & - \\
\hline \multirow{3}{*}{2010} & Gasolina C & 0,023 & 0,034 & 0,002 \\
\hline & $\begin{array}{c}\text { Flex - Gasolina } \\
\text { C }\end{array}$ & 0,019 & 0,019 & 0,002 \\
\hline & $\begin{array}{l}\text { Flex - Etanol } \\
\text { hidratado }\end{array}$ & 0,017 & 0,017 & - \\
\hline \multirow{3}{*}{2011} & Gasolina C & 0,021 & 0,024 & 0,002 \\
\hline & $\begin{array}{c}\text { Flex - Gasolina } \\
\text { C }\end{array}$ & 0,019 & 0,024 & 0,002 \\
\hline & $\begin{array}{l}\text { Flex - Etanol } \\
\text { hidratado }\end{array}$ & 0,017 & 0,017 & - \\
\hline \multirow{3}{*}{2012} & Gasolina C & 0,021 & 0,024 & 0,002 \\
\hline & $\begin{array}{c}\text { Flex - Gasolina } \\
\text { C }\end{array}$ & 0,019 & 0,026 & 0,002 \\
\hline & $\begin{array}{l}\text { Flex - Etanol } \\
\text { hidratado }\end{array}$ & 0,017 & 0,017 & - \\
\hline
\end{tabular}

Tabela 7: Fatores de emissão de $\mathrm{N}_{2} \mathrm{O}$ por categoria para veículos do ciclo Diesel (MMA, 2013)

\begin{tabular}{l|c}
\multicolumn{1}{c|}{ Categoria } & $\mathbf{N}_{\mathbf{2}} \mathbf{O}(\mathbf{g} / \mathbf{k m})$ \\
\hline Comerciais Leves Diesel & 0,02 \\
\hline Ônibus & 0,03 \\
\hline Caminhões & 0,03 \\
\hline
\end{tabular}

O fator de emissão de $\mathrm{N}_{2} \mathrm{O}$ para veículos movidos a GNV em g/km é 0,313 (MMA, 2013).

Normalização: A pontuação deve ser atribuída de acordo com os valores de referência a seguir, definidos a partir da média de redução de custos anuais de poluentes calculados para duas ciclovias brasilienses. A fim de garantir maior consistência a estes valores de referência, propõe-se nas Considerações Finais, a realização de novos estudos científicos, com a aplicação deste método em número representativo de ciclovias brasileiras, de modo a estabelecer valores médios, que representem a realidade brasileira.

\begin{tabular}{c|l}
\hline Pontuação & \multicolumn{1}{c}{ Valores de Referência } \\
\hline 1,00 & $\begin{array}{l}\text { A redução anual de emissão de poluentes de gases de efeito estufa é } \\
\geq 123,35 \text { toneladas de } \mathrm{CO}_{2 \text { eq. }}\end{array}$ \\
\hline 0,75 & $\begin{array}{l}\text { A redução anual de emissão de poluentes de gases de efeito estufa é } \\
\geq 88,10 \text { e }<123,35 \text { toneladas de } \mathrm{CO}_{2 \text { eq. }}\end{array}$ \\
\hline 0,50 & $\begin{array}{l}\text { A redução anual de emissão de poluentes de gases de efeito estufa é } \\
\geq 58,73 \text { e }<88,10 \text { toneladas de } \mathrm{CO}_{2 \text { eq. }}\end{array}$ \\
\hline
\end{tabular}




\begin{tabular}{|c|l|}
\hline 0,25 & $\begin{array}{l}\text { A redução anual de emissão de poluentes de gases de efeito estufa é } \\
\geq 35,24 \text { e }<58,73 \text { toneladas de } \mathrm{CO}_{2 \text { eq. }}\end{array}$ \\
\hline 0,00 & $\begin{array}{l}\text { A redução anual de emissão de poluentes de gases de efeito estufa é } \\
<35,24 \text { toneladas de } \mathrm{CO}_{2 \text { eq. }}\end{array}$ \\
\hline
\end{tabular}

Nome do Indicador: Redução de emissão de poluentes locais.

Dimensão de sustentabilidade: ambiental.

Descrição: indicador que mede a quantidade de poluentes locais deixada de ser emitida (mitigada) por ano proveniente da transferência de viagens motorizadas para o modo cicloviário, com o propósito de verificar se a implantação da ciclovia promove a redução de poluentes locais.

Unidade de medida: toneladas de poluentes locais (monóxido de carbono (CO) e óxidos de nitrogênio, $\left(\mathrm{NO}_{\mathrm{x}}\right)$ por ano).

Como medir: por meio de entrevistas diretas com os usuários da ciclovia devem ser obtidas as quantidades e distâncias das viagens anteriormente realizadas por meio de veículos automotores, o tipo de combustível e ano do veículo que costumava ser utilizado para realizá-las. Com estes dados, o cálculo do combustível fóssil economizado por ano (mitigado) proveniente da transferência de viagens motorizadas para o modo cicloviário será possível, a partir das Tabelas 8 "Fatores de emissão de escapamento de $\mathrm{CO}$ e $\mathrm{NO}_{\mathrm{x}}$ para automóveis e veículos comerciais leves novos movidos a gasolina $\mathrm{C}$ e a etanol hidratado em $\mathrm{g} / \mathrm{km}$ ", Tabela 9 "Fatores de emissão de $\mathrm{CO}$ e $\mathrm{NO}_{\mathrm{x}}$ para veículos movidos a GNV em g/km", Tabela 10 "Fatores de emissão de CO e $\mathrm{NO}_{x}$ para motocicletas em g/km" e Tabela 11 "Fatores de emissão de $\mathrm{CO}$ e $\mathrm{NO}_{x}$ para motores Diesel em goluente $/ \mathrm{km}$ ", constantes no $2^{\circ}$ Inventário Nacional de Emissões Atmosféricas por Veículos Automotores Rodoviários (MMA, 2013).

No caso de um ônibus, admitiu-se que a ocupação média no meio urbano é de 30 passageiros, dado utilizado pelo Sistema de Informações da Mobilidade Urbana da ANTP (2010b) para calcular os custos para usar ônibus, moto e automóvel no Brasil.

Alguns poluentes locais não puderam ser considerados, pois no $2^{\circ}$ Inventário Nacional de Emissões Atmosféricas por Veículos Automotores Rodoviários (MMA, 2013) não constam os parâmetros de cálculos para todos os tipos de veículos e combustíveis utilizados neste modelo.

Admitiu-se, para fins de cálculos, a idade média da frota circulante de ônibus urbano no ano de 2014 de 9 anos (ABIPEÇAS e SINDIPEÇAS, 2015)

Tabela 8: Fatores de emissão de escapamento de $\mathrm{CO}$ e $\mathrm{NO}_{\mathrm{x}}$, para automóveis e veículos comerciais leves novos, movidos a gasolina $\mathrm{C}$ e a etanol hidratado, em g/km (MMA, 2013)

\begin{tabular}{c|c|c|c}
\hline Ano/modelo & Combustível & $\mathbf{C O}$ & $\mathbf{N O}_{\mathbf{x}}$ \\
\hline \multirow{2}{*}{ Até 1983} & Gasolina C & 33 & 1,4 \\
\cline { 2 - 4 } & $\begin{array}{c}\text { Etanol } \\
\text { hidratado }\end{array}$ & 18 & 1 \\
\hline $1984-1985$ & Gasolina C & 28 & 1,6 \\
\hline
\end{tabular}




\begin{tabular}{|c|c|c|c|}
\hline & $\begin{array}{c}\text { Etanol } \\
\text { hidratado }\end{array}$ & 16,9 & 1,2 \\
\hline \multirow[b]{2}{*}{ 1986-1987 } & Gasolina C & 22 & 1,9 \\
\hline & $\begin{array}{c}\text { Etanol } \\
\text { hidratado }\end{array}$ & 16 & 1,8 \\
\hline \multirow[b]{2}{*}{1988} & Gasolina C & 18,5 & 1,8 \\
\hline & $\begin{array}{c}\text { Etanol } \\
\text { hidratado }\end{array}$ & 13,3 & 1,4 \\
\hline \multirow[b]{2}{*}{1989} & Gasolina C & 15,2 & 1,6 \\
\hline & $\begin{array}{c}\text { Etanol } \\
\text { hidratado }\end{array}$ & 12,8 & 1,1 \\
\hline \multirow[b]{2}{*}{1990} & Gasolina C & 13,3 & 1,4 \\
\hline & $\begin{array}{c}\text { Etanol } \\
\text { hidratado }\end{array}$ & 10,8 & 1,2 \\
\hline \multirow[b]{2}{*}{1991} & Gasolina C & 11,5 & 1,3 \\
\hline & $\begin{array}{c}\text { Etanol } \\
\text { hidratado }\end{array}$ & 8,4 & 1 \\
\hline \multirow[b]{2}{*}{1992} & Gasolina C & 6,2 & 0,6 \\
\hline & $\begin{array}{c}\text { Etanol } \\
\text { hidratado }\end{array}$ & 3,6 & 0,5 \\
\hline \multirow[b]{2}{*}{1993} & Gasolina C & 6,3 & 0,8 \\
\hline & $\begin{array}{c}\text { Etanol } \\
\text { hidratado }\end{array}$ & 4,2 & 0,6 \\
\hline \multirow[b]{2}{*}{1994} & Gasolina C & 6 & 0,7 \\
\hline & $\begin{array}{c}\text { Etanol } \\
\text { hidratado }\end{array}$ & 4,6 & 0,7 \\
\hline \multirow[b]{2}{*}{1995} & Gasolina $\mathrm{C}$ & 4,7 & 0,6 \\
\hline & $\begin{array}{c}\text { Etanol } \\
\text { hidratado }\end{array}$ & 4,6 & 0,7 \\
\hline \multirow[b]{2}{*}{1996} & Gasolina C & 3,8 & 0,5 \\
\hline & $\begin{array}{c}\text { Etanol } \\
\text { hidratado }\end{array}$ & 3,9 & 0,7 \\
\hline \multirow[b]{2}{*}{1997} & Gasolina C & 1,2 & 0,3 \\
\hline & $\begin{array}{c}\text { Etanol } \\
\text { hidratado }\end{array}$ & 0,9 & 0,3 \\
\hline \multirow[b]{2}{*}{1998} & Gasolina C & 0,79 & 0,23 \\
\hline & $\begin{array}{c}\text { Etanol } \\
\text { hidratado }\end{array}$ & 0,67 & 0,24 \\
\hline \multirow[b]{2}{*}{1999} & Gasolina C & 0,74 & 0,23 \\
\hline & $\begin{array}{c}\text { Etanol } \\
\text { hidratado }\end{array}$ & 0,6 & 0,22 \\
\hline \multirow[b]{2}{*}{2000} & Gasolina C & 0,73 & 0,21 \\
\hline & $\begin{array}{c}\text { Etanol } \\
\text { hidratado }\end{array}$ & 0,63 & 0,21 \\
\hline \multirow[b]{2}{*}{2001} & Gasolina C & 0,48 & 0,14 \\
\hline & $\begin{array}{c}\text { Etanol } \\
\text { hidratado }\end{array}$ & 0,66 & 0,08 \\
\hline \multirow[b]{2}{*}{2002} & Gasolina C & 0,43 & 0,12 \\
\hline & $\begin{array}{c}\text { Etanol } \\
\text { hidratado }\end{array}$ & 0,74 & 0,08 \\
\hline 2003 & Gasolina C & 0,4 & 0,12 \\
\hline
\end{tabular}




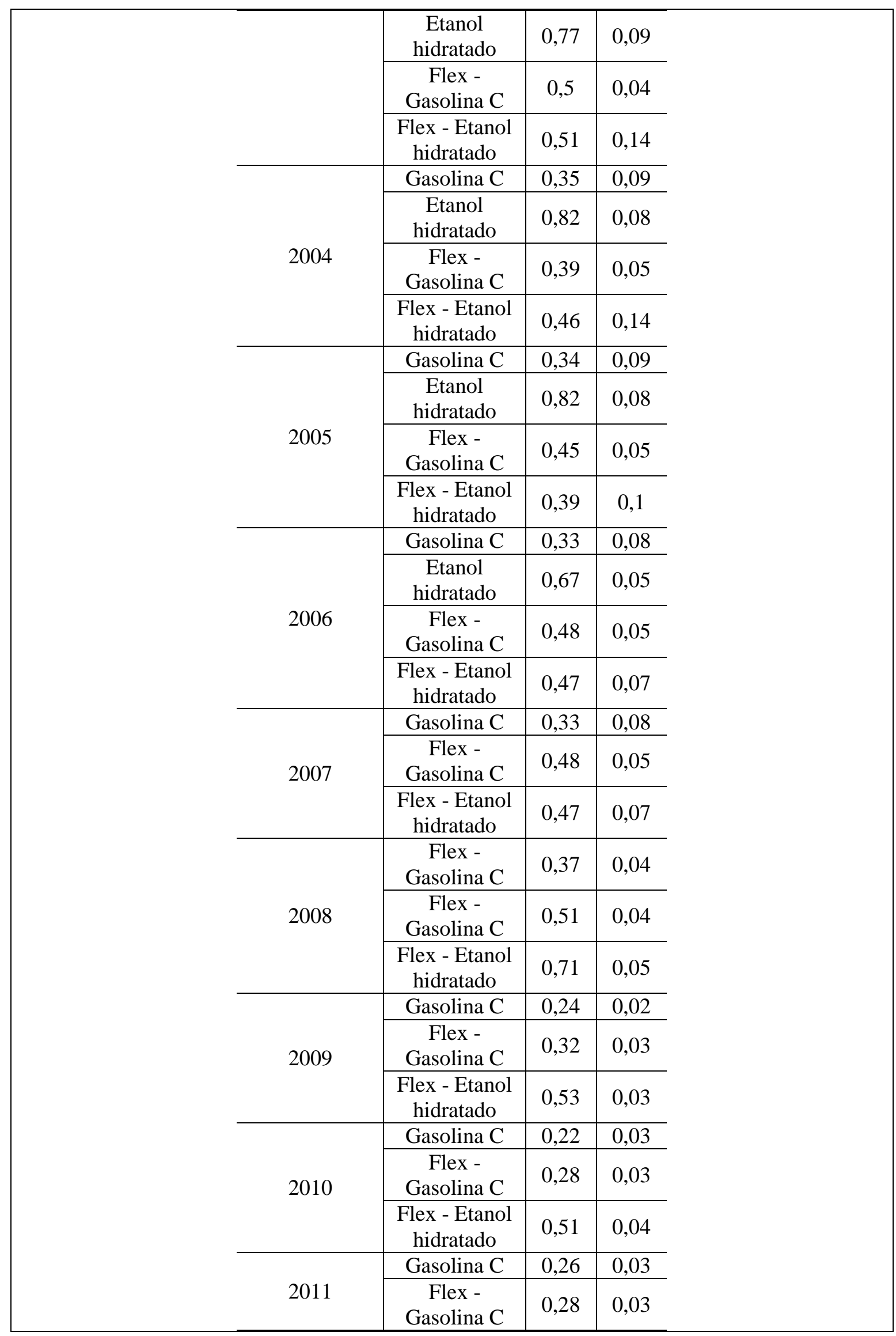




\begin{tabular}{|l|c|c|c}
\hline & $\begin{array}{c}\text { Flex - Etanol } \\
\text { hidratado }\end{array}$ & 0,49 & 0,03 \\
\hline \multirow{2}{*}{2012} & Gasolina C & 0,25 & 0,03 \\
\cline { 2 - 4 } & $\begin{array}{c}\text { Flex - } \\
\text { Gasolina C }\end{array}$ & 0,27 & 0,03 \\
\cline { 2 - 4 } & $\begin{array}{c}\text { Flex - Etanol } \\
\text { hidratado }\end{array}$ & 0,47 & 0,03 \\
\hline
\end{tabular}

Tabela 9: Fatores de emissão de $\mathrm{CO}$ e $\mathrm{NO}_{\mathrm{x}}$ para veículos movidos a $\mathrm{GNV}$, em g/km (MMA, 2013)

\begin{tabular}{c|c}
\hline $\mathrm{CO}$ & $\mathrm{NO}_{\mathrm{x}}$ \\
\hline 0,56 & 0,29 \\
\hline
\end{tabular}

Tabela 10: Fatores de emissão de $\mathrm{CO}$ e $\mathrm{NO}_{\mathrm{x}}$ para motocicletas em g/km (MMA, 2013)

\begin{tabular}{|c|c|c|c|}
\hline Ano/modelo & Combustível & $\mathrm{CO}$ & $\mathrm{NO}_{\mathbf{x}}$ \\
\hline Até 2002 & Gasolina C & 19,7 & 0,1 \\
\hline 2003 & Gasolina C & 5,03 & 0,15 \\
\hline 2004 & Gasolina C & 6,17 & 0,18 \\
\hline 2005 & Gasolina C & 2,65 & 0,16 \\
\hline 2006 & Gasolina C & 2,18 & 0,18 \\
\hline 2007 & Gasolina C & 1,82 & 0,17 \\
\hline 2008 & Gasolina C & 1,4 & 0,12 \\
\hline \multirow{3}{*}{2009} & Gasolina C & 1,09 & 0,1 \\
\hline & $\begin{array}{c}\text { Flex - Gasolina } \\
\text { C }\end{array}$ & 0,75 & 0,05 \\
\hline & $\begin{array}{c}\text { Flex - Etanol } \\
\text { hidratado }\end{array}$ & 0,58 & 0,07 \\
\hline \multirow{3}{*}{2010} & Gasolina C & 0,74 & 0,07 \\
\hline & $\begin{array}{c}\text { Flex - Gasolina } \\
\mathrm{C}\end{array}$ & 0,75 & 0,05 \\
\hline & $\begin{array}{c}\text { Flex - Etanol } \\
\text { hidratado }\end{array}$ & 0,58 & 0,07 \\
\hline \multirow{3}{*}{2011} & Gasolina C & 0,7 & 0,08 \\
\hline & $\begin{array}{c}\text { Flex - Gasolina } \\
\text { C }\end{array}$ & 0,76 & 0,06 \\
\hline & $\begin{array}{l}\text { Flex - Etanol } \\
\text { hidratado }\end{array}$ & 0,68 & 0,06 \\
\hline \multirow{3}{*}{2012} & Gasolina C & 0,57 & 0,08 \\
\hline & $\begin{array}{c}\text { Flex - Gasolina } \\
\text { C }\end{array}$ & 0,74 & 0,04 \\
\hline & $\begin{array}{l}\text { Flex - Etanol } \\
\text { hidratado }\end{array}$ & 0,9 & 0,04 \\
\hline
\end{tabular}

Tabela 11: Fatores de emissão de $\mathrm{CO}$ e $\mathrm{NO}_{\mathrm{x}}$ para motores Diesel em g goluente/km (MMA, 2013)

\begin{tabular}{c|c|c|c|c}
\hline $\begin{array}{c}\text { Ano } \\
\text { Modelo }\end{array}$ & \multicolumn{2}{|c|}{ Categoria } & CO & NOx \\
\hline \multirow{3}{*}{ Até 1999 } & \multirow{2}{*}{ Caminhões } & Semileves & 0,764 & 4,394 \\
\cline { 3 - 5 } & & Leves & 1,250 & 7,190 \\
\cline { 3 - 5 } & & Médios & 1,250 & 7,190 \\
\hline
\end{tabular}




\begin{tabular}{|c|c|c|c|c|}
\hline & & Semipesados & 2,014 & $\begin{array}{c}11,58 \\
5\end{array}$ \\
\hline & & Pesados & 2,014 & $\begin{array}{c}11,58 \\
5\end{array}$ \\
\hline & \multirow{4}{*}{ Ônibus } & Urbanos & 3,021 & $\begin{array}{c}17,37 \\
7\end{array}$ \\
\hline & & Micro-ônibus & 1,805 & $\begin{array}{c}10,38 \\
6 \\
\end{array}$ \\
\hline & & Rodoviários & 2,292 & $\begin{array}{c}13,18 \\
2\end{array}$ \\
\hline & & Comerciais Leves & 0,739 & 4,250 \\
\hline \multirow{9}{*}{$\begin{array}{l}2000- \\
2001\end{array}$} & \multirow{5}{*}{ Caminhões } & \multirow{5}{*}{$\begin{array}{c}\text { Semileves } \\
\text { Leves } \\
\text { Médios } \\
\text { Semipesados } \\
\text { Pesados }\end{array}$} & 0,687 & 2,776 \\
\hline & & & 1,124 & 4,543 \\
\hline & & & 1,124 & 4,543 \\
\hline & & & 1,810 & 7,319 \\
\hline & & & 1,810 & 7,319 \\
\hline & \multirow{4}{*}{ Ônibus } & \multirow{4}{*}{$\begin{array}{c}\text { Urbanos } \\
\text { Micro-ônibus } \\
\text { Rodoviários } \\
\text { Comerciais Leves }\end{array}$} & 2,715 & $\begin{array}{c}10,97 \\
9\end{array}$ \\
\hline & & & 1,623 & 6,562 \\
\hline & & & 2,138 & 8,646 \\
\hline & & & 0,689 & 2,787 \\
\hline \multirow{9}{*}{$\begin{array}{l}2002- \\
2003\end{array}$} & \multirow{5}{*}{ Caminhões } & Semileves & 0,374 & 2,710 \\
\hline & & Leves & 0,612 & 4,435 \\
\hline & & Médios & 0,612 & 4,435 \\
\hline & & Semipesados & 0,986 & 7,146 \\
\hline & & Pesados & 0,986 & 7,146 \\
\hline & \multirow{4}{*}{ Ônibus } & Urbanos & 1,479 & $\begin{array}{c}10,71 \\
8\end{array}$ \\
\hline & & Micro-ônibus & 0,884 & 6,406 \\
\hline & & Rodoviários & 1,122 & 8,131 \\
\hline & & Comerciais Leves & 0,362 & 2,621 \\
\hline \multirow{9}{*}{$\begin{array}{l}2004- \\
2008\end{array}$} & \multirow{5}{*}{ Caminhões } & \multirow{5}{*}{$\begin{array}{c}\text { Semileves } \\
\text { Leves } \\
\text { Médios } \\
\text { Semipesados } \\
\text { Pesados }\end{array}$} & 0,357 & 2,276 \\
\hline & & & 0,584 & 3,725 \\
\hline & & & 0,584 & 3,725 \\
\hline & & & 0,941 & 6,001 \\
\hline & & & 0,941 & 6,001 \\
\hline & \multirow{4}{*}{ Ônibus } & Urbanos & 1,412 & 9,002 \\
\hline & & Micro-ônibus & 0,844 & 5,381 \\
\hline & & Rodoviários & 1,071 & 6,829 \\
\hline & & Comerciais Leves & 0,345 & 2,202 \\
\hline \multirow{7}{*}{2009} & \multirow{5}{*}{ Caminhões } & \multirow{5}{*}{$\begin{array}{c}\text { Semileves } \\
\text { Leves } \\
\text { Médios } \\
\text { Semipesados } \\
\text { Pesados }\end{array}$} & 0,454 & 1,869 \\
\hline & & & 0,667 & 3,230 \\
\hline & & & 0,522 & 3,134 \\
\hline & & & 0,963 & 5,226 \\
\hline & & & 0,897 & 5,149 \\
\hline & \multirow{2}{*}{ Ônibus } & \multirow{2}{*}{$\begin{array}{c}\text { Urbanos } \\
\text { Micro-ônibus }\end{array}$} & 1,628 & 7,657 \\
\hline & & & 0,973 & 4,576 \\
\hline
\end{tabular}




\begin{tabular}{|c|c|c|c|c|}
\hline \multirow{11}{*}{2010} & & \multirow[t]{2}{*}{ Rodoviários } & 0,643 & 5,909 \\
\hline & & & 0,547 & 1,768 \\
\hline & & \multirow{5}{*}{$\begin{array}{c}\text { Leves } \\
\text { Médios } \\
\text { Semipesados } \\
\text { Pesados }\end{array}$} & 0,449 & 1,877 \\
\hline & & & 0,522 & 3,141 \\
\hline & & & 0,509 & 3,168 \\
\hline & & & 0,919 & 5,215 \\
\hline & & & 0,653 & 5,138 \\
\hline & \multirow{3}{*}{ Ônibus } & \multirow{3}{*}{$\begin{array}{c}\text { Urbanos } \\
\text { Micro-ônibus } \\
\text { Rodoviários }\end{array}$} & 1,744 & 7,773 \\
\hline & & & 1,042 & 4,646 \\
\hline & & & 0,693 & 5,657 \\
\hline & Comerciais Leves & & 0,837 & 2,190 \\
\hline \multirow{9}{*}{2011} & \multirow{5}{*}{ Caminhões } & \multirow{5}{*}{$\begin{array}{c}\text { Semileves } \\
\text { Leves } \\
\text { Médios } \\
\text { Semipesados } \\
\text { Pesados }\end{array}$} & 0,474 & 1,747 \\
\hline & & & 0,521 & 3,110 \\
\hline & & & 0,517 & 3,063 \\
\hline & & & 1,015 & 4,776 \\
\hline & & & 0,729 & 4,726 \\
\hline & \multirow{3}{*}{ Ônibus } & \multirow{3}{*}{$\begin{array}{c}\text { Urbanos } \\
\text { Micro-ônibus } \\
\text { Rodoviários }\end{array}$} & 1,462 & 7,682 \\
\hline & & & 0,874 & 4,591 \\
\hline & & & 0,661 & 5,855 \\
\hline & Comerciais Leves & & 0,484 & 1,490 \\
\hline \multirow{8}{*}{2012} & \multirow{5}{*}{ Caminhões } & \multirow{5}{*}{$\begin{array}{c}\text { Semileves } \\
\text { Leves } \\
\text { Médios } \\
\text { Semipesados } \\
\text { Pesados }\end{array}$} & 0,004 & 0,511 \\
\hline & & & 0,120 & 0,771 \\
\hline & & & 0,051 & 1,025 \\
\hline & & & 0,275 & 1,645 \\
\hline & & & 0,111 & 1,544 \\
\hline & \multirow{3}{*}{ Ônibus } & \multirow{3}{*}{$\begin{array}{c}\text { Urbanos } \\
\text { Micro-ônibus } \\
\text { Rodoviários }\end{array}$} & 0,440 & 2,103 \\
\hline & & & 0,263 & 1,257 \\
\hline & & & 0,334 & 1,750 \\
\hline \multicolumn{5}{|c|}{$\begin{array}{l}\text { Normalização: A pontuação deve ser atribuída de acordo com os valores de referência a } \\
\text { seguir, definidos a partir da média de redução de emissão de poluentes locais calculados } \\
\text { para duas ciclovias brasilienses. A fim de garantir maior consistência a estes valores de } \\
\text { referência, propõe-se nas Considerações Finais, a realização de novos estudos científicos } \\
\text { com a aplicação deste método em número representativo de ciclovias brasileiras de modo } \\
\text { a estabelecer valores médios que representem a realidade brasileira. }\end{array}$} \\
\hline Pontuação & \multicolumn{4}{|c|}{ Valores de Referência } \\
\hline 1,00 & \multicolumn{4}{|c|}{ A redução anual de emissão de poluentes locais é $\geq 1,26$ toneladas. } \\
\hline 0,75 & \multicolumn{4}{|c|}{$\begin{array}{l}\text { A redução anual de emissão de poluentes locais é } \geq 0,90 \text { e }<1,26 \\
\text { toneladas. }\end{array}$} \\
\hline 0,50 & \multicolumn{4}{|c|}{$\begin{array}{l}\text { A redução anual de emissão de poluentes locais é } \geq 0,62 \text { e }<0,90 \\
\text { toneladas. }\end{array}$} \\
\hline 0,25 & \multicolumn{4}{|c|}{$\begin{array}{l}\text { A redução anual de emissão de poluentes locais é } \geq 0,37 \text { e }<0,62 \\
\text { toneladas. }\end{array}$} \\
\hline 0,00 & \multicolumn{4}{|c|}{ A redução anual de emissão de poluentes locais é $<0,37$ toneladas. } \\
\hline
\end{tabular}


Nome do Indicador: Redução do nível de pressão sonora proveniente da transferência de viagens motorizadas para o modo cicloviário.

Dimensão de sustentabilidade: ambiental.

Descrição: indicador que verifica se a transferência de viagens realizadas anteriormente por meio de veículos motorizados para o modo cicloviário (ciclovia) promoveu redução do nível de pressão sonora em áreas habitacionais ou comerciais próximas.

Unidade de medida: muito boa, boa, nem boa/nem ruim, ruim, muito ruim.

Como medir: entrevistas diretas com os usuários da ciclovia.

Normalização: atribuir a pontuação correspondente à média das entrevistas com os usuários de acordo com os seguintes valores de referência:

\begin{tabular}{c|l}
\hline Pontuação & \multicolumn{1}{c}{ Valores de Referência } \\
\hline 1,00 & Muito boa. \\
\hline 0,75 & Boa. \\
\hline 0,50 & Nem boa/nem ruim. \\
\hline 0,25 & Ruim. \\
\hline 0,00 & Muito ruim. \\
\hline
\end{tabular}

Nome do Indicador: Promoção de áreas verdes.

Dimensão de sustentabilidade: ambiental.

Descrição: indicador que verifica, por meio do nível de satisfação dos ciclistas, a qualidade das áreas verdes nas imediações da ciclovia.

Unidade de medida: Muito boa, boa, nem boa/nem ruim, ruim, e muito ruim.

Como medir: entrevistas diretas com os usuários da ciclovia.

Normalização: atribuir a pontuação correspondente à média das entrevistas com os usuários de acordo com os seguintes valores de referência:

\begin{tabular}{c|l}
\hline Pontuação & \multicolumn{1}{c}{ Valores de Referência } \\
\hline 1,00 & Muito boa. \\
\hline 0,75 & Boa. \\
\hline 0,50 & Nem boa/nem ruim. \\
\hline 0,25 & Ruim \\
\hline 0,00 & Muito ruim. \\
\hline
\end{tabular}


Nome do Indicador: Qualidade das áreas nas imediações da ciclovia em termos de não abandono e degradação.

Dimensão de sustentabilidade: ambiental.

Descrição: indicador que verifica a existência de áreas abandonadas ou degradadas, incluindo, se necessário, a verificação se durante o processo de implantação ou de manutenção da ciclovia houve preocupação com a recuperação de áreas abandonadas ou degradadas, com o propósito de promover a requalificação urbana por meio da recuperação dessas áreas.

Unidade de medida: Muito boa, boa, nem boa/nem ruim, ruim, e muito ruim.

Como medir: por meio da verificação das áreas nas imediações da ciclovia em termos de não abandono e degradação, incluindo, se necessário, a análise do projeto executivo cicloviário para saber se este previu ações destinadas à recuperação de áreas degradadas.

Normalização: atribuir a pontuação correspondente à avaliação do técnico de acordo com os seguintes valores de referência:

\begin{tabular}{c|l}
\hline Pontuação & \multicolumn{1}{c}{ Valores de Referência } \\
\hline 1,00 & Muito boa. \\
\hline 0,75 & Boa. \\
\hline 0,50 & Nem boa/nem ruim. \\
\hline 0,25 & Ruim. \\
\hline 0,00 & Muito ruim. \\
\hline
\end{tabular}

Nome do Indicador: Compatibilidade_da ciclovia com o uso e ocupação do solo e com a legislação em vigor.

Dimensão de sustentabilidade: ambiental.

Descrição: indicador que verifica se a implantação ou reforma da ciclovia foi realizada de forma compatibilizada com o uso e ocupação do solo, incluindo planos e projetos para a região, e com o atendimento às normas ambientais, de desenvolvimento urbano, mobilidade e acessibilidade.

Unidade de medida: Muito boa, boa, nem boa/nem ruim, ruim, e muito ruim.

Como medir: por meio de inspeções junto à ciclovia; análise de planos, estudos e projetos para a região; e verificação do atendimento às normas existentes.

Normalização: atribuir a pontuação correspondente à avaliação do técnico de acordo com os seguintes valores de referência:

\begin{tabular}{c|l}
\hline Pontuação & \multicolumn{1}{c}{ Valores de Referência } \\
\hline 1,00 & Muito boa. \\
\hline 0,75 & Boa. \\
\hline 0,50 & Nem boa/nem ruim. \\
\hline
\end{tabular}




\begin{tabular}{l|l}
\hline 0,25 & Ruim. \\
\hline 0,00 & Muito ruim. \\
\hline
\end{tabular}

Nome do Indicador: Intensidade de danos causados ao meio ambiente devido à construção ou restauração da ciclovia.

Dimensão de sustentabilidade: ambiental.

Descrição: indicador que verifica a existência de danos causados ao meio ambiente devido às atividades de implantação e restauração da ciclovia.

Unidade de medida: sem impactos, impactos de pequeno porte, impactos significativos.

Como medir: por meio da verificação de danos ambientais decorrentes do processo de implantação da ciclovia e da evolução desses danos ao longo do tempo.

Normalização: atribuir a pontuação correspondente à avaliação do técnico de acordo com os seguintes valores de referência:

\begin{tabular}{c|l}
\hline Pontuação & \multicolumn{1}{c}{ Valores de Referência } \\
\hline 1,00 & Sem impactos significativos. \\
\hline 0,50 & Impactos de pequeno porte. \\
\hline 0,0 & Impactos significativos. \\
\hline
\end{tabular}




\section{B QUESTIONÁRIO PARA OS USUÁRIOS DA CICLOVIA}

1 - Qual é o motivo desta sua viagem?

$\square$ Trabalho $\square$ Escola $\square$ Lazer $\square$ Outro

Se não for por lazer, realizar a seguinte pergunta:

1.1 - Você também utiliza essa ciclovia por motivo de lazer?

$\square \operatorname{Sim} \square$ Não

2 - Você costuma pedalar, sem parar, por pelo menos 15 minutos?

$\square \operatorname{Sim} \quad \square$ Não

3 - Em sua opinião, esta ciclovia aumenta sua qualidade de vida? Como você avalia este aumento de qualidade de vida?

$\square$ Muito bom $\square$ Bom $\square$ Nem bom/nem ruim $\quad \square$ Ruim $\square$ Muito ruim

4 - Existem estacionamentos para a sua bicicleta junto à ciclovia? Como você avalia esta questão?

$\square$ Muito bom $\square$ Bom $\square$ Nem bom/nem ruim $\square$ Ruim $\square$ Muito ruim

5 - Em sua opinião, ocorrem muitos roubos e furtos nesta ciclovia?

$\square$ Ocorrência muito elevada $\square$ Ocorrência elevada $\square$ Ocorrência média

$\square$ Ocorrência baixa $\square$ Ocorrência muito baixa 
6 - Como você avalia a frequência de policiais nas imediações da ciclovia?

$\square$ Muito boa $\square$ Boa $\quad \square$ Nem boa/nem ruim $\quad \square$ Ruim $\square$ Muito ruim

7 - Como você avalia a localização desta ciclovia e sua conectividade com outras?

$\square$ Muito boa $\square$ Boa $\quad \square$ Nem boa/nem ruim $\quad \square$ Ruim $\square$ Muito ruim

8 - Como você avalia a segurança da ciclovia (qualidade da sinalização da ciclovia, qualidade dos cruzamentos desta com as vias de tráfego e tratamento dado aos locais perigosos)?

$\square$ Muito boa $\square$ Boa $\square$ Nem boa/nem ruim $\quad \square$ Ruim $\square$ Muito ruim

9 - Como você avalia a qualidade do pavimento desta ciclovia?

$\square$ Muito boa $\square$ Boa $\quad \square$ Nem boa/nem ruim $\quad \square$ Ruim $\square$ Muito ruim

10 - Como você avalia a qualidade da drenagem (escoamento da água na ciclovia)?

$\square$ Muito boa $\square$ Boa $\quad \square$ Nem boa/nem ruim $\quad \square$ Ruim $\quad \square$ Muito ruim

11 - Como você avalia a iluminação na ciclovia?

$\square$ Muito boa $\square$ Boa $\quad \square$ Nem boa/nem ruim $\quad \square$ Ruim $\square$ Muito ruim

12 - Como você avalia as áreas verdes nas imediações da ciclovia?

$\square$ Muito boa $\square$ Boa $\quad \square$ Nem boa/nem ruim $\quad \square$ Ruim $\square$ Muito ruim 
13 - Em sua opinião, você acha que houve redução de ruído nas áreas habitacionais ou comerciais próximas à ciclovia devido a uma transferência de viagens realizadas anteriormente por meio de veículos motorizados para o modo cicloviário? Como você avalia esta questão?

$\square$ Muito boa $\square$ Boa $\square$ Nem boa/nem ruim $\quad \square$ Ruim $\square$ Muito ruim

14 - Você possui um veículo particular?

$\square \operatorname{Sim} \quad \square$ Não

Se sim, realizar a seguinte pergunta:

14.1 - Que tipo de veículo particular você possui?

$\square$ Automóvel $\quad \square$ Moto $\quad \square$ Outro

15 - Antes da construção desta ciclovia, você fazia o trajeto a pé por falta de condições financeiras?

$\square$ Sim $\square$ Não $\square$ Outro (não realizava este trajeto antes da construção da ciclovia)

16 - Esta ciclovia trouxe para você algum benefício (obtenção de um trabalho, de oportunidade de estudo ou outro) que você não conseguiria obter sem utilizar a ciclovia?

$\square \operatorname{Sim} \quad \square$ Não 
17 - O seu gasto com transporte (locomoção) diminuiu com o uso desta ciclovia?

$\square \operatorname{Sim} \quad \square$ Não

Se sim, quanto você gastava por mês antes de utilizar esta ciclovia e o quanto você economizou?

Antes: reais por dia

Economia: reais por dia

18 - Você deixou de fazer alguma viagem com veículo automotor devido à implantação ou utilização da ciclovia e passou a fazê-la com bicicleta?

$\square \operatorname{Sim} \square$ Não

Se sim, você poderia nos informar qual era o trajeto, o tipo de veículo, ano de fabricação e o combustível utilizado? E quantas viagens você fazia por semana?

Trajeto antes realizado com veículo automotor e que agora é feito com o uso da bicicleta:

Início: Via Desde:

Final: Via Até:

Quantidade de viagens por semana:

Distância total aproximada de cada viagem: $\mathrm{km}$ 
Veículo utilizado:

$\square$ Carro à gasolina $\quad \square$ Carro a álcool $\square$ Carro flex $\quad \square$ Carro a gás $\quad \square$ Moto Ônibus

Ano do carro: 


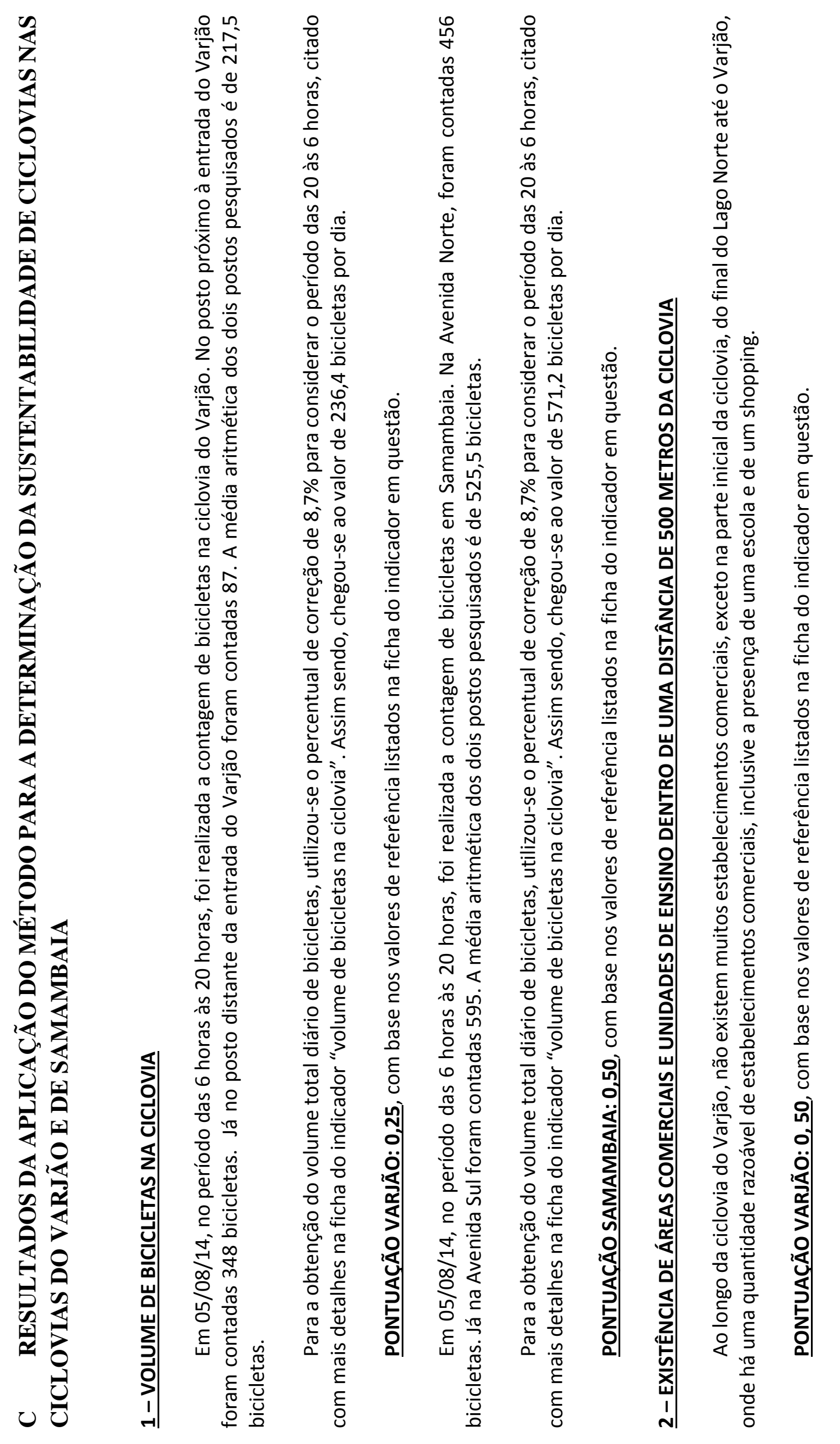




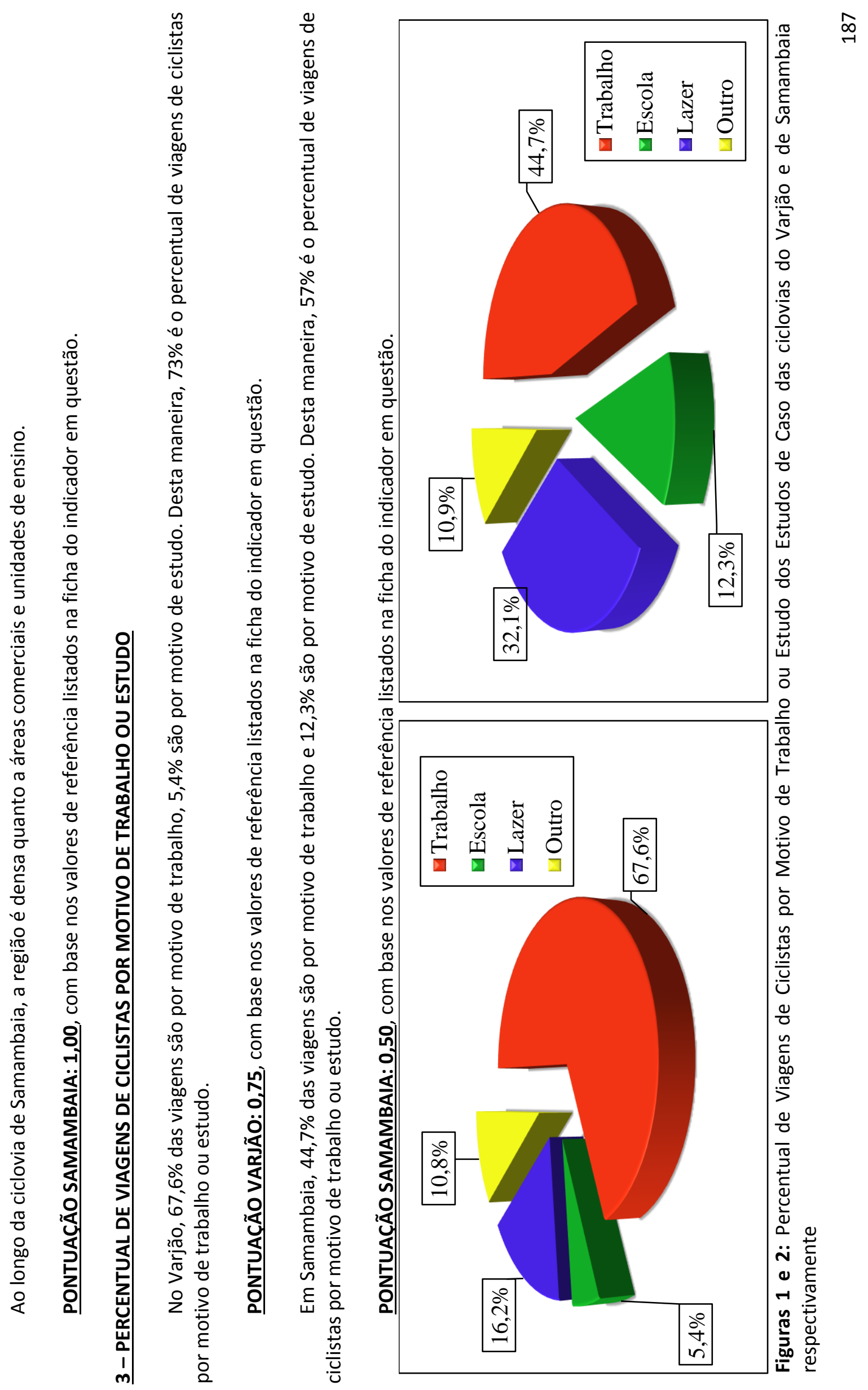



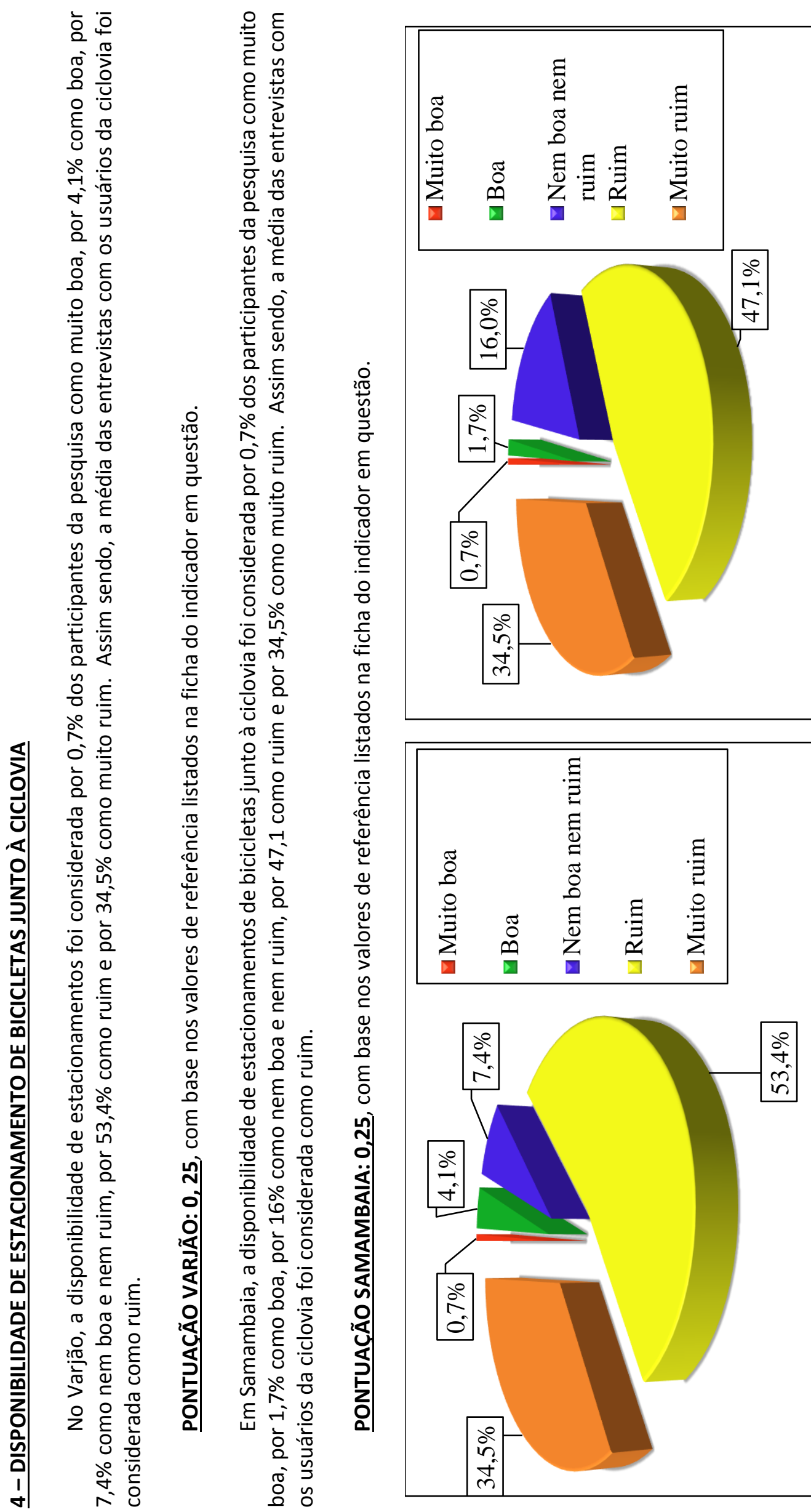

$\stackrel{\infty}{\infty}$

-

온

.气

崩

.

음

足 $\frac{E}{3}$

है

일

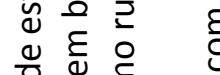

¿

要

웡

는 흥ํㅇ

०

䨌

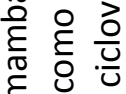

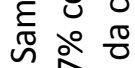

도ำ

흠 뜬

กั

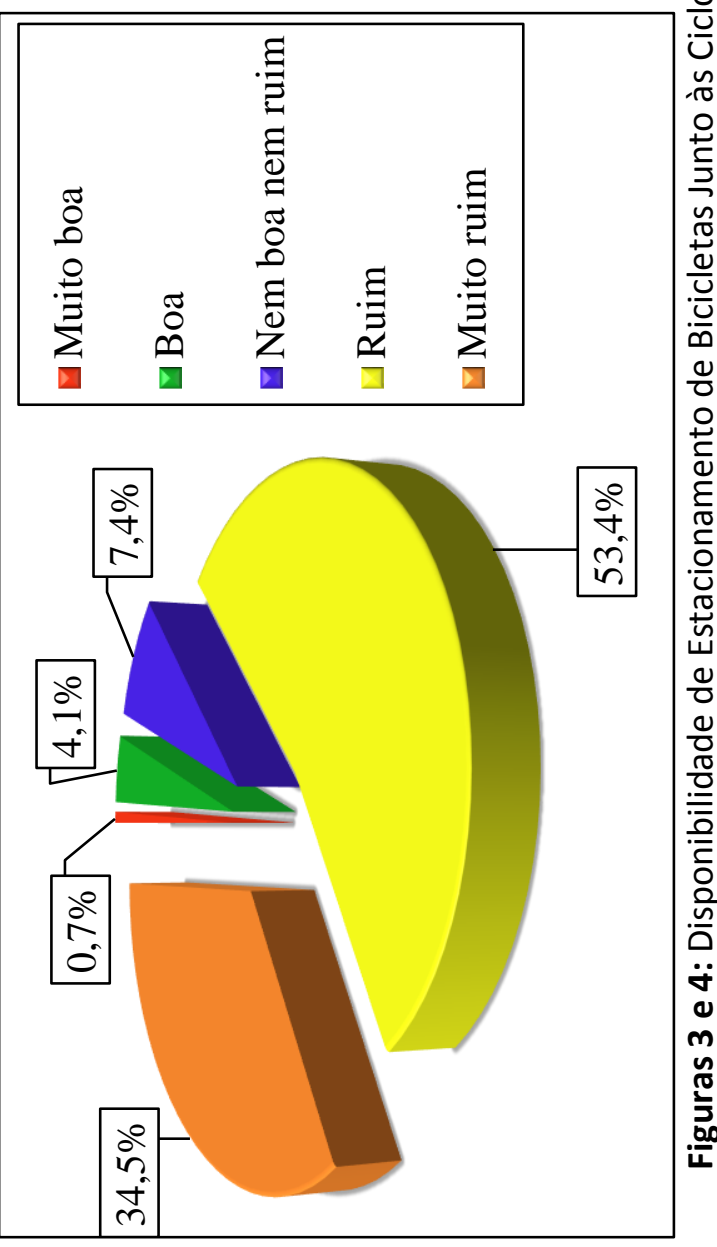




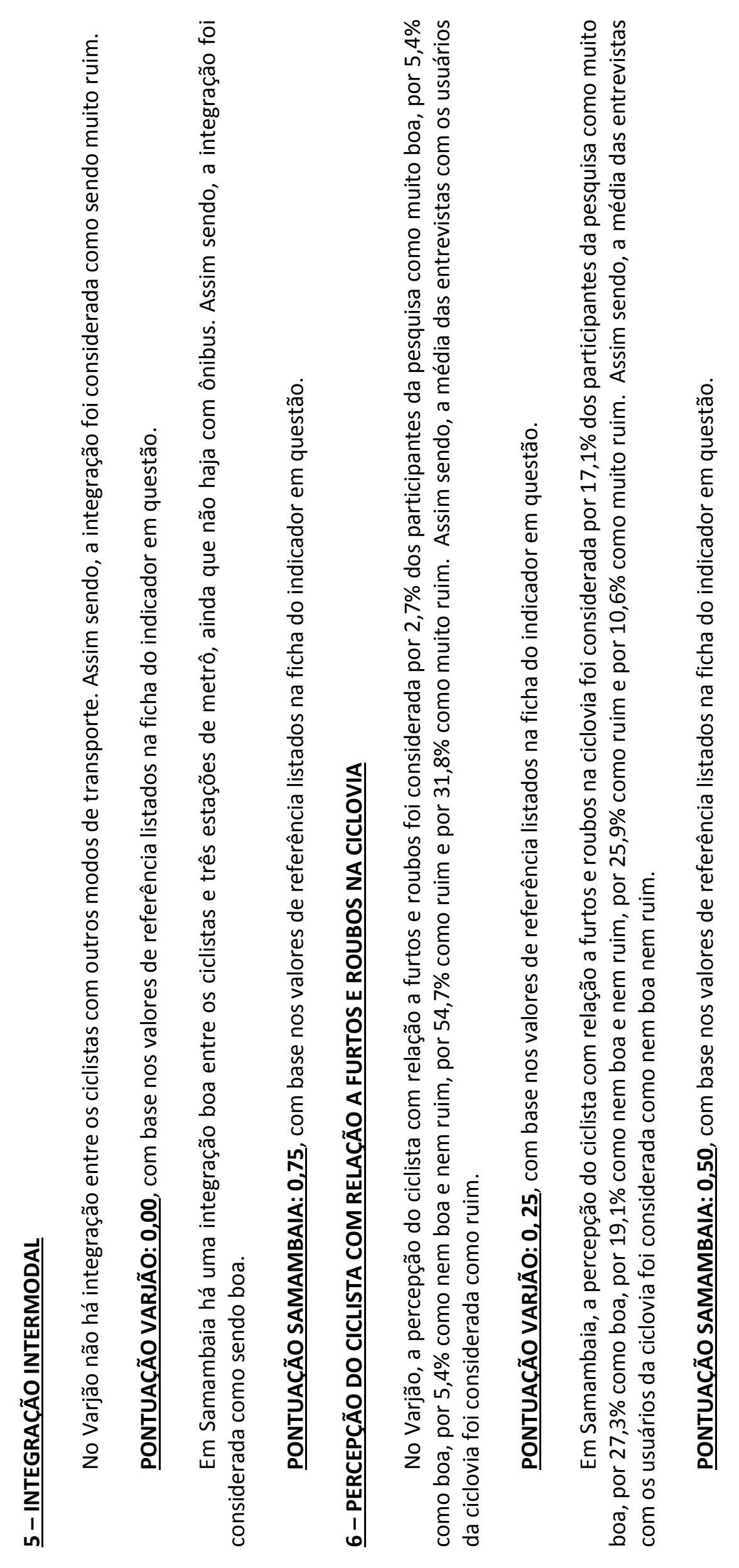



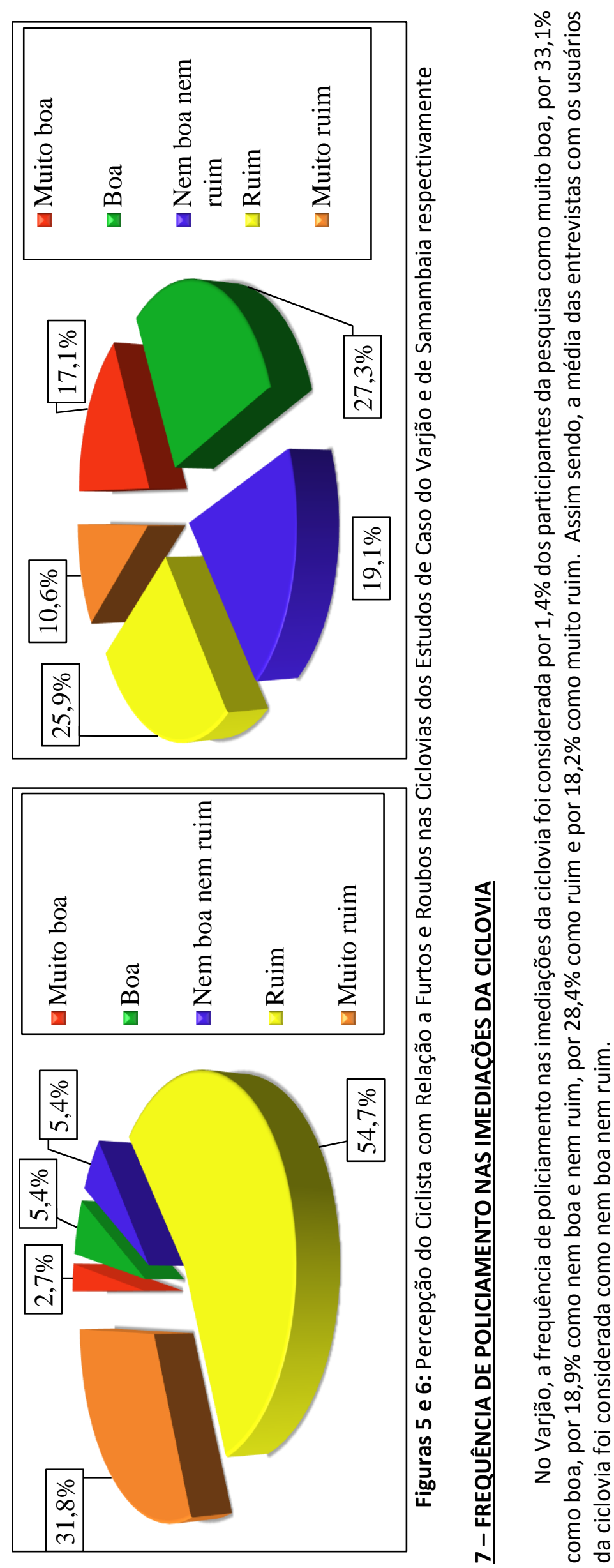

효욤

กิ

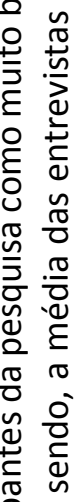

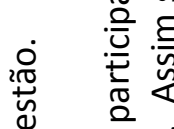

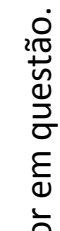

음 $\frac{\dot{\varepsilon}}{3}$

ㅇํㅇ 흥

ㅎํ है

요용

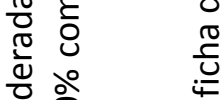

ก

ㅇำ

त 0 类

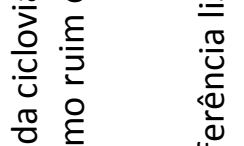

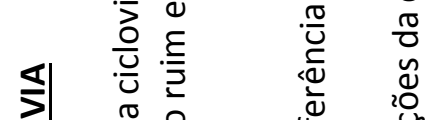

¿

范 워 व

要守产

हूँ $\frac{0}{\pi}$

है 气

율 혼

है

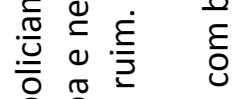

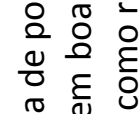

ㅇํ तु

ஸे̀

<ब

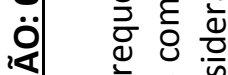

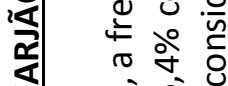

co

त्र

है 흘 을

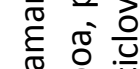

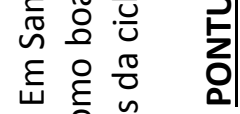

웅.으

ํำ 

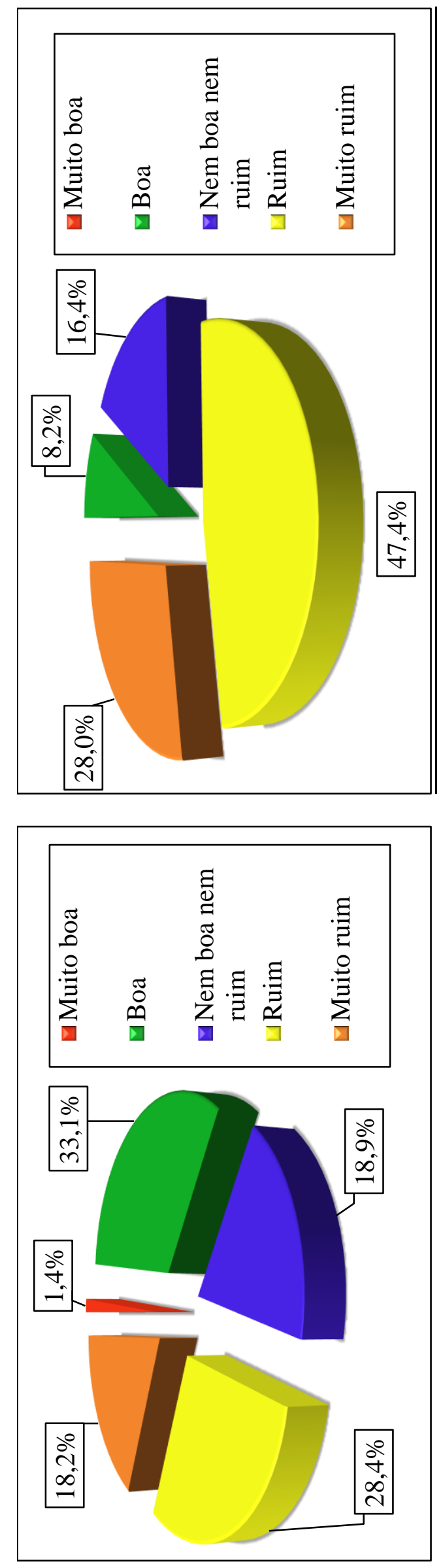

흐

कृ

녹

है

는

穿

ญू

중

嗐

을

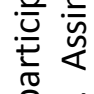

号

ㅇํㅇำ

ํ. ํ.ำ

ㅎํำ

$\frac{\pi}{0}$ O

흉

¿

ㅇํㅇำ

प̄

告 $\frac{5}{3}$

彳) 는

荧

ठㅇ

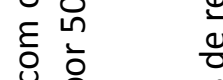

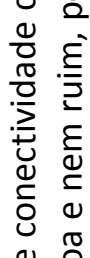

ป

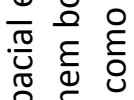

는

2:

응

ชั

응

$\pi$.

20 응

흥

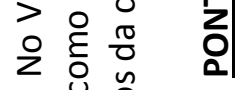

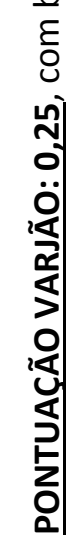

중

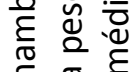

ह $\frac{\pi}{0}$

๙

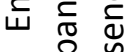

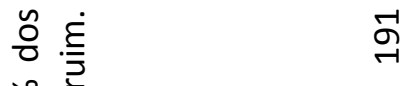

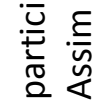




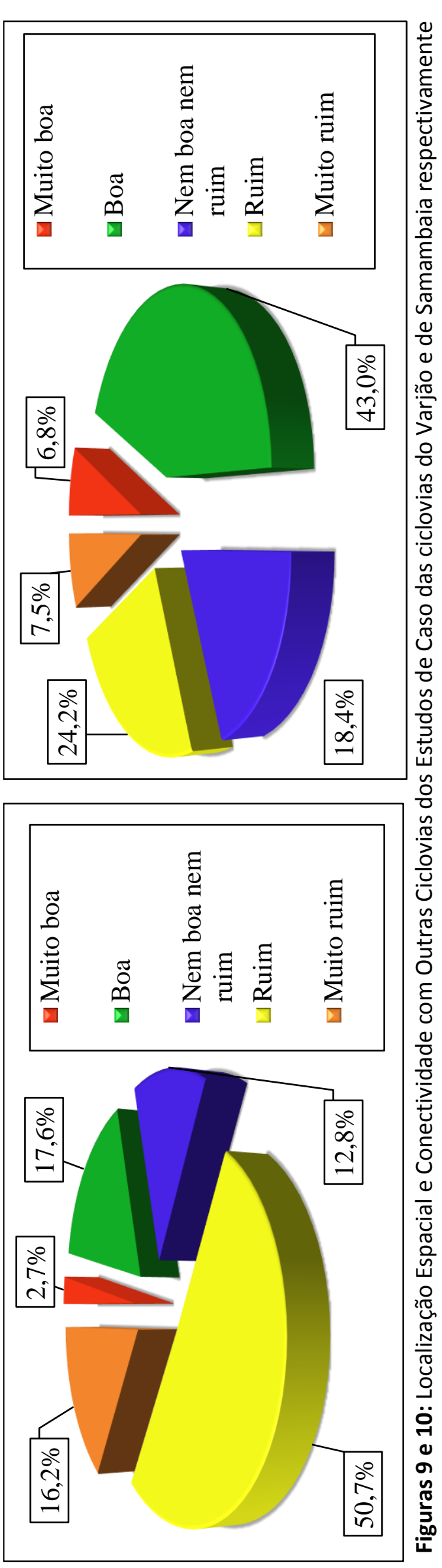

$\frac{8}{8}$

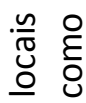

ฐ

강.

흐

융

응

는

ㅇํㄴ

흥 음

븜웜

는

ป

으 ㅇํํ

กิ กั

量

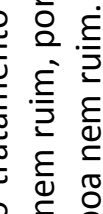

응 용

०)

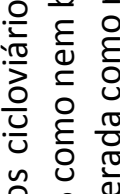

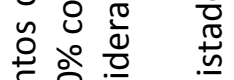

응 ํำ

ㄴำ

ฮे ํำ

劳 $\frac{\mathrm{E}}{\mathrm{T}}$

응 통

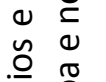

需 용

은 틀 을

는

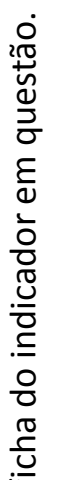

웡

in

믐

है 율 है

N $\stackrel{n}{N}$

บั ปั

음 융

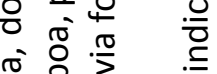

응으은 응

는 언

중유 은

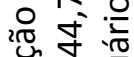

蛋

ते थे

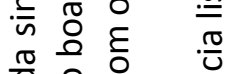

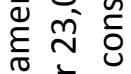

곤 ㅎํ

o.

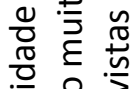

음 $\frac{n}{>}$ 迎

응 :

은 $\frac{1}{0}$

음 원 $\frac{0}{0}$

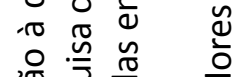

200

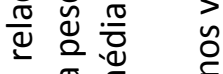

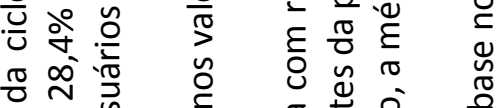

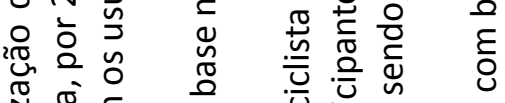

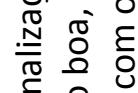

ज은

ช

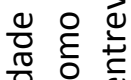

응 0

类 $\frac{0}{=} \frac{\pi}{0}$

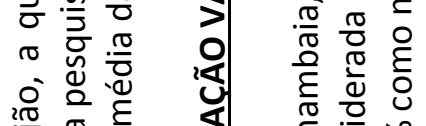

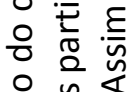

위 2000

일

齐

ते

त $\frac{10}{2}$

है $\frac{0}{0}$ ठ

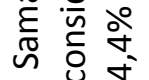

뜨 흔

苍

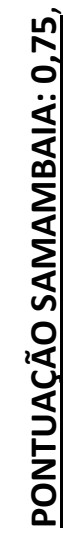

$\frac{\frac{1}{0}}{\frac{0}{\pi}} \cdot \frac{5}{5}$ 


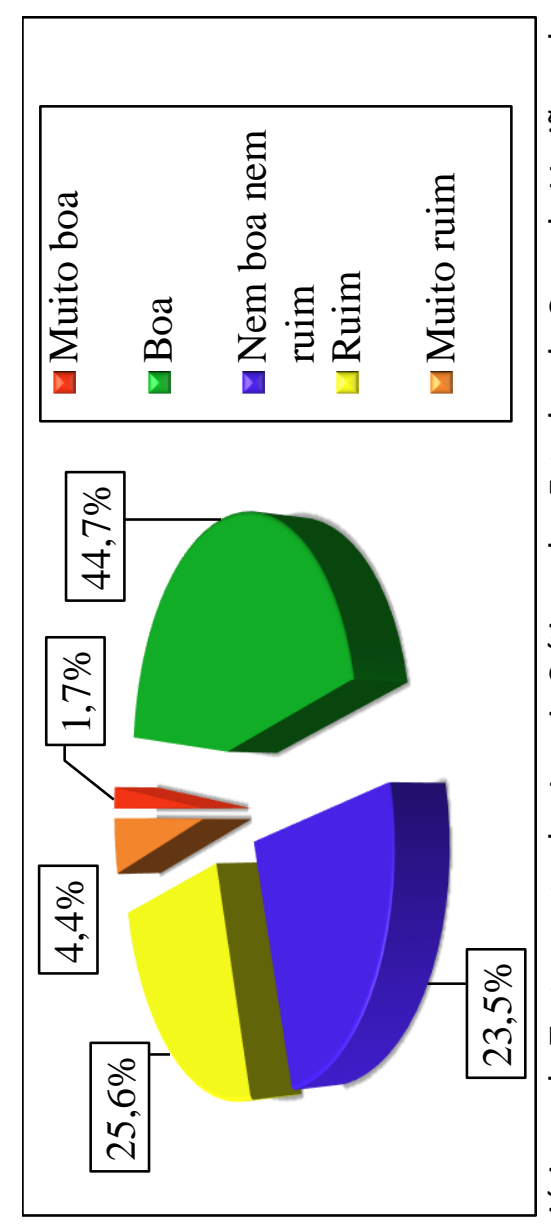

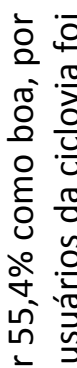

ᄒे

ำ

旁营

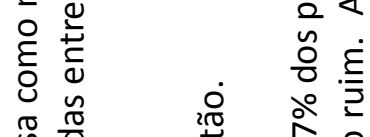

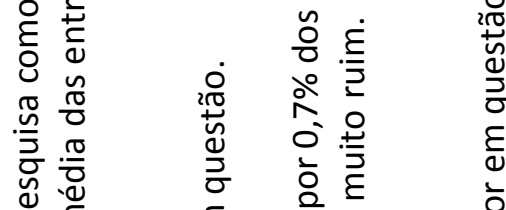

ฝे

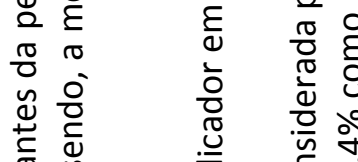

응

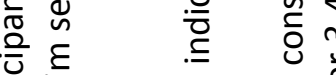

严皆

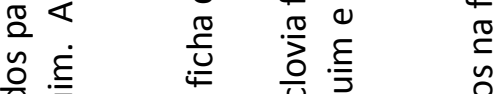

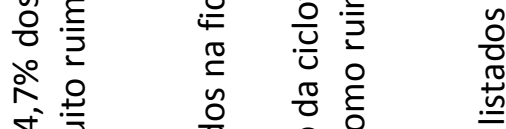

广产

일

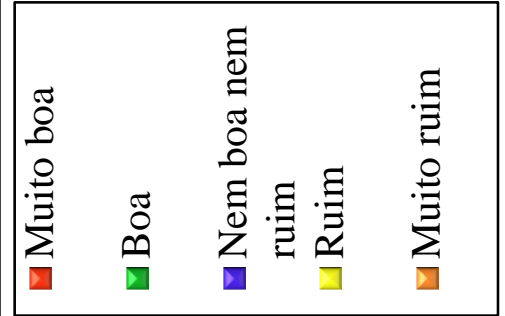

중

ब。ำ

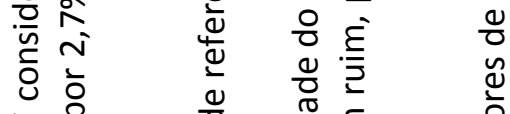

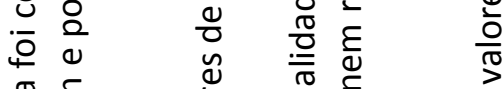

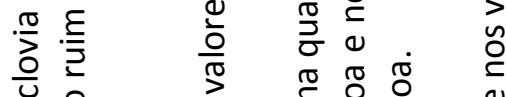

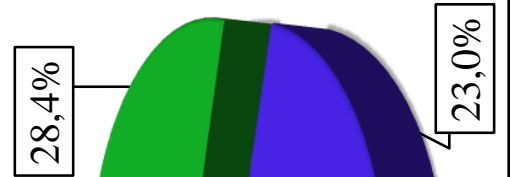

든

$\varangle \quad \frac{\pi}{0} 8$

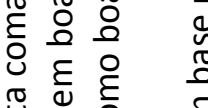

ํำ

ปิ

市市

ำ 20ํํㅇำ

융 है

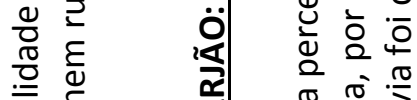

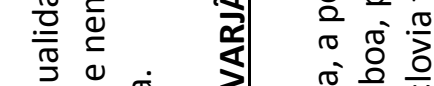

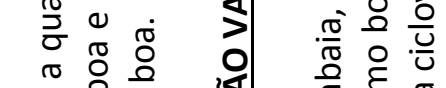

०े है

㝕

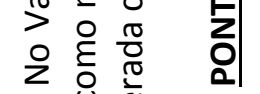

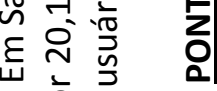

م⿱

$\stackrel{m}{9}$ 


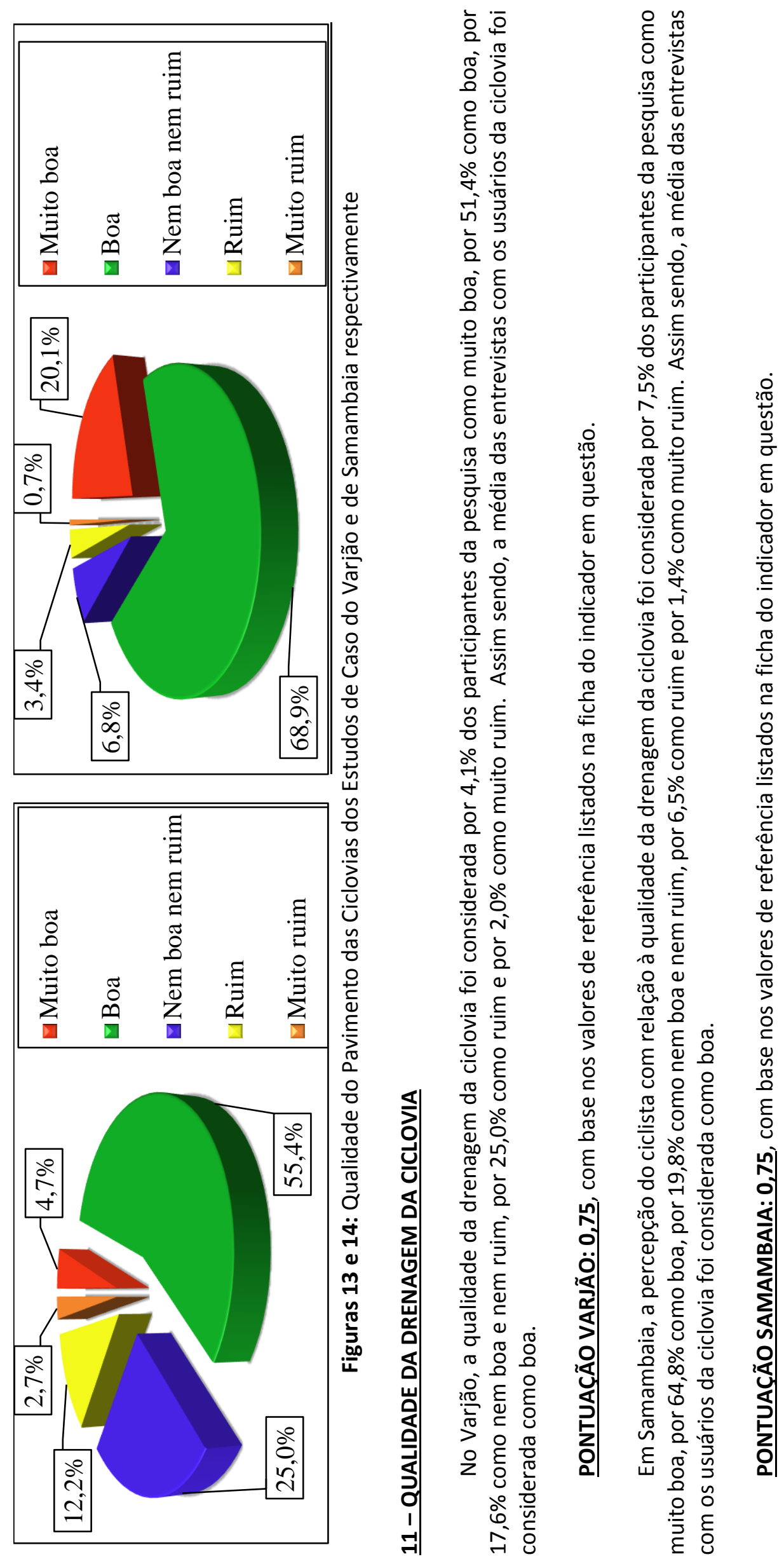




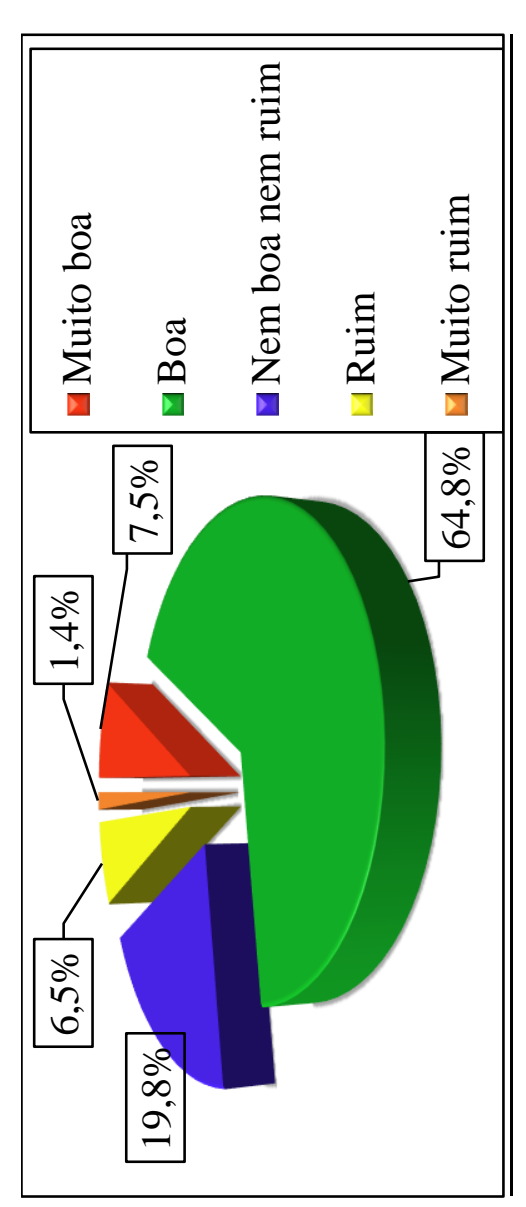

ํํㅇ

응 $\frac{\dot{\xi}}{3}$

号

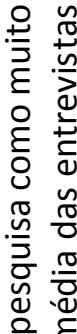

ำ

중

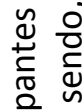

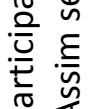

觉

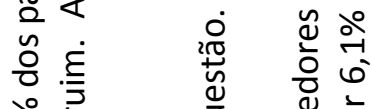

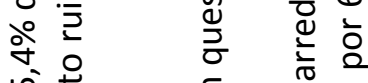

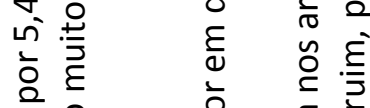

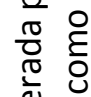

응

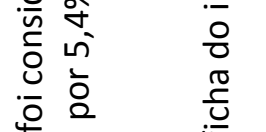

응

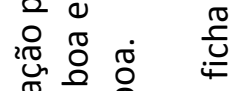

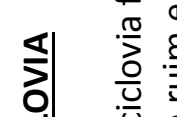

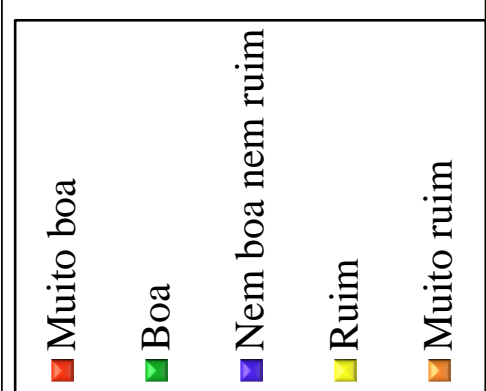

ก

U)

ญे ㅇํㅇ

㟧 竞

ठั.

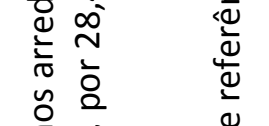

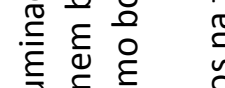

喜

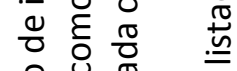

200

\%

층 ㅇำ

흥 흔

은 के

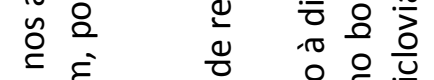

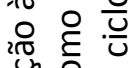

중 웅

Ф ㅇํㅇ 은

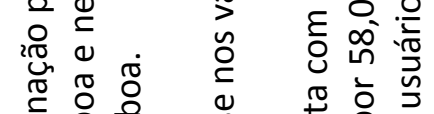

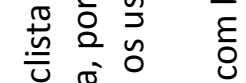

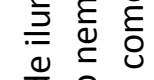

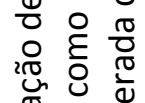

ำ 웜

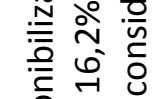

등 ㅎำ

กั

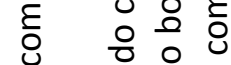

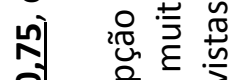

○े

这

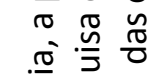

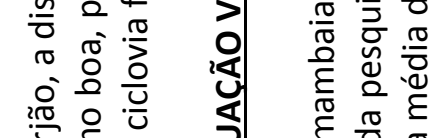

放 $\frac{1}{3} \frac{\pi}{0}$

은 ㅇํㅇำ

过

ò जิ

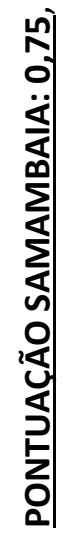

तิ

ํㅡ ชั

है

음

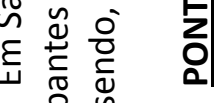

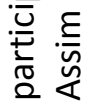




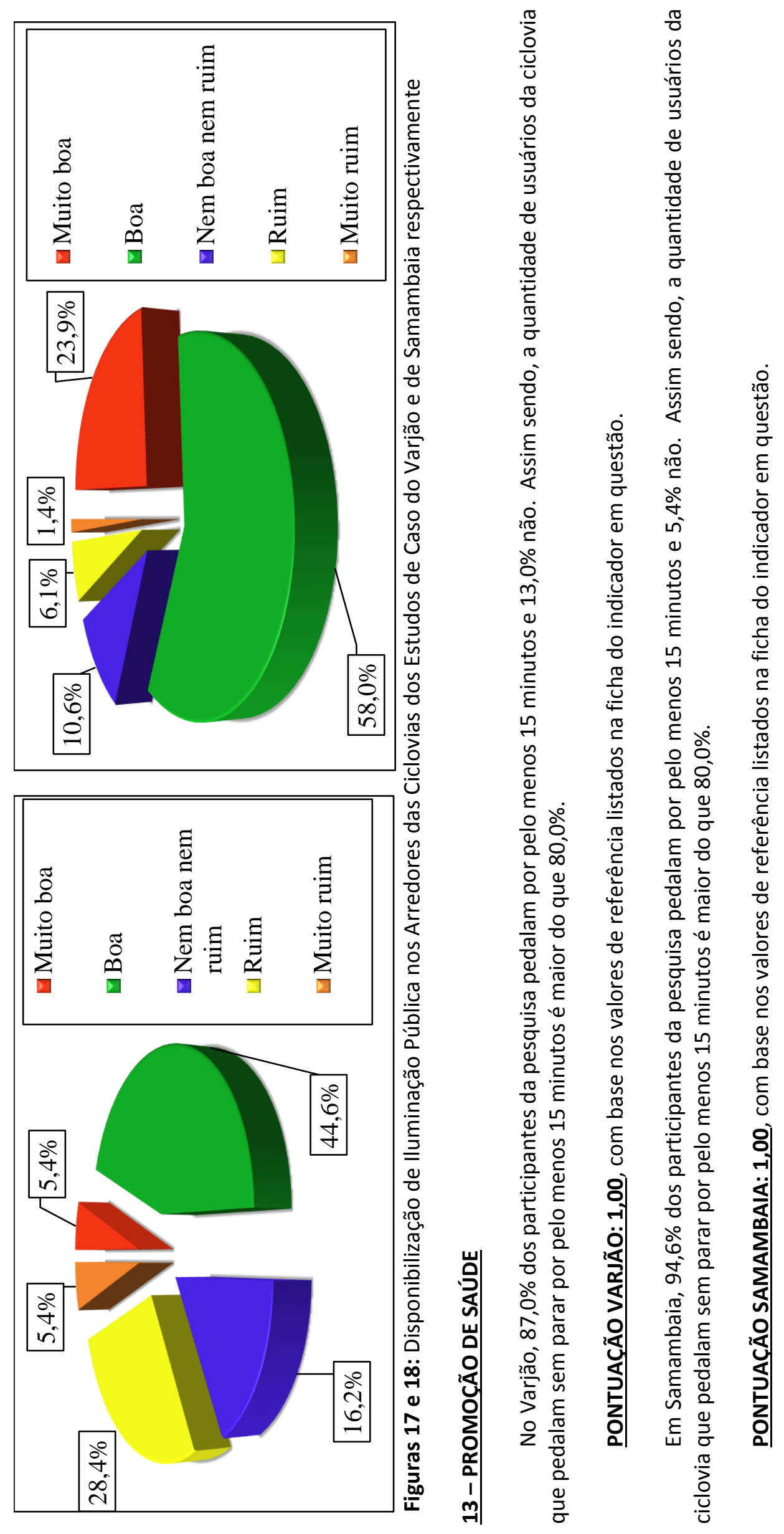

๑ั 

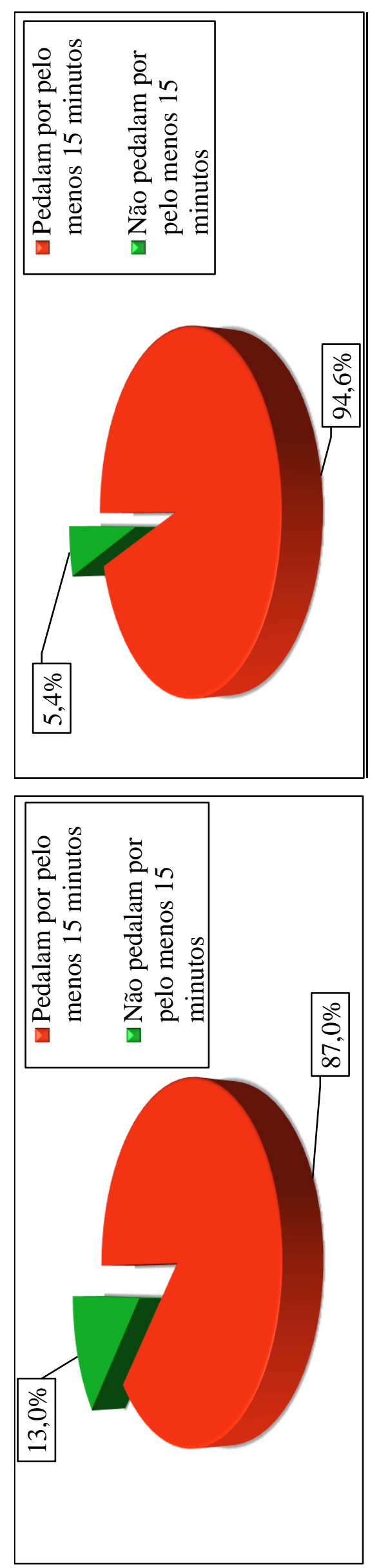

$\sigma$

음

跣

음

\%

㐫

든

ㅇํㅇ

党

है

$\frac{\pi}{\frac{\pi}{\sigma}}$

语

든

$\frac{0}{2} \frac{\pi}{0}$

กั .ำ

$\frac{0}{0} \frac{10}{3}$

ㅎํㅇ

ডั

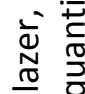

즌

$\frac{2}{\sqrt{0}} \frac{0}{2}$

$\frac{\pi}{3} \frac{1}{4}$

은 $\frac{E}{\sqrt{5}}$

ह

语

กำ

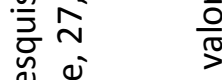

ฮั

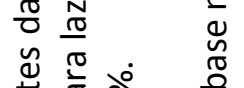

岀

牙

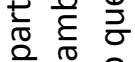

웡 웅

응 乞ํ 흐

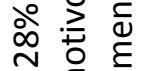

N $E$ व

กิ ถัㅇํㅇ

得

ग $\frac{0}{0} \frac{\pi}{0}$

2

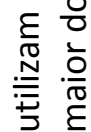

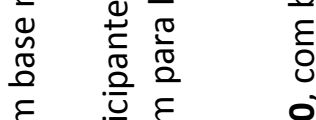

음

ฮै 음

吾

0 응

离

즐 잉

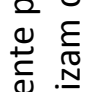

㲅

$\frac{\varepsilon}{\frac{\pi}{2}} \frac{0}{\frac{1}{2}}$

돌

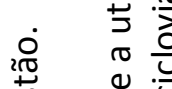

竞

둉

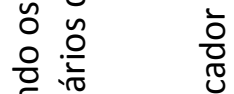

กั

은 응

잉 $\frac{0}{0} \quad \frac{\pi}{0}$

空售

एँ

20 0

응 웅

은

ब $\frac{5}{5}$

ह岁㐫

잉

禋

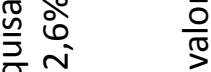

घั ซ

$\frac{\pi}{2}$

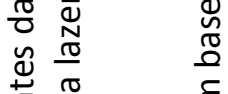

늘

ก) 约

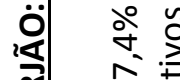

क

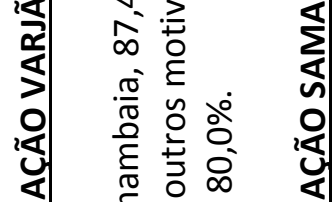

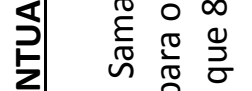

음

Е늘 웅

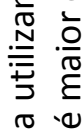

0. 


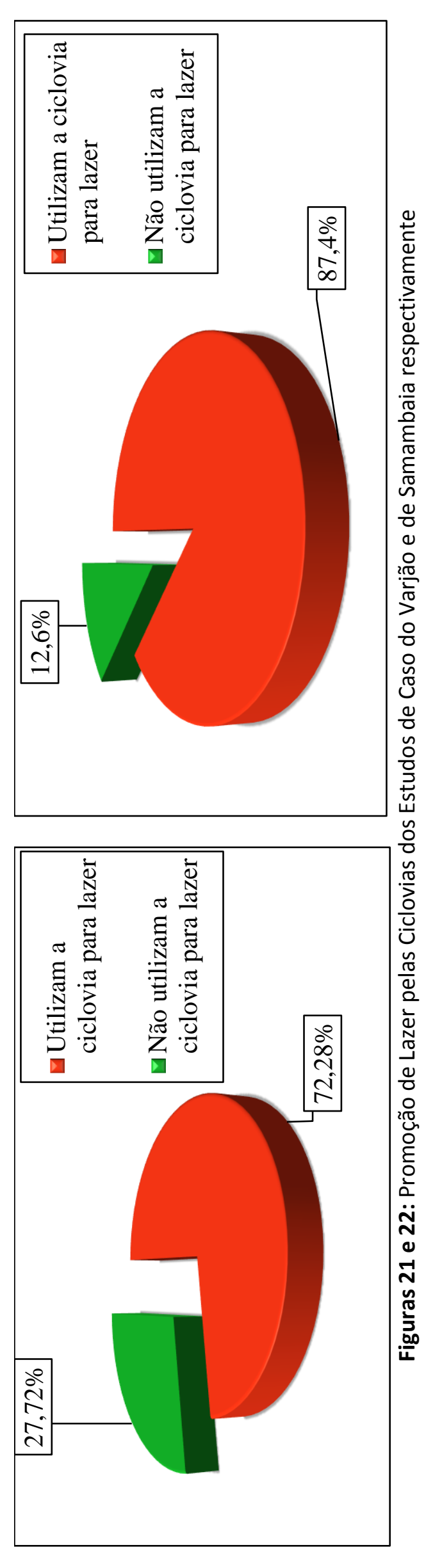

ㅇํㅇ ह่

芩舵

$\stackrel{\infty}{\rightarrow}$

ने 웜

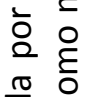

중

卷

능

पे

要言

을

ㅇํㅇ ㅇำ

总

잉

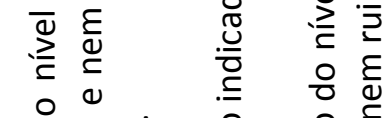

กิ่

훙

宽

के

ปे ๖ำ

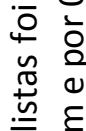

苞

ơ

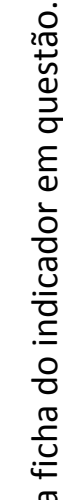

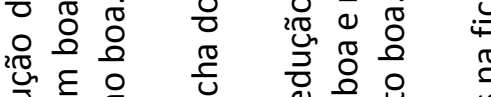

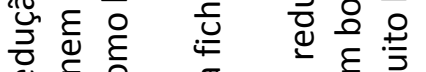

ब $\frac{E}{\mathrm{v}} \overrightarrow{\mathrm{F}}$

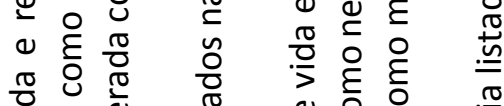

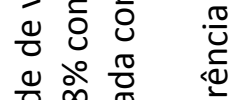

웅

西 $+\frac{0}{4}$

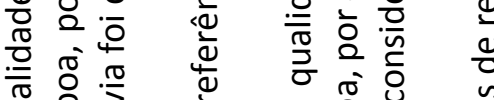

茪

गृ.

$\frac{\sigma}{\omega}, \frac{0}{0}$

ㅇํㅇ

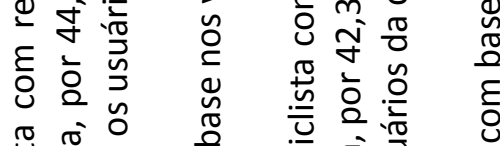

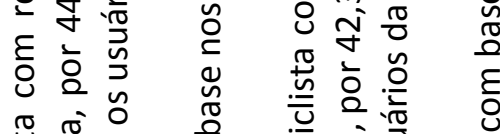

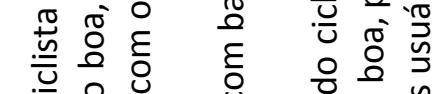

8)

ปे

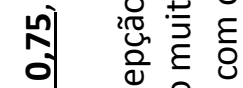

일

尊

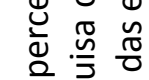

o.

$2 \frac{0}{2} \frac{0}{0} \frac{0}{0}$

$>$ 造

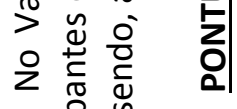

एँ

造记

$\pi$ 吸

㐘旁

है

空䨌

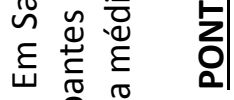

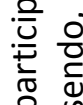



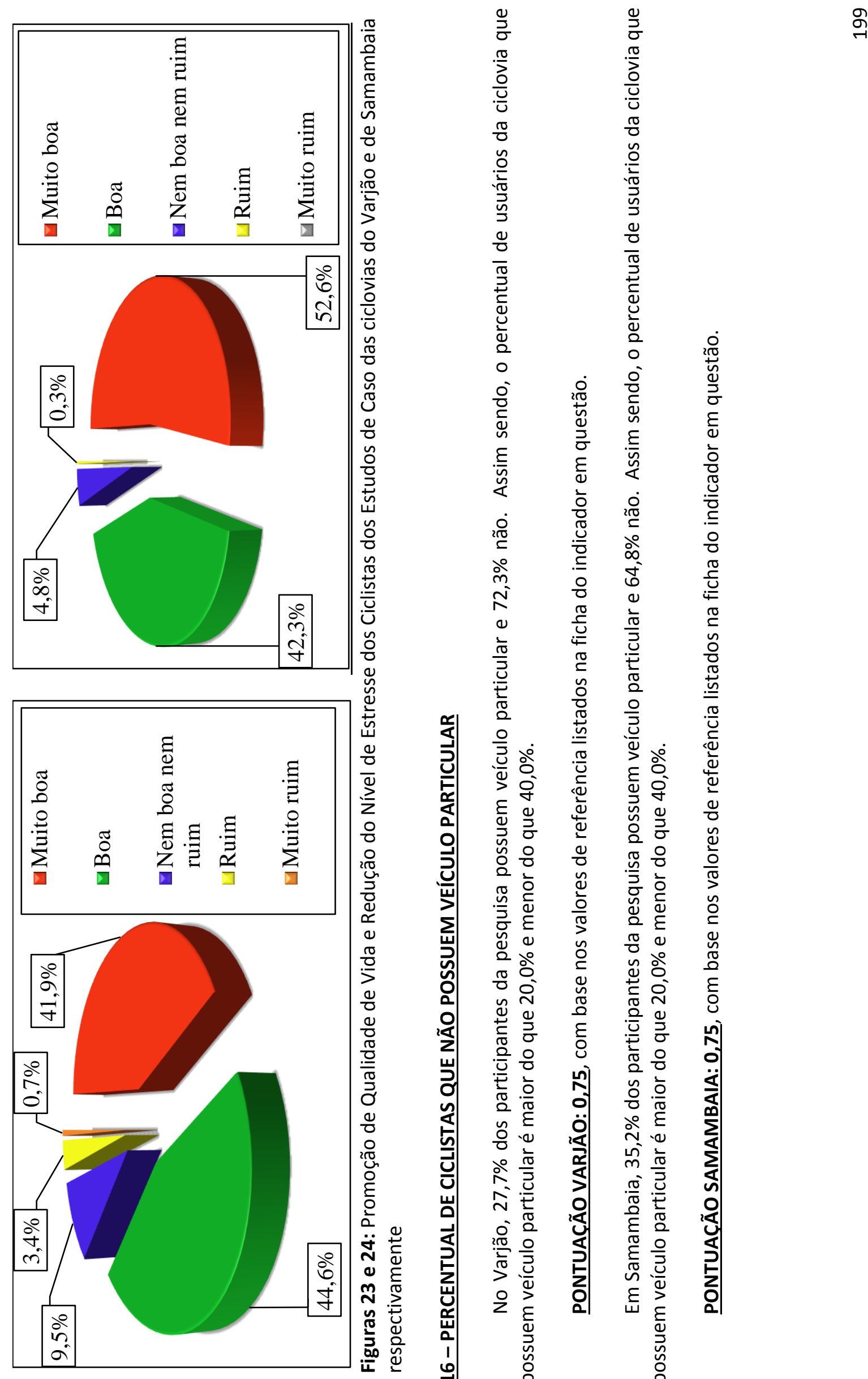

్ㅏㅁ

$\frac{\sqrt{2}}{\frac{0}{2}}$

$\frac{\text { OO }}{. \frac{U}{U}}$

중

.$\frac{2}{2}$

$\frac{\text { 은 }}{\sqrt{\frac{10}{3}}}$

$\frac{8}{8}$

$\stackrel{\sqrt[T]{2}}{\stackrel{2}{2}}$

ปัญ

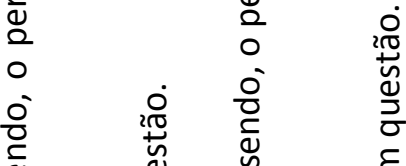

ఖ

$\frac{E}{4}$

ㅇำ

$\frac{8}{4}$

욜.

ㅇำ 음

ㄴ.

- $\frac{\pi}{5} \frac{1}{\frac{\pi}{7}} \frac{\pi}{5}$

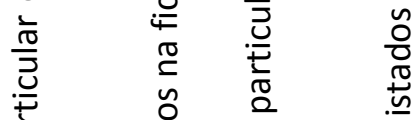

()

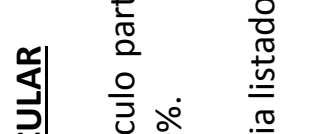

$\frac{2}{\frac{0}{3}}$

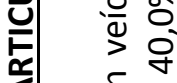

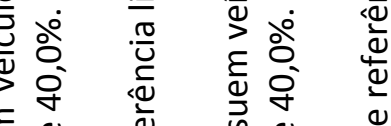

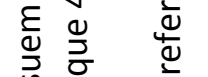

ज割

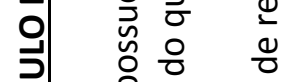

음 의

해

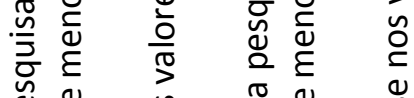

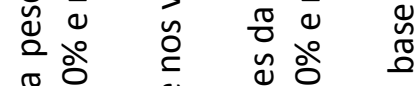

đั

워

응 웅

$\frac{2}{\frac{1}{5}} \frac{0}{\square}$

กิ

븡 흔 흔

彳ิ $\frac{1}{2} \cdot \frac{\pi}{8}$

जू

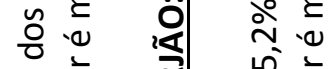

ஓำ

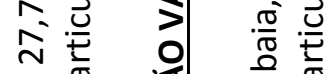

ำ

这

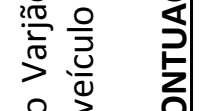

$\frac{\sum^{\pi}}{\pi} \stackrel{0}{0}$

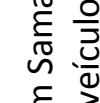

운

$\frac{\varepsilon}{0}$

Eี

气ิ 

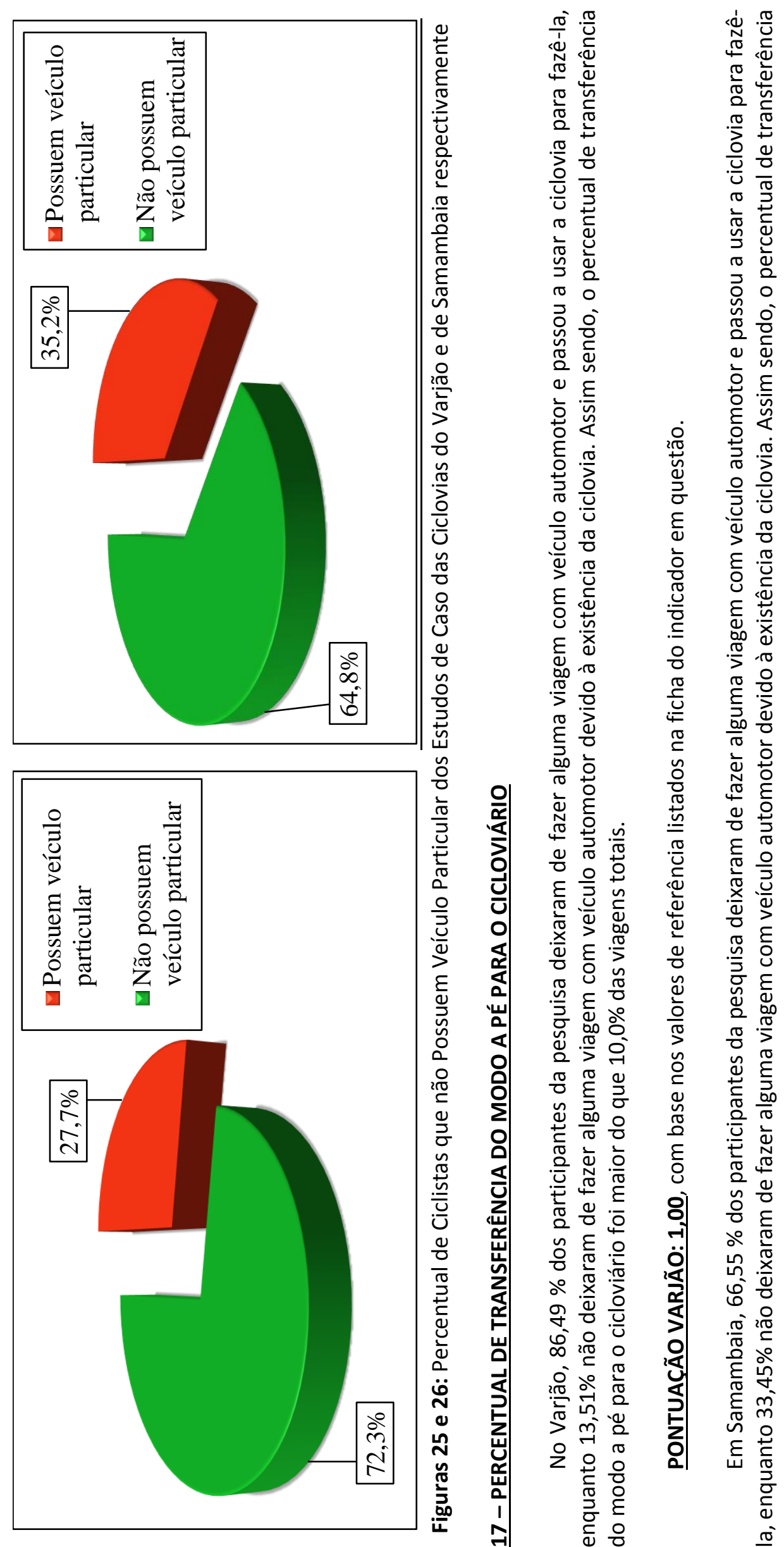

유

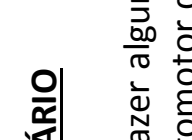

¿

근 을 온

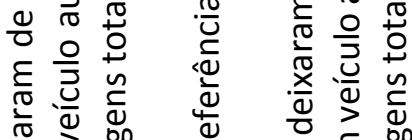

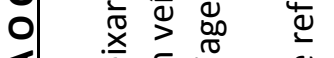

$\overleftarrow{a}$ 造

준

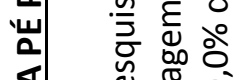

ष

이 중

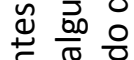

我 힝

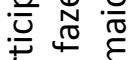

윰 웜

유 든 은

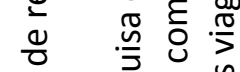

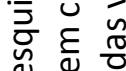

잉

ज प

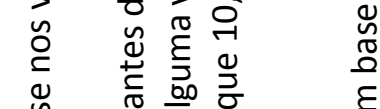

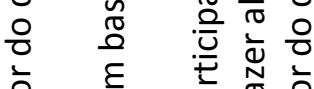

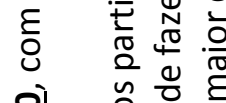

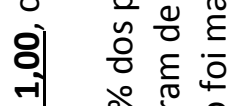

de $\frac{\sqrt{0}}{\sqrt{2}}$

웜 음

山)

市 通

ग $\frac{5}{m}$

\begin{tabular}{cccc} 
& 7 & 0 & 5 \\
2 & 0 & 0 & 0 \\
\hline & 0 & 0 & 0
\end{tabular}

ㅇํㄹำ

剂

$\$ \quad \frac{0}{\pi} 2 \frac{0}{\check{c}}$

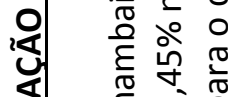

है กे

荿

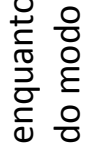

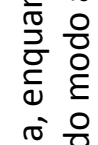

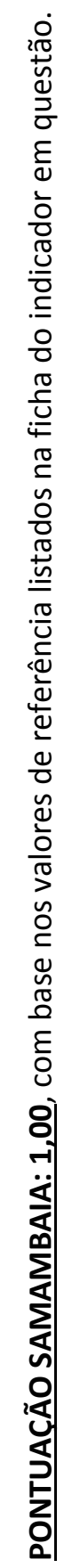




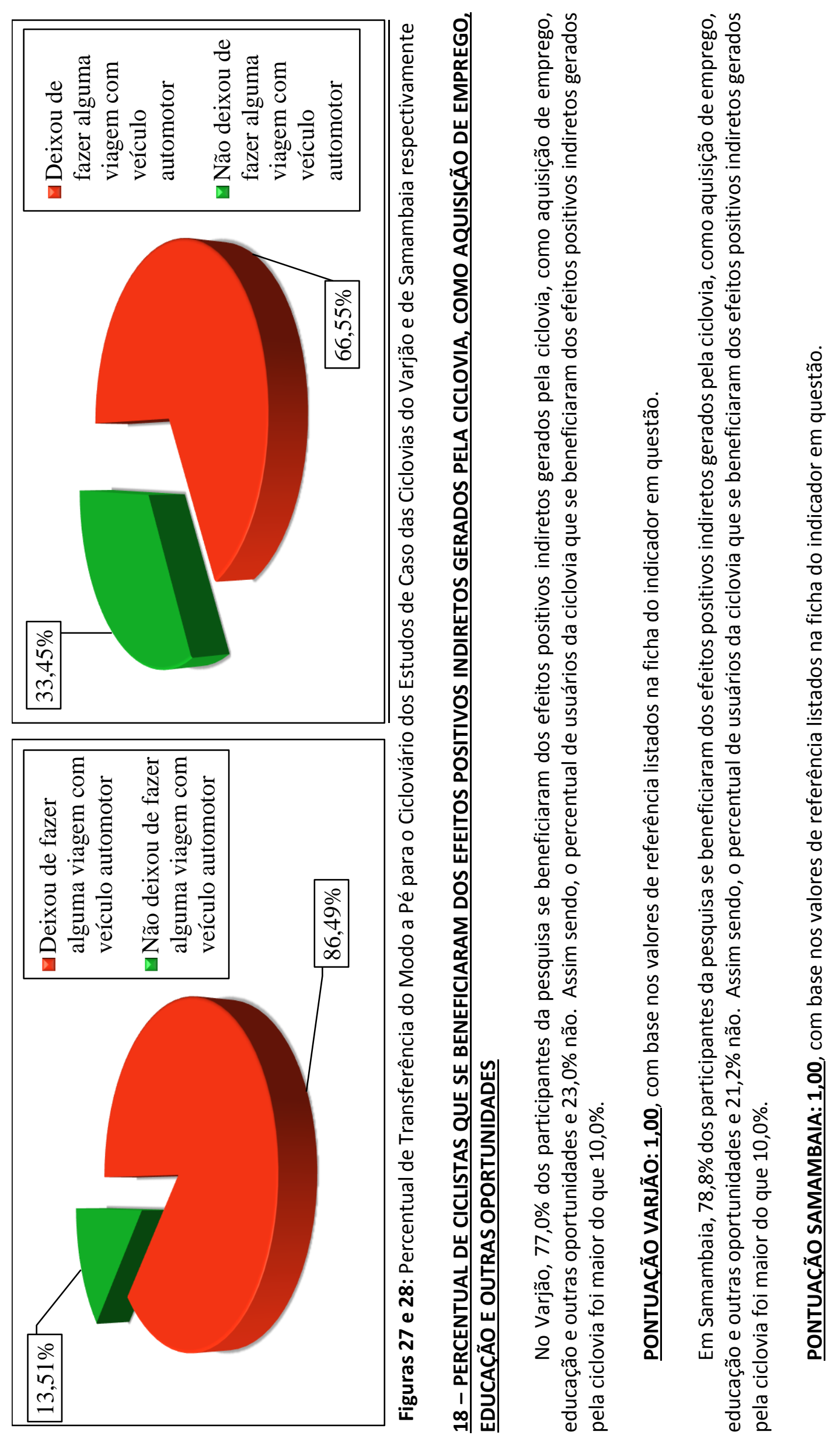



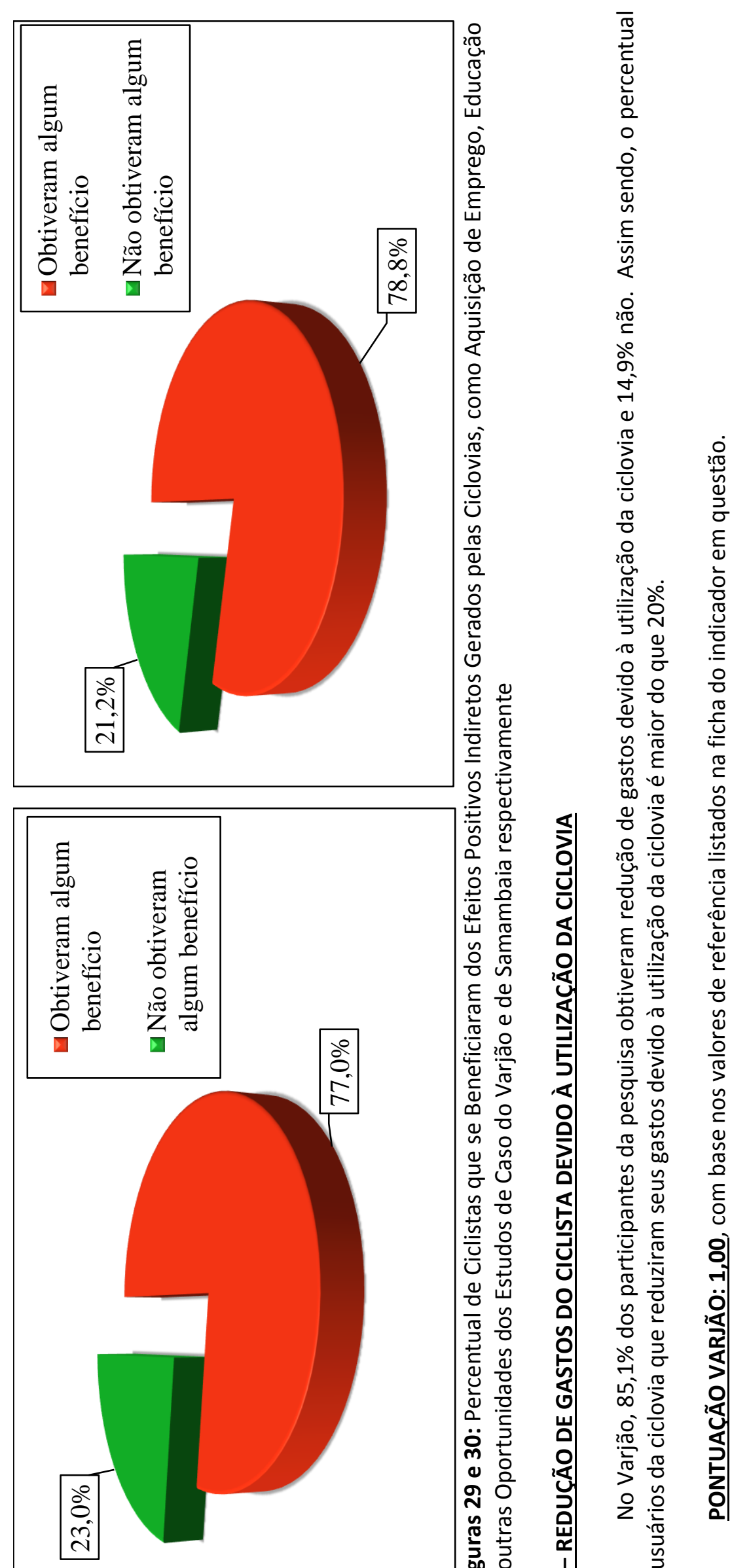

กี

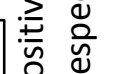

氐

$\frac{0}{2 \pi}$

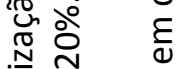

言焉

응 응 흥

깅 $\frac{0}{\pi}$ 응

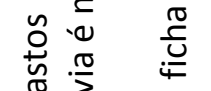

吸

응 는

$2 \pi \frac{\pi}{0} \quad \frac{\pi}{0}$

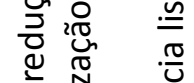

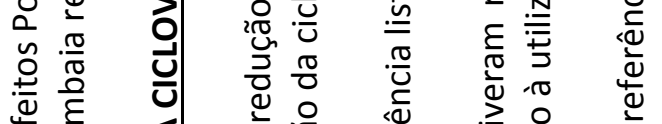

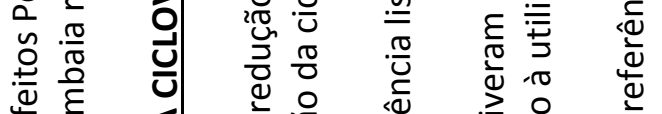

岀

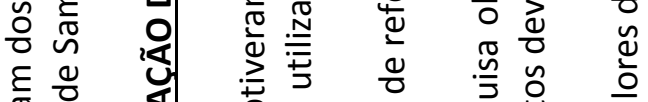

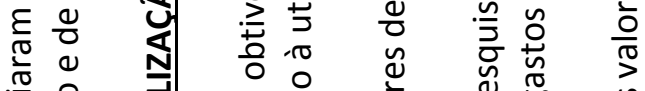

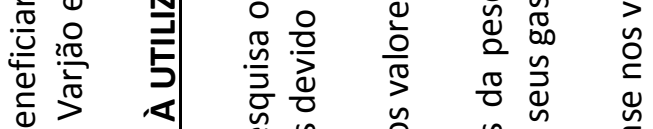

बे

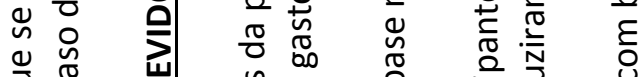

咅

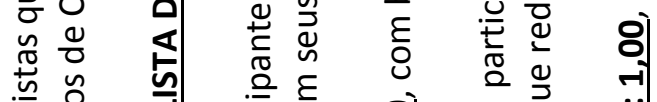

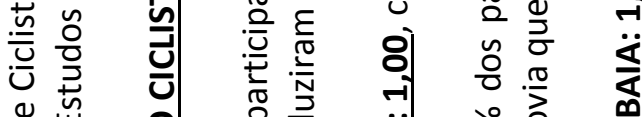

莙

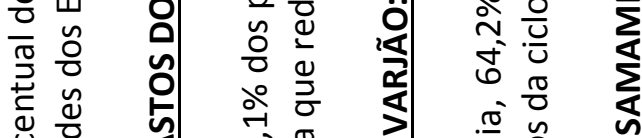

융

밀

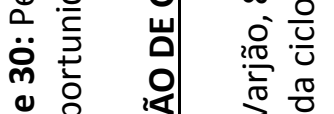

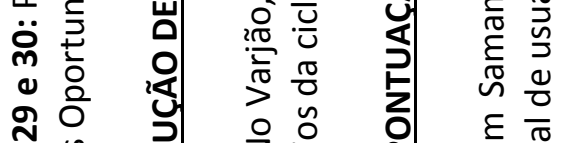

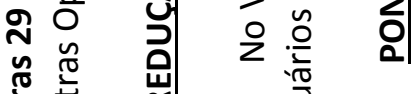

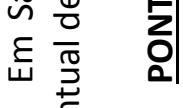




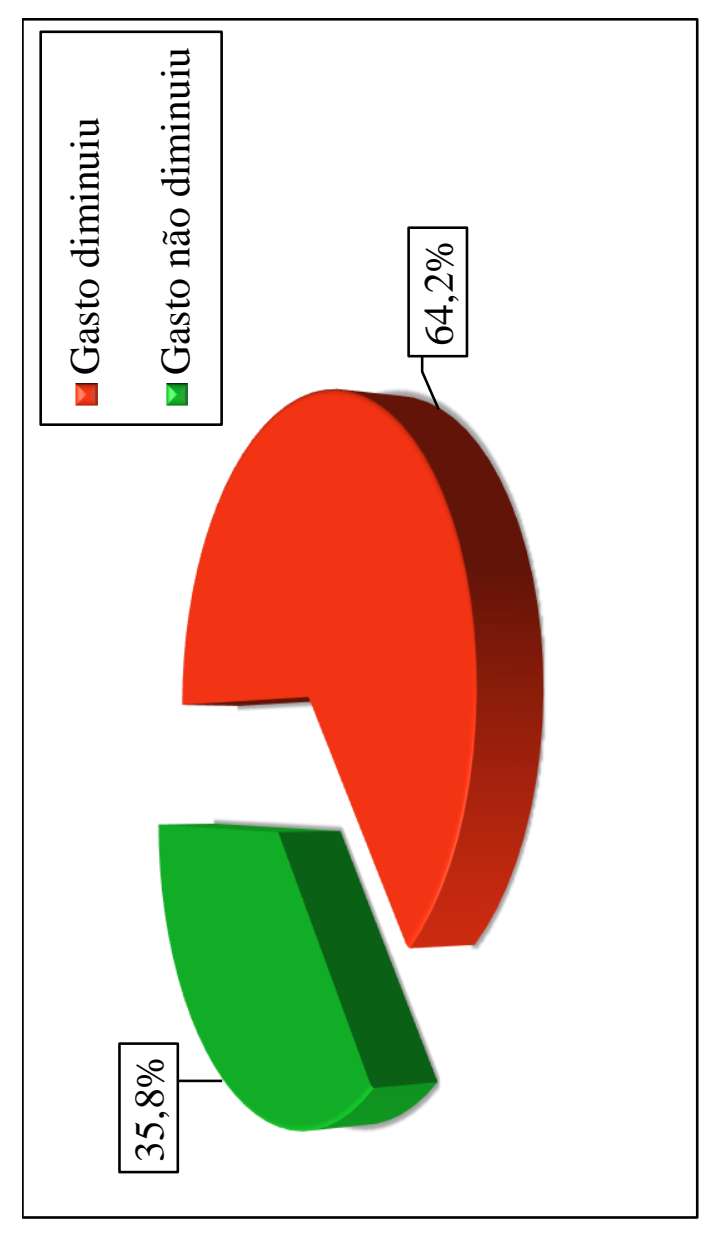

$\begin{array}{lll}\frac{\pi}{\pi} & \overline{0} & \\ \frac{\pi}{\sqrt{\pi}} & \frac{\pi}{\pi} & 0 \\ \frac{\pi}{\pi} & \frac{\pi}{\pi} & 0\end{array}$

:

@̊
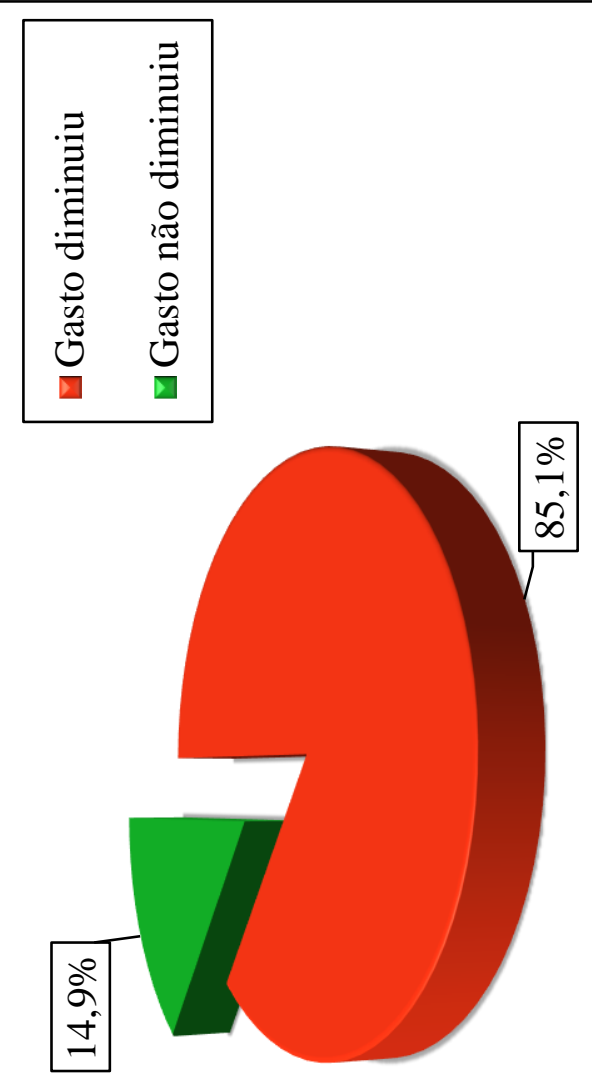

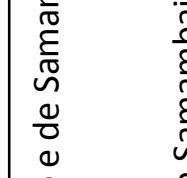

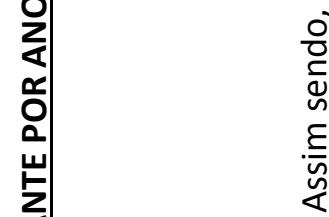

它

峁

$\frac{0}{0}$

인

응

$\stackrel{气}{\rightleftarrows}$

흥

ह $\stackrel{m}{\circ}$

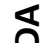

这 $\quad$ i

i্ণ

苞

응

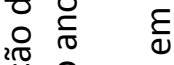

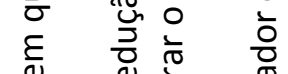

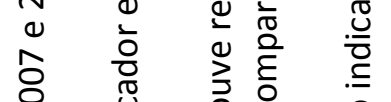

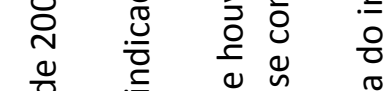

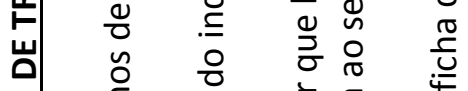

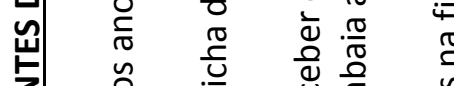

늘

氜

岂

응

षै है

ญ

गั

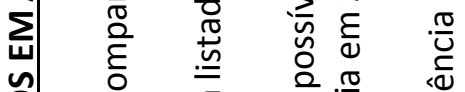

ก ช

.

空

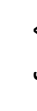

產

这

ब

국

융

( )

造 $\frac{20}{20}$

य गे

ปั

กิ

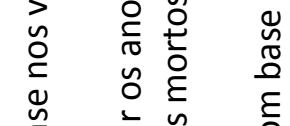

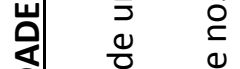

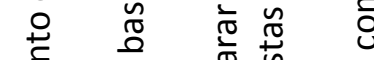

는

这 है

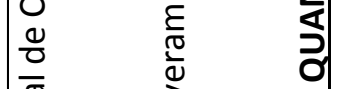

ह $\stackrel{\frac{\pi}{\pi}}{\frac{\pi}{2}}$

है

$\begin{array}{llll}0 & 0 & 0 & 0 \\ 0 & 0 & 0 & 0 \\ 0 & 0 & 0 & 0\end{array}$

익

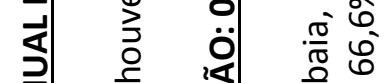

官

造)

ब.

ใิ

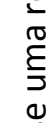

这 


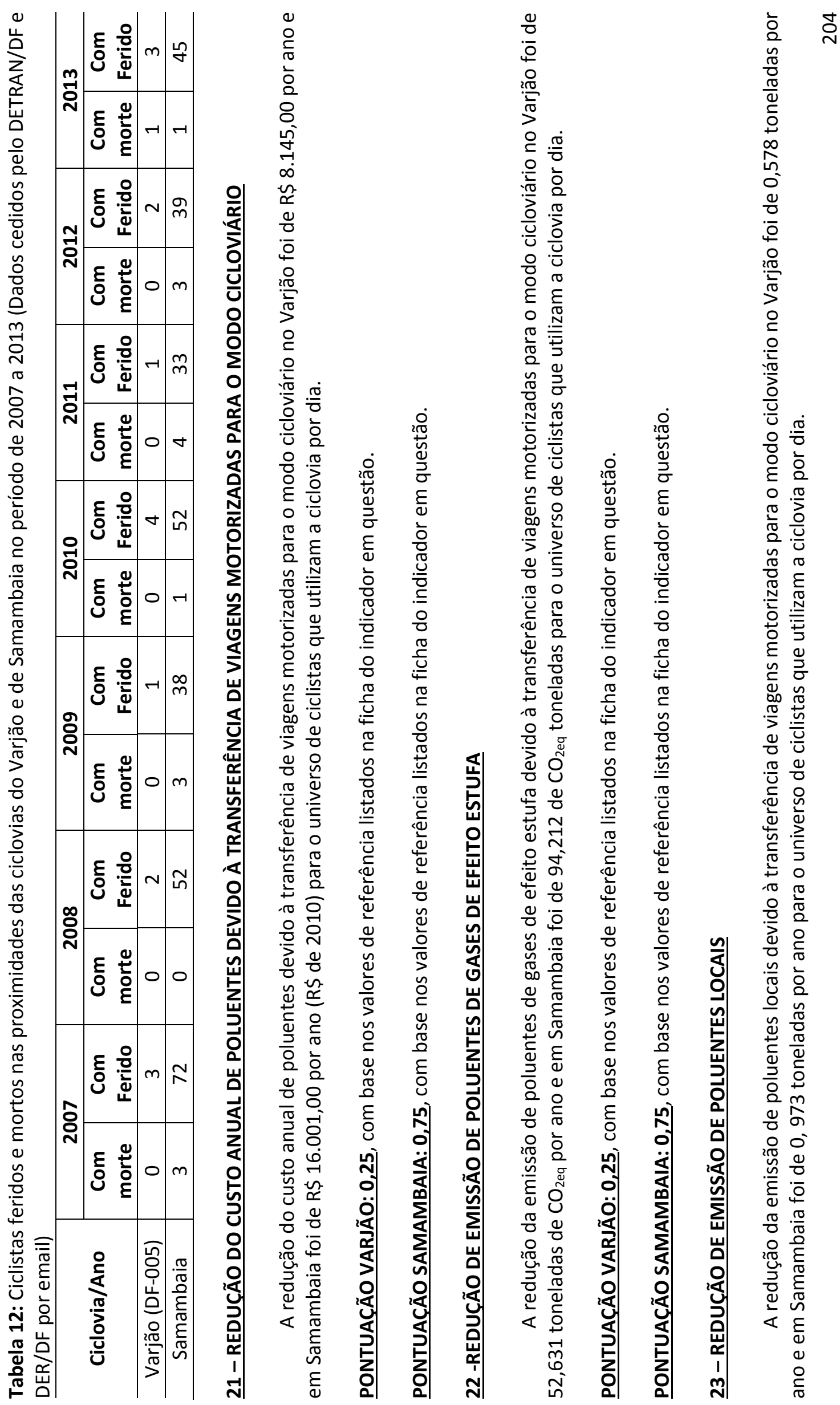




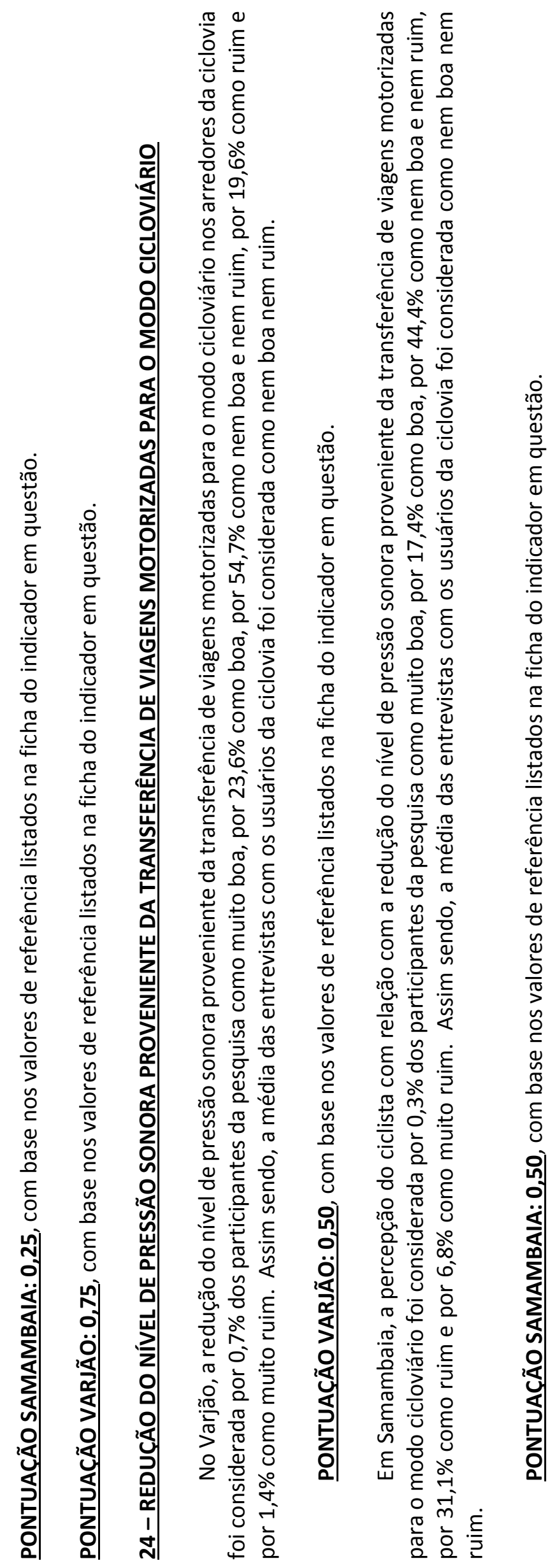

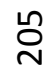



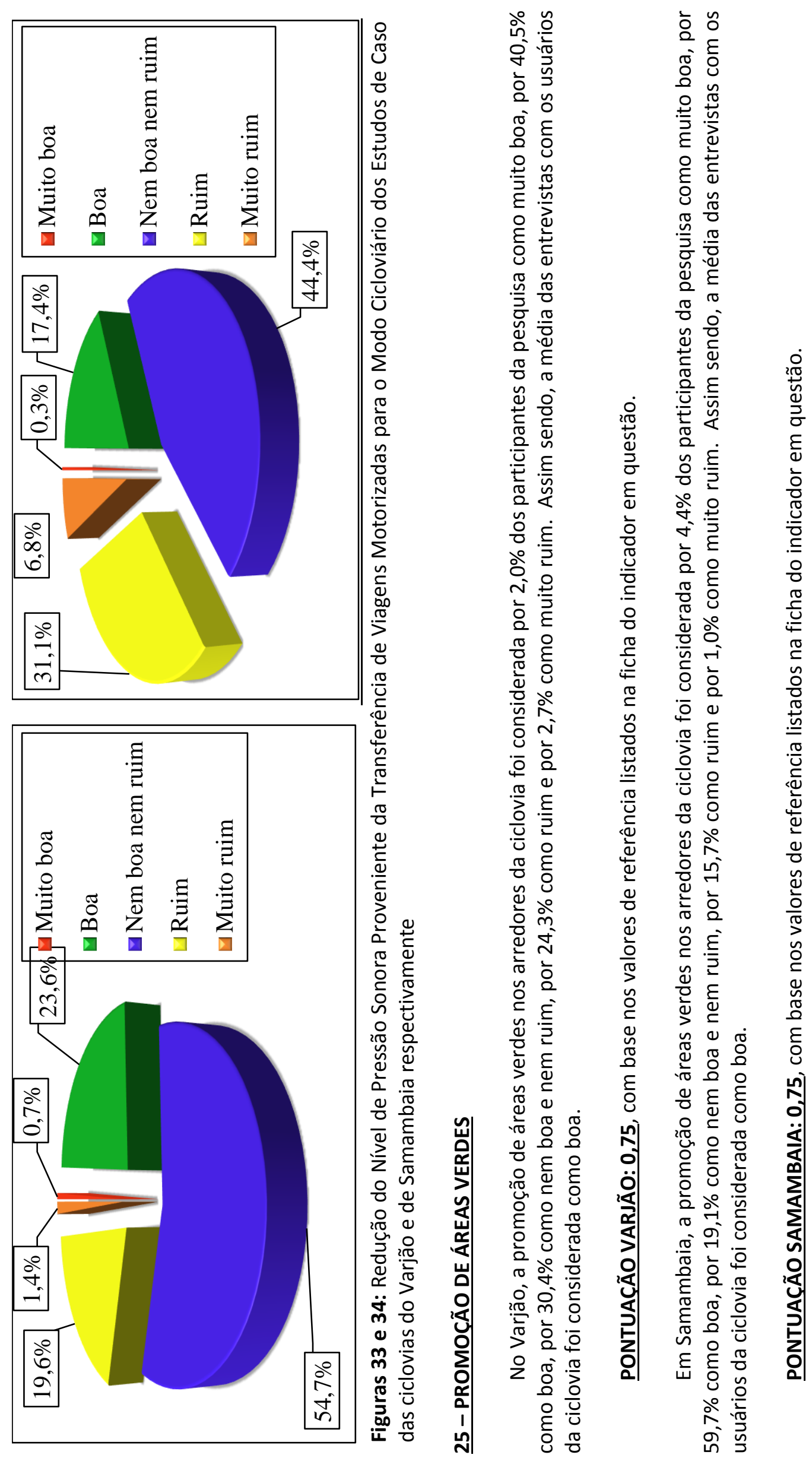


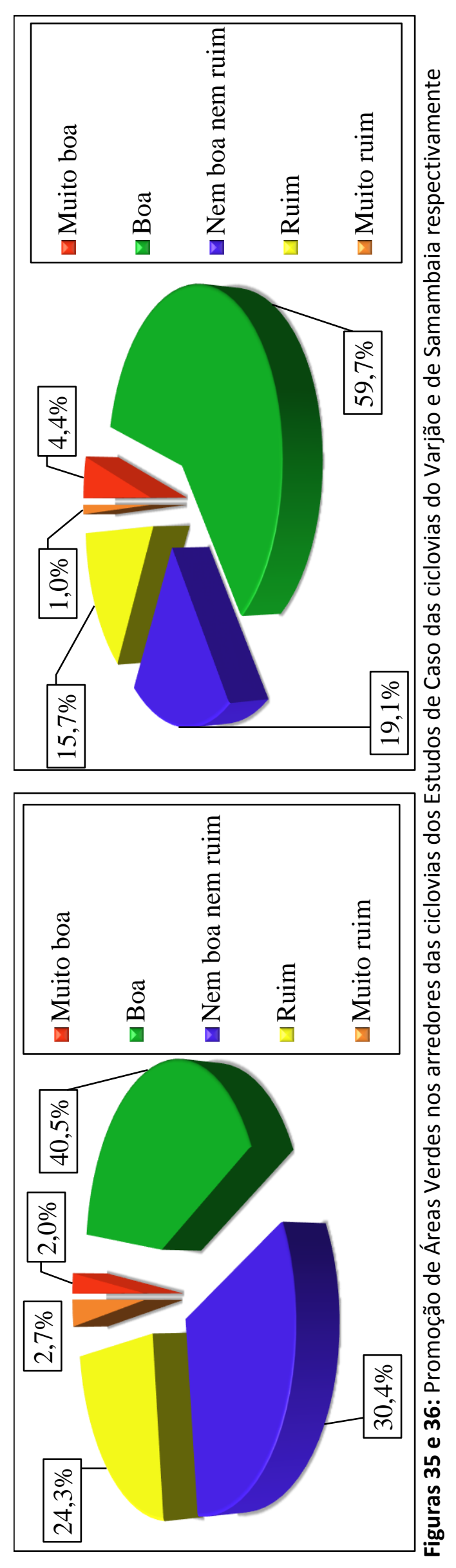

$\frac{0}{0}$
$\frac{0}{7}$
$\frac{1}{0}$
$\frac{0}{0}$
$\frac{0}{0}$
$\frac{0}{0}$
$\frac{0}{0}$
0
.$\frac{7}{3}$
$\frac{1}{1}$

$\frac{1}{2} \stackrel{\frac{\pi}{2}}{\circ}$

융 윤

원

즐 을

$\frac{\pi}{0} \sum^{\circ}$

$\stackrel{2}{0}$

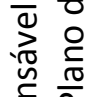

ํํำ

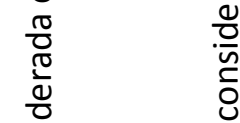

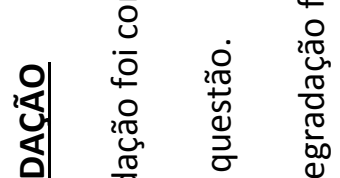

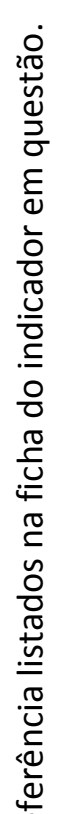

के

虫

रे

荷 范

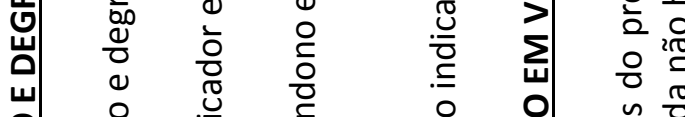

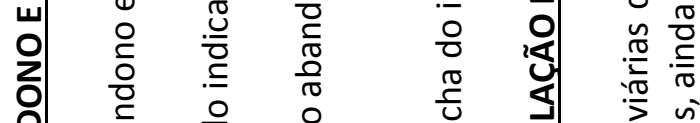

늘

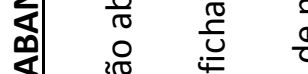

i) 임

แथ 을

ปิ हू

$\sum_{\infty} \frac{8}{d}$

点 $\frac{\pi}{2}$

느 은 는

ป

늠

जิ 은 는

芩

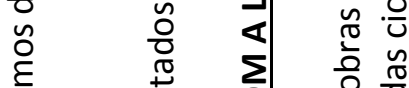

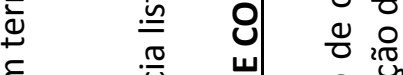

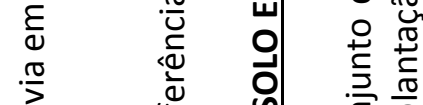

产 㐫

ปे

임 0 웜

의

ธ $\frac{\pi}{7}$

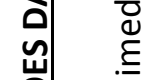

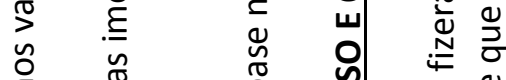

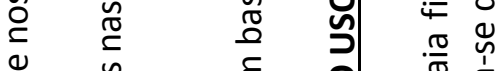

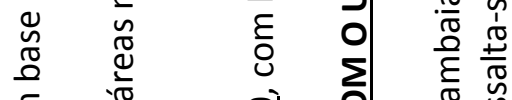

บิ

岂 ญ

$\sum \quad$

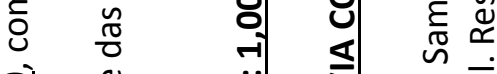

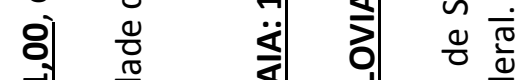

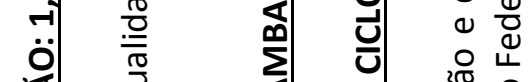

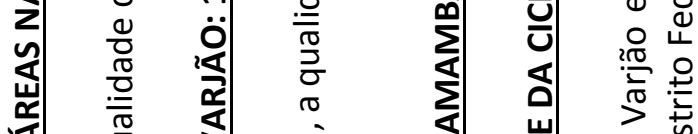

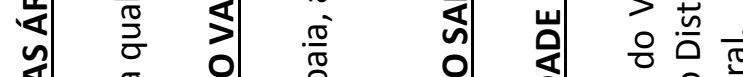

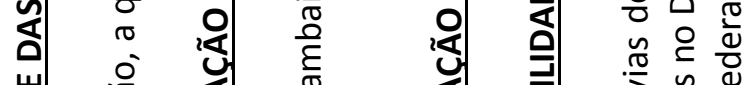

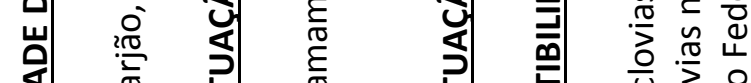

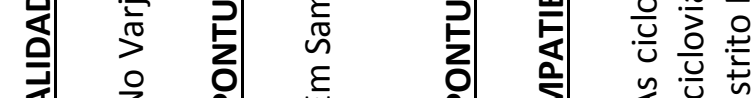

这 눈

ํ.

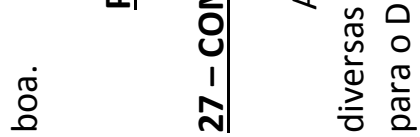




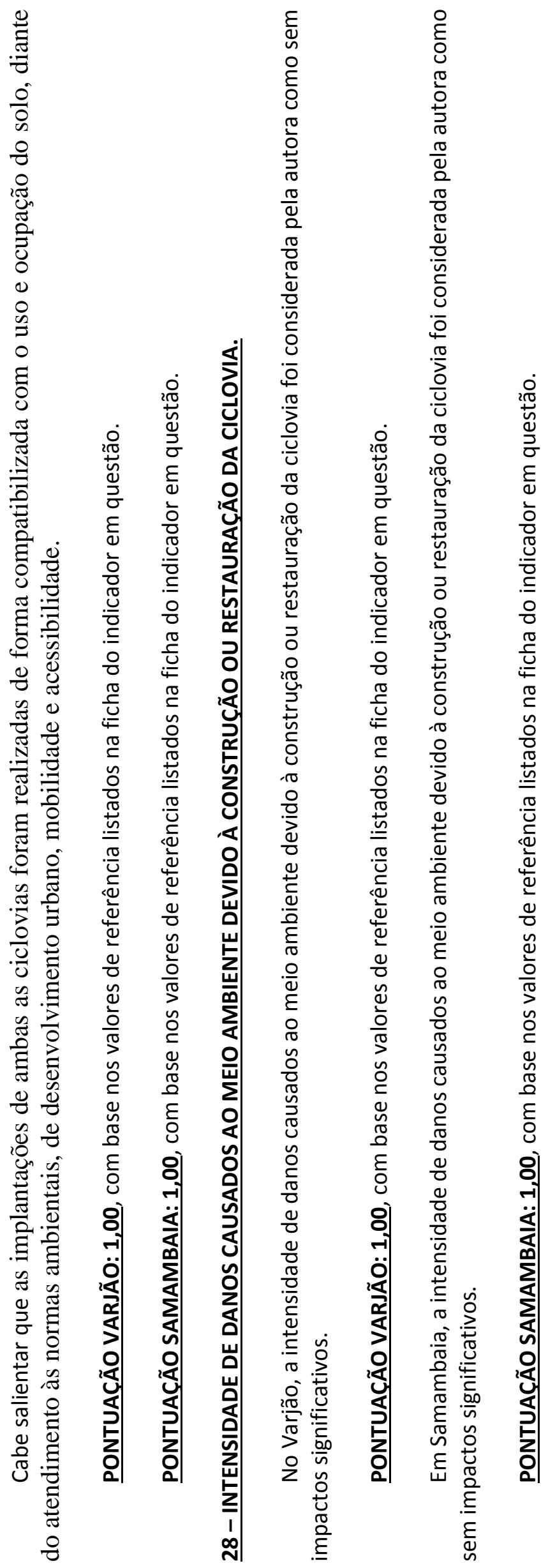


ANEXOS 


\section{A SISTEMAS DE INDICADORES}

Costa (2008) desenvolveu o Índice de Mobilidade Urbana Sustentável (IMUS) para auxiliar a análise e monitoração da mobilidade urbana e a elaboração de políticas públicas visando à sustentabilidade dos sistemas de mobilidade. O IMUS é um índice composto de nove domínios, 37 temas e 87 indicadores (Tabela 2). A identificação de indicadores foi desenvolvida a partir de 3.545 indicadores oriundos de 52 sistemas desenvolvidos no Brasil e no exterior. Os pesos para os critérios que compõem o IMUS foram obtidos por meio de um painel de especialistas nas áreas de planejamento urbano, transporte, mobilidade e sustentabilidade do Brasil, Portugal, Alemanha, Estados Unidos e Austrália. Por sua vez, o método de agregação proposto para o IMUS consiste em uma combinação linear ponderada, onde os critérios são combinados por meio de uma média ponderada.

Tabela 13: Indicadores selecionados para compor o IMUS (COSTA, 2008)

\begin{tabular}{|c|c|c|c|}
\hline Domínio & Tema & Indicador & Unidade de medida \\
\hline \multirow{10}{*}{ Acessibilidade } & \multirow{3}{*}{$\begin{array}{c}\text { Acessibilidade aos } \\
\text { sistemas de } \\
\text { transportes }\end{array}$} & $\begin{array}{l}\text { Acessibilidade ao } \\
\text { transporte público }\end{array}$ & $\%$ \\
\hline & & $\begin{array}{c}\text { Transporte público para } \\
\text { pessoas com } \\
\text { necessidades especiais }\end{array}$ & $\begin{array}{c}\% \text { ou existência de } \\
\text { serviço especial }\end{array}$ \\
\hline & & Despesas com transporte & $\%$ \\
\hline & \multirow{5}{*}{$\begin{array}{l}\text { Acessibilidade } \\
\text { Universal }\end{array}$} & $\begin{array}{l}\text { Travessias adaptadas a } \\
\text { pessoas com } \\
\text { necessidades especiais }\end{array}$ & $\%$ \\
\hline & & $\begin{array}{l}\text { Acessibilidade a espaços } \\
\text { abertos }\end{array}$ & $\%$ \\
\hline & & $\begin{array}{c}\text { Vagas de estacionamento } \\
\text { para pessoas com } \\
\text { necessidades especiais }\end{array}$ & Número \\
\hline & & $\begin{array}{l}\text { Acessibilidade a edifícios } \\
\text { públicos }\end{array}$ & $\%$ \\
\hline & & $\begin{array}{c}\text { Acessibilidade a serviços } \\
\text { essenciais }\end{array}$ & $\%$ \\
\hline & Barreiras físicas & Fragmentação urbana & Número \\
\hline & $\begin{array}{l}\text { Legislação para } \\
\text { pessoas com } \\
\text { necessidades }\end{array}$ & $\begin{array}{c}\text { Ações para acessibilidade } \\
\text { universal }\end{array}$ & Tipos de medidas \\
\hline \multirow{4}{*}{$\begin{array}{l}\text { Aspectos } \\
\text { ambientais }\end{array}$} & \multirow{4}{*}{$\begin{array}{l}\text { Controle dos } \\
\text { impactos no meio } \\
\text { ambiente }\end{array}$} & Emissões de CO & $\%$ \\
\hline & & Emissões de $\mathrm{CO}_{2}$ & $\%$ \\
\hline & & $\begin{array}{l}\text { População exposta ao } \\
\text { ruído de tráfego }\end{array}$ & $\%$ \\
\hline & & $\begin{array}{c}\text { Estudos de impacto } \\
\text { ambiental }\end{array}$ & Sim/Não, Tipo \\
\hline
\end{tabular}




\begin{tabular}{|c|c|c|c|}
\hline Domínio & Tema & Indicador & Unidade de medida \\
\hline & & Consumo de combustível & L/hab/ano \\
\hline & Recursos Naturais & $\begin{array}{c}\text { Uso de energia limpa e } \\
\text { de combustíveis } \\
\text { alternativos }\end{array}$ & $\%$ \\
\hline \multirow{5}{*}{ Aspectos sociais } & Apoio ao cidadão & $\begin{array}{c}\text { Informação disponível ao } \\
\text { cidadão }\end{array}$ & Tipos de informação \\
\hline & Inclusão social & Equidade vertical (renda) & Número \\
\hline & Educação e cidadania & $\begin{array}{c}\text { Educação para o } \\
\text { desenvolvimento } \\
\text { sustentável }\end{array}$ & Tipos de ações \\
\hline & Participação popular & $\begin{array}{l}\text { Participação na tomada } \\
\text { de decisão }\end{array}$ & Grau de participação \\
\hline & Qualidade de vida & Qualidade de vida & $\%$ \\
\hline \multirow{7}{*}{$\begin{array}{l}\text { Aspectos } \\
\text { políticos }\end{array}$} & \multirow{2}{*}{$\begin{array}{l}\text { Integração de ações } \\
\text { políticas }\end{array}$} & $\begin{array}{c}\text { Integração entre níveis de } \\
\text { governo }\end{array}$ & $\begin{array}{l}\text { Frequência, grau de } \\
\text { interação }\end{array}$ \\
\hline & & $\begin{array}{c}\text { Parcerias } \\
\text { público/privadas }\end{array}$ & Sim/Não \\
\hline & \multirow{4}{*}{$\begin{array}{c}\text { Captação e } \\
\text { gerenciamento de } \\
\text { recursos }\end{array}$} & Captação de recursos & $\%$ \\
\hline & & $\begin{array}{c}\text { Investimentos em } \\
\text { sistemas de transportes }\end{array}$ & $\begin{array}{c}\text { Áreas, tipos de } \\
\text { investimentos }\end{array}$ \\
\hline & & $\begin{array}{c}\text { Distribuição dos recursos } \\
\text { (público x privado) }\end{array}$ & Número \\
\hline & & $\begin{array}{l}\text { Distribuição dos recursos } \\
\text { (motorizados x não } \\
\text { motorizados) }\end{array}$ & Número \\
\hline & $\begin{array}{c}\text { Política de } \\
\text { Mobilidade Urbana }\end{array}$ & $\begin{array}{c}\text { Política de Mobilidade } \\
\text { Urbana }\end{array}$ & $\begin{array}{l}\text { Sim/Não, estágio de } \\
\text { implantação }\end{array}$ \\
\hline \multirow{5}{*}{ Infraestrutura } & \multirow{4}{*}{$\begin{array}{c}\text { Provisão e } \\
\text { manutenção de } \\
\text { infraestrutura de } \\
\text { transportes }\end{array}$} & Densidade da rede viária & $\begin{array}{l}\mathrm{Km} / \mathrm{km}^{2} \text {, grau de } \\
\text { conectividade }\end{array}$ \\
\hline & & Vias pavimentadas & $\%$ \\
\hline & & $\begin{array}{c}\text { Despesas com } \\
\text { manutenção da } \\
\text { infraestrutura de } \\
\text { transportes }\end{array}$ & Tipos de despesas \\
\hline & & Sinalização viária & Parcela da população \\
\hline & $\begin{array}{l}\text { Distribuição da } \\
\text { infraestrutura de } \\
\text { transportes }\end{array}$ & $\begin{array}{l}\text { Vias para transporte } \\
\text { coletivo }\end{array}$ & $\%$ \\
\hline \multirow{9}{*}{$\begin{array}{l}\text { Modos não } \\
\text { motorizados }\end{array}$} & \multirow{3}{*}{$\begin{array}{l}\text { Transporte } \\
\text { cicloviário }\end{array}$} & $\begin{array}{c}\text { Extensão e conectividade } \\
\text { de ciclovias }\end{array}$ & $\begin{array}{c}\%, \text { grau de } \\
\text { conectividade }\end{array}$ \\
\hline & & Frota de bicicletas & Bicicletas/100 habitantes \\
\hline & & $\begin{array}{c}\text { Estacionamento para } \\
\text { bicicletas }\end{array}$ & $\%$ \\
\hline & \multirow{2}{*}{ Deslocamentos a pé } & Vias para pedestres & $\%$, conectividade \\
\hline & & Vias com calçadas & $\%$ \\
\hline & \multirow{4}{*}{ Redução de viagens } & Distância de viagem & $\mathrm{Km}$ \\
\hline & & Tempo de viagem & Min \\
\hline & & Número de viagens & Viagens/habitante/dia \\
\hline & & $\begin{array}{l}\text { Ações para redução do } \\
\text { tráfego motorizado }\end{array}$ & Sim/Não, tipo \\
\hline
\end{tabular}




\begin{tabular}{|c|c|c|c|}
\hline Domínio & Tema & Indicador & Unidade de medida \\
\hline \multirow{18}{*}{$\begin{array}{l}\text { Planejamento } \\
\text { integrado }\end{array}$} & \multirow{2}{*}{$\begin{array}{l}\text { Capacitação de } \\
\text { gestores }\end{array}$} & $\begin{array}{l}\text { Nível de formação de } \\
\text { técnicos e gestores }\end{array}$ & $\%$ \\
\hline & & $\begin{array}{c}\text { Capacitação de técnicos e } \\
\text { gestores }\end{array}$ & Horas/funcionário/ano \\
\hline & $\begin{array}{l}\text { Áreas centrais de } \\
\text { interesse histórico }\end{array}$ & Vitalidade do centro & Número \\
\hline & Integração regional & $\begin{array}{c}\text { Consórcios } \\
\text { intermunicipais }\end{array}$ & Sim/Não, Tipo \\
\hline & $\begin{array}{l}\text { Transparência do } \\
\text { processo de } \\
\text { planejamento }\end{array}$ & $\begin{array}{l}\text { Transparência e } \\
\text { responsabilidade }\end{array}$ & Sim/Não \\
\hline & \multirow{5}{*}{$\begin{array}{l}\text { Planejamento e } \\
\text { controle do uso e } \\
\text { ocupação do solo }\end{array}$} & Vazios urbanos & $\%$ \\
\hline & & Crescimento urbano & Número \\
\hline & & $\begin{array}{c}\text { Densidade populacional } \\
\text { urbana }\end{array}$ & Habitantes $/ \mathrm{km}^{2}$ \\
\hline & & Índice de uso misto & $\%$ \\
\hline & & Ocupações irregulares & $\%$ \\
\hline & \multirow{2}{*}{$\begin{array}{l}\text { Planejamento } \\
\text { estratégico e } \\
\text { integrado }\end{array}$} & $\begin{array}{l}\text { Planejamento urbano, } \\
\text { ambiental e de } \\
\text { transportes integrado }\end{array}$ & $\begin{array}{l}\text { Sim/Não, grau de } \\
\text { cooperação }\end{array}$ \\
\hline & & $\begin{array}{c}\text { Efetivação e } \\
\text { continuidade das ações }\end{array}$ & Programas/projetos \\
\hline & \multirow{3}{*}{$\begin{array}{c}\text { Planejamento de } \\
\text { infraestrutura urbana } \\
\text { e urbanos }\end{array}$} & Parques e áreas verdes & $\mathrm{M}^{2} /$ habitante \\
\hline & & $\begin{array}{l}\text { Equipamentos urbanos } \\
\text { (escolas) }\end{array}$ & Escolas/1000 habitantes \\
\hline & & $\begin{array}{l}\text { Equipamentos urbanos } \\
\text { (hospitais) }\end{array}$ & $\begin{array}{c}\text { Postos de saúde/100.000 } \\
\text { habitantes }\end{array}$ \\
\hline & \multirow{3}{*}{$\begin{array}{c}\text { Plano Diretor e } \\
\text { legislação urbanística }\end{array}$} & Plano Diretor & Sim/Não, atualização \\
\hline & & Legislação urbanística & Sim/Não \\
\hline & & $\begin{array}{c}\text { Cumprimento da } \\
\text { legislação urbanística }\end{array}$ & Sim/Não, tipo \\
\hline \multirow{10}{*}{$\begin{array}{l}\text { Tráfego e } \\
\text { Circulaçãão } \\
\text { Urbana }\end{array}$} & \multirow{3}{*}{ Acidentes de trânsito } & Acidentes de trânsito & $\begin{array}{c}\text { Mortos/100.000 } \\
\text { habitantes/ano }\end{array}$ \\
\hline & & $\begin{array}{c}\text { Acidentes com pedestres } \\
\text { e ciclistas }\end{array}$ & $\%$ \\
\hline & & Prevenção de acidentes & $\%$ \\
\hline & $\begin{array}{l}\text { Educação para o } \\
\text { trânsito }\end{array}$ & Educação para o trânsito & $\%$ \\
\hline & \multirow[b]{2}{*}{ Fluidez e circulação } & Congestionamento & Horas/dia \\
\hline & & $\begin{array}{l}\text { Velocidade média de } \\
\text { tráfego }\end{array}$ & $\mathrm{Km} / \mathrm{h}$ \\
\hline & $\begin{array}{c}\text { Operação e } \\
\text { fiscalização de } \\
\text { trânsito }\end{array}$ & $\begin{array}{l}\text { Violação às leis de } \\
\text { trânsito }\end{array}$ & $\%$ \\
\hline & \multirow[b]{2}{*}{ Transporte individual } & Índice de motorização & Autos/1.000 habitantes \\
\hline & & $\begin{array}{c}\text { Taxa de ocupação dos } \\
\text { veículos }\end{array}$ & Passageiros/auto \\
\hline & & $\begin{array}{l}\text { Extensão da rede de } \\
\text { transporte público }\end{array}$ & $\%$ \\
\hline
\end{tabular}




\begin{tabular}{|c|c|c|c|}
\hline Domínio & Tema & Indicador & Unidade de medida \\
\hline \multirow{17}{*}{$\begin{array}{c}\text { Sistemas de } \\
\text { transporte } \\
\text { urbano }\end{array}$} & \multirow{7}{*}{$\begin{array}{l}\text { Disponibilidade e } \\
\text { qualidade do } \\
\text { transporte público }\end{array}$} & $\begin{array}{l}\text { Frequência de } \\
\text { atendimento do } \\
\text { transporte público }\end{array}$ & Minutos \\
\hline & & Pontualidade & $\%$ \\
\hline & & $\begin{array}{l}\text { Velocidade média do } \\
\text { transporte público }\end{array}$ & $\mathrm{Km} / \mathrm{h}$ \\
\hline & & $\begin{array}{l}\text { Idade média da frota do } \\
\text { transporte público }\end{array}$ & anos \\
\hline & & $\begin{array}{c}\text { Índice de passageiros por } \\
\text { quilômetro }\end{array}$ & Passageiros $/ \mathrm{km}$ \\
\hline & & $\begin{array}{l}\text { Passageiros transportados } \\
\text { anualmente }\end{array}$ & Número \\
\hline & & $\begin{array}{l}\text { Satisfação do usuário } \\
\text { com o serviço de } \\
\text { transporte público }\end{array}$ & $\%$ \\
\hline & \multirow{3}{*}{ Diversificação modal } & $\begin{array}{c}\text { Diversidade de modos de } \\
\text { transporte }\end{array}$ & Número \\
\hline & & $\begin{array}{c}\text { Transporte público } \mathrm{x} \\
\text { transporte privado }\end{array}$ & Número \\
\hline & & $\begin{array}{l}\text { Modos motorizados X } \\
\text { modos não motorizados }\end{array}$ & Número \\
\hline & \multirow{2}{*}{$\begin{array}{c}\text { Regulação e } \\
\text { fiscalização do } \\
\text { transporte público }\end{array}$} & Contratos e licitações & $\%$ \\
\hline & & Transporte clandestino & Participação, tipo \\
\hline & \multirow{2}{*}{$\begin{array}{l}\text { Integração do } \\
\text { transporte público }\end{array}$} & Terminais intermodais & $\%$ \\
\hline & & $\begin{array}{l}\text { Integração do transporte } \\
\text { público }\end{array}$ & Grau, tipo \\
\hline & \multirow{3}{*}{ Política tarifária } & Descontos e gratuidades & $\%$ \\
\hline & & Tarifas de transportes & Variação \% \\
\hline & & Subsídios públicos & Sim/Não, tipo \\
\hline
\end{tabular}

Magagnin (2008) desenvolveu uma ferramenta computacional baseada em um software livre concebido para a internet para a elaboração de um sistema de suporte à decisão denominado PLANUTS (PLANejamentoUrbano e de Transportes Integrado e Sustentável). O PLANUTS pode ser utilizado para auxiliar no planejamento e monitoramento da mobilidade urbana, principalmente em cidades brasileiras de pequeno e médio porte. 


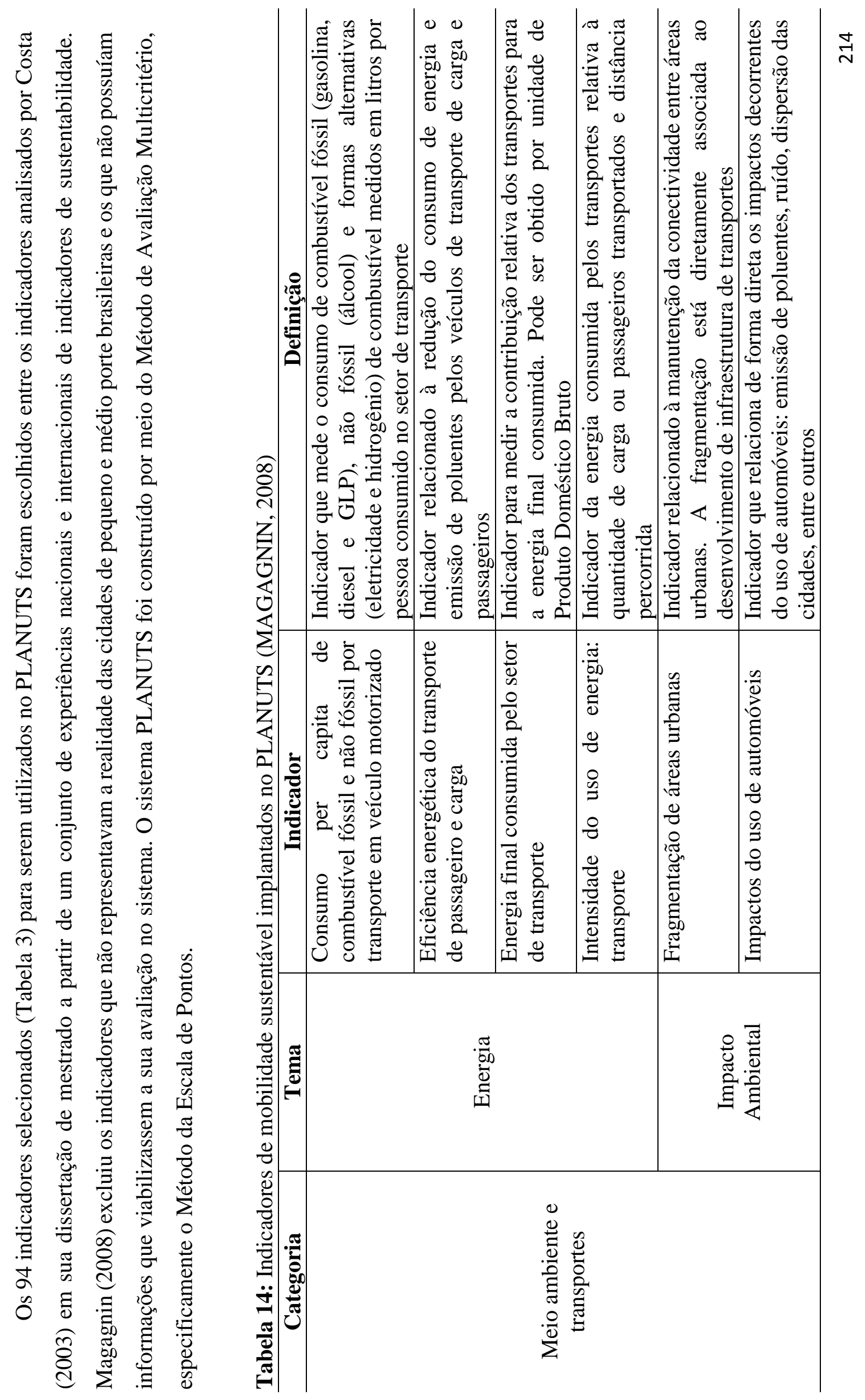




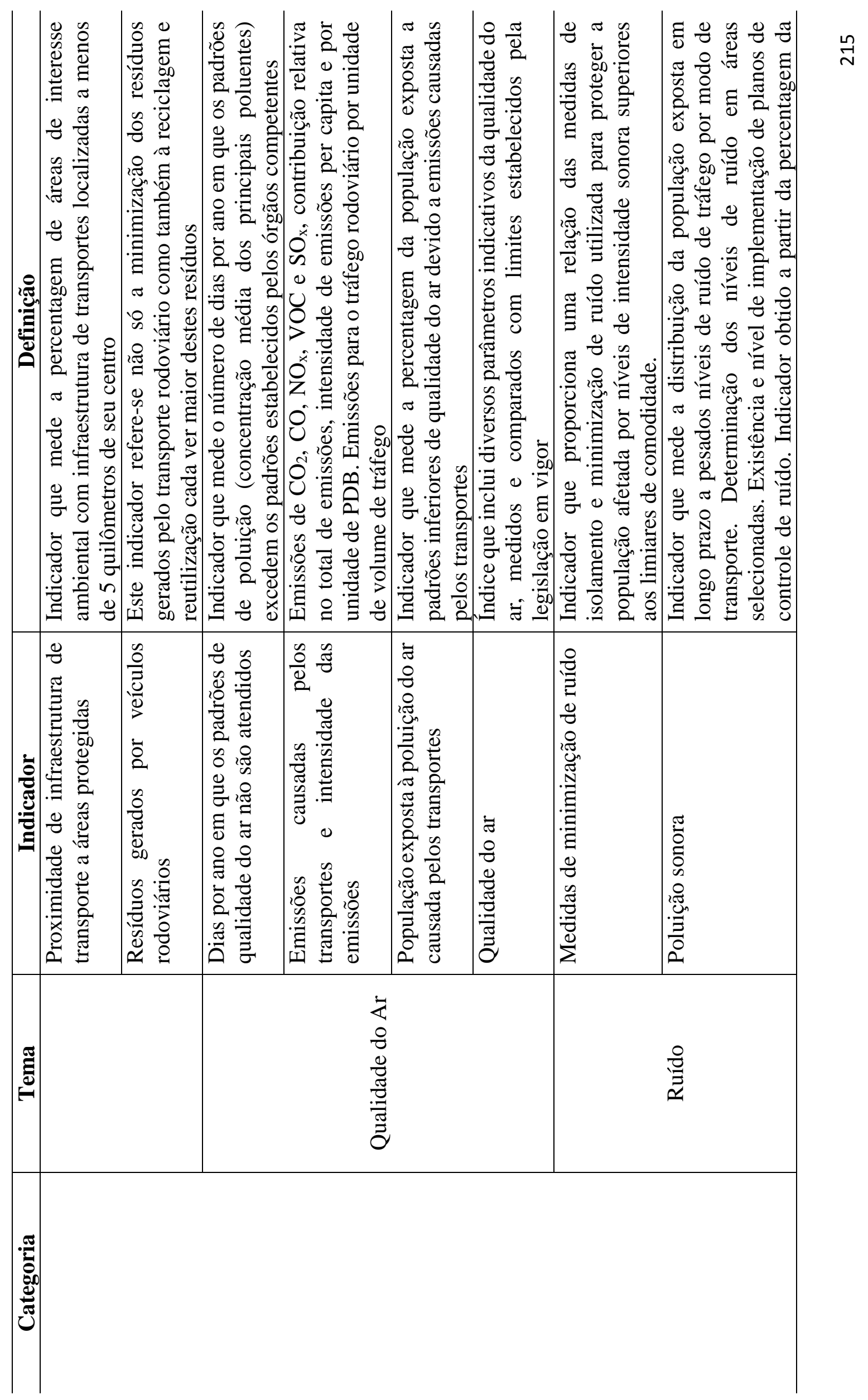




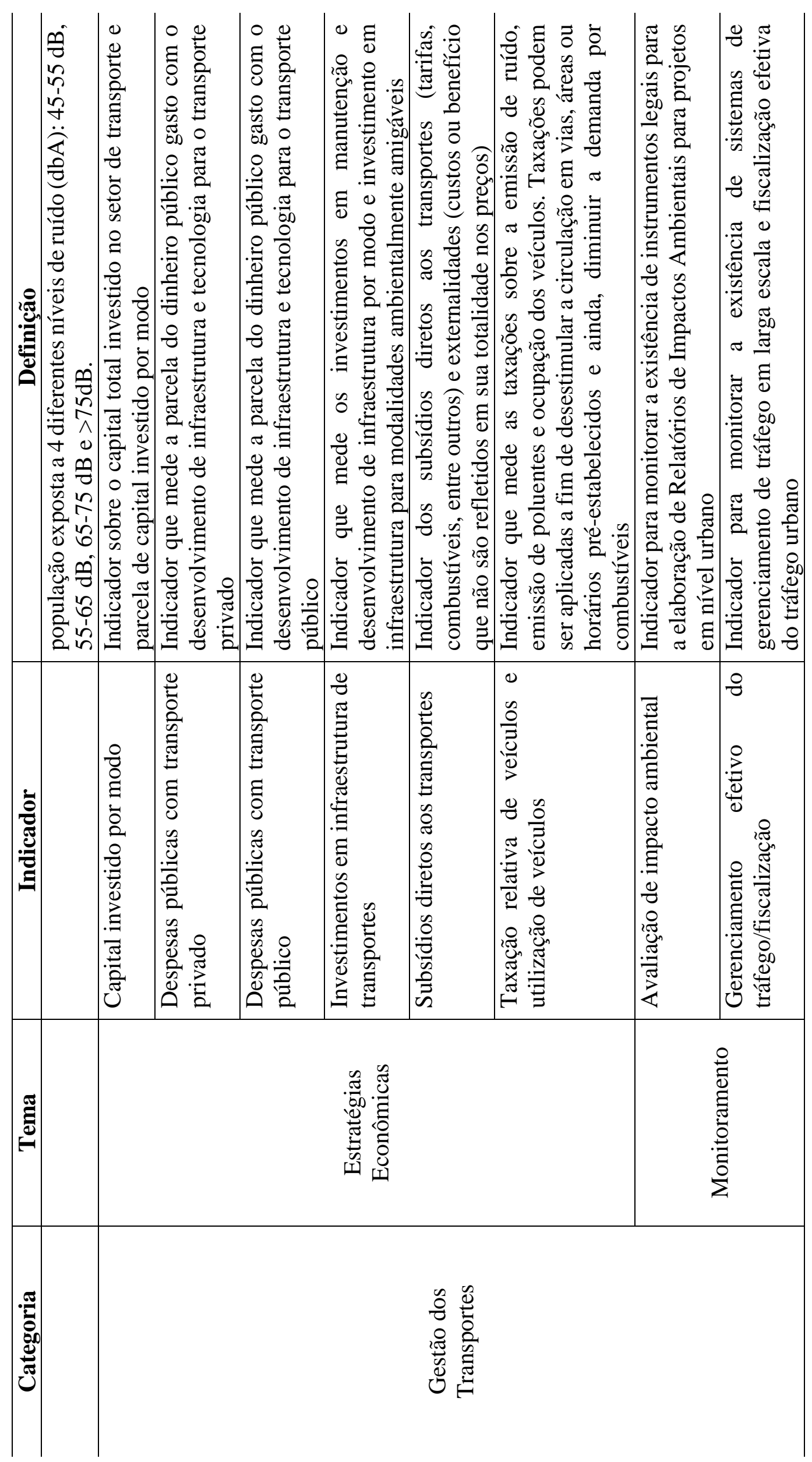

$\stackrel{\bullet}{\sim}$ 


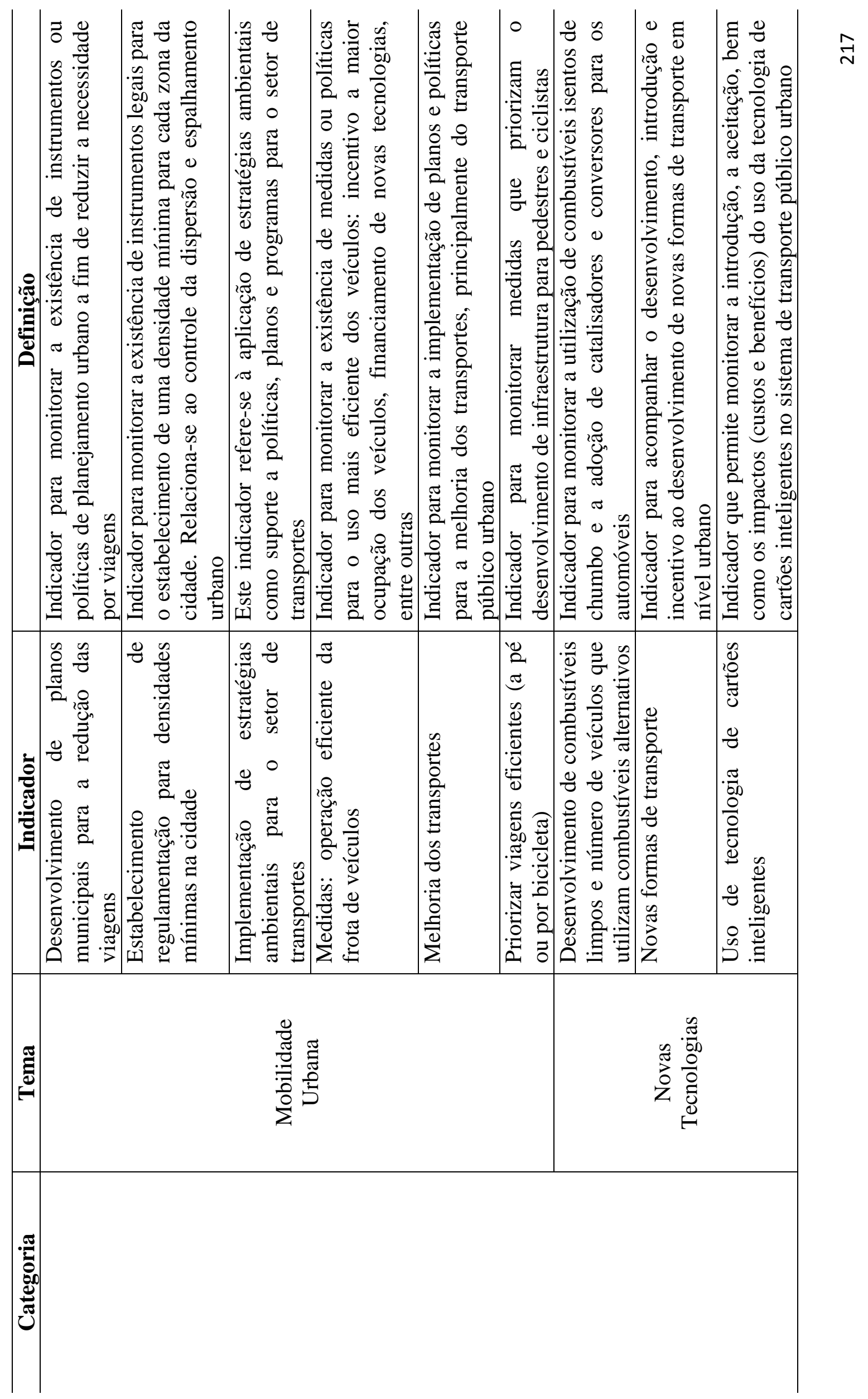




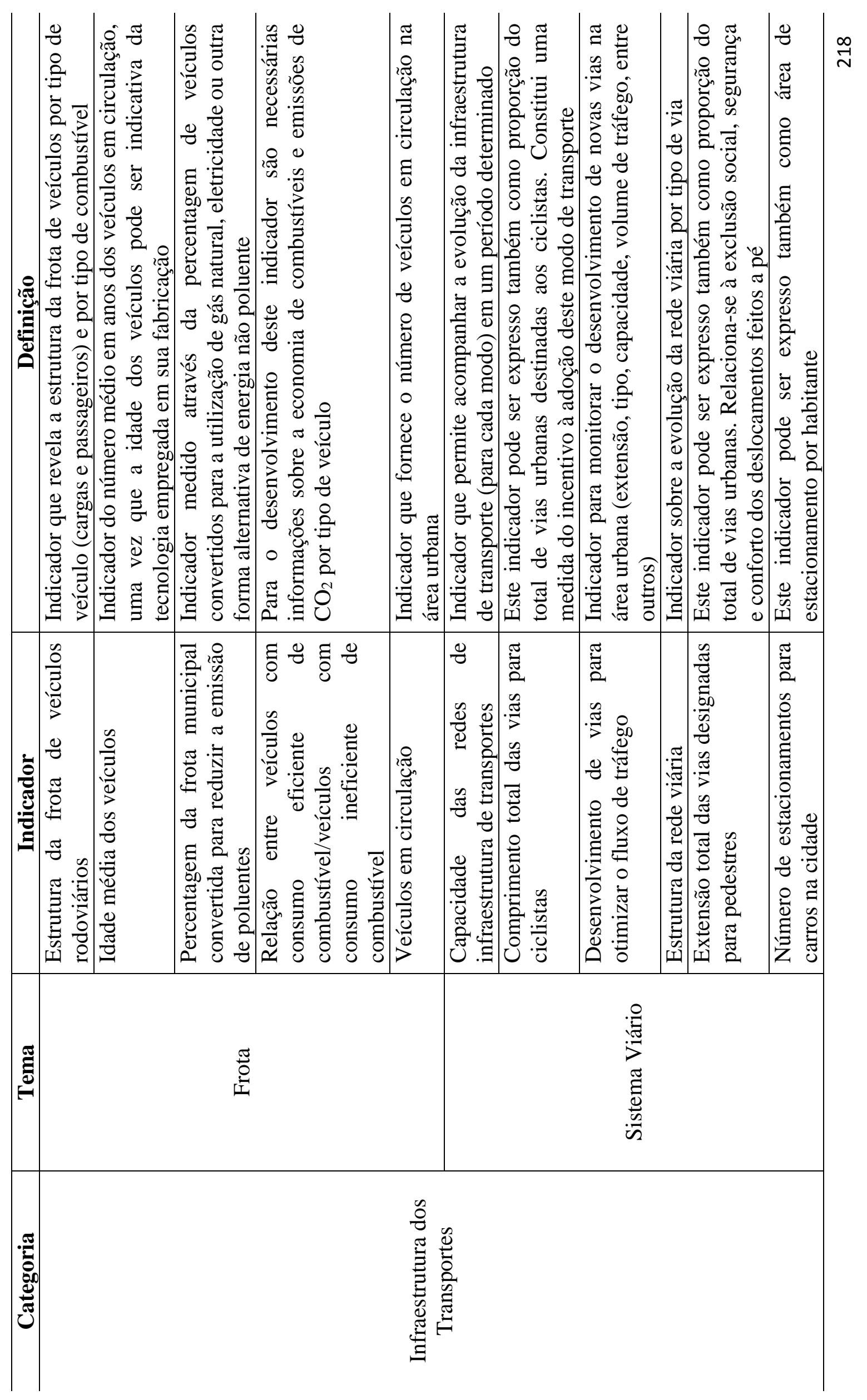




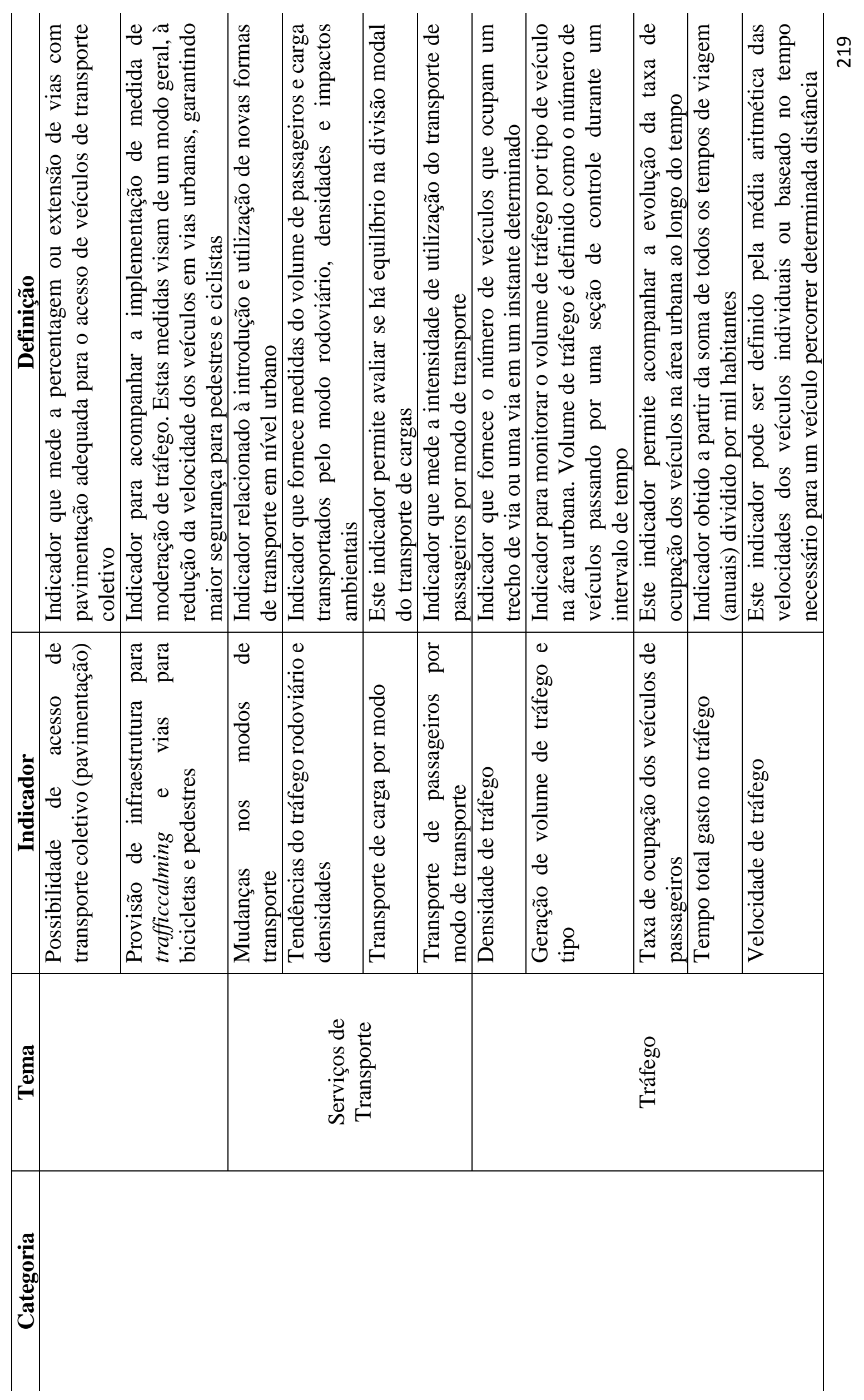




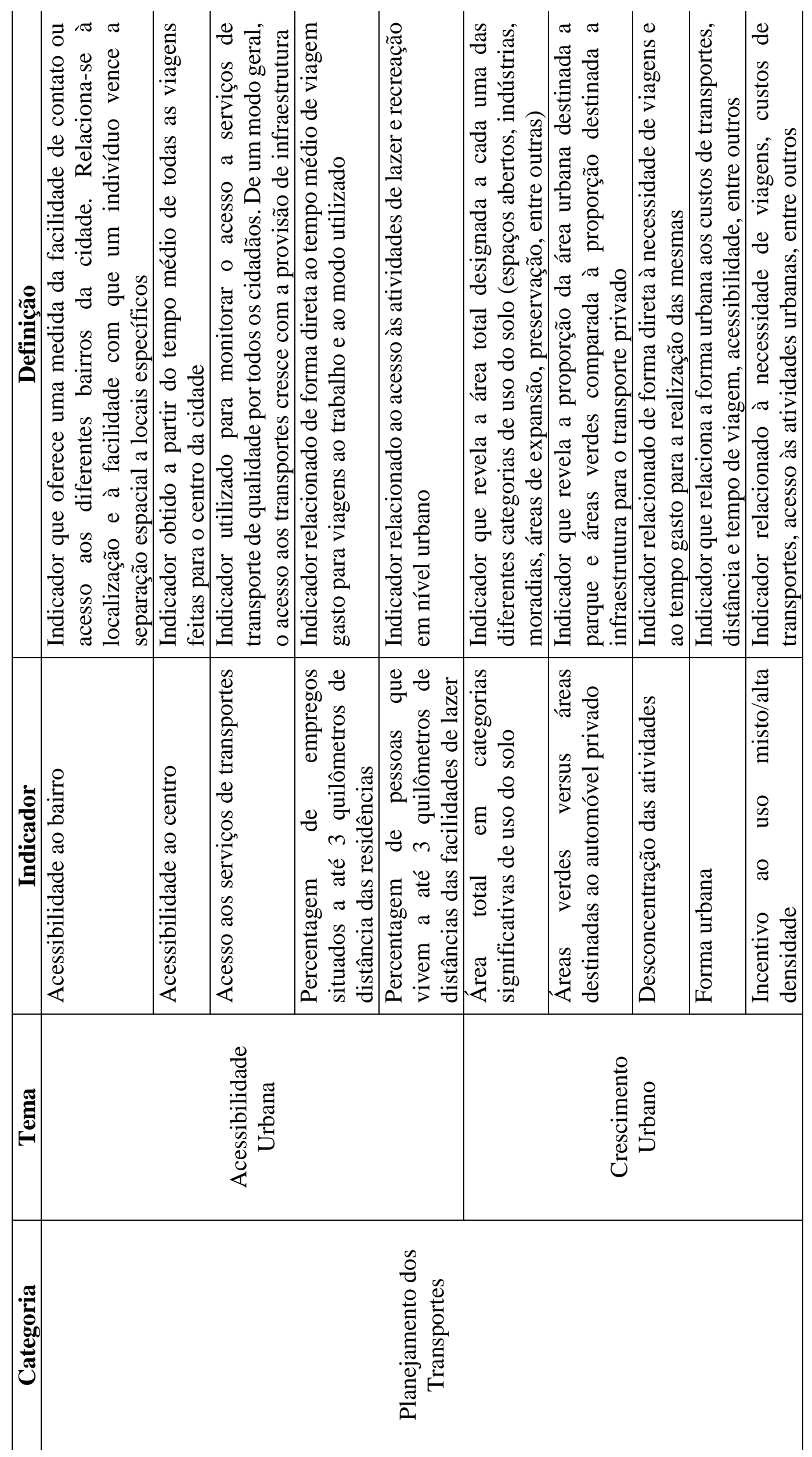




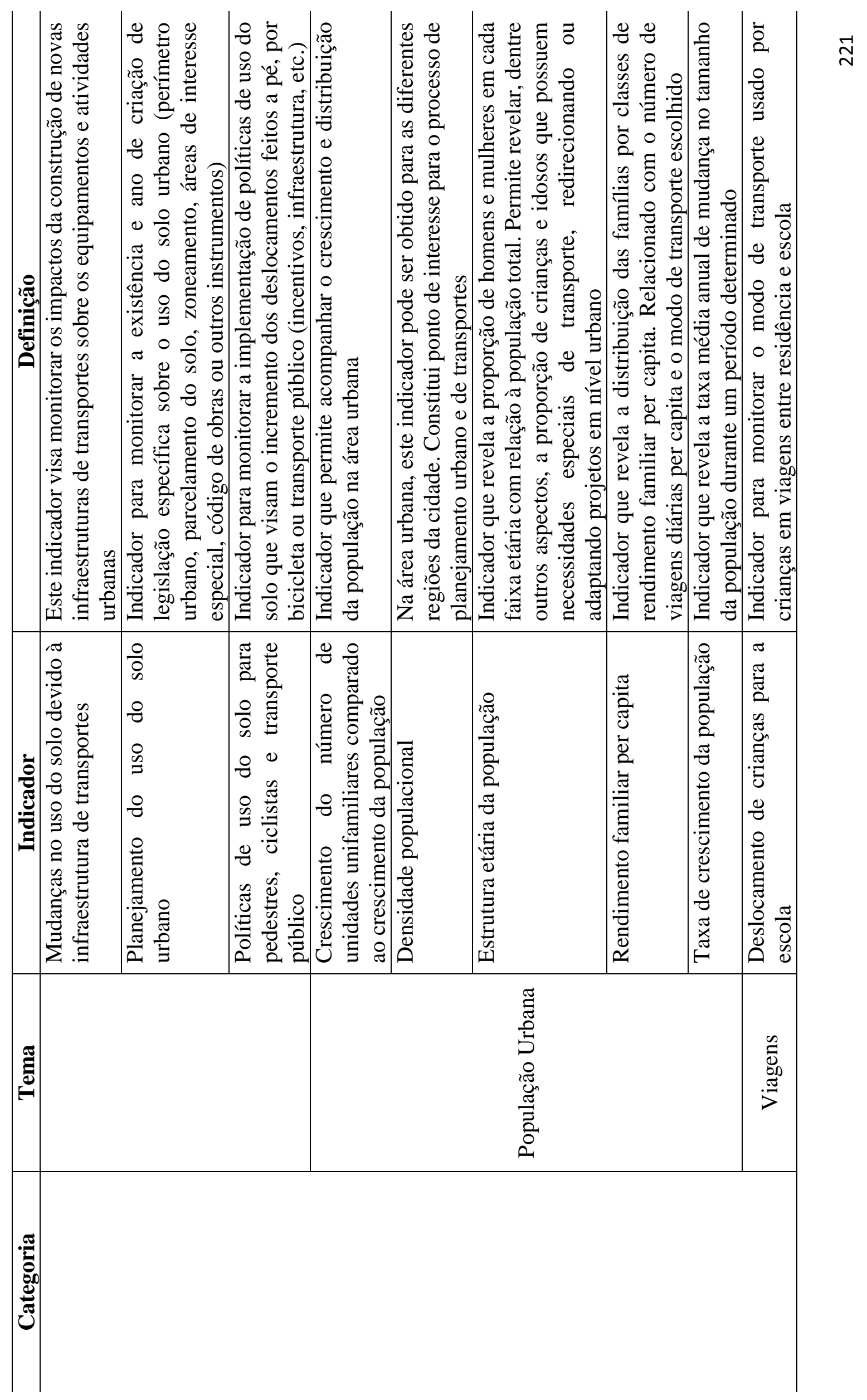




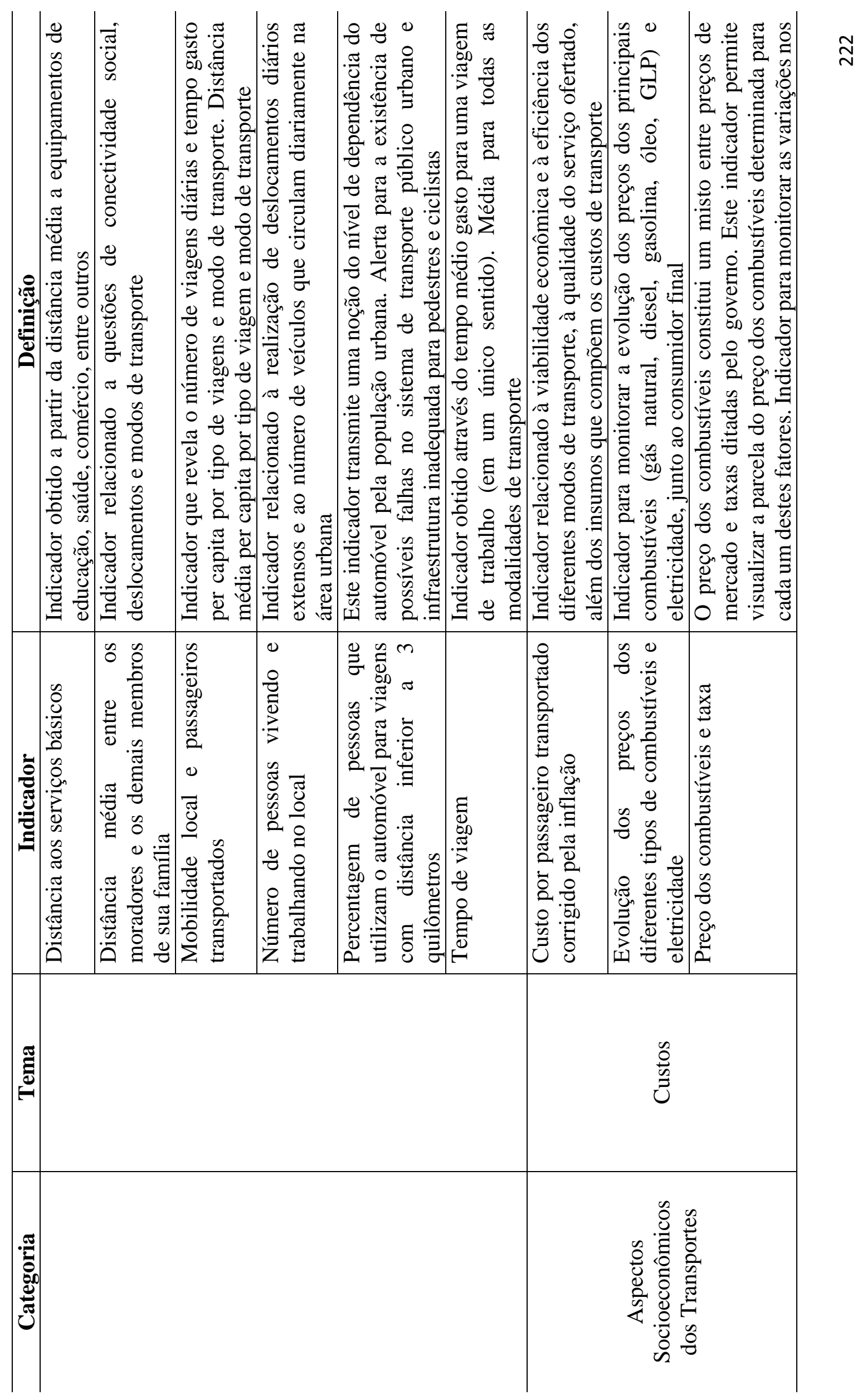




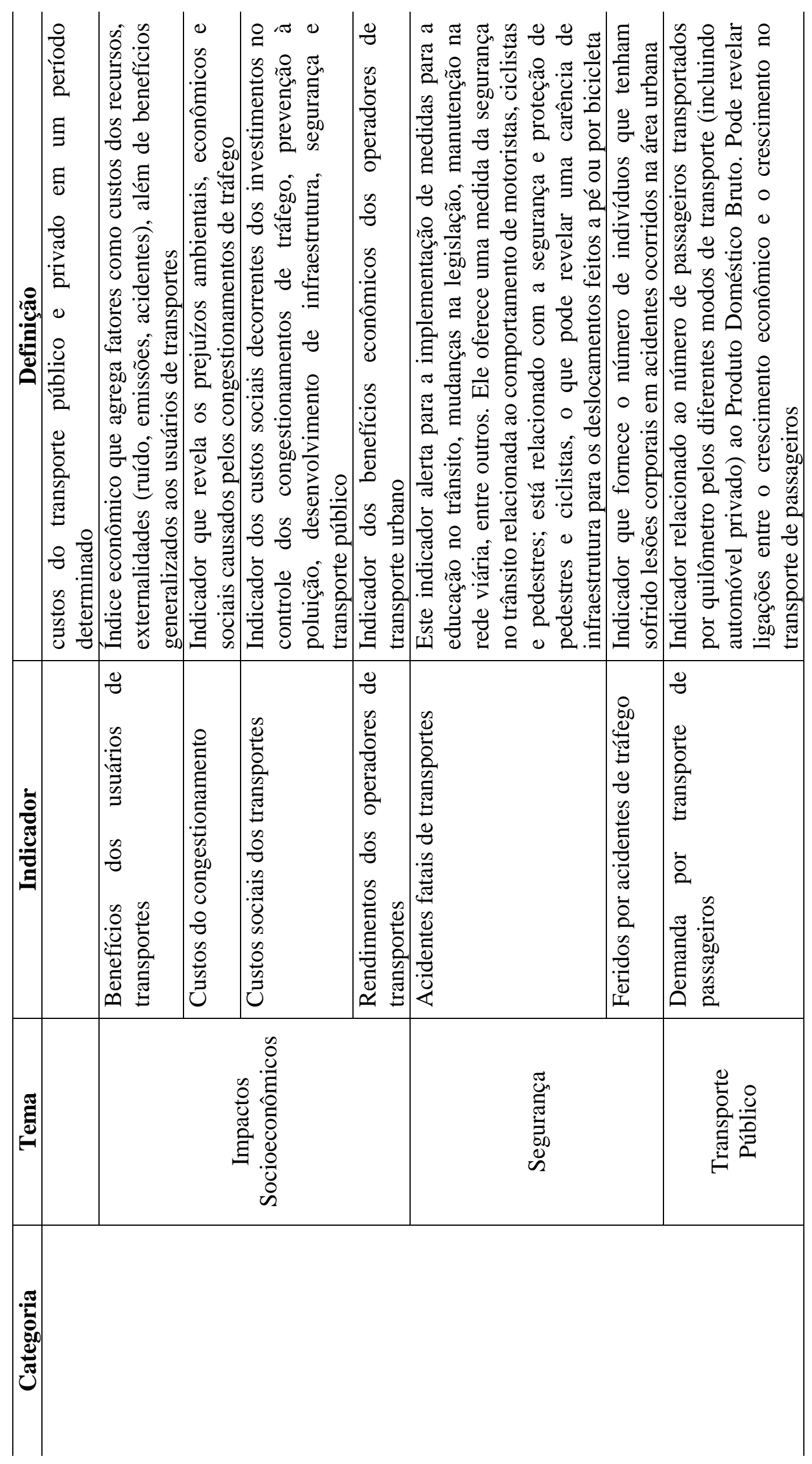

$\stackrel{\sim}{\sim}$ 


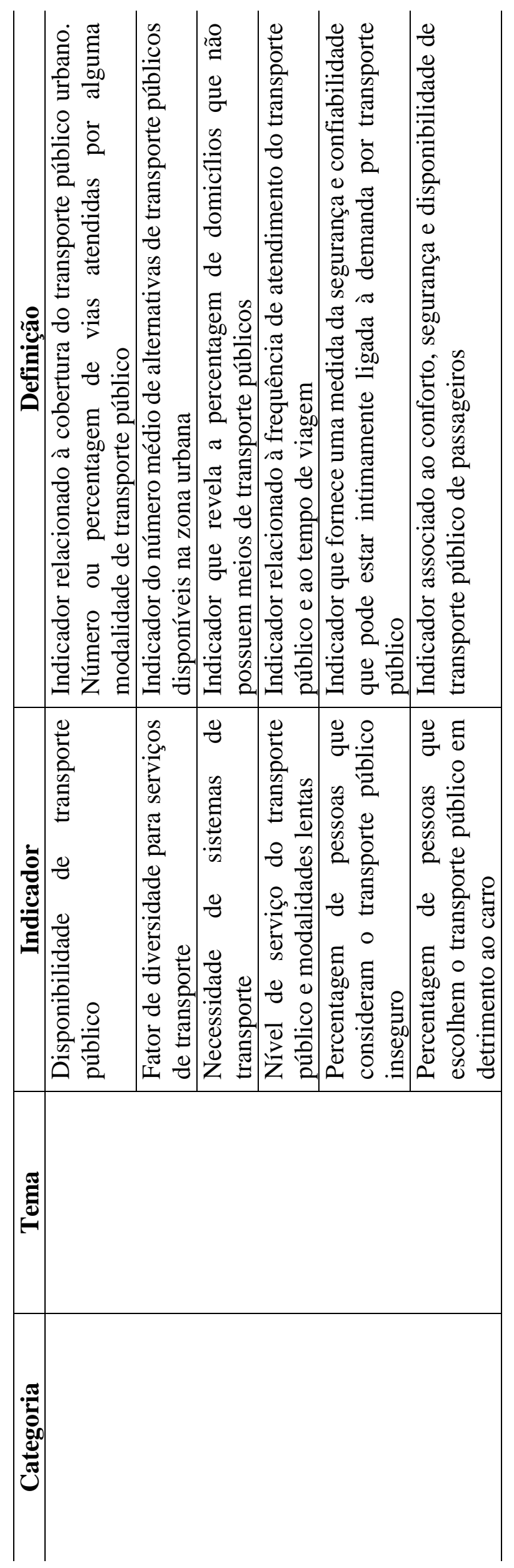

$\underset{N}{ }$ 
Machado (2010) desenvolveu o Índice de Mobilidade Sustentável (IMS) para representar os principais impactos da mobilidade na sustentabilidade e na qualidade de vida urbanas. Por meio de revisão bibliográfica sobre os conceitos de sustentabilidade, vida e mobilidade, um conjunto de indicadores foi selecionado (Tabela 4), tendo em vista a disponibilidade de dados.

O processo de elaboração matemática do IMS seguiu os passos da metodologia utilizada pelo IMUS (COSTA, 2008), à exceção da metodologia para obtenção dos pesos dos indicadores. A princípio, o método de obtenção de pesos para o sistema de indicadores do IMS foi o de Análise Hierárquica Multicritério, no entanto, dificuldades foram constatadas uma vez que muitos técnicos não entenderam o processo de avaliação par a par. Assim sendo, optou-se por utilizar metodologia de avaliação mais simples de ordenação por importância, sendo 1 o mais importante e o 3 o menos importante para a mobilidade sustentável. Os indicadores foram confrontados entre si recebendo nota crescente de acordo com o grau de importância, de forma que o peso do indicador foi definido pelo valor médio dessas notas. $\mathrm{O}$ peso do indicador foi dado pela média das notas atribuídas pelos especialistas.

Tabela 15: Indicadores selecionados para o IMS (MACHADO, 2010)

\begin{tabular}{|c|c|c|}
\hline Dimensão & Tema & Indicador \\
\hline \multirow[t]{3}{*}{ Social } & Acidentes com mortes & $\begin{array}{l}\text { Porcentagem de mortes em acidentes de } \\
\text { trânsito/número de veículos }\end{array}$ \\
\hline & Oferta de transporte coletivo & Passageiros transportados per capita \\
\hline & Intermodalidade & Número de estações intermodais \\
\hline \multirow[t]{3}{*}{ Econômica } & $\begin{array}{l}\text { Orçamento gasto em transporte } \\
\text { (tarifa) }\end{array}$ & $\begin{array}{l}\text { Valor médio da tarifa } \mathrm{x} \text { mês/salário } \\
\text { mínimo }\end{array}$ \\
\hline & Eficiência transporte coletivo & Índice de passageiros por km (IPK) \\
\hline & $\begin{array}{l}\text { Investimentos públicos no } \\
\text { setor de transportes }\end{array}$ & Porcentagem de gastos em transportes/PIB \\
\hline \multirow[t]{3}{*}{ Ambiental } & Taxa de motorização & $\begin{array}{l}\text { Número de veículos em circulação per } \\
\text { capita }\end{array}$ \\
\hline & $\begin{array}{l}\text { Consumo de combustíveis } \\
\text { fósseis }\end{array}$ & $\begin{array}{l}\text { Venda combustível fóssil (Gasolina }+ \\
\text { diesel) per capita }\end{array}$ \\
\hline & $\begin{array}{l}\text { Consumo de combustíveis } \\
\text { alternativos }\end{array}$ & Venda de álcool hidratado per capita \\
\hline
\end{tabular}


Visando contribuir para a mobilidade sustentável e consequentemente para o desenvolvimento sustentável, Campos e Melo (2005) definiram 12 indicadores (Tabela 5) de ocupação urbana para serem utilizados em procedimentos de análise da compatibilidade entre o desenvolvimento urbano e o sistema viário.

Tabela 16: Indicadores de ocupação urbana relacionados com o sistema viário (CAMPOS e MELO, 2005)

\begin{tabular}{|c|c|}
\hline Indicador & Forma de medir \\
\hline Densidade populacional & População total dividida pelo total de áreas residenciais \\
\hline Densidade residencial & Número de residências por área residencial líquida \\
\hline $\begin{array}{l}\text { Densidade de lojas de } \\
\text { varejo (comercial) }\end{array}$ & Número de lojas de varejo por área desenvolvida líquida \\
\hline $\begin{array}{l}\text { Número de } \\
\text { estabelecimentos } \\
\text { comerciais dentro de uma } \\
\text { área }\end{array}$ & $\begin{array}{l}\text { Quantidade de estabelecimentos comerciais dentro de um } \\
\text { raio de } 400 \text { metros }\end{array}$ \\
\hline Índice de dissimilaridade & $\begin{array}{l}\text { Proporção de usos diferentes do solo dentro de uma célula de } \\
1 \text { hectare na área estudada }\end{array}$ \\
\hline $\begin{array}{l}\text { Proporção de usos } \\
\text { comerciais do solo }\end{array}$ & $\begin{array}{l}\text { Número de lojas de conveniência, serviços, supermercados, } \\
\text { lojas de comida e lazer }\end{array}$ \\
\hline $\begin{array}{l}\text { Acessibilidade } \\
\text { transporte público }\end{array}$ & $\begin{array}{l}\text { Número de carros de transporte coletivo, número de assentos } \\
\text { disponíveis, porcentagem das residências dentro de uma } \\
\text { distância de caminhada do ponto de embarque }\end{array}$ \\
\hline $\begin{array}{l}\text { Índice acessibilidade ao } \\
\text { pedestre }\end{array}$ & $\begin{array}{l}\text { Medidas de ruas atravessáveis, pouco inclinadas, taxa de } \\
\text { calçadas, acesso aos edifícios e ruas com tráfego controlado. }\end{array}$ \\
\hline $\begin{array}{l}\text { Amenidades } \\
\text { pedestres }\end{array}$ & $\begin{array}{l}\text { Presença de calçadas dos dois lados da rua; calçadas } \\
\text { pavimentadas; presença de iluminação pública nas quadras; } \\
\text { presença de arborização nas calçadas; presença de } \\
\text { sinalização específica para o pedestre; e largura das ruas. }\end{array}$ \\
\hline Faixas de ciclistas & $\begin{array}{l}\text { Comprimento das faixas para ciclistas e facilidades como } \\
\text { sinalização específica }\end{array}$ \\
\hline Tamanho das quadras & Comprimento médio das faces das quadras \\
\hline $\begin{array}{l}\text { Velocidade média dos } \\
\text { veículos }\end{array}$ & Média da velocidade da rua principal ao redor da vizinhança \\
\hline
\end{tabular}


Campos e Ramos (2005) elaboraram uma proposta de indicadores de mobilidade sustentável com base na conjugação das características do uso e ocupação do solo e do sistema de transportes, baseando-se em indicadores de diferentes estudos, principalmente de cidades europeias. A Tabela 17 apresenta os indicadores selecionados.

Tabela 17: Proposta de indicadores de mobilidade sustentável (CAMPOS e RAMOS, 2005)

\begin{tabular}{|c|c|c|}
\hline \multirow{2}{*}{$\begin{array}{c}\text { Dimensões da } \\
\text { Sustentabilidade }\end{array}$} & \multicolumn{2}{|c|}{ Indicadores de Mobilidade Sustentável } \\
\hline & Ocupação Urbana/Uso do Solo & Transporte \\
\hline \multirow{8}{*}{ Meio Ambiente } & & Parcela de veículos (oferta de \\
\hline & & lugares) do $\quad$ Transporte \\
\hline & & $\underline{\text { Público Urbano (TPU) }}$ \\
\hline & Extensão de vias com traffic calming & utilizando energia limpa - \\
\hline & $\begin{array}{l}\text { - razão entre a extensão de vias com } \\
\text { implantação de medidas de traffic } \\
\text { calminge a extensão total de vias na } \\
\text { região. Unidade: } \mathrm{km} / \mathrm{km}(\%) \text {. }\end{array}$ & $\begin{array}{l}\text { razão entre a capacidade de } \\
\text { transporte público utilizando } \\
\text { energia elétrica, ou a gás, e a } \\
\text { capacidade total de } \\
\text { transportes } \\
\text { Unidade: } \\
\text { capacidade/capacidade T }(\%) \text {. }\end{array}$ \\
\hline & $\begin{array}{l}\text { Parcela de interseções com faixas } \\
\text { para pedestres - percentual de } \\
\text { interseções com faixas para } \\
\text { pedestres em relação ao total de } \\
\text { interseções. Unidade: num. inter. } \\
\text { faixa. ped./num. total inter. }(\%) \text {. }\end{array}$ & $\begin{array}{l}\text { Horas de congestionamento } \\
\text { nos corredores de transportes, } \\
\text { próximos ou de passagem na } \\
\underline{\text { região }- \text { média diária mensal }} \\
\text { de horas de tráfego, com nível } \\
\text { de serviço F, em vias } \\
\text { coletoras ou arteriais dentro } \\
\text { da região ou nos limites da } \\
\text { mesma, ou seja, com } \\
\text { velocidades médias inferiores } \\
\text { a } 35 \mathrm{~km} / \text { hora. Unidade: horas. }\end{array}$ \\
\hline & $\begin{array}{l}\text { Parcela de vias com calçadas - } \\
\text { percentual de vias com calçadas em } \\
\text { ambos os lados, com largura superior } \\
\text { a } 1,20 \mathrm{~m} \text {, em relação à extensão total } \\
\text { de vias. Unidade: } \mathrm{km} / \mathrm{km}(\%) \text {. }\end{array}$ & \multirow{2}{*}{$\begin{array}{l}\text { Acidentes com pedestres e } \\
\text { ciclistas por } 1.000 \text { habitantes } \\
\text { - média mensal de acidentes } \\
\text { envolvendo pedestres ou } \\
\text { ciclistas com veículos para } \\
\text { cada mil habitantes. Unidade: } \\
\text { número de acidentes } / 1000 \\
\text { hab. }\end{array}$} \\
\hline & $\begin{array}{l}\text { População residente com acesso a } \\
\text { áreas verdes ou de lazer, dentro de } \\
\text { um raio de } 500 \text { metros das mesmas - } \\
\text { razão entre a população total dentro } \\
\text { de um raio com distância de } \\
\text { caminhada de no máximo } 500 \mathrm{~m} \text {, em } \\
\text { vias com calçadas, (pop1) e a } \\
\text { população total da área (popT). } \\
\text { Unidade: pop1/popT }(\%) \text {. }\end{array}$ & \\
\hline
\end{tabular}




\begin{tabular}{|c|c|c|}
\hline \multirow{2}{*}{$\begin{array}{c}\text { Dimensões da } \\
\text { Sustentabilidade }\end{array}$} & \multicolumn{2}{|c|}{ Indicadores de Mobilidade Sustentável } \\
\hline & Ocupação Urbana/Uso do Solo & Transporte \\
\hline \multirow{6}{*}{ Sociedade } & $\begin{array}{l}\text { População residente com distância } \\
\text { medida de caminhada inferior a 500 } \\
\text { metros das estações/paradas de TPU } \\
\text { - população residente num raio de } \\
500 \mathrm{~m} \text { de um ponto de acesso ao } \\
\text { transporte público. Unidade: } \\
\text { População }\end{array}$ & $\begin{array}{l}\text { Oferta de TPU (oferta de } \\
\underline{\text { lugares) }} \text { - número de lugares } \\
\text { ofertados no transporte } \\
\text { público em hora de pico. } \\
\text { Unidade: capacidade }\end{array}$ \\
\hline & $\begin{array}{l}\text { Parcela de área de comércio (uso } \\
\underline{\text { misto) }} \text { - razão entre a área total de } \\
\text { uso comercial (varejo) e a área total } \\
\text { construída. Unidade: ha/ha }(\%) \text {. }\end{array}$ & $\begin{array}{l}\text { Frequência de TPU } \\
\text { frequência horária de veículos } \\
\text { de TPU, no horário de pico. } \\
\text { Unidade: veículos/hora. }\end{array}$ \\
\hline & $\begin{array}{l}\text { Diversidade de uso comercial e } \\
\text { serviços dentro de um bloco ou } \\
\text { quadra de } 500 \text { metros x } 500 \text { metros } \\
\text { razão entre número de diferentes } \\
\text { tipos de estabelecimentos de } \\
\text { comércio e serviço e o total de } \\
\text { estabelecimentos numa quadra. } \\
\text { Unidade: núm. estabelecimentos/ } \\
\text { num estabelecimentos. }\end{array}$ & $\begin{array}{l}\text { Oferta de transporte para } \\
\text { pessoas de mobilidade } \\
\text { reduzida - capacidade média } \\
\text { diária de veículos especiais de } \\
\text { transporte público para } \\
\text { deslocamento de pessoas com } \\
\text { mobilidade reduzida (PMR). } \\
\text { Ou, o número de veículos } \\
\text { diários com facilidades para } \\
\text { transporte de pessoas com } \\
\text { mobilidade reduzida. } \\
\text { Unidade: número de } \\
\text { passageiros PMR/dia ou } \\
\text { veículos PMR/dia. }\end{array}$ \\
\hline & $\begin{array}{l}\text { Extensão de ciclovias - razão entre a } \\
\text { extensão de vias com ciclovias e a } \\
\text { extensão total de vias coletoras e } \\
\text { arteriais. Unidade: } \mathrm{km} / \mathrm{km}(\%) \text {. }\end{array}$ & $\begin{array}{l}\text { Tempo médio de viagem no } \\
\text { TPU para o núcleo central de } \\
\text { atividades e comércio - tempo } \\
\text { médio de viagem na hora de } \\
\text { pico entre o centróide da } \\
\text { região de estudo e o núcleo } \\
\text { central da cidade. Unidade: } \\
\text { minutos. }\end{array}$ \\
\hline & $\begin{array}{l}\text { Distância média de caminhada às } \\
\text { escolas - média das maiores } \\
\text { distâncias entre os limites da região } \\
\text { e as escolas da mesma. Ou, quando } \\
\text { houver disponibilidade de } \\
\text { informação, este indicador pode ser } \\
\text { medido pela distância média de } \\
\text { caminhada dos alunos até as } \\
\text { residências. Unidade: Distância } \\
\text { máxima total a cada escola / número } \\
\text { de escolas. }\end{array}$ & $\begin{array}{l}\text { Demanda de viagens por } \\
\text { automóveis na região - fluxo } \\
\text { de tráfego médio diário de } \\
\text { transporte por automóvel } \\
\text { gerado na região para outras } \\
\text { regiões dentro da cidade. } \\
\text { Unidade: número de } \\
\text { viagens/dia. }\end{array}$ \\
\hline & $\begin{array}{l}\text { Número de lojas de varejo por área } \\
\text { desenvolvida líquida - razão entre o }\end{array}$ & $\begin{array}{l}\text { Tempo médio de viagem TPU } \\
\text { x tempo médio de viagem por }\end{array}$ \\
\hline
\end{tabular}




\begin{tabular}{|c|c|c|}
\hline \multirow{4}{*}{$\begin{array}{c}\text { Dimensões da } \\
\text { Sustentabilidade }\end{array}$} & \multicolumn{2}{|c|}{ Indicadores de Mobilidade Sustentável } \\
\hline & Ocupação Urbana/Uso do Solo & Transporte \\
\hline & $\begin{array}{l}\text { número de lojas e a área total } \\
\text { construída. Unidade: num. lojas/ha. }\end{array}$ & \multirow{2}{*}{$\begin{array}{l}\text { automóvel - razão entre o } \\
\text { tempo médio de viagem no } \\
\text { transporte público e o tempo } \\
\text { de viagem por automóvel } \\
\text { entre o núcleo central da } \\
\text { região e o núcleo da cidade. } \\
\text { Unidade: } 1 \text { - (\% min.TPU/ } \\
\text { min.Auto). }\end{array}$} \\
\hline & $\begin{array}{l}\text { População dentro de uma distância } \\
\text { de } 500 \text { metros de vias com uso } \\
\text { predominante de comércios e } \\
\text { serviços - média de população } \\
\text { residente dentro de uma faixa de } 500 \\
\text { m ao longo de vias com uso } \\
\text { predominante, acima de } 50 \% \text { de } \\
\text { comércio e serviço. Unidade: } \\
\text { População. }\end{array}$ & \\
\hline \multirow{4}{*}{ Economia } & \multirow{2}{*}{$\begin{array}{l}\text { Renda média da população/custo } \\
\text { mensal do transporte público - razão } \\
\text { entre a renda média mensal da } \\
\text { população e o custo total mensal no } \\
\text { transporte público referente a duas } \\
\text { viagens diárias (ida e volta ao centro } \\
\text { urbano). Unidade: \$renda/ \$tarifa } \\
(\%) .\end{array}$} & $\begin{array}{l}\text { Custo médio de viagem no } \\
\text { transporte público para o } \\
\text { núcleo central de atividades - } \\
\text { valor médio pago por viagem } \\
\text { no transporte público até o } \\
\text { núcleo central da cidade, } \\
\text { compreendendo o uso de um } \\
\text { ou mais sistemas de } \\
\text { transporte. Unidade: } \$ \text {. }\end{array}$ \\
\hline & & $\begin{array}{l}\text { Veículo- } \\
\text { viagens/comprimento total da } \\
\text { via ou corredor - razão entre o } \\
\text { tráfego médio diário de } \\
\text { veículos privados nas vias } \\
\text { coletoras dentro da região de } \\
\text { estudo e a extensão total } \\
\text { destas vias. Unidade: número } \\
\text { de veículos/km. }\end{array}$ \\
\hline & \multirow{2}{*}{$\begin{array}{l}\text { Baías para carga e descarga - média } \\
\text { da razão entre a extensão de baías de } \\
\text { carga e descarga em vias de uso } \\
\text { comercial e a extensão dessas vias. } \\
\text { Unidade: } \mathrm{km} / \mathrm{km}(\%) \text {. }\end{array}$} & $\begin{array}{l}\text { Parcela de veículos de carga } \\
\text { com uso de energia menos } \\
\text { poluente - razão entre o } \\
\text { volume diário de veículos de } \\
\text { carga movidos a eletricidade } \\
\text { ou a gás e o volume total de } \\
\text { veículos de carga circulando } \\
\text { na região. Unidade: } \\
\text { veículos/veículos }(\%) \text {. }\end{array}$ \\
\hline & & $\begin{array}{l}\text { Total de veículos-viagens/per } \\
\text { capita - razão entre o número } \\
\text { de viagens diárias por } \\
\text { automóvel na região e a } \\
\text { população ativa. Unidade: } \\
\text { número de viagens/população } \\
\text { ativa. }\end{array}$ \\
\hline
\end{tabular}


O Sistema de Informações da Mobilidade Urbana da Associação Nacional de Transportes Públicos (ANTP) se propõe a coletar e tratar os dados de transporte público e tráfego urbano dos municípios brasileiros com população superior a 60 mil habitantes de forma a alimentar análises e avaliações, além de auxiliar na formulação e implementação de políticas públicas no setor (ANTP, 2012). Para tanto, gera anualmente indicadores:

- Específicos que permitem análises comparativas com indicadores similares observados internacionalmente, contribuindo para a elaboração de políticas públicas no setor de transportes;

- Agregados nacionais que permitem uma avaliação do que representa o setor de transporte em patrimônio investido, custos gerais e participação no PIB, bem como nos processos de consumo de espaço e energia, e de produção de externalidades como a poluição e os acidentes;

- Voltados à análise de séries históricas, visando à monitoração dos impactos de políticas públicas para o setor de transporte;

- Quantitativos que permitem uma qualificação das propostas da ANTP e demais entidades interessadas em defender políticas públicas para o setor de transporte, em especial junto à opinião pública e aos poderes executivo, legislativo e judiciário.

Os indicadores utilizados atualmente pela ANTP (2012) referem-se a:

- Dados socioeconômicos;

- Mobilidade;

- Divisão Modal;

- Análise espacial: deslocamentos feitos pelas pessoas;

- Equipamentos usados na mobilidade;

- Recursos humanos usados na mobilidade;

- Distâncias percorridas pelas pessoas;

- Tempo gasto pelas pessoas na circulação;

- Energia consumida;

- Poluentes emitidos;

- Custos da mobilidade; 
- Custos das externalidades;

- Custos totais;

- Patrimônio envolvido na mobilidade.

A fim de acompanhar e avaliar Programas Nacionais de Transporte por parte do Ministério dos Transportes foi firmado convênio entre este Ministério e o Centro de Formação de Recursos Humanos em Transportes (CEFTRU) da Universidade de Brasília (BRASIL, 2007a) para desenvolver indicadores apropriados. Foram desenvolvidos, no total, 46 indicadores (Tabela 18). 


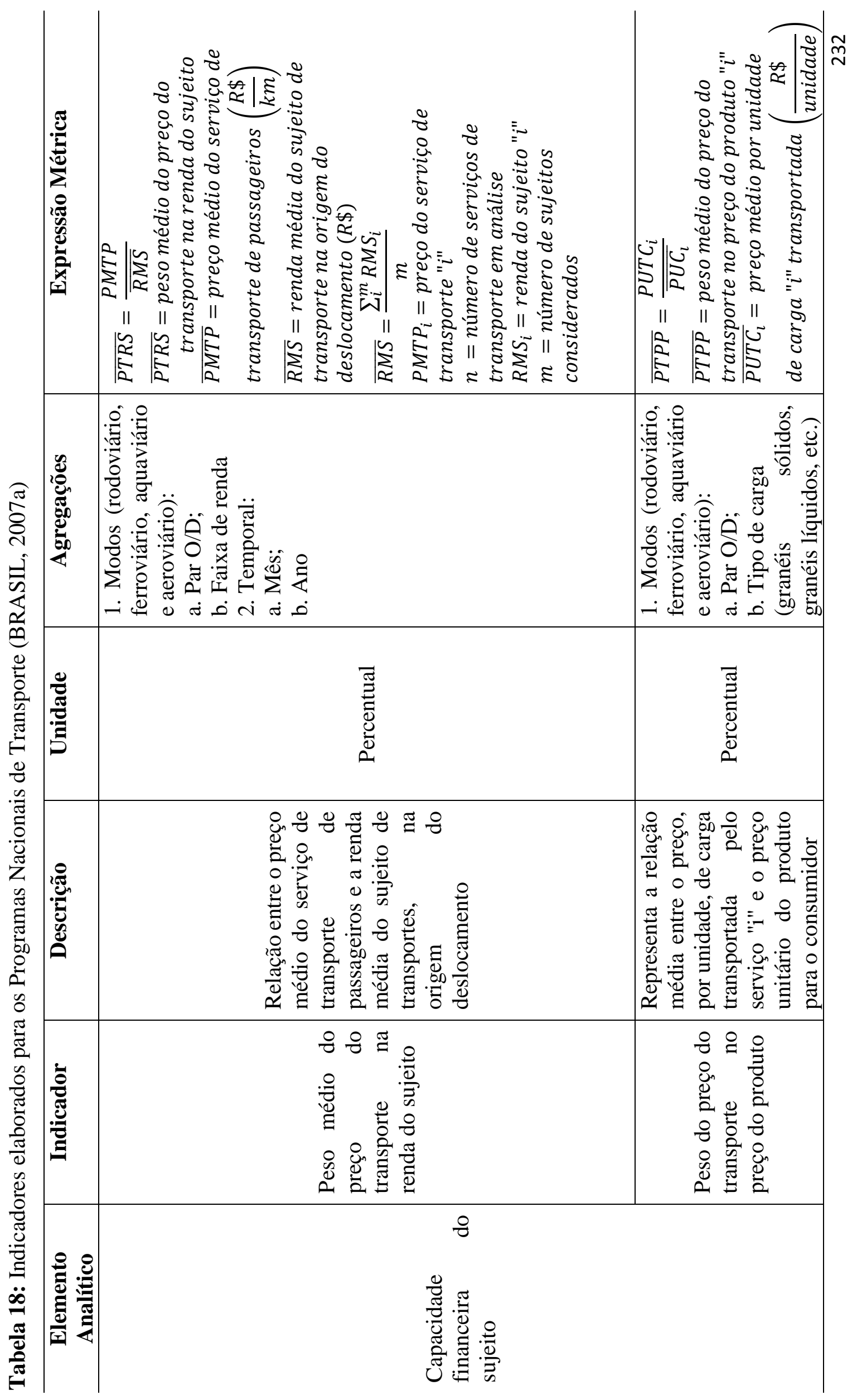




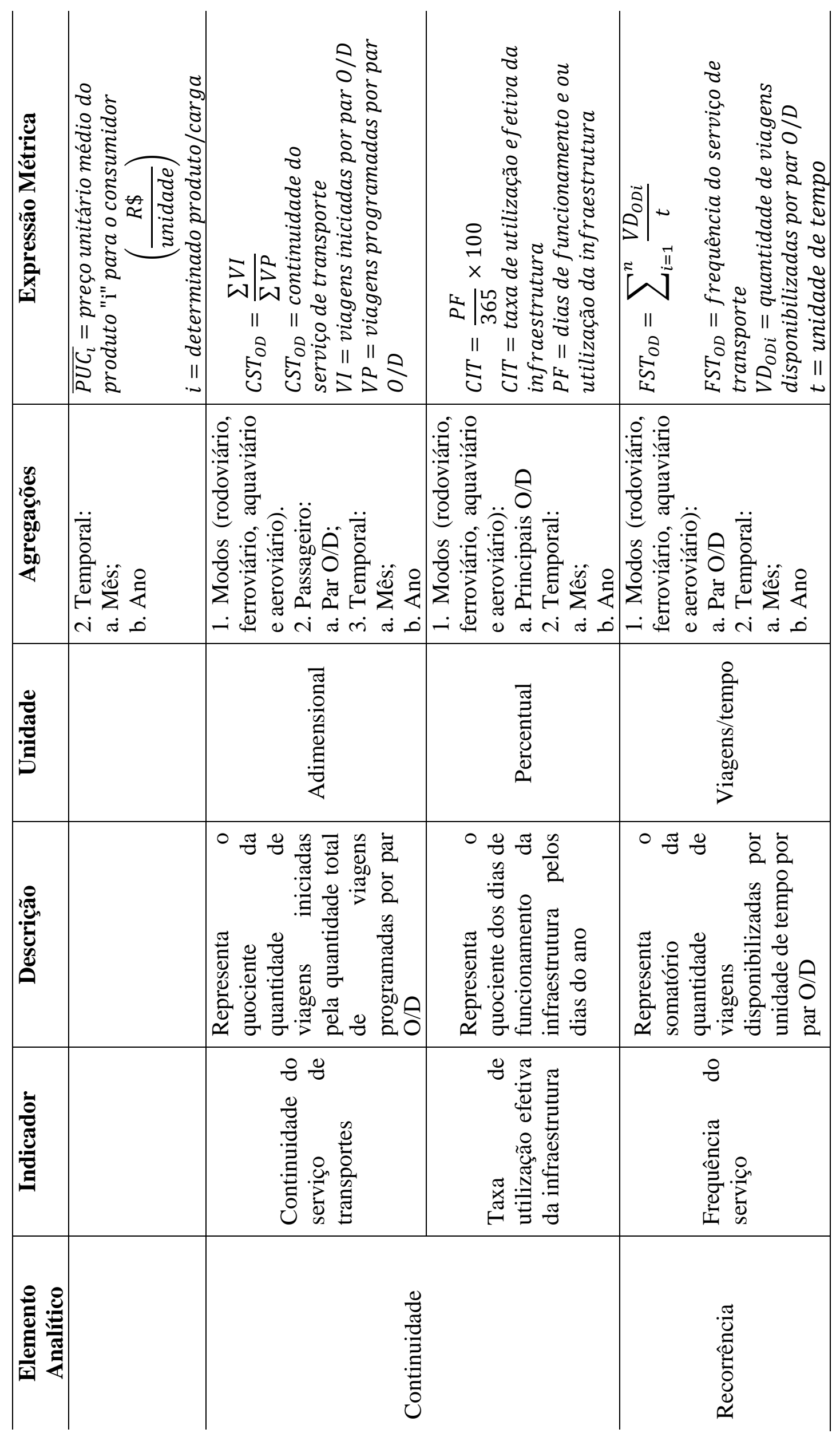

$\stackrel{m}{\sim}$ 


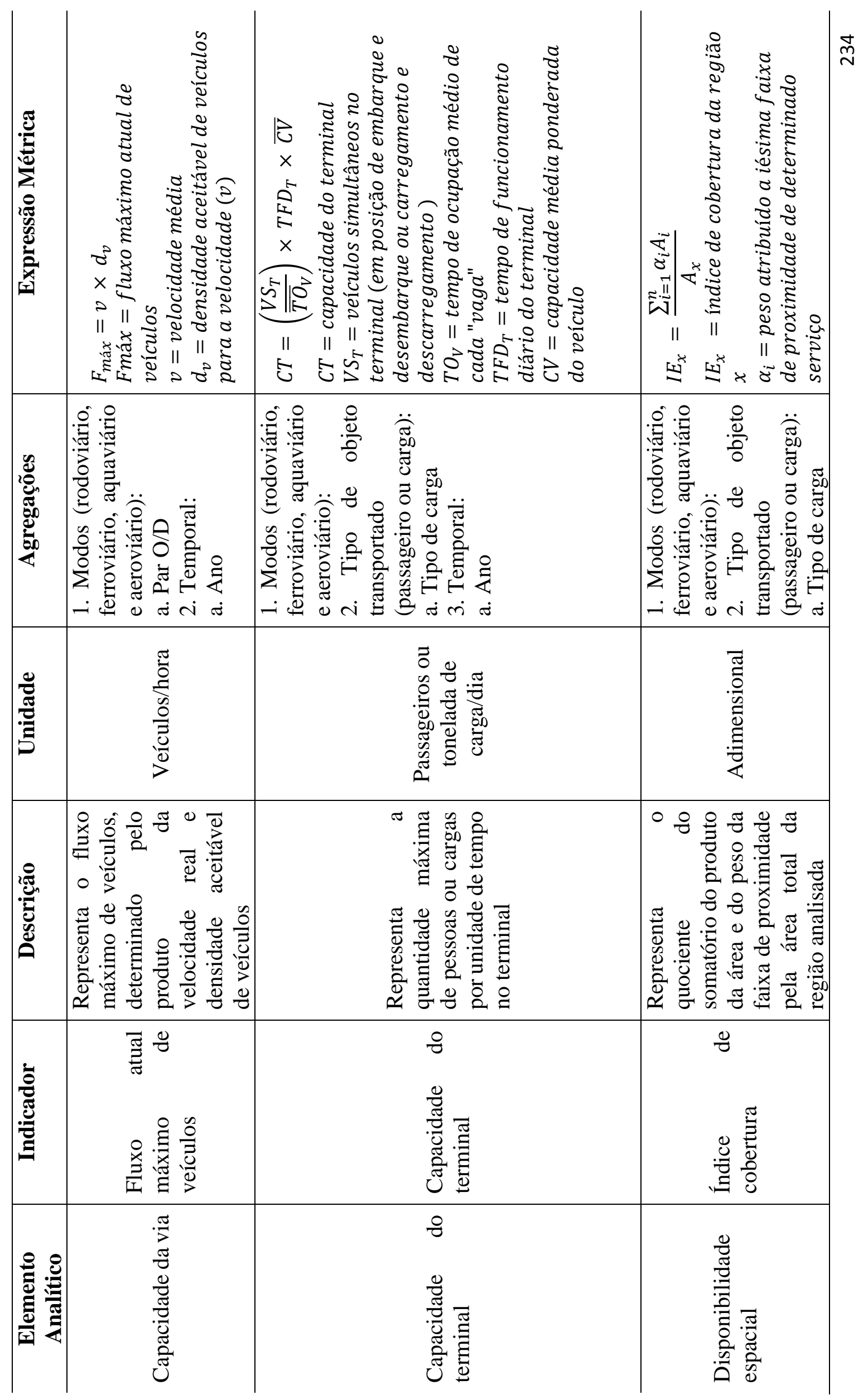




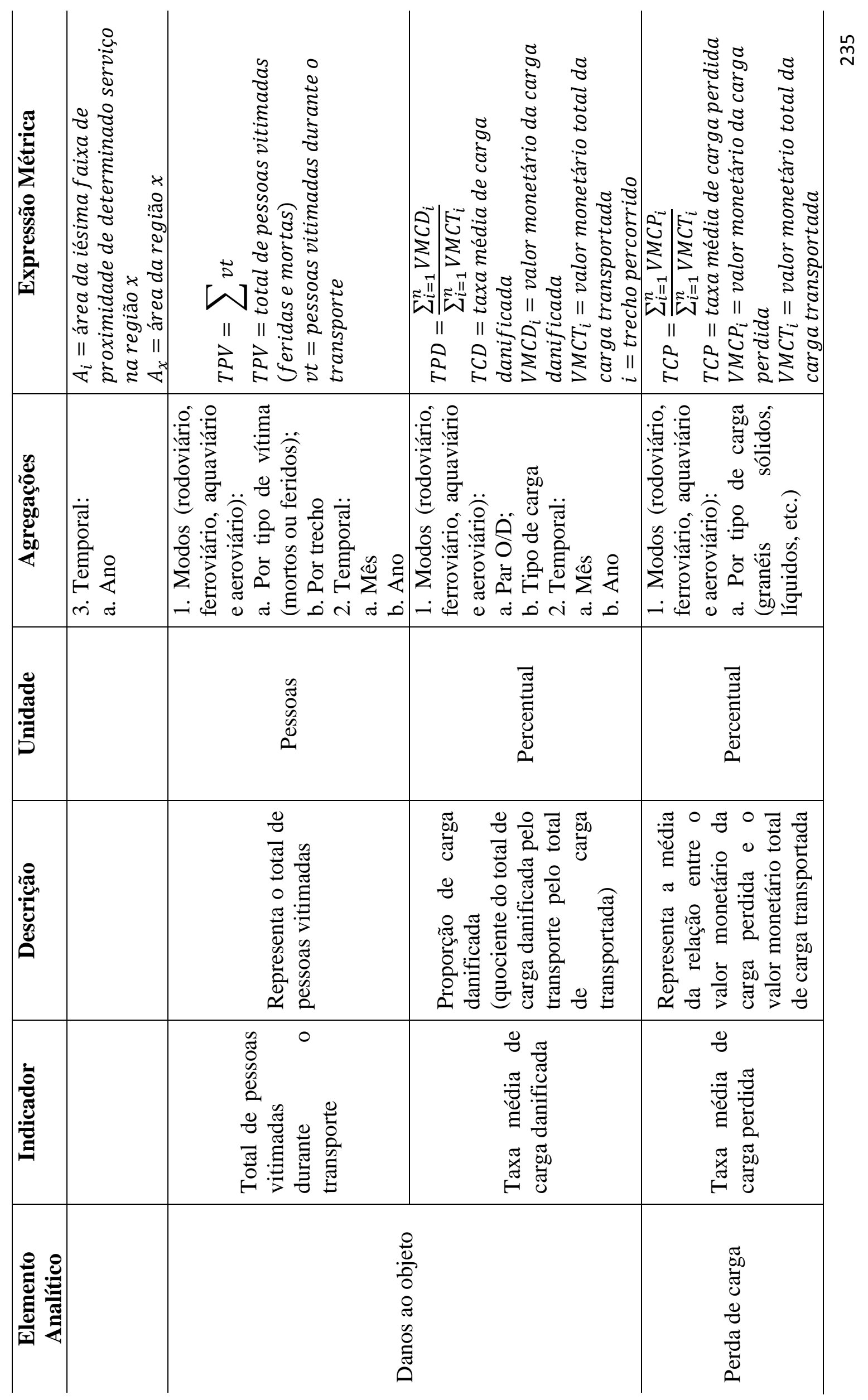




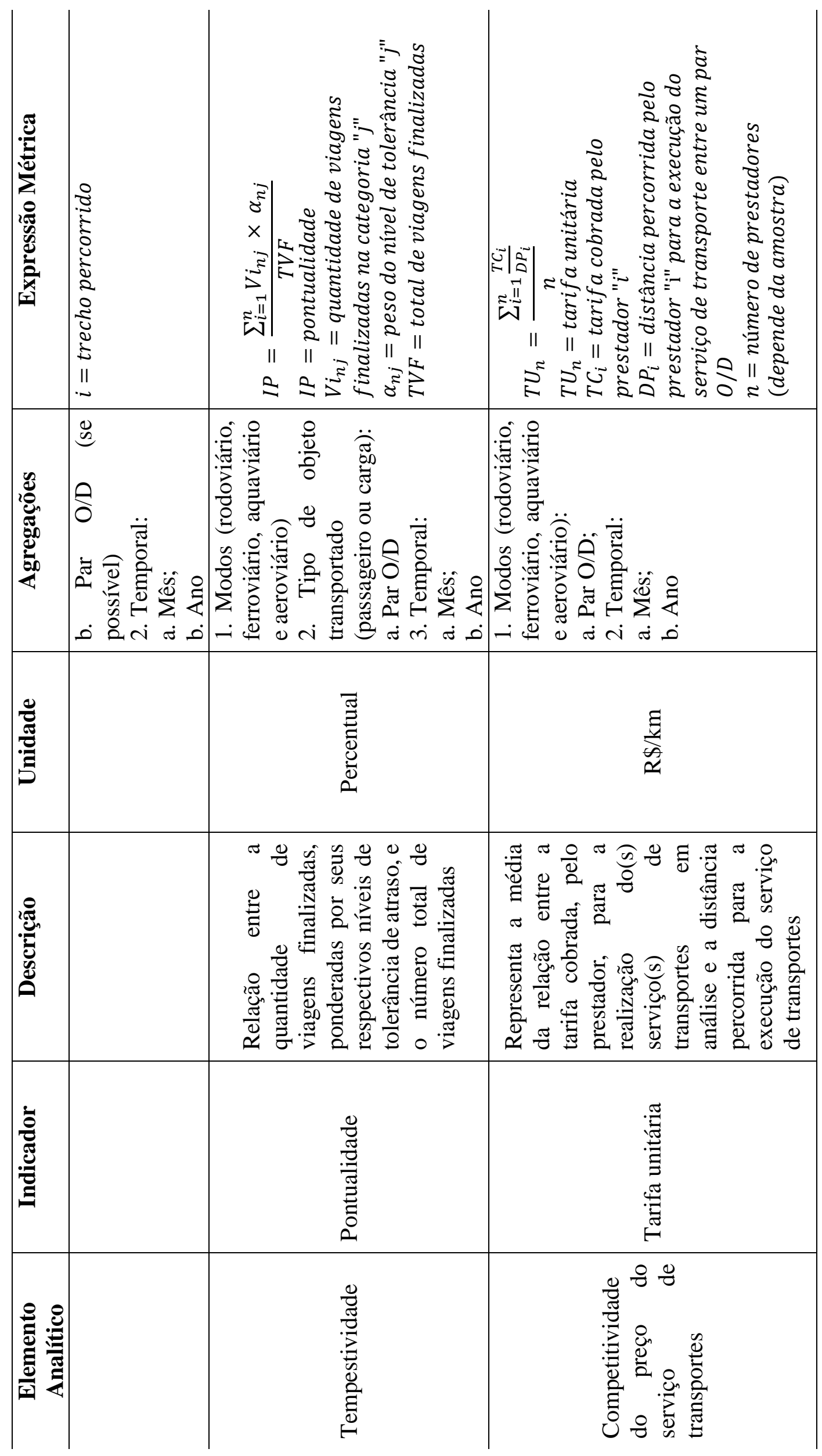

$\stackrel{\sim}{\sim}$ 


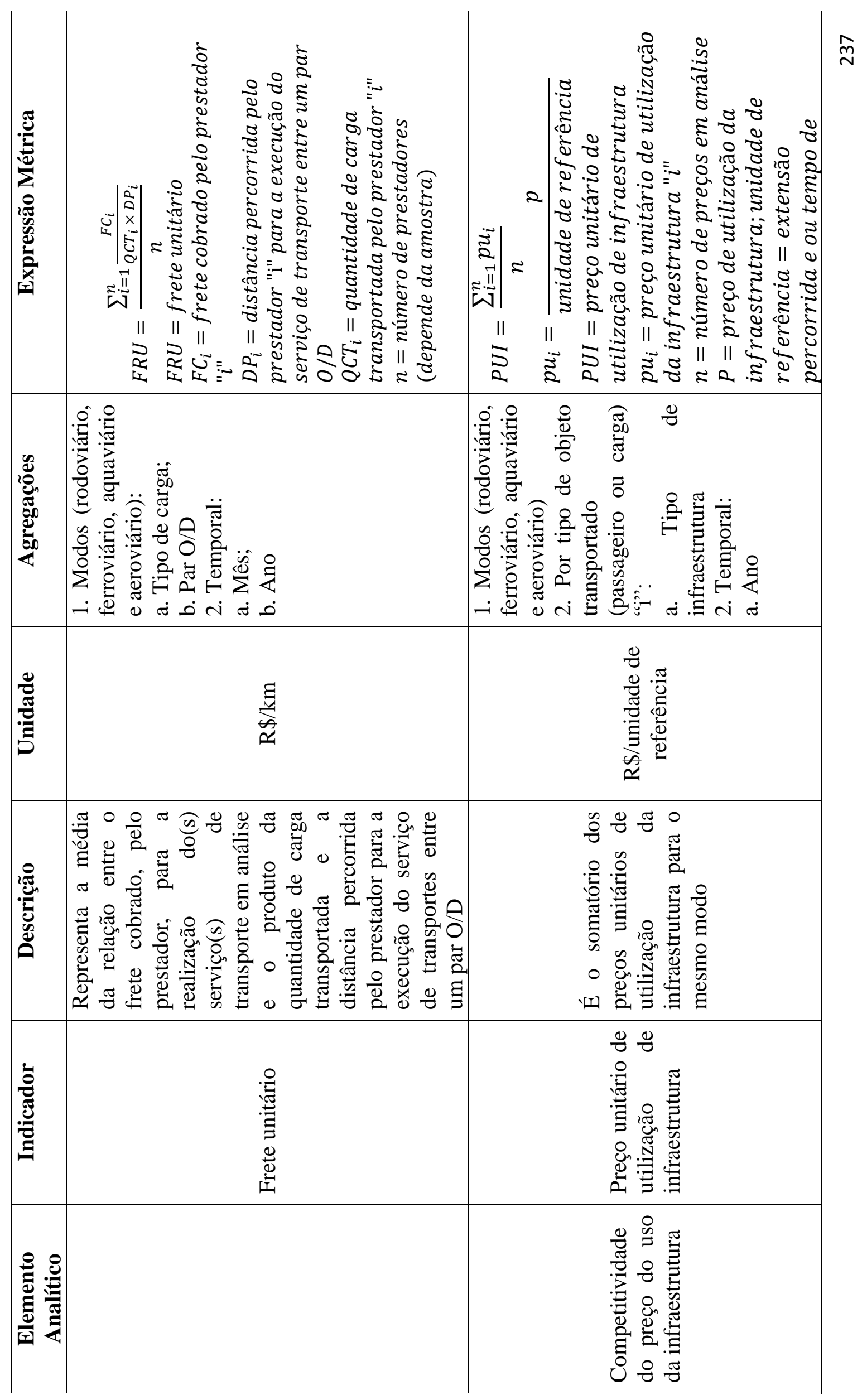




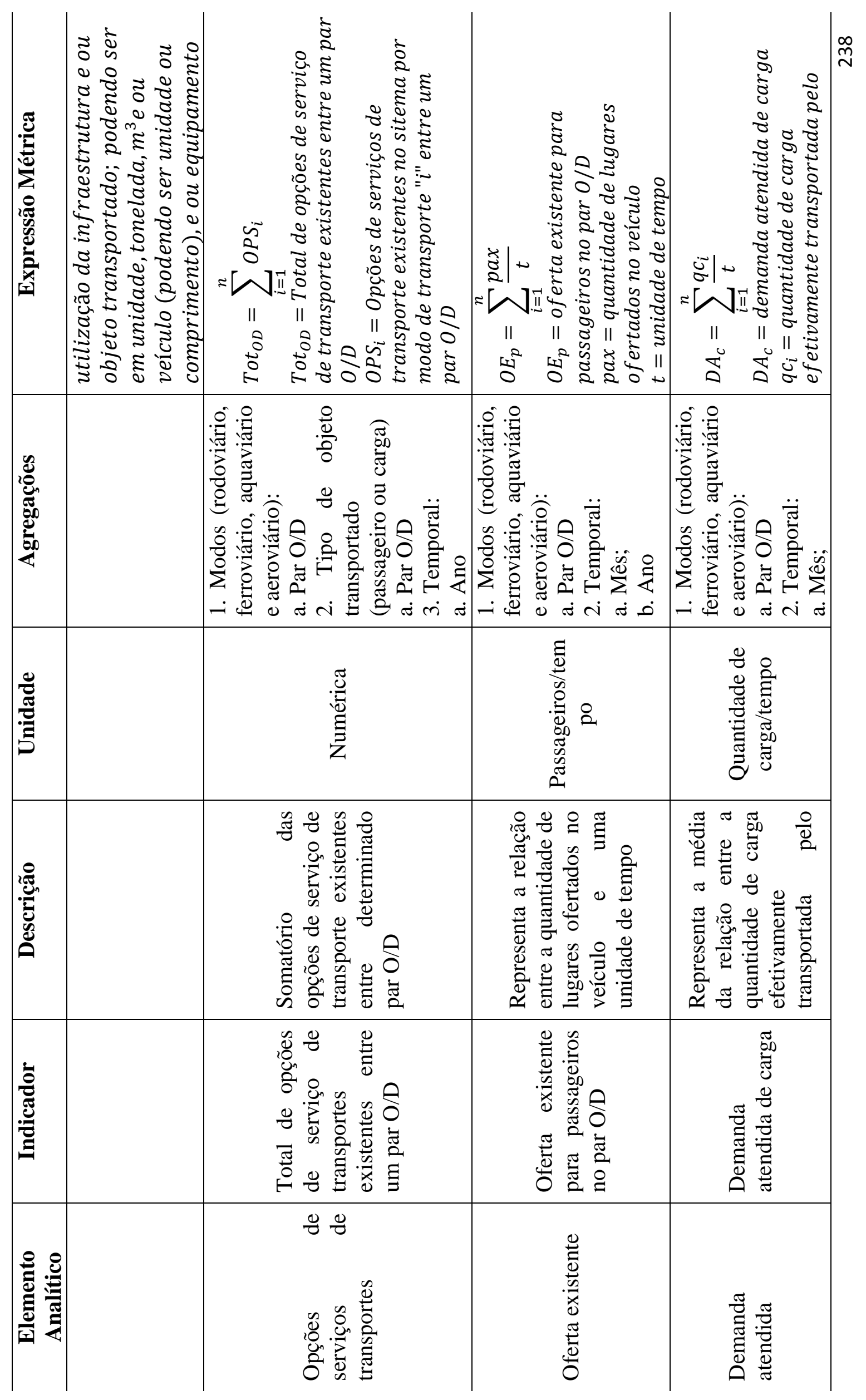




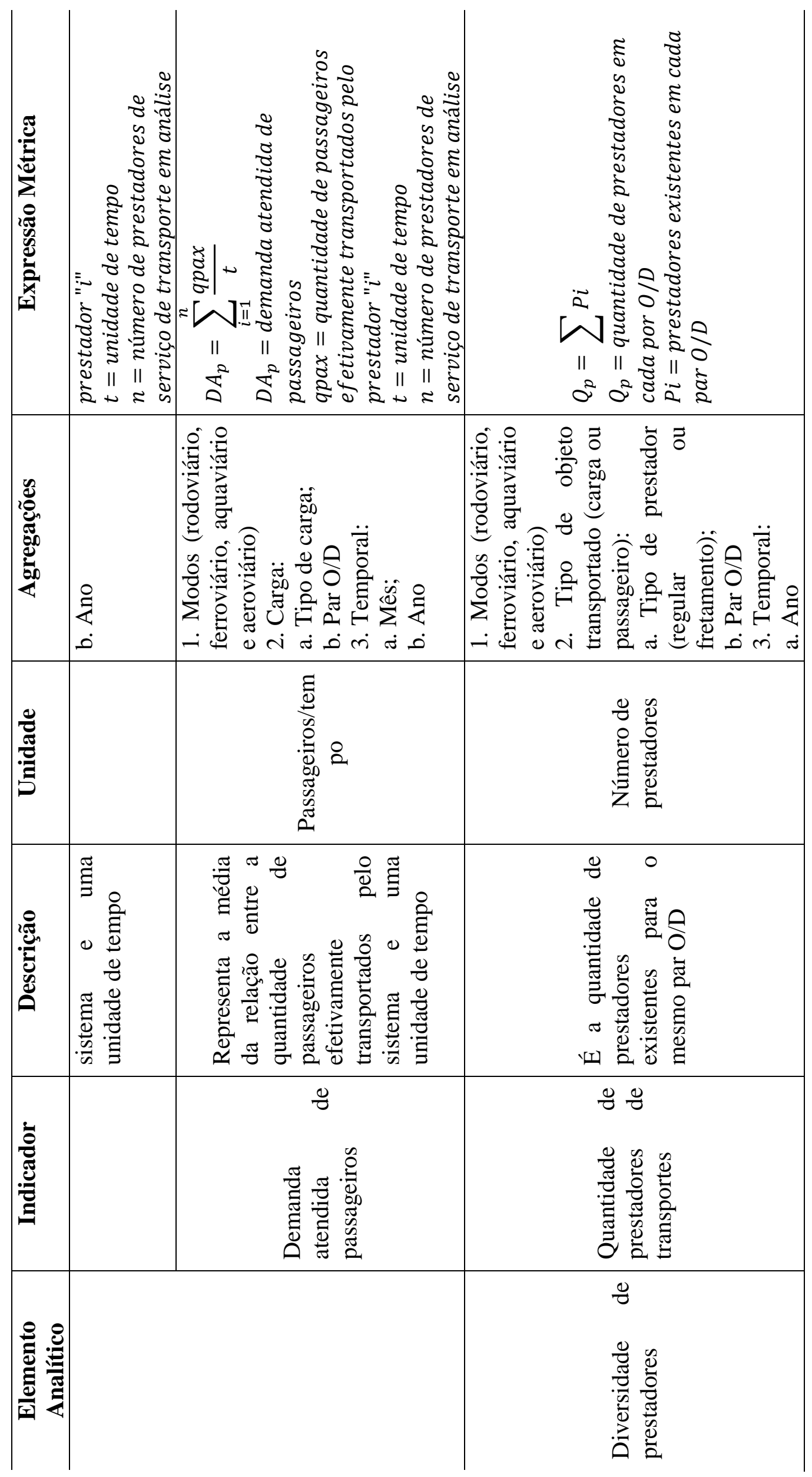

్ㅗำ 


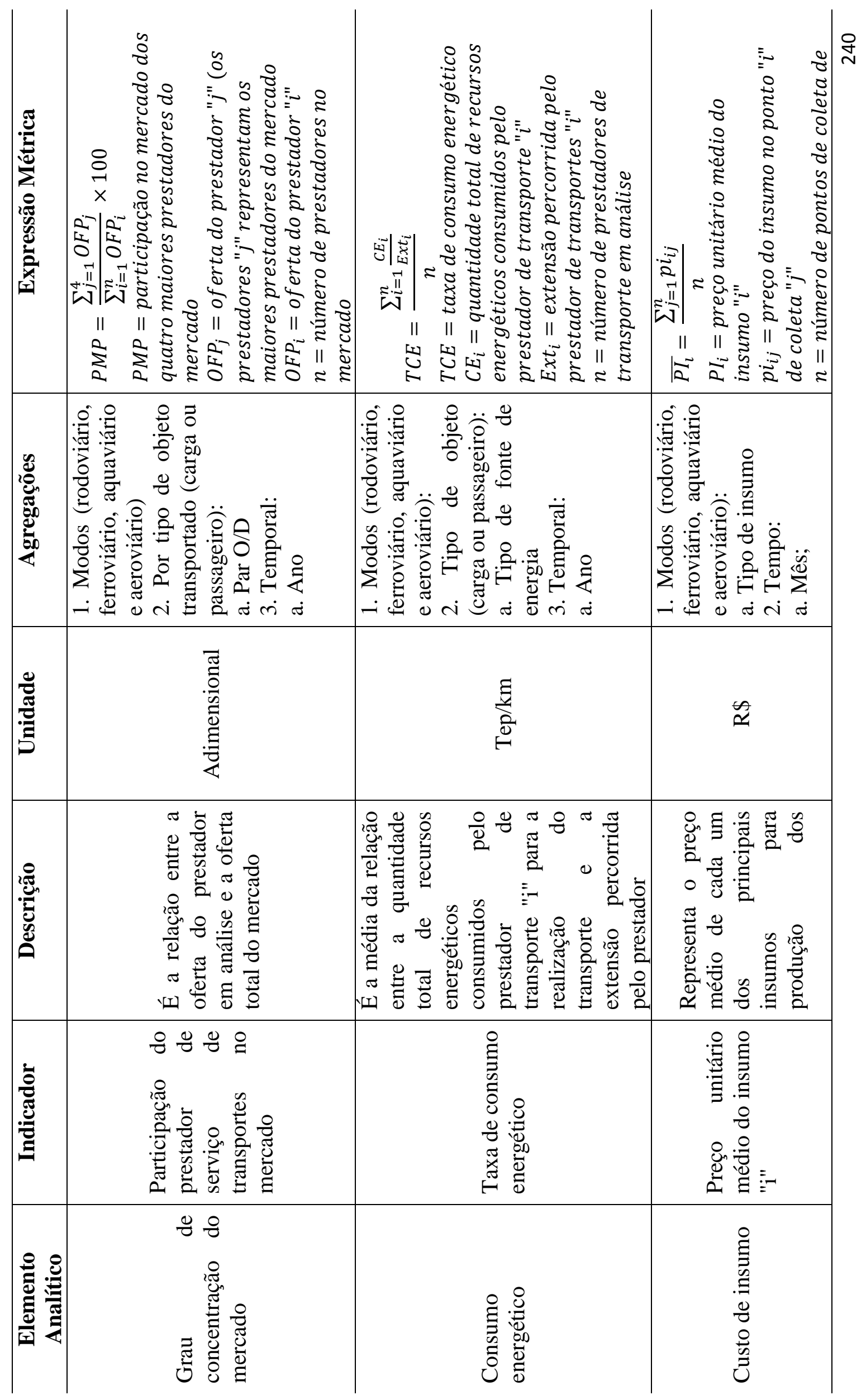




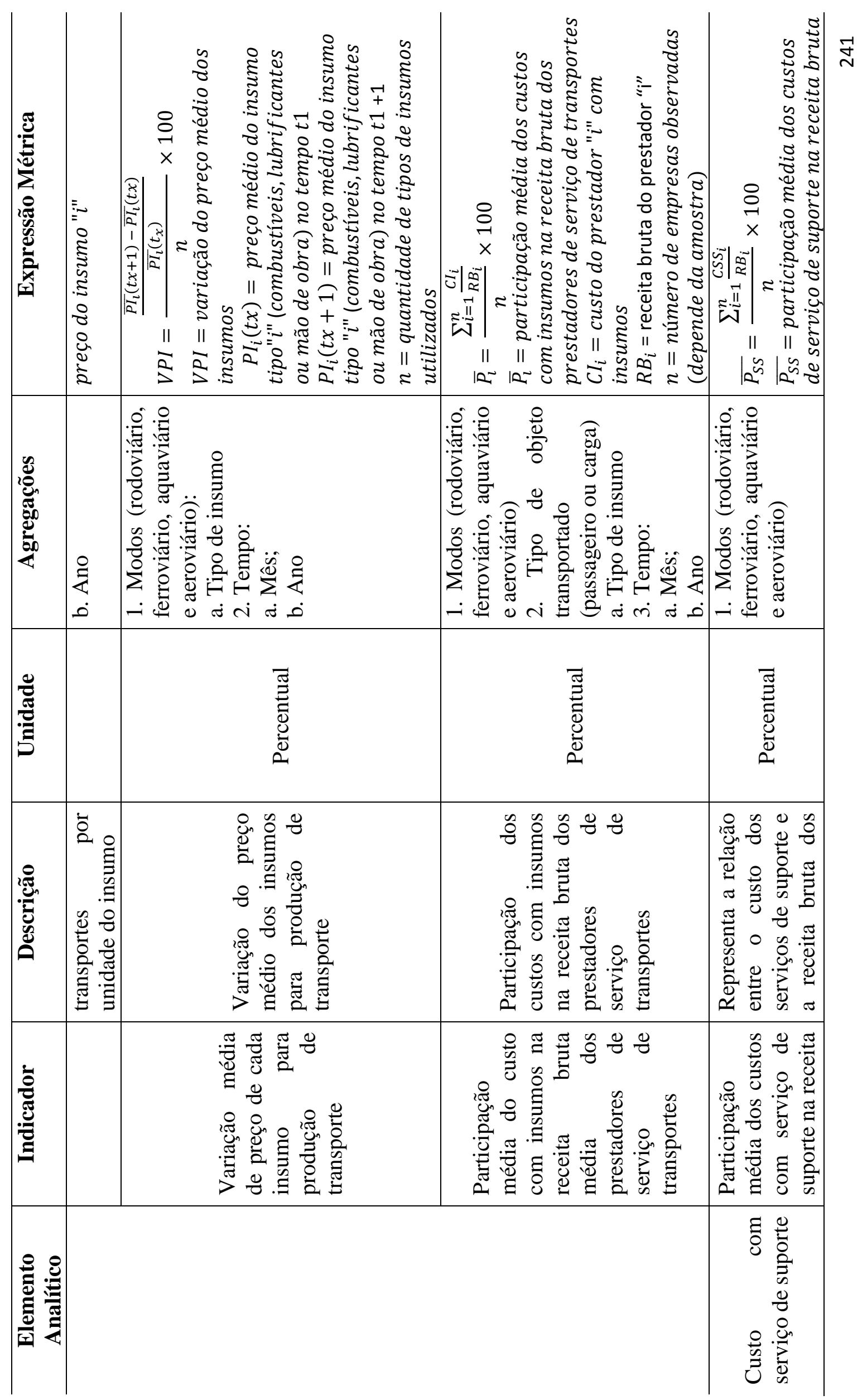




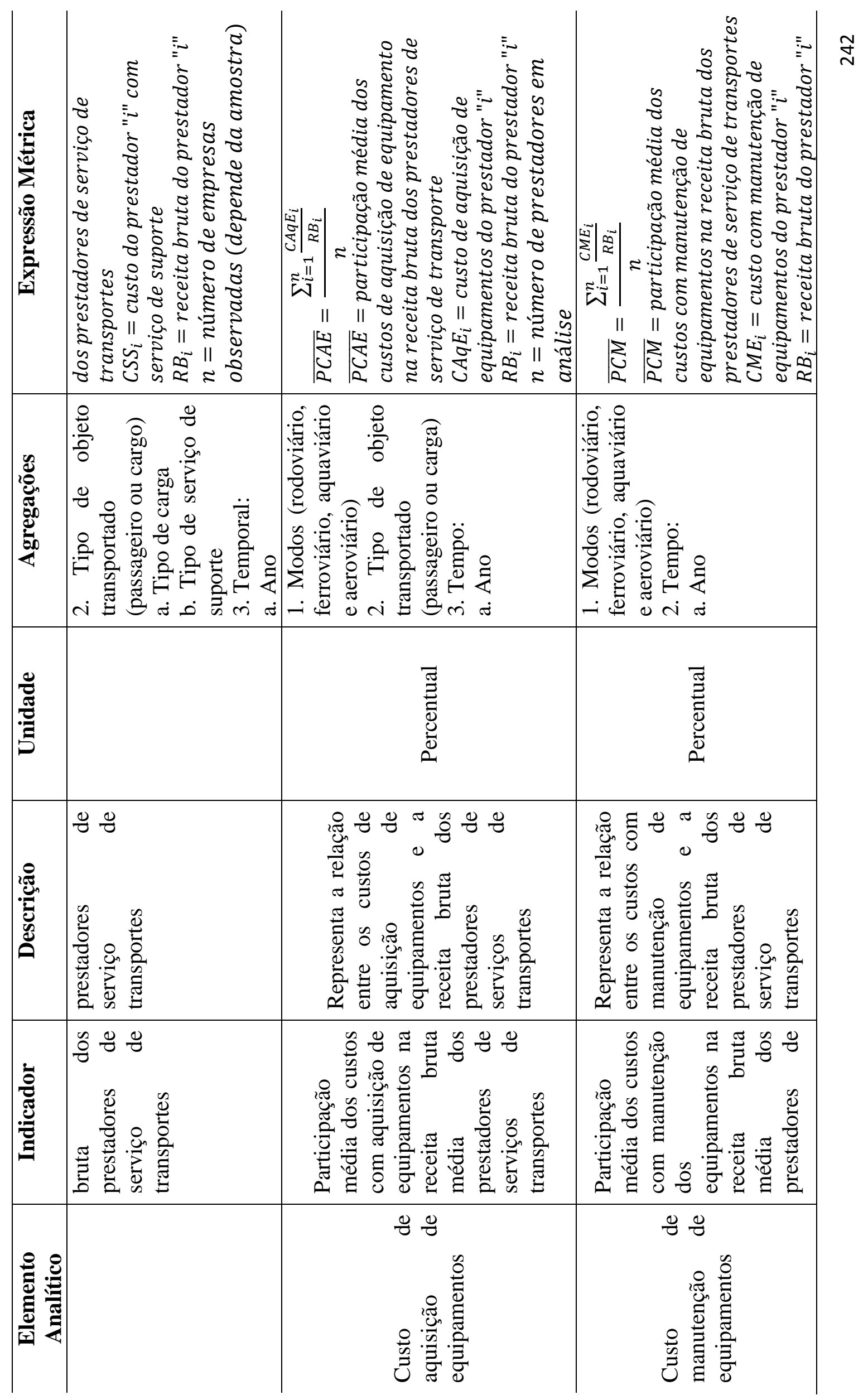




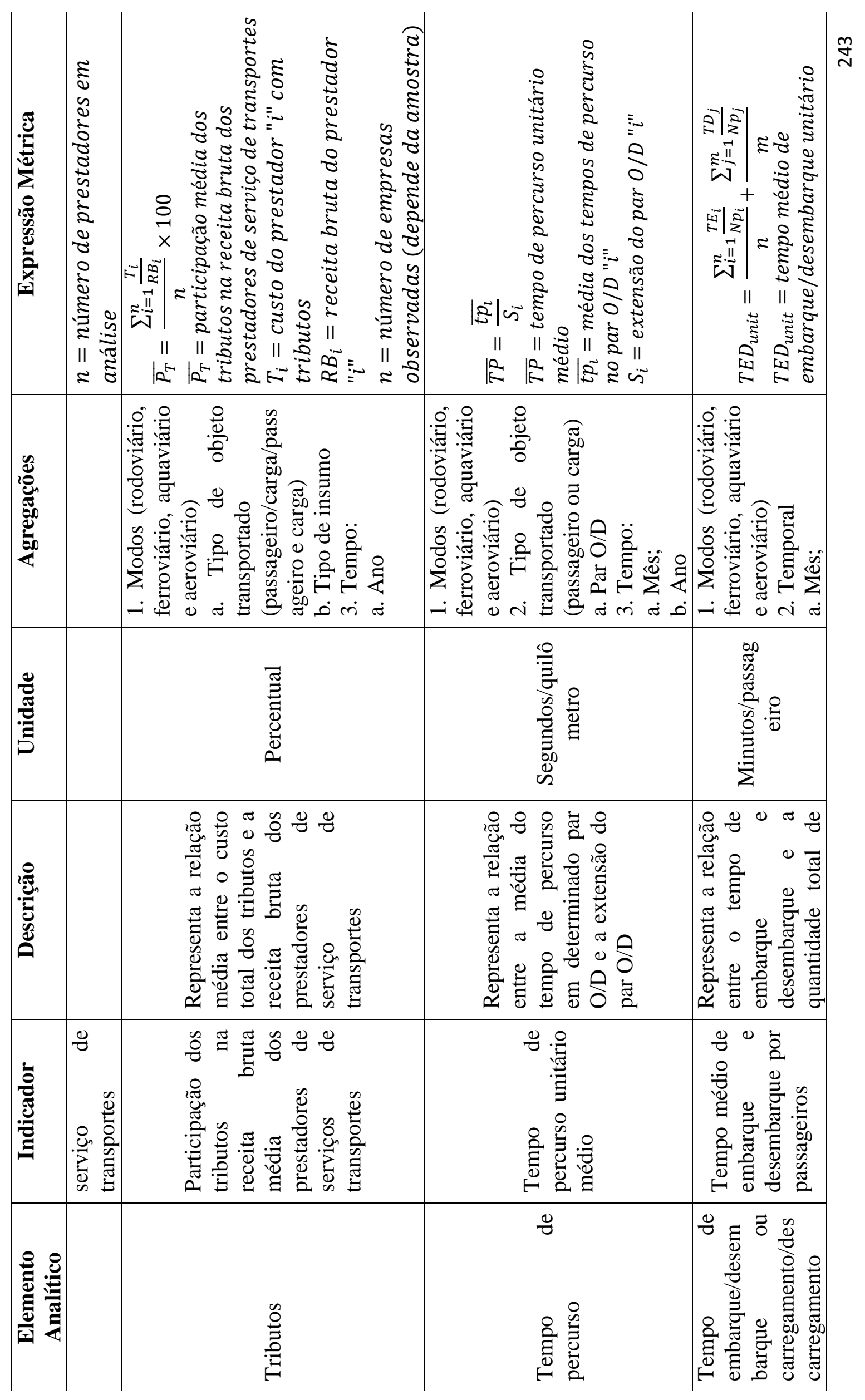




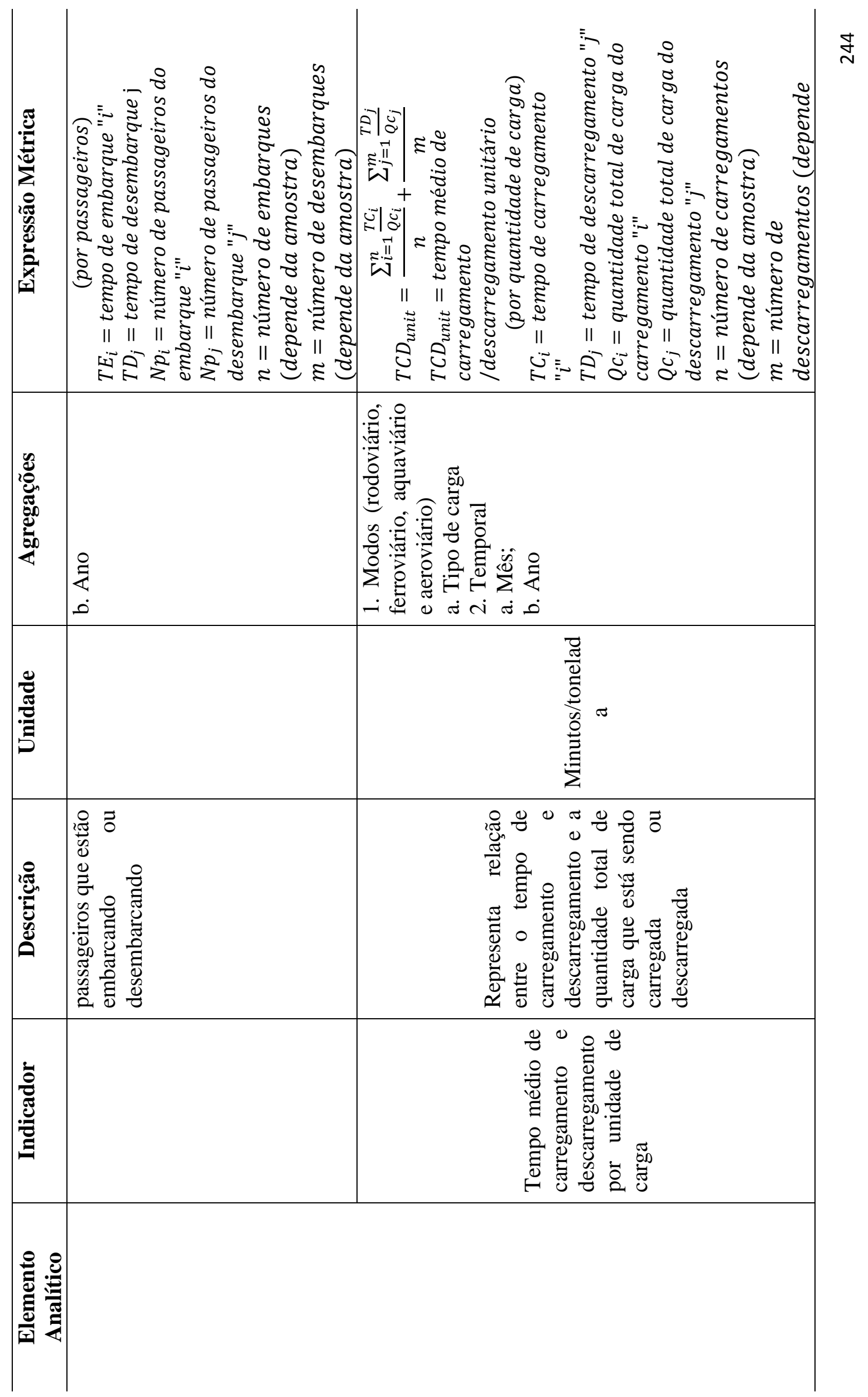




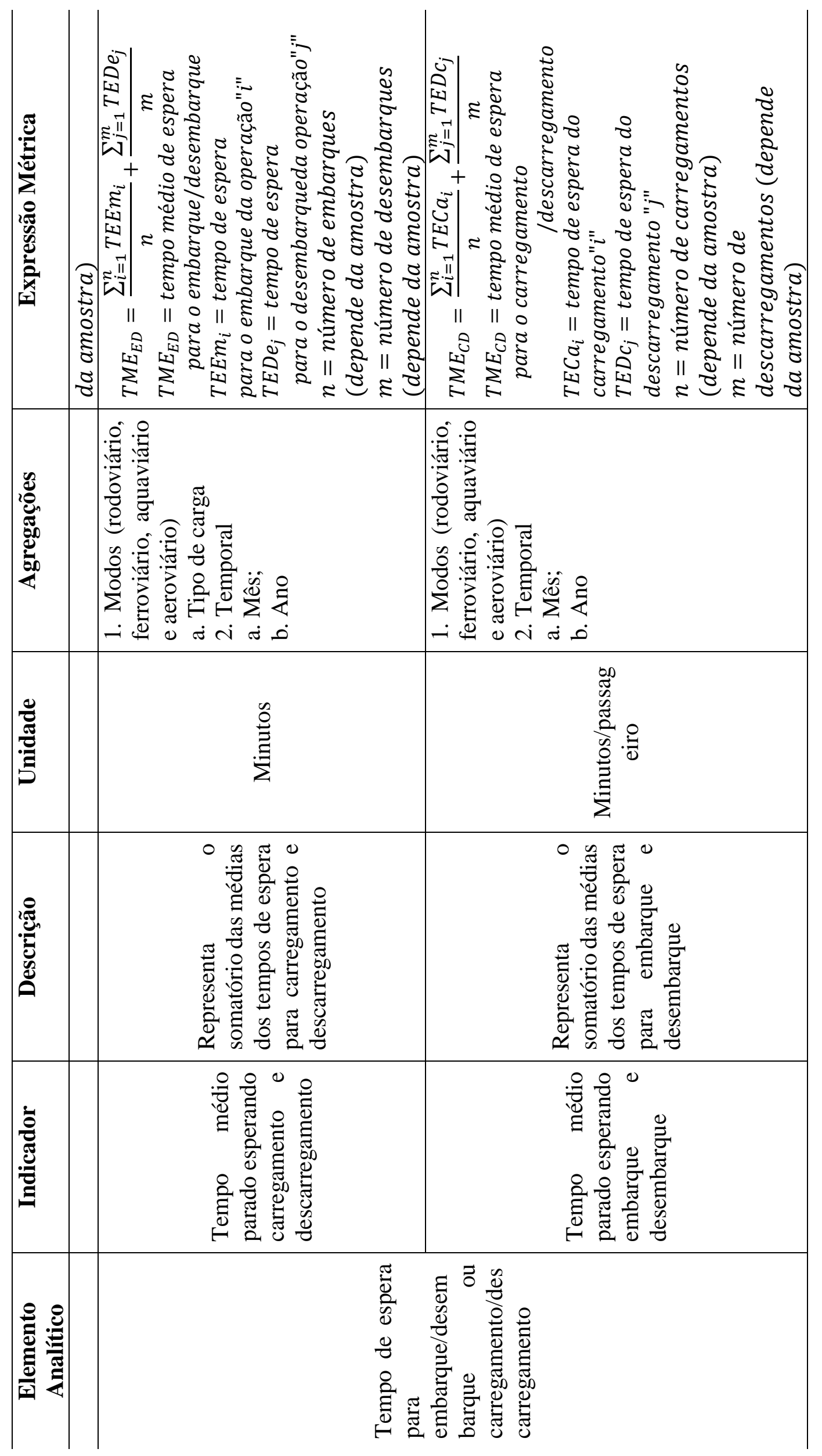

$\stackrel{\sim}{\sim}$ 


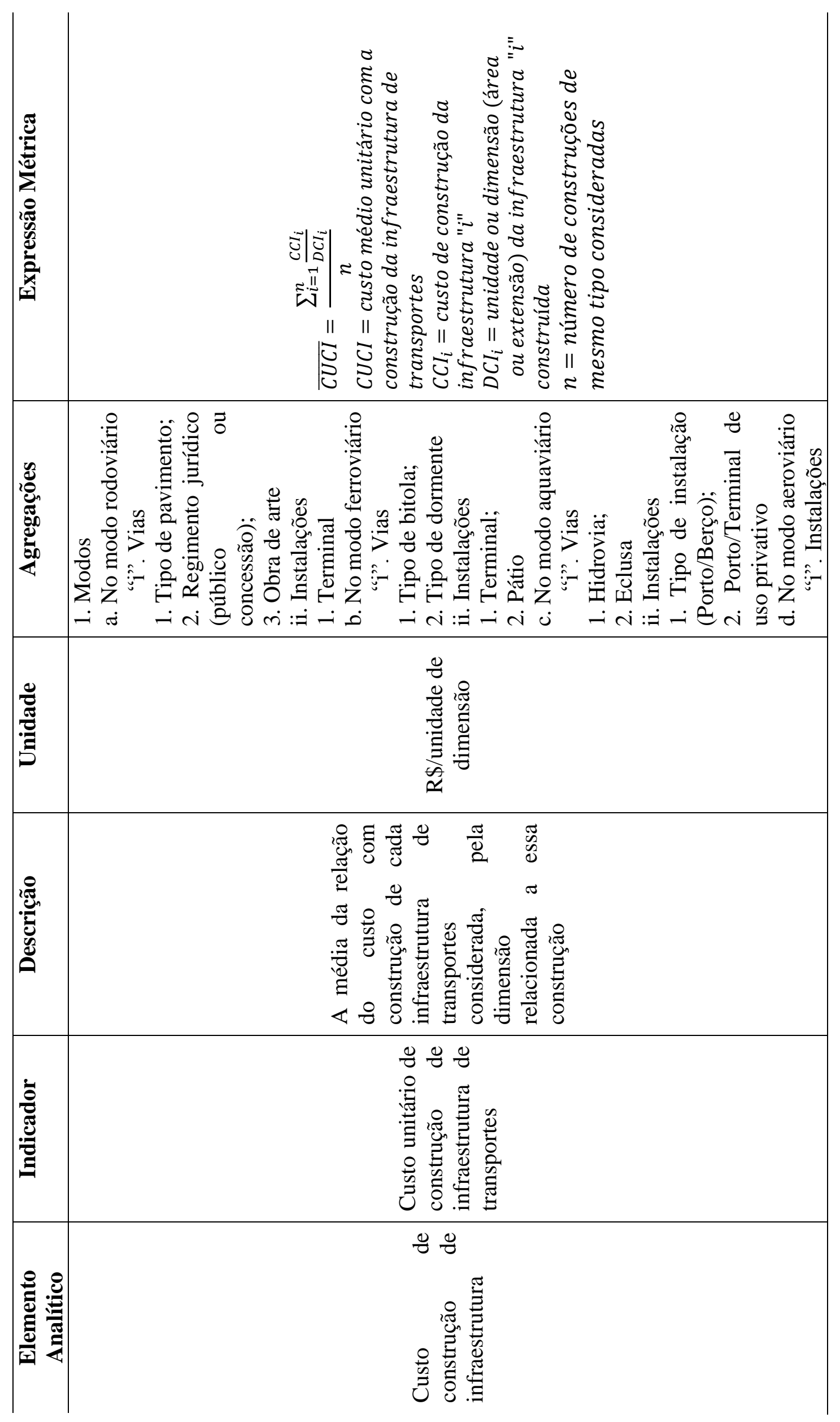




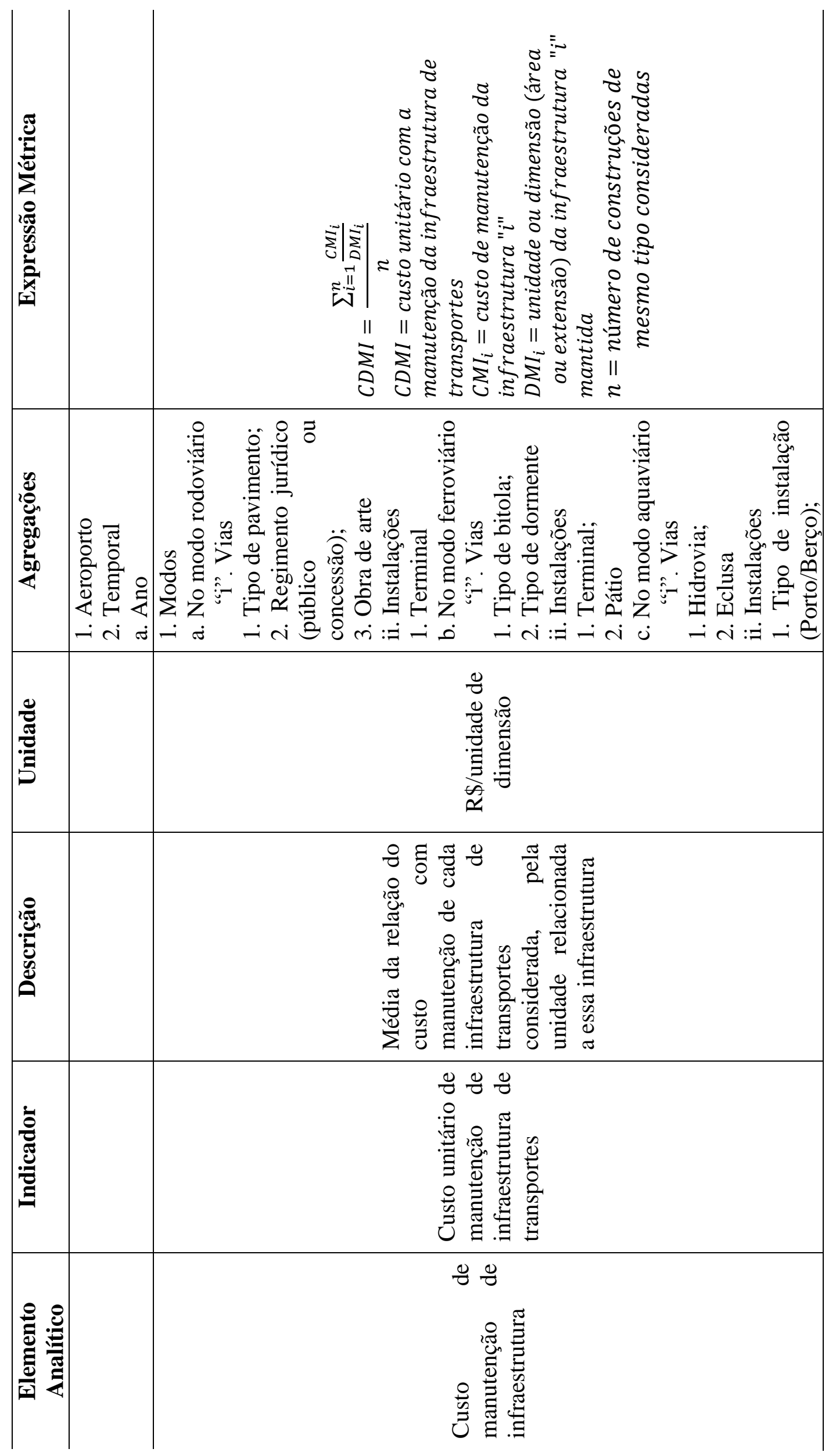

守 


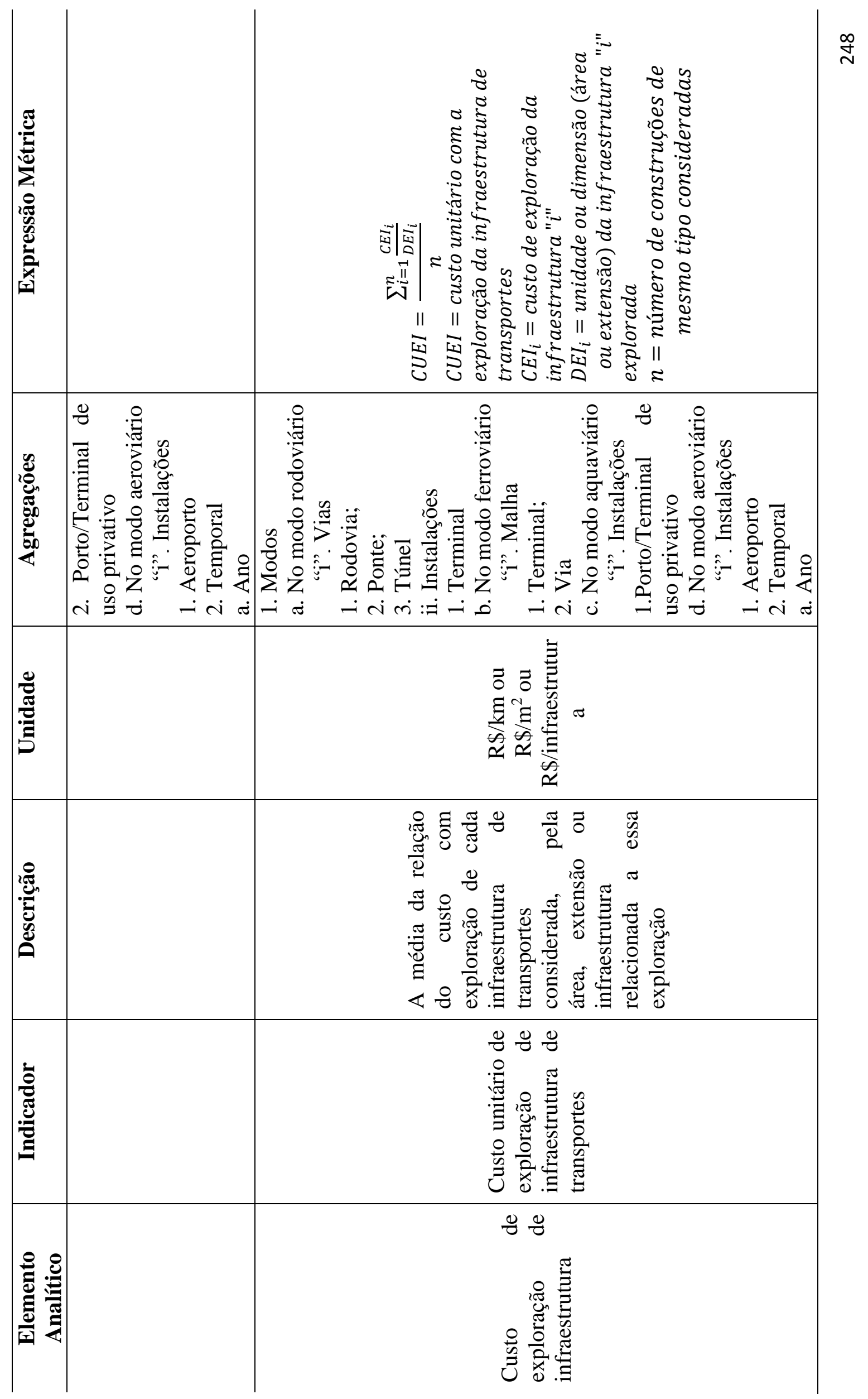




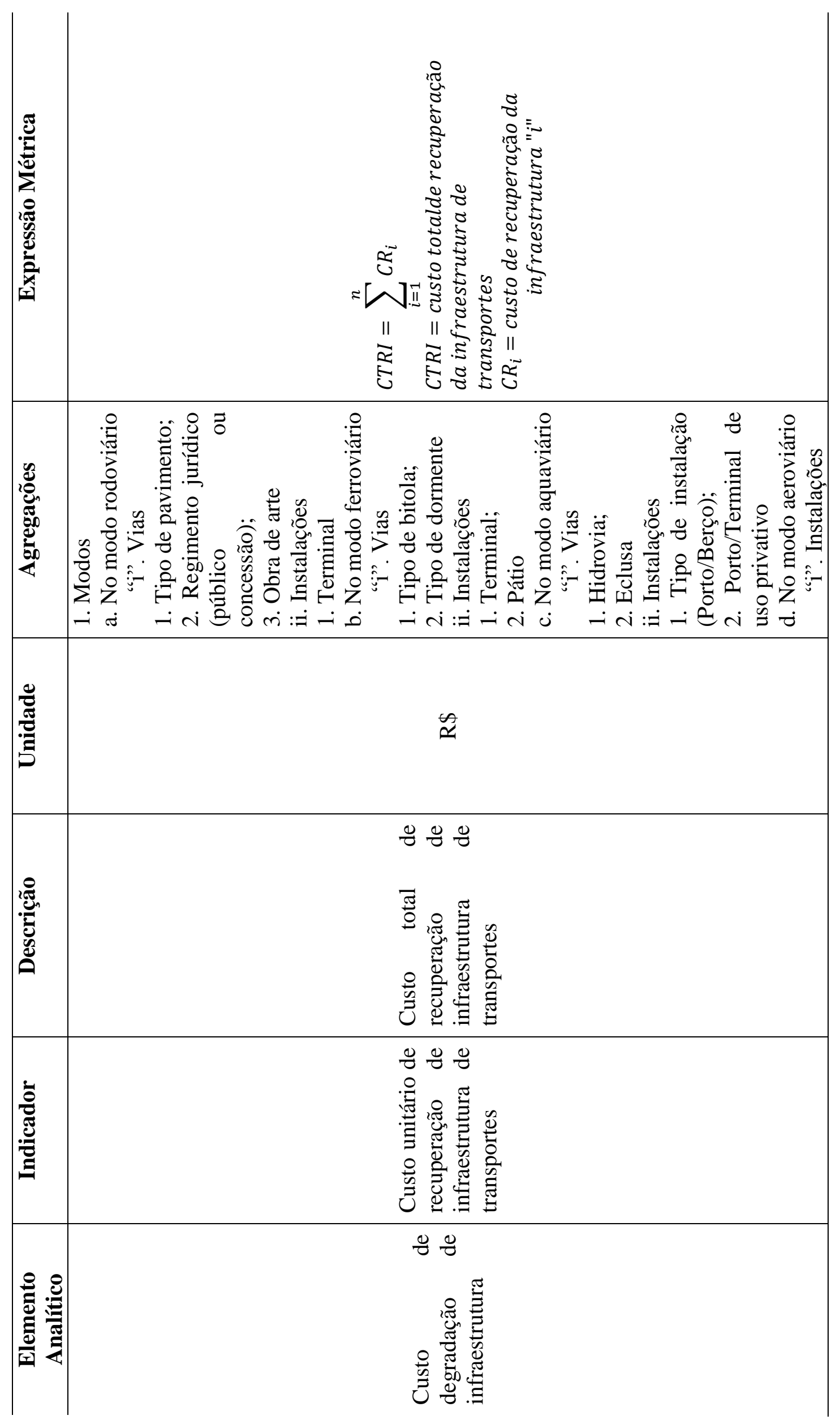

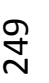




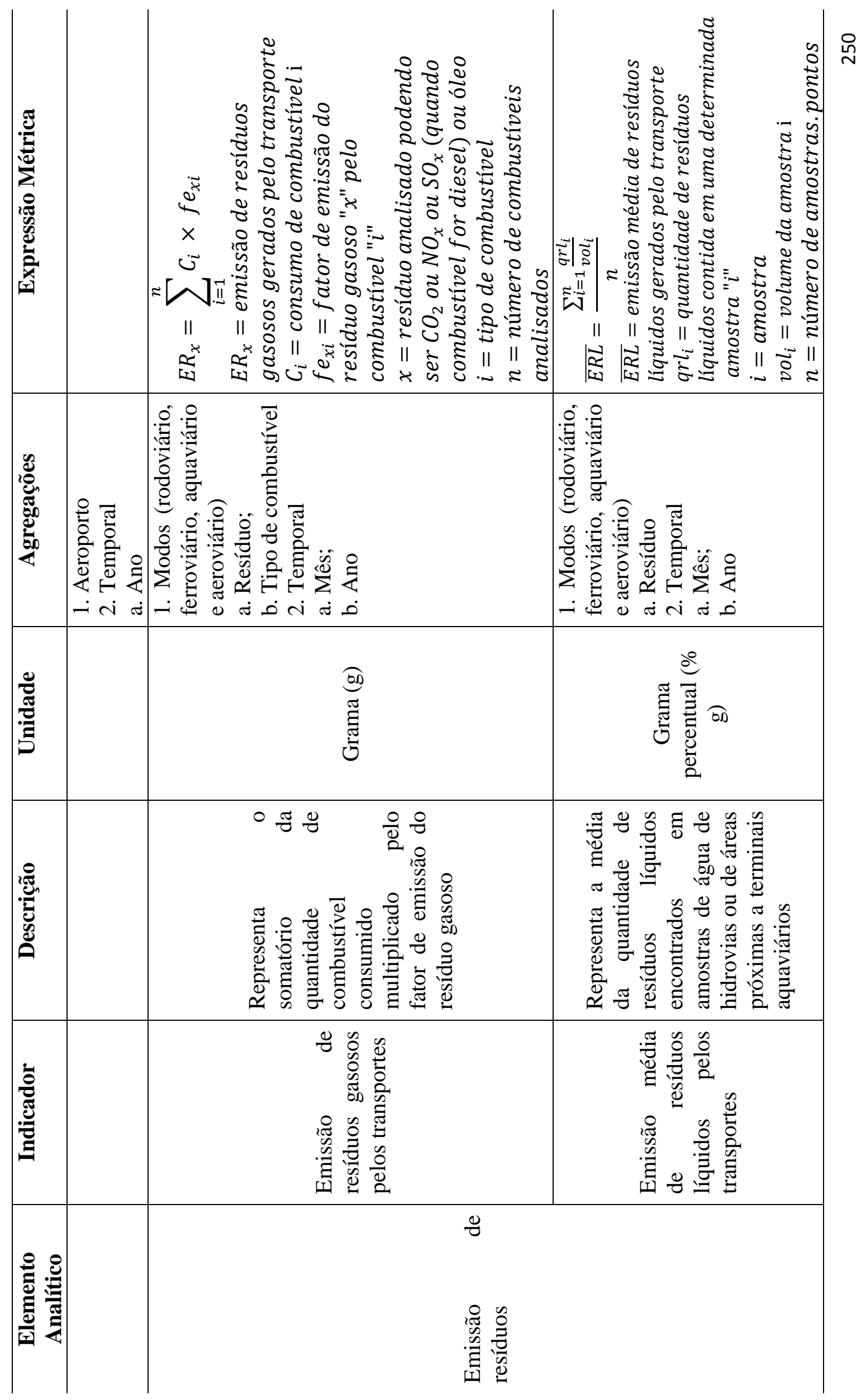




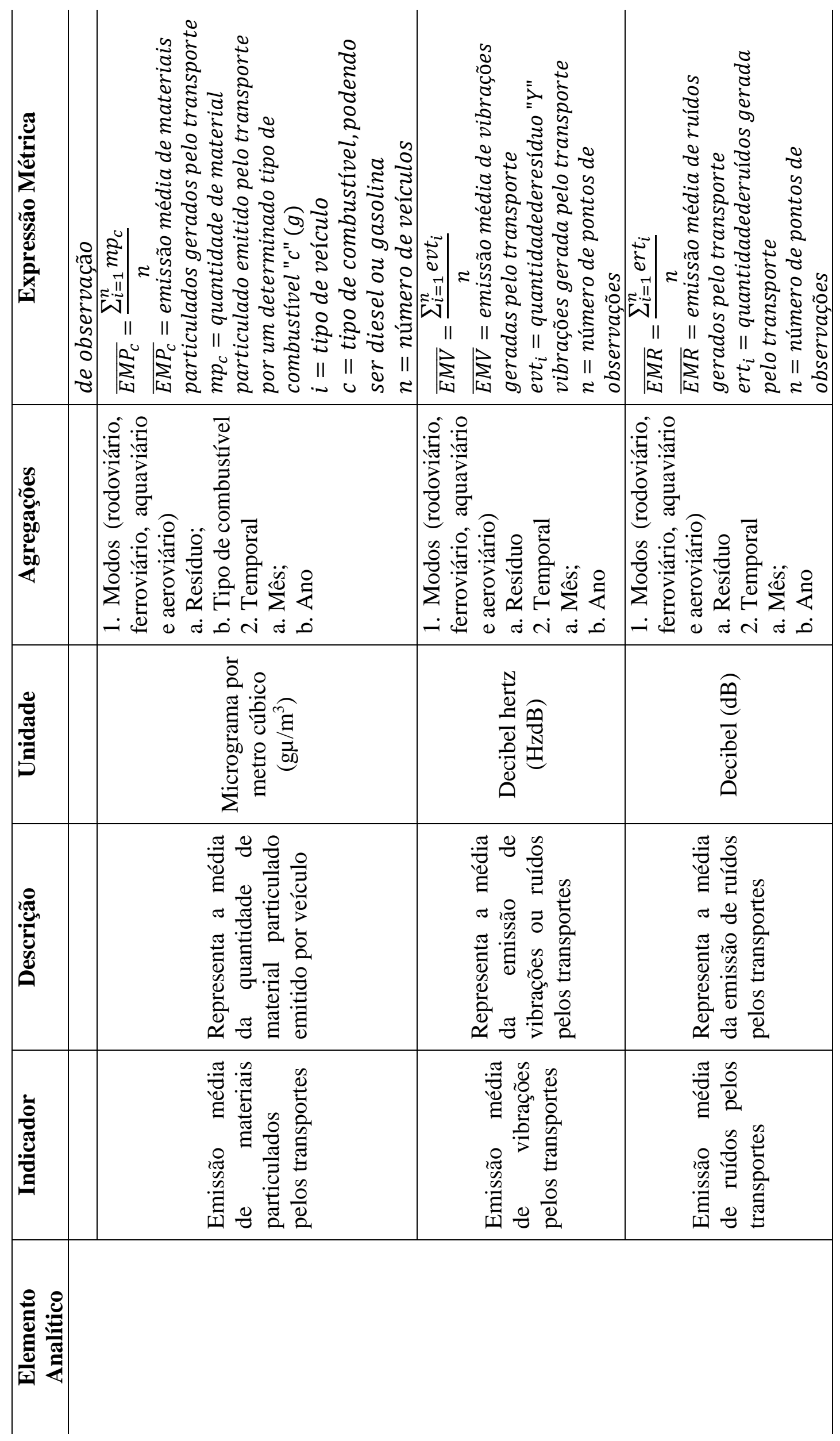




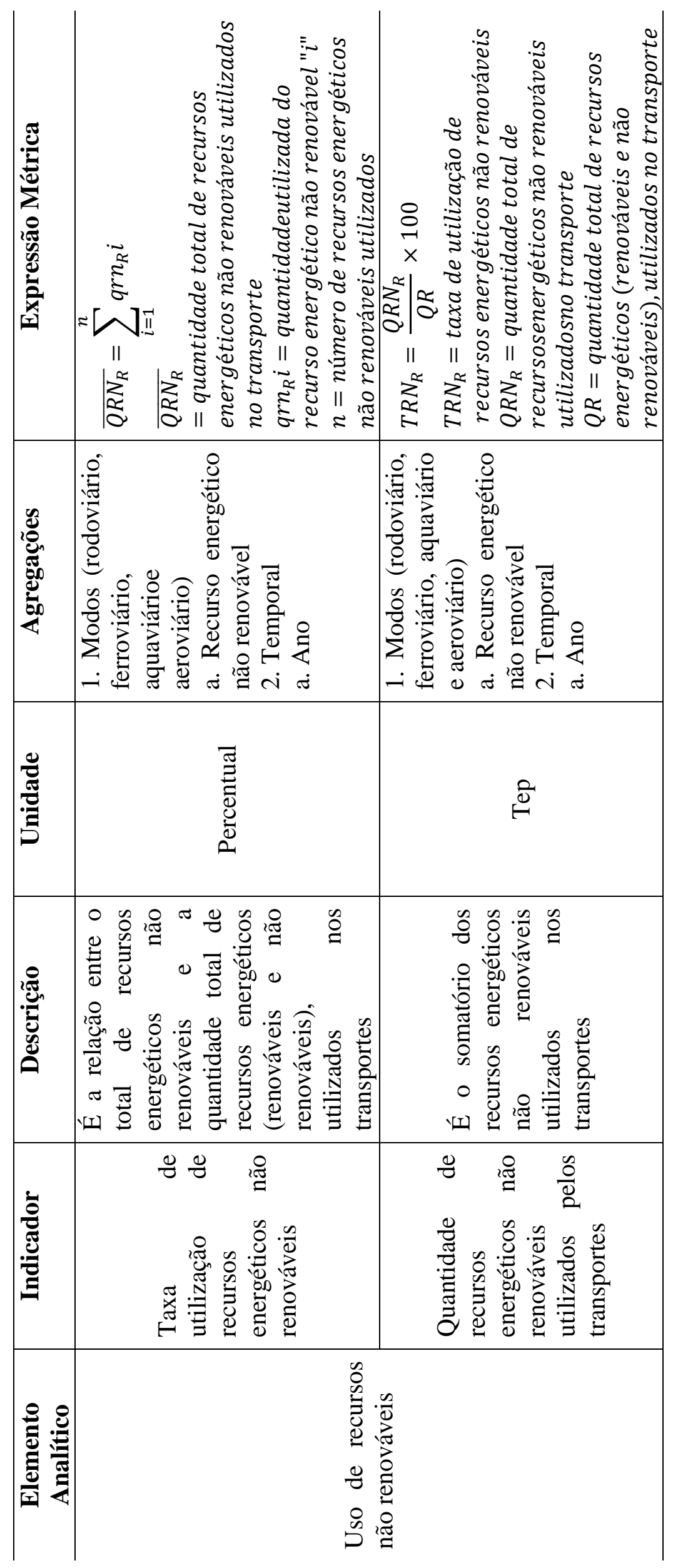

స్ 
Litman (2008b) elaborou um guia para auxiliar na seleção de indicadores de mobilidade sustentável. Por meio da discussão do conceito de sustentabilidade e a função dos indicadores no planejamento, descreve fatores que devem ser considerados durante a escolha de indicadores, como identificar problemas potenciais e apresenta recomendações para situação particulares. Litman (2008b) cita exemplos de conjuntos de indicadores de mobilidade sustentável sociais (Tabela 19), econômicos (Tabela 20) e ambientais (Tabela 21).

Tabela 19: Indicadores Sociais de Mobilidade Sustentável (LITMAN, 2008b)

\begin{tabular}{l|l}
\hline \multicolumn{1}{c|}{ Indicador } & \multicolumn{1}{c}{ Definição } \\
\hline Satisfação do usuário & $\begin{array}{l}\text { Taxa de satisfação do sistema de transporte pelos usuários } \\
\text { desfavorecidos }\end{array}$ \\
\hline Segurança & Acidentes incapacitantes e mortes per capita \\
\hline Exercício físico & $\begin{array}{l}\text { Parcela da população que caminha e pedala suficientemente para se } \\
\text { exercitar contribuindo para a saúde (15 minutos ou mais por dia) }\end{array}$ \\
\hline $\begin{array}{l}\text { Qualidade de vida da } \\
\text { comunidade }\end{array}$ & $\begin{array}{l}\text { Grau em que as atividades de transportes apoiam os objetivos de } \\
\text { qualidade de vida da comunidade (qualidade ambiental local) }\end{array}$ \\
\hline Preservação cultural & $\begin{array}{l}\text { Grau em que os valores culturais e históricos são refletidos e } \\
\text { preservados nas decisões de planejamento dos transportes }\end{array}$ \\
\hline Pedestres & $\begin{array}{l}\text { Qualidade dos serviços de transportes e acessibilidade para os } \\
\text { pedestres }\end{array}$ \\
\hline $\begin{array}{l}\text { Capacidade } \\
\text { pagamento }\end{array}$ & $\begin{array}{l}\text { Percentual dos orçamentos gastos em transporte por famílias de } \\
\text { baixa renda }\end{array}$ \\
\hline $\begin{array}{l}\text { Transporte } \\
\text { motorizado }\end{array}$ & Qualidade de caminhada e condições para pedalar \\
\hline Viagens de crianças & $\begin{array}{l}\text { Porção da viagem de crianças à escola e outros destinos locais a pé } \\
\text { ou de bicicleta }\end{array}$ \\
\hline $\begin{array}{l}\text { Planejamento } \\
\text { inclusivo }\end{array}$ & $\begin{array}{l}\text { Envolvimento substancial de pessoas afetadas, com esforços } \\
\text { especiais para assegurar que os grupos desfavorecidos e vulneráveis } \\
\text { estão envolvidos }\end{array}$ \\
\hline
\end{tabular}

Tabela 20: Indicadores Econômicos de Mobilidade Sustentável (LITMAN, 2008b)

\begin{tabular}{l|l}
\hline \multicolumn{1}{c|}{ Indicador } & \multicolumn{1}{c}{ Definição } \\
\hline Satisfação do usuário & Taxa de satisfação geral dos usuários de transporte \\
\hline Tempo de viagem & Média do tempo de viagem porta a porta \\
\hline Acessibilidade ao trabalho & $\begin{array}{l}\text { Número de empregos e serviços comerciais até 30 minutos de } \\
\text { viagem de distância das residências }\end{array}$ \\
\hline Uso do solo & $\begin{array}{l}\text { Número médio de unidades de serviços básicos (escolas, lojas e } \\
\text { escritórios do governo) com distância caminhável das ou para } \\
\text { as residências }\end{array}$ \\
\hline Comunicação eletrônica & Porção da população com acesso à internet \\
\hline $\begin{array}{l}\text { Viagens por veículos } \\
\text { motorizados }\end{array}$ & $\begin{array}{l}\text { Milhas percorridas por veículos motorizados, per capita, } \\
\text { particularmente em condições de horário de pico }\end{array}$ \\
\hline
\end{tabular}




\begin{tabular}{|c|c|}
\hline Indicador & Definição \\
\hline Diversidade de transportes & $\begin{array}{l}\text { Variedade e qualidade de opções de transporte disponíveis em } \\
\text { uma comunidade }\end{array}$ \\
\hline Divisão modal & $\begin{array}{l}\text { Porção de viagens realizadas por transporte não motorizado: } \\
\text { caminhadas, ciclismo, compartilhamento de veículos, } \\
\text { transporte público e "teletrabalho" }\end{array}$ \\
\hline $\begin{array}{l}\text { Atrasos causados por } \\
\text { congestionamentos }\end{array}$ & Atrasos causados por congestionamentos per capita \\
\hline Custos de viagem & Parcela dos gastos familiares dedicados ao transporte \\
\hline $\begin{array}{l}\text { Eficiência dos custos de } \\
\text { transportes }\end{array}$ & $\begin{array}{l}\text { Custos de transporte como uma parcela da atividade econômica } \\
\text { total e por unidade do PIB }\end{array}$ \\
\hline Custos de infraestrutura & $\begin{array}{l}\text { Gastos com vias, estacionamentos e serviços de tráfego per } \\
\text { capita }\end{array}$ \\
\hline Eficiência dos custos & $\begin{array}{l}\text { Gastos com vias e estacionamentos suportados diretamente } \\
\text { pelos usuários }\end{array}$ \\
\hline $\begin{array}{l}\text { Eficiência do transporte de } \\
\text { carga }\end{array}$ & Velocidade e custo do transporte de carga \\
\hline Serviços de entrega & $\begin{array}{l}\text { Quantidade e qualidade dos serviços de entrega (correio } \\
\text { internacional e nacional e lojas que oferecem este serviço) }\end{array}$ \\
\hline Transporte comercial & $\begin{array}{l}\text { Qualidade dos serviços de transporte para os usuários de } \\
\text { comércio (empresas, órgãos públicos, turistas, participantes de } \\
\text { convenções, etc.) }\end{array}$ \\
\hline Custos de colisões & Custos de colisões per capita \\
\hline $\begin{array}{l}\text { Qualidade } \\
\text { planejamento }\end{array}$ & $\begin{array}{l}\text { Abrangência do processo de planejamento: se este considera } \\
\text { que todos os impactos significativos e utiliza as práticas de } \\
\text { avaliação mais atuais }\end{array}$ \\
\hline $\begin{array}{l}\text { Gerenciamento } \\
\text { mobilidade }\end{array}$ & $\begin{array}{l}\text { Implementação de programas de gestão de mobilidade visando } \\
\text { solucionar problemas e aumentar a eficiência do sistema de } \\
\text { transportes }\end{array}$ \\
\hline Medidas restritivas & $\begin{array}{l}\text { Implementação de medidas restritivas tais como taxas de } \\
\text { congestionamento, taxas de estacionamento, etc. }\end{array}$ \\
\hline $\begin{array}{l}\text { Planejamento do uso do } \\
\text { solo }\end{array}$ & $\begin{array}{l}\text { Aplicação da prática de planejamento da expansão do uso do } \\
\text { solo inteligente, resultando em comunidades multimodais mais } \\
\text { acessíveis }\end{array}$ \\
\hline
\end{tabular}

Tabela 21: Indicadores Ambientais de Mobilidade Sustentável (LITMAN, 2008b)

\begin{tabular}{l|l}
\hline \multicolumn{1}{c|}{ Indicador } & \multicolumn{1}{c}{ Definição } \\
\hline $\begin{array}{l}\text { Emissões da mudança } \\
\text { climática }\end{array}$ & $\begin{array}{l}\text { Consumo de combustível per capita e emissões de } \mathrm{CO}_{2} \text { e outras } \\
\text { emissões causadoras da mudança climática }\end{array}$ \\
\hline $\begin{array}{l}\text { Outras poluições } \\
\text { atmosféricas }\end{array}$ & $\begin{array}{l}\text { Emissão de poluentes convencionais per capita }\left(\mathrm{CO}, \mathrm{VOC}, \mathrm{NO}_{\mathrm{x}},\right. \\
\text { particulados, etc) }\end{array}$ \\
\hline Poluição do ar & Frequência da violação dos padrões de poluição do ar \\
\hline Poluição sonora & $\begin{array}{l}\text { Porção da população exposta a altos níveis de ruído devido ao } \\
\text { tráfego }\end{array}$ \\
\hline Poluição da água & Perda de fluidos de veículos per capita \\
\hline Impactos no uso do solo & Solo utilizado por instalações de transporte per capita \\
\hline Proteção do Habitat & $\begin{array}{l}\text { Preservação de habitats de alta qualidade de vida selvagem (zonas } \\
\text { úmidas, florestas, etc.) }\end{array}$ \\
\hline
\end{tabular}




\begin{tabular}{l|l}
\hline \multicolumn{1}{c|}{ Indicador } & \multicolumn{1}{c}{ Definição } \\
\hline $\begin{array}{l}\text { Fragmentação do } \\
\text { Habitat }\end{array}$ & $\begin{array}{l}\text { Tamanho médio de áreas preservadas para a fauna silvestre, sem a } \\
\text { existência de rodovias }\end{array}$ \\
\hline Eficiência de recursos & $\begin{array}{l}\text { Consumo de recursos não renováveis na produção e uso de } \\
\text { veículos e facilidades de transportes }\end{array}$ \\
\hline
\end{tabular}

As Tabelas 22, 23 e 24 apresentam os indicadores de mobilidade sustentável desenvolvidos pelo projeto patrocinado pela Comissão Europeia denominado "Medidas de Mobilidade Sustentável e Avaliação" (Sustainable Mobility Measures and Assessment SUMMA) para avaliar a dimensão dos problemas de sustentabilidade associados ao transporte, identificar medidas políticas para promover o transporte sustentável e desenvolver um sistema de indicadores para monitorar a sustentabilidade do setor de transporte (EUROPEAN COMMISSION, 2005).

Tabela 22: Indicadores econômicos de mobilidade sustentável (EUROPEAN COMMISSION, 2005).

\begin{tabular}{|c|c|c|c|}
\hline $\begin{array}{c}\text { Área de } \\
\text { Interesse }\end{array}$ & $\begin{array}{l}\text { Nome do } \\
\text { Indicador }\end{array}$ & Definição do Indicador & Unidade \\
\hline \multirow{4}{*}{ Acessibilidade } & $\begin{array}{l}\text { Instalações de } \\
\text { terminais } \\
\text { intermodais }\end{array}$ & $\begin{array}{l}\text { Instalações de terminais com } \\
\text { acesso por sistema intermodal } \\
\text { de tráfego (rodoviário, } \\
\text { ferroviário, aquaviário) }\end{array}$ & $\begin{array}{c}\text { Percentual de } \\
\text { terminais com } \\
\text { acesso por mais de } \\
\text { uma modalidade }\end{array}$ \\
\hline & $\begin{array}{c}\text { Acessibilidade } \\
\text { de origens e } \\
\text { destinos } \\
\end{array}$ & $\begin{array}{c}\text { Índice de acessibilidade entre } \\
\text { centros econômicos importantes } \\
\text { e regiões por modalidade }\end{array}$ & Índice (valor) \\
\hline & $\begin{array}{c}\text { Acesso a } \\
\text { serviços básicos }\end{array}$ & $\begin{array}{c}\text { Tempo médio de viagem } \\
\text { familiar para a realização das } \\
\text { finalidades básicas }\end{array}$ & Minuto \\
\hline & $\begin{array}{l}\text { Acesso ao } \\
\text { transporte } \\
\text { público }\end{array}$ & $\begin{array}{l}\text { Percentual de famílias a uma } \\
\text { distância de } 5 \text { minutos de uma } \\
\text { parada de transporte público }\end{array}$ & $\begin{array}{l}\text { Percentual de } \\
\text { domicílios }\end{array}$ \\
\hline \multirow{4}{*}{$\begin{array}{l}\text { Custos } \\
\text { Operacionais } \\
\text { de Transportes }\end{array}$} & $\begin{array}{c}\text { Custos } \\
\text { operacionais }\end{array}$ & $\begin{array}{l}\text { Custos monetários do operador } \\
\text { de transporte (componentes fixa } \\
\text { e variável) }\end{array}$ & Euros por ano \\
\hline & $\begin{array}{c}\text { Gastos familiares } \\
\text { com transportes }\end{array}$ & $\begin{array}{l}\text { Média de gastos de transporte } \\
\text { relacionada com o tipo de } \\
\text { família }\end{array}$ & $\begin{array}{l}\text { Percentual de } \\
\text { gastos }\end{array}$ \\
\hline & \multirow[t]{2}{*}{$\begin{array}{l}\text { Preços do } \\
\text { Transporte }\end{array}$} & \multirow[t]{2}{*}{$\begin{array}{c}\text { Preço do transporte por } \\
\text { passageiro por modalidade }\end{array}$} & $\begin{array}{c}\text { Euros por } \\
\text { passageiro por } \\
\text { quilômetro } \\
\text { (transporte } \\
\text { público) }\end{array}$ \\
\hline & & & $\begin{array}{c}\text { Euros por veículo } \\
\text { por quilômetro }\end{array}$ \\
\hline
\end{tabular}




\begin{tabular}{|c|c|c|c|}
\hline $\begin{array}{l}\text { Área de } \\
\text { Interesse }\end{array}$ & $\begin{array}{l}\text { Nome do } \\
\text { Indicador }\end{array}$ & Definição do Indicador & Unidade \\
\hline & & & $\begin{array}{l}\text { (transporte } \\
\text { privado) }\end{array}$ \\
\hline & & $\begin{array}{l}\text { Preço do transporte de carga por } \\
\text { modalidade }\end{array}$ & $\begin{array}{l}\text { Euros por tonelada } \\
\text { por quilômetro }\end{array}$ \\
\hline \multirow{8}{*}{$\begin{array}{l}\text { Eficiência da } \\
\text { produtividade }\end{array}$} & $\begin{array}{c}\text { Custos do } \\
\text { transporte de } \\
\text { carga } \\
\text { relacionados } \\
\text { com os custos } \\
\text { dos produtos } \\
\end{array}$ & $\begin{array}{l}\text { Percentagem média dos custos } \\
\text { de transporte de carga no custo } \\
\text { do produto por setor }\end{array}$ & $\begin{array}{l}\text { Percentual dos } \\
\text { custos dos } \\
\text { produtos }\end{array}$ \\
\hline & \multirow{4}{*}{$\begin{array}{l}\text { Taxas de } \\
\text { utilização }\end{array}$} & \multirow{2}{*}{$\begin{array}{c}\text { Taxa média de ocupação dos } \\
\text { veículos }\end{array}$} & $\begin{array}{c}\text { Número de } \\
\text { passageiros por } \\
\text { viagem por } \\
\text { veículo (transporte } \\
\text { particular) } \\
\end{array}$ \\
\hline & & & $\begin{array}{l}\text { Percentual de } \\
\text { capacidade } \\
\text { (transporte } \\
\text { público) }\end{array}$ \\
\hline & & $\begin{array}{c}\text { Taxa média de carregamento } \\
\text { dos veículos de carga }\end{array}$ & $\begin{array}{l}\text { Percentual de } \\
\text { capacidade }\end{array}$ \\
\hline & & $\begin{array}{l}\text { Taxa média de utilização dos } \\
\text { terminais de transbordo }\end{array}$ & $\begin{array}{l}\text { Percentual de } \\
\text { capacidade }\end{array}$ \\
\hline & $\begin{array}{l}\text { Eficiência do } \\
\text { consumo de } \\
\text { energia do setor } \\
\text { de transportes }\end{array}$ & $\begin{array}{l}\text { Consumo de energia por } \\
\text { unidade do PIB gerado pelo } \\
\text { setor de transportes }\end{array}$ & Joule/Euro PIB \\
\hline & \multirow{2}{*}{$\begin{array}{l}\text { Eficiência } \\
\text { energética }\end{array}$} & $\begin{array}{l}\text { Intensidade do consumo de } \\
\text { energia do transporte de } \\
\text { passageiro por modalidade }\end{array}$ & $\begin{array}{c}\text { Toneladas de óleo } \\
\text { equivalente } \\
\text { (toe)/passageiro } \\
\text { por quilômetro }\end{array}$ \\
\hline & & $\begin{array}{l}\text { Intensidade do consumo de } \\
\text { energia do transporte de carga } \\
\text { por modalidade }\end{array}$ & $\begin{array}{l}\text { Toneladas de óleo } \\
\text { equivalente } \\
\text { (toe)/toneladas- } \\
\text { quilômetros }\end{array}$ \\
\hline \multirow{3}{*}{$\begin{array}{c}\text { Custos para a } \\
\text { economia }\end{array}$} & \multirow{3}{*}{$\begin{array}{c}\text { Custos de } \\
\text { infraestrutura }\end{array}$} & \multirow{2}{*}{$\begin{array}{l}\text { Custos públicos e privados de } \\
\text { construção no sistema de tráfego } \\
\text { por modalidade }\end{array}$} & $\begin{array}{l}\text { Euros por } \\
\text { quilômetro por } \\
\text { ano (rede de } \\
\text { tráfego) }\end{array}$ \\
\hline & & & $\begin{array}{l}\text { Euros por tonelada } \\
\text { por ano (terminais } \\
\text { de transbordo) }\end{array}$ \\
\hline & & $\begin{array}{l}\text { Custos públicos e privados de } \\
\text { melhoria e manutenção no } \\
\text { sistema de tráfego por } \\
\text { modalidade }\end{array}$ & $\begin{array}{l}\text { Euros por } \\
\text { quilômetro por } \\
\text { ano (rede de } \\
\text { tráfego) }\end{array}$ \\
\hline
\end{tabular}




\begin{tabular}{|c|c|c|c|}
\hline $\begin{array}{l}\text { Área de } \\
\text { Interesse }\end{array}$ & $\begin{array}{l}\text { Nome do } \\
\text { Indicador }\end{array}$ & Definição do Indicador & Unidade \\
\hline & & & $\begin{array}{c}\text { Euros por tonelada } \\
\text { por ano (terminais } \\
\text { de transbordo) } \\
\end{array}$ \\
\hline & $\begin{array}{l}\text { Subsídios } \\
\text { públicos }\end{array}$ & $\begin{array}{c}\text { Gastos públicos/investimentos } \\
\text { em transporte e mobilidade no } \\
\text { setor (exemplos: } \\
\text { desenvolvimento de veículos, } \\
\text { tecnologias embarcadas, } \\
\text { informações de mobilidade, } \\
\text { tecnologia de comunicação, } \\
\text { pesquisa e operação de } \\
\text { transporte }\end{array}$ & Euros por ano \\
\hline & & $\begin{array}{c}\text { Custos de acidentes por } \\
\text { modalidade }\end{array}$ & Euros por ano \\
\hline & $\begin{array}{l}\text { Custos de } \\
\text { transporte }\end{array}$ & $\begin{array}{l}\text { Custos de atraso devido a } \\
\text { congestionamentos }\end{array}$ & Euros por ano \\
\hline & & $\begin{array}{c}\text { Custos ambientais por } \\
\text { modalidade }\end{array}$ & Euros por ano \\
\hline & & $\begin{array}{l}\text { Consumo final energético do } \\
\text { setor de transportes por } \\
\text { modalidade e por uso de energia }\end{array}$ & $\begin{array}{c}\text { Milhão de } \\
\text { toneladas de óleo } \\
\text { equivalentes }\end{array}$ \\
\hline & energético & $\begin{array}{c}\text { Percentual do consumo } \\
\text { energético final do setor de } \\
\text { transportes produzido por fontes } \\
\text { renováveis de energia }\end{array}$ & Percentual \\
\hline \multirow{4}{*}{$\begin{array}{c}\text { Benefícios para } \\
\text { a economia }\end{array}$} & $\begin{array}{c}\text { Valor } \\
\text { acrescentado } \\
\text { bruto } \\
\end{array}$ & $\begin{array}{c}\text { Percentual de valor bruto } \\
\text { acrescentado na economia } \\
\text { gerado pelo setor de transportes }\end{array}$ & $\begin{array}{l}\text { Percentual do } \\
\text { acréscimo }\end{array}$ \\
\hline & \multirow{2}{*}{$\begin{array}{l}\text { Receitas públicas } \\
\text { provenientes de } \\
\text { impostos e taxas } \\
\text { do sistema de } \\
\text { tráfego }\end{array}$} & $\begin{array}{c}\text { Receitas públicas provenientes } \\
\text { de taxas do sistema de tráfego } \\
\text { (instrumentos e taxas de } \\
\text { utilização) }\end{array}$ & Euros por ano \\
\hline & & $\begin{array}{l}\text { Receitas públicas provenientes } \\
\text { de taxas do setor de transportes } \\
\text { (petróleo, veículos e taxas de } \\
\text { emissão) }\end{array}$ & Euros por ano \\
\hline & $\begin{array}{l}\text { Benefícios do } \\
\text { transporte }\end{array}$ & $\begin{array}{l}\text { Crescimento positivo indireto e } \\
\text { efeitos estruturais gerados pelo } \\
\text { setor de transportes }\end{array}$ & Euros por ano \\
\hline
\end{tabular}


Tabela 23: Indicadores ambientais de mobilidade sustentável (EUROPEAN COMMISSION, 2005)

\begin{tabular}{|c|c|c|c|}
\hline $\begin{array}{l}\text { Área de } \\
\text { Interesse }\end{array}$ & Nome do Indicador & Definição do Indicador & Unidade \\
\hline \multirow{6}{*}{$\begin{array}{l}\text { Uso de } \\
\text { recurso }\end{array}$} & \multirow{2}{*}{ Consumo energético } & $\begin{array}{l}\text { Consumo final energético do } \\
\text { setor de transportes por } \\
\text { modalidade e por fonte de } \\
\text { energia }\end{array}$ & $\begin{array}{c}\text { Milhão de } \\
\text { toneladas de óleo } \\
\text { equivalentes }\end{array}$ \\
\hline & & $\begin{array}{l}\text { Percentual do consumo } \\
\text { energético final do setor de } \\
\text { transportes produzido por } \\
\text { fontes renováveis de energia }\end{array}$ & $\begin{array}{c}\text { Milhão de } \\
\text { toneladas de óleo } \\
\text { equivalentes }\end{array}$ \\
\hline & \multirow{2}{*}{$\begin{array}{l}\text { Consumo de matéria } \\
\text { prima de materiais } \\
\text { sólidos }\end{array}$} & $\begin{array}{c}\text { Matérias primas utilizadas na } \\
\text { construção de infraestrutura } \\
\text { de transporte por tipo de } \\
\text { material }\end{array}$ & Toneladas \\
\hline & & $\begin{array}{c}\text { Matérias primas utilizadas } \\
\text { em veículos manufaturados } \\
\text { por tipo de material }\end{array}$ & Toneladas \\
\hline & \multirow[b]{2}{*}{ Ocupação do solo } & $\begin{array}{c}\text { Ocupação do solo por } \\
\text { infraestrutura de transporte } \\
\text { por modalidade }\end{array}$ & $\mathrm{km}^{2}$ \\
\hline & & $\begin{array}{c}\text { Percentual de ocupação do } \\
\text { solo por infraestrutura de } \\
\text { transportes por modalidade } \\
\text { em relação à superfície total } \\
\text { do país }\end{array}$ & Percentual \\
\hline \multirow{7}{*}{$\begin{array}{l}\text { Intrusão } \\
\text { ecológica } \\
\text { direta }\end{array}$} & Fragmentação do solo & Tamanho de malha efetiva & $\mathrm{km}^{2}$ \\
\hline & $\begin{array}{c}\text { Dano ao habitats } \\
\text { subaquáticos }\end{array}$ & $\begin{array}{l}\text { Quantidade de dragagem nos } \\
\text { portos, hidrovias, etc., por } \\
\text { tipo de área de dragagem }\end{array}$ & $\mathrm{m}^{3}$ \\
\hline & $\begin{array}{l}\text { Perda de áreas } \\
\text { naturais }\end{array}$ & $\begin{array}{c}\text { Perda de áreas naturais } \\
\text { devido à construção de } \\
\text { infraestruturas de transportes } \\
\text { por modalidade e percentual } \\
\text { do total de perda de áreas } \\
\text { naturais }\end{array}$ & $\begin{array}{c}\mathrm{km}^{2} \text { e percentual } \\
\text { de perda de áreas } \\
\text { naturais }\end{array}$ \\
\hline & $\begin{array}{c}\text { Proximidade da } \\
\text { infraestrutura de } \\
\text { transporte em relação } \\
\text { a Unidades de } \\
\text { Conservação } \\
\end{array}$ & $\begin{array}{l}\text { Unidades de Conservação } \\
\text { próximas a infraestruturas de } \\
\text { transporte no total e por } \\
\text { modalidade }\end{array}$ & $\begin{array}{c}\mathrm{km}^{2} \text { e percentual } \\
\text { de áreas de } \\
\text { Unidades de } \\
\text { Conservação }\end{array}$ \\
\hline & Emissões de luz & $\begin{array}{c}\text { Área iluminada de } \\
\text { infraestruturas de transporte }\end{array}$ & $\mathrm{km}^{2}$ \\
\hline & $\begin{array}{c}\text { Choques com animais } \\
\text { selvagens }\end{array}$ & $\begin{array}{l}\text { Número anual de choques } \\
\text { com animais selvagens por } \\
\text { modalidade }\end{array}$ & $\begin{array}{l}\text { Número de } \\
\text { colisões por ano }\end{array}$ \\
\hline & $\begin{array}{c}\text { Introdução de } \\
\text { espécies não nativas }\end{array}$ & $\begin{array}{l}\text { Número de espécies não } \\
\text { nativas introduzidas por }\end{array}$ & $\begin{array}{l}\text { Número de } \\
\text { espécies }\end{array}$ \\
\hline
\end{tabular}




\begin{tabular}{|c|c|c|c|}
\hline $\begin{array}{l}\text { Área de } \\
\text { Interesse }\end{array}$ & Nome do Indicador & Definição do Indicador & Unidade \\
\hline & & $\begin{array}{l}\text { transporte marítimo e na } \\
\text { construção de infraestrutura } \\
\text { de transporte }\end{array}$ & \\
\hline \multirow{4}{*}{$\begin{array}{c}\text { Emissões } \\
\text { atmosféricas }\end{array}$} & $\begin{array}{l}\text { Emissões de gases de } \\
\text { efeito estufa } \\
\text { provenientes do setor } \\
\text { de transporte }\end{array}$ & $\begin{array}{l}\text { Emissões de gases de efeito } \\
\text { estufa por modalidade e por } \\
\text { tipo de poluente }\end{array}$ & $\begin{array}{c}\text { Toneladas de } \mathrm{CO}_{2} \\
\text { equivalentes }\end{array}$ \\
\hline & $\begin{array}{c}\text { Emissões de gases de } \\
\text { efeito estufa } \\
\text { provenientes de } \\
\text { produção e } \\
\text { manutenção }\end{array}$ & $\begin{array}{l}\text { Emissões de gases de efeito } \\
\text { estufa provenientes da } \\
\text { produção de veículos e da } \\
\text { produção de peças e } \\
\text { manutenção por modalidade } \\
\text { e poluente }\end{array}$ & $\begin{array}{c}\text { Toneladas de } \mathrm{CO}_{2} \\
\text { equivalentes }\end{array}$ \\
\hline & $\begin{array}{c}\text { Emissões de } \\
\text { poluentes } \\
\text { atmosféricos } \\
\text { provenientes do setor } \\
\text { de transporte }\end{array}$ & $\begin{array}{l}\text { Emissões de poluentes } \\
\text { atmosféricos por modalidade } \\
\text { e por tipo de poluente }\end{array}$ & Mil toneladas \\
\hline & $\begin{array}{l}\text { Emissões de } \\
\text { poluentes } \\
\text { atmosféricos } \\
\text { provenientes de } \\
\text { fabricação e } \\
\text { manutenção }\end{array}$ & $\begin{array}{l}\text { Emissões de poluentes } \\
\text { atmosféricos provenientes da } \\
\text { produção de veículos, de } \\
\text { peças e manutenção por } \\
\text { modalidade e poluente }\end{array}$ & Mil toneladas \\
\hline \multirow[b]{2}{*}{ Ruído } & \multirow{2}{*}{$\begin{array}{l}\text { Exposição ao ruído } \\
\text { proveniente do setor } \\
\text { de transportes }\end{array}$} & $\begin{array}{l}\text { População exposta aos níveis } \\
\text { de ruído de tráfego que } \\
\text { afetam a saúde (> } 65 \mathrm{dBA}) \\
\text { por modalidade }\end{array}$ & $\begin{array}{l}\text { Número e } \\
\text { percentual de } \\
\text { população }\end{array}$ \\
\hline & & $\begin{array}{l}\text { População exposta aos níveis } \\
\text { de ruído de tráfego que } \\
\text { afetam o bem-estar (entre } 40 \\
\text { e } 65 \text { decibéis) por } \\
\text { modalidade }\end{array}$ & $\begin{array}{l}\text { Número e } \\
\text { percentual de } \\
\text { população }\end{array}$ \\
\hline Resíduos & $\begin{array}{l}\text { Geração de resíduos } \\
\text { não recicláveis }\end{array}$ & $\begin{array}{l}\text { Quantidade total de resíduos } \\
\text { não recicláveis provenientes } \\
\text { do setor de transportes por } \\
\text { modalidade e tipo de resíduo }\end{array}$ & Toneladas \\
\hline
\end{tabular}


Tabela 24: Indicadores sociais de mobilidade sustentável (EUROPEAN COMMISSION, 2005)

\begin{tabular}{|c|c|c|c|}
\hline $\begin{array}{l}\text { Área de } \\
\text { Interesse }\end{array}$ & $\begin{array}{l}\text { Nome do } \\
\text { Indicador }\end{array}$ & Definiçãa do Indicador & Unidade \\
\hline \multirow{5}{*}{$\begin{array}{l}\text { Acessibilidade e } \\
\text { capacidade de } \\
\text { pagamento }\end{array}$} & $\begin{array}{c}\text { Acesso aos } \\
\text { serviços básicos }\end{array}$ & $\begin{array}{c}\text { Tempo médio de viagem } \\
\text { por domicílio para acesso } \\
\text { a serviços básicos }\end{array}$ & Minutos \\
\hline & $\begin{array}{c}\text { Acesso ao } \\
\text { transporte público }\end{array}$ & $\begin{array}{c}\text { Percentual de domicílios } \\
\text { a uma distância de } 5 \\
\text { minutos de uma parada } \\
\text { de transporte público }\end{array}$ & $\begin{array}{l}\text { Percentual de } \\
\text { domicílios }\end{array}$ \\
\hline & $\begin{array}{c}\text { Autonomia } \\
\text { devida ao } \\
\text { automóvel } \\
\end{array}$ & $\begin{array}{l}\text { Percentual de domicílios } \\
\text { sem um automóvel }\end{array}$ & $\begin{array}{l}\text { Percentual de } \\
\text { domicílios }\end{array}$ \\
\hline & $\begin{array}{l}\text { Capacidade de } \\
\text { pagamento }\end{array}$ & $\begin{array}{c}\text { Percentual da média de } \\
\text { gastos familiares com } \\
\text { transportes } \\
\end{array}$ & Percentual de gastos \\
\hline & $\begin{array}{l}\text { Extensão da } \\
\text { viagem }\end{array}$ & $\begin{array}{c}\text { Percentual de viagens } \\
\text { curtas no total de viagens }\end{array}$ & Percentual de viagens \\
\hline \multirow{6}{*}{$\begin{array}{l}\text { Segurança e } \\
\text { Proteção }\end{array}$} & \multirow{4}{*}{$\begin{array}{l}\text { Vítimas fatais e } \\
\text { lesões graves de } \\
\text { acidentes }\end{array}$} & $\begin{array}{l}\text { Número de acidentes de } \\
\text { transportes responsáveis } \\
\text { por vítimas fatais e lesões } \\
\text { graves por ano por } 1.000 \\
\text { habitantes }\end{array}$ & $\begin{array}{c}\text { Número de pessoas por } \\
\text { ano por } 1.000 \\
\text { habitantes }\end{array}$ \\
\hline & & $\begin{array}{c}\text { Número de crianças } \\
\text { menores de } 18 \text { anos } \\
\text { seriamente feridas ou } \\
\text { mortas por } 1.000 \text { crianças } \\
\text { da mesma faixa etária }\end{array}$ & $\begin{array}{c}\text { Número de crianças por } \\
\text { ano por } 1.000 \\
\text { habitantes }\end{array}$ \\
\hline & & $\begin{array}{c}\text { Número de adultos de } 18 \\
\text { a } 65 \text { anos seriamente } \\
\text { feridos ou mortos por } \\
1.000 \text { adultos da mesma } \\
\text { faixa etária }\end{array}$ & $\begin{array}{c}\text { Número de adultos por } \\
\text { ano por } 1.000 \\
\text { habitantes }\end{array}$ \\
\hline & & $\begin{array}{c}\text { Número de pessoas com } \\
\text { mais de } 65 \text { anos } \\
\text { seriamente feridas ou } \\
\text { mortas por } 1.000 \text { pessoas } \\
\text { da mesma faixa etária }\end{array}$ & $\begin{array}{c}\text { Número de idosos por } \\
\text { ano por } 1.000 \\
\text { habitantes }\end{array}$ \\
\hline & $\begin{array}{l}\text { Furto de veículos } \\
\text { e outras infrações } \\
\text { relacionadas com } \\
\text { veículos }\end{array}$ & $\begin{array}{c}\text { Furtos de veículos e } \\
\text { outras infrações } \\
\text { relacionadas com } \\
\text { veículos registradas por } \\
\text { ano e por } 1.000 \\
\text { habitantes }\end{array}$ & $\begin{array}{l}\text { Número de furtos e } \\
\text { outras infrações } \\
\text { relacionadas com } \\
\text { veículos por ano por } \\
1.000 \text { habitantes }\end{array}$ \\
\hline & $\begin{array}{l}\text { Segurança no } \\
\text { transporte público }\end{array}$ & $\begin{array}{l}\text { Número de incidentes } \\
\text { (crimes }+ \text { crimes contra } \\
\text { passageiros + crimes } \\
\text { contra operadores) por }\end{array}$ & $\begin{array}{l}\text { Número de incidentes } \\
\text { por ano por } 1.000 \\
\text { habitantes }\end{array}$ \\
\hline
\end{tabular}




\begin{tabular}{|c|c|c|c|}
\hline $\begin{array}{l}\text { Área de } \\
\text { Interesse }\end{array}$ & $\begin{array}{l}\text { Nome do } \\
\text { Indicador }\end{array}$ & Definição do Indicador & Unidade \\
\hline & & $\begin{array}{c}\text { ano por } 1.000 \\
\text { quilômetros }\end{array}$ & \\
\hline $\begin{array}{c}\text { Exercício e } \\
\text { saúde (usuários) }\end{array}$ & $\begin{array}{l}\text { Caminhada ou } \\
\text { ciclismo como } \\
\text { meios de } \\
\text { transporte para } \\
\text { viagens de curta } \\
\text { distância }\end{array}$ & $\begin{array}{c}\text { Percentual de } \\
\text { viagens/jornadas curtas } \\
\text { realizadas por caminhada } \\
\text { ou bicicletas }\end{array}$ & Percentual de viagens \\
\hline \multirow{4}{*}{$\begin{array}{l}\text { Qualidade de } \\
\quad \text { vida e } \\
\text { conveniência } \\
\text { (habitantes, } \\
\text { sociedade e } \\
\text { afetados) }\end{array}$} & $\begin{array}{l}\text { Caminhada } \\
\text { (facilidades para } \\
\text { os pedestres) }\end{array}$ & $\begin{array}{c}\text { Extensão total de vias } \\
\text { separadas para caminhada } \\
\text { e/ou áreas especiais para } \\
\text { pedestres, como } \\
\text { percentual do } \\
\text { comprimento de toda } \\
\text { rede de transportes }\end{array}$ & $\begin{array}{l}\text { Percentual em relação } \\
\text { ao comprimento de toda } \\
\text { rede de transportes }\end{array}$ \\
\hline & $\begin{array}{l}\text { Trânsito tranquilo } \\
\text { (Trafic calming) }\end{array}$ & $\begin{array}{l}\text { Extensão total das ruas da } \\
\text { cidade com limites de } \\
\text { velocidade máximo de } 30 \\
\text { quilômetros por hora, } \\
\text { como percentual do } \\
\text { comprimento de toda } \\
\text { rede de transportes }\end{array}$ & $\begin{array}{l}\text { Percentual do } \\
\text { comprimento de toda } \\
\text { rede de transportes }\end{array}$ \\
\hline & $\begin{array}{l}\text { Jornada das } \\
\text { crianças às } \\
\text { escolas }\end{array}$ & $\begin{array}{l}\text { Percentual de crianças } \\
\text { levadas de automóvel às } \\
\text { escolas }\end{array}$ & Percentual de crianças \\
\hline & $\begin{array}{l}\text { Disponibilidade } \\
\text { de espaço aberto } \\
\text { e acessibilidade }\end{array}$ & $\begin{array}{c}\text { Percentual de } \\
\text { habitantes/domicílios a } \\
\text { uma distância de no } \\
\text { máximo } 15 \text { minutos de } \\
\text { caminhada até áreas } \\
\text { urbanas verdes }\end{array}$ & $\begin{array}{c}\text { Percentual de } \\
\text { habitantes/domicílios }\end{array}$ \\
\hline \multirow{4}{*}{$\begin{array}{l}\text { Equidade } \\
\text { (usuários e } \\
\text { afetados) }\end{array}$} & $\begin{array}{l}\text { Equidade } \\
\text { horizontal } \\
\text { (justiça) }\end{array}$ & $\begin{array}{c}\text { Percentual de gastos em } \\
\text { transporte pelos usuários } \\
\text { diferenciados por } \\
\text { modalidade }\end{array}$ & Percentual de gastos \\
\hline & \multirow{3}{*}{$\begin{array}{l}\text { Equidade vertical } \\
\text { (renda) }\end{array}$} & $\begin{array}{c}\text { Relação de gastos } \\
\text { familiares entre os } 20 \% \\
\text { mais ricos e os } 20 \% \text { mais } \\
\text { pobres em transportes }\end{array}$ & Número \\
\hline & & $\begin{array}{c}\text { Relação de gastos } \\
\text { familiares entre os } 20 \% \\
\text { mais ricos e os } 20 \% \text { mais } \\
\text { pobres para acesso aos } \\
\text { serviços básicos }\end{array}$ & Número \\
\hline & & $\begin{array}{c}\text { Relação de gastos } \\
\text { familiares entre os } 20 \% \\
\text { mais ricos e os } 20 \% \text { mais }\end{array}$ & Número \\
\hline
\end{tabular}




\begin{tabular}{|c|c|c|c|}
\hline $\begin{array}{l}\text { Área de } \\
\text { Interesse }\end{array}$ & $\begin{array}{l}\text { Nome do } \\
\text { Indicador }\end{array}$ & Definiçãa do Indicador & Unidade \\
\hline & & $\begin{array}{l}\text { pobres dependentes dos } \\
\text { transportes públicos }\end{array}$ & \\
\hline & \multirow{2}{*}{$\begin{array}{l}\text { Equidade vertical } \\
\text { (necessidade de } \\
\text { mobilidade) }\end{array}$} & $\begin{array}{l}\text { Gastos dos transportes } \\
\text { públicos explicitamente } \\
\text { subsidiados para } \\
\text { deficientes e idosos no } \\
\text { percentual total do custo } \\
\text { do transporte público }\end{array}$ & Percentual de gastos \\
\hline & & $\begin{array}{l}\text { Percentual de veículos de } \\
\text { piso baixo de fácil acesso } \\
\text { em percentual da frota } \\
\text { total do transporte urbano }\end{array}$ & Percentual de veículos \\
\hline & $\begin{array}{c}\text { Equidade } \\
\text { intergeracional }\end{array}$ & $\begin{array}{l}\text { Resultados importantes } \\
\text { de interesse, mas } \\
\text { indicadores não são } \\
\text { sugeridos }\end{array}$ & - \\
\hline & $\begin{array}{l}\text { Equidade inter- } \\
\text { regional } \\
\text { (espacial) }\end{array}$ & $\begin{array}{l}\text { Resultados importantes } \\
\text { de interesse, mas } \\
\text { indicadores não são } \\
\text { sugeridos }\end{array}$ & - \\
\hline \multirow{3}{*}{$\begin{array}{l}\text { Coesão social } \\
\text { (habitantes, } \\
\text { sociedade e } \\
\text { afetados) }\end{array}$} & $\begin{array}{l}\text { Perfil da opinião } \\
\text { pública sobre } \\
\text { problemas } \\
\text { políticos de } \\
\text { transporte } \\
\end{array}$ & $\begin{array}{l}\text { Percentual de adultos que } \\
\text { apoiam posições radicais } \\
\text { a favor e contra veículos } \\
\text { particulares na discussão } \\
\text { da política de transportes }\end{array}$ & Percentual de adultos \\
\hline & $\begin{array}{l}\text { Violação das } \\
\text { regras de tráfego }\end{array}$ & $\begin{array}{l}\text { Percentual de condutores } \\
\text { que violam as regras e } \\
\text { regulamentos de trânsito }\end{array}$ & $\begin{array}{l}\text { Percentual de } \\
\text { condutores }\end{array}$ \\
\hline & $\begin{array}{l}\text { Passageiros de } \\
\text { longa distância }\end{array}$ & $\begin{array}{c}\text { Percentual diário de } \\
\text { passageiros pendulares } \\
\text { para distâncias acima de } \\
\text { dez quilômetros }\end{array}$ & $\begin{array}{l}\text { Percentual de } \\
\text { passageiros }\end{array}$ \\
\hline
\end{tabular}


A Organização para a Cooperação Econômica e Desenvolvimento (Organisation for Economic Co-operation and Development - OECD, 1999) recomenda os indicadores apresentados na Tabela 25 para o acompanhamento das preocupações ambientais nas políticas de transporte.

Tabela 25: Indicadores de mobilidade sustentável (OECD, 1999)

\begin{tabular}{|c|c|c|}
\hline $\begin{array}{l}\text { Tendências setoriais de } \\
\text { importância ambiental }\end{array}$ & $\begin{array}{c}\text { Interações com o meio } \\
\text { ambiente }\end{array}$ & $\begin{array}{c}\text { Aspectos econômicos e } \\
\text { políticos }\end{array}$ \\
\hline 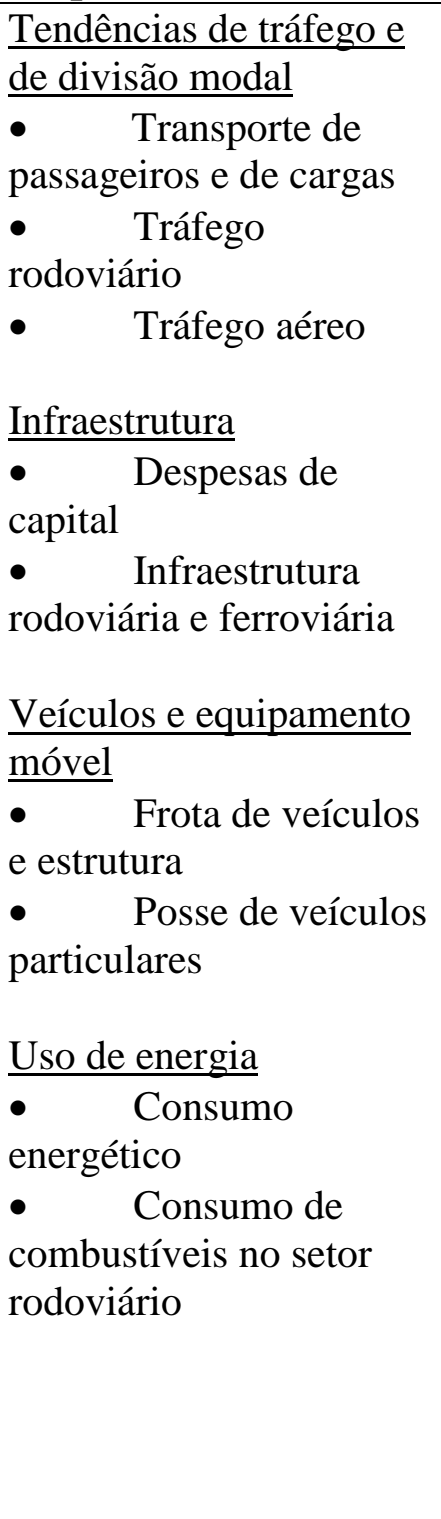 & 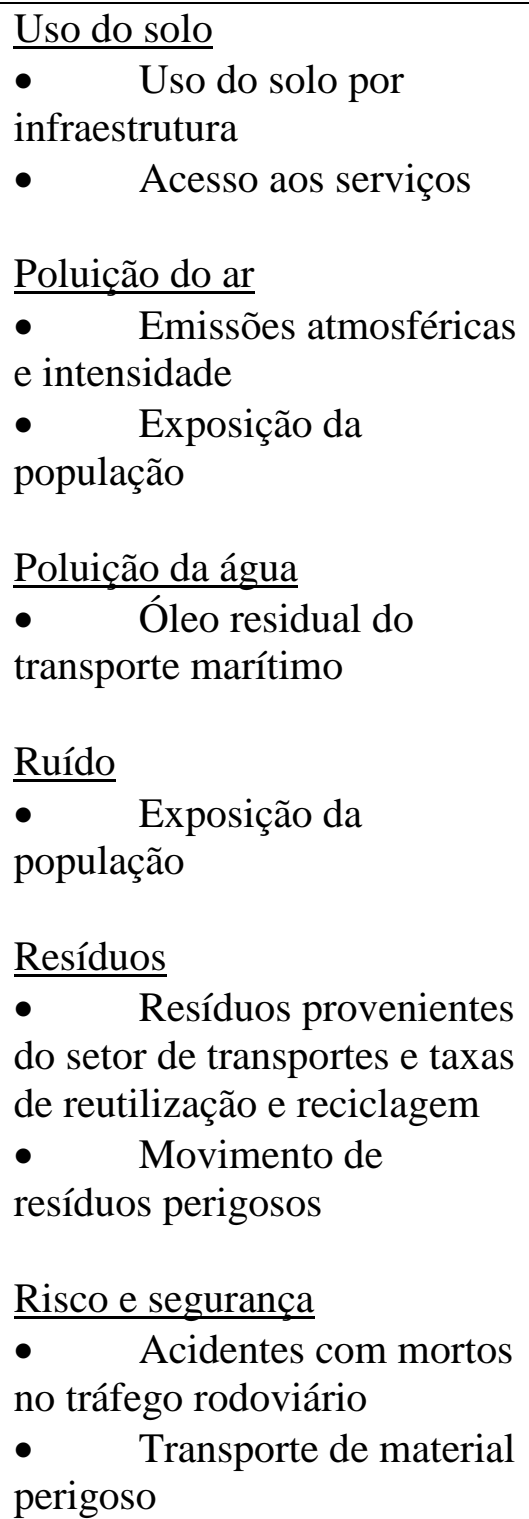 & $\begin{array}{l}\text { Dano ambiental } \\
\text { - } \quad \text { Dano ambiental } \\
\text { Gasto ambiental } \\
\text { poluição e controle } \\
\text { - Gastos em redução da } \\
\text { desenvolvimento de veículos } \\
\text { não poluentes e em } \\
\text { combustíveis limpos } \\
\text { Tributação e subsídios } \\
\text { - Subsídios ao transporte } \\
\text { - Impostos sobre } \\
\text { veículos e sobre o uso de } \\
\text { veículos } \\
\text { Estruturas de preços } \\
\text { - } \quad \text { Preços de } \\
\text { combustíveis rodoviários } \\
\text { - Preços do transporte } \\
\text { público } \\
\text { Comércio e meio ambiente } \\
\text { - A ser desenvolvido }\end{array}$ \\
\hline
\end{tabular}


A Tabela 26 apresenta os indicadores de mobilidade sustentável desenvolvidos em 2003 pelo Conselho Empresarial Mundial de Mobilidade Sustentável (World Business Council's Sustainable Mobility) (WBCSD, 2003).

Tabela 26: Indicadores de mobilidade sustentável (WBCSD, 2003)

\begin{tabular}{|c|c|c|}
\hline $\begin{array}{c}\text { Preocupações com o } \\
\text { usuário }\end{array}$ & $\begin{array}{c}\text { Preocupações com a } \\
\text { sociedade }\end{array}$ & Preocupações com os negócios \\
\hline $\begin{array}{l}\text { - } \quad \text { Facilidade de } \\
\text { acesso aos meios de } \\
\text { mobilidade } \\
\text { - } \quad \text { Esforço financeiro } \\
\text { exigido do usuário } \\
\text { - Média de tempo } \\
\text { requerido para viagens } \\
\text { porta a porta } \\
\text { - Confiabilidade } \\
\text { medida como variabilidade } \\
\text { na média de tempo } \\
\text { requerido para viagens } \\
\text { porta a porta } \\
\text { - Segurança (chance } \\
\text { de o usuário se envolver } \\
\text { em acidente grave) } \\
\text { - Segurança (chance } \\
\text { de o usuário ser roubado ou } \\
\text { assaltado, etc.) }\end{array}$ & 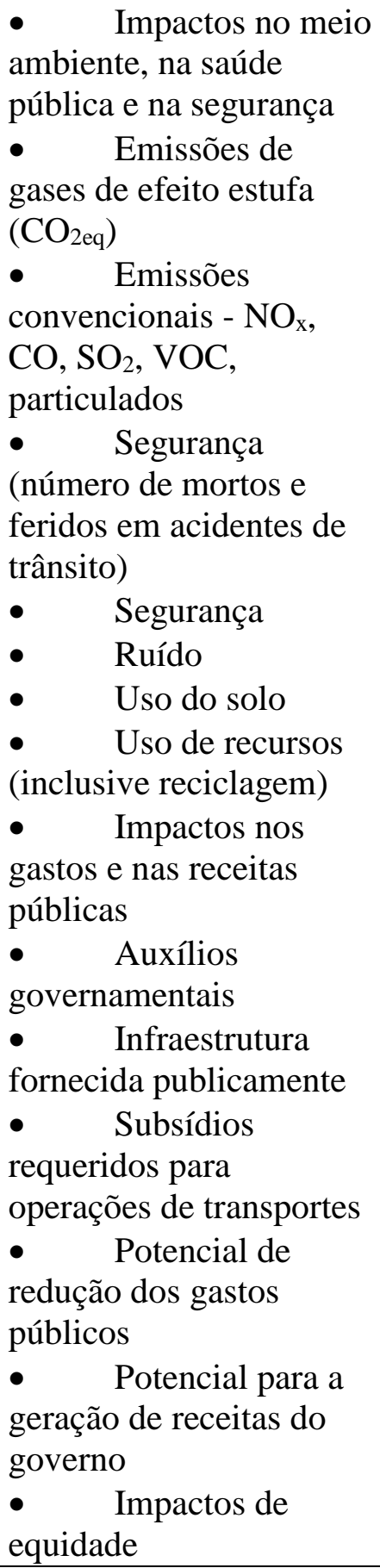 & 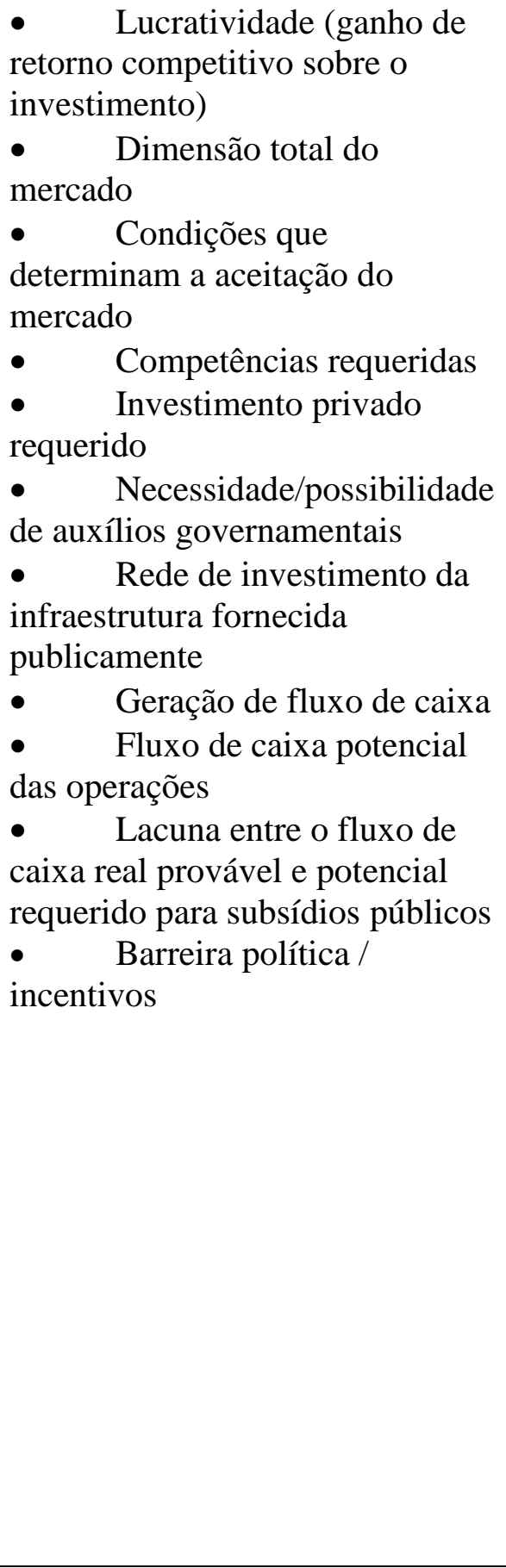 \\
\hline
\end{tabular}


A Tabela 27 apresenta 12 indicadores de mobilidade sustentável desenvolvidos em 2004 pelo Conselho Empresarial Mundial de Mobilidade Sustentável, com a cooperação de 200 especialistas (WBCSD, 2004).

Tabela 27: Indicadores de mobilidade sustentável (WBCSD, 2004)

\begin{tabular}{|c|c|c|}
\hline Indicador & Mobilidade pessoal & Mobilidade de bens \\
\hline Acessibilidade & $\begin{array}{l}\text { O percentual de domicílios com } \\
\text { acesso a veículos motorizados } \\
\text { pessoais mais o percentual de } \\
\text { domicílios localizados a uma certa } \\
\text { distância de transporte público com } \\
\text { o mínimo de qualidade desejável. }\end{array}$ & $\begin{array}{l}\text { Combinação de tempo de resposta } \\
\text { (tempo de recebimento da remessa } \\
\text { após solicitação de serviço ou } \\
\text { tempo de entrega da remessa após } \\
\text { sua chegada) e a distância que o } \\
\text { remetente ou cliente devem } \\
\text { percorrer para entregar ou receber } \\
\text { a encomenda. }\end{array}$ \\
\hline $\begin{array}{c}\text { Gastos exigidos } \\
\text { dos usuários }\end{array}$ & $\begin{array}{l}\text { Percentual do orçamento individual } \\
\text { (ou familiar) dedicado a viagens } \\
\text { pessoais. }\end{array}$ & $\begin{array}{l}\text { Total de custos logísticos por } \\
\text { unidade (peso ou valor) e por } \\
\text { unidade de distância: } \\
\text { alternativamente, a participação no } \\
\text { preço de um bem de todos os } \\
\text { custos logísticos associados à sua } \\
\text { produção e entrega final. }\end{array}$ \\
\hline $\begin{array}{l}\text { Tempo de } \\
\text { Viagem }\end{array}$ & $\begin{array}{l}\text { Tempo médio necessário desde a } \\
\text { origem até o destino, incluindo } \\
\text { todas as paradas do veículo e tempo } \\
\text { de espera. }\end{array}$ & $\begin{array}{l}\text { Mobilidade de produtos: média de } \\
\text { tempo da origem ao destino } \\
\text { necessário para o envio. }\end{array}$ \\
\hline Confiabilidade & $\begin{array}{l}\text { Variabilidade de tempo de viagem } \\
\text { porta a porta para um usuário } \\
\text { "típico" do sistema de mobilidade. }\end{array}$ & $\begin{array}{l}\text { Variabilidade no tempo de origem } \\
\text { ao destino para envio de produtos } \\
\text { típicos de diferentes tipos. }\end{array}$ \\
\hline Segurança & $\begin{array}{l}\text { A probabilidade que um indivíduo } \\
\text { possui de ser morto ou ferido em } \\
\text { um acidente enquanto utiliza um } \\
\text { sistema de mobilidade o o número } \\
\text { total de mortes e ferimentos graves } \\
\text { (incapacitantes) por ano por } \\
\text { categoria (caminhão, ônibus, } \\
\text { motocicleta, bicicleta, não } \\
\text { motorizado, etc.). } \\
\text { Para indivíduos, a probabilidade } \\
\text { que alguém possa ser molestado, } \\
\text { roubado ou fisicamente agredido } \\
\text { durante uma viagem. } \\
\text { Para a sociedade, em adição a isso, } \\
\text { o número total de incidentes (talvez } \\
\text { ponderado pela severidade). }\end{array}$ & $\begin{array}{l}\text { A probabilidade de que um } \\
\text { determinado produto remetido seja } \\
\text { danificado ou destruído e o valor } \\
\text { total dos bens danificados ou } \\
\text { destruídos em um acidente. } \\
\text { Para indivíduos, a probabilidade de } \\
\text { que uma remessa seja roubada ou } \\
\text { danificada por roubo ou furto. Para } \\
\text { a sociedade, em adição a isto, o } \\
\text { valor total de mercadorias perdidas } \\
\text { em roubos e furtos. }\end{array}$ \\
\hline
\end{tabular}




\begin{tabular}{|c|c|}
\hline Indicador & Mobilidade de bens \\
\hline $\begin{array}{l}\text { Emissões de } \\
\text { gases de efeito } \\
\text { estufa (GEE) }\end{array}$ & $\begin{array}{l}\text { Emissões de GEE por período de tempo medidas em unidades de carbono } \\
\text { equivalentes. }\end{array}$ \\
\hline $\begin{array}{l}\text { Impacto no meio } \\
\text { ambiente e no } \\
\text { bem-estar } \\
\text { público }\end{array}$ & $\begin{array}{l}\text { - Emissões convencionais provenientes do setor de transportes } \\
\text { Emissões de } \mathrm{NO}_{\mathrm{x}}, \mathrm{CO} \text {, particulados, hidrocarbonetos não queimados por } \\
\text { período de tempo. } \\
\text { - Impacto nos ecossistemas } \\
\text { Impactos nos ecossistemas provenientes do setor de transportes } \\
\text { (exemplos: habitats, água). } \\
\text { - Ruído proveniente do setor de transportes } \\
\text { O número de indivíduos (ou percentual da população) expostos a } \\
\text { elevados níveis de ruído provenientes do setor de transportes por período } \\
\text { longo de tempo. }\end{array}$ \\
\hline Uso de recursos & $\begin{array}{l}\text { - Uso de energia e segurança energética proveniente do setor de } \\
\text { transportes } \\
\text { Para o uso de energia: total de diferentes combustíveis utilizados nos } \\
\text { transportes. } \\
\text { Para a segurança energética: percentual de suprimento de energia de uma } \\
\text { região vinda de fora da região ou de fontes inseguras. } \\
\text { - Uso do solo pelo setor de transportes } \\
\text { Quantidade (ou percentual) de solo dedicado às atividades de transportes. } \\
\text { - Uso de materiais pelo setor de transportes } \\
\text { Volume total de material utilizado pelo setor de transportes; percentual } \\
\text { de uso total de material utilizado pelo setor de transportes; taxas de } \\
\text { reciclagem reais. }\end{array}$ \\
\hline $\begin{array}{l}\text { Implicações da } \\
\text { equidade }\end{array}$ & $\begin{array}{l}\text { Acesso aos meios de mobilidade, o custo de obtenção de mobilidade } \\
\text { pessoal e de bens, exposição aos efeitos das emissões convencionais e de } \\
\text { ruído e ameaças à segurança. }\end{array}$ \\
\hline $\begin{array}{l}\text { Impactos nas } \\
\text { receitas e } \\
\text { despesas } \\
\text { públicas }\end{array}$ & $\begin{array}{l}\text { O nível, a mudança no nível de capital público e as despesas operacionais } \\
\text { para a prestação de serviços de transporte e infraestrutura de transporte. } \\
\text { Isto inclui auxílios governamentais, capital para infraestrutura pública, } \\
\text { subsídios operacionais, receitas arrecadadas pelo governo a partir de } \\
\text { operações de transporte, taxas de utilização e redução nos gastos do } \\
\text { governo devido à quantidade e qualidade dos serviços de transporte. }\end{array}$ \\
\hline $\begin{array}{l}\text { Taxa prospectiva } \\
\text { de retorno de } \\
\text { negócios } \\
\text { privados }\end{array}$ & $\begin{array}{l}\text { O retorno potencial sobre o investimento de em um negócio privado para } \\
\text { prover a mobilidade de bens e serviços particulares - inclui custos (capital } \\
\text { e operação), receitas privadas, receitas governamentais (auxílios } \\
\text { governamentais, subsídios operacionais, subvenções de funcionamento } \\
\text { dos fundos púbicos para financiar o capital, etc.), e custos impostos por } \\
\text { políticas governamentais de regulamentação. }\end{array}$ \\
\hline
\end{tabular}


O Centro de Transporte Sustentável do Canadá (THE CENTRE FOR SUSTAINABLE TRANSPORTATION, 2003) recomenda 14 indicadores de desempenho (Tabela 28) para mensurar o nível de sustentabilidade do setor de transportes.

Tabela 28: Indicadores de desempenho (THE CENTRE FOR SUSTAINABLE TRANSPORTATION, 2003)

\begin{tabular}{|c|c|}
\hline Indicadores & Definição \\
\hline $\begin{array}{l}\text { Uso de energia pelo setor } \\
\text { de transportes }\end{array}$ & $\begin{array}{l}\text { Este indicador representa o consumo de recursos não } \\
\text { renováveis de combustíveis fósseis pelo setor de transportes }\end{array}$ \\
\hline $\begin{array}{l}\text { Emissões de gases de } \\
\text { efeito estufa }\end{array}$ & $\begin{array}{l}\text { Este indicador representa as emissões de gases de efeito estufa } \\
\text { emitidas pelos transportes }\end{array}$ \\
\hline $\begin{array}{l}\text { Outras emissões de } \\
\text { transportes }\end{array}$ & $\begin{array}{l}\text { Este indicador é anual e representa as emissões de poluentes } \\
\text { locais: monóxido de carbono }(\mathrm{CO}) \text {, dióxido de enxofre }\left(\mathrm{SO}_{2}\right) \text {, } \\
\text { óxidos de nitrogênio }\left(\mathrm{NO}_{\mathrm{x}}\right) \text { e compostos orgânicos voláteis } \\
\text { (VOCs) }\end{array}$ \\
\hline Mortos e feridos & $\begin{array}{l}\text { Este indicador representa os dados de mortos e feridos no } \\
\text { transporte rodoviário }\end{array}$ \\
\hline Transporte de pessoas & $\begin{array}{l}\text { Este indicador representa o total de transporte motorizado de } \\
\text { pessoas, em pessoas - quilômetros }\end{array}$ \\
\hline Transporte de cargas & $\begin{array}{l}\text { Este indicador representa o total de movimento de cargas em } \\
\text { toneladas - quilômetro }\end{array}$ \\
\hline $\begin{array}{l}\text { Viagens por veículos } \\
\text { particulares e aviões }\end{array}$ & $\begin{array}{l}\text { Este indicador refere-se à participação das viagens realizadas } \\
\text { pelos modos motorizados mais poluentes: aeronaves e veículos } \\
\text { particulares. }\end{array}$ \\
\hline $\begin{array}{l}\text { Movimento de veículos } \\
\text { particulares }\end{array}$ & $\begin{array}{l}\text { Este indicador representa a distância total percorrida por } \\
\text { veículos particulares em veículos - quilômetros }\end{array}$ \\
\hline Uso de solo urbano & Este indicador representa o uso de solo urbano por habitantes \\
\hline $\begin{array}{l}\text { Extensão de rodovias } \\
\text { pavimentadas }\end{array}$ & Este indicador representa a extensão de rodovias pavimentadas \\
\hline Gastos domésticos & $\begin{array}{l}\text { Este indicador representa o gasto doméstico em transportes em } \\
\text { relação ao total de despesas após impostos }\end{array}$ \\
\hline Custos de transportes & $\begin{array}{l}\text { Este indicador representa a relação da tarifa de transporte } \\
\text { urbano com o custo principal de operação de um veículo, ou } \\
\text { seja, o custo de combustível }\end{array}$ \\
\hline $\begin{array}{l}\text { Intensidade energética de } \\
\text { veículos particulares e de } \\
\text { caminhões }\end{array}$ & $\begin{array}{l}\text { Este indicador representa a quantidade de combustível } \\
\text { utilizado por quilômetro percorrido por veículos particulares e } \\
\text { caminhões de todos os tamanhos }\end{array}$ \\
\hline Intensidade de emissões & $\begin{array}{l}\text { Este indicador representa as taxas de poluição local emitida } \\
\text { pelos veículos rodoviários }\end{array}$ \\
\hline
\end{tabular}


A Agência Europeia do Meio Ambiente (EUROPEAN ENVIRONMENTAL AGENCY, 2011) desenvolveu indicadores para verificar o estado do setor de transportes a partir dos aspectos mais importantes do sistema de transportes e do meio ambiente (força motriz - pressão - estado - impacto - resposta). São eles:

- Consumo final de energia consumida por modo;

- Emissões dos transportes de gases de efeito estufa;

- Emissões dos transportes de poluentes atmosféricos;

- Superação dos limites de qualidade do ar devido ao tráfego;

- Exposição e aborrecimento causado pelo ruído do tráfego;

- Volume de passageiros por modo de transporte e distribuição modal;

- Volume de carga por modo de transporte e distribuição modal;

- Mudanças dos preços dos transportes por modo;

- Preços de combustíveis e impostos;

- Eficiência energética e emissões específicas de $\mathrm{CO}_{2}$;

- Aceitação de combustíveis menos poluentes e alternativos;

- Proporção da frota de veículos atendendo padrões de emissão determinados. 
Nicolas et al. (2003) desenvolveram indicadores de mobilidade sustentável para o caso dos transportes urbanos e mobilidade diária dos habitantes das cidades de Lyon e de Paris localizadas na França. O conjunto de indicadores apresentados na Tabela 29 permite a comparação de diferentes estratégias de transportes entre os diferentes contextos urbanos ao longo do tempo.

Tabela 29: Indicadores de mobilidade sustentável (NICOLAS et al., 2003)

\begin{tabular}{|c|c|}
\hline $\begin{array}{c}\text { Dimensão de } \\
\text { sustentabilidade }\end{array}$ & Indicador \\
\hline \multicolumn{2}{|l|}{ Mobilidade } \\
\hline $\begin{array}{l}\text { Serviço prestado } \\
\text { Organização da } \\
\text { mobilidade urbana }\end{array}$ & $\begin{array}{l}\text { Número de viagens diárias } \\
\text { Finalidades das viagens } \\
\text { Média diária do tempo de viagem } \\
\text { Divisão modal } \\
\text { Média diária da distância percorrida } \\
\text { Velocidade média }\end{array}$ \\
\hline \multicolumn{2}{|l|}{ Econômica } \\
\hline $\begin{array}{l}\text { Custos para a } \\
\text { comunidade }\end{array}$ & $\begin{array}{l}\text { Custos anuais exigidos dos residentes devido à sua mobilidade } \\
\text { (total, por habitante e por passageiro - quilômetro) }\end{array}$ \\
\hline \multirow[t]{3}{*}{$\begin{array}{l}\text { Custos das partes } \\
\text { envolvidas }\end{array}$} & $\begin{array}{l}\text { Custos familiares: } \\
\text { Gastos anuais médios de mobilidade urbana (por pessoa) }\end{array}$ \\
\hline & $\begin{array}{l}\text { Empresas } \\
\text { Custos com estacionamento dos empregados } \\
\text { Subsídios para os empregados (carros da empresa) } \\
\text { Impostos locais (total, por residente e por empregado) }\end{array}$ \\
\hline & $\begin{array}{l}\text { Autoridades Públicas } \\
\text { Gastos anuais de investimentos e operacionais (total e por } \\
\text { residente) }\end{array}$ \\
\hline Social & $\begin{array}{l}\text { Proporção de famílias que possuem zero, um ou mais carros } \\
\text { Distância percorrida } \\
\text { Custos com mobilidade urbana: } \\
\text { • Custos com os transportes privado/público e custo } \\
\text { fixo/variável dos veículos } \\
\text { - Participação da renda média familiar }\end{array}$ \\
\hline \multicolumn{2}{|l|}{$\underline{\text { Meio Ambiente }}$} \\
\hline $\begin{array}{l}\text { Poluição do ar - } \\
\text { problema global }\end{array}$ & $\begin{array}{l}\text { Consumo anual de energia e emissões de } \mathrm{CO}_{2} \text { (total e por } \\
\text { habitante) }\end{array}$ \\
\hline
\end{tabular}




\begin{tabular}{c|l}
\hline $\begin{array}{c}\text { Dimensão de } \\
\text { sustentabilidade }\end{array}$ & \multicolumn{1}{c}{ Indicador } \\
\hline $\begin{array}{c}\text { Poluição do ar }- \\
\text { problema local }\end{array}$ & $\begin{array}{l}\text { Níveis de } \mathrm{CO}, \mathrm{NO}_{\mathrm{x}} \text {, hidrocarbonetos e partículas }\left(\mathrm{em} \mathrm{g} / \mathrm{m}^{2}, \text { total }\right. \\
\text { e por habitante) }\end{array}$ \\
Consumo do espaço & $\begin{array}{l}\text { Consumo individual diário de espaço público destinado a } \\
\text { viagens e estacionamentos }\left(\mathrm{em} \mathrm{m}^{2} \mathrm{xh}\right) \\
\text { Espaço ocupado por infraestruturas de transportes }\end{array}$ \\
Outros itens & $\begin{array}{l}\text { Níveis de intensidade sonora } \\
\text { Risco de acidentes }\end{array}$ \\
\hline
\end{tabular}

O Centro Científico Federal de Políticas da Bélgica (BELGIAN FEDERAL SCIENCE POLICY, 2002) elaborou um conjunto de 120 indicadores para o desenvolvimento sustentável dos transportes na Bélgica, apresentado na Tabela 30. A abordagem escolhida para estruturar este conjunto de indicadores corresponde à abordagem "força motriz - pressão - estado - impacto - resposta". Segundo este método, a partir de uma cadeia de elos causais, iniciada com a força motriz, movendo-se sobre a pressão, ocorre o estado, em seguida, o impacto, que provoca uma resposta social orientada para estas ligações. Sem a pretensão de oferecer uma modelagem exaustiva das interações existentes entre os vários componentes sociais, econômicos e ambientais de desenvolvimento, esta abordagem mostra as conexões entre as causas dos problemas ambientais, seus impactos e as respostas geradas na sociedade. 
O desenvolvimento dos indicadores baseou-se em quatro etapas: abordagem do conceito de desenvolvimento sustentável, caracterização das fontes não sustentáveis no setor dos transportes, abordagem do conceito de transporte sustentável e a caracterização de ferramentas para o desenvolvimento sustentável do setor de transportes (BELGIAN FEDERAL SCIENCE POLICY, 2002).

Tabela 30: Indicadores de desenvolvimento sustentável dos transportes (BELGIAN FEDERAL SCIENCE POLICY, 2002)

\begin{tabular}{|c|c|}
\hline Força motriz & Indicador \\
\hline \multirow{6}{*}{$\begin{array}{l}\text { Tendências no tráfego } \\
\text { rodoviário }\end{array}$} & Volume total de tráfego rodoviário \\
\hline & Intensidade de tráfego per capita \\
\hline & Intensidade de tráfego por superfície \\
\hline & $\begin{array}{l}\text { Intensidade de tráfego por unidade de comprimento da } \\
\text { rede }\end{array}$ \\
\hline & Intensidade de tráfego por unidade do PIB \\
\hline & Composição do tráfego \\
\hline \multirow[t]{6}{*}{ Tendências no tráfego aéreo } & $\begin{array}{l}\text { Número de viagens por avião registradas em aeroportos } \\
\text { nacionais }\end{array}$ \\
\hline & $\begin{array}{l}\text { Distribuição do tráfego aéreo em Bruxelas - Aeroporto } \\
\text { nacional por período diurno / noturno }\end{array}$ \\
\hline & $\begin{array}{l}\text { Distribuição do tráfego aéreo em Bruxelas - Aeroporto } \\
\text { nacional por nível de ruído dos aviões }\end{array}$ \\
\hline & Número de passageiros transportados \\
\hline & Número de toneladas de cargas transportadas \\
\hline & $\begin{array}{l}\text { Número de passageiros - quilômetros gerenciados pelas } \\
\text { principais empresas europeias }\end{array}$ \\
\hline \multirow{7}{*}{ 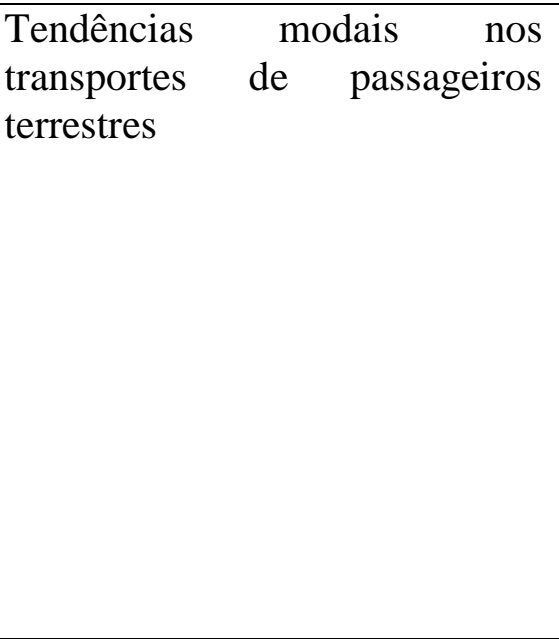 } & $\begin{array}{l}\text { Número de passageiros - quilômetros pelo principal modo } \\
\text { de transporte terrestre }\end{array}$ \\
\hline & $\begin{array}{l}\text { Distâncias médias percorridas por modo de transporte, per } \\
\text { capita e por ano }\end{array}$ \\
\hline & $\begin{array}{l}\text { Quilometragem anual média percorrida na Bélgica por } \\
\text { meio de veículos particulares }\end{array}$ \\
\hline & $\begin{array}{l}\text { Número anual total de viajantes utilizando o modo } \\
\text { ferroviário ou o transporte público }\end{array}$ \\
\hline & $\begin{array}{l}\text { Número de viagens pelo modo ferroviário ou realizadas } \\
\text { pelo transporte público per capita e por ano }\end{array}$ \\
\hline & Duração média de uma viagem por trem \\
\hline & $\begin{array}{l}\% \text { de viagens realizadas por bicicleta em cidades } \\
\text { europeias }\end{array}$ \\
\hline \multirow[t]{3}{*}{$\begin{array}{l}\text { Escolhas modais relacionadas } \\
\text { ao tráfego suburbano }\end{array}$} & $\begin{array}{l}\text { Percentual dos vários modos de transportes em viagens } \\
\text { pendulares relacionadas com trabalho e educação }\end{array}$ \\
\hline & $\begin{array}{l}\text { Percentual dos vários modos de transportes de viagens } \\
\text { pendulares por sexo }\end{array}$ \\
\hline & $\begin{array}{l}\text { Evolução dos modos de transportes utilizados em viagens } \\
\text { pendulares }\end{array}$ \\
\hline
\end{tabular}




\begin{tabular}{|c|c|}
\hline Força motriz & Indicador \\
\hline & $\begin{array}{l}\text { Modos principais de transportes utilizados para viagens } \\
\text { pendulares por local de residência }\end{array}$ \\
\hline \multirow[t]{6}{*}{$\begin{array}{l}\text { Tendências modais no } \\
\text { transporte de carga terrestre }\end{array}$} & $\begin{array}{l}\text { Transporte de carga pelos modos principais de transporte } \\
\text { terrestre }\end{array}$ \\
\hline & Estrutura modal da distribuição de carga \\
\hline & Intensidade do transporte de carga por unidade do PIB \\
\hline & $\begin{array}{l}\text { Quilometragem anual total percorrida por caminhões } \\
\text { belgas no território nacional }\end{array}$ \\
\hline & $\begin{array}{l}\text { Distâncias médias percorridas por uma tonelada de carga } \\
\text { pelos modos principais de transporte terrestre }\end{array}$ \\
\hline & $\begin{array}{l}\text { Percentual de transporte multimodal no transporte de } \\
\text { carga }\end{array}$ \\
\hline \multirow[t]{6}{*}{ Estoque de veículos rodoviários } & Frota de veículos rodoviários \\
\hline & Taxa de posse de veículos \\
\hline & $\begin{array}{l}\text { Percentual de domicílios que possuem } 0,1,2 \text { ou mais do } \\
\text { que } 2 \text { veículos particulares }\end{array}$ \\
\hline & $\begin{array}{l}\text { Percentual de domicílios que possuem } 0,1,2 \text { ou mais do } \\
\text { que } 2 \text { bicicletas }\end{array}$ \\
\hline & Frota de veículos particulares por sexo \\
\hline & Frota de veículos de empresas \\
\hline \multirow[t]{6}{*}{$\begin{array}{l}\text { Características estruturais da } \\
\text { frota rodoviária de veículos }\end{array}$} & $\begin{array}{l}\text { Estrutura da frota rodoviária de veículos por tipo de } \\
\text { combustível }\end{array}$ \\
\hline & Registro de novos veículos por tipo de combustível \\
\hline & $\begin{array}{l}\text { Percentual da frota de veículos que respeita as normas } \\
\text { legais de emissão }\end{array}$ \\
\hline & Média da capacidade cúbica da frota de veículos \\
\hline & Registro de novos veículos por potência média \\
\hline & Média de idade da frota de veículos \\
\hline \multirow{5}{*}{$\begin{array}{l}\text { Consumo anual de combustíveis } \\
\text { rodoviários }- \text { Intensidade } \\
\text { estrutura por tipo de } \\
\text { combustível }\end{array}$} & Consumo de combustível anual \\
\hline & Estrutura do consumo de combustível rodoviário \\
\hline & Intensidade do consumo de combustível per capita \\
\hline & $\begin{array}{l}\text { Intensidade do consumo de combustível por volume de } \\
\text { tráfego }\end{array}$ \\
\hline & $\begin{array}{l}\text { Média de consumo de combustível da frota de veículos } \\
\text { novos }\end{array}$ \\
\hline \multirow{8}{*}{$\begin{array}{l}\text { Eficiência do uso de transporte: } \\
\text { taxas de ocupação e } \\
\text { carregamento }\end{array}$} & Taxa média de ocupação de veículos \\
\hline & Média de passageiros por trem \\
\hline & Taxa de ocupação média de aviões (empresas nacionais) \\
\hline & $\begin{array}{l}\text { Transporte rodoviário: distância total (em quilômetros) } \\
\text { percorrida por uma carga }\end{array}$ \\
\hline & $\begin{array}{l}\text { Transporte rodoviário: taxa de ocupação média de } \\
\text { caminhões }\end{array}$ \\
\hline & $\begin{array}{l}\text { Transporte de navegação interior: distância total (em } \\
\text { quilômetros) percorrida por uma carga }\end{array}$ \\
\hline & $\begin{array}{l}\text { Transporte de navegação interior: taxa média de ocupação } \\
\text { de embarcações }\end{array}$ \\
\hline & Transporte ferroviário: tonelagem média por trem \\
\hline
\end{tabular}




\begin{tabular}{l}
\hline \multicolumn{2}{c|}{ Força motriz } \\
\hline Emissões de poluentes \\
atmosféricos provenientes do \\
setor de transportes
\end{tabular}

Número de mortos e feridos devido os acidentes de trânsito e intensidade
Ruído do tráfego
Indicador

Total de emissões de $\mathrm{CO}_{2}, \mathrm{NO}_{x}, \mathrm{COV}, \mathrm{CO}$ e $\mathrm{SO}_{2}$ pelo setor de transportes

Intensidade de emissões de $\mathrm{CO}_{2}$ devido ao tráfego rodoviário por unidade de volume de tráfego

Intensidade de emissões de $\mathrm{CO}_{2}$ devido ao tráfego rodoviário per capita

Intensidade de emissões de $\mathrm{CO}_{2}$ devido ao tráfego rodoviário por unidade do PIB

Contribuição relativa de emissões de $\mathrm{CO}_{2}, \mathrm{NO}_{x}, \mathrm{COV}, \mathrm{CO}$

e $\mathrm{SO}_{2}$ do total de emissões antrópicas

Número de pessoas mortas em acidentes rodoviários

Número de pessoas feridas em acidentes rodoviários

Intensidade de mortes em acidentes rodoviários por volume de tráfego

Intensidade de mortes em acidentes rodoviários per capita

Severidade dos acidentes

Distribuição do número de mortos por tipo de usuário da rodovia

Comparação do número de mortos e feridos graves por bilhão de viajantes - quilômetros para ciclistas e usuários de veículos particulares

Comparação do número de mortos e feridos graves por milhão de passageiros - quilômetros para usuários de trem e de veículos particulares

Evolução do número de mortos e feridos graves por categorias de usuários

Número de mortos de acordo com a idade e sexo do usuário

Comparação da segurança viária em autoestradas, estradas regionais e estradas municipais

Evolução do número de mortos de acordo com o tipo de rodovia e usuário

Evolução dos prejuízos causados por acidentes de trânsito por tipo de rodovia

Percentual de acidentes onde um ou mais condutores estão sob a influência de álcool

Percentual de acidentes com mortos e feridos graves onde um ou mais condutores estão sob a influência de álcool

Evolução do número de acidentes de trânsito que resultem em prejuízos e vítimas envolvendo caminhões e comparação com o volume do tráfego de caminhões

Distribuição dos fatores de acidentes considerando os acidentes com mortos

Percentual da população exposta ao ruído do tráfego rodoviário nas regiões de Flandres e Bruxelas

Percentual da população exposta ao ruído do tráfego ferroviário nas regiões de Flandres e Bruxelas 


\begin{tabular}{|c|c|}
\hline Força motriz & Indicador \\
\hline & $\begin{array}{l}\text { Percentual da população exposta ao ruído do tráfego aéreo } \\
\text { nas regiões de Flandres e Bruxelas }\end{array}$ \\
\hline \multirow{8}{*}{$\begin{array}{l}\text { Duração média de viagens } \\
\text { pendulares }\end{array}$} & Evolução da duração média de viagens pendulares \\
\hline & $\begin{array}{l}\text { Distribuição, por classificação de duração, de viagens } \\
\text { pendulares relacionadas com trabalho e educação }\end{array}$ \\
\hline & $\begin{array}{l}\text { Velocidades médias de viagens pendulares por modo de } \\
\text { transporte }\end{array}$ \\
\hline & $\begin{array}{l}\text { Duração média de viagens pendulares por modo de } \\
\text { transporte por diferentes tipos de viagens interurbanas }\end{array}$ \\
\hline & $\begin{array}{l}\text { Duração média de viagens pendulares por modo de } \\
\text { transporte e por diferentes tipos de viagens interurbanas } \\
\text { na região de Bruxelas }\end{array}$ \\
\hline & $\begin{array}{l}\text { Tempo, distâncias e velocidades médias de viagens } \\
\text { pendulares por sexo }\end{array}$ \\
\hline & Evolução da duração de viagens pendulares \\
\hline & $\begin{array}{l}\text { Distribuição, por classificação de duração, de viagens } \\
\text { pendulares por local de residência }\end{array}$ \\
\hline \multirow[t]{4}{*}{$\begin{array}{l}\text { Gastos domésticos dedicados } \\
\text { aos transportes }\end{array}$} & $\begin{array}{l}\text { Comparação internacional do percentual dos orçamentos } \\
\text { familiares utilizados em transportes e telecomunicações }\end{array}$ \\
\hline & $\begin{array}{l}\text { Comparação da importância dos gastos domésticos com } \\
\text { transportes nos níveis internacional e regional }\end{array}$ \\
\hline & $\begin{array}{l}\text { Evolução dos gastos médios em transportes anuais } \\
\text { discriminados por quartil de renda e estrutura dos gastos }\end{array}$ \\
\hline & $\begin{array}{l}\text { Evolução dos gastos médios de transportes comparados } \\
\text { com a renda familiar média disponível a nível nacional e } \\
\text { por quartil de renda }\end{array}$ \\
\hline \multirow{6}{*}{$\begin{array}{l}\text { Consumo final energético anual } \\
\text { por setor de transportes - } \\
\text { Intensidade e desagregação por } \\
\text { modo }\end{array}$} & Consumo final energético pelo setor de transportes \\
\hline & $\begin{array}{l}\text { Intensidade do uso energético pelo setor de transportes } \\
\text { comparada com o número de habitantes }\end{array}$ \\
\hline & $\begin{array}{l}\text { Intensidade do uso energético pelo setor de transportes } \\
\text { comparado ao PIB }\end{array}$ \\
\hline & $\begin{array}{l}\text { Percentual do setor de transportes no consumo final total } \\
\text { de energia (considerando todos os setores) }\end{array}$ \\
\hline & Percentual dos vetores energéticos no setor de transportes \\
\hline & Consumo final energético - PIB \\
\hline \multirow{3}{*}{$\begin{array}{l}\text { Distância média de viagens } \\
\text { pendulares }\end{array}$} & Evolução da distância média de viagens pendulares \\
\hline & $\begin{array}{l}\text { Distribuição, por classificação de distância, de viagens } \\
\text { pendulares relacionadas com trabalho ou educação }\end{array}$ \\
\hline & $\begin{array}{l}\text { Distribuição, por classificação de distância, de viagens } \\
\text { pendulares por local de residência }\end{array}$ \\
\hline \multirow[t]{2}{*}{$\begin{array}{l}\text { Evolução } \quad \text { de } r \text { volumes } \\
\text { populacionais por tipo de espaço }\end{array}$} & $\begin{array}{l}\text { Evolução dos volumes populacionais agrupados (por } \\
\text { classificação de importância) e áreas residenciais } \\
\text { espalhadas }\end{array}$ \\
\hline & $\begin{array}{l}\text { Evolução da superfície e do volume populacional das } \\
\text { áreas residenciais urbanas }\end{array}$ \\
\hline
\end{tabular}




\begin{tabular}{|c|c|}
\hline Força motriz & Indicador \\
\hline & $\begin{array}{l}\text { Evolução dos volumes populacionais por categoria de } \\
\text { municipalidade, de acordo com o grau de urbanização } \\
\text { funcional }\end{array}$ \\
\hline Acesso a serviços básicos & $\begin{array}{l}\text { Evolução, ao longo do tempo, dos serviços básicos (lojas, } \\
\text { bancos, correios, jardim de infância, escolas de } 1^{\circ} \text { grau e } \\
\text { hospitais) }\end{array}$ \\
\hline \multirow{2}{*}{$\begin{array}{l}\text { Preço de combustíveis } \\
\text { rodoviários e impostos }\end{array}$} & Preço dos combustíveis e impostos \\
\hline & $\begin{array}{l}\text { Diferença entre impostos e preços de venda dos } \\
\text { combustíveis }\end{array}$ \\
\hline \multirow[t]{2}{*}{$\begin{array}{lccc}\text { Índices } & \text { de } & \text { preços } & \text { para } \\
\text { transporte } & \text { de } & \text { passageiros } & \end{array}$} & $\begin{array}{l}\text { Evolução dos índices de custos relacionados ao transporte } \\
\text { de passageiros em comparação com a evolução do índice } \\
\text { de preços do consumidor, com o índice de saúde e com a } \\
\text { média da renda per capita }\end{array}$ \\
\hline & $\begin{array}{l}\text { Evolução dos índices com relação aos custos fixos e } \\
\text { variáveis do uso de veículos }\end{array}$ \\
\hline \multirow{12}{*}{$\begin{array}{l}\text { Suprimento e qualidade } \text { do } \\
\text { transporte ferroviário e do } \\
\text { transporte público }\end{array}$} & Evolução da acessibilidade da rede ferroviária belga \\
\hline & Evolução do fornecimento da cobertura da rede \\
\hline & Evolução da pontualidade das viagens da rede belga \\
\hline & $\begin{array}{l}\text { Evolução da velocidade das viagens da rede ferroviária } \\
\text { belga }\end{array}$ \\
\hline & $\begin{array}{l}\text { Evolução do nível de satisfação dos usuários de transporte } \\
\text { ferroviário }\end{array}$ \\
\hline & $\begin{array}{l}\text { Evolução regional de acessibilidade a redes belgas de } \\
\text { transporte público }\end{array}$ \\
\hline & Evolução regional do suprimento de transporte público \\
\hline & $\begin{array}{l}\text { Evolução da velocidade comercial do transporte público } \\
\text { na região de Bruxelas }\end{array}$ \\
\hline & $\begin{array}{l}\text { Evolução do nível de satisfação dos usuários do transporte } \\
\text { público (regiões de Bruxelas e Flandres) }\end{array}$ \\
\hline & Evolução da segurança do transporte ferroviário \\
\hline & Evolução do conforto do transporte ferroviário \\
\hline & Evolução do conforto e segurança do transporte público \\
\hline
\end{tabular}

Borken (2003) posicionou-se contra sistemas com muitos indicadores, uma vez que se tornam complexos e de difícil aplicação. Por conseguinte, desenvolveu sete indicadores derivados das medidas de transportes que causam os impactos ambientais mais importantes, selecionando-os por meio da análise de ciclo de vida.

- Impermeabilização do solo;

- Fragmentação do solo;

- Emissão de dióxido de carbono $\left(\mathrm{CO}_{2}\right)$;

- Concentração de PM10;

- Emissão de óxidos de nitrogênio $\left(\mathrm{NO}_{\mathrm{x}}\right)$; 
- Nível de ozônio;

- Nível de ruído.

Mameli e Marletto (2009) selecionaram 14 indicadores (Tabela 31) a partir da definição de um quadro conceitual que permitiu ligar parâmetros a objetivos específicos de políticas urbanas. A seleção dos indicadores foi realizada por meio de abordagem metodológica de cima para baixo (top-down).

Tabela 31: Indicadores recomendados para monitoramento de políticas de mobilidade sustentável (MAMELI e MARLETTO, 2009)

\begin{tabular}{|c|c|}
\hline Objetivos & Indicadores \\
\hline $\begin{array}{l}\text { Alternativas para a } \\
\text { mobilidade }\end{array}$ & $\begin{array}{l}\text { Serviços públicos e privados acessíveis via telefone e } \\
\text { computador }\end{array}$ \\
\hline \multirow{4}{*}{ Mobilidade fácil } & Congestionamento \\
\hline & Índice de caminhada \\
\hline & Índice de ciclismo \\
\hline & Quantidade/qualidade de serviços de transporte público \\
\hline \multirow{2}{*}{$\begin{array}{l}\text { Disponibilidade de espaço } \\
\text { público }\end{array}$} & Número de veículos motorizados por $\mathrm{km}^{2}$ \\
\hline & Densidade de viagens de veículos (veículos - quilômetros $/ \mathrm{km}^{2}$ ) \\
\hline Silêncio & $\begin{array}{l}\text { Percentual da população exposta a níveis de pressão sonora } \\
\text { provenientes do setor de transportes que excedam os padrões } \\
\text { nacionais }\end{array}$ \\
\hline Ar limpo & $\begin{array}{l}\text { Emissões provenientes do setor de transportes: } \mathrm{PM}_{10} \text {, } \\
\text { COVNM, } \mathrm{NO}_{\mathrm{x}}, \mathrm{CO}\end{array}$ \\
\hline Segurança & $\begin{array}{l}\text { Quantidade de mortos e feridos em acidentes no setor de } \\
\text { transportes }\end{array}$ \\
\hline $\begin{array}{l}\text { Redução de emissões de } \\
\text { gases de efeito estufa }\end{array}$ & Emissões de $\mathrm{CO}_{2}$ provenientes do setor de transportes \\
\hline Redução do uso do solo & Solo ocupado por infraestruturas de transportes \\
\hline $\begin{array}{l}\text { Redução de resíduos de } \\
\text { transportes }\end{array}$ & Resíduos gerados por atividades do setor de transportes \\
\hline $\begin{array}{l}\text { Redução de custos de } \\
\text { mobilidade }\end{array}$ & $\begin{array}{l}\text { Média de gastos anuais com mobilidade (domicílios, empresas } \\
\text { e órgãos públicos) }\end{array}$ \\
\hline
\end{tabular}

